\title{
Umkämpfte Kirche
}

Innerkatholische Konflikte im österreichischungarischen Küstenland 1890-1914

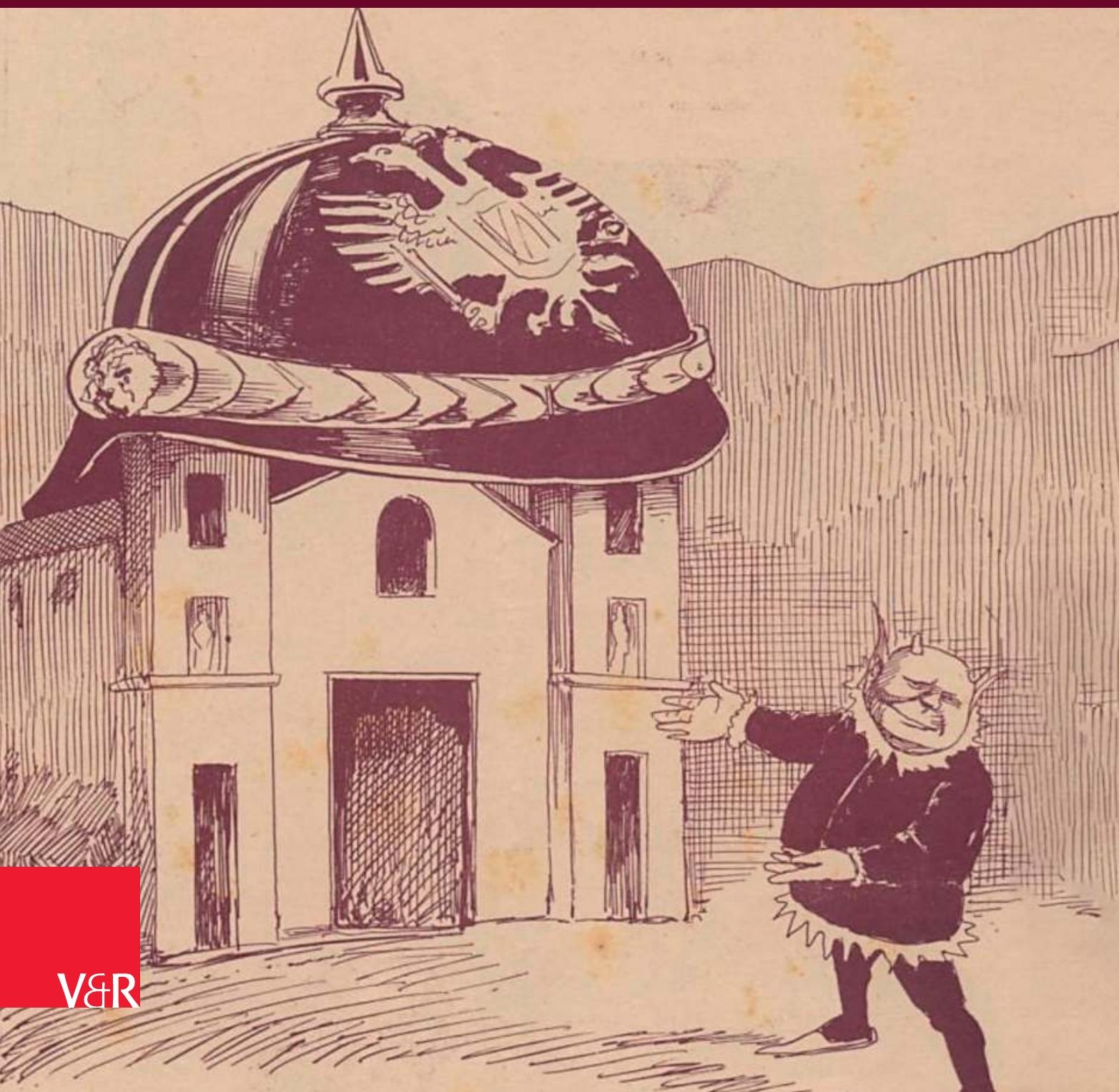



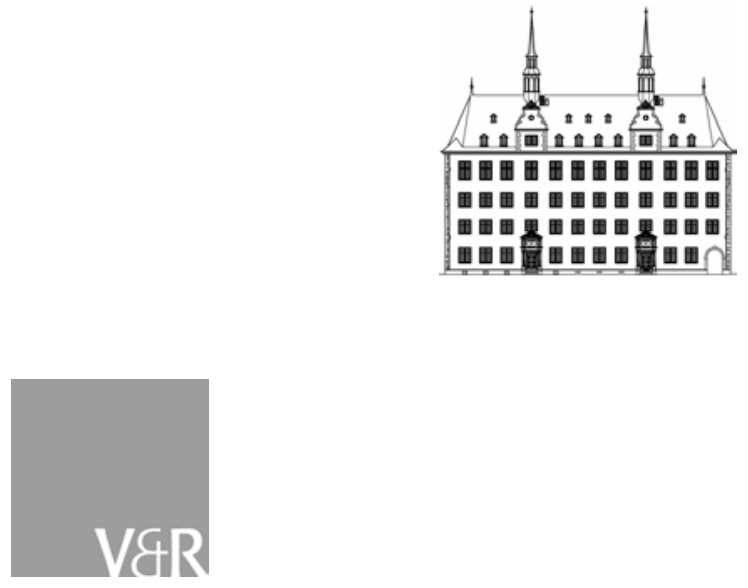

(c) 2021, Vandenhoeck \& Ruprecht GmbH \& Co. KG, Göttingen https://doi.org/10.13109/9783666356964 | CC BY-NC-ND 4.0 


\title{
Veröffentlichungen des Instituts für Europäische Geschichte Mainz
}

\author{
Abteilung für Universalgeschichte \\ Herausgegeben von Johannes Paulmann
}

Band 263 


\title{
Umkämpfte Kirche
}

\author{
Innerkatholische Konflikte im \\ österreichisch-ungarischen Küstenland 1890-1914
}

\author{
von \\ Péter Techet
}

Vandenhoeck \& Ruprecht 
Die Publikation wurde durch den Open-Access-Publikationsfonds für Monografien der Leibniz-Gemeinschaft gefördert.

Der Arbeit wurde der Förderpreis der Fritz und Helga Exner-Stiftung für herausragende Leistungen im Bereich der Südosteuropa-Forschung verliehen.

Bibliografische Information der Deutschen Nationalbibliothek: Die Deutsche Nationalbibliothek verzeichnet diese Publikation in der Deutschen Nationalbibliografie; detaillierte bibliografische Daten sind im Internet über https://dnb.de abrufbar.

(C) 2021, Vandenhoeck \& Ruprecht GmbH \& Co. KG, Theaterstraße 13, D-37073 Göttingen

Das Werk und seine Teile sind urheberrechtlich geschützt.

Das Werk ist als Open-Access-Publikation im Sinne der Creative-Commons-Lizenz BY-NC-ND International 4.0 (»Namensnennung - Nicht kommerziell - Keine Bearbeitung «) unter dem DOI 10.13109/9783666356964 abzurufen. Um eine Kopie dieser Lizenz zu sehen, besuchen Sie https://creativecommons.org/licenses/by-nc-nd/4.0/. Jede Verwertung in anderen als den durch diese Lizenz erlaubten Fällen bedarf der vorherigen schriftlichen Einwilligung des Verlages.

Coverabbildung: »Ricmanjsko vprašanje« [»Die Ricmanje-Frage«], Karikatur in der Wochenzeitung »Škrat» (Triest), unbekannter Autor, 14. April 1906, Bd. 4, H. 15, Quelle: »Digitalna Knjižnice Slovenije« [Digitale Bibliothek von Slowenien], URL: http://www.dlib.si/?URN=URN:NBN:SI:DOC-X54A66T5, Pravice javna domena [Public Domain].

Satz: Vanessa Weber, IEG Mainz

\section{Vandenhoeck \& Ruprecht Verlage | www.vandenhoeck-ruprecht-verlage.com}

ISSN 2197-1048

ISBN 978-3-666-35696-4 


\section{Für Marlene}




\section{Inhaltsverzeichnis}

Bemerkung zu den Personen- und Ortsnamen ..................................................... 11

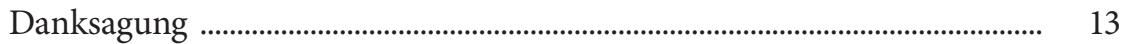

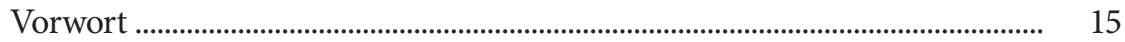

1. Einführung: Konzept, Verortung, Methode ................................................. 19

1.1 Thematische, räumliche und zeitliche Einordnung der Forschungsfrage ................................................................................... 22

1.1.1 Forschungsfrage ............................................................................ 22

1.1.2 Innerkatholische Gewaltmomente im Kontext der »Nationalitätenfrage« ................................................................ 23

1.1.3 Historiographie von Nation und Religion:

Nationalismus oder nationale Indifferenz? ..................................... 27

1.1.4 Räumliche Verortung ..................................................................... 37

1.1.5 Zeitlicher Fokus ..................................................................................... 45

1.2 Methode und Konzepte ........................................................................ 45

1.2.1 Mikrogeschichte mit vergleichender Kontextualisierung ............ 45

1.2.2 »Identifizierung« ........................................................................... 48

1.2.3 Gewalt ............................................................................................ 49

1.3 Quellenlage und Aufbau der Arbeit ........................................................... 52

1.3.1 Quellenlage ................................................................................. 52

1.3.2 Aufbau der Arbeit ............................................................................... 56

2. Imperium, Nation und Katholizismus in der Habsburgermonarchie .. 59

2.1 Imperium und Nation ................................................................................ 61

2.1.1 Österreich als Rechtsordnung für seine Völker ................................ 61

2.1.2 Ungarn als Imperium der magyarischen Elite .............................. 66

2.2 Katholizismus und Nation ..................................................................... $\quad 70$

2.2.1 Unterschiedlicher Stellenwert des Katholizismus .......................... 71

2.2.2 Die Sprache der Liturgie: Glagoljica im oberadriatischen Raum ................................................................... $\quad 75$

3. Österreichisches Küstenland ....................................................................... 85

3.1 Konflikte um die Nationalisierung des kirchlichen Raumes

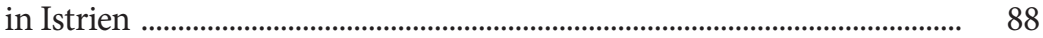

3.1.1 Istrien: Ethnische Vielfalt und religiöse Homogenität ................ 90 
3.1.2 Konfliktgeschichten: Angegriffene Priester, zerstrittene Kirchengemeinden ..................................................... 96

3.1.3 Konfliktanalyse: Nationalisierbare Konfliktlinien ........................ 115

3.1.4 Historischer Kontext: Supranationales Selbstverständnis der Kirche ...................................................................................... 122

3.2 Kirchenstreit im ländlichen Hinterland der Hafenstadt Triest ............... 126

3.2.1 Ricmanje: Slowenischsprachiges Dorf an der sprachkulturellen Grenze zu Triest

3.2.2 Konfliktgeschichte: Vom Kampf um die Pfarrei bis zum Kampf gegen die Kirche

3.2.3 Konfliktanalyse: Situative Identifizierungen auf mehreren Konfliktebenen

3.2.4 Historischer Kontext: Lokaler Widerstand gegen kirchliche Vereinheitlichung

3.3 Fazit: Konkurrierende und proaktive Selbstbehauptung ländlicher Katholiken

4. Ungarisch-Kroatisches Küstenland

4.1 Konflikte um und gegen die altslawische Liturgiesprache im Bistum Senj

4.1.1 Einführung der altslawischen Liturgiesprache in der ehemaligen Militärgrenze

4.1.2 Konfliktgeschichte: Lokaler Widerstand gegen die altslawische Liturgiesprache

4.1.3 Konfliktanalyse: Nationale Indifferenz oder antiserbischer Hass?

4.1.4 Historischer Kontext: Altslawische Sprache als nationales Thema

4.2 Kirchenstreit im ländlichen Hinterland der Hafenstadt Fiume/Rijeka

4.2.1 Drenova: Kroatischsprachige Gemeinde in einem multiethnischen Raum

4.2.2 Konfliktgeschichte: Abwehr kirchlicher Einmischungen ........... 212

4.2.3 Konfliktanalyse: Nationalistische Erwartungen aus der Stadt ... 227

4.2.4 Historischer Kontext: Staat/Stadt-Kirche-Konflikt in und um Fiume/Rijeka

4.3 Fazit: Reaktiver Selbstschutz ländlicher Katholiken 236

5. Konfliktdynamiken: Nationale Nonkonformität und religiöse Peripherie

5.1 Nationalitätenkonflikt? .............................................................................. 242

5.1.1 Intraethnische Konflikte 
5.1.2 Nationale und/oder religiöse Indifferenz? ..................................... 246

5.2 Erfolgschancen der lokalen Akteure ........................................................ 250

5.2.1 Interessenartikulation in Österreich und Ungarn ........................ 250

5.2.2 Antihierarchische (soziale) Gewalt ................................................. 253

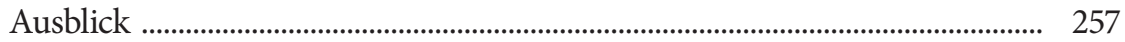

Quellen- und Literaturverzeichnis ...................................................................... 263

Archivmaterial ....................................................................................... 263

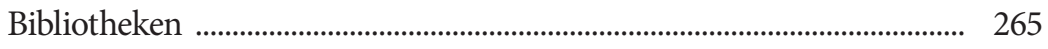

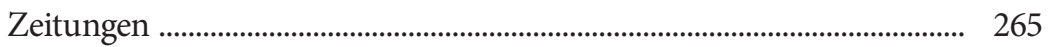

Digitale Sammlungen ................................................................................. 267

Zeitgenössische Literatur .......................................................................... 267

Sekundärliteratur ……………………………………………………….... 268

Ortsnamen in den landesüblichen Sprachen .......................................................... 289

Personen ...................................................................................................... 295

Verzeichnis von Abbildungen, Karten und Tabellen ........................................ 297

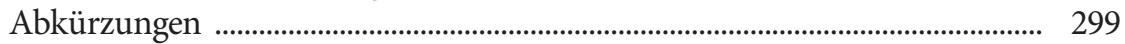

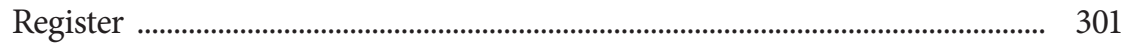

1. Ortsregister ................................................................................................ 301

2. Personenregister ........................................................................................... 303 


\section{Bemerkung zu den Personen- und Ortsnamen}

In der folgenden Arbeit kommen Orts- und Personennamen in unterschiedlichen Sprachen (Italienisch, Kroatisch, Slowenisch, Deutsch, Ungarisch) vor. Bei den Namen verwende ich immer die sprachliche Version, welche der (zumindest vermeintlichen) Muttersprache der jeweiligen Person entspricht. Bei den Ortsnamen verwende ich immer mehrsprachige Versionen, es sei denn, die Ortschaft hat schon einen im heutigen deutschen Sprachgebrauch eingebürgerten Namen. (Im Falle von Triest schreibe ich deswegen nicht Trieste/Trst.) Bei allen anderen Ortsnamen verwende ich immer Versionen von den zwei Sprachen, die vor Ort am meisten verbreitet waren: etwa Fiume/Rijeka, Veglia/Krk usw. Wenn die Ortschaft ethnisch-sprachlich (fast) homogen war, verwende ich die Version der lokalen Sprache, auch wenn die Ortschaft sonst einen deutschen Namen hatte: etwa nur Senj statt Senj/ Zengg.

Die Betonung der Mehrsprachigkeit entspricht nicht nur der historischen Realität der lokalen Vielfalt, sondern auch der immer noch aktuellen Intention, gerade in den entsprechenden Gebieten die historisch bedingte Mehrsprachigkeit besser anzuerkennen und entgegen homogenisierender Tendenzen stärker zu fördern. 


\section{Danksagung}

»Denn jeder denkbare erste Satz ist bereits ein Ende - auch wenn es weitergeht. Er steht am Ende von Abertausenden von Seiten, die nie geschrieben wurden: der Vorgeschichte. ${ }^{1}$ Der erste Satz dieses Buches bedeutet ebenso ein Ende: das Ende von sehr interessanten Jahren der Recherche, die mich nicht nur an neue Quellen, sondern an neue Menschen, oft Freundschaften brachten. Ohne diese Menschen, als glückliche Vorgeschichte, hätte diese Arbeit nie fertiggestellt werden können. Sie haben mich ermutigt, sie haben mir Richtung und Tipps gegeben, sie haben mir Interesse und Freundschaft geschenkt.

Zuerst bedanke ich mich bei Dr. Konrad Clewing, dem Mitarbeiter des Leibniz-Institutes für Ost- und Südosteuropaforschung (IOS) in Regensburg. Aus früherer Mitarbeit bei ihm brachte ich ein großes Interesse an der Habsburgermonarchie mit. Ich bedanke mich sodann vor allem bei meiner Betreuerin Dr. Eveline G. Bouwers und dem Institutsdirektor Professor Dr. Johannes Paulmann sowie dem ganzen Leibniz-Institut für Europäische Geschichte (IEG) in Mainz. Besonders profitierte mein Dissertationsprojekt von der Zusammenarbeit in der Emmy Noether-Nachwuchsgruppe "Glaubenskämpfe: Religion und Gewalt im katholischen Europa, 1848-1914", wofür ich Dr. Eveline G. Bouwers als Leiterin und meiner Kollegin Sara Mehlmer außerordentlich dankbar bin. Darüber hinaus bedanke ich mich bei Professor Dr. Jan Kusber und Professor Dr. Hans-Christian Maner vom Arbeitsbereich der Osteuropäischen Geschichte an der Universität Mainz, die die Begutachtung meiner Dissertation übernahmen. Für die Aufnahme meiner Dissertation in die »Veröffentlichungen des Institutes für Europäische Geschichte « möchte ich mich ganz besonders bei Professor Dr. Johannes Paulmann bedanken. Bei der Vorbereitung des Textes für die Publikation halfen mir Dr. Christiane Bacher, Sabine Mischner und Vanessa Weber.

Während der Forschungsjahre konnte ich Menschen in verschiedenen Ländern treffen, die mit interessanten Tipps oder Gesprächen meine Arbeit unterstützten. In Rom gilt mein Dank Professorin Dr. Ester Capuzzo, Dr. Andreas Gottsmann sowie Dr. Mario Micich. In Triest gilt mein Dank vor allem Dr. Pierpaolo Dorsi, außerdem Gianna Fumo, Dr. Giovanni Luca, Monsignore Professor Dr. Ettore Malnati, Marco (Markus) Manin, Dr. Paolo Santoboni, Alessandro Sgambati sowie Don Pietro Zovatto. In Fiume/ Rijeka gilt mein Dank vor allem Dr. Boris Zakošek, außerdem Professor Dr. Vanni

1 Robert Menasse, Die Hauptstadt, Frankfurt a. M. 2017, S. 17. 
D’Alessio, Professor Dr. Boris Dudaš, Christian Grailach, Dr. Ivan Jeličić sowie Dr. Marko Medved. Ich bedanke mich in Zagreb bei Professor Dr. Marijan Bobinac und Dr. Željko Holjevac.

Ich konnte während der Forschungsjahre immer wieder Teilaspekte und Teilergebnisse meiner Arbeit auf verschiedenen Tagungen vorstellen. Für die Einladungen und die nützlichen Kommentare bedanke ich mich bei Dr. Bernhard Bachinger (Graz), Professor Dr. Wolfgang Höpken (Leipzig), Dr. Heidi Hein-Kircher (Marburg), Dr. Sabine Jagodzinski (Warschau), Professorin Dr. Nataša Mišković (Basel), Dr. Jana Osterkamp (München), Dr. Robert Pyrah (Oxford), Professor Dr. Matthias Riedl (Budapest) sowie Professor Dr. Sebastian Schüler (Leipzig). Ein besonderer Dank gilt Professor Dr. Pieter M. Judson (Florenz). Ich bedanke mich außerdem bei Professor Dr. Martin Aust (Bonn), Dr. Franco Baldasso (New York), Professor Dr. Rainer Bendel (Tübingen), Dr. Nicola Camilleri (Padua/Berlin), Dr. Amerigo Caruso (Saarbrücken), Dr. Gábor Egry (Budapest), Dr. Laura Di Fabio (Rom), Dr. Wolfgang Göderle (Graz), Professorin Dr. Catherine Horel (Paris), Dr. Aleksandra Kmak-Pamirska (Warschau), Pierre Leforban (Paris), Dr. René Moehrle (Trier), Samantha Paul (New York), Dr. Stefano Petrungaro (Venedig), Don Robert Rapljenović (Eichstätt/Zagreb), Professor Dr. Máté Rigó (Singapore), Dr. Sabine Rutar (Potsdam/Regensburg), Professor Dr. Marko Trogrlić (Split), Professor Dr. Karl Vocelka (Wien) und Professor Dr. Larry Wolff (New York).

Dass ich mich vier Jahre lang ruhig und finanziell abgesichert auf meine Arbeit konzentrieren konnte, ist dem Emmy Noether-Programm der Deutschen Forschungsgemeinschaft (DFG) zu verdanken. 


\section{Vorwort}

Ich war gerade in der kroatischen Stadt Fiume/ Rijeka auf einer Archivreise, als ich in der Früh beim morgendlichen Kaffee die Tageszeitung der dortigen italienischen Minderheit, La Voce del Popolo, aufschlug und einen Artikel über einen kroatischen Priester las, der sich geweigert habe, im istrianischen Dorf Piemonte/Završje italienische Gottesdienste zu zelebrieren. ${ }^{1}$ Der örtliche Vorsteher der italienischen Minderheit, Franco Biloslavo, war der Meinung, dass sich das Verhältnis der italienischen Gemeinschaft mit dem kroatischen Priester, Don Ante Jukopila, auch aus persönlichen Gründen in der letzten Zeit immer mehr verschlechtert habe.

Ähnliche lokale Konflikte innerhalb einer Kirchengemeinschaft ereigneten sich auch zu habsburgischen Zeiten. Sie wurden allerdings als Beweise für die These eines durch und durch nationalisierten und dadurch immer mehr auseinanderklaffenden öffentlichen Lebens herangezogen, als ob nicht einmal die supranational konzipierte katholische Kirche einen Raum multiethnischen Treffens geboten hätte. Ob diesen inner- (und teils anti)kirchlichen Konflikten tatsächlich nationale Motive zugrunde lagen, ist aber unklar, da die zeitgenössische nationalistische Publizistik der lokalen Komplexität ein vereinfachendes Schema aufbürden wollte.

Das Ziel meiner Forschung besteht darin, die lokale Realität - anhand von oft noch nicht ausgewerteten Archivmaterialien - aus ihrer Komplexität heraus zu verstehen und zu rekonstruieren. So kann auch hinterfragt werden, warum alle innerkirchlichen Konflikte des Küstenlandes entlang nationaler Differenzen interpretiert wurden. Das bedeutet aber keinesfalls, dass ich der lokalen Realität ein vorgefertigtes Präkonzept etwa über einen oberadriatischen Raum voller Harmonie aufzwingen will. Als ich mein Forschungsvorhaben konzipierte, ging ich davon aus, dass meine Fallstudien eher die nationale Polarisierung der lokalen Ebene und der lokalen Kirche beweisen würden - und ich war oft selbst überrascht, wie sich die Realität so einer Vor- und Darstellung doch nicht fügt.

Die folgende Arbeit ist ein Produkt von solchen Überraschungen. Statt der erwarteten klaren Frontlinien etwa zwischen »Italienern«, »Slowenen« und "Kroaten" sind die geschilderten innerkatholischen Konflikte viel komplexer. Indem die Komplexität lokaler Konflikte erforscht wird, lässt sich - wie

1 La Voce del Popolo, 11. April 2016, URL: <http://www.editfiume.info/lavoce/istria/ 18424-piemonte-d-istria-i-difficili-rapporti-con-il-parroco $>(15.10 .2019)$. 
Pieter Judson schreibt - aufzeigen, »welche vollkommen unterschiedlichen Bedeutungen solche an der Oberfläche als national erscheinende Konflikte haben können ${ }^{2}{ }^{2}$

Es handelt sich um soziale, konfliktbeladene Prozesse, die auch anderswo in Europa anzutreffen waren. Wenn die Konflikte als Teil dieser Prozesse erzählt werden, lässt sich aufzeigen, wie wenig sich die Habsburgermonarchie von anderen europäischen Staaten unterschied. Der vermeintliche, überbetonte Unterschied hätte im »Nationalitätenkonflikt« bestanden. In der Arbeit werden aber die sozialen, religiösen, parteipolitischen und persönlichen Komponenten, die sich hinter den national erzählten Konflikten verbargen, hervorgehoben - mit Fokus auf einem kleinen Raum und einer marginalisierten Personengruppe (die ländlichen Katholiken des oberadriatischen Raumes).

In den letzten zehn bis fünfzehn Jahren erhöhte sich das wissenschaftliche und populär-wissenschaftliche Interesse an der Habsburgermonarchie, deren Bestehen und Ableben Reminiszenzen bezüglich der heutigen innereuropäischen Krisen (Nationalismus, Populismus, staatsrechtliche Debatten, Identitätsfragen usw.) hervorrufen. Die Habsburgermonarchie gilt in der Wissenschaft und der Erinnerungskultur der späteren Nachfolgestaaten längst nicht mehr als "Völkerkerker", wie sie in den nationalistischen Vorwürfen oft beschrieben wurde. Vielmehr anerkennen Wissenschaftler, Intellektuelle und interessierte Menschen die zivilisatorischen und friedenssichernden Leistungen der Habsburger in einer Region wie Ostmittel- und Südosteuropa, die nach dem Zerfall des österreichischen (ab 1867: österreichisch-ungarischen) Imperiums totalitäre Regime rechter und linker Prägung, Kriege, Massenmorde, Vertreibungen sowie wirtschaftliche und politische Bedeutungsverluste erleben musste.

In einer Zeit, in der die nationalen und religiösen Fragen in Europa wiederum polarisieren, kann eine Arbeit, die sich mit der Komplexität nationaler und religiöser Selbst- und Fremdwahrnehmungen sowie national und religiös (miss)verstandenen Konfliktsituationen auseinandersetzt, einen relevanten Beitrag für das Verständnis multiethnischer Räume liefern.

2 Pieter Judson, Die Habsburgermonarchie - neue Interpretationen, in: Jana OsterKAMP (Hg.), Kooperatives Imperium. Politische Zusammenarbeit in der späten Habsburgermonarchie, Göttingen 2018, S. 315-324, hier S. 316. 
Im Rahmen der Emmy Noether-Nachwuchsgruppe »Glaubenskämpfe: Religion und Gewalt im katholischen Europa (1848-1914) « am Leibniz-Institut für Europäische Geschichte (Mainz) war ich Teil der Forschungsgruppe, die sich mit Gewaltmomenten in der Geschichte des europäischen Katholizismus zwischen 1848 und 1914 beschäftigte und dadurch das Gewaltpotenzial im religiösen bzw. kirchlichen Bereich in den Blick nahm. Meine Forschung konzentrierte sich dabei auf die Fragen, wie und warum im religiösen oder kirchlichen Bereich Gewalt mit nationaler Konnotation entsteht und wie damit umgegangen wird. In diesem Sinne wird eine mikrohistorisch angelegte Erforschung religionsbezogener Konflikte aus dem ländlichen Hinterland der österreichischen und ungarischen Küstenstädte der späten Habsburgermonarchie angestrebt. Meine Arbeit reiht sich somit in die historiographische Tendenz ein, die Habsburgermonarchie jenseits der strukturbedingten "Nationalitätenkonflikte« bzw. mit einem starken Fokus auf die lokale Ebene neu verstehen zu wollen - hoffentlich mit Erkenntnisgewinn für diejenigen, die sich mit religiös oder national motivierten, interpretierten, lokalen Gewaltakten und ländlichen Konflikten aus anderen europäischen oder außereuropäischen Regionen beschäftigen.

Das vorliegende Buch ist eine überarbeitete und gekürzte Fassung meiner Dissertation, die ich an der Johannes Gutenberg-Universität Mainz im Fach Mittlere und Neuere Geschichte im Sommersemester 2019 erfolgreich verteidigte. Die Arbeit wurde mit dem Förderpreis der Fritz und Helga ExnerStiftung ausgezeichnet.

New York, im Sommer 2020

Péter Techet 


\section{Einführung: Konzept, Verortung, Methode}

».. Terminologien sind alles andere als unschuldig ..."

(Jürgen Habermas) ${ }^{1}$

Wir leben leider in einer Zeit, wo die politischen und National-Parteien auch die [katholische] Kirche und die Diener derselben für ihre Zwecke ausnützen wollen;... [...] In Parenzo [Poreč] beschuldigten mich die slawischen Blätter, daß ich die Italiener begünstige und die Slawen vernachläßige; in Triest wurde mir vor zwei Jahren als ich die slowenische Predigt von der Cathedralkirche in jene von Mariahilf übertrug, von den slowenischen Blättern derselbe Vorwurf gemacht, während man mir am Tage, als die slowenische Predigt in der Mariahilfer-Kirche wieder aufgenommen wurde, eine Petarde hinters Hausthor [des Bischofspalais] stellte, weil ich die slowenische Predigt nicht ganz aufgelassen habe; ... ${ }^{2}$

Ivan Nepomuk Glavina, der slowenischsprachige Bischof der österreichischen Hafenstadt Triest, empfand eine tiefe Enttäuschung angesichts des öffentlichen, nationalen Hasses, dem er oft begegnete. Wie den traurigen Zeilen des Triestiner Bischofs Glavina zu entnehmen ist, schienen die angeblichen »Nationalitätenkonflikte« auch im Küstenland die katholische Kirche, die Priester und die Kirchgänger erreicht zu haben.

Die Fragen, ob eine gemeinsame Konfession (wie die katholische) die ethnisch-sprachlichen Unterschiede absorbiert oder ob die ethnisch-sprachlichen Unterschiede die gemeinsame Konfession aufspalten, ${ }^{3}$ lässt sich in

1 Jürgen Habermas, Inklusion - Einbeziehen oder Einschließen? Zum Verhältnis von Nation, Rechtsstaat und Demokratie. Für Hans-Ulrich Wehler zum 65. Geburtstag, in: Ders., Die Einbeziehung des Anderen. Studien zur politischen Theorie, Frankfurt a. M. 1999, S. 154-184, hier S. 154.

2 Brief vom Triestiner Bischof Glavina an die Statthalterei des Österreichischen Küstenlandes (30. November 1894), in: Archivio di Stato di Trieste (Staatsarchiv von Triest, weiter: AST), Imperial Regia Luogotenenza (Kaiserlich-Königliche Statthalterei, weiter: Luogotenenza), Atti Presidiali (Präsidialakten, weiter: AP), busta (b.) 169, fasc. 4.2.1, 1894/2343.

3 Zum Verhältnis zwischen dem universellen Katholizismus und den partikularen Nationalismen siehe u. a. Péter Teснet, Nationalismus und Katholizismus in Ungarn 
den religiös homogenen, aber ethnisch-sprachlich heterogenen Regionen am besten erforschen. ${ }^{4}$ Während die kirchliche Obrigkeit aus Angst vor nationalkirchlichen Schismen sowie aus legalistischer Akzeptanz jeglicher Autorität den Nationalismus ablehnte, ${ }^{5}$ griffen nationalistische Akteure und Bewegungen unter den katholischen Völkern in der Tat auch auf die Religion bzw. den kirchlichen Raum zurück. Die katholischen Völker sind zwar keine "Konfessionsnationen" (die nationale und die religiöse Zugehörigkeit sind bei ihnen nicht deckungsgleich). ${ }^{6}$ Die nationalistischen Ansprüche schafften dennoch imaginierte Grenzen innerhalb des kirchlichen Raumes. In Gebieten, in denen mehrere Völker nebeneinander zusammenlebten, waren diese "Grenzen« freilich nicht geographisch, sondern nur als Ausgrenzungsimaginationen vorhanden, ${ }^{7}$ nach deren Logik solche Räume als "nationaler Besitz « nur einer "Nation" gehörten. ${ }^{8}$ Die Raumimaginationen wirkten sich auf die eine katholische Kirche ebenso aus. Daher wurde um die Deutungshoheit über den kirchlichen Raum, also um die Frage, zu welchem "nationalen Raum« der kirchliche gehören sollte, gerungen. ${ }^{9}$

und Kroatien. Sakralisierung der Nation und Nationalisierung der Religion?, in: Rainer BENDEL (Hg.), Die ostmitteleuropäischen Nationalstaaten nach 1918. Transformationen nach dem Zusammenbruch der Kaiserreiche, Münster 2019, S. 157-190, hier S. $159 \mathrm{ff}$.

4 Thies Schulze, Nationalism and the Catholic Church: Papal Politics and "Nationalist " Clergy in Border Regions (1918-1939), in: Isabella LöHr/Roland WenzLHuemer (Hg.), The Nation State and Beyond. Governing Globalization Processes in the Nineteenth and Early Twentieth Centuries, Heidelberg/New York 2013, S. 235-256, hier S. 243.

5 Victor Conzemius, Kirchen und Nationalismen im Europa des 19. Jahrhunderts und 20. Jahrhunderts, in: Albrecht LAngner (Hg.), Katholizismus, nationaler Gedanke und Europa seit 1800, Paderborn u. a. 1985, S. 11-50, hier S. 17.

6 Zum Konzept der "Konfessionsnation" siehe Emanuel TurCzynski, Konfession und Nation. Zur Frühgeschichte der rumänischen und serbischen Nationsbildung, Düsseldorf 1976.

7 Pieter Judson, Marking National Space on the Habsburg Austrian Borderlands 1880-1918, in: Omer Bartov/Eric Weitz (Hg.), Shatterzone of Empires. Coexistence and Violence in the East, Central, and Southeast European Borderlands, Bloomington / Indianapolis 2013, S. 122-135, hier S. 123.

8 Die »Nationalitätenkämpfe« wurden um die Deutungshoheit über die gemischt bewohnten Grenzregionen ausgefochten, weil die nationalen Narrative diese Regionen als ihren "Besitz« betrachteten; dazu siehe: Pieter Judson, Guardians of the Nation. Activists on the Language Frontier in Imperial Austria, Cambridge MA / London 2006, S. 2; über die Kategorie des imagined territory (also des national-diskursiv beanspruchten und imaginierten Raumes) siehe Peter Haslinger, Nation und Territorium im tschechischen politischen Diskurs 1880-1938, München 2010, S. $30 \mathrm{ff}$.

9 In Bezug auf die ähnlich multiethnisch und monokonfessionell zusammengesetzte Region des österreichischen Tirol siehe Florian Huber, Grenzkatholizismen. Religion, Raum und Nation in Tirol 1830-1848, Göttingen 2016, S. 42. 
Die oberadriatische Region war nicht nur von ethnisch-sprachlichen Gegensätzen geprägt, zumal selbst diese Gegensätze entweder fluid oder von anderen Gegensätzen überlagert bzw. durchkreuzt waren. Die makropolitischen Narrative suggerierten dennoch bei jeglichen Konflikten eine eindeutige Vorgeschichte, in der die angeblichen ethnisch-sprachlichen Unterschiede als einzige Konfliktmotivation dargestellt wurden. Die Erzählung der Vorgeschichte ist allerdings - wie Albrecht Koschorke schreibt - immer "ein rückwirkender Vorgang ", ${ }^{10}$ in dem viele Fragen und Aspekte, die eine andere Erklärung nahelegen würden, ausgeblendet werden. In den damaligen Erzählungen von ländlichen innerkatholischen Konflikten blieben Ereignisse tatsächlich ausgeklammert, die das "nationale« Narrativ infrage gestellt hätten.

Warum verweigerten etwa kroatischsprachige Menschen kroatischsprachigen Priestern den Zutritt in die Kirchen? Warum warfen slowenischsprachige Menschen Steine und Kot nach slowenischsprachigen Priestern auf der Straße und in der Kirche? Warum wurde ein italienischsprachiger Bischof von italienischsprachigen Menschen beschimpft und letztendlich aus ihrem Dorf verbannt? Warum "tauften" kroatischsprachige Dorfbewohner ihre Kinder allein, anstatt einen kroatischsprachigen Priester ins Dorf zu rufen? Warum beharrten slowenischsprachige Menschen auf Begräbnissen ohne slowenischsprachige Priester? Und warum hielt ein italienischsprachiger Priester Predigten gegen die »Italiener«? Mit nationalen Gegensätzen (zwischen »Italienern«, »Kroaten" und »Slowenen«) ließen sich die - in den folgenden Kapiteln näher zu schildernden - Beispiele nicht erklären.

In meiner Arbeit strebe ich die Rekonstruktion gewaltbefrachteter innerkatholischer Konflikte an, um die internen Konfliktgründe zu erkennen und diese mit ihrer externen Wahrnehmung zu konfrontieren. So lassen sich die Vielschichtigkeit lokaler Gesellschaften und die innerkatholischen Machtverhältnisse zum Vorschein bringen. Indem innerkirchliche Konflikte jenseits ethnisch-nationaler Differenzen, mit einem starken Fokus auf soziale, religiöse Zugehörigkeit, erzählt werden, lassen sie sich als Gewalt- und Emanzipationstendenzen - das heißt als Erscheinungen konfliktbeladener, sozialer Modernisierung - erkennen, welche in allen anderen europäischen Ländern anzutreffen waren. ${ }^{11}$ Dabei lässt sich beobachten, ob und wie Men-

10 Albrecht Коsсновке, Wie werden aus Spannungen Differenzen? Feldtheoretische Überlegungen zur Konfliktsemantik, in: Heinz Fassmann u. a. (Hg.), Kulturen der Differenz. Transformationsprozesse in Zentraleuropa nach 1989, Göttingen 2009, S. 271-285, hier S. 272 [Hervorhebung im Orig.].

11 Zur Bedeutung der Neuinterpretation sozialer Konflikte in der Habsburgermonarchie siehe (in concreto bezüglich der Arbeiterbewegung) Claire Morelon, Social Conflict, National Strife, or Political Battle? Violence and Strikebreaking in Late Habsburg Austria, in: European History Quarterly 49 (2019), S. 650-676, hier S. 651f. 
schen der gleichen Konfession auf der ländlichen Ebene - wie es etwa bezüglich des westeuropäischen Bauerntums gut aufgearbeitet wurde - auch in der Habsburgermonarchie immer mehr in nationalistischen Kategorien wahrgenommen wurden. ${ }^{12}$

\subsection{Thematische, räumliche und zeitliche Einordnung der Forschungsfrage}

\subsubsection{Forschungsfrage}

Die Komplexität lokaler Selbstverortungen und Interessen, die Vielschichtigkeit der Machtstrukturen und Marginalisierungen - auch innerhalb des kirchlichen Raumes - erschließen sich erst in mikrohistorisch fokussierten Nahaufnahmen. In der folgenden Arbeit setzt daher das Forschungsinteresse an der Schnittstelle mehrerer solcher Nahaufnahmen an: (1) in einer kleinen Region wie dem oberadriatischen Raum (Raumebene), (2) thematisch und institutionell bezüglich der lokalen katholischen Kirche als einer subimperialen Institution (institutionelle Ebene), (3) unter der (meistens südslawischen) Bevölkerung des ländlich geprägten Hinterlandes als einer gesellschaftlich marginalisierten, peripheren und in der Historiographie lange übersehenen, weniger beachteten gesellschaftlichen Schicht (Akteursebene) und (4) in ihren Interaktionen untereinander bzw. mit den lokalen Priestern (Handlungsebene).

Auch wenn die üblichen Fragen der Habsburgerforschung (nationale, sprachliche, ethnische »Identitäten" und ihre Konflikte) in der Arbeit ebenso vorkommen, stehen anders gewichtete, akzentuierte Fragen im Mittelpunkt: Nicht die Diskurse und die Narrative interessieren mich - sie bilden nur die Oberfläche der Konfliktgeschichten -, sondern die konkreten Konfliktereignisse: in der Kirche, vor der Kirche, vor dem Pfarramt, auf dem Friedhof, auf der Straße, in der Kneipe. Welche Umstände auf der lokalen Ebene führten zu Gewaltmomenten zwischen Kirchengängern und Kirchenvertretern? Wie wurden diese Umstände nach außen hin kommuniziert und von außen her wahrgenommen? Welche Ansprüche äußerten sich in den Gewaltmomenten zwischen Priestern und Kirchgängern bzw. unter den Kirchgängern? Aus welchen vorhandenen mikrogeschichtlichen Differenzen entstanden die

12 Zur Geschichte der Akteure in Osteuropa im Rahmen der voranschreitenden nationalisierenden Kategorisierungen siehe John Connely, From Peoples into Nations. A History of Eastern Europe, Princeton 2020. 
Konflikte? Und welche wurden für die makrogeschichtlichen Erklärungen, für die »Meistererzählungen" in den städtischen Diskursen, von den nationalistischen oder kirchlichen Akteuren herangezogen?

\subsubsection{Innerkatholische Gewaltmomente im Kontext der »Nationalitätenfrage»}

Im Mittelpunkt meiner Untersuchungen stehen gewaltbefrachtete Konfliktfälle aus der ländlichen Umgebung größerer Städte des oberadriatischen Raumes. Auch wenn sie sich im kirchlichen Bereich ereigneten, waren sie nicht religiös motiviert. Die Akteure in den Gewaltmomenten beanspruchten für sich keine religiös richtige Position - wie es in Fällen religiöser Gewalt $\mathrm{zu}$ beobachten ist $^{13}$-, und sie rechtfertigten sich nicht mit religiösen Lehren. ${ }^{14}$ Die Konflikte entstanden unter demselben Transzendenzhorizont: Die religiöse Lehre wurde nicht an sich verworfen, und keine andere religiöse Überzeugung wurde angestrebt. Die Gewalt wurde weder im Namen des Katholizismus noch gegen den Katholizismus oder eine andere Konfession ausgetragen.

Die lokalen Konfliktakteure wollten unter demselben römisch-katholischen Glauben bzw. in derselben kollektiven Sinnstiftung des Katholizismus die Symbole und die Rituale der Kirche mehr mitgestalten und -bestimmen können. In den Konflikten wurden daher vor allem die Repräsentanten der Amtskirche zur Zielscheibe: Priester wurden angegriffen, Bischöfe ausgebuht, kirchliche Zeremonien und Symbole abgelehnt. Es kam aber nicht zu Konflikten unter den katholischen Kirchengängern oder mit Menschen anderer Konfessionen. Auch wenn etwa serbischsprachige Orthodoxe, italienisch- oder ungarischsprachige Juden in der Nähe lebten, waren sie nicht von der Gewalt betroffen. Andersgläubige spielten keine Rolle, weil sie außerhalb des Referenzraumes, das heißt der katholischen Kirche, standen.

In einigen Fällen wandten sich die Menschen zwar von der Organisation oder den institutionalisierten Formen der katholischen Kirche ab, indem sie etwa »zivile Taufen« einführten oder ihren Austritt deklarierten. Sie handelten aber nicht aus einer anderen religiösen Überzeugung heraus, sondern

13 Zum Überblick über die Theorien bezüglich der Gewalt und Religion (Glaube) siehe u. a. Eveline G. Bouwers, Glaube und Gewalt. Ein Beziehungsgeflecht auf dem Prüfstand, in: Dies. (Hg.), Glaubenskämpfe. Katholiken und Gewalt im 19. Jahrhundert, Göttingen 2019, S. 13-38, hier S. 25-33.

14 Zum Verständnis der »religiösen Gewalt« als einer im Namen einer Religion durchgeführten Gewalt siehe u.a. Reinhard Schulze, Islamischer Puritanismus und die religiöse Gewalt, in: Christine Aввт / Donata Schoeller (Hg.), Im Zeichen der Religion. Gewalt und Friedfertigkeit in Christentum und Islam, Frankfurt a. M./New York 2008, S. 34-56, hier S. 44. 
infolge von Meinungsunterschieden mit der kirchlichen Obrigkeit. Wenn Menschen etwa den Priester nicht akzeptierten und ihre Kinder daher nicht von ihm taufen ließen, bedeutete es noch keinen Konflikt um den richtigen Glauben - vielmehr war es ein Konflikt um die weltlich sichtbare Ebene der Religion, sprich: um die Priester, die Organisationen, die Rituale. Dabei zeigte sich ein Konkurrenzkampf um das religiöse Feld zwischen der »offiziellen« Kirche (den kirchlichen Obrigkeiten) und den »einfachen« Kirchgängern. Die katholische Kirche stellte dabei den Raum der Konflikte dar - nicht (nur) physikalisch-räumlich, sondern vielmehr im Sinne von Geltungsbereich und Bezugspunk $\mathrm{t}^{15}$-, in dem sich die Gewalthandlungen ereigneten bzw. auf den sich diese Handlungen letztendlich bezogen.

In den untersuchten Konflikten ging es demnach um die Frage, wer die Ressourcen im kirchlichen Raum kontrollieren dürfe und solle: die tradierten Autoritäten wie die Priester? Die nationalistischen Agitatoren, die diese Ressourcen für das politische Feld fruchtbar machen wollten? Die lokalen Akteure, die ihr Kirchenleben vor Ort, ohne den katholischen Glauben aufzugeben, immer mehr mitbestimmen wollten? Im Mittelpunkt der Konflikte stand also die Frage, wem der kirchliche Raum gehört. Diese Frage betrifft nicht die Richtigkeit einer Lehre, sondern die gesellschaftliche Teilhabe innerhalb desselben religiösen Referenzrahmens. Auch wenn die Gewalt in gewisser Hinsicht religionsbezogen war, waren die Motive in Europa nicht mehr primär religiös (wie etwa in den frühneuzeitlichen Religionskriegen). Einerseits wurde selbst der »katholische Raum» pluraler, vielschichtiger. Andererseits lagen der Gewalt andere (meist politische und/oder soziale) Komponenten, Gründe, Differenzen zugrunde. ${ }^{16}$ Rogers Brubaker stellt dementsprechend fest, dass moderne Konflikte um den kirchlichen Raum eigentlich nicht religiös, sondern vielmehr politisch motiviert seien. ${ }^{17}$ Die Konflikte innerhalb desselben religiösen Feldes entstehen nicht um theologische Unterschiede, sondern um die Machtfrage - diese mag zwar mit theologischen Konsequenzen (in puncto, wer die Lehre bestimmt) zusammenhängen, aber sie ist primär politischer Natur. ${ }^{18}$ Auch im Falle des Küs-

15 Zur Begrifflichkeit vom »Gewaltraum« als einem Handlungs- und Geltungsbereich gewalttätiger Akte siehe u.a. Ulrike Jureit, Raum und Gewalt. Eine Einleitung, in: Dies. (Hg.), Umkämpfte Räume. Raumbilder, Ordnungswille und Gewaltmobilisierung, Göttingen 2016, S. 9-25, hier S. 10.

16 Zur Frage, wie säkulare Differenzen die "religiöse Gewalt» im 19. Jahrhundert bestimmten, siehe Eveline G. Bouwers, Die Wandlungen im Verhältnis von Glaube und Gewalt im 19. Jahrhundert, in: Dies. (Hg.), Glaubenskämpfe, S. 337-345, hier S. 339.

17 Rogers Brubaker, Religious Dimensions of Political Conflict and Violence, in: Sociological Theory 33 (2015), S. 1-19, hier S. 4.

18 Kwame Anthony Appiah, The Lies that Bind. Rethinking Identity, New York/London 2019, S. 40. 
tenlandes bezog sich die Frage, wem bzw. wie die kirchlichen Räume und Rituale zugänglich gemacht werden sollten, auf die politischen und gesellschaftlichen Machtverhältnisse und Teilhabemöglichkeiten - das heißt auf eine eminent politische und soziale Frage, welche innerhalb der katholischen Kirche zu sozial bedingten Konflikten führten, weil die Konfliktparteien in der sozialen Hierarchie unterschiedliche Positionen hatten.

Dass die katholische Kirche im ganzen Küstenland ethnisch-sprachlich heterogen war, erleichterte eine nationalisierende Erklärung für jegliche lokale Konfliktfälle. Der ethnisch-sprachlichen Heterogenität war freilich ein gewisses Konfliktpotenzial immanent - das will ich in meiner Arbeit auf keinen Fall leugnen. Das heterogeniebedingte Konfliktpotenzial konnte allerdings erst durch Prozesse der Modernisierung aktiviert und verstärkt werden. ${ }^{19}$ Insofern wurden Konflikte, die mit der Herausbildung einer modernen, fragmentierten Gesellschaft zusammenhingen, entlang der vorhandenen und verstärkt wahrgenommenen Heterogenität (das heißt der sprachlichen, ethnischen Unterschiede) inszeniert. Infolge der Überbetonung der nationalen Komponente gerieten auch die innerkatholischen Konflikte in den politischen Makrodiskurs der »Nationalitätenkonflikte«. Chantal Mouffe analysiert in ihrer politischen Theorie, wie und warum antagonistische (das heißt Freund/Feind) Gegensätze aus einfachen Differenzen (das heißt agonistischen Gegner/Gegner-Situationen) entstehen können. ${ }^{20}$ Die antagonistischen Konflikte folgen einer eigenen Logik, jener des Politischen. Diesem liegen zwei Logiken zugrunde: die Logik der Differenz (das heißt dass das Eigene durch komplette Ausschließung eines Anderen definiert wird) und die Logik der Äquivalenz (das heißt dass das Eigene nach innen homogenisiert wird). ${ }^{21}$ Die harten, "klaren « Gegensätze treten aus den weichen, fluiden Differenzen erst in einem politischen Konflikt hervor. Sie sind demnach nicht Ursache, sondern Folge der Konflikte. Das heißt in Bezug auf die »Nationalisierung« jeglicher Konflikte: Nur weil ein Konflikt im politischen Vokabular des »Nationalitätenkonfliktes« vorgetragen wird, bedeutet es dementsprechend noch nicht, dass dem Konflikt die ethnischsprachlichen Differenzen als Ursache zugrunde lagen.

Dass die angegriffenen Priester und die angreifenden Kirchgänger nicht selten zur selben Nationalität gehörten oder dass die Nationalität in den ländlichen Gebieten anders erlebt wurde als in den städtischen Diskursen,

19 Moritz CsÁky, Mitteleuropa/Zentraleuropa. Ein komplexes kulturelles System, in: Österreichische Musikzeitschrift 60 (2005), S. 9-16, hier S. 14f.

20 Chantal Mouffe, Über das Politische. Wider die kosmopolitische Illusion, Frankfurt a. M. 2007, S. $16 \mathrm{ff}$.

21 Thomas Bedorf, Das Politische und die Politik - Konturen einer Differenz, in: Ders./Kurt Röttgers (Hg.), Das Politische und die Politik, Frankfurt a.M. 2010, S. 13-37, hier S. 21f. 
wurde in den externen Konfliktwahrnehmungen komplett ausgeblendet. Der "Nationalitätenkonflikt« stellte als Interpretationsnarrativ ein dominierendes Sagbarkeitsregime dar: Es spiegelte die damalige Machtstruktur wider, in welcher das Gesagte seine Bedeutung gewinnen konnte. In meiner Forschung hinterfrage ich daher das ethnisch (ethnopolitisch) aufgeladene Narrativ der »Nationalitätenkonflikte« auch bezüglich der innerkatholischen Konflikte, denn

[s]o genannte »ethnische" Konflikte sind [...] nicht als Konflikte zu betrachten, denen Ethnizität als eine eigenständige, vorgängige und unabhängige Ursache bzw. Bedingung zu Grunde liegt. Vielmehr gilt es zu klären, wann und wie in sozialen Konfliktdynamiken auf ethnisierende Artikulationsangebote von Problemen und Interessen sowie auf ethnisierende Interpretationsangebote von sozialen Ungleichheiten, Macht und Herrschaftsverhältnissen, Etablierten-Außenseiter-Konflikten, der Folgen und Nebenfolgen sozialer Ausgrenzung usw. zurückgegriffen wird und wann nicht. ${ }^{22}$

Ethnizität (Nationalität) beschreibt insofern soziale Ungleichheit. ${ }^{23}$ In den innerkatholischen Konfliktfällen lässt sich besonders die Situation der südslawischen, katholischen Landbevölkerung in dieser Hinsicht betrachten. Die sozialen Hintergründe der Konflikte konnten in der Machtstruktur, in der die südslawische, katholische Landbevölkerung mehrfach marginalisiert wurde, kaum zum Tragen kommen. Daher bietet sich die Intersektionalität als Erklärung an: Mit dieser werden Positionen beschrieben, die nicht aus einem hierarchisch bedingten Machtverhältnis, ${ }^{24}$ sondern aus der Überlappung mehrerer Asymmetrien und Diskriminierungen zu verstehen sind. ${ }^{25}$ So lässt sich die Vielschichtigkeit der Macht- und Unterdrückungsverhältnisse - jenseits von einseitigen, kategorisierenden und hierarchischen Erklä-

22 Ulrike Hormel / Albert SCHerr, Was heißt »Ethnien« und »ethnische Konflikte« in der modernen Gesellschaft?, in: Alex Groenemeyer / Jürgen Mansel (Hg.), Die Ethnisierung von Alltagskonflikten, Wiesbaden 2003, S. 47-66, hier S. 48.

23 Alex Groenemeyer, Kulturelle Differenz, ethnische Identität und die Ethnisierung von Alltagskonflikten. Ein Überblick sozialwissenschaftlicher Thematisierungen, in: Ders. / MAnsel (Hg.), Die Ethnisierung von Alltagskonflikten, S. 11-46, hier S. 35ff.

24 Kimberle Crenshaw, Demarginalizing the Intersection of Race and Sex. A Black Feminist Critique of Antidiscrimination Doctrine, Feminist Theory and Antiracist Policies, in: University of Chicago Legal Forum 1989, S. 139-167, hier S. 139f.; sowie dies., Mapping the Margins. Intersectionality, Identity Politics, and Violence against Women of Color, in: Stanford Law Review 43 (1991), S. 1241-1299, hier S. 1244.

25 Andrea Griesebner/Susanne Hehenberger, Intersektionalität. Ein brauchbares Konzept für die Geschichtswissenschaften?, in: Vera Kallenberg u.a. (Hg.), Intersectionality und Kritik. Neue Perspektiven für alte Fragen, Wiesbaden 2013, S. 105-124, hier S. 107. 
rungen und Modellen - aufzeigen, ${ }^{26}$ in der sich die Menschen $»$ in Wechselwirkungen ungleichheitsgenerierender sozialer Strukturen « befinden. ${ }^{27}$

Die katholische, südslawische Landbevölkerung des Küstenlandes wurde mehrfach und vielschichtig peripherisiert und marginalisiert. Als Südslawen waren sie an der politischen Peripherie einer Öffentlichkeit, die eher von den italienischsprachigen, nationalliberalen Eliten der Küstenstädte bestimmt war; als Katholiken waren sie an der Peripherie einer Öffentlichkeit, in der die nationalliberalen, antiklerikalen Ideen die Diskurse bestimmten; und als Bewohner ländlicher Gebiete waren sie an der Peripherie des ethnischnational markierten, urbanen Raumes. Sie wurden darüber hinaus sowohl innerhalb der katholischen (klerikalen) als auch der jeweiligen »eigenen « "nationalen« Öffentlichkeit peripherisiert und marginalisiert. Dort galten sie entweder als religiös indifferent (weil sie ihren Glauben anders erleben und praktizieren wollten) oder als national indifferent (weil sie sich dem südslawischen Nationalismus der Elitendiskurse nicht unterwarfen). Die diesbezüglichen Vorwürfe sind in den untersuchten Konfliktfällen anzutreffen. Einerseits versuchten nationalistische Akteure, die innerkirchlichen Konflikte entlang ethnisch-nationaler Polarisierungen zu erklären. Andererseits bezichtigten die südslawischen Nationalisten die südslawische Landbevölkerung, falls diese den nationalistischen Erwartungen nicht entsprach, der »nationalen Indifferenz«.

\subsubsection{Historiographie von Nation und Religion: \\ Nationalismus oder nationale Indifferenz?}

Das Spannungsverhältnis mit den partikularen Nationalismen stellt besonders im Falle der katholischen Völker ein auch philosophisch-theologisch relevantes Problem dar. ${ }^{28}$ In der Historiographie sind die Wechselwirkungen zwischen Nation und Religion (im Besonderen: zwischen Nation und Katholizismus) theoretisch ${ }^{29}$ wie auch bezüglich der ostmittel- und südosteuropä-

26 Vivian M. MAY, Pursuing Intersectionality, Unsettling Dominant Imaginaries, New York/ London 2015, S. 1ff.

27 Gabriele Winker / Nina Degele, Intersektionalität. Zur Analyse sozialer Ungleichheiten, Bielefeld 2009, S. 12f.

28 Über die Problematik eines nationalistischen Katholizismus siehe u.a. György GeréBy, A népek angyalai, avagy lehetséges-e nemzeti kereszténység? [Die Engel der Völker - oder ist ein nationaler Katholizismus möglich?], in: Pannonhalmi Szemle 16 (2008), S. 35-55; Dorian S. J. Llewelyn, Toward a Catholic Theology of Nationality, Lanham 2010.

29 Siehe u. a. Heinz-Gerhard Haupt, Religion and Nation in Europe in the 19th Century: Some Comperative Notes, in: Estudos avançados 22 (1998), S. 77-94; Urs AltermatT, Religion und Nation - Die Rolle der Religion bei der Nationalstaatenbildung Europas im 19. und 20. Jahrhundert, in: Dieter Ruloff (Hg.), Religion und Politik, 
ischen Region ${ }^{30}$ weit erforscht. Hinsichtlich der Habsburgermonarchie ist dieses Verhältnis in der imposanten Monographie von Andreas Gottsmann

Chur/Zürich 2001, S. 27-52; Harmut Lehmann, Die Säkularisierung der Religion und die Säkularisierung der Nation im 20. Jahrhundert. Varianten einer komplementären Relation, in: Hans-Christian Maner / Martin Schulze Wessel (Hg.), Religion im Nationalstaat zwischen den Weltkriegen 1918-1939. Polen - Tschechoslowakei Ungarn - Rumänien, Stuttgart 2002, S. 13-27; Martin Geyer/Hartmut LehmanN (Hg.), Religion und Nation. Nation und Religion, Göttingen 2004; Martin Schulze Wessel, Nationalisierung der Religion und Sakralisierung der Nation im östlichen Europa, in: Ders. (Hg.), Nationalisierung der Religion und Sakralisierung der Nation im östlichen Europa, Stuttgart 2006, S. 7-14; Urs Altermatt, Katholizismus und Nation. Vier Modelle in europäisch-vergleichender Perspektive, in: Ders./Franziska Metzger (Hg.), Religion und Nation. Katholizismen im Europa des 19. und 20. Jahrhunderts, Stuttgart 2007, S. 15-31; Thomas Bremer, Religion and Conceptual Boundary in Central and Eastern Europe. Introductory Remarks, in: Ders. (Hg.), Religion and Conceptual Boundary in Central and Eastern Europe, New York 2007, S. 1-15; William Safran, Language, Ethnicity and Religion. A Complex and Persistent Linkage, in: Nations and Nationalism 14 (2008), S. 171-190; Urs AlterMatт, Konfession, Nation und Rom. Metamorphosen im schweizerischen und europäischen Katholizismus des 19. und 20. Jahrhunderts, Frauenfeld 2009; Franziska Metzger, Religion, Geschichte, Nation. Katholische Geschichtsschreibung in der Schweiz im 19. und 20. Jahrhundert - kommunikationstheoretische Perspektiven, Stuttgart 2010; Rogers Brubaker, Religion and Nationalism. Four approaches, in: Nation and Nationalism 18 (2012), S. 2-20; ders., Language, Religion, and the Politics of Difference, in: Ders., Grounds for Difference, Cambridge MA/London 2015, S. 85-101; John Carter WooD, "Blessed is the Nation«? Christianity and National Identity in Twentieth-Century Europe, in: Ders. (Hg.), Christianity and National Identity in Twentieth-Century Europe. Conflict, Community, and the Social Order, Göttingen 2016, S. 11-31.

30 Siehe u.a. Stefan MalfÈr, Der Kampf um die slawische Liturgie in der österreichisch-ungarischen Monarchie - ein religiöses oder ein nationales Anliegen?, in: Mitteilungen des Österreichischen Staatsarchivs 44 (1996), S. 165-193; Rolf WörsDÖRFER, »Slawischer« und »lateinischer« Katholizismus im Nationalitätenkonflikt. Der Streit um die Liturgie- und Unterrichtssprache in den adriatischen Diözesen Österreich-Ungarns, Italiens und Jugoslawiens (1861-1941), in: Archiv für Sozialgeschichte 40 (2000), S. 171-201; Moritz Csáky/Klaus Zeyringer (Hg.), Pluralitäten, Religionen und kulturelle Codes. Religion-Mythos-Nation, Innsbruck u. a. 2001; Martin Schulze Wessel, Das 19. Jahrhundert als "Zweites Konfessionelles Zeitalter«? Thesen zur Religionsgeschichte der böhmischen Länder in europäischer Hinsicht, in: Zeitschrift für Ostmitteleuropa-Forschung 50 (2001), S. 514-530; Maner/Schulze Wessel (Hg.), Religion im Nationalstaat zwischen den Weltkriegen; Mitja Slane, Kirche und Nation. Die slowenische nationale Frage und der Katholizismus bis zum 1. Weltkrieg, Klagenfurt 2003; Klaus Buchenau, Orthodoxie und Katholizismus in Jugoslawien 1945-1991. Ein serbisch-kroatischer Vergleich, Wiesbaden 2004; Stipan Trogrlić, Katolička crkva u Istri. Nacionalno-političke i idejne podjele 1880-1914 [Katholische Kirche in Istrien. Nationalpolitische und ideelle Polarisierungen], Pula 2006; James BJork, Neither German nor Pole. Catholicism and National Indifference. Catholicism and National Indifference in a Central European Borderland, Ann Arbor 2008; Martin Schulze Wessel, Religion, Politics and the Limits of Imperial Integration. Comparing the Habsburg Monarchy and the Russian Empire, in: Jörn Leonhard/Ulrike von HirschHausen (Hg.), Comparing Empires. Encounters and Transfers in the Long Nineteenth Century, Göttin- 
über die nationalen Katholizismen bereits sehr gut erforscht. ${ }^{31}$ Gottsmann beleuchtet dabei die makropolitischen Wellen, welche durch die einzelnen, lokalen Konflikte angestoßen wurden. Weil der »Nationalitätenkonflikt« ein wichtiges Thema sowohl für die imperiale als auch die päpstliche Politik darstellte, wurden die lokalen Konflikte in dessen Kontext aufgefasst. Gottsmann zeichnet diesen Kontext und die daraus entstandene öffentliche Wahrnehmung der innerkatholischen Konfliktfälle - von lokalen Gewaltmomenten bis hin zu den Querelen um kirchenorganisatorische Problemfelder - aufgrund einer immensen Quellenarbeit minutiös und überzeugend nach. Gottsmanns Monographie deckt die ganze Donaumonarchie ab. Seine These der nationalen Spaltung kirchlicher Räume, die schon bei Moritz Csáky in seiner bewusst im Plural gehaltenen Begrifflichkeit »Katholizismen « der Habsburgermonarchie anzutreffen ist, ${ }^{32}$ zeigt, dass das Narrativ der »Nationalitätenkonflikte« sowohl die kirchliche Öffentlichkeit als auch die politischen und diplomatischen Debatten über den kirchlichen Raum stark bestimmte. Die Erkenntnisse von Gottsmann lassen sich jedenfalls von der Perspektive von unten, die in dieser Arbeit angestrebt wird, in vieler Hinsicht ergänzen und teilweise relativieren. Was für die "hohe Politik" ein weiteres Beispiel des »Nationalitätenkonfliktes « bedeutete - was im oberadriatischen Raum sogar als Zeichen der vermeintlich sinkenden Integrationskraft des Katholizismus im Zeitalter des "nationalen Erwachens" gedeutet wurde -, war auf der lokalen Ebene vom Zusammenwirken unterschiedlicher persönlicher oder sozialer Interessen geprägt, die oft nicht politisch, geschweige denn nationalpolitisch motiviert waren.

Wegen der lang anhaltenden Dominanz der nationalstaatlichen (und nationalstaatlich organisierten) Historiographien in den posthabsburgischen Staaten wurden die makropolitischen »Nationalitätenkonflikte« sehr detailliert aufgearbeitet und erinnert. ${ }^{33}$ Diese Perspektive erklärt sich frei-

gen 2011, S. 337-358; Ksenija Petrovic, Nationale Identität und Religion in Serbien und Kroatien im Vergleich, Wiesbaden 2013; Aleksandar JAKIR/Marko TrogrLIĆ (Hg.), Klerus und Nation in Südosteuropa vom 19. bis zum 21. Jahrhundert, Frankfurt a. M. 2014; Heiner Grunert, Glauben im Hinterland. Die Serbisch-Orthodoxen in der habsburgischen Herzegowina 1878-1918, Göttingen 2016; Theodora Dragostinova / Yana Hashamova, Introduction. Beyond Mosque, Church, and State. Alternative Narratives of the Nation in the Balkans, in: Dies. (Hg.), Beyond Mosque, Church, and State. Alternative Narratives of the Nation in the Balkans, Budapest/ New York 2016, S. 1-27.

31 Andreas Gottsmann, Rom und die nationalen Katholizismen in der Donaumonarchie. Römischer Universalismus, habsburgische Reichspolitik und nationale Identitäten 1878-1914, Wien 2010.

32 Moritz CsÁky, Paradigma Zentraleuropa. Pluralitäten, Religionen und kulturelle Codes. Religion - Mythos - Nation. Einführende Überlegungen, in: Ders. / ZEYRINGER (Hg.), Pluralitäten, Religionen und kulturelle Codes, S. 9-17, hier S. 13.

33 Judson, Die Habsburgermonarchie - neue Interpretationen, S. 317. 
lich aus der Fokussierung auf Elitendiskurse und Presse- und Parlamentsdebatten, die fälschlicherweise als Widerspiegelung der gesellschaftlichen Dynamiken aufgefasst wurden. ${ }^{34}$ Somit verkam die komplexe Geschichte des Habsburgerreiches zu Parallelgeschichten von sich ständig in Konkurrenzkampf befindenen Völkern. ${ }^{35}$ Dabei wird die europäische Geschichte auf die Nationalstaaten verengt und zur Norm einer angeblichen Fortschrittsgeschichte verklärt. ${ }^{36}$ Dieser "methodologische Nationalismus « bestimmte sowohl inhaltlich als auch wissenstechnisch und wissenssoziologisch die Arbeiten über die Habsburgermonarchie, weil die Historiographie (und die Erinnerungspolitik) der posthabsburgischen Nationalstaaten an der Nationalisierung ihrer Vorgeschichte und an der Essentialisierung ihrer Identitäten ein großes Interesse hatten. ${ }^{37}$ Die neuen "Nationalstaaten " erklärten dementsprechend rückwirkend die Habsburgermonarchie zu einem »Völkerkerker «, um ihre eigene Existenz dadurch begründen und legitimieren zu können. ${ }^{38}$ Dieser "methodologische Nationalismus « schließt - wie Ulrich Beck feststellt - die Vielfältigkeit der untersuchten Gesellschaften aufgrund "monolithischer Imaginationen « aus: ${ }^{39}$ Die Gesellschaften werden dabei nur im Rahmen einer konstruierten (oder imaginierten) homogenen Einheitlichkeit analysiert. ${ }^{40}$

Weder die Kraft des Nationalismus noch die vorhandenen ethnischsprachlichen Identifizierungen sollen allerdings in dieser Arbeit infrage gestellt werden. Der Nationalismus ist jedoch ein Eliteprogramm - insofern lassen sich lokale Dynamiken nicht (allein) durch ihn erklären. Die innerhabsburgische Gesellschaft war - wie etwa Benno Gammerl in seiner hervorragenden Monographie über die unterschiedlichen Differenzaushandlungsprozesse im Britischen und im Habsburgischen Reich nachzeich-

34 Moritz Csáky, Ideologie der Operette und Wiener Moderne. Ein kulturhistorischer Essay zur österreichischen Identität, Wien u. a. 1996, S. 227.

35 Kerstin S. Јовsт u. a., Neue Imperiumsforschung in der Osteuropäischen Geschichte: die Habsburgermonarchie, das Russländische Reich und die Sowjetunion, in: Comparativ. Zeitschrift für Globalgeschichte und Gesellschaftsordnung 18 (2008), S. 27-56, hier S. 32f.

36 Jörn LeOnhard/Ulrike von Hirschausen, Empires und Nationalstaaten im 19. Jahrhundert, Göttingen 2009, S. 9 f.

37 Als Fallbeispiel siehe etwa die Slowakisierung der davor mehrheitlich deutschsprachigen Stadt Preßburg/Pozsony/Prešporok; vgl. dazu Iris Engemann, Die Slowakisierung Bratislavas. Universität, Theater und Kultusgemeinden 1918-1948, Wiesbaden 2012.

38 Krishan Kumar, Visions of Empire. How Five Imperial Regimes Shaped the World, Princeton / Oxford 2017, S. 212.

39 Ulrich Beck, The Cosmopolitan Society and Its Enemies, in: Theory, Culture \& Society 19 (2002), S. 17-44, hier S. 18.

40 Ders./Edgar Grande, Jenseits des methodologischen Nationalismus. Außereuropäische und europäische Variationen der Zweiten Moderne, in: Soziale Welt 61 (2010), S. 187-216, hier S. 189. 
net - statt klarer Grenzen und Abgrenzungen eher von Verflechtungen, Fluidität sowie einer »Sowohl-als-auch«-Realität (trotz der antagonistisch anmutenden Strukturen) geprägt. ${ }^{41}$ Die lokalen Differenzen wurden nicht nur nach den nationalen und nationalistischen Kategorien und Erwartungen ausgehandelt, ${ }^{42}$ was besonders im multiethnischen oberadriatischen Raum zum Konflikt zwischen dem elitären Nationalismus und der lokalen Realität führte. ${ }^{43}$

In der Habsburger-Historiographie setzte sich dementsprechend allmählich eine neue Richtung durch: Indem das historische Interesse jenseits und unterhalb der Makrodiskurse - das heißt der Theatralität der »Nationalitätenkonflikte ${ }^{44}$ - ansetzt, kommt die komplexe Realität der (in ihren zwei Reichshälften an sich unterschiedlichen) Donaumonarchie zum Vorschein. Dabei gelten die Werke als erkenntnisbringend und perspektivisch, ${ }^{45}$ die sich sehr stark auf die lokalen Realitäten von kleineren Räumen, ${ }^{46}$

41 Benno Gammerl, Untertanen, Staatsbürger und Andere. Der Umgang mit ethnischer Heterogenität im Britischen Weltreich und im Habsburgerreich 1867-1918, Göttingen 2010, S. 143.

42 Daniela Simon, Kulturelle Hybridität als Bedrohung? Istrien im ausgehenden 19. Jahrhundert, in: Jahrbücher für europäische Ethnologie 14 (2019), S. 53-76, hier S. $55 f$.

43 Ebd., S. 59.

44 Pieter M. Judson, L' Autriche-Hongrie était-elle un empire?, in: Annales. Histoire, Sciences Sociales 63 (2008), S. 563-596, hier S. 586.

45 Angesichts der zu erfassenden Kompliziertheit des (post)habsburgischen Raumes meint Pieter Judson sogar, dass die Habsburgerforschung für die allgemeine Geschichtswissenschaft ein »laboratory for creative innovation « geworden sei; Pieter Judson, The Habsburg Empire. A New History, Cambridge / London 2016, S. 11.

46 Bahnbrechend dabei war das Buch Gary B. Cohen, The Politics of Ethnic Survival. Germans in Prague, 1861-1914, Princeton 1981; aus der neueren Literatur siehe u. a. Laurence COLE, »Für Gott, Kaiser und Vaterland«. Nationale Identität der deutschsprachigen Bevölkerung Tirols 1860-1914, Frankfurt a. M. / New York 2000; Jeremy KING, Budweisers into Czechs and Germans. A Local History of Bohemien Politics, 1848-1948, Princeton NJ 2002; Eleonóra BABEJovÁ, Fin-de-siècle Pressburg. Conflict and Cultural Coexistence in Bratislava, 1897-1914, Boulder 2003; Vanni D’ Alessio, Il cuore conteso. Il nazionalismo in una comunità multietnica. L' Istria asburgica [Das umworbene Herz. Der Nationalismus in einer multiethnischen Gemeinschaft. Das habsburgische Istrien], Napoli 2004; Hans-Christian MANER (Hg.), Grenzregionen der Habsburgermonarchie im 18. und 19. Jahrhundert. Ihre Bedeutung und Funktion aus der Perspektive Wiens, Münster 2005; Chris Hann / Paul Robert Magocsi (Hg.), Galicia. A Multicultured Land, Toronto 2005; Judson, Guardians of the Nation; Alison Fleig Frank, Oil Empire. Visions of Prosperity in Austrian Galicia, Cambridge MA 2007; Hans-Christian MANER, Galizien. Eine Grenzregion im Kalkül der Donaumonarchie im 18. und 19. Jahrhundert, München 2007; Julia RICHERs, Jüdisches Budapest. Kulturelle Topographien einer Stadtgemeinde im 19. Jahrhundert, Köln 2009; Kurt SCHARR, "Die Landschaft Bukowina«. Das Werden einer Region an der Peripherie 1774-1918, Wien 2010; Norbert Spannenberger/Szabolcs VARGA (Hg.), Ein Raum im Wandel. Die osmanisch-habsburgische Grenzregion vom 16. bis zum 18. Jahrhundert, Stuttgart 2014; Robert Pyrah / Jan Fellerer, Redefining »Sub-culture«: A New Lens for Understanding Hybrid Cultural Identities in East- 
speziellen gesellschaftlichen Schichten, ${ }^{47}$ einzelnen Biographien, ${ }^{48}$ imperialen oder subimperialen Praktiken, ${ }^{49}$ gescheiterten oder parallelen »Nationsbildungen $\aleph^{50}$ (o.ä.) fokussieren.

Central Europe with a Case Study from Early 20th Century L'viv-Lwów-Lemberg, in: Nations and Nationalism 21 (2015), S. 700-720; Frank Henschel, »Das Fluidum der Stadt ...«Urbane Lebenswelten in Kassa / Košice / Kaschau zwischen Sprachenvielfalt und Magyarisierung 1867-1918, Göttingen 2017; Mihai I. Spariosu (Hg.), Intercultural Conflict and Harmony in the Central European Borderlands. The Cases of Banat and Transylvania 1849-1939, Göttingen 2017; Magdalena BARANSzołtys / Olena Dvoretska u.a. (Hg.), Galizien in Bewegung. Wahrnehmungen Begegnungen - Verflechtungen, Göttingen 2018.

47 Aus der neueren Literatur siehe u. a. Keely Stauter-Halsted, Nation in the Village. The Genesis of Peasant National Identity in Austrian Poland, 1848-1914, Ithaca / London 2001; Hannes Grandits, Familie und sozialer Wandel im ländlichen Kroatien (18.-20. Jahrhundert), Wien u. a. 2002; Sabine Rutar, Kultur - Nation Milieu. Sozialdemokratie in Triest vor dem Ersten Weltkrieg, Essen 2004; Kai Struve, Bauern und Nation in Galizien. Über Zugehörigkeit und soziale Emanzipation im 19. Jahrhundert, Göttingen 2005; Harold BInDER, Galizien in Wien. Parteien, Wahlen, Fraktionen und Abgeordnete im Übergang zur Massenpolitik, Wien 2008; Andriy Zayarnyuk, Framing the Ukrainian Peasantry in Habsburg Galicia, 1846-1914, Edmonton / Toronto 2013; Isabel RösKAU-RydeL, Zwischen Akkulturation und Assimilation. Karrieren und Lebenswelten deutsch-österreichischer Beamtenfamilien in Galizien (1772-1918), München 2016; Jakub S. BEnEš, Workers and Nationalism. Czech and German Social Democracy in Habsburg Austria, 1890-1918, Oxford 2017; Jan Surman, Universities in Imperial Austria, 1848-1918. A Social History of a Multlingual Space, West Lafayette 2019.

48 Aus der neuen Literatur siehe u.a. Martin Aust / Frithjof Benjamin Schenk (Hg.), Imperial Subjects. Autobiographische Praxis in den Vielvölkerreichen der Romanovs, Habsburger und Osmanen im 19. und frühen 20. Jahrhundert, Wien u. a. 2015; Tim Buchen / Malte Rolf (Hg.), Eliten im Vielvölkerreich. Imperiale Biographien in Russland und Österreich-Ungarn, Berlin/Boston 2015; Stephanie Weismann, Das Potenzial der Peripherie. Leopold von Sacher-Masoch (1836-1895) und Galizien, Göttingen 2017; Anna Ransmayr, Untertanen des Sultans und des Kaisers. Struktur und Organisationsformen der beiden Wiener griechischen Gemeinden von den Anfängen im 18. Jahrhundert bis 1918, Göttingen 2018.

49 Aus der neueren Literatur siehe u.a. Maria Bucur/Nancy M. Wingfield (Hg.), Staging the Past. The Politics of Commemoration in Habsburg Central Europe, 1848 to the Present, West Lafayette 2001; Rosita Rindler Schjerve (Hg.), Diglossia and Power. Language Policies and Practice in the 19th Century Habsburg Empire, Berlin / New York 2003; Daniel L. Unowsky, The Pomp and Politics of Patriotism. Imperial Celebrations in Habsburg Austria 1848-1916, West Lafayette 2005; Tara ZAHRA, Kidnapped Souls. National Indifference and the Battle for Children in the Bohemian Lands. 1900-1948, Ithaca/London 2008; Laurence Cole, Military Culture and Popular Patriotism in Late Imperial Austria, Oxford 2014; Kathrin KrognerKornaliK, Tod in der Stadt. Religion, Alltag und Festkultur in Krakau 1869-1914, Göttingen 2015; Bálint VARGA, The Monumental Nation. Magyar Nationalism and Symbolic Politics in Fin-de-siècle Hungary, New York/ Oxford 2016.

50 Aus der neueren Literatur siehe u. a. Konrad Clewing, Staatlichkeit und nationale Identitätsbildung. Dalmatien in Vormärz und Revolution, München 2001; Anna Milo, Trieste, 1830-1870. From Cosmopolitanism to the Nation, in: Laurence Cole (Hg.), Different Paths to the Nation. Regional and National Identities in Central Europe and Italy, 1830-1870, New York 2007, S. 60-81; Tomasz Kamusella, Silesia 
Vielen von diesen Studien liegt die Erkenntnis zugrunde, dass die Nation als politische Idee und politischer Gestaltungsraum eine Konstruktion sei. ${ }^{51}$ Diese Erkenntnis bleibt jedoch selbst in einem modernistischen Paradigma verfangen, weil die konstruktivistische Nationalismusforschung das Phänomen anderer Selbstverortungen nicht - oder nur als Zeichen von Rückständigkeit - erklären kann. ${ }^{52}$ Sowohl die konstruktivistischen Theorien als auch die Nationalismen betrachteten und betrachten die einfachen Menschen als Objekte im Prozess der Nationsentstehung. Was für die Nationalismen ein Programm darstellte, erscheint in der konstruktivistischen Theorie als historische Beschreibung.

Es brauchte also eine andere Methode und Herangehensweise, in der die »einfachen« Menschen ebenso auf die historische Bühne als Akteure sozialer Vorgänge »kommen" können. Um ihnen eine Stimme zu geben und somit die spätere historiographische Fokussierung auf die "Nationalitätenfrage» kritisieren zu können, führte Tara Zahra das heuristische und innovative Konzept der »nationalen Indifferenz« als analytische Kategorie ein. ${ }^{53}$ Diese

and Central European Nationalisms. The Emergence of National and Ethnic Groups in Prussian Silesia and Austrian Silesia, 1848-1918, West Lafayette 2007; Hannes Grandits, Herrschaft und Loyalität in der spätosmanischen Gesellschaft. Das Beispiel der multikonfessionellen Herzegowina, Wien u.a. 2008; Nathalie Clayer u.a. (Hg.), Conflicting Loyalities in the Balkans. The Great Powers, the Ottoman Empire and Nation Building, London 2011; Dominique ReIll Kirchner, Nationalists Who Feared the Nation. Adriatic Multi-Nationalism in Habsburg Dalmatia, Trieste, and Venice, Stanford 2012; Daniel BARIC, Langue allemande, identité croate. Au fondement d'un particularisme culturel, Paris 2013; Stijn Vervaet, Centar i periferija u Austro-Ugarskoj. Dinamika izgradnje nacionalnih identiteta u Bosni i Hercegovini od 1878. do 1918. godine na primjeru književnih tekstova [Zentrum und Peripherie in Österreich-Ungarn. Die Dynamik des Aufbaus nationaler Identitäten in Bosnien und Herzegowina von 1878 bis 1918 am Beispiel literarischer Texte], Sarajevo 2013; Jernej Kosi, Kako je nastal slovenski narod. Začetki slovenskega nacionalnega gibanja v prvi polovici 19. stoletja [Wie die slowenische Nation entstand. Die Anfänge der slowenischen Nationalbewegung in der ersten Hälfte des 19. Jahrhunderts], Ljubljana 2013; Edin Hajdar pasic, Whose Bosnia? Nationalism and Political Imagination in the Balkans, 1840-1914, Ithaca/London 2015; Luciano Monzali, The Italians of Dalmatia. From Italian Unification to World War, Toronto 2016; Vahidin PreLjević, Nakon imperije. Književnost i politička imaginacija u (post)habsburškom kulturnom prostoru [Nach dem Imperium. Literatur und politische Imagination im (post) habsburgischen Kulturraum], Zagreb 2018; Alexander MAxwell, Everyday Nationalism in Hungary. 1789-1867, Boston / Berlin 2019; Ágoston Berecz, Empty Signs, Historical Imaginaries. The Entangled Nationalization of Names and Naming in a Late Habsburg Border Region, New York 2020.

51 Ernest Gellner, Nations and nationalism, Oxford 1983; Eric Hobsbawm, Nations and Nationalism since 1780. Programme, Myth, Reality, Cambridge 1990; Benedict Anderson, Imagined Communities. Reflections on the Origin and Spread of Nationalism, London 2006.

52 BJORк, Neither German nor Pole, S. 4ff.

53 Tara Zahra, Imagined Non-Communities: National Indifference as a Category of Analysis, in: Slavic Review 69 (2010), 93-119, hier S. 93. 
solle alle Lebensformen und Identifizierungen (vom Regionalismus bis hin zum Katholizismus) umfassen, welche nicht eindeutig den klaren nationalen Kategorien zuzuordnen seien. Zahra will somit die kritiklose und unreflektierte Übernahme nationalistischer Selbstbeschreibungen und Kategorien vermeiden, indem sie die Tragweite nationalistischer Politik infrage stellt:

The problem is that historians who analyze nations as »imagined communities « risk remaining imprisoned within nationalists' own discursive universe, analyzing the contested content of nationalist ideologies and cultures without questioning the extent to which those ideologies resonated among their audience. ${ }^{54}$

Zahras Konzept beleuchtet das Spannungsverhältnis zwischen Nation und Religion neu, weil dieses mit Hinweis auf die »nationale Indifferenz« konfessionsgebundener Selbstverortungen aufgehoben bzw. relativiert wird. Gerade die religiöse (besonders: die katholische) Identifizierung ermöglichte eine Auflockerung der ethnisch-sprachlichen Cluster. ${ }^{55}$

Zahra verwies dabei auf mehrere neue Studien, welche die Eindeutigkeit und Ausschließlichkeit der ethnisch-nationalen Identifizierungen - anhand lokaler Beispiele - dekonstruierten. In diesen Studien wurden die religiöse Überlagerung ethnisch-sprachlicher Identitäten, ${ }^{56}$ die Fluidität der sprachkulturellen Grenzen $^{57}{ }^{57}$ oder die wechselnden Selbstverortungen in den Grenzregionen ${ }^{58}$ herausgearbeitet. Das Zahrasche Konzept konnte auch an anderen Fallbeispielen mit Wissensgewinn erprobt werden. ${ }^{59}$ Das Ziel, die lokale Komplexität (»nationale Indifferenz«) zu verstehen und nicht die zeitgenössischen Makrodiskurse darüber (»Nationalitätenkonflikte«) zu reproduzieren, ermöglicht einen sozialgeschichtlichen Ansatz, in dem die Akteure

54 Ebd., S. 111f.

55 Siehe bezüglich der italienischsprachigen Katholiken Péter Теснет, Imperiale Loyalität unter den italienischsprachigen Katholiken in Triest der späten Habsburgermonarchie, in: Osterkamp (Hg.), Kooperatives Imperium, S. 297-314, hier S. 303ff; "national indifferente« Elemente blieben auch später im zentraleuropäischen Katholizismus anzutreffen, siehe bezüglich des Nachkriegspolens Jim BJorK, "I Have Removed the Boundaries of Nations". Nations Switching and the Roman Catholic Church during and after the Second World War, in: Maarten Van GinderACHTER/Jon Fox, National Indifference and the History of Nationalism in Modern Europe, London / New York 2019, S. 204-224, hier S. 218.

56 BJORK, Neither German nor Pole.

57 Judson, Guardians of the Nation.

58 Zahra, Kidnapped Souls.

59 Siehe die Beiträge aus: Austrian History Yearbook 43 (2012); VAn Ginderachter / Fox, National Indifference and the History of Nationalism; sowie Jan FeLLERER u.a. (Hg.), Identities In-between in East-Central Europe, London / New York 2019. 
nicht (nur) als Träger »nationaler« »Identitäten«, sondern vielmehr in ihrem sozio-ökonomischen Umfeld erfasst werden. ${ }^{60}$

In meiner Arbeit kommen ebenso mehrere Akteure vor, die den nationalistischen Erwartungen nicht entsprachen. Schon damals wurde die "nationale Indifferenz« als nationalistischer Vorwurf gegen sie erhoben, als ob sie sich ihrer »eigentlichen« Identität noch nicht bewusst gewesen wären. Diese Vorwürfe beweisen die Richtigkeit des Zahraschen Konzeptes, Räume und »Identitäten«, welche jenseits der nationalistischen Erwartungen und Imaginationen existierten, mehr in den Vordergrund historischer Forschungen zu rücken.

Es ist aber fraglich, ob die Menschen, die sich den nationalistischen Erwartungen und Vorstellungen nicht fügten, wirklich analytisch als "national indifferent « $\mathrm{zu}$ beschreiben seien, oder ob diese Begrifflichkeit nicht selbst zu einer dichotomischen Perspektive führt. ${ }^{61}$ Die Ablehnung der nationalistischen Erwartungen bedeutete nicht zwangsweise, dass diese Menschen kein nationales Bewusstsein gehabt hätten. Der Nationalismus war zwar ein Elitendiskurs, der oft auf Ablehnung oder Missverständnisse auf der lokalen Ebene stieß. Dennoch konnten sich die dortigen Akteure ethnisch-national verorten. Michael Billig verstand das Vorhandensein nationaler Themen im Alltag vieler Menschen als »banal nationalism«, was die alltägliche Reproduzierung nationalistischer Symbole, Sprache, Praktiken (usw.) auf der lokalen Ebene bedeutet. ${ }^{62}$ Billigs betrachtet diesen »banalen Nationalismus « als Grund der politischen Gemeinschaft einer Nation. Auch in der Habsburgermonarchie waren Formen eines solchen Nationalismus - sowohl für das Imperium als auch für die einzelnen Nationalitätenöffentlichkeiten - vorhanden, welche sich überlappen und ergänzen konnten.

Für die Frage, ob die Menschen national indifferent waren oder den nationalistischen Vorstellungen folgten, eignet sich allerdings das Konzept der »everyday ethnicity", das heißt eines alltäglichen Ausdruckes ethnischsprachlicher wie auch national indifferenter Selbstverortungen, ${ }^{63}$ besser als Beschreibung. Mit diesem Konzept denkt Gábor Egry die von John Fox und

60 Maarten Van Ginderachter/Jon Fox, Introduction. National Indifference and the History of Nationalism in Modern Europe, in: Dies. (Hg.), National Indifference and the History of Nationalism, S. 1-14, hier S. 2.

61 Zur Zusammenfassung der in der Forschungsliteratur zum Ausdruck gekommenen Kritik des Zahraschen Konzeptes siehe Ágoston Berecz, Recepciótörténeti széljegyzet Tara Zahra tanulmányához [Rezeptionsgeschichtliche Randnotiz zur Studie von Tara Zahra], in: Regio 25 (2017), S. 43-50.

62 Michael Billig, Banal Nationalism, Los Angeles u. a. 1995.

63 Gábor Egry, Beyond Politics. National Indifference as Everyday Ethnicity, in: VAN Ginderachter / Fox (Hg.), National Indifference and the History of Nationalism, S. 145-160, hier S. 146ff. 
Cynthia Miller-Idriss formulierte Idee der »everyday nationhood « weiter. ${ }^{64}$ Beide Konzepte versuchen die Gefahr einer dichotomischen Perspektive zu vermeiden, in der die Menschen entweder ethnisch-national vollkommen »bewusst" oder "national indifferent" seien. Das Konzept von »everyday ethnicity« (oder »everyday nationhood«) begreift die Ablehnung nationalistischer (externer) Erwartungen und das praktizierte Bewusstsein einer ethnisch-sprachlichen Identität nicht als dichotomische Entweder-Oder-Optionen, sondern als gleichzeitige Phänomene. Dieses Konzept bedeutet insofern keinesfalls einen alltäglichen (politischen) Nationalismus, es ist vielmehr das unpolitische Bewusstsein, national different zu sein (was das Zusammenleben auf der lokalen Ebene bzw. im imperialen Rahmen nicht ausschließt). Daher spricht Maria Todorova etwa vom "weichen Nationalismus" (»weak nationalism«), der nicht als Gegenpol eines »harten Nationalismus« zu verstehen sei, sondern vielmehr das Hauptmerkmal der ethnisch-nationalen Zugehörigkeit, deren Weichheit, Flexibilität, Situativität und Wechselbarkeit zum Ausdruck bringen solle. ${ }^{65}$

Dies zeigte sich besonders bei der Sprachenfrage. ${ }^{66}$ Auch wenn einerseits die Mehrsprachigkeit in vielen Teilen des oberadriatischen Raumes verbreitet war und andererseits die nationalistischen Diskurse die alltägliche Realität nur begrenzt widerspiegelten, benutzten die meisten Menschen doch eine Sprache, mit welcher sie sich identifizieren konnten und anhand welcher sie sich bestimmten und verorteten. »Nationale Indifferenz«, etwa im Sinne vom Desinteresse an nationalistischen, nationsbezogenen Themen, kann auf der lokalen Ebene durchaus attestiert werden. Aber es bedeutete keinesfalls eine »sprachliche Indifferenz $«{ }^{67}$ Dass die Menschen eine Muttersprache hatten und dass sie sich daran orientierten und damit identifizierten, war in der letzten Hälfte des 19. Jahrhunderts auch in der Habsburgermonarchie, sogar in den ländlichen Gebieten, immer stärker präsent. ${ }^{68}$

64 Jon Fox/Cynthia Miller-Idriss, Everyday Nationhood, in: Ethnicities 8 (2008), S. 536-563, hier S. 536ff.; dazu auch Jon E. Fox/Maarten Van Ginderachter, Introduction. Everyday Nationalism's Evidence Problem, in: Nations and Nationalism 24 (2018), S. 546-552, hier S. 546f.

65 Maria Todorova, Is There Weak Nationalism and Is It a Useful Category?, in: Nations and Nationalism 21 (2015), S. 681-699, hier S. 686.

66 Zur Sprachenfrage in der späten Habsburgermonarchie siehe Markian РвокоPOVYCH u. a. (Hg.), Language Diversity in the Late Habsburg Empire, Leiden 2019.

67 Gerald Stourzh, The Ethnicizing of Politics and "National Indifference» in Late Imperial Austria, in: Ders., Der Umfang der österreichischen Geschichte. Ausgewählte Studien 1990-2010, Wien u. a. 2011, S. 283-323, hier S. 303ff.

68 Konrad Clewing, Staatensystem und innerstaatliches Agieren im multiethnischen Raum. Südosteuropa im langen 19. Jahrhundert, in: Ders. / Oliver Jens Sснмітт (Hg.), Geschichte Südosteuropas. Vom frühen Mittelalter bis zur Gegenwart, Regensburg 2011, S. 432-553, hier S. 505f. 
Auch in dieser Arbeit kommen Akteure zu Wort, die dementsprechend nicht gegenüber allem Nationalen indifferent waren. Sie waren sich ihrer ethnisch-nationalen Zugehörigkeit und mithin ihrer Muttersprache sogar sehr wohl bewusst. Aber das bedeutete keinesfalls, dass die Konflikte wegen dieses Bewusstseins entstanden wären. Dass sich die lokalen Konfliktakteure mal in und mit den nationalen (nationalistischen) Diskursen verorten konnten, ist kein Beweis für ihren eigenen Nationalismus, sondern es beweist nur die Kraft des elitären Nationalismus, welcher sich die Peripherie - wenn sie gehört und gesehen werden wollte - nicht komplett enziehen konnte. Soziale, parteipolitische oder persönliche Anliegen der Peripherie konnten mit der nationalistischen Sprache für die städtische Öffentlichkeit (für das »Zentrum«) hör- und sichtbar gemacht werden (vgl. Kapitel 5.2.1). Ein Rekurs auf die Ethnizität konnte für sozial benachteiligte Gruppen und Schichten eine gewisse Selbstbehauptung ermöglichen. ${ }^{69}$ Wie Joanna PfaffCzernacka schreibt, ist die Sprache der Ethnizität »eine Ressource in definitorischen Kämpfen um soziale Ordnung - um legitime Prinzipien sozialer Wirklichkeitskonstruktionen ${ }^{70}{ }^{70}$

\subsubsection{Räumliche Verortung}

Auf der heutigen Europakarte ist das nordöstliche Adriagebiet zwischen der dreisprachigen italienischen Autonomen Region Friuli Giulia Venezia/ Furlanija Julijska Krajina/Friûl Vignesie Julie, der teilweise zweisprachigen slowenischen Region Primorska/Littorale und der zweisprachigen kroatischen Gespanschaft Istra/Istria aufgeteilt. Wenn wir einen Blick auf eine Karte der Österreichisch-Ungarischen Monarchie werfen, trifft man auf die Bezeichnungen »Österreichisches Küstenland « und »Ungarisch-Kroatisches Küstenland «. ${ }^{71}$ Nach den Kategorien der politischen und historischen Geographie umfasste der oberadriatische Raum der Habsburgermonarchie auf der österreichischen Seite die reichsunmittelbare Stadt Triest, die Markgrafschaft Istrien und die Gefürstete Grafschaft Görz und Gradiska ${ }^{72}$ sowie auf der ungarisch-kroatischen Seite die damalige ungarische Hafenstadt

69 Groenemeyer, Kulturelle Differenz, ethnische Identität, S. 31.

70 Joanna Pfaff-Czarnecka, Zugehörigkeit in der mobilen Welt. Politiken der Verortung, Göttingen 2012, S. 63.

71 Zur Regionalität des österreichisch-ungarischen Küstenlandes siehe u.a. Péter Techet, Die österreichisch-ungarische Küstenregion. Differenzen, Imaginationen und imperialer Kontext in einer historischen Landschaft, in: Sabine JAGodzinski u.a. (Hg.), Regionalität als historische Kategorie. Ostmitteleuropäische Perspektiven, Osnabrück 2019, S. 281-297, hier S. 287ff.

72 Aus dem Österreichischen Küstenland wird das Kronland Gefürstete Grafschaft Görz-Gradiska in die Analyse nicht einbezogen, Görz-Gradiska wies bezüglich der 
Fiume / Rijeka mit ihrer Umgebung (also mit Teilen der damaligen kroatischen Gespanschaften Modrus-Fiume/Modruš-Rijeka und Lika-Krbava). Dem Österreichischen Küstenland stand ein Statthalter vor, der von Wien ernannt wurde und in Triest residierte; die einzelnen Kronländer hatten ihre eigenen Landtage und Landeshauptmänner (in Triest: Stadtrat und Bürgermeister). Dem Ungarisch-Kroatischen Küstenland (de facto nur der ungarischen Stadt Fiume/ Rijeka und ihrer Umgebung) stand ein Gouverneur vor, der von Budapest ernannt wurde; die kroatischen Gespanschaften, welche die großen Teile des Küstenlandes abdeckten, hatten ihre eigenen administrativen Strukturen.

Weil sich die zu schildernden Konflikte innerkatholisch ereigneten, ist es angebracht, das Gebiet kirchenrechtlich zu verorten: Der österreichische Teil (mit den Bistümern Triest-Capodistria/Koper, Pola/Pula-Parenzo/Poreč sowie Veglia/Krk) gehörte zum Erzbistum von Görz. Der ungarisch-kroatische Teil, samt der ungarischen Stadt Fiume/ Rijeka, war innerhalb des Erzbistums von Zagreb dem kroatischen Bistum Senj unterstellt. ${ }^{73}$

Staats- und kirchenrechtlich war also der oberadriatische Raum in der Habsburger Zeit einerseits strikt zweigeteilt, er gehörte zu Österreich und Ungarn bzw. zu den Erzbistümern Görz und Zagreb. Andererseits war sie von der ethnisch markierten Dichotomie urbaner und ländlicher Räume geprägt: Die adriatischen Küstenstädte waren eher italienischsprachig bewohnt und eindeutig von einer italienischsprachigen, liberalen, antiklerikalen Elite politisch und kulturell geprägt. Das bestimmte auch das Verhältnis zwischen "Stadt« und Kirche negativ. Im Gegensatz dazu war das ländliche Hinterland eher von einer südslawischen (kroatisch- oder slowenischsprachigen) Bevölkerung bewohnt, deren Identität stark von ihrem katholischen Glauben geprägt war.

In der Öffentlichkeit der Donaumonarchie galt der oberadriatische Raum als national umkämpfter Raum, in dem das »italienische« und »südslawische« Erwachen (risorgimento, preporod) konfliktbeladen aufeinander geprallt seien. ${ }^{74}$ Die Historiographie interessierte sich für die Region - wenn

»Nationalitätenfrage« und ihrer Auswirkung auf die katholische Kirche (etwa infolge des starken politischen Katholizismus vor Ort) andere Dynamiken auf.

73 Die Konstellation, dass auch die ungarische Stadt Fiume/Rijeka einem kroatischen Bistum unterstellt war, führte zu kirchenrechtlichen Separationsforderungen und Spannungen mit dem örtlichen Klerus; darüber siehe das Kapitel 4.2.4.

74 Nicht nur werden die Konflikte in der Historiographie nach nationalen Kategorien interpretiert - als ob ständig »Italiener« und »Südslawen« gegeneinandergestanden hätten -, sondern die jeweiligen Nationalismen werden auch unterschiedlich erklärt: Während der »italienische« Nationalismus als ein westeuropäischer, liberaler Nationalismus begriffen wird, gilt der südslawische als Ausdruck des »Balkans«. Insofern wurde der oberadriatische Raum auch in der gegenwärtigen Nationalismus-Forschung auf der Grenze zwischen zwei imaginierten Welten, dem »Westen« (»Italiener») und dem »Osten« (»Südslawen«), verortet; vgl. Glenda SLUGA, The Nation 


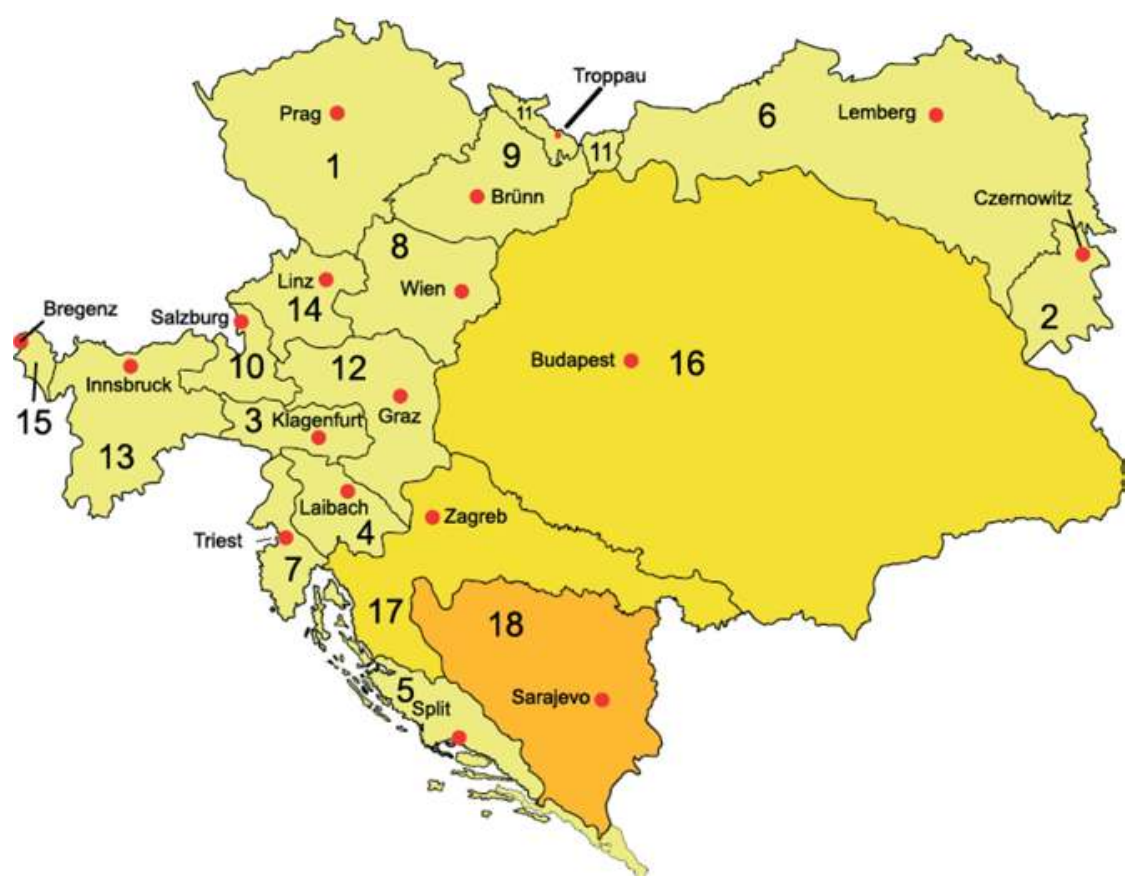

Abbildung 1: Karte der Österreichisch-Ungarischen Monarchie nach 1878

überhaupt - lange nur deswegen, weil sich Nationsbildungsprozesse verschiedener und verschieden bewerteter Nationen (»Kulturnation«, "geschichtslose Nation «) hier in einem relativ kleinen Raum beobachten ließen. ${ }^{75}$

Mehrere Gründe sprechen also dafür, den oberadriatischen Raum als Untersuchungsraum für meine Fragestellung auszuwählen. (1) Es handelt sich um eine Region, die von der Gleichzeitigkeit ethnisch-sprachlicher Heterogenität und konfessioneller Homogenität (sprich: von mehreren katholischen Völkern) geprägt war. ${ }^{76}$ Im Unterschied etwa zum österreichischen Galizien,

and the Comparative Imagination, in: Delborah Cohen/ Maura O' Connor (Hg.), Comparison and History. Europe in Cross-National Perspective, New York 2004, S. 103-114, hier S. 105.

75 Siehe u. a. Antoni Cetnarowicz, Narodni preporod u Istri (1860-1907) [Nationales Erwachen in Istrien (1860-1907)], Zagreb 2014, S. 5; Matej SAnti, Zwischen drei Kulturen. Musik und Nationalitätsbildung in Triest, Wien 2015, S. 13.

76 Andere Religionen waren einerseits durch die ungarisch- und italienischsprachigen Juden bzw. die wenigen deutsch- oder ungarischsprachigen Protestanten in den zwei großen Hafenstädten, andererseits durch die serbischsprachigen Orthodoxen in der kroatischen Gespanschaft Lika-Krbava vertreten. 
zu Bosnien, zur Bukowina oder zu vielen Gebieten der ungarischen Reichshälfte trennte die Religion im oberadriatischen Raum die meisten Völker nicht voneinander. Die autochthonen »Italiener«, »Kroaten« und »Slowenen« gehörten fast ausschließlich zur römisch-katholischen Kirche. (2) Die oberadriatische Region war weder nur peripher noch nur zentral: Sie lag zwar an der südlichen Peripherie der Donaumonarchie, aber mit der drittgrößten Stadt der österreichischen Reichshälfte, der bedeutendsten Hafenstadt Triest bzw. mit ihrem ungarischen Pendant Fiume/Rijeka war die Region für das ganze Imperium von hoher, wirtschaftlicher und politischer Bedeutung. Das ländliche Hinterland - sowohl hinter den Hafenstädten als auch im Inneren von Istrien und in der ungarisch-kroatischen Gespanschaft Lika-Krbava war aber in der Tat peripher-ländlich, und was noch wichtiger ist: als "peripher" markiert und damit marginalisiert. (3) Dieser oberadriatische Raum war darüber hinaus staatsrechtlich zwischen Österreich und Ungarn (und sogar innerhalb der ungarischen Reichshälfte: zwischen Ungarn und Kroatien) aufgeteilt. Insofern lässt sich auch erforschen, wie ähnliche Dynamiken der lokalen Ebene in unterschiedlichen Makrorahmen - in einem supranationalen Staat wie der österreichischen (transleithanischen) Reichshälfte bzw. in einem "nationalisierenden " Imperium wie der ungarischen (cisleithanischen) Reichshälfte - wahrgenommen und ausgehandelt werden konnten. ${ }^{77}$ Sowohl die Handlungsstrategien als auch die Erfolgschancen der ländlichen Akteure gegenüber der Amtskirche unterschieden und erklärten sich demnach (vgl. Kapitel 5.2.1).

Der oberadriatische Raum der Habsburgermonarchie stellt sowohl wegen seiner multiethnischen, mehrsprachigen Dichte als auch wegen seiner staatsrechtlichen Lage einen interessanten Kleinraum dar, an dem sich makropolitisch relevante Fragen mit einem mikrogeschichtlichen Fokus beobachten und erforschen lassen. Moritz Csáky beschreibt die ganze Donaumonarchie als ein von endogenen und exogenen Einflüssen geprägtes staatliches wie kulturelles Gebilde. ${ }^{78}$ Als Grenzgebiet und Kontaktzone war der oberadriatische

77 Anita Sujoldžić, Transnational and Intercultural Practices in the Adriatric Littoral of the Late Habsburg Empire, in: Collegium Antropologicum 40 (2016), S. 1-12, hier S. 2.

78 Moritz CsÁky, Historische Reflexionen über das Problem einer österreichischen Identität, in: Herwig Wolfram / Walter PoHL (Hg.), Probleme der Geschichte Österreichs und ihrer Darstellung, Wien 1991, S. 29-47, hier S. 38; Moritz Csáky, Die Ambivalenz des kulturellen Erbes. Zentraleuropa. Moderne und / oder postmoderne Befindlichkeit, in: Ders. / Klaus Zeyringer (Hg.), Ambivalenz des kulturellen Erbes. Vielfachcodierung des historischen Gedächtnisses. Paradigma: Österreich, Innsbruck u. a. 2000, S. 29-47, hier S. 35ff.; sowie ders., Culture as a Space of Communication, in: Johannes Feichtinger/Gary B. Cohen (Hg.), Understanding Multiculturalism. The Habsburg Central European Experience, New York/ Oxford 2014, S. 187-208, hier S. 189f. 
Raum von solchen Einflüssen und Kulturen durchkreuzt: ${ }^{79}$ Eine Grenzregion - mit ihrer kulturellen Innendynamik - kann keiner Nation eindeutig zugeordnet werden. ${ }^{80}$ Neben der ethnischen Heterogenität (endogene Vielfalt) wirkten sich exogene Faktoren wie die imperialen Zentren (Wien und Budapest), andere Nationalstaaten (Italien, Serbien) sowie unterschiedliche historische Erben, etwa die venezianische Vergangenheit Istriens raumbestimmend aus. Darüber hinaus wurde die Region der innerhabsburgischen und gesamteuropäischen »Kulturkämpfe» teilhaftig. Insofern spielte die katholische Kirche als gleichzeitig exo- und endogener Faktor eine wichtige Rolle vor Ort.

Nach der klassischen Imperiums-Definition bedeutet das Imperium ein Herrschaftssystem, in dem die »Peripherien« von einem imperialen Zentrum unterschiedlich gelenkt worden seien. ${ }^{81}$ Die Struktur und Funktionsweise der Habsburgermonarchie lassen sich aber nicht nur mit dieser imperialen Radialität erklären. Jana Osterkamp führt das Konzept des »kooperativen Imperiums« ein, mit dem sie die Ebene und die Chancen kooperativer Binnenstrukturen beschreiben kann. ${ }^{82}$ Das Konzept betont die Integration, die Gleichberechtigung und die Symmetrien unter den imperialen »Peripherien «. ${ }^{83}$ Die Habsburgermonarchie lässt sich demnach als Verflechtung mehrerer Zentren und Peripherien verstehen, in welcher sich ein komplexes Mehrebenen-System jenseits der imperialen Zentren etablieren konnte. ${ }^{84}$ In einer solchen Verflechtungsstruktur sind die Zentralität und Peripherität einer Region kontextabhängig. ${ }^{85}$ Insofern bedeuteten die Zentralität und Peripherität auch im ländlichen Hinterland des Küstenlan-

79 Gilbert Bosetti, Les limites de la pluriculturalité. Le cas de Trieste et de Rijeka/ Fiume sous les Habsbourg, in: Chroniques allemandes 11 (2006/2007), S. 203-217, hier S. 203ff.

80 Peter Thaler, Fluid Identities in Central European Borderlands, in: European History Quarterly 31 (2001), S. 519-548, hier S. 541.

81 Jürgen Osterhammel, Die Verwandlung der Welt. Eine Geschichte des 19. Jahrhunderts, Bonn 2010, S. 614.

82 Jana Osterkamp, Cooperative Empires. Provincial Initiatives in Imperial Austria, in: Austrian History Yearbook 47 (2016), S. 128-146, hier S. 128ff.; dies., Kooperatives Imperium. Eine neue Perspektive auf Anspruch und Wirklichkeit imperialer Herrschaft, in: Dies. (Hg.), Kooperatives Imperium, S. 1-21, hier S. 1-13.

83 Dies., »Kooperatives Imperium«. Loyalitätsgefüge und Reich-Länder-Finanzausgleich in der späten Habsburgermonarchie, in: Geschichte und Gesellschaft 42 (2016), S. 592-620, hier S. 593.

84 Dies., Föderale Schwebelage - Die Habsburgermonarchie als politisches Mehrebenesystem, in: Gerold Amrosius u. a. (Hg.), Föderalismus in historisch vergleichender Perspektive, Baden-Baden 2015, Bd. 2: Föderale Systeme. Kaiserreich - Donaumonarchie - Europäische Union, S. 197-219, hier S. 214.

85 Endre HÁRs u.a., Zentren peripher. Vorüberlegungen zu einer Denkfigur, in: Dies. (Hg.), Zentren, Peripherien und kollektive Identitäten in Österreich-Ungarn, Tübingen / Basel 2006, S. 1-15, hier S. 7. 
des - oder in seinem Verhältnis zu den Küstenstädten - keine eindeutigen, räumlich-geographisch bestimmbaren Grenzen, sondern vielmehr Diskurse, derer sich Akteure je nach ihren gesellschaftlichen Positionen und Interessen bedienen konnten.

Damit nicht die Perspektive und die Narrative der Zentren dominieren, wird in der Arbeit besonders das ländliche Hinterland in den Blick genommen. Einerseits fehlen die Studien über die gesellschaftliche wie räumliche »Peripherie« des Küstenlandes. Ihre historiographische Erschließung stellt also eine größere Herausforderung dar und verspricht neue Erkenntnisgewinne. Über die urbanen Räume liegen einige historischen Studien, sogar Monographien bereits vor: Besonders das österreichische Triest ist - vor allem politik- und sozialgeschichtlich - gut erforscht ${ }^{86}$ auch zur Kirchengeschichte

86 Siehe u.a. Jože Pirjevec, Slovene nationalism in Trieste. 1848-1982, in: Nationalities Papers 11 (1983), S. 152-161; Marina Cattaruzza, I conflitti nazionali a Trieste nell' ambito della questione nazionale nell' impero asburgico: 1850-1914 [Die Nationalitätenkonflikte in Trieste im Bereich der Nationalitätenfrage im Habsburgerreich: 1850-1914], in: Quaderni Giuliani di Storia 10 (1989), S. 131-148; dies., Sloveni e italiani a Trieste. La formazione dell' identità nazionale [Slowenen und Italiener in Triest. Die Herausbildung der nationalen Identität], in: Clio, rivista trimestrale di studi storici 25 (1989), S. 27-58; dies., Trieste nell' Ottocento. Le trasformazioni di una società civile [Trieste im 19. Jahrhundert. Die Verwandlungen einer zivilen Gesellschaft], Udine 1995; Lois C. Doвin, The Port Jews of Habsburg Trieste. Absolutist Politics and Enlightenment Culture, Stanford 1999; Tullia Catalan, La comunità ebreica di Trieste 1781-1914 [Die jüdische Gemeinde von Triest 1781-1914], Trieste 2000; Eduard Winkler, Wahlrechtsreformen und Wahlen in Trieste 1905-1909. Eine Analyse der politischen Partizipation in einer multinationalen Stadtregion der Habsburgermonarchie, München 2000; Roberto Finzi / Giovanni Panjek (Hg.), Storia economica e sociale di Trieste. Vol. 1: La città dei gruppi 1719-1918 [Wirtschaftsund Sozialgeschichte von Triest. Erster Bd.: Die Stadt der Gruppen 1719-1918], Trieste 2001; Oliver Schneider, »Triest«. Eine Diskursanalyse, Würzburg 2003; Rutar, Kultur - Nation - Milieu; Angelo Ara / Claudio Magris, Trieste. Un'identità di frontiere [Triest. Eine Grenzidentität], Torino 2007; Milo, Trieste, 1830-1870; Marta Verginella, La comunità nazionale slovena e il mito della Trieste slovena [Die slowenische Nationalgemeinschaft und der Mythos des slowenischen Triest], in: Qualestoria 35 (2007), S. 103-118; Angelo ArA, Fra nazione e impero. Trieste, gli Asburgo, la Mitteleuropa [Zwischen Nation und Imperium. Triest, die Habsburger und Mitteleuropa], Milano 2009; Rolf WörsDörfer, Nationale Identitätskonzepte im Alpen-Adria-Raum. "Italiener « und »Slowenen « im 19. und 20. Jahrhundert, in: France Bernik / Reinhard LAuer (Hg.), Die Grundlagen der slowenischen Kultur. Bericht über die Konferenz der Kommission für interdisziplinäre Südosteuropa-Forschung im September 2002 in Göttingen, Berlin / New York 2010, S. 51-82; Marina Cattaruzza, Sozialisten an der Adria. Plurinationale Arbeiterbewegung in der Habsburgermonarchie, Berlin 2011; Borut Klabjan, Nicht Ost, nicht West. Triest, in: Ost-West. Europäische Perspektiven 2013, S. 114-120; Andrea Griffante, Between Empire and Nation State. Urban Space and Conflicting Memories in Trieste (19thEarly 20th Century), in: Journal of Architecture and Urbanism 39 (2015), S. 17-27; SAnti, Zwischen drei Kulturen; Salvator Žıтко, Avstrijsko Primorje v vrtincu nacionalnih, političnih in ideoloških nasprotij v času ustavne dobe (1861-1914) [Österreichisches Küstenland in der Spirale nationaler, politischer und ideologischer Kon- 
der Stadt entstanden einige Arbeiten. ${ }^{87}$ Das ungarische Fiume/ Rijeka ist historiographisch weniger umfassend bearbeitet. Es wurden bis jetzt nur einige Teilaspekte historiographisch beleuchtet, ${ }^{88}$ besonders die Kirchengeschichte

flikte während der Verfassungszeit (1861-1914)], Koper 2016; Marina Silvestri, Lassù nella Trieste asburgica. La questione dei regnicoli e l'identità rimossa [Da oben im habsburgischen Triest. Die Frage der Reichsitaliener und die gebliebene Identität], Gorizia 2017; Luca G. Manenti / Martina Schuster (Hg.), Le nazioni, gli uomini e i gruppi. Trieste mosaico di genti (secoli XVIII-XX) [Die Nationen, die Menschen und die Gruppen. Triest, Mosaik der Menschen (18-20. Jahrhundert)], Trieste 2018.

87 Pietro Zovatto, Cattolicesimo a Trieste. (Appunti) [Katholizismus in Triest. (Notizen)], Trieste 1980; Giampaolo Valdevit, Chiesa e lotta nazionali. Il caso die Trieste (1850-1918) [Kirche und Nationalitätenkampf. Der Fall von Triest (1850-1918)], Udine 1979; Stipan Trogrlić, Katolički pokret u Istri 1895-1914. [Katholische Bewegung in Istrien 1895-1914], Zagreb 2000; ders., Katolička crkva u Istri.

88 Siehe u.a. Ljubinka KARpowiCz, Riječki Corpus separatum: 1868-1924 [Fiumaner Corpus Separatum: 1868-1914], Ljubljana 1986 [unveröff. Doktorarbeit]; Franjo Butorac u.a., Povijest Rijeke [Geschichte von Fiume/Rijeka], Rijeka 1988; Ester Capuzzo, L'autonomia della città di Fiume [Die Autonomie der Stadt von Fiume], in: Dies., Dall' Austria all' Italia. Aspetti istituzionali e problemi normativi nella storia di una frontiera [Von Österreich bis Italien. Institutionelle Aspekte und normative Probleme in der Geschichte einer Grenze], Roma 1996, S. 7-32; Igor Žıc, Kratka povijest grada Rijeke [Kurze Geschichte der Stadt Rijeka], Rijeka 2001; Ilona FrIED, Emlékek városa - Fiume [Stadt der Erinnerungen - Fiume], Budapest 2001; Gianluca VolPI, Fiumani, ungheresi, italiani. La formazione dell'identità nazionale a Fiume nell' epoca dualista (1867-1914) [Fiumaner, Ungarn, Italiener. Die Herausbildung der nationalen Identität in Fiume/Rijeka im dualistischen Zeitalter (1867-1914)], in: Marina Cattaruzza (Hg.), Nazionalismi di frontiera. Identità contrapposte sull'Adriatico nord-orientale 1850-1950 [Grenznationalismen. Entgegengesetzte Identitäten im nordöstlichen Adriaraum 1850-1950], Bologna 2003, S. 47-72; Ilona Fried, Fiume [Fiume], Budapest 2004; Csaba Kiss Gy (Hg.), Fiume és a magyar kultúra. Művelődéstörténeti tanulmányok [Fiume und die ungarische Kultur. Kulturgeschichtliche Aufsätze], Budapest 2004; Daniel BARIC, Von Fiume bis Rijeka, in: Thomas Serrier (Hg.), Die Aneignung fremder Vergangenheiten in Nordosteuropa am Beispiel plurikultureller Städte, in: Nordost-Archiv. Zeitschrift für Regionalgeschichte 15 (2006), S. 324-334; Bosetti, Les limites de la pluriculturalité; William Klinger, Negotiating the Nation. Fiume - From Autonomism to State Making (1848-1924). Thesis, Florence 2007 [unveröff. Doktorarbeit]; Guido ZucConi, Una città cosmopolita. Fiume e il suo fronte-mare nell' età dualistica (1870-1914) [Eine kosmopolitische Stadt. Fiume und seine Meeresküste im dualistischen Zeitalter (1870-1914)], Roma 2008; László Domonkos, A kicserélt város. Fiume. Volt és van [Die ausgetauschte Stadt. Fiume/Rijeka war und ist], Budapest 2010; William KLINGER, Dall' autonomismo alla constituzione dello Stato. Fiume 1848-1918 [Vom Autonomismus bis zur Konstituierung des Staates. Fiume 1848-1918], in: Emmanuel Betta u. a. (Hg.), Forme del politico. Studi di storia per Raffaele Romanelli [Formen des Politischen. Festschrift für Raffaele Romanelli], Roma 2012, S. 45-60; William KLINGer, Un capitolo della Questione d'Oriente. Il Corpus separatum di Fiume (1773-1923) [Ein Kapitel über die Ostfrage. Das Corpus Separatum von Fiume (1773-1923)], in: Quaderni Vergeriani 9 (2013), S. 123-163; Giovanni STELLI, Gli autonomisti fiumani. Storia di due liquidazioni [Die Fiumaner Autonomisten. 
ist sehr sporadisch erforscht. ${ }^{89}$ Im Gegensatz zu den urbanen Räumen ist das ländliche Hinterland jedenfalls kaum oder nur im Kontext der »Nationalitätenkonflikte « behandelt. ${ }^{90}$ Andererseits lässt sich die Fokussierung auf das ländliche Hinterland damit begründen, dass diese Ebene durch die Gleichzeitigkeit ähnlicher, mikrohistorischer Dynamiken und unterschiedlicher, makrohistorischer Rahmenbedingungen gekennzeichnet war.

Geschichte von zwei Liquidationen], in: Dino Renato Nardelli/ders. (Hg.), Istria, Fiume, Dalmazia laboratorio d' Europa. La minoranza italiana in Slovenia e Croazia [Istrien, Fiume/Rijeka, Dalmatien als Laboratorium von Europa. Die italienische Minderheit in Slowenien und Kroatien], Perugia 2014, S. 191-217; Marco Boncoddo, Alba e tramonto di un sogno mitteleuropeo. Gli anni dell' »idillio fiumano-magiaro" [Sonnenaufgang und Sonnenuntergang eines mitteleuropäischen Traumes. Die Jahre der »fiumanerisch-magyarischen Idylle«], Messina 2014/ 2015 [unveröff. Doktorarbeit]; Ivan Jeličić, Nell' ombra dell' autonomismo. Il movimento socialista a Fiume, 1901-1921 [Im Schatten des Autonomismus. Die sozialistische Bewegung in Fiume, 1901-1921], Trieste 2015/2016 [unveröff. Doktorarbeit]; Giovanni STELLI, Storia di Fiume. Dalle origini ai giorni nostre [Die Geschichte von Fiume. Von den Anfängen bis zu unseren Tagen], Pordenone 2016; Andrea BežAnić-Roknić/Markus LEIDECK, Rijeka und Liburnien während der österreichischen Herrschaft, in: Aneta Stojić / Anita Pintarić Pavić (Hg.), Kroatiens Küste im Lichte der Habsburgermonarchie, Wien 2017, S. 55-78; Ljubinka Karpowicz TošEva, Freemasonry, Politics and Rijeka (Fiume) (1785-1944), Washington 2017; Raoul Pupo, Fiume. Città di passione [Fiume. Stadt der Leidenschaft], Bari 2018.

89 Società di Studi Fiumani / Lega Fiumana di Roma (Hg.), Giornata di studio sugli aspetti di vita cattolica nella storia di Fiume. Roma, 26 gennaio 1985 [Studientag über Aspekte des katholischen Lebens in der Geschichte von Fiume/Rijeka. Rom, 26. Januar 1985], Roma 1988; Mile Bogović, Crkvena povijest Rijeke od 1889.-1924. [Kirchengeschichte von Fiume/Rijeka von 1889 bis 1924], in: Matica Hrvatska / Ograna Rijeke (Hg.), Bernardin Nikola Škrivanić i njegovo vrijeme. Zbornik radova [Bernardin Nikola Skrivanić, und seine Zeit. Sammelband], Rijeka 1997, S. 7-42; zur posthabsburgischen Kirchengeschichte siehe u. a. Marko Medved, La gerarchia cattolica italiana e la questione linguistica in diocesi plurinazionali. Il caso della Chiesa di Rijeka (Fiume) durante il fascismo [Die italienische katholische Hierarchie und die Sprachenfrage in den multiethnischen Bistümern. Der Fall der Kirche von Rijeka (Fiume) während des Faschismus], in: Revue d'histoire ecclésiastique 108 (2013), S. 931-953; sowie ders., Riječka Crkva u razdoblju fašizma. Nastanak biskupije i prvi talijanski upravitelji [Die Kirche von Rijeka während des Faschismus. Entstehung des Bistums und die ersten italienischen Administratoren], Zagreb 2015.

90 Siehe u. a. Božo Milanović, Hrvatski narodni preporod u Istri [Kroatische nationale Bewegung in Istrien], Pazin 1973; Dragovan ŠEPIĆ, O procesu integracije hrvatske nacije u Istri [Über den Integrationsprozess der kroatischen Nation in Istrien], in: Mirjana Gross (Hg.), Društveni razvoj u Hrvatskoj [Gesellschaftliche Entwicklung in Kroatien], Zagreb 1981, S. 251-281; Nevio ŠETIĆ, O procesu nastanka suvremene hrvatska nacije u Istri - skica za buduća istraživanje [Über den Prozess der Entstehung der zeitgenössischen kroatischen Nation in Istrien - eine Skizze für zukünftige Forschung], in: Društvena istraživanja 2 (1993), S. 587-605; Egidio Ivetic (Hg.), Istra kroz vrijeme. Pregled povijesti Istre sa osvrtom na grad Rijeku [Istrien im Laufe der Zeit. Ein Überblick über die Geschichte Istriens mit Blick auf die Stadt Rijeka], Rovinj / Rovigno 2009; Cetna RowiCZ, Narodni preporod u Istri. 


\subsubsection{Zeitlicher Fokus}

Zeitlich liegt der Fokus auf der Periode zwischen 1890 und 1914. Das Enddatum lässt sich mit dem Ausbruch des Ersten Weltkrieges erklären, der infolge seiner anderen Gewaltqualität auch auf der lokalen Ebene - nicht mehr in die Untersuchung einbezogen wurde. Das Anfangsdatum ist zwar heuristisch gewählt, es gibt aber gute Gründe dafür, die Geschichten ab 1890 zu erzählen: die Intensivierung der nationalpolitischen Debatten als Elitendiskurse in den beiden Reichshälften (vor allem auf der Ebene der "hohen Politik«); die südslawophile Ausrichtung des Hl. Stuhls unter Papst Leo XIII, was auch auf die südslawisch bewohnten Teile der Habsburgermonarchie Auswirkungen zeigte (vgl. Kapitel 2.2); die Beschleunigung der internen Mobilität (Zuzug in die urbanen Räume); Formierung zuerst der nationalpolitisch, dann nationsübergreifend konzipierten Parteien und politischen Strömungen, usw.

In der Arbeit behandele ich einzelne Konfliktbeispiele, die sich zwischen 1894 und 1914 ereigneten. Sie dauerten nur wenige Wochen, Monate (Kapitel 3.1, 4.1) oder sogar mehrere Jahre (Kapitel 3.2, 4.2). Ihre Wahrnehmung war jedenfalls von gesellschaftlichen Dynamiken, politischen Frontlinien und staatlichen bzw. kirchlichen Interessen geprägt, die zwischen 1890 und 1914 die öffentlichen Debatten in der Habsburgermonarchie makrogeschichtlich bestimmten.

\subsection{Methode und Konzepte}

\subsubsection{Mikrogeschichte mit vergleichender Kontextualisierung}

Der Historiker hat bezüglich der Vergangenheit nicht mit einer objektiv vollkommen zugänglichen und rekonstruierbaren "Wirklichkeit", geschweige denn »Wahrheit« zu tun - sondern mit deren Repräsentationen. ${ }^{91}$ Die Vergangenheit wird durch Quellen (das heißt die in diesen Quellen festgeschriebenen Interpretationen) und ihre Interpretationen (also praktisch: durch die Interpretation der Interpretationen) verstanden. Um eine mögliche Diskrepanz zwischen den Makro-Erwartungen und den lokalen Mikro-Ereignissen verstehen zu können, ist es allerdings wichtig, die konkreten Konflikte nicht makrogeschichtlich - von oben her -, sondern so nah wie möglich an den konkreten Ereignissen mikrogeschichtlich zu rekonstruieren, damit von der Makrogeschichte abweichende Repräsentationen und Interpretationen der

91 Jörg Baberowski, Der Sinn der Geschichte. Geschichtstheorien von Hegel bis Foucault, München 2014, S. 22. 
Vergangenheit ebenso ermöglicht werden. Die Fokussierung auf die »Nationalitätenkonflikte« stellt in diesem Sinne »eine unzulässige Verengung der Perspektive dar. ${ }^{92}$ Diese Arbeit strebt demnach eine Perspektive an, mit welcher die nationsfixierten Erklärungen durch andere Elemente, Momente und Motive ergänzt und dadurch die Meistererzählung von einem alles dominierten »Nationalitätenkonflikt« infrage gestellt werden können. Ich versuche dementsprechend, die lokalen Konflikte, die sich innerhalb religiös konnotierter Räume, Bereiche und Kontexte bewegten, von den lokalen Situationen her zu verstehen.

Eine solche Herangehensweise lässt sich als mikrogeschichtlich bezeichnen. Mikrogeschichte bedeutet eine intensive historiographische Beschäftigung mit einem klar abgegrenzten, kleinen Objekt / Ereignis / Dorf (o.ä.). Statt mit Teleskop wird dabei mit einem Mikroskop gearbeitet. ${ }^{93}$ Diese Methode entstand vor allem in der italienischen Historiographie (microstoria): Italien ist ein polyzentrisches Land, auch seine Geschichten gestalten (und gestalteten) sich polyzentrisch, und insofern lässt sich die Realität der lokalen Ebene nicht von der Perspektive eines Zentrums oder eines allgemeinen Narratives erfassen. ${ }^{94}$ Auch der (post)habsburgische Raum kann nicht nur von den damaligen oder den später entstandenen Zentren und ihren Narrativen her erklärt werden.

Mikrogeschichte ist aber nicht nur eine Fallstudie oder eine Ansammlung von Fallstudien. Mikrogeschichte besteht - wie Otto Ulbricht schreibt - »aus wenigen Grundsätzen, einem guten $\mathrm{Ma}$ an theoretischer Reflexion und großer Vielfalt in der Praxis«.95 Die lokale Realität darf nicht kontextlos als rein anekdotischer Fall dargestellt werden. Mikrogeschichte bedeutet insofern auch die theoretische Reflexion und historische Kontextualisierung lokal erfasster Ereignisse. Auch wenn mikrogeschichtlich gearbeitet wird, soll sich also das Ergebnis in einen größeren Kontext einbetten können oder im besten Falle soll das Ergebnis den bestehenden Kontext neu beleuchten und somit neue Erkenntnisse für andere Fälle bringen. ${ }^{96}$

92 Steffi Marung u.a., Territorialisierung in Ostmitteleuropa bis zum Ersten Weltkrieg, in: Frank Hadler u.a. (Hg.), Handbuch einer transnationalen Geschichte Ostmitteleuropas, Göttingen 2017, Bd. I: Von der Mitte des 19. Jahrhunderts bis zum Ersten Weltkrieg, S. 37-130, hier S. 62.

93 Sigurður Gylfi Magnússon / István M. Szijártó, What is Microhistory? Theory and Practice, Abingdon / New York 2013, S. 4f.

94 Carlo Ginzburg/Carlo Poni, Il nome e il come. Scambio ineguale e mercato storiografica [Der Name und das Wie. Ungleicher Austausch und historiographischer Markt], in: Quaderni storici 14 (1979), S. 181-190, hier S. 189.

95 Otto Ulbricht, Mikrogeschichte. Menschen und Konflikte in der Frühen Neuzeit, Frankfurt a. M. / New York 2009, S. 13.

96 Ebd., S. 15. 
Meine Herangehensweise besteht also darin, unterschiedliche lokale Konflikte sehr detailliert zu rekonstruieren. Daraus ergeben sich zuerst nur diverse Einzelmomente, die auf den ersten Blick die Kontingenz des Lebens beweisen könnten. Indem aber diese Einzelmomente - entsprechend dem alltagsgeschichtlichen Ansatz von Alf Lüdtke - rekonstruktiv vernetzt werden, ${ }^{97}$ entsteht ein neues Bild von der lokalen Ebene und ihren Konflikten. Durch die Konflikte lässt sich - wie Roy Beth in seiner Fallstudie über dörfliche Gewalt betonte - die tiefe soziale Realität eines Mikrokosmos zum Vorschein bringen. ${ }^{98}$ Ein solches Bild zeigt etwa auf der lokalen Ebene der Habsburgermonarchie keine dichotomische Helligkeit und Dunkelheit, mit starken und klaren Grenzen, sondern Schattierungen und Grauzonen. Oder wie Moritz Csáky - der Metapher von Ernst Gellner folgend - formuliert: Statt eines klar strukturierten Modigliani-Bildes lässt sich die lokale Ebene der ganzen Habsburgermonarchie vielmehr mit einem Kokoschka-Bild - mit ihren unscharfen und ineinanderfließenden Farben - darstellen. ${ }^{99}$

Wie können aber die lokalen, verschwommenen Realitäten jenseits der elitären, städtischen Diskurse und ihrer hellen Kategorien überhaupt erkannt werden? Während die städtischen Debatten archivarisch und erinnerungspolitisch gut dokumentiert sind - was freilich nicht bedeuten soll, dass ihre quantitative Intensivität das reale Alltagsleben in den Städten widerspiegelte -, lässt sich die abweichende Realität in den ländlichen Gebieten quellenmäßig schwieriger aufspüren. Bauern und andere marginalisierte Gruppen beschreiben selten ihre eigenen Intentionen. ${ }^{100}$ Sie werden meistens von anderen Akteuren und ihren Diskursen dargestellt - aber in dieser Repräsentation werden sie "fremdgeschrieben«. Die Geschichte wird hingegen in der mikrogeschichtlichen Perspektive immer von den konkreten Menschen "gemacht«, die die Narrative oder die Machtstrukturen erzeugen, aufrechterhalten oder eben infrage stellen oder bekämpfen. ${ }^{101}$ Dabei zeigen sich freilich nicht nur »heroische« Intentionen - wie die großen Erzählungen es suggerieren würden -, sondern oft sehr persönliche, banale Aspekte, die erst jenseits oder unterhalb der großen Meistererzählungen zum Vorschein kommen können.

Alf LüDTKe, Was ist und wer treibt Alltagsgeschichte?, in: Ders. (Hg.), Alltagsgeschichte. Zur Rekonstruktion historischer Erfahrungen und Lebensweisen, Frankfurt a. M. / New York 1989, S. 9-47, hier S. 20.

98 Beth Roy, Some Troubles with Cows. Making Sense of Social Conflict, Berkeley u. a. 1994, S. 3.

99 Moritz CsÁky, Die Vielfalt der Habsburgermonarchie und die nationale Frage, in: Urs Altermatt (Hg.), Nation, Ethnizität und Staat in Mitteleuropa, Wien u.a. 1996, S. 44-64, hier S. 64.

100 Zahra, Imagined Non-Communities, S. 106.

101 Magnússon/ Szijártó, What is Microhistory?, S. 5. 
In der folgenden Arbeit werden daher die agierenden Menschen in ihren Handlungen bei konkreten Einzelmomenten (Konfliktfällen, Gewaltmomenten) erfasst. Ihre Handlungen werden einerseits aus den lokalen (mal national, mal vollkommen unpolitisch motivierten und bestimmten) Umständen erzählt, andererseits mit den nationalisierenden Narrativen konfrontiert. Insofern wird das Mikroskop immer wieder auch mit einem Teleskop ergänzt. Die zwei Perspektiven interagieren miteinander: Der vermeintliche Kontext erklärt nicht »von oben her « die lokalen Ereignisse, das teleskopisch aufgenommene Bild (»Kontext«) ändert sich ständig aufgrund der mikroskopischen Nahaufnahmen. ${ }^{102}$

\section{$1.2 .2 »$ Identifizierung»}

In den bearbeiteten Fällen bedienten sich die beteiligten lokalen oder beobachtenden städtischen Akteure des nationalen Vokabulars, als ob die Konfliktlinien auch innerhalb ländlicher Kirchengemeinden entlang ethnischsprachlicher Differenzen verlaufen wären. Eine solche Perspektive blendet allerdings alle anderen Unterschiede aus, die etwa auf der lokalen Ebene oder zwischen ländlichen und urbanen Räumen vorhanden waren. Die Konflikte werden dabei schablonenhaft beschrieben. Eine dynamische Perspektive ist nur dann möglich, wenn die Identität der handelnden Personen nicht als starres Wesen (als feste Ursache ihrer Handlungen), sondern - im Sinne von Roger Brubaker und Frederick Cooper - als prozesshafte, fluide, situative und relative Identifizierung, das heißt als ein Ereignis verstanden wird. ${ }^{103}$ Niklas Luhmann betont, dass Identität in Selbstwiederholungen entsteht, aber die Wiederholungen erfolgen immer in anderen Situationen, die dementsprechend andere Kontexte und Bedeutungen aktivieren. ${ }^{104}$ Die »Identität« kann eben deswegen nicht ausschließlich und kontextunabhängig immerwährend (»essentialistisch «) sein. ${ }^{105}$ Daher ist es irreführend, nach dem Inhalt der »nationalen Identität« zu fragen. Sie ist nicht ständig vorhan-

102 Zur Verflechtung (und zur gleichzeitigen Problematik) von Mikro- und Makroperspektiven siehe u. a. Charles Tilly, Micro, Macro, or Megim?, in: Jürgen Schlumвонм (Hg.), Mikrogeschichte - Makrogeschichte. Komplementär oder inkommensurabel?, Göttingen 1998, S. 33-51.

$103 \mathrm{Zu}$ diesem Verständnis siehe Rogers Brubaker/Frederick Cooper, Beyond »identity«, in: Theory and Society 29 (2000), S. 1-47, hier S. 14f.

104 Niklas Lummann, Die Religion der Gesellschaft. Hg. von André Kieserling, Frankfurt a. M. 2000, S. 56.

$105 \mathrm{Zu}$ diesem Verständnis siehe u. a. Héctor Gr AD / Luisa Rojo, Identities in Discourse. An Integrative View, in: Rosana Dolón / Júlia Todolí (Hg.), Analysing Identities in Discourse, Amsterdam / Philadelphia 2008, S. 3-28, hier S. $7 f$. 
den (im Sinne von einer objektiven Eigenschaft), sondern sie wird erst durch die Repräsentationen (etwa durch die nationalistischen Bezüge) erzeugt.

In der Arbeit wird Identität dementsprechend nicht als Eigenschaft, sondern als Ereignis (als situative Prozesse) begriffen. Sie drückt sich situativ und relativ in den konkreten Handlungen aus. Identität formiert sich während und infolge der Konflikte, aber sie ist nicht die Ursache der Konflikte. ${ }^{106}$ Insofern lagen den Konflikten nicht irgendwelche Identitätskollisionen zugrunde. Vielmehr formierten sich die Identitäten erst angesichts der Konflikt- und Gewaltmomente. Indem der Fokus dieser Arbeit nah an der lokalen Ebene angesetzt wird, lassen sich die Akteure jenseits ihrer (selbst-)propagierten oder wahrgenommen »Gruppenzugehörigkeiten« beobachten - als Menschen, die eigene, spezielle Interessen verfolgten. Dass dabei auch auf „Gruppen« Bezug genommen wurde, beweist nicht die Existenz dieser Gruppen, sondern die Vorstellungskraft einzelner Akteure. ${ }^{107}$ Identität ist also eine Selbst-Interpretation angesichts wechselnder Situationen. ${ }^{108}$ Somit lässt sich eine starke Fokussierung auf angeblich vorhandene, geschlossene Gruppen vermeiden: Einerseits sind die Gruppen (»Völker« usw.) nicht klar umreißbar und begrenzbar vorhanden. Gruppen (»Identitäten«) stellen vielmehr Diskurse dar, ${ }^{109}$ mit denen die Elitenakteure wie etwa nationalistische Agitatoren aus den Städten Macht über andere Menschen beanspruchen können. Andererseits entstehen die Konflikte nicht zwischen unterschiedlichen Gruppen, sondern immer zwischen konkreten Menschen. ${ }^{110}$

\subsubsection{Gewalt}

In der Arbeit behandele ich Konfliktfälle, in denen verbale Beschimpfungen, Drohungen oder physische (handgreifliche) Gewalt vorkamen. Daher wird hier kurz erläutert, was in der Arbeit unter Gewalt verstanden wird. Gewalt ist ein Phänomen, dessen Bedeutung für historische Prozesse nicht

106 Doug McAdam u. a., Dynamics of Contention, Cambridge 2004, S. 141.

107 Auch die Nation entsteht als Gruppe infolge von solchen Vorstellungen; vgl. ANDERson, Imagined Communities, S. 6f.; Brubaker stellt jedenfalls infrage, ob die Nationen überhaupt Gruppen wären - er sieht die Imagination nicht nur bei der »Geburt « der Nation maßgebend, sondern auch in ihrer Existenz; vgl. Rogers BrUBA KER, Ethnicity without Groups, Cambridge 2004, S. 11.

108 Bernd Simon / Amélie Mummendey, Selbst, Identität und Gruppe. Eine sozialpsychologische Analyse des Verhältnisses von Individuum und Gruppe, in: Dies. (Hg.), Identität und Verschiedenheit. Zur Sozialpsychologie der Identität in komplexen Gesellschaften, Bern 1997, S. 11-38, hier S. 21.

109 Ruth WODAK u.a., Zur diskursiven Konstruktion nationaler Identität, Frankfurt a. M. 1998, S. 61.

$110 \mathrm{Zu}$ diesem Verständnis siehe BrUBAKER, Ethnicity without Groups, S. $10 \mathrm{ff}$. 
zu leugnen, aber sehr schwer zu definieren ist. ${ }^{111}$ Ist Gewalt die Konsequenz konfliktgenerierender Diskurse? Oder handelt es sich um Emanzipationsversuche marginalisierter Schichten? Oder um irrationale, eigensinnige Wutausbrüche (im Sinne von Alf Lüdtke)? Während Jörg Baberowski die individuelle und rational schwer nachvollziehbare Innenseite der Gewaltakte in den Vordergrund rückt, ${ }^{112}$ versuchen die Theorien der strukturellen Gewalt, die Gewalt aus vorhandenen Strukturen zu erklären und sie somit einer rationalen Kritik zu unterziehen. ${ }^{113}$ Aber weder die Irrationalität der Gewalt noch die Strukturen liefern eine befriedigende Antwort auf das Wesen der Gewalt.

In der folgenden Arbeit werde ich unter Gewalt (bzw. Androhung von Gewalt) physische, körperliche Handlungen und verbale Beleidigungen, also keine Strukturen oder Symbole, sondern konkrete Taten verstehen. Wie Jörg Baberowski lapidar feststellt: "Gewalt schmerzt. . $^{114}$ Das Gewaltphänomen lässt sich leichter erkennen, wenn ihm ideologische, wertende Bedeutungen nicht anhaften. ${ }^{115}$ Somit lässt sich die Gewalt als konkreter, schmerzverursachender Akt von konkreten Tätern begreifen.

Die Akte lassen sich zwar in größere Kontexte einbetten oder mit versteckten Strukturen erklären. Aber die Handlungen sind mit diesen Kontexten und Strukturen nicht gleichzusetzen. Die "Nationalitätenfrage« als politische Kommunikation stellte in der Habsburgermonarchie für die »hohe Politik« und die städtische Publizistik ein gern bedientes Vokabular dar, um komplexe Sachverhalte zu simplifizieren bzw. in den parteipolitischen Diskussionen Emotionen zu mobilisieren, was allerdings nicht bedeutet, dass die lokale Ebene, also das Alltagsleben, von diesem "gewaltigen" Vokabular wirklich geprägt war. Gewalt entsprach immer einzelnen, konkreten Taten. Eine Auffassung der Gewalt als strukturelle Gewalt im Sinne von permanenter Unterdrückung wäre irreführend und übertrieben. Die Meistererzählungen der "Nationalitätenkonflikte" suggerieren eine solche strukturelle Gewalt auf der lokalen Ebene.

111 Einige meinen sogar, dass die Unklarheit zum Wesen der Gewalt gehöre; vgl. Wilhelm Heitmayer/Hans-Georg Soeffner, Einleitung. Gewalt. Entwicklungen, Strukturen, Analyseprobleme, in: Dies. (Hg.), Gewalt. Entwicklungen, Strukturen, Analyseprobleme, Frankfurt a. M. 2004, S. 11-17, hier S. 11.

112 Jörg BABERowsKi, Gewalt verstehen, in: Zeithistorische Forschungen/Studies in Contemporary History 5 (2008), S. 5-17, hier S. $12 \mathrm{ff}$.

113 Das Konzept wurde von Johan Galtung eingeführt, siehe Johann GaLtung, Strukturelle Gewalt. Beiträge zur Friedens- und Konfliktforschung, Reinbek bei Hamburg 1979.

114 Jörg Baberowski, Räume der Gewalt, Bonn 2016, S. 110.

115 Dirk Schumann, Gewalt als Grenzüberschreitung. Überlegungen zur Sozialgeschichte der Gewalt im 19. und 20. Jahrhundert, in: Archiv für Sozialgeschichte 37 (1997), S. 366-386, hier S. 374. 
Die Gewaltmomente, die ich in der Arbeit untersuche, waren also zeitlich und räumlich begrenzte Ausnahmesituationen, die von einem friedlichen Alltag abwichen. Gewalt lässt sich somit als intensive, nicht legitime, punktuelle Grenzüberschreitung verstehen. ${ }^{116}$ Die Gewaltmomente erschließen sich zwar mit einer alltagsgeschichtlichen Methode, das heißt den punktuellen Nahaufnahmen am besten, ${ }^{117}$ aber sie geben nicht den Alltag wieder. ${ }^{118}$ Die Gewalt ging immer von wenigen Menschen aus - Randall Colling schreibt diesbezüglich von »violent $f e w \ll{ }^{119}$ Wieso sollten wir uns aber mit Gewaltmomenten befassen, wenn sie ohnehin nur kurze Momente und wenige Menschen mit einbezogen? Mit der Definition der Gewalt als begrenzte Momente einzelner, weniger Menschen wird nicht die makropolitische Wirkung der Gewalt, die sehr groß war, sondern ihre alltägliche Gegenwärtigkeit infrage gestellt. Die Fokussierung auf die Gewaltmomente - eben als Momente relativiert die lokale Bedeutung der "Nationalitätenfrage« als einer angeblich strukturellen (immerwährenden, ständig lauernden) Gewalt.

Machtstrukturen und gesellschaftliche Kräfteverhältnisse müssen bei der Gewaltanalyse mit einbezogen werden, damit die Gewaltakte der konkreten Akteure im ganzen Kontext der Handlung verstanden werden können: Die Gewalt ist zwar nicht notwendigerweise strukturell immanent, aber unter anderem von sozialen Strukturen möglicherweise bedingt. ${ }^{120}$ Zwischen einem Priester und seiner Kirchengemeinde, zwischen einem Bischof und einem Priester, zwischen einem Bischof und den lokalen Kirchgängern, zwischen der städtischen Elite und der katholischen Kirche bestanden viele Ebenen asymmetrischer Machtverhältnisse. Die Gewaltakte können mit Hinweis auf die soziale Position der Angreifer und der Angreifenden in solchen Verhältnissen besser erklärt und verstanden werden - aber immer als konkrete Handlungen konkreter Personen, die auch anders hätten handeln können.

116 Ebd., S. 373.

117 Gewalt lässt sich am besten aus den alläglichen Nahaufnahmen beobachten; vgl. Thomas Lindenberger/Alf LüDtKe, Physische Gewalt - eine Kontinuität der Moderne, in: Dies. (Hg.), Physische Gewalt. Studien zur Geschichte der Neuzeit, Frankfurt a. M. 1995, S. 9-47, hier S. 30.

118 Jörg Baberowski meint im Gegensatz dazu, dass die Gewalt eine ständig lauernde Potenzialität der Normalität (praktisch der menschlichen Natur) und keine Abweichung von ihr sei; vgl. Jörg BABERowski, Einleitung. Ermöglichungsräume exzessiver Gewalt, in: Ders. / Gabriele Metzler (Hg.), Gewalträume. Soziale Ordnungen im Ausnahmezustand, Frankfurt a. M. / New York 2012, S. 7-27, hier S. $10 \mathrm{ff}$.

119 Randall Collins, Violence. A Micro-sociological Theory, Princeton/Oxford 2008, S. $370 \mathrm{ff}$.

120 Michaela Christ/Christian Gudenus, Gewalt - Begriffe und Forschungsprogramme, in: Dies. (Hg.), Gewalt. Ein interdisziplinäres Handbuch, Stuttgart 2013, S. 1-16, hier S. 11. 


\subsection{Quellenlage und Aufbau der Arbeit}

\subsubsection{Quellenlage}

Die Quellen zur Erfassung alltäglicher Handlungen entstanden oft im Kontext eines vorherrschenden nationalen (nationalistischen) Narratives, insofern bieten sie - und dies soll quellenkritisch angemerkt sein - nur begrenzt ein klares Bild darüber, wie sich Menschen auf der lokalen Ebene, in ihren alltäglichen Interaktionen definierten. ${ }^{21}$ Gerade die Quellen, die von Konflikten berichten - wie die meisten der in dieser Arbeit behandelten Quellen -, tendieren zu einer dichotomischen Gruppenbildung, in der die binären Schemata (wie etwa das Narrativ des "Nationalitätenkonfliktes«) Konflikte simpel und verständlich darstellen und erklären können. Dabei ist es also interessant, wie eine solche dichotomische Gruppenbildung als nationales oder nationalistisches Narrativ entlarvt und dekonstruiert werden kann, welches die lokalen Akteure als problematische, zu belehrende Fälle nationaler und / oder religiöser Indifferenz betrachtete.

Die Ereignisse aus dem ländlichen Hinterland eignen sich sehr gut für die Infragestellung urbaner Diskurse. Ihre Erschließung stellt jedoch eine Herausforderung dar. Am besten sollte dabei auf Quellen ländlicher Akteure zurückgegriffen werden. ${ }^{122}$ Wenn diese aber nicht oder nicht in genügender Zahl vorliegen, kann die ländliche Perspektive auch aus den städtischen Quellen herausgelesen werden. Infolge des weitgehenden Fehlens eigener Aussagen der lokalen Akteure muss ich mich dementsprechend oft auf Elitendiskurse (wie Zeitungen, kirchliche, ministeriale, kommunale Korrespondenzen) bzw. institutionalisierte Aussagen (wie Polizeiberichte, Protokolle) als schriftliche Quellen stützen. Nur in wenigen Quellen meldeten sich die lokalen Akteure zu Wort. Außer der Selbstdarstellungen in Briefen standen daher die anderen Quellen zu entnehmenden Handlungen der Dorfbewohner den in eigenen Quellen festgehaltenen städtischen Deutungen entgegen. Die eigene Perspektive der lokalen Akteure lässt sich aber auch in diesen städtischen Deutungen (Zeitungsartikeln, internen Korrespondenzen) erkennen. ${ }^{123}$ Eine kritische Analyse ermöglicht ein anderes,

121 Gábor Egry, Etnicitás, identitás, politika. Magyar kisebbségek regionalizmus és nacionalizmus között Csehszlovákiában és Romániában 1918-1944 [Ethnizität, Identität, Politik. Ungarische Minderheiten zwischen Regionalismus und Nationalismus in der Tschechoslowakei und in Rumänien 1918-1944], Budapest 2015, S. 37f.

122 Beate Носк, Forschungen zur kulturellen Dimension transnationaler Verflechtungen Ostmitteleuropas von den 1870er Jahren bis 1914, in: HAdLER/ MiddelL (Hg.), Handbuch einer transnationalen Geschichte Ostmitteleuropas, S. 189-255, hier S. 519.

123 Marnix Beyen/Maarten Van Ginderachter, General Introduction. Writing the 
näheres Verständnis für die nur indirekt geäußerten, lokalen Intentionen. Sie sind den Quellen a contrario zu entnehmen. Eine gewisse Enttäuschung oder Verwunderung war zum Beispiel in den nationalistischen Zeitungen eindeutig zu beobachten, wenn die lokalen Akteure nicht nach ihren Erwartungen handelten. Diese Reaktionen sind quellenmäßig gut nachzuzeichnen. Solche Diskurse bildeten die Erwartungsebene, welche in der Arbeit mit den konkreten Handlungen vor Ort konfrontiert wird.

Bei der Rekonstruktion lokaler Ereignisse stütze ich mich vordergründig auf staatliche sowie kirchliche Quellen. Sie bilden den hauptsächlichen Quellencorpus dieser Arbeit: Polizeiberichte, Protokolle, staatliche und kirchliche Korrespondenzen in unterschiedlichen Sprachen (Deutsch, Ungarisch, Italienisch, Kroatisch, Slowenisch). Diese werden mit den damaligen Presseberichten ergänzt.

Besonders aus der österreichischen Reichshälfte, wo die staatliche Macht neutral mit den Nationalitätenkonflikten umging, eignen sich die Polizeiberichte sehr gut für eine realitätsnahe Erfassung der Ereignisse. ${ }^{124}$ Die staatlichen Quellen liegen in den staatlichen Archiven von Wien (hauptsächlich ministeriale Korrespondenzen), ${ }^{125}$ Triest (Polizeiberichte, Korrespondenzen der Statthalterei, Briefe von kirchlichen Amtsträgern), ${ }^{126}$ Pisino / Pazin (Polizeiberichte, Briefe von kirchlichen Amtsträgern). ${ }^{127}$ Die kirchlichen Quellen bezüglich der österreichischen Reichshälfte stammen aus dem bischöflichen Archiv von Triest (bischöfliche Korrespondenzen, Briefe von einzelnen

Mass into a Mass Phenomenon, in: Dies. (Hg.), Nationhood from Below. Europe in the Long Nineteenth Century, New York / Basingstoke 2012, S. 3-22, hier S. 10.

124 Judson, Guardians of the Nation, S. 10.

125 Aus dem Haus- Hof- und Staatsarchiv (HHStA) des Österreichischen Staatsarchives (ÖStA) wurden die Bestände zur altslawischen Liturgie konsultiert (AT-OeSta/ HHStA PA XI 260, V/1-4; AT-OeSta/HHStA PA XI 260, V/5; AT-Oesta/HHStA PA XI 261, Liasse Rom V/6; AT-Oesta/HHStA PA XI 261, Liasse Rom V/7), aus dem Allgemeinen Verwaltungsarchiv (AVA) des ÖStA wurden die Bestände zu den katholischen Pfarreien im Küstenland (455: Pfarren im Küstenland) konsultiert.

126 Aus dem Staatsarchiv von Triest (Archivio di Stato di Trieste, AST) wurden alle Bestände der Statthalterei (Impero Regia Luogotenenza) und der Polizei (Polizia) bezüglich religiöser und polizeilicher Angelegenheiten zwischen 1890 und 1914 sowie einige Bestände der Bezirkshauptmannschaft von Capodistria/Koper (Capitanato distrettuale di Capodistria) aus dem Bereich des Kultus konsultiert. Aus dem anderen staatlichen Archiv von Triest, der slowenischsprachigen Volks- und Studienbibliothek in Triest (Narodna in študijska knjižnica v Trstu, NŠKT), wurden Bestände von Fotografien aus der Abteilung für Geschichte (Odsek za zgodovino, OZ) konsultiert.

127 Aus dem Staatsarchiv in Pisino/Pazin (Državni Arhiv u Pazinu, DAP) wurden alle Bestände der Allgemeinen Schriften der Bezirkshauptmannschaft von Parenzo/Poreč (Kotarsko poglavarstvo u Poreču) zwischen 1890 und 1914 sowie einige Bestände der Gemeinde Rovigno/Rovinj (Općina Rovinj) aus dem Jahre 1908 konsultiert. 
Priestern oder Kirchengemeinden), ${ }^{128}$ den Pfarrarchiven von Ricmanje ${ }^{129}$ und Dolina ${ }^{130}$ (Briefe von einzelnen Priestern oder Kirchengemeinden) sowie dem vatikanischen Geheimarchiv (Korrespondenz der Wiener Nuntiatur mit der lokalen Ebene und dem Hl. Stuhl). ${ }^{131}$ Viele kirchliche Quellen sind auch in den erwähnten staatlichen Archiven aufbewahrt.

Bezüglich der ungarisch-kroatischen Reichshälfte ist eine viel kritischere Bewertung der staatlichen und kirchlichen Quellen geboten. Die staatliche Macht war in Ungarn parteiisch und mit eigenen nationalistischen Zielen in die lokalen Konflikte involviert. Insofern ergriffen Budapest und seine lokalen Akteure für eine Seite in den Konflikten Partei - meistens zuungunsten der südslawischen Bevölkerung. Diese Quellen liegen in den staatlichen Archiven von Budapest (hauptsächlich ministeriale Korrespondenzen), ${ }^{132}$ Fiume / Rijeka (Polizeiberichte, Korrespondenzen des Gouverneuramtes und des Stadtmagistrates, Briefe von kirchlichen Amtsträgern ${ }^{133}$ sowie Zagreb (Polizeiberichte). ${ }^{134}$

128 Aus dem Bischöflichen Archiv von Triest (Archivio Diocesano di Trieste, ADT) wurden Dokumente bezüglich konkreter Konfliktfälle aus beiden Hauptbeständen der Allgemeinen Verwaltung (Gestione ordinare) sowie der Besonderen Verwaltung (Gestione particolare) konsultiert.

129 Ausdem sonstgeschlossenen Pfarrarchivvon Ricmanje(ŽupnijskiarhivvRicmanjih / Archivio parocchiale di Ricmanje, ŽAR) wurden die Bestände, die bezüglich des lokalen Konfliktfalles von einem früheren Pfarrer, Angel Kosmač, zusammengestellt wurden, sowie das Tagebuch von Don Jakob Ukmar konsultiert.

130 Aus dem ebenso sonst geschlossenen Pfarr- und Dekanatsarchiv in Dolina (Župnijski in dekanijski arhiv Dolina / Archivio decanato e parocchiale di Dolina, ŽDAD) wurden die Chronik der Pfarrei (Kronika županije 1900-1984) sowie die Pfarrakten und Schriften aus dem Jahre 1909 (Župnijski akti in dopisi: 1909) konsultiert.

131 Aus dem Vatikanischen Apostolischen Archiv (Archivio Apostolico Vaticano, AAV) wurde der Bestand der Wiener Nuntiatur (Archivio della Nunziatura di Vienna, ANV) konsultiert. Das Archiv hieß bis Oktober 2019 Vatikanisches Geheimarchiv (Archivio segreto vaticano).

132 Aus dem Staatsarchiv (Országos Levéltár, OL) des Ungarischen Nationalarchivs (Magyar Nemzeti Levéltár, MNL) wurden die Bestände des Ministerpräsidiums (Miniszterelnökség, ME) zu den Fiumaner Angelegenheiten (Fiumei Ügyek, FÜ) konsultiert.

133 Aus dem Staatsarchiv in Fiume / Rijeka (Državni Arhiv u Rijeci, DAR) wurden die Bestände des Gouverneuramtes (Kraljevskij gubernij za Rijeku i Ugarsko-Hrvatsko Primorje) zwischen 1890 und 1914 bezüglich religiöser und polizeilicher Angelegenheiten, einige Bestände des Stadtmagistrates (Gradsko Poglavarstvo Rijeka) sowie die Bestände der Bezirkshauptmannschaft von Lussin/Lošinj (Kotarsko poglavarstvo Lošinj) konsultiert.

134 Aus dem Kroatischen Staatsarchiv in Zagreb (Hrvatski Državni Arhiv, HDA) wurden die Bestände des Präsidiums (Predsjedništvo) der Landesregierung (Zemaljska vlada) bezüglich der Konfliktfälle von Lika-Krbava (1894/ 1895) konsultiert. 
Im Gegensatz zur österreichischen Kirchenobrigkeit bezog die kirchliche Obrigkeit in der ungarisch-kroatischen Hälfte des oberadriatischen Raumes - konkret: das Bistum Senj, dem das Ungarisch-Kroatische Küstenland unterstellt war - nationalpolitisch eindeutigere Positionen. Dies hing in vieler Hinsicht mit der oft antikroatischen und eindeutig säkular-liberalen Einstellung der ungarischen Regierungen zusammen. Insofern engagierten sich die Bischöfe in Senj für nationalpolitische (kroatisch-nationale) Anliegen. Ihre Korrespondenzen bedürfen daher, ähnlich zu den staatlichen Quellen aus Ungarn-Kroatien, einer kritischen Analyse. Die kirchlichen Quellen stammen - neben den erwähnten staatlichen Archiven - aus dem erzbischöflichen Archiv von Zagreb (bischöfliche Korrespondenzen), ${ }^{135}$ dem bischöflichen Archiv von Senj (Priesterberichte), ${ }^{136}$ dem Pfarrarchiv von Drenova (Kirchenbuch über die Konflikte) ${ }^{137}$ sowie dem vatikanischen Apostolischen Archiv (Korrespondenz der Wiener Nuntiatur mit der lokalen Ebene und dem Hl. Stuhl). ${ }^{138}$

Zeitungen werden einerseits zur Rekonstruktion der lokalen Konfliktfälle, andererseits zur Rekonstruktion der städtischen, nationalistischen oder klerikalen Narrative herangezogen. Einige davon sind von der Österreichischen Nationalbibliothek (Austrian Newspapers Online, ANNO), ${ }^{139}$ der Digitalen Bibliothek Sloweniens (Digitalna Knjižnica Slovenije, DLIB), ${ }^{140}$ dem Themenportal "SiStory - Geschichte Sloweniens" (SiStory.si - Zgodovina Slovenije) ${ }^{141}$ und der $»$ Arcanum Digitalen Wissenssammlung " (Arcanum Digitális Tudománytár) ${ }^{142}$ digitalisiert. Viele Zeitungen, besonders aus Triest und Fiume / Rijeka liegen aber nur (und zwar oft nicht in ganzen Jahrgängen)

135 Aus dem Erzbischöflichen Archiv von Zagreb (Nadbiskupski Arhiv u Zagrebu, NbAZ) wurden die Bestände des Vermächtnisses des Erzbischofs Jurij Posilović (Ostavština Jurija Posilovića, OJP) konsultiert.

136 Aus dem Bischöflichen Archiv von Senj (Biskupski Arhiv u Senju, BAS) wurden die Bestände der bischöflichen Schriften (Spisi) sowie das Album der Priester (R 22: Album svećenika senjske i modruške biskupije u dva sveska) konsultiert.

137 Aus dem sonst geschlossenen Pfarrarchiv von Drenova bei Fiume/Rijeka (Arhiv Župe na Drenovi, AŽD) wurde das Kirchenbuch (Liber Insertionis Historiae neoerectae Parochiae Drenovensis ab anno 1837) konsultiert.

138 Aus dem Vatikanischen Apostolischen Archiv (Archivio Apostolico Vaticano, AAV) wurde auch hier der Bestand der Wiener Nuntiatur (Archivio della Nunziatura di Vienna, ANV) konsultiert.

139 Österreichische Nationalbibliothek, Austrian Newspapers Online, URL: <http:// anno.onb.ac.at/> (15.10.2019).

140 Digitalna Knjižnica Slovenije [Digitatalienischen Autonomen Region Friuli Giulia Veneziale Bibliothek von Slowenien], URL: <https://dlib.si/> (15.10.2019).

141 SiStory.si - Zgodovina Slovenije [SiStory.si - Geschichte von Slowenien], URL: <http://www.sistory.si/> (15.10.2019).

142 Arcanum Digitális Tudománytár [Arcanum Digitale Wissenssammlung], URL: $<$ https://adtplus.arcanum.hu/hu/> (15.10.2019). 
in verschiedenen Bibliotheken von Triest, ${ }^{143}$ Rom, ${ }^{144}$ Fiume/ Rijeka ${ }^{145}$ und Budapest ${ }^{146}$ vor; die kroatischen Zeitungen aus Banus-Kroatien (KroatienSlawonien) sind in der Nationalen und Universitären Bibliothek in Zagreb (Nacionalna i Sveučilišna Knjižnica u Zagrebu) vorzufinden. Bei der Arbeit musste ich oft auf Sekundärliteratur, besonders wenn es um italienische oder kroatische Lokalgeschichte ging, zurückgreifen, die in den deutschen Bibliotheken nicht vorhanden war. Sie war in den Bibliotheken von Triest, ${ }^{147}$ Fiume / Rijeka, ${ }^{148}$ Budapest, ${ }^{149}$ Rom $^{150}$ oder Florenz ${ }^{151}$ vorzufinden; viele kroatischsprachige Aufsätze sind von der Seite »Hrčak - Portal znanstvenih časopisa Republike Hrvatske« digitalisiert. ${ }^{152}$

\subsubsection{Aufbau der Arbeit}

Die Arbeit gliedert sich in fünf Kapitel. Zunächst werden Phänomene wie Imperium, Nation und Katholizismus in Bezug auf die Habsburgermonarchie und ihre Binnenstruktur im Kapitel 2 erklärt. Gerade im oberadriatischen Raum, wo die katholische Religion von mehreren Völkern in unterschiedlichen Sprachen er- und gelebt wurde, ist das in Ungarn und Österreich vollkommen unterschiedlich konzipierte Verhältnis zwischen Nation und Religion (im Besonderen: Nation und Katholizismus) von höchster Relevanz. Dabei wird auf ein Thema kurz eingegangen, das in vielen Konfliktfällen als möglicher Konfliktgrund vorkommt: Es geht um das mittelalterliche Privileg südslawischer, katholischer Völker des Ostadriaraumes, die Gottesdienste in

143 Die konsultierten Zeitungen liegen in der Stadtbibliothek Attilio Hortis (Biblioteca Civica Attilio Hortis) sowie der Staatsbibliothek Triest (Biblioteca Statale di Trieste) vor.

144 Die konsultierten Zeitungen liegen im römischen Historischen Archiv-Museum von Fiume (Archivio-Museo Storico di Fiume) vor.

145 Die konsultierten Zeitungen liegen in der Universitätsbibliothek in Fiume/Rijeka (Sveučilišna Knjižnica u Rijeci) vor.

146 Die konsultierten Zeitungen liegen in der Széchenyi Staatsbibliothek (Országos Széchenyi Könyvtár) vor.

147 Stadtbibliothek Attilio Hortis (Biblioteca Civica Attilio Hortis), Staatsbibliothek Triest (Biblioteca Statale di Trieste), Bibliothek des Bischöflichen Priesterseminars (Biblioteca del Seminario vescovile di Trieste).

148 Universitätsbibliothek von Fiume/Rijeka (Sveučilišna Knjižnica u Rijeci), Bibliothek der Theologie (Knjižnica Teologije u Rijeci).

149 Parlamentsbibliothek Ungarns (Magyarország Országgyülésének Könyvtára).

150 Bibliothek des Institutes Luigi Sturzo (Biblioteca del' Istituto Luigi Sturzo) sowie die Bibliothek des Österreichischen Historischen Institutes (ÖHI) in Rom.

151 Bibliothek des Europäischen Hochschulinstitutes (Library of European University Institute).

152 Hrčak - Portal znanstvenih časopisa Republike Hrvatske [Hamster - Portal der wissenschaftlichen Aufsätze der Republik Kroatien], URL: <https://hrcak.srce.hr/> (15.10.2019). 
der sog. altslawischen (glagolitischen) Liturgiesprache lesen und beten zu dürfen, was in der untersuchten Periode ein eher nationalpolitisch bespieltes Thema darstellte.

Den Hauptteil bilden die Kapitel 3 und 4. In diesen Kapiteln werden die innerkatholischen Konfliktfälle aus der lokalen Ebene zuerst erzählt (Mikrogeschichte), dann in einem zweiten Schritt analysiert und kontextualisiert (Makrogeschichte). Die Fälle in Kapitel 3 ereigneten sich in unterschiedlichen Dörfern auf der istrianischen Halbinsel (Kapitel 3.1) bzw. in einem Dorf unweit der Adriametropole Triest (Kapitel 3.2). In Istrien stellten die Kirchgänger konkurrierende Ansprüche bezüglich des religiösen Raumes: Besonders um die Frage der Liturgie- und Predigtsprache kamen Differenzen zwischen Katholiken unterschiedlicher Muttersprache zum Ausdruck. In vielen untersuchten Fällen lagen den Handlungen jedoch andere Motivationen zugrunde: Streit zwischen Priestern und Kirchgängern bzw. unter Kirchgängern konnte wegen unterschiedlicher, oft persönlicher, banaler Gründe wie etwa des Alkoholkonsums eines Priesters entstehen die dann dennoch als nationalpolitische Konflikte inszeniert und rezipiert werden konnten. In einem anderen Fall aus dem Dorf Ricmanje in der Nähe von Triest (Kapitel 3.2), der mehr als zehn Jahre lang andauerte und die Wiener bzw. die päpstliche Politik beschäftigte, stand die Sprachenfrage im Mittelpunkt, welche gerade an der sprachkulturellen Grenze zum multiethnischen, aber »italienisch" dominierten Triest eine besondere Brisanz gewann.

Nach dem österreichischen Teil kommen in Kapitel 4 Fälle aus dem Ungarisch-Kroatischen Küstenland, die sich in unterschiedlichen Dörfern in der Gespanschaft Lika-Krbava bzw. in einem Dorf unweit der ungarischen Hafenstadt Fiume/Rijeka ereigneten. In den kroatischsprachigen und katholischen Dörfern, inmitten der kroatisch (katholisch) und serbisch (orthodox) bewohnten Gespanschaft Lika-Krbava, lehnten die kroatischsprachigen, katholischen Bauern die altslawische Liturgiesprache ab, nachdem der dortige kroatische Bischof sie eingeführt hatte (Kapitel 4.1). Um den überraschenden, reaktiven Anspruch, keine altslawischen Gottesdienste beten zu müssen, entstanden unterschiedliche Diskurse in den städtischen Zeitungen, die die Widerstände im Kontext nationaler Indifferenz oder des ungarisch-kroatischen bzw. kroatisch-serbischen "Nationalitätenkonfliktes" uminterpretierten. In einem anderen Fall, in Drenova bei der ungarischen Hafenstadt Fiume/Rijeka, leisteten kroatischsprachige Bauern Widerstand im Interesse eines abgesetzten Priesters (Kapitel 4.2). In den beiden Kapiteln steht besonders die Frage im Mittelpunkt, warum die nationalisierenden Tendenzen auf der lokalen Ebene auf keine Akzeptanz stießen, obwohl die nationalistischen Akteure aus dem urbanen Raum der gleichen Nationalität angehörten wie die Dorfbewohner. 
Im letzten Kapitel (Kapitel 5) werden die lokalen Dynamiken - hinsichtlich ihrer eigentlichen Ziele und ihrer unterschiedlichen Strategien - theoretisiert und analysiert. Dabei wird der Versuch angestrebt, der lokalen Perspektive mehr Verständnis jenseits der städtischen und elitären Repräsentation einzuräumen. Die Erklärung der unterschiedlichen Strategien trägt hoffentlich zu einem besseren Gesamtverständnis der zweigeteilten und in den jeweiligen Reichshälften unterschiedlich konzipierten Habsburgermonarchie bzw. zu den inneren Entwicklungen der katholischen Kirche bei. 


\title{
2. Imperium, Nation und Katholizismus in der Habsburgermonarchie
}

\author{
»Von mehreren Sprachen hatte er je ein Stückchen Mensch, \\ von keiner einen ganzen Menschen erhalten - \\ aber dieses Chaos war seine Heimat. ${ }^{1}$ \\ (Carl Techet)
}

Kakania was an empire based on a dynasty with its roots deep in the Middle Ages, with a claim to a supreme authority in Central Europe even outside its own family domains, and with very important and intimate links to religion... [...] Though one language happened to be dominant in Central Europe and was naturally the language of the imperial court [i. e. German - P. T.], the Empire was not an ethnic empire and did not have very special links to any one ethnic group or language. ${ }^{2}$

Mit diesen Sätzen fasste Ernest Gellner die komplizierte und historisch verwurzelte Supranationalität der Habsburgermonarchie zusammen: Dynastische und supranationale Legitimität bestimmten die Staatlichkeit. Die Habsburgermonarchie war nicht nur ein dynastisches Konstrukt, weil ihr Fortbestehen - im Sinne des berühmten, wobei später von ihm selbst zurückgenommenen Satzes von František Palacký ${ }^{3}$ - auch im Interesse ihrer Völker stand, ${ }^{4}$ die in Mitteleuropa zwischen dem deutschen und dem russischen Imperialismus allein nicht hätten überleben können. ${ }^{5}$

1 Carl Techet, Vom toten Österreich, Leipzig 1922, S. 17.

2 Ernest Gellner, Language and Solitude. Wittgenstein, Malinowski and the Habsburg Dilemma, Cambridge 2004, S. 30.

3 »Wahrlich, existirte der österreichische Kaiserstaat nicht schon längst, man müsste im Interesse Europa's, im Interesse der Humanität selbst sich beeilen, ihn zu schaffen.« Zitiert nach: Franz PalackÝ, Eine Stimme über Österreichs Anschluß an Deutschland. An den Fünfziger-Ausschuß zu Händen des Herren Präsidenten Soiron in Frankfurt a. M., in: Ders., Oesterreichs Staatsidee, Prag 1866, S. 85.

4 Robert A. Kann, The Dynasty and the Imperial Idea, in: Austrian History Yearbook 3 (1967), S. 11-31, hier S. 30.

5 François Fejtö (Ferenc Fejtő) betont in seinem Buch über das Ende der Habsburgermonarchie, dass die entstandenen "Nationalstaaten" ebenso multiethnisch und mehrsprachig blieben (was für die Minderheiten oft eine schlechtere Position erzeugte als in Österreich-Ungarn), aber nicht mehr fähig gewesen seien, sich 
Die Habsburgermonarchie war insofern ein paradigmatischer Raum für Zentraleuropa. ${ }^{6}$ Aber alles, was sich bezüglich dieses Raumes über dynastische Supranationalität, gelebte Multikulturalität, verfassungsrechtlich verankerte sprachlich-nationale Gleichberechtigung behaupten lässt, bezieht sich nur auf die österreichische Reichshälfte. Die habsburgische Idee eines nicht ethnisch-national vereinigten Zentraleuropa konnte nach dem österreichisch-ungarischen Ausgleich (osztrák-magyar kiegyezés, 1867) nur in der österreichischen Reichshälfte weitergelebt und ausgeweitet werden. Ungarn, dem der Ausgleich eine hegemoniale Position über einen Teil der Habsburgermonarchie zuerkannte, schlug den Weg eines ethnizisierenden Nationalstaates ein, ${ }^{7}$ in dem - wie der damalige ungarische, radikal-linksbürgerliche Politiker, Oszkár Jászi schrieb - alle Nationalitäten schlechter gestellt gewesen seien als etwa die schwächste Nation in Österreich. ${ }^{8}$ Der österreichischungarische Ausgleich lieferte die Nationalitäten Ungarns der ungarischmagyarischen Hegemonie aus. ${ }^{9}$ Außerdem blockierte er nötige Reformen der imperialen Gesamtstruktur, weil Budapest - im Gegensatz zu Wien, das die Politik der Ausgleiche auch nach 1867 fortsetzte $^{10}$ - nicht willens war, den Nationalitäten irgendwelche Zugeständnisse bezüglich der gesamtstaatlichen Struktur einzuräumen. ${ }^{11}$

Im Folgenden werden die unterschiedlichen Staats- und Nationskonzepte in den zwei Reichshälften (Kapitel 2.1) sowie die innerkirchlichen, nationalen Tendenzen (Kapitel 2.2) kurz erörtert. Besonders im oberadriatischen Raum sind diese Unterschiede von mikrogeschichtlichem Belang, weil das Gebiet zweigeteilt war. Insofern hatten die ähnlichen Prozesse und Dynamiken der lokalen Ebene jeweils einen anderen Rahmen: Ähnliche Phänomene ließen sich in der österreichischen und der ungarisch-kroatischen Hälfte anders begreifen und beschreiben.

gegenüber den deutschen und sowjetisch-russischen Imperialismen zu behaupten. Siehe François Fejtö, Requiem pour un empire défunt. Histoire de la destruction de l'Autriche-Hongrie, Paris 1993, S. 27.

6 Moritz Csáky, Die Stadt in Zentraleuropa - ein hybrider Kommunikationsraum, in: Bernd Stiegler / Sylwia Werner (Hg.), Laboratorien der Moderne. Orte und Räume des Wissens in Mittel- und Osteuropa, Paderborn 2016, S. 31-59, hier S. 35, 40.

7 Judson, L' Autriche-Hongrie était-elle un empire?, S. 580.

8 Oscar Jászi, The Dissolution of the Habsburg Monarchy, Chicago 1961 [1929], S. 287.

9 Robert J. Evans, Der ungarische Nationalismus im internationalen Vergleich, in: Ulrike von HirschHausen / Jörn LeONhard (Hg.), Nationalismen in Europa. Westund Osteuropa im Vergleich, Göttingen 2001, S. 291-305, hier S. $301 \mathrm{ff}$.

10 Österreich blieb weiterhin ein multiethnisch-supranationaler Staat, der einzelnen Teilen weitere Rechte (durch neue Ausgleiche wie etwa in Mähren 1909 oder Galizien 1914) einräumte; vgl. Börries Kuzmany, Habsburg Austria. Experiments in NonTerritorial Autonomy, in: Ethnopolitics 15 (2016), S. 43-65, hier S. 44ff.

11 Clewing, Staatensystem und innerstaatliches Agieren im multiethnischen Raum, S. $520 f$. 


\subsection{Imperium und Nation}

Die Österreichisch-Ungarische Monarchie wird immer als ein einheitlicher Staat betrachtet, der zwar infolge des Ausgleichs von 1867 in zwei Reichshälften geteilt, aber einheitlich aufgebaut und strukturiert gewesen sei. Diese Perspektive, die oft der starken Fokussierung auf die österreichische Hälfte in der westeuropäischen Historiographie geschuldet ist, ${ }^{12}$ blendet die inneren, staatsrechtlichen und daraus folgenden gesellschaftlichen Unterschiede der beiden Reichshälften aus. Diese Unterschiede betrafen das Staatskonzept, die Idee der Nation(en), den Stellenwert der Religionen und im Besonderen den Stellenwert des Katholizismus. In der nach außen hin einheitlich agierenden Donaumonarchie trafen zwei vollkommen unterschiedliche Verfassungsund Nationskonzepte aufeinander: ${ }^{13}$ ein supranational konzipiertes, katholisch begründetes, durch die gleichen Staatsbürgerrechte zusammengehaltenes Österreich, in dem die Staatlichkeit nicht nationalisiert wurde, sowie ein nationalstaatlich konzipiertes, liberal-säkular begründetes, durch die informelle Vormachtstellung der magyarischen Elite und die Unterdrückung der Nationalitäten zusammengehaltenes Ungarn, in dem die Staatlichkeit immer mehr ethno-nationalisiert wurde. ${ }^{14}$

\subsection{1 Österreich als Rechtsordnung für seine Völker}

Imperien werden meistens als Herrschaftsstrukturen verstanden, die vom Zentrum aus ohne gesellschaftliche Basis staats- und machtpolitisch zusammengehalten seien. ${ }^{15}$ Aufgrund der radial angelegten Strukturen, wie Jürgen Osterhammel die Imperien beschreibt, sei eine gesamtimperiale Gesellschaft überhaupt nicht möglich, weil Imperien nur eine politische, aber keine soziale Integration darböten. ${ }^{16}$ Mit seinem supranationalen Selbstverständnis und der einheitlichen, auf gleichberechtigten Kronländern und Staatsbür-

12 Die ganze Habsburgermonarchie ließe sich nur aufgrund österreichischer Quellen nicht verstehen, die ungarische und kroatische Seite seien dem Gesamtbild hinzuzufügen, vgl. William M. Johnston, Zur Kulturgeschichte Österreichs und Ungarns 1890-1938. Auf der Suche nach verborgenen Gemeinsamkeiten, Wien u.a. 2015, S. 91.

13 Matthias Weber, Ein Modell für Europa? Die Nationalitätenpolitik in der Habsburgermonarchie - Österreich und Ungarn 1867-1914 im Vergleich, in: Geschichte in Wissenschaft und Unterricht (1996), S. 651-672, hier S. 668.

14 Gammerl, Untertanen, Staatsbürger und Andere, S. 246f., S. 285.

15 Siehe u.a. Alexander Motyl, Thinking about Empire, in: Karen Barkey/Mark von Hagen (Hg.), After Empire. Multiethnic Societies and Nation-Building. Soviet Union and the Russian, Ottoman, and Habsburg Empires, Colorado 1997, S. 19-29; sowie Osterhammel, Die Verwandlung der Welt, S. 610ff.

16 Ebd., S. 612. 
gern basierenden Staatsstruktur entsprach aber Österreich diesem klassischen Verständnis von Imperien nicht. Der unter den europäischen Imperien feststellbaren Tendenz, sich nationalistisch, quasi-nationalstaatlich zu entwickeln, ${ }^{17}$ widerstand die österreichische Reichshälfte infolge ihrer supranationalen Struktur, der staatsrechtlich garantierten Gleichstellung aller Staatsbürger und der lokalen Vielfältigkeit. ${ }^{18}$ Deswegen plädiert Benno Gammerl dafür, dass die Imperien nach ihrem Umgang mit ethnischer Heterogenität unterschieden werden sollten. ${ }^{19}$ Dabei könnte die in vieler Hinsicht einzigartige Struktur und Staatspolitik Österreichs - als Gegenmodell zu Ungarn und den anderen Imperien Europas auch - mehr hervorgehoben werden. Die staatsbürgerliche Gleichheit, welche durch die Staatsgrundgesetze von 1867 (vor allem durch das "Staatsgrundgesetz über die allgemeinen Rechte der Staatsbürger«) in Österreich garantiert wurde, ermöglichte eine imperiale Gesellschaft.

Die Staatlichkeit wurde in Österreich nicht nationalisiert, ${ }^{20}$ Österreich war keine Nation. ${ }^{21}$ Die österreichische Reichshälfte der Habsburgermonarchie räumte keinem Volk eine verfassungsrechtlich verankerte Vormachtstellung ein, ${ }^{22}$ weil ein Volk im Sinne einer politischen Nation fehlte. ${ }^{23}$ Dem Imperium lag nicht der Gedanke nationaler Homogenität und nationaler Hegemonie zugrunde (wie in der ungarischen Reichshälfte). Der österreichische Staat wurde daher vor allem aufgrund der dynastischen Legitimität und der formalistischen Legalität zusammengehalten. Besonders dem Recht wurde eine sehr wichtige Legitimationsfunktion beigemessen. ${ }^{24}$ Trotz der ethnisch-sprachlichen, religiösen und regionalen Vielfältigkeit, welche

17 Andrea Komlosy, Imperial Cohesion, Nation-Building, and Regional Integration in the Habsburg Monarchy, in: Stefan Berger/Alexei Miller (Hg.), Nationalizing Empires, Budapest 2015, S. 369-427, hier S. 375.

18 Zum imperialen Charakter von Österreich (aber eben im Sinne eines "Imperiums seiner Völker«) siehe Miloš Řezník, Die Habsburgermonarchie - ein Imperium ihrer Völker? Einführende Überlegungen zu »Österreichs Staatsidee«, in: Bernhard BACHINGER u.a. (Hg.), Österreich-Ungarns imperiale Herausforderungen. Nationalismen und Rivalitäten im Habsburgerreich um 1900, Göttingen 2020, S. 45-66.

19 Gammerl, Untertanen, Staatsbürger und Andere, S. 336.

20 Ulrike von Hirschinausen, Citizenship in Austria-Hungary 1867-1923 between Imperial Inclusion and National Exclusion, in: European Review of History 16 (2009), S. 551-573, hier S. 564.

21 Johannes Feichtinger, Wissenschaft als reflexives Projekt. Von Bolzano über Freud zu Kelsen. Österreichische Wissenschaftsgeschichte 1848-1938, Bielefeld 2010, S. 40.

22 Judson, L' Autriche-Hongrie était-elle un empire?, S. 593.

23 Peter Urbanitsch, Pluralist Myth and National Realities. The Dynastic Myth of the Habsburg Monarchy - a Futile Exercise in the Creation of Identity?, in: Austrian History Yearbook 35 (2004), S. 101-141, hier S. 103.

24 James Shedel, The Problem of Being Austrian. Religion, Law, and Nation from Empire to Anschluß, in: CsÁky / Zeyringer (Hg.), Pluralitäten, Religionen und kulturelle Codes, S. 117-129, hier S. 118ff. 
weder die Hegemonie eines Volkes noch eine demokratische Nationalstaatlichkeit ermöglicht hätte, genossen alle Staatsbürger - unbeachtet ihrer ethnischen und religiösen Zugehörigkeit bzw. ihrer Umgangssprache - die gleichen Rechte. ${ }^{25}$

Die österreichische Reichshälfte der Donaumonarchie nahm also in ihrem Versuch, ein Imperium jenseits des nationalstaatlichen oder national-imperialen Gedankens aufrechtzuerhalten, Ansätze eines postnationalstaatlichen Zeitalters des Politischen vorweg. ${ }^{26}$ Der gesellschaftlichen Plurikulturalität und der imperial-supranationalen Struktur entsprach ein formalistischlegalistisches Rechtsverständnis, ${ }^{27}$ das statt metajuristisch-fiktionaler und emotional aufgeladener Kategorien wie »Volk» oder »Staat« die dynamische Prozesshaftigkeit und die positivistische Formalität des Rechtssystems in den Vordergrund rückte. ${ }^{28}$ Österreich war nach 1867 insofern weder ein »typisches« Imperium noch ein Nationalstaat - sondern eine dynastisch legitimierte, gesellschaftlich akzeptierte Rechtsordnung, die allen Staatsbürgern die gleichen Rechte, unbeachtet ihrer ethnischen, sprachlichen, religiösen »Identitäten«, gewährte. Das Fehlen eines einheitlichen »Volkes« - und sogar das Fehlen von einer solchen Staatsidee ${ }^{29}$ - begünstigte ein Modell, in dem das Recht (das Gesetz) und die Administration (als Funktion) im Mittelpunkt der staatlichen Tätigkeit stehen konnte. ${ }^{30}$ Dies erklärt die stark

$25 \mathrm{Zu}$ den Sprachen- und Nationalitätenrechten in der österreichischen Reichshälfte nach 1867 siehe Gerald Stourzh, Die Gleichberechtigung der Nationalitäten in der Verfassung und Verwaltung Österreichs 1848-1918, Wien 1985, S. 83-248. Die sprachliche Toleranz der österreichischen Reichshälfte erklärt Peter Haslinger weniger mit einer postnationalen Einstellung, sondern vielmehr mit den machtpolitischen Interessen der Habsburger; vgl. Peter Haslinger, Sprachenpolitik, Sprachendynamik und imperiale Herrschaft in der Habsburgermonarchie 1740-1914, in: Zeitschrift für Ostmitteleuropa-Forschung 57 (2008), S. 81-111, hier S. 110.

26 Darüber, was - jenseits der Struktur - im kulturellen Sinne »Österreichisch" an Österreich sein konnte, siehe u. a. Steven BELler, What is Austrian about Austrian Culture?, in: Gertraud Diem-Wille u.a. (Hg.), Weltanschauungen des Wiener Fin de Siècle 1900/2000. Festgabe für Kurt Rudolf Fischer zum achtzigsten Geburtstag, Frankfurt a. M. u. a. 2002, S. 25-41; bzw. die Pionierwerke über den österreichischen Geist: Robert A. KANN, A Study in Austrian Intellectual History. From Late Baroque to Romanticism, New York 1960; William M. Johnston, The Austrian Mind. An Intellectual and Social History 1848-1938, Berkely 1972.

27 Johann Dvořak, Politik und Kultur der Moderne in der späten Habsburgermonarchie, Innsbruck/ Wien 1997, S. 196f.

28 Urbanitsch, Pluralist Myth and National Realities, S. 140.

29 In den meisten europäischen Imperien der damaligen Zeit - vom Deutschen Reich über die ungarische Reichshälfte bis hin zum Russländischen Reich - war ebenso keine ethnische Homogenität vorhanden, aber eine solche Homogenität wurde dennoch staatspolitisch imaginiert und (besonders in Ungarn) mit staatlichen Mitteln angestrebt.

30 Die antiliberalen Strömungen der österreichischen Zwischenkriegszeit lehnten eben deswegen das »habsburgische Erbe« eines nichtetatistischen, nichtvölkischen Staatswesens ab; siehe Eric VoEgelin, Der autoritäre Staat. Versuch über das österreichische 
legalistische Tradition des österreichischen Rechtsdenkens, ${ }^{31}$ was auch nach 1918 (eigentlich bis heute) nachwirkt. ${ }^{32}$

Die Staatsbürger in der österreichischen Reichshälfte waren nicht in einer asymmetrischen Struktur einem imperialen Zentrum und einer einzigen imperialen Nation unterworfen. Deswegen konnten sie sich religiös, national, regional, lokal (usw.) unterschiedlich identifizieren und gleichzeitig Teil der österreichisch-imperialen Gesellschaft werden. ${ }^{33}$ Sogar die "Nationalitätenkonflikte « zeigen die Herausbildung einer gemeinsamen, imperialen Gesellschaft, ${ }^{34}$ in der über die gleichen Probleme mit den gleichen Mitteln debattiert wurde. Österreich erzeugte den rechtlichen Rahmen für »Nationalitätenkonflikte«, insofern kann keine Rede von einem »Völkerkerker« sein. Der österreichische Staat anerkannte - vielen anderen europäischen Staaten im Voraus - die nationalen und religiösen »Identitäten « - eigentlich im Sinne von der Charles Taylor'schen "politics of recognition ${ }^{35}$ - als gleichwertig, und er stattete sie mit gleichen Rechten aus.

Staatsproblem, Wien 1936, S. 2ff. Nicht zufällig sehen einige Autoren Ähnlichkeiten zwischen der Habsburgermonarchie und der Europäischen Union. Auch wenn ein solcher Vergleich anachronistisch ist, lassen sich Strukturähnlichkeiten - Zusammenhalt vieler Völker durch das Recht - in der Tat erkennen; vgl. u. a. Steven BELLER, What Has the Empire Ever Done for Us? The Surprising Legacies of the Habsburg Monarchy, and the Lessons for Today's European Union, in: Eurozine, 3. November 2017, URL: <http://www.eurozine.com/what-has-the-empire-ever-done-for-us/> (15.10.2019).

31 Manfred Baldus, Hapsburgian Multiethnicity and the "Unity of the State«. On the Structural Setting of Kelsen's Legal Thought, in: Dan Diner/Michael Stolleis (Hg.), Hans Kelsen and Carl Schmitt. A Juxtaposition, Gerlingen 1999, S. 13-23, hier S. 18ff.; Theo ÖHlinger, The Genesis of the Austrian Model of Constitutional Review of Legislation, in: Ratio Juris 16 (2003), S. 206-222, hier S. 215f.; Ewald Wiederin, Denken vom Recht her. Über den modus austriacus in der Staatsrechtslehre, in: Helmut Schulze-Fielitz (Hg.), Staatsrechtslehre als Wissenschaft. Die Verwaltung, in: Zeitschrift für Verwaltungsrecht und Verwaltungswissenschaften. Beiheft 7, Berlin 2007, S. 293-317, hier S. 295ff.

32 Nicht zufällig in dieser Rechtstradition erschien die von Hans Kelsen entwickelte, radikal-legalistische Theorie der »Reinen Rechtslehre«; vgl. Hans Kelsen, Autobiographie (1947), in: Matthias Jestaedt (Hg.), Hans Kelsen Werke, Tübingen 2007, Bd. 1, S. 29-91, hier S. 60; René MarCIC, Verfassungsgerichtsbarkeit und Reine Rechtslehre, Wien 1966, S. 56; Ewald Wiederin, Der österreichische Verfassungsgerichtshof als Schöpfung Hans Kelsens und sein Modellcharakter als eigenständiges Verfassungsgericht, in: Thomas Simon/Johannes Kalwoda (Hg.), Schutz der Verfassung. Normen, Institutionen, Höchst- und Verfassungsgerichte. Der Staat. Beiheft 22, Berlin 2014, S. 283-306, hier S. 286ff.

33 Judson, The Habsburg Empire, S. 3ff.

34 Gary B. Cohen, Nationalist Politics and the Dynamics of State and Civil Society in the Habsburg Monarchy, 1867-1914, in: Central European History 40 (2007), S. 241-278, hier S. 243ff.

35 Charles Taylor, The Politics of Recognition, in: Amy Gutmann (Hg.), Multiculturalism. Examining the Politics of Recognition, Princeton 1994, S. 25-73. 
Diese liberale und supranationale Politik hatte aber eine negative Kehrseite, weil sie gleichzeitig die diskursive Basis der "Nationalitätenkonflikte« ermöglichte. Die Basis, auf der sich das Modell der Anerkennung aufbaut, ist das staatlich abverlangte und festgestellte Bekenntnis zu einer eindeutigen »Identität«. Insofern klammert es sowohl die wechselbare Situativität der "Identitäten « (Rogers Brubaker) als auch die nationalen Indifferenzen (Tara Zahra) aus. Auch wenn das habsburgische Zentraleuropa kein geschlossener Containerraum, ${ }^{36}$ sondern ein wandelndes Gefüge war, konnte die dynamische, prozesshafte Fluidität, die Plurikulturalität der Gesellschaft, wegen der multikulturellen (also einordnenden, kategorisierenden) Staatspolitik weniger zum Ausdruck kommen. ${ }^{37}$ Daher wurden Schule oder Wahlregister nach vermeintlichen ethnisch-sprachlichen Differenzen gespalten und organisiert bzw. wurde daher in der Statistik nur nach einer Umgangssprache gefragt (und somit alle anderen im Alltag benutzten Sprachen nicht berücksichtigt), was die mehrsprachliche Realität komplett ausblendete. Die Anerkennung der ethnisch-nationalen (usw.) »Identitäten « führte zu einer kommunitaristischen Absonderung und Begrenzung, das heißt zu einer von außen her auferlegten »Gruppenbildung«. Die Anerkennung der »Gruppenidentitäten« geht - wie Kwame Anthony Appiah betont - auch mit ihrer Essentialisierung einher. ${ }^{38}$ Das österreichische Modell schaffte insofern nicht nur einen supranationalen Rahmen ohne ethnische Homogenität und Hegemonie, sondern auch eine Öffentlichkeit, in der - trotz der ambivalenten, fluiden, oft indifferenten Realität der lokalen Ebene - immer mehr das nationalistische Clusterdenken die politische Sprache und die politischen Debatten bestimmten.

Das staatlich geschaffene und nationalistisch bediente Clusterdenken prägte auch die spätere historiographische und erinnerungspolitische Wahrnehmung der ganzen Habsburgermonarchie, als ob alle Menschen einer "Nationalität« (als einer klar definierbaren und begrenzbaren Gruppe) angehört hätten bzw. als ob alle Akteuren nur im Rahmen und im Interesse ihres ethnisch-nationalen Clusters gehandelt hätten.

36 Johannes Feichtinger, Zwischen Mittel- und Zentraleuropa. Oder: Vom politisch überformten Raum zum heuristischen Konzept, in: Jacques LaJARRIGE u.a. (Hg.), »Mitteleuropa«. Geschichte eines transnationalen Diskurses im 20. Jahrhundert, Dresden 2011, Bd. 1, S. 53-73, hier S. 66ff.

37 Zum Unterschied zwischen Multi- und Plurikulturalität siehe: Ebd., S. 68f.

38 Appiah, The Lies that Bind, S. 97. 


\subsubsection{Ungarn als Imperium der magyarischen Elite}

Ungarn verfolgte einen anderen Weg: jenen einer imperialen, hegemonial konzipierten Nation. ${ }^{39}$ Das ungarische Modell, das nur eine einzige Nation anerkannte, entsprach daher vielmehr der zeitgenössischen Tendenz der anderen europäischen Imperien und Staaten, die sich ebenso national/nationalstaatlich konzipierten. Ungarn stellte insofern ein typisches Beispiel eines nationalisierenden Imperiums dar. ${ }^{40}$ Nach dem Ausgleich von 1867 setzte Ungarn in seiner Reichshälfte die Zentralisierung fort, die die ungarisch-magyarische Elite zuvor noch gegenüber Wien abgelehnt hatte. $^{41}$

Ungarn entwickelte sich in einem imperialen Rahmen immer mehr zu einem Nationalstaat. In diesem Sinne lässt sich der ungarische Weg als »imperial nation « beschreiben: Diese gestaltet sich im Rahmen eines Imperiums im Interesse einer Nation. ${ }^{42}$ Im Gegensatz zu Österreich verstand sich Ungarn - trotz der anders anmutenden demographischen Lage ${ }^{43}$ - als säkular-liberaler Nationalstaat, in dem nur eine Nation, die ungarische, als politisches Kollektiv anerkannt wurde. Alle anderen Nationalitäten hatten zwar individuelle Rechte etwa im Sprach- oder Schulbereich, aber sie wurden als Teil der ungarischen Nation begriffen. ${ }^{44}$ Obwohl die ungarische Staatsidee ursprünglich ebenso supranational konzipiert war (mit dem Konzept der »Länder der Stephanskrone«), entwickelte sich der ungarische Staat immer

39 Zur Herausbildung der ethnozentrischen ungarisch-magyarischen Nationsidee aus der mittelalterlichen-frühneuzeitlichen, supranationalen ungarischen Nation siehe u. a. Tofik M. Islamov, From Natio Hungarica to Hungarian Nation, in: Richard L. Rudolph / David F. Good (Hg.), Nationalism and Empire. The Habsburg Empire and the Soviet Union, New York 1992, S. 159-183.

40 Leonhard / HirschHausen, Empires und Nationalstaaten, S. 13.

41 Osterkamp, Föderale Schwebelage, S. 206.

42 Zur »imperial nation" siehe Stefan Berger/Alexei Miller, Building Nations in and with Empires - A Reassesment, in: Dies. (Hg.), Nationalizing Empires, S. 1-30, hier S. 4.

43 Bis 1900 stellten die Nationalitäten die absolute Mehrheit in der ungarischen Reichshälfte dar. Nur infolge der jüdischen Assimilation konnte die Zahl der Ungarn (d.h. derjenigen, die das Ungarische als ihre Muttersprache angaben) im Jahre 1900 eine knappe absolute Mehrheit in Ungarn (ohne Kroatien-Slawonien) erreichen. Ohne Kroatien-Slawonien machten die Ungarn im Jahre 190051.4 \% und im Jahre 1910 54.1 \% der Gesamtbevölkerung aus; Daten von 1900 und 1910 aus: Magyar Királyi Központi Statisztikai Hivatal (Hg.), A Magyar Szent Korona Országainak 1910. évi népszámlálása. Első rész: A népesség főbb adatai községek és népesebb puszták, telepek szerint [Die Volkszählung der Länder der Ungarischen Heiligen Krone im Jahre 1910. Erster Teil: Die Hauptdaten der Bevölkerung in den Gemeinden, bevölkerungsreicheren Puszten, Siedlungen], Budapest 1912, S. 6.

44 Gerald Stourzh, The Multinational Empire Revisited. Reflections on Late Imperial Austria, in: Austrian History Yearbook 23 (1992), S. 1-22, hier S. 14. 
mehr ethno-nationalistisch: Die ungarisch-magyarische Elite kehrte sich von der Supranationalität ab. ${ }^{45}$

In den Sprachen der Nationalitäten drückte sich diese Entwicklung in der Unterscheidung zwischen "ungarisch « und »magyarisch « aus. ${ }^{46}$ Diese Unterscheidung war etwa für die kroatische Öffentlichkeit von großer Relevanz: Während unter Mađarska nur die ungarischsprachigen (magyarischen) Teile der ungarischen Reichshälfte gemeint waren, stand Ugarska für das ganze multiethnische Reich der ungarischen Krone. ${ }^{47}$ Auf Ungarisch wurde (und wird) hingegen zwischen diesen Ebenen nicht unterschieden (beide Ebenen heißen magyar), was eine Gleichstellung Ungarns (als Staat) mit der magyarischen Nationalität impliziert. Ungarn konnte letztendlich diese Nationsidee gegen die Nationalitäten nicht durchsetzen. ${ }^{48}$ Aber der Horizont der "Nationalitätenkonflikte « blieb in Ungarn stets anders als in Österreich. Die Nationalitäten stellten den gesamtimperialen Rahmen nicht infrage, sie wollten sich von der ungarischen Hegemonie loslösen. Dieses Ziel lässt sich auch in der nationalistischen Öffentlichkeit in Kroatien beobachten: Loslösung von Ungarn, aber weiterer Verbleib in der Habsburgermonarchie waren die Hauptforderungen. ${ }^{49}$

Kroatien stellte einen speziellen Fall innerhalb der ungarischen Reichshälfte dar. Weil einige Fallbeispiele aus dem Ungarisch-Kroatischen Küstenland, das teilweise zu Kroatien gehörte, stammen (vgl. Kapitel 4.1), ist es angebracht, die Situation Kroatiens kurz anzusprechen. Kroatien bildete nach 1102 mit Ungarn eine Personalunion: ${ }^{50}$ Die jeweiligen ungarischen Könige waren, ohne dafür gesondert gekrönt werden zu müssen, auch kroatische Könige. Nach der Neustrukturierung der innerimperialen Verhältnisse der Habsburgermonarchie (1867) wurden die zwei Kronländer Kroatien (auch Banus-Kroatien oder Zivil-Kroatien genannt) bzw. Slawonien weiterhin unter ungarische Hegemonie gestellt. Kroatien war insofern auch nach 1867 Teil der ungarischen Reichshälfte, sein Status war aber umstritten. Ungarn

45 Gammerl, Untertanen, Staatsbürger und andere, S. 143.

46 Robert J. W. Evans, Language and State Building. The Case of the Habsburg Monarchy, in: Austrian History Yearbook 35 (2004), S. 1-24, hier S. 10f.

47 Dénes Sokcsevits [Dinko ŠokČEvić], Magyar múlt horvát szemmel [Ungarische Vergangenheit mit kroatischen Augen], Budapest 2004, S. 69.

48 Solomon Wank, Some Reflections on the Habsburg Empire and Its Legacy in the Nationalities Question, in: Austrian History Yearbook 28 (1997), S. 142.

49 Vgl. Jure Krišto, Prešućena povijest. Katolička Crkva u hrvatskoj politici 1850.1918. [Verschwiegene Geschichte. Katholische Kirche in der kroatischen Politik, 1850-1918], Zagreb 1994, S. 83; Fernando Veliz, The Politics of Croatia-Slavonia 1903-1918. Nationalism, State Allegiance and the Changing International Order, Wiesbaden 2012, S. 67.

$50 \mathrm{Zu}$ den Anfängen der ungarisch-kroatischen Personalunion siehe u.a. Dinko ŠoKčEvić [Dénes SoKCSEviTs], Hrvatska od stoljeća 7. do danas [Kroatien vom 7. Jahrhundert bis heute], Zagreb 2016, S. 60-120. 
schloss mit Kroatien ein Jahr nach dem österreichisch-ungarischen Ausgleich einen anderen Ausgleich (magyar-horvát kiegyezés/hrvatsko-ugarska nagodba; 1868), der den Ländern Kroatien und Slawonien eine gewisse Autonomie in den inneren Angelegenheiten, der Justiz-, Religions- bzw. Bildungspolitik zuerkannte. ${ }^{51}$ Dem Land stand der vom ungarischen Ministerpräsidenten vorgeschlagene Banus (bán/ban) vor. In der ungarischen Regierung wurde ein eigener Minister für die Angelegenheiten Kroatiens und Slawoniens beauftragt. ${ }^{52}$

Der verfassungsrechtliche Status von Kroatien ließ sich jedoch unterschiedlich auslegen..$^{53}$ Auch in der damaligen rechtswissenschaftlichen Literatur entbrannte ein Streit zwischen dem berühmten deutschen Juristen, Georg Jellinek, und dem Zagreber Staatsrechtler, Josip Pliverić, bezüglich der Frage, ob Kroatien ein eigenes Land wäre. ${ }^{54}$ Pliverić versuchte, den deutschen Rechtsgelehrten Jellinek davon zu überzeugen, dass Kroatien als ein eigener Staat mit Ungarn einen Ausgleich geschlossen hätte. Nach dieser Auffassung wäre die Donaumonarchie nicht dualistisch, sondern trialistisch gewesen: österreichisch, ungarisch und kroatisch. Georg Jellinek widerlegte aber diese These: Kroatien sei ein autonomer Teil des ungarischen Staates. ${ }^{55}$ Darüber, auf welcher Basis sich eine kroatische Staatlichkeit hätte formulieren sollen, gingen die Meinungen auch in Kroatien auseinander: Dies hing damit

51 Zur Verfassungsgeschichte des ungarisch-kroatischen Ausgleichs siehe u.a. László HEKA, A magyar-horvát államközösség alkotmány- és jogtörténete [Die Verfassungsund Rechtsgeschichte der ungarisch-kroatischen Staatsgemeinschaft], Szeged 2004, S. 167ff.; Dalibor ČEPulo/Mirela KrešIĆ, Hrvatsko-ugarska nagodba. Institucije i stvarnost [Kroatisch-ungarischer Ausgleich. Institutionen und Wirklichkeit], in: Dinko ŠokćEvić [Dénes Sokcsevits] (Hg.), »Mint nemzet a nemzettel...«. Tudományos konferencia a magyar-horvát kiegyezés 140. évfordulója emlékére/»Kao narod s narodom..." Konferencija u spomen 140. obljetnici Hrvatsko-ugarske nagodbe [»Als Nation mit der Nation ... Wissenschaftliche Konferenz anlässlich des 140. Jubiläums des ungarisch-kroatischen Ausgleiches], Budapest 2011, S. 141-155; Daniel BARIC, Entre construction juridique, tensions nationales et modernisation. Le compromis hungaro-croate de 1868, in: Jean-Numa DuCANGE / Jacques LAJARRIGE (Hg.), L' empire austro-hongrois. Les enjeux de la présence allemande en Europe centrale (1867-1918), in: Austriaca 73 (2011), S. 31-48; sowie Ivan Kosnica, Das Problem der Staatsbürgerschaft in Kroatien und Slawonien im Ausgleichszeitraum (1868-1918), in: Gábor Máthé / Barna Mezey (Hg.), Kroatisch-ungarische öffentlich-rechtliche Verhältnisse zur Zeit der Doppelmonarchie, Budapest 2015, S. $188 \mathrm{ff}$.

52 Der Titel des Ministers lautete offiziell »Minister für die kroatischen, slawonischen und dalmatinischen Angelegenheiten ", weil Ungarn aufgrund historischer Staatsrechte auch Dalmatien für sich beanspruchte.

53 Mirjana Gross, Anfänge des modernen Kroatien, Wien u. a. 1993, S. 117.

54 Georg Jellinek/Josip Pliverić, Das rechtliche Verhältnis Kroatiens zu Ungarn, Agram [Zagreb] 1885.

55 Zur Problematik der pseudo-staatlichen Strukturen siehe Georg JelLINEK, Über Staatsfragmente, Heidelberg 1896, S. 35-46. 
zusammen, dass historische Staatsrechte und moderne Nationskonzepte den kroatischen, nationalen Diskurs gleichzeitig bestimmten. ${ }^{56}$

Das Verhältnis zwischen Ungarn und Kroatien-Slawonien war nicht nur staats- und nationspolitisch, sondern auch kirchenpolitisch angespannt. Während das multikonfessionelle Ungarn in vielen Hinsichten eine säkulare Politik verfolgte, verstand die kroatische Elite den Katholizismus als nationale Identität, welche gegen die als »Magyarisierung « empfundenen, säkularen Tendenzen zu bewahren sei. Der Ausgleich zwischen Wien und Budapest lieferte das katholische Leben den ungarischen Nationalisierungszielen in der Tat aus. ${ }^{57}$ Kroatien nahm daher den Katholizismus gegen das »liberale Ungarn" in Anspruch. ${ }^{58}$ Die Säkularisierung galt in Kroatien-Slawonien schlechthin als »Magyarisierung", weil die dadurch vermeintlich eintretende Schwächung der katholischen Kirche auch die Schwächung des kroatischen Nationalismus - nach der Auffassung der national-klerikalen Kreise bedeutet hätte. ${ }^{59}$ In dieser Hinsicht verschränkten sich die antiungarischen Meinungen zu einem antiliberalen Hass. ${ }^{60}$

Beispielhaft war dafür, wie die kroatischen Eliten auf die Zivilehe reagierten, die in Ungarn 1894 eingeführt worden war. ${ }^{61}$ Die nationalistischen Kreise Kroatiens nahmen es als eine gleichzeitig antikroatische und antika-

56 Zur Bedeutung des kroatischen Staatsrechtes siehe Wolfgang KessLer, Vom Recht der Stände zum »kroatischen Staatsrecht«. Zum historischen Recht in der politischen Kultur des 19. Jahrhunderts in Kroatien, in: Dietmar Willoweit / Hans Lemberg (Hg.), Reiche und Territorien in Ostmitteleuropa. Historische Beziehungen und politische Herrschaftslegitimation, München 2006, S. 379-403.

57 Ĺuboslav Нroмjáк, Il ruolo del clero cattolico nella nazione slovacca dalle origini fino alla prima metà del Novecento [Die Rolle des katholischen Klerus in der slowakischen Nation von den Anfängen bis zur Mitte des 20. Jahrhunderts], in: Aleksandar JAKIR / Marko Trogrlić (Hg.), Klerus und Nation in Südosteuropa vom 19. bis zum 21. Jahrhundert, Frankfurt a. M. 2014, S. 15-48, hier S. 44.

58 Die Auffassung, dass der Katholizismus die kroatische Identität ausmache, wird auch in der heutigen kroatischen Historiographie vertreten, vgl. Ivo BANAC, Hrvati i Crkva. Kratka povijest hrvatskog katoličanstva u modernosti [Kroaten und die Kirche. Kurze Geschichte des kroatischen Katholizismus in der Modernität], Zagreb 2013, S. 10; kritisch dazu siehe Teснeт, Nationalismus und Katholizismus, S. 182ff.

59 Mario Strecha, „Sve za vjeru i domovinu«. Idejna strujanja u katolicizmu u banskoj Hrvatskoj potkraj XIX. stoljeća [»Alles für den Glauben und die Heimat«. Ideologische Strömungen im Katholizismus im Banus-Kroatien Ende des 19. Jahrhunderts], in: Croatica Christiana Periodica 38 (1996), S. 73-132, hier S. 90.

60 Marija Vulesica, Die Formierung des politischen Antisemitismus in den Kronländern Kroatien und Slawonien 1879-1906, Berlin 2012, S. 186, 316.

61 Zur Debatte um die Zivilehe siehe Moritz Csáky, Der Kulturkampf in Ungarn. Die kirchenpolitische Gesetzgebung der Jahre 1894/1895, Graz u.a. 1967; sowie Péter Techet, Verzahnung kirchen- und nationalpolitischer Frontlinien in Fiume/ Rijeka. "Liberale« Ungarn und Italiener zur Zeit des ungarischen »Kulturkampfes" (1894 / 1895), in: BACHINGER u.a. (Hg.), Österreich-Ungarns imperiale Herausforderungen, S. $302 \mathrm{ff}$. 
tholische Bedrohung wahr. ${ }^{62}$ Das antiungarische und antisemitische Ressentiment als politisches Programm erschien in Kroatien erstmals während des Wahlkampfes von 1897, als sich die nationalistische Opposition als klerikale Kraft gegen eine mögliche Einführung der Zivilehe hetzte. ${ }^{63}$

Die nationalliberalen Kreise in Kroatien fühlten sich dabei eingeengt zwischen einem liberalen, aber ungarisch-nationalen und angeblich »jüdisch" geprägten Ungarn und einem klerikalen, katholischen, aber supranational geprägten Österreich, weil beide Mächte die »Kroaten" - wie es auf einer Karikatur in der Zagreber Satirezeitschrift Trn dargestellt wurde ${ }^{64}$ - ausnutzen würden. Auf der oberen Spalte der Karikatur fährt zuerst eine typisch »jüdisch" dargestellte Person einen »Kroaten" mit der Kutsche "Zivilehe» (»civilni brak») an die Wand (dabei schiebt eine typisch "ungarisch" gekleidete Person die Kutsche an); auf der unteren Spalte fährt ein österreichischer Soldat einen anderen "Kroaten" mit der Kutsche "Reaktion" (»reakcija») an die Wand. Diese Karikatur drückt plastisch aus, wie in der national-oppositionellen Öffentlichkeit von Kroatien-Slawonien über die zwei Reichshälften gedacht wurde.

\subsection{Katholizismus und Nation}

Die unterschiedlichen Staats- und Nationskonzepte, die in den zwei Reichshälften der Donaumonarchie vorherrschten, bestimmten auch den Stellenwert des Katholizismus. ${ }^{65}$ Die österreichische Reichshälfte war mehrheitlich katholisch: Weil sich kein Volk einer hegemonialen Position oder hegemonialer Vorrechte erfreute, diente die gemeinsame, nationsübergreifende Konfession als verbindendes Element. In Ungarn war hingegen der Katholizismus weder gesellschaftlich noch staatspolitisch so dominierend, wie er in Österreich war, auch wenn sich die katholische Amtskirche in Ungarn der ungarischen Staats- und Nationsidee unterwarf. Nur in Kroatien gestaltete

62 Mario Strecha, O procesu politizacije katolicizma u Banskoj Hrvatskoj potkraj 19. stoljeća [Über den Prozess der Politisierung des Katholizismus im Banus-Kroatien Ende des 19. Jahrhunderts], in: Bosna Franciscana, 26 (2007), S. 91-125, hier S. $100 \mathrm{ff}$.

63 Über die national-klerikale Thematisierung im kroatisch-slawonischen Wahlkampf von 1897 siehe u.a. Mirjana Gross, Povijest pravaške ideologije [Geschichte der staatsrechtlerischen Ideologie], Zagreb 1973, S. 315; Stjepan Matković, Afirmacija Khuenove autokracije. Izbori za Hrvatski sabor 1897. [Affirmation der Khuen'schen Autokratie. Wahlen zum kroatischen Parlament 1897], in: Časopis za suvremenu povijest 29 (1997), S. 469-489, hier S. 478; VulesicA, Die Formierung des politischen Antisemitismus, S. 48.

64 Trn, 5. Juni 1895.

65 Dazu auch Techet, Nationalismus und Katholizismus, S. 162ff. 
sich die katholische Amtskirche in einem betont nationalen, sogar nationalistischen Diskurs.

Im Folgenden werden diese Unterschiede kurz erläutert (Kapitel 2.2.1) und hinsichtlich der Liturgiesprachenfrage, welche ein bedeutendes Thema im oberadriatischen Raum darstellte, für die lokale Ebene erklärt und kontextualisiert (Kapitel 2.2.2).

\subsubsection{Unterschiedlicher Stellenwert des Katholizismus}

In Ungarn stellte die katholische Religion eine knappe Mehrheit in der Bevölkerung dar. ${ }^{66}$ Viele Nationalitäten Ungarns (Serben, Rumänen, Deutsche usw.) gehörten anderen Religionen an, und selbst die ungarischsprachige Bevölkerung war multikonfessionell (römisch und griechisch-katholisch, calvinistisch, evangelisch und jüdisch). ${ }^{67}$ Staatspolitisch konnte sich der Katholizismus in Ungarn keinesfalls als einende Idee darbieten, zumal ein großer Teil der herrschenden ungarisch-magyarischen Elite calvinistisch (reformiert) war. ${ }^{68}$ Der Calvinismus, auch wenn er sogar unter den ethnischmagyarischen Menschen nur eine Minderheit ausmachte, verstand sich als die magyarische Religion, während hingegen dem Katholizismus eine Habsburg-treue Supranationalität und demzufolge eine gewisse "nationale» »Untreue anhaftete. ${ }^{69}$ Auch der staatlich-katholische Stephanskult um den staatsgründenden, ersten König Hl. Stephan gefiel vielen protestantischen Kreisen nicht. ${ }^{70}$ Es gab immerhin Versuche, ethnisch-magyarische und imperial-katholische Inhalte zusammenzuführen. ${ }^{71}$ Jenseits der demographischen Struktur und der nationalpolitischen Verortung der verschiedenen Konfessionen war Ungarn nicht nur nationalstaatlich, sondern auch liberalsäkular geprägt. Insofern wurde der Katholizismus nur in einer staatspolitisch untergeordneten Rolle akzeptiert. Die ungarische Kirchenpolitik trug

66 Im Jahre 1900 waren 48.7 \% der Bevölkerung von Ungarn (ohne Kroatien-Slawonien) römisch-katholisch; im Jahre 1910 waren es 49.8 \%; Daten aus: A Magyar Szent Korona Országainak 1910. évi népszámlálása, S. 8.

67 Robert Nemes, The Uncivil Origins of Civil Marriage. Hungary, in Christoph Clark / Wolfram Kaiser (Hg.), Culture Wars. Secular-Catholic Conflict in Nineteenth-Century Europe, Cambridge 2003, S. 313-335, hier S. $316 f$.

68 Clewing, Staatensystem und innerstaatliches Agieren im multiethnischen Raum, S. $514 f$.

69 Ârpád von KLIMó, Ein »konfessionelles Zeitalter« Ungarns (1848-1948)?, in: Altermatt / Metzger (Hg.), Religion und Nation, S. 215-228, hier S. 217ff.

70 Ders., Nation, Konfession, Geschichte. Zur nationalen Geschichtskultur Ungarns im europäischen Kontext, München 2003, S. 99 f.

71 Bálint VARGA, Writing Imperial History in the Age of High Nationalism. Imperial Historians on the Fringes of the Habsburg Monarchy, in: European Review of History/ Revue européenne d' histoire 24 (2016), S. 1-16, hier S. 3. 
somit zur Nationalisierung des katholischen Kirchenlebens bei: Entweder weil sich die (hohe) Kirchenhierarchie, wie es der Fall in den meisten Bistümern des ungarischen Staates war, der ungarischen Staats- und Nationsidee verpflichtete, ${ }^{72}$ oder weil sich Teile des (niederen) Klerus für die nationale Emanzipation katholischer Nationalitäten (wie etwa bei den Slowaken oder den Kroaten) einsetzen mussten/wollten. ${ }^{73}$ Weil sich Budapest dabei als nationaler Akteur positionierte, hatte die katholische Kirche in Ungarn keine supranationale Staatlichkeit, mit der sie sich jenseits der nationalen Polarisierungen hätte identifizieren können.

In Österreich hingegen lagen die demographischen Gegebenheiten für einen Katholizismus als einende Idee des Imperiums vor. Die überwiegende Mehrheit der multiethnischen Bevölkerung gehörte nationalitätsübergreifend der katholischen Religion an: 1890 waren $79.3 \%$ der Bevölkerung römisch-katholisch, ${ }^{74} 190079,0 \%{ }^{75}$ und $191078,85 \%{ }^{76}$ Die römisch-katholische Religion war nicht nur insgesamt die größte Konfession, sie stellte im Gegensatz zu Ungarn - auch fast unter allen Nationalitäten Österreichs die größte und wichtigste Religion dar. Die deutsch-, tschechisch-, polnisch-, italienisch-, slowenisch- und kroatischsprachigen Menschen waren mehrheitlich römisch-katholisch, nur die ukrainischsprachige Bevölkerung (mit dem griechischen Katholizismus) sowie die serbischsprachige Bevölkerung (mit der Orthodoxie) wichen von dieser Tendenz ab (Die muslimischen und jüdischen Bevölkerungen betrachteten sich nicht als eigene Nationalitäten). Die religiös-konfessionelle Zusammensetzung der Gesellschaft, gepaart mit einem supranationalen Staatsgedanken, konnte die staatspolitische Aufwertung eines supranationalen Katholizismus ermöglichen.

Die Habsburgermonarchie (in diesem Fall: ihre österreichische Hälfte) war eine durch Widersprüchlichkeit und Heterogenität geprägte komplexe Struktur, weshalb Imaginationen, die die Einheit jenseits der nationalen

72 Gábor Adriányi, Fünfzig Jahre ungarischer Kirchengeschichte 1895-1945, Mainz 1974, S. 24ff.

73 Ders., Die katholische Kirche und die Nationalitätenfrage in Ungarn im 19. und 20. Jahrhundert, in: Der Donauraum 20 (1975), S. 47-57, hier S. 49.

74 Bureau der K. K. Statistischen Central-Commission (Hg.), Die Ergebnisse der Volkszählung vom 31. Dezember 1890 in den im Reichsrathe vertretenen Königreichen und Ländern, 1. Heft: Die summarischen Ergebnisse der Volkszählung, Wien 1892, S. XVII.

75 Dass. (Hg.), Die Ergebnisse der Volkszählung vom 31. Dezember 1900 in den im Reichsrathe vertretenen Königreichen und Ländern, 1. Heft: Die summarischen Ergebnisse der Volkszählung, Wien 1900, S. XXXII.

76 Dass. (Hg.), Die Ergebnisse der Volkszählung vom 31. Dezember 1910 in den im Reichsrathe vertretenen Königreichen und Ländern, 1. Heft: Die summarischen Ergebnisse der Volkszählung, Wien 1912, S. 54. 
Vielfältigkeit versprachen, auf allen Ebenen des Reiches verbreitet waren. ${ }^{77}$ Der universale Katholizismus stützte in diesem Sinne die ebenso universale Reichsidee bis zum Ende der Donaumonarchie. ${ }^{78}$ Die katholische Religion als eine nicht national gebundene Religion - bot den Gläubigen unterschiedlicher Nationalität eine gemeinsame Identifizierungsmöglichkeit. ${ }^{79}$ Es gab zwar kein einheitliches Staatsvolk - aber eine katholische Dynastie, gegenüber der sich die katholischen Völker (schon aus religiösen Gründen) loyal verhalten konnten. ${ }^{80}$ Die Habsburger konnten den Anspruch einer nationalen Dynastie im Interesse eines einzigen Volkes nicht erheben. Deswegen formulierte Wien den traditionellen, dynastischen Patriotismus als Loyalitätsbasis, die über die nationalen Differenzen hinaus verbindend wirkte. ${ }^{81}$

Im Mittelpunkt dieses Patriotismus stand der religiös aufgeladene Kult um die Dynastie. ${ }^{82}$ Die Religionen stellten insofern eine wichtige Legitimationsbasis für die Dynastie und das Reich dar. Nicht nur in den katholischen, sondern auch in den protestantischen, orthodoxen Kirchen, muslimischen Moscheen und jüdischen Synagogen wurde für die katholische Dynastie gebetet. Wie Joseph Roth in seinem Radetzkymarsch schrieb: »Und hunderttausendmal verstreut im ganzen weiten Reich war der Kaiser Franz Joseph, allgegenwärtig unter seinen Untertanen wie Gott in der Welt. ${ }^{83}$ Kaiser und König Franz Joseph I. stand dabei nicht mehr als ein katholischer, sondern als ein allgemein religiöser Monarch da, mit dem sich die unterschiedlichen Religionsgruppen identifizieren konnten. ${ }^{84}$

Die Religion konnte als (wenn auch nicht ausschließliche) Legitimationsbasis nicht nur für das Imperium - dem die Staatsnation als Legitimationsbezug fehlte -, sondern auch für die Nationsbewegungen - denen

77 Johannes Feichtinger, Habsburg (post-)colonial. Anmerkungen zur inneren Kolonialisierung in Zentraleuropa, in: Ders. u.a. (Hg.), Habsburg postcolonial. Machtstrukturen und kollektives Gedächtnis, Innsbruck u. a. 2003, S. 13-31, hier S. 15.

78 Gottsmann, Rom und die nationalen Katholizismen, S. 9.

79 James Shedel, Emperor, Church, and People. Religion and Dynastic Loyalty during the Golden Jubilee of Franz Joseph, in: The Catholic Historical Review 76 (1990), S. 71-92, hier S. 74 .

80 John W. Boyer, Religion and Political Development in Central Europe around 1900. A View from Vienna, in: Austrian History Yearbook 25 (1994), S. 13-57, hier S. 13.

81 Daniel L. Unowsky, Dynastic Symbolism and Popular Patriotism. Monarchy and Dynasty in the Late Imperial Austria, in: Hirschhausen/Leonhard (Hg.), Comparing Empires, S. 237-265, hier S. 239.

82 Laurence Cole, Der Habsburger-Mythos, in: Emil Brix u.a. (Hg.), Memoria Austriae I. Menschen, Mythen, Zeiten, Wien 2004, S. 472-504, hier S. 474f.

83 Zitiert nach der Ausgabe: Joseph Rотн, Radetzkymarsch, Zürich 2010, S. 102.

84 Über die Wichtigkeit der omnipräsenten Figur des streng gläubigen Franz Joseph I. siehe u. a. Michaela Vocelka / Karl Vocelka, Franz Joseph I. Kaiser von Österreich und König von Ungarn. 1830-1916. Eine Biographie, München 2015, S. 9ff. 
die Staatlichkeit als territoriale Ordnung fehlte - dienen, ${ }^{85}$ auch wenn das Zusammenspiel nationaler und religiöser Selbstverortungen unterschiedlich geartet und wahrgenommen werden konnte. Nation und Religion standen insofern in der Habsburgermonarchie - wie Moritz Csáky schreibt - weder antagonistisch noch synchron, vielmehr dialektisch zueinander:

So avancierte der Katholizismus zum Symbol unterschiedlicher, zum Teil gegensätzlicher nationalpolitischer Konzepte. Für die Nationsbildung der Slowaken oder Kroaten bekam der Katholizismus eine nationsstiftende Funktion, während die offizielle Gesamtstaatsrhetorik Wiens sich der transnationalen Funktion des Katholizismus bediente. ${ }^{86}$

Obgleich die Identifizierung und ihre öffentliche/politische Konsequenz, die Loyalität, kein Nullsummenspiel sind, in dem eine Identifizierung nur auf Kosten einer anderen möglich wäre, ${ }^{87}$ bestimmte die nationale Frage auch das Kirchenleben und die Selbstverortungen der Gläubigen. Auch wenn die nationale Selbstverortung - besonders bei den katholischen Gläubigen - nicht notwendigerweise ausschließlich (exklusiv) war, sondern sich dynamisch und dialektisch entwickelte und änderte, lässt sich die Tatsache, dass die nationale Identifizierung auch unter den katholischen Gläubigen, in der katholischen Kirche und besonders bezüglich der katholischen Kirche immer mehr an Bedeutung gewann, nicht wegdenken. Der Katholizismus diente insofern nicht nur von oben her als eine mögliche Legitimationsressource. Auch die nationalistischen Bewegungen bedienten sich der integrativen Kraft des Katholizismus. ${ }^{88}$

Daher spricht Moritz Csáky nicht von einem, sondern mehreren Katholizismen innerhalb der Donaumonarchie. ${ }^{89}$ Die »Katholizismen " bedeuteten aber nicht unbedingt nationalpolitisch gespaltene, innerkirchliche Räume, sondern vielmehr eine lokale Ebene, die ihren Katholizismus innerhalb der katholischen Kirche gegenüber den institutionalisierten Formen, Praktiken oder den kirchlichen Obrigkeiten normabweichend erleben und bestimmen wollte. Der Katholizismus stellte für ländliche Regionen bzw. für die in der lokalen Machtstruktur benachteiligten Völker den inhaltlichen und

85 Beate Носк, Kulturelle Dimensionen der Transnationalen Verflechtungen Ostmitteleuropas 1870er Jahre bis 1914, in: HAdLER / MidDELL (Hg.), Handbuch einer transnationalen Geschichte Ostmitteleuropas, S. 189-255, hier S. 239.

86 Csáky, Paradigma Zentraleuropa, S. 13.

87 Martin Schulze Wessel, »Loyalität« als geschichtlicher Grundbegriff und Forschungskonzept. Zur Einleitung, in: Ders. (Hg.), Loyalitäten in der Tschechoslowakischen Republik 1918-1938. Politische, nationale und kulturelle Zugehörigkeiten, München 2004, S. 1-22, hier S. 10.

88 Ders., Nationalisierung der Religion und Sakralisierung der Nation, S. 12.

89 Csáky, Paradigma Zentraleuropa, S. 13. 
organisatorischen Rahmen für die soziale Emanzipation dar. Im oberadriatischen Raum verbündete sich daher ein bedeutender Teil des südslawischen Klerus mit südslawisch-nationalen Ideen. ${ }^{90}$ Dass der Klerus auf der ländlichen Ebene im österreichischen Küstenland in der Tat die gesellschaftliche Emanzipation südslawischer Bevölkerungsteile unterstützte, ${ }^{91}$ erklärt sich einerseits mit der Tatsache, dass sich der Klerus sehr stark aus dem südslawischen Bauerntum rekrutierte, ${ }^{92}$ andererseits mit der kirchlichen Intention, die Hegemonie einer italienischsprachigen, nationalliberalen, urbanen Elite zu durchbrechen. Die Kirche setzte sich auch anderswo auf der lokalen Ebene der Habsburgermonarchie für die "nationalen« Forderungen marginalisierter Völker ein, wie etwa der Slowaken (in Oberungarn) und der Kroaten (in Istrien). ${ }^{93}$ In anderen europäischen Ländern lässt sich ebenso beobachten, wie der Katholizismus eine Art »Minderheitenmentalität« entwickelte und daher auch für periphere Gruppen anschlussfähig wurde. ${ }^{94}$

\subsubsection{Die Sprache der Liturgie:}

Glagoljica im oberadriatischen Raum

Die religiösen Inhalte und Symbole konnten - wie Martin Schulze Wessel betont - etwa infolge einer stärkeren nationalen, national-sprachlichen Akzentuierung sogar neue Bedeutung, Intensivität und lokale Akzeptanz erreichen. ${ }^{95}$ In der katholischen Kirche des Küstenlandes herrschte zwar Latein, eine nichtnational markierte, tote Sprache, vor, aber das ganze Kir-

90 Vanni D’ Alessio, From Central Europe to the northern Adriatic. Habsburg Citizens between Italians and Croats in Istria, in: Journal of Modern Italian Studies 13 (2008), S. 237-258, hier S. 250.

91 Zovatto, Cattolicesimo a Trieste, S. 11.

92 Paolo Blasina, Santa Sede, vescovi e questioni nazionali. Documenti vaticani sull' espiscopato di A.M Sterk a Trieste (1896-1901) [Hl. Stuhl, Bischöfe und die nationalen Fragen. Vatikanische Dokumente über die bischöfliche Zeit von A.M. Sterk in Triest /1896-1901)], in: Rivista di Storia e Letteratura religiosa 24 (1988), S. 471-502, hier S. 473; sowie ders., Die Kirche und die nationale Frage in den adriatischen Gebieten 1870-1914, in: Angela Ara / Eberhard Kolв (Hg.), Grenzregionen im Zeitalter der Nationalismen, Berlin 1998, S. 177-199, hier S. 179.

93 Rupert Klieber, Grandi e piccole comunità religiose nella monarchia asburgica fra lealismo e identità nazionali [Große und kleine religiöse Gemeinschaften in der Habsburgermonarchie zwischen Loyalität und nationaler Identität], in: Brigitte Mazohl / Paolo Pombeni (Hg.), Minoranze negli imperi. Popoli fra identità nazionale e ideologia imperiale [Minderheiten in den Imperien. Völker zwischen nationaler Identität und imperialer Ideologie], Bologna 2012, S. 375-396, hier S. $389 f$.

94 Kurt Kluxen, Religion und Nationalstaat im 19. Jahrhundert, in: Julius H. Schoeps (Hg.), Religion und Zeitgeist im 19. Jahrhundert, Stuttgart/Bonn 1982, S. 37-57, hier S. 43.

95 Schulze Wessel, Das 19. Jahrhundert als »Zweites Konfessionelles Zeitalter«?, S. 515. 
chenleben war von mehreren nationalen Sprachen (der italienischen, der slowenischen und/oder der kroatischen) geprägt. Die Sprache schafft nicht nur eine Kommunikationsgesellschaft, sondern auch Zugehörigkeitsgefühl. Insofern konnte sie immer mehr als Vorlage für nationalistische Selbstverortungen und Ansprüche dienen - auch innerhalb der einen katholischen Kirche.

In vielen innerkatholischen Konfliktfällen (vgl. Kapitel 3.1, 3.2, 4.1) stand die Sprache der Predigten oder der Gottesdienste im Vordergrund. Indem der Sprache in der ganzen Gesellschaft eine alleinige Unterscheidungsfunktion beigemessen wurde ${ }^{96}$ konnte sie die religiös-konfessionelle Zusammengehörigkeit übertönen. ${ }^{97}$ Die Aufwertung der Sprache ermöglichte nationalistische Ansprüche bezüglich des kirchlichen Raumes. Im Küstenland, besonders in den mehrsprachigen Gebieten, wurde die Sprache als ethnozentriertes Unterscheidungsmerkmal wahrgenommen, das nicht nur ein bloßes Kommunikations-, sondern vielmehr ein Identifikations- und Abgrenzungsmittel darstellen würde. ${ }^{98}$ In einer Region, wo mehrere Sprachen gleichzeitig benutzt wurden, führt eine solche Neubewertung der Sprache selbstverständlich zu neuen Konflikten:

Unterschiedliche Sprachen, die natürlich in der Tat auch im Alltag ein besonders auffallendes Abgrenzungskriterium darstellen, wurden ethnozentristisch als objektiv gegebene, auf alle Lebensbereiche einwirkende Unterscheidungsmerkmale zwischen sozialen Gruppen (Nationalitäten) definiert... ${ }^{99}$

Die sprachenbezogenen Ansprüche bedeuteten die Imagination ethnischnational homogener Räume. ${ }^{100}$ Statt der alten religiösen Hegemonieansprüche, die sich im Motto "cuius regio, eius religio « ausdrückten, wurde die Sprache in den jeweiligen nationalistischen Diskursen zum neuen herrschaftsbestimmenden Faktor (»cuius regio, eius lingua«) erhoben. ${ }^{101}$ Mit der

Elena Mannová/Jozef Tancer, Mehrsprachigkeit, in: Johannes Feichtinger/ Heidemarie UHL (Hg.), Habsburg neu denken. Vielfalt und Ambivalenz in Zentraleuropa. 30 kulturwissenschaftliche Stichworte, Wien 2016, S. 133-139, hier S. 135.

97 SAFran, Language, Ethnicity and Religion, S. 171ff.

98 Peter Urbanitsch, Der Ausgleich zwischen den Nationen untereinander und zwischen den Nationen und dem Staat in Cisleithanien, in: Pierre BéHar / Eva PhilipPOFF (Hg.), Von der Doppelmonarchie zur Europäischen Union. Österreichs Vermächtnis und Erbe, Hildesheim u. a. 2011, S. 63-92, hier S. $65 f$.

99 Peter Stachel, Ein Staat, der an einem Sprachfehler zugrunde ging. Die »Vielsprachigkeit" des Habsburgerreiches und ihre Auswirkungen, in: Johannes Feichtinger / ders. (Hg.), Das Gewebe der Kultur. Kulturwissenschaftliche Analysen zur Geschichte und Identität Österreichs in der Moderne, Innsbruck u. a. 2001, S. 11-45, hier S. 20.

100 Zum »imagined territory« siehe u. a. Haslinger, Nation und Territorium, S. 31ff.

101 Altermatt, Konfession, Nation und Rom, S. 32. 
Sprachenfrage ließ sich die Kirche als Raum ethnozentristisch beanspruchen und narrativ begrenzen, als ob die Kirche nur einer "Nationalität" gehören dürfte. Durch solche Raumansprüche erhöhte sich das sprachenbezogene Konfliktpotenzial. Die Frage etwa, ob die Messe lateinisch oder altslawisch (glagolitisch) gelesen sowie die Predigten auf der Muttersprache der jeweiligen Kirchgänger gehalten werden sollten, spaltete nicht nur Kirchengemeinden, die ethnisch-sprachlich heterogen waren wie etwa in Istrien (Kapitel 3.1), sondern auch die ethnisch-sprachlich homogenen Kirchengemeinden im Triestiner Hinterland (Kapitel 3.2) oder am Ungarisch-Kroatischen Küstenland (Kapitel 4.1). Besonders die Frage der altslawischen Liturgie - ein mittelalterliches Privileg mehrerer ostadriatischer Bistümer - sorgte für kirchen- und nationalpolitische Debatten (vgl. Kapitel 3.1.4, 4.1.4, 4.2.4).

Worum handelte es sich dabei ursprünglich? Das Privileg, altslawische Gottesdienste lesen zu dürfen, entstand noch im Kontext der Christianisierung des europäischen Ostens und Südostens im Mittelalter. ${ }^{102}$ Im 9. Jahrhundert wurden Kyrill und Method, zwei byzantinische Missionare, zu den Südslawen geschickt, um sie zu christianisieren. ${ }^{103}$ Dazu wurde ein eigenes Alphabet, das sog. »Glagoljica«, entworfen. ${ }^{104}$ Nach dem Ost-West-Schisma durften einige Diözesen in Westkroatien, Istrien und Dalmatien das Alphabet und die dazu gehörige altslawische Sprache als Liturgiesprache einer sonst nach lateinischem Ritus zelebrierten Messe beibehalten. ${ }^{105}$ Der Ritus blieb also lateinisch, ${ }^{106}$ aber innerhalb dieses Ritus wurde die Verwendung der altslawischen Sprache und der glagolitischen Schrift (als eigener Usus) ab dem 10. Jahrhundert zuerst nur geduldet, ${ }^{107}$ dann ab 1248 mit einer Ent-

102 Peter Plank, Die geschichtliche Entwicklung der orthodoxen Kirche im Südosten und Osten Europas, in: Wilhelm Nyssen u.a. (Hg.), Handbuch der Ostkirchenkunde, Düsseldorf 1984, Bd. 1, S. 133-223, hier S. 136f.

103 Vgl. Anton Benvin, Prenošenje glagoljske tradicije u liturgiji [Übertragung der glagolitischen Tradition in der Liturgie], in: Croatica Christiana Periodica 4 (1980), S. 124-135, hier S. $125 \mathrm{ff}$.

104 Zum glagolitischen Alphabet siehe u.a. Wilhelm Lettenbauer, Zur Entstehung des glagolitischen Alphabets, in: Slovo. Časopis Staroslavenskoga Instituta u Zagrebu (1953), S. 35-50; einige Theorien gehen aber von einer gothischen Herkunft des glagolitischen Alphabets aus, siehe dazu Josip ŠKunCA, O podrijetlu glagoljice [Von der Herkunft der Glagolica], in: Riječki teološki časopis 22 (2014), S. 135-162.

105 Mile Bogović, Hrvatsko glagoljaštvo kao inkulturacijski proces [Kroatische Glagolica als Inkulturationsprozess], in: Riječki teološki časopis 23 (2015), S. 317-324, hier S. 317f.

106 Zur Begrifflichkeit vom lateinischen Ritus und glagolitischen Usus siehe u.a. Stephan SMEžıK, The Glagolitic or Roman-Slavonic Liturgy, Cleveland / Rome 1959, S. 15f.; sowie Predrag Bukovec, Der glagolitische Usus des römischen Ritus, in: Ostkirchliche Studien 64 (2015), S. 96-129, hier S. 97.

107 Es ist schwierig - wegen der sporadischen Quellenlage - festzustellen, ab wann westkroatische und dalmatinische Pfarreien die glagolitische Liturgiesprache praktizierten. Die erste Erwähnung der altslawischen Liturgiesprache aus kroatischsprachigen Gebieten war gerade ein Verbot, das während des Konzils von Spalato / Split 
scheidung vom Papst Innozenz IV offiziell erlaubt. ${ }^{108}$ Mit diesem sprachenbezogenen Privileg wollte Rom das Vordringen der Orthodoxie in den kroatisch bewohnten Gebieten Südosteuropas aufhalten.

Im oberadriatischen Raum bewährte sich diese Tradition sehr lange, aber ab dem 18. Jahrhundert wurde sie entweder von muttersprachlichen (das heißt kroatischen) Messen oder der wiedererstarkenden lateinischen Tradition (die freilich von den italienischsprachigen Katholiken der Region gefordert wurde) verdrängt. Die altslawische Liturgie war im 19. Jahrhundert, in der Zeit der aufkommenden Nationalismen, in vielen Kirchengemeinden, die diese Tradition früher noch gehabt hatten, erloschen. Nach langer Vergessenheit wurde die altslawische Liturgiesprache im 19. Jahrhundert dennoch von oben her neu entdeckt: Die altslawische Tradition hätte eine katholische Einheit unter den Südslawen (klerikales Ziel) sowie die südslawische Nationalisierung der lokalen Kirchengemeinden (nationalistisches Ziel) ermöglichen sollen. ${ }^{109}$ Insofern gewann das Thema einen stark politischen Kontext. ${ }^{110}$

Die Forderung, die altslawische Liturgiesprache in den südslawisch dominierten, lokalen Kirchengemeinden wiedereinzuführen - wie es im ungarisch-kroatischen Bistum Senj (1894), dann im österreichischen Bistum Veglia/Krk (1901) in der Tat erfolgte - entsprang aber keineswegs der lokalen Ebene. Es handelte sich um Bestrebungen der kirchlichen Obrigkeiten, das Kirchenleben gegen lokale Partikularitäten (etwa die Praxis der vollkommen muttersprachlichen Messe) zu vereinheitlichen oder den kirchlichen Raum im Dienste südslawischer sozialer und nationaler Emanzipation zu beherrschen. Weil aber das Thema der altslawischen Liturgiesprache in der breiten Öffentlichkeit nicht von unten her betrachtet wurde, sondern im Lichte makropolitischer Interessen, geriet die Frage in den Kontext staats- und außenpolitischer Debatten zwischen Wien, Budapest und dem Hl. Stuhl. Es ging darum, was für eine Kirchenpolitik den unterschiedlichen (österreichischsupranationalen, ungarisch-nationalstaatlichen sowie katholisch-universellen) Interessen entspräche. ${ }^{111}$ Das Thema der altslawischen Liturgiesprache

aus dem Jahre 925 ausgesprochen wurde. Dies zeigt jedoch, dass die Sprache schon davor im adriatischen Raum verbreitet sein sollte; vgl. SMEžıK, The Glagolitic or Roman-Slavonic Liturgy, S. 41f.

108 Bukovec, Der glagolitische Usus, S. 100f.

109 WÖRSDÖRFER, »Slawischer« und »lateinischer« Katholizismus, S. $186 f$.

110 Mile Bogović, Hrvatsko glagoljsko tisućljeće [Kroatisches glagolitisches Jahrtausend], in: Senjski zbornik 25 (1998), S. 1-140, hier S. 122f.; ders., Senjska glagoljska baština [Glagolitisches Erbe von Senj], in: Senjski zbornik 35 (2008), S. 11-26, hier S. 22.

111 Über das allgemeine Verhältnis des Hl. Stuhls gegenüber den aufkommenden Nationalismen und Nationalstaaten im 19. Jahrhundert siehe u.a. Schulze, Nationalism and the Catholic Church, S. 240. 
sprengte insofern seinen ursprünglichen kirchenrechtlichen, kirchenhistorischen Rahmen, und es wurde ein politisiertes Schlachtfeld. ${ }^{112}$

Unter Papst Leo XIII kam der kirchenpolitische Gedanke, sich mit dem katholischen Südslawentum in der Donaumonarchie zu verbünden, in der katholischen Kirche auf. ${ }^{113}$ Eine solche »Allianz« hätte dem politischen Ziel, die panslawische Orthodoxie aufzuhalten, sowie dem missionarischen Ziel, alle südslawischen Völker für den Katholizismus wiederzugewinnen, dienen sollen. Der altslawischen Liturgiesprache wurde dabei die eminente Rolle zugeschrieben, eine emotionale und organisatorische "Brücke» zwischen Rom und dem ganzen (auch orthodoxen) Südslawentum herzustellen. Papst Leo XIII sympathisierte mit der vom slawonischen Bischof Josip Jurij Strossmayer propagierten Idee, mithilfe der Einführung und Verbreitung der altslawischen Liturgiesprache die kirchliche Einheit aller Südslawen unter der Ägide des Katholizismus zu erreichen. ${ }^{114}$ Dass sich die südslawisch-nationalistischen Ideen unter Papst Leo XIII einer besonderen Unterstützung erfreuten, ${ }^{115}$ manifestierte sich bereits in der Enzyklika "Grande manus" (1880), mit der die »Slawenapostel« Kyrill und Method in die Reihe der Heiligen der römisch-katholischen Kirche aufgenommen wurden. ${ }^{116}$ Andererseits glaubte der Hl. Stuhl, die katholischen Südslawen mit der altslawischen Liturgiesprache vor eventueller Orthodoxisierung und russisch-panslawischen Einflüssen abschirmen zu können. ${ }^{117}$ Wien hoffte ebenso darauf, dass sich der Panslawismus somit aufhalten ließe - wobei die panslawistischen

112 Über die altslawische Liturgiesprache und ihre neue Bedeutung im "Zeitalter des Nationalismus" siehe u.a. Gottsmann, Rom und die nationalen Katholizismen, S. 38f.

113 Über die gemeinsamen Interessen von Wien und dem Hl. Stuhl in der südslawophilen Politik von Papst Leo XIII siehe Friedrich EngeL-JAnosi, The Church and the Nationalities in the Habsburg Monarchy, in: Austrian History Yearbook 3 (1967), S. 67-82, hier S. 71ff.

114 Über die sog. kyrillo-methodianische Idee siehe u.a. Angello Tamborra, L'idea cirillo-metodiana in Europa nei secoli XIX-XX [Die kyrillo-methodianische Idee in Europa der 19. und 20. Jahrhunderte], in: Storia e politica 27 (1979), S. 666-702; Klaus Buchenau, Katholizismus und Jugoslawismus. Zur Nationalisierung der Religion bei den Kroaten, 1918-1945, in: Geyer/Hartmut (Hg.), Religion und Nation, S. 225-254, hier S. 228f.; sowie Franjo ŠAnJEK, L'église catholique et la supranationalité en Autriche-Hongrie. Le cas croate, in: Les Cahiers Irice 13 (2015), S. 27-35, hier S. 28.

115 Alojz IvanišEvić, Die Bemühungen Josip Juraj Strossmayers um die slawische Liturgie aus der Sicht der österreichisch-ungarischen Zentralbehörden und des Vatikans, in: Österreichische Osthefte 37 (1995), S. 423-445, hier S. 425.

116 Gottsmann, Rom und die nationalen Katholizismen, S. 34ff.

117 Petar VRankić, Franz Joseph I. und Papst Leo XIII. Ihre Sorge um die katholische Kirche bei den Ost- und Südslawen, in: Archivum Historiae Pontificiae 33 (1995), S. 247-273, hier S. 248 f. 
Kreise später selbst die Forderung nach der altslawischen Liturgiesprache übernahmen. ${ }^{118}$

Die Ermöglichung einer sprachlichen Partikularität wie der altslawischen Messe auf der lokalen Ebene konnte allerdings - wie die Wiener Presse 1894 die Befürchtungen wiedergab - »ein Aufgeben des durch die lateinische Sprache zum Ausdruck gelangenden einheitlichen und internationalen Charakters der römisch-katholischen Kirche« auslösen. ${ }^{119}$ Die Meinungen über die mögliche Bedeutung der altslawischen Liturgiesprache gingen dementsprechend innerhalb der katholischen Kirche, sogar unter den südslawischen Bischöfen auseinander: Ist die altslawische Liturgiesprache als kirchliches oder als nationales Privileg zu betrachten? Soll die altslawische Liturgiesprache als Klerikalisierung (das heißt klerikale, Rom-treue Vereinheitlichung) oder als Nationalisierung (das heißt Verbreitung neuer, nationaler Ideen) auf der lokalen Ebene eingeführt werden?

Der Bischof im slawonischen Đakovo, Josip Juraj Strossmayer, wollte mit der altslawischen Liturgiesprache eher nationalpolitische Ziele (die jugoslawische Idee) vorantreiben, ${ }^{120}$ auch wenn dies sogar antirömische Tendenzen verstärken konnte. ${ }^{121}$ Strossmayer betrachtete die Sprachenfrage als nationalpolitischen Bereich, deswegen engagierte er sich - etwa mit der Gründung der Jugoslawischen Akademie der Wissenschaften und Künste sowie der Universität in Zagreb - für die Vormachtstellung der kroatischen Sprache im öffentlichen Leben von Kroatien-Slawonien. ${ }^{122}$ Analog dazu hielt er die altslawische Sprache für Ausdruck der kroatischen (oder jugoslawischen) Identität der Katholiken in den kroatisch bewohnten Gebieten der Donaumonarchie.

Im Gegensatz zu diesem nationalen Verständnis betrachtete etwa Antun Mahnič, der slowenischsprachige Bischof in Veglia/Krk (im Österreichischen Küstenland), die altslawische Liturgiesprache als kirchliches Privileg, das nur im Einverständnis mit dem Hl. Stuhl und nicht als nationalpolitisches Instrument eingeführt und praktiziert werden dürfe. Mahnič enga-

118 Liliana Ferrari, Liturgia paleoslava. Il revival del XIX secolo [Altslawische Liturgie. Die Wiederbelebung im 19. Jahrhundert], in: Quaderni Giuliani di Storia 36 (2015), S. 23-34, hier S. 23ff.

119 Die Presse, 28. August 1894.

120 Jure KRIšTo, Hrvatski katolički pokret 1903-1945 [Kroatische katholische Bewegung 1903-1945], Zagreb 2004, S. 19.

121 Alojz IvanišEvić, Katholizismus und die nationale Identität der Kroaten von der Mitte des 19. Jahrhunderts bis 1918, in: Alois Moser (Hg.), "Gottes auserwählte Völker«. Erwählungsvorstellungen und kollektive Selbstfindung in der Geschichte, Frankfurt a. M. 2001, S. 217-232, hier S. 222.

122 Leopold Auburger, Grundzüge der kroatischen und südslawischen Kulturpolitik von Josip Juraj Strossmayer, in: Zeitschrift für Balkanologie 48 (2012), S. 22-50, hier S. 31f. 
gierte sich zwar für die altslawische Liturgiesprache, ${ }^{123}$ aber er prangerte »die förmliche Anarchie« im Bereich der Liturgiesprache an: ${ }^{124}$ Darunter verstand er die Lage, wenn die Liturgiesprache nicht im Einverständnis mit den päpstlichen Vorschriften festgelegt wurde. Er war dagegen, dass Bischöfe oder Pfarrer in der Region nach eigenem Gutdünken entschieden, welche Liturgiesprache vor Ort einzuführen sei. ${ }^{125}$ In seinen Augen war die altslawische Liturgiesprache vordergründig kein nationalpolitisches Mittel, sondern sie sollte die »römische« Treue der katholischen, südslawischen Bevölkerung verstärken. ${ }^{126}$ Als Bischof unterstützte er zwar die südslawische Emanzipation - aber er lehnte jegliche Unordnung ab, die den kirchlichen Interessen hätte schaden können. Volkssprachliche Gottesdienste, die einige kroatischnationalistische Agitatoren in seinem Bistum forderten, untersagte er deswegen. ${ }^{127} 1900$ gründete er ein neues Institut in Veglia/Krk, dem die Pflege der altslawischen Sprache aufgetragen wurde. Im September 1900 führte die bischöfliche Synode in allen Kirchen des kleinen Bistums von Veglia/Krk die altslawische Liturgiesprache ein. Nur einigen Gemeinden, die mehrheitlich italienischsprachig und stark urban geprägt waren wie etwa Lussinpiccolo / Mali Lošinj oder Ossero / Osor, wurde die Ausnahme zugesichert, weiterhin lateinische Gottesdienste abzuhalten. ${ }^{128}$

Eine dezidiert ablehnende Meinung gegen die altslawische Liturgiesprache kam aus Budapest. Die ungarische Regierung wurde von der italienischsprachigen, nationalliberalen, städtischen Elite des Küstenlandes bestärkt, die eine südslawische Dominanz innerhalb der katholischen Kirche - und eine damit einhergehende soziale Emanzipation südslawischer Bevölkerungs-

123 Zum Engagement von Mahnič für die altslawische Sprache siehe u.a. Anton BozAnić, Biskup Antun Mahnič i hrvatski katolički pokret - inicijative i ostvarenja u javnom životu [Bischof Antun Mahnič und die kroatische katholische Bewegung - Initiative und Verwirklichung im öffentlichen Leben], in: Riječki teološki časopis 18 (2010), S. 511-532, hier S. 512f.

124 Brief von Mahnič an die Triestiner Statthalterei über die Zustände in seinem Bistum (1. Oktober 1897), in: AST, Luogotenenza, AP, b. 256, fasc. 4.1.5., 1897/2421.

125 Bischof Mahnič stellte die kirchlichen Interessen über die »nationalen«, vgl. Aleš Maver, Die Rolle des Klerus im nationalen Emanzipationsprozess der Slowenen, in: JAKIR / Trogrlić (Hg.), Klerus und Nation in Südosteuropa, S. 49-58, hier S. 54.

126 Später öffnete sich aber Bischof Mahnič der jugoslawischen Idee; vgl. Jan Dutoit / Boris Previšić, Stammesdenken und internationale Solidarität. Bradstvo im Ersten und Zweiten Jugoslawien, in: Tanja Zimmermann (Hg.), Brüderlichkeit und Bruderzwist. Mediale Inszenierung des Aufbaus und des Niedergangs politischer Gemeinschaften in Ost- und Südosteuropa, Göttingen 2014, S. 73-98, hier S. 78.

127 Brief von Bischof Mahnič (7. Mai 1898), in: AST, Luogotenenza, AP, b. 212, fasc. 4.5.2., 1898/ 1098.

128 Bericht der Bezirkshauptmannschaft von Lussin/Lošinj über die bischöfliche Synode (12. September 1901), in: AST, Luogotenenza, AP, b. 244, fasc. 4.1.5., 1901/2078. 
teile - ebenso befürchtete. Auf der makropolitischen Ebene vertrat Budapest diese Befürchtungen. Ungarn wollte nicht nur den kirchlichen Obrigkeiten die Entscheidungsmacht über die lokale Liturgiesprache zusichern, sondern die ungarische Regierung wollte eine Kommission, welcher auch staatliche und städtische Akteure angehört hätten, damit beauftragen, die Liturgiesprache vor Ort zu bestimmen. ${ }^{29}$ Die ungarische Regierung übte großen Druck auf das gemeinsame Außenministerium in Wien aus, beim Hl. Stuhl gegen jegliche südslawenfreundliche Linie zu intervenieren. Budapest baute seine Reichshälfte nicht aufgrund supranationaler, katholischer Ideen aus. Insofern sah die ungarische Regierung in einem Südslawentum, das in seiner katholischen Religion und südslawischer Identität erstarken würde, eine Gefahr für die Idee eines magyarisch dominierten Ungarn. ${ }^{130}$ Budapest betrachtete die katholische Kirche - wie im Kapitel 4.2.4 noch näher erörtert wird - als Raum für die ungarische, magyarisierende Nations- und Nationalitätenpolitik, die eine parallele, südslawische Nationalisierung des lokalen Kirchenlebens nicht erdulden konnte und wollte. In der Kirchenpolitik bekämpfte Budapest daher jegliche Zugeständnisse zugunsten nichtmagyarischer Nationalitäten - und dabei fand die ungarische Regierung gerade in der italienischsprachigen Elite der Küstenstädte einen Verbündeten.

Budapest stellte die kirchliche Intention infrage, mit der altslawischen Liturgiesprache eine katholische Einheit unter den südslawischen Völkern herbeiführen zu können. In diesem letzten Aspekt hatte die ungarische Kritik angesichts der innerkatholischen Konflikte recht, die von der altslawischen Liturgiesprache verursacht wurden. Der nationalistisch eingestellte ungarische Kultusminister, Albert von Apponyi, stellte 1907, also schon nach dem Tod von Leo XIII, fest, dass

die Genehmigung der glagolitischen [altslawischen] Liturgie die Anziehungskraft auf die Menschen griechisch-orientalischer Konfession, welche in Rom früher erhofft worden war, keineswegs ausübte; [die altslawische Liturgiesprache] ist vielmehr fähig, die Entfernung des katholischen Elementes [im Küstenland] von der Einheit der römischen Kirche vorzubereiten. ${ }^{131}$

129 Bericht des österreichischen Kultusministeriums an die Statthalterei über die Meinung des ungarischen Kultusministeriums (22. Dezember 1905), in: AST, Luogotenenza, AP, b. 293, fasc. 4.1.5., 4136/1905.

130 Über die ablehnende Haltung der ungarischen Politik gegenüber der altslawischen Liturgiesprache siehe u. a. IvanišEvić, Die Bemühungen Josip Juraj Strossmayers um die slawische Liturgie, S. 431ff.

131 Brief von Apponyi an den gemeinsamen Außenminister in Wien (18. Januar 1907), in: Österreichisches Staatsarchiv (weiter: ÖStA), Haus-, Hof- und Staatsarchiv (weiter: HHStA), Akten zur slawischen Liturgie, PA XI 261, Liasse Rom V/7 (weiter: Slawische Liturgie V/7), fol. 74f. [übersetzt aus dem Ungarischen von mir]. 
Die altslawische Liturgiesprache war ein prägender Aspekt in vielen Konfliktfällen. Auf der lokalen Ebene wirkte sich diese Debatte aber oft anders aus. Auch wenn viele Konflikte auf die Sprache der Liturgie bzw. der Predigte zurückzuführen waren, nahm die lokale Bevölkerung die altslawische Liturgiesprache meistens nicht den makropolitischen Erwartungen und Debatten entsprechend wahr. In den homogen kroatischsprachigen Kirchengemeinden des Ungarisch-Kroatischen Küstenlandes, wo eine lokale Befürwortung und Akzeptanz der altslawischen Liturgiesprache am meisten zu erwarten gewesen wären, trat das Gegenteil ein: Mit Gewalt lehnten die kroatischsprachigen Bauern die als "nationales Privileg« angepriesene altslawische Liturgiesprache ab (vgl. Kapitel 4.1). Aber auch in den ethnisch-sprachlich heterogenen Kirchengemeinden von Istrien, wo die altslawische Liturgiesprache unter den italienischsprachigen Kirchgängern freilich Ablehnung und Irritation auslöste (vgl. Kapitel 3.1), wurde die Sprachenfrage - sowohl seitens der südslawischen Priester als auch der italienischsprachigen Kirchgänger - oft deswegen öffentlichkeitswirksam thematisiert, um anderen, lokalen, sprachen- und nationalitätsunabhängigen Konflikten und persönlichen Animositäten mehr Gehör verschaffen zu können. Die altslawische Liturgiesprache stellte immerhin ein Thema dar, das auch die lokalen Akteure in ihren Handlungen - oder zumindest in ihren Handlungsbegründungen - beeinflusste. 


\section{3. Österreichisches Küstenland}

»Mi smo tisti, ki smo bili prej; tistega boga verjamemo,

ki smo verjali poprej. ${ }^{1}$

(Uršula Pregarc, Bewohnerin in Ricmanje, 1903)

In den frühen Morgenstunden, am 14. Juni 1900, musste die Polizei in einem Triestiner Vorort einschreiten, um den örtlichen slowenischsprachigen Priester vor den versammelten slowenischensprachigen Gläubigen zu beschützen. Vor der Kirche San Giacomo / Sveti Jakob wurde er beleidigt, ausgebuht und angegriffen. Mehrere Personen wurden daraufhin festgenommen, bevor sie in die Innenstadt der österreichischen Adriametropole Triest hätten weiterziehen können. Sie wollten ursprünglich an der dortigen Fronleichnamsprozession mit einer eigenen Kirchenflagge teilnehmen. ${ }^{2}$ Noch im Mai 1900 hatte der Hl. Method und Kyrill-Verein ihre slowenischsprachig beschriftete Fahne segnen lassen. ${ }^{3}$ Die städtische Polizei bat den Verein, die Flagge an den Prozessionen nicht mitzutragen, weil diese im mehrheitlich italienischsprachig bewohnten und antiklerikal geprägten Triest als Provokation empfunden werden könne. ${ }^{4}$ Auch der Bischof Andrej Marija Šterk war dieser Ansicht, er

1 Auf Deutsch: »Wir sind dieselben, die wir zuvor waren; wir glauben an denselben Gott, an den wir zuvor glaubten." [übersetzt aus dem Slowenischen von mir]; Bericht über die Austrittsgründe von Uršula Pregarc aus der römisch-katholischen Kirche in Ricmanje (24. März 1903), in: AST, Capitanato distrettuale di Capodistria (Bezirkshauptmannschaft von Capodistria/Koper, weiter: C.d. Capodistria), Culto (Kultus, weiter: Culto), b. 170, fol. 678 .

2 Über die Vorkommnisse siehe Polizeibericht (14. Juni 1900), in: AST, Luogotenenza, AP, b. 229, fasc. 1.16.7, 1900/43.

3 Zur Flaggenweihe und den städtischen Protesten siehe Pavel Stranj, Afera cerkvene zastava Sv. Cirila in Metoda pri Sv. Jakobu [Affäre der Kirchenflagge von Hl. Kyrill und Method bei San Giacomo/Sv. Jakob], in: Jadranski koledar, 1970, S. 191-195; sowie Silvio ŠUligoJ, Župnija in njena vloga v življenju Slovencev pri Sv. Jakobu [Die Pfarrgemeinde und ihre Rolle im Leben der Slowenen bei San Giacomo/Sv. Jakob], in: Lida Debelli-Turk (Hg.), Sv. Jakob. Zgodovinski razgledi po življenju Slovencev v tržaškem delavskem okraju [San Giacomo/Sv. Jakob. Historische Ansichten über das Leben der Slowenen im Triestiner Arbeiterviertel], Trst [Triest] 1980, S. 159-179, hier S. 164ff.

4 Brief der städtischen Polizei an den Bischof (4. Juni 1900), in: Archivio Diocesano di Trieste (Bischöfliches Archiv von Triest, weiter: ADT), Gestione Particolare (Besondere Verwaltung, weiter: GP), 1900/87. 
forderte den Verein mit Hinweis auf die katholische Idee auf, bei kirchlichen Feierlichkeiten keine national markierten Symbole zu verwenden: »Kommt alle [...] als gute Christen «. ${ }^{5}$ Die nationalliberale, italienischsprachige Elite von Triest lehnte die slowenischsprachig beschrifteten, kirchlichen Fahnen ebenso ab - freilich nicht aus christlicher, sondern antislawischer Überzeugung. ${ }^{6}$ Wie der Triestiner Stadtrat Zanetti hinsichtlich einer späteren Prozession sagte, die slowenischen Kirchenfahnen seien ein "Angriff auf das nationale Gefühl des Landes «? Trotz der bischöflichen und städtischen Aufforderungen gab der slowenischsprachige Kirchenverein nicht nach. Am Tag der Fronleichnamsprozession erschienen daher "zahlreiche Slowenen aus allen Theilen der Umgebung " - wie der Polizeibericht schrieb - bei der Kirche San Giacomo/Sveti Jakob, um mit ihrer slowenischsprachigen Kirchenflagge in die Innenstadt zu marschieren. Als ihnen der örtliche Pfarrer die bischöfliche Untersagung mitteilte - Bischof Šterk hatte Angst vor Gewaltakten während der Prozession -, kam es tatsächlich zu Zusammenstößen. ${ }^{8}$ Aber nicht mit den »Italienern«, wie es befürchtet wurde, sondern zwischen den slowenischsprachigen Teilnehmern und dem ebenso slowenischsprachigen Priester. Die Polizei schaltete sich sofort ein. Sechs Männer wurden festgenommen und wegen Körperverletzung angeklagt: Nur drei davon wurden letztendlich zu 3-5 Monaten verschärften Kerkers verurteilt. Die Polizei stellte von den festgenommenen Personen fest, dass »[k]ein einziger [...] im Triester Gebiete geboren oder heimatsberechtigt« sei. ${ }^{9}$ Sie waren slowenischsprachige Katholiken aus dem ländlichen Hinterland.

Auf den ersten Blick scheint dieser Vorfall die These eines national umkämpften, gespaltenen Kirchenlebens zu bestätigen, in dem nationale Polarisierungen und Selbstverortungen die Autorität der Kirche immer mehr geschwächt hätten. Eine solche Interpretation des Falles wäre keineswegs neu, sie würde der lange dominierenden historiographischen Tendenz entsprechen, die katholische Kirche des österreichischen Küstenlandes, besonders in Triest und Istrien, in der Spätphase des Habsburgerreiches als national gespalten zu beschreiben..$^{10}$ Der Vorfall in der Triestiner Vorstadt ließe

5 Italienische Übersetzung des slowenischsprachigen, bischöflichen Briefes an den Verein (8. Juni 1900), in: Ebd. [übersetzt aus dem Italienischen von mir].

6 Im Gegensatz dazu zeigte die italienischsprachige, katholische Zeitung von Triest und Istrien, La Ricreazione, Verständnis und Sympathie für die slowenisch beschriftete Kirchenflagge, die gemäß der Zeitung keine guten Christen stören dürfe; La Ricreazione, 1. Juli 1900.

7 Rede von Zanetti (21. Juni 1900), in: Verbali del Consiglio della Città di Trieste. Annata XL - 1900 [Protokolle des Stadtrates von Triest, Jahr XL, 1900], Trieste 1900, S. 43 [übersetzt aus dem Italienischen von $\mathrm{mir}$ ].

8 Polizeibericht (14. Juni 1900), in: AST, Luogotenenza, AP, b. 229, fasc. 1.16.7, 1900/43.

9 Polizeibericht (21. Oktober 1900), in: Ebd., fasc. 1.16.33, 1900/2970.

$10 \mathrm{Zu}$ dieser Meinung siehe u. a. Blasina, Die Kirche und die nationale Frage in den adriatischen Gebieten, S. 187ff.; Frank Wiggermann, K. u. K. Kriegsmarine und 
sich außerdem im Kontext des ebenso oft bedienten »Stadt «-»Land «-Konfliktes darstellen. Der geschilderte Vorfall vor der Kirche San Giacomo/Sveti Jakob könnte so nicht nur die nationale Polarisierung des Kirchenlebens und die Überbetonung der national-partikularen Identität zuungunsten einer katholisch-universellen Identität beweisen, sondern auch das - in diesem Fall wörtlich gemeinte - Vordringen slowenischer Landbevölkerung in die »italienische« Stadt Triest.

War es aber wirklich ein Konflikt zwischen »Völkern«? Attackierten die Gläubigen den Pfarrer als nationalen Feind, als »das nationale Andere«? Der italienischsprachige, nationalliberale Magistrat von Triest protestierte zwar selbst gegen die Fahnen, verboten wurden sie aber letztendlich vom kroatischsprachigen Bischof von Triest, Andrej Marija Šterk, woraufhin die Gläubigen mit einem slowenischsprachigen Pfarrer in einen handgreiflichen Konflikt gerieten. Das nationale Vokabular verschleierte einerseits intraethnische, andererseits innerkatholische Differenzen, die etwa zwischen der kirchlichen Obrigkeit und den Kirchgängern bestanden.

Die in diesem Kapitel näher besprochenen Fälle aus Istrien (Kapitel 3.1) und dem Triestiner Hinterland (Kapitel 3.2) könnten ebenso nach den gängigen Erklärungsmustern beschrieben und verstanden werden: als Fälle innerkatholischer "Nationalitätenkonflikte«, als Fälle einer vermeintlich immer mehr national-ethnisch auseinanderdividierenden lokalen Ebene, in der klare, geschlossene, nationale Gruppenidentitäten das tagtägliche Leben bestimmt hätten. Es kommen Priester vor, die in ihren Kirchengemeinden angegriffen wurden, oder Kirchengemeinden, in denen national bestimmte Forderungen erhoben wurden. In Istrien wurden die Kirchengemeinden vor allem entlang der Frage, welche Sprache in der Kirche zu benutzen sei, polarisiert. In Ricmanje, einem winzigen Dorf im Triestiner Hinterland, lösten sich die slowenischsprachigen Gläubigen letztendlich sogar von der katholischen Kirche los, weil ihnen eine eigene Pfarrei und die muttersprachliche Liturgie verweigert wurden.

In den Kapiteln gehe ich folgendermaßen vor: Ich stelle die Konfliktfälle anhand von primären, bis jetzt nicht oder kaum bearbeiteten Quellen-Korpora dar. Die Fälle werden in einem zweiten Schritt unter anderem mit dem Narrativ der "Nationalitätenkonflikte« konfrontiert: Inwiefern lässt sich dieses Narrativ anhand der lokalen Beispiele belegen oder widerlegen? Die zeitgenössische mediale Wahrnehmung solcher Kirchenkonflikte war eindeutig vom Narrativ der "Nationalitätenkonflikte« bestimmt, was sowohl die innerkirchlichen als auch die sozialen Gründe verdrängte. Dieser makrogeschichtliche Kontext wird daher in allen Kapiteln kritisch besprochen.

Politik. Ein Beitrag zur Geschichte der italienischen Nationalbewegung in Istrien, Wien 2004, S. 144; Cetnarowicz, Narodni preporod u Istri, S. 197ff. 
Dazu werden die anderen Konfliktlinien herausgearbeitet, welche jenseits der ethnisch-sprachlichen Differenzen vorzufinden waren und möglicherweise die ausgebrochenen Konflikte bestimmten. Für die Erforschung der Fälle kann ich nur begrenzt auf vorhandene Sekundärliteratur zurückgreifen. Die »Nationalitätenkonflikte« der Halbinsel sind quellenmäßig zwar gut dokumentiert und historiographisch mit einigen bahnbrechenden Arbeiten gut erfasst ${ }^{11}-$ aber nur wenig infrage gestellt. ${ }^{12}$

\subsection{Konflikte um die Nationalisierung des kirchlichen Raumes in Istrien}

Im Folgenden stelle ich einige innerkirchliche Konflikte aus der Halbinsel Istrien und den Kvarner-Inseln dar (siehe Abbildung 2). Die Merkmale, wegen derer sich der oberadriatische Raum als geeigneter Untersuchungsraum erweisen kann, waren in Istrien noch konzentrierter vorhanden: Gleichzeitigkeit religiöser Homogenität und ethnischer Heterogenität, nationalpolitisch instrumentalisierte »Stadt«-»Land«-Konflikte, nationalpolitisch beanspruchter kirchlicher Raum, supranationales Selbstverständnis der katholischen Kirche, in der städtischen Öffentlichkeit und der späteren Historiographie vorherrschendes Narrativ der "Nationalitätenkonflikte« sowie imperiale Strukturen. Istrien war von einer ethnischen Heterogenität und religiösen Homogenität geprägt. Obwohl die katholische Kirche multiethnisch war, geriet sie in die Diskurse, die den kirchlichen Raum nationalpolitisch beanspruchen oder ablehnen wollten. Während südslawisch-

$11 \mathrm{Zu}$ den wichtigsten Monographien über das Thema siehe u.a. Milanović, Hrvatski narodni preporod u Istri; ŚEPIĆ, O procesu integracije hrvatske nacije u Istri; Nevio ŠETIĆ, Istra između tradicionalnog i modernog ili o procesu integracije suvremene hrvatske nacije u Istri, Pazin 1995; Wiggermann, K. u. K. Kriegsmarine und Politik; Rolf Wörsdörfer, Krisenherd Adria 1915-1955. Konstruktion und Artikulation des Nationalen im italienisch-jugoslawischen Grenzraum, Paderborn 2004; Almerigo Apollonio, La »belle époque« e il tramonto dell' Impero asburgico sulle rive dell' Adriatico (1902-1918). Gli anni prebellici (1902-1914) [Die »belle époque« und der Niedergang des Habsburgerreiches am Adriaufer (1902-1918). Die Vorkriegsjahre (1902-1914)], Trieste 2014.

12 Siehe u. a. Elke-Nicole Kappus, Imperial Ideologies of Peoplehood in Habsburg - an Alternative Approach to Peoples and Nations in Istria, in: Annales - Anali za istrske in mediteranske studije, 2002, S. 321-330; Vanni D'Alessio, Croatian Urban Life and Political Sociability in Istria from the 19th to the Early 20th Century, in: Jahrbücher für Geschichte und Kultur Südosteuropas 8 (2006), S. 133-152; Marta VergiNELLA, Il paradigma città / campagna e la rappresentazione dualistica di uno spazio multietnico [Das Paradigma Stadt / Land und die dualistische Repräsentation eines multiethnischen Raumes], in: Contemporanea 11 (2008), S. 779-792; ReILl KIRCHNER, Nationalists Who Feared the Nation; SUJOLDžIć, Transnational and Intercultural Practices in the Adriatric Littoral; Simon, Kulturelle Hybridität als Bedrohung? 


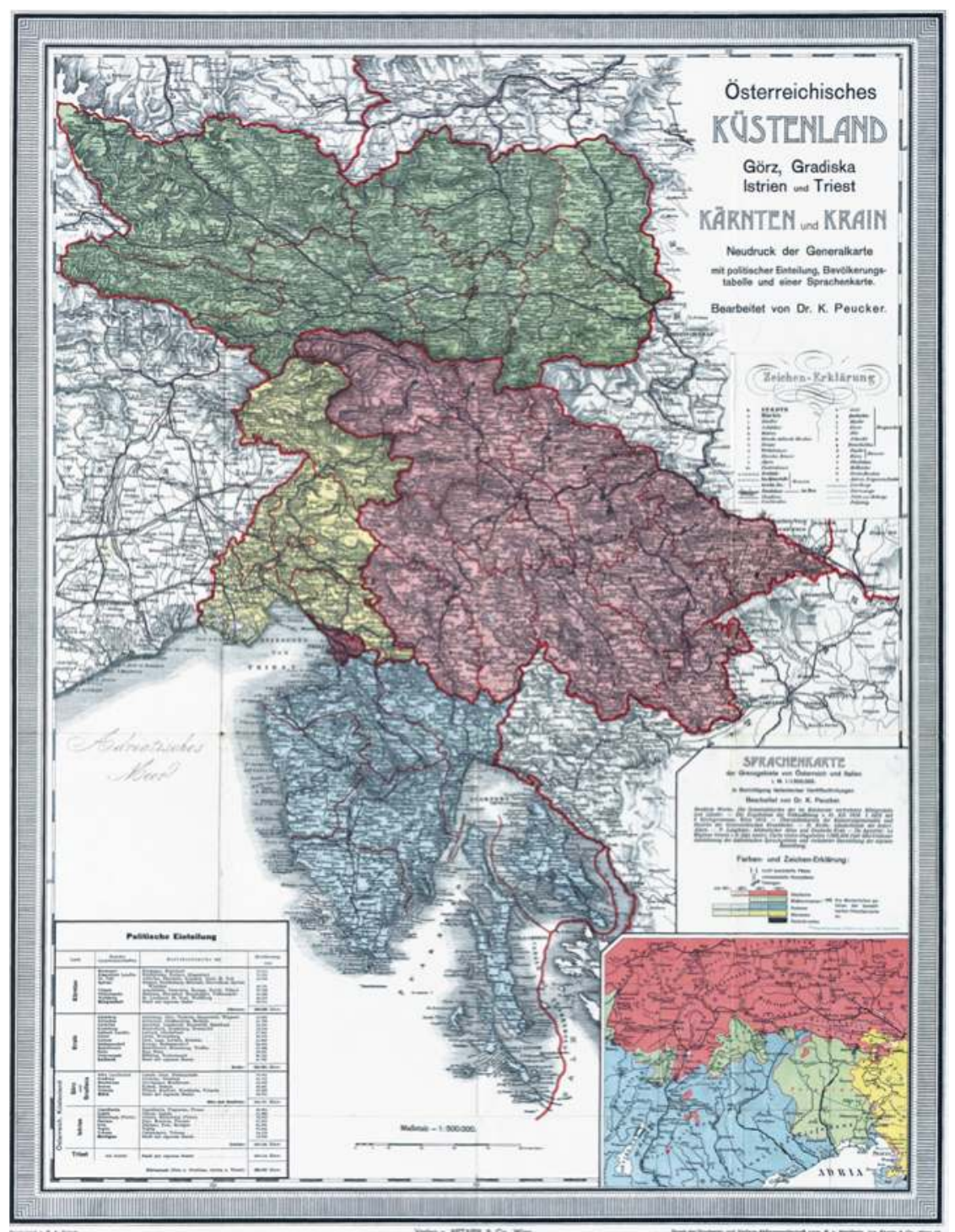

Abbildung 2: Karte vom Österreichischen Küstenland, Kärnten und Krain (1915) 
nationalistische Akteure die katholische Kirche als »nationalen Besitz« des Südslawentums betrachteten, lehnten italienisch-nationalistische Akteure die katholische Kirche als einen »südslawischen Raum«ab.

In diesem Kapitel werden mehrere Fälle geschildert. Im Gegensatz zu den Kapiteln 3.2, 4.1 und 4.2, wo immer ein Fallbespiel ausführlich erzählt wird, kommen in diesem Kapitel unterschiedliche, oft sehr kurze Konfliktgeschichten vor, an denen sich dennoch Tendenzen und tiefere Konfliktgründe erarbeiten und aufzeigen lassen. Die Nationalitäten- und Sprachenfrage zog sich dabei wie ein roter Faden durch die Fallbeispiele. Dieser rote Faden war allerdings möglich, weil Einzelheiten, persönliche Motive und lokal verwurzelte, unpolitische Gegebenheiten, die die nationalisierten Konflikte erst auslösten, in den makrogeschichtlichen Wahrnehmungen ausgeblendet wurden - diese gilt es, in der Konfliktbeschreibung ereignisgeschichtlich nachzuzeichnen (Kapitel 3.1.2). Nach der Rekonstruktion einzelner Konfliktbeispiele wird in einem nächsten Schritt versucht, die Hintergründe des nationalen Vokabulars (Nationalisierung der »Stadt«-»Land«-Konkurrenz, Elitenangst vor sozialer Emanzipation der benachteiligten, meist südslawischen Bevölkerungsteile, Verschleierung eigentlich antiklerikaler Positionen usw.) herauszuarbeiten (Kapitel 3.1.3). Dabei stellt sich die Frage im Allgemeinen, wie die katholische Kirche, deren Klerus ähnlich multiethnisch war, und das lokale Kirchenleben auf die Tendenz national motivierter (oder interpretierter) Konfliktfälle reagierten. In der historischen Kontextualisierung zu diesem Unterkapitel steht insofern das supranationale Selbstverständnis der kirchlichen Obrigkeit in Istrien im Vordergrund (Kapitel 3.1.4).

\subsubsection{Istrien: Ethnische Vielfalt und religiöse Homogenität}

Istrien war ein Grenzgebiet an der adriatischen Peripherie von Österreich. Die Halbinsel befand sich jahrhundertelang in der Kontakt- und Kampfzone zwischen venezianischen und habsburgischen Interessen, sie war bis zum Untergang der venezianischen Republik zwischen der Serenissima und dem Habsburgerreich aufgeteilt. ${ }^{13}$ In der Selbstwahrnehmung der Bewohner wirkte bis zum Ende der Donaumonarchie nach, ob sie aus dem venezianischen (eher lateinisch-mediterran geprägten) oder dem habsburgischen (eher

13 Vgl. u. a. D’ Alessio, Il cuore conteso, S. 39ff.; über die Anfänge der venezianischen Herrschaft in Istrien siehe u. a. Miroslav BertošA, Mletačka Istra u XVI i XVII stoljeću. I.: Kolonizacija (Teme i problemi) [Venezianisches Istrien im 16. und 17. Jahrhundert. I.: Kolonisierung (Themen und Probleme)], Pula 1986, S. $45 \mathrm{ff}$. 
mitteleuropäisch-balkanisch geprägten) Teil der kleinen Halbinsel stammten, auch wenn Istrien nach den napoleonischen Kriegen unter österreichische Herrschaft geriet. ${ }^{14}$ Erst unter der habsburgischen Herrschaft wurde Istrien zu einer administrativen Einheit. ${ }^{15}$ Österreich organisierte das Gebiet samt den Kvarner-Inseln (Veglia/Krk, Lussin/Lošinj, Cherso/Cres usw.) als Markgrafschaft mit eigenem Landtag. ${ }^{16}$ Die Halbinsel als eigenes Kronland gehörte neben der Gefürsteten Grafschaft Görz und Gradiska sowie der reichsunmittelbaren Stadt Triest zum sog. Österreichischen Küstenland, dem ein aus Wien ernannter Statthalter in Triest vorstand. Die politischen Debatten spielten sich im istrianischen Landtag (Dieta/Sabor) in Parenzo/Poreč $a b$, der eine öffentlichkeitswirksame, aber die Realität nur begrenzt widerspiegelnde politische Bühne für die »Nationalitätenkonflikte« darbot, wo die nationalistischen Kräfte (aller Nationalitäten) und die kirchlichen Autoritäten zusammentrafen. ${ }^{17}$

Innerhalb Österreichs war Istrien eines der religiös homogensten (das heißt fast ausschließlich katholischen) ${ }^{18}$ und ethnisch heterogensten Kronländer. Daher galt der Raum - wie Reinhard Johler schreibt - als »ein getreues Abbild des Vielvölkerstaates «. ${ }^{19}$ Istrien stand in den Wiener Diskursen pars pro toto dafür, was sich die prohabsburgischen Kreise gern als eine imperiale, nicht ethnisch gebundene Österreich-Identität vorstellten. ${ }^{20}$ Die ethnische, sprachliche Vielfalt erzeugte in Istrien eine gelebte und praktizierte Multikulturalität mit Mischidentitäten und Mischsprachen. Besonders im ländlichen Hinterland waren ethnisch-sprachliche Mischungen stark vorhanden. ${ }^{21}$ Mehrere Ethnien lebten nicht nur nebeneinander, sondern ineinander

14 Zur österreichischen Geschichte von Istrien siehe u.a. Maja Ćutić GoRUP, Istrien zur Zeit der österreichischen Herrschaft, in: Stojić/Pintarić Pavić (Hg.), Kroatiens Küste, S. 41-53.

15 Egidio Ivetic, La popolazione dell' Istria nell' eta moderna [Die Bevölkerung vom Istrien in der Neuzeit], Rovigno 1997, S. 40.

16 D' Alessio, Il cuore conteso, S. 48ff.

17 Zur geschichtlichen Bedeutung des istrianischen Landtages siehe u. a. Petar Strčić, Prilog povijesti istarskog sabora (1861.-1916.) [Beitrag zum istrianischen Landtag (1861-1916)], in: Arhivski vjesnik 34 / 35 (1991 / 1992), S. 53-64.

18 In Istrien stellten die anderen Religionsgemeinschaften wirklich eine quantité négligeable dar: Nur unter den deutschsprachigen Bewohnern in einigen Städten mit deutschsprachiger Tradition sowie den Urlaubsorten der ost-istrianischen Küste (etwa im eleganten Kurort Abbazia / Opatija) waren Judentum und Protestantismus sporadisch vorhanden.

19 Reinhard JohleR, »Hibridismus«, Istrien, die Volkskunde und die Kulturtheorie, in: Zeitschrift für Volkskunde 108 (2012), S. 1-21, hier S. 8, zum großen Interesse an der Halbinsel in der österreichischen Volkskunde siehe ebd., S. $15 f$.

20 Ebd., S. 11f.

21 Lidija Nikočević, State Culture and the Laboratory of Peoples. Istrian Ethnography during the Austro-Hungarian Monarchy, in: Narodna umjetnost 43 (2006), S. 41-57, hier S. 44f., 54f. 
verwoben, weshalb kategorisierende Trennungen die istrianische Realität nur ungenügend wiedergeben können. In der österreichischen Volkskunde wurde der Begriff »Hybridismus« für die Beschreibung dieser komplexen und somit den nationalistischen Vorstellungen widersprechenden - Realität geprägt. Der Begriff nahm vieles vorweg, was in den Postcolonial Studies gegenwärtig unter »Hybridität« behandelt wird. ${ }^{22}$

Italiener, Kroaten, Slowenen und Istro-Rumänen bewohnten die Halbinsel, nebst mehreren kleineren Mischgruppen. In einigen Städten (vor allem in der militärischen Marinebasis Pola/Pula sowie der alten Burgstadt des "habsburgischen Istriens", Pisino / Pazin / Mitterburg) war auch die deutsche Kultur und Sprache historisch stark verwurzelt. Die Halbinsel war sprachlich ebenso vielfältig: Sowohl die italienische als auch die slowenische und kroatische Sprache hatten verschiedene Dialekte, die von den jeweiligen Standardsprachen stark abwichen. Die italienischsprachige Bevölkerung der westistrianischen Küstenstädte benutzte meistens eine lokale Version des venezianischen Dialektes (dialetto istro-veneto), während die kroatischsprachige Bevölkerung der ländlichen Gebiete hauptsächlich den sog. čakawischen Dialekt und seine Dutzenden lokalen Versionen sprach. Istrien war ein Paradies für ethnologische, sprachwissenschaftliche, anthropologische Forschungen - und dementsprechend rühmte das Prestigewerk der Donaumonarchie, das vom Kronprinzen Rudolph initiierte »ÖsterreichUngarn in Wort und Bild« (1891), das adriatische Kronland ob seiner Vielfalt:

Istrien gehört, so klein es ist, in ethnographischer Beziehung zu den interessantesten Ländern der österreichisch-ungarischen Monarchie. Bruchtheile von zwei Slawenund zwei Romanenstämmen bevölkern das Ländchen, wie sie die mächtige Gewalt des Völkerstromes, der in früheren Jahrhunderten an der Halbinsel vorbeiflutete und sich zum Theil in dieselbe ergoß, neben einander ablagerte oder durcheinander schob. $^{23}$

Diese Vielfalt wurde aber in den österreichischen Volkszählungen nicht erfasst: ${ }^{24}$ Es durfte nur eine einzige Sprache als Umgangssprache angegeben werden. Damit wurden die Menschen praktisch von staatlicher Seite zu einer Identitätswahl gezwungen, ${ }^{25}$ obgleich der österreichische K. K. Verwal-

22 JOHLER, »Hibridismus«, S. 2ff.

23 Anton KLodić, Slawische Sprache und Literatur, in: Die österreichisch-ungarische Monarchie in Wort und Bild. Das Küstenland (Görz, Gradiska, Triest und Istrien), Wien 1891, S. 231. (Das Buch ist auch als »Kronprinzenwerk« bekannt).

24 Pieter Judson, Do Multiple Languages Mean a Multicultural Society? Nationalist »Frontiers « in Rural Austria, 1880-1918, in: Feichtinger / Cohen (Hg.), Understanding Multiculturalism, S. 61-82, hier S. 68.

25 Evans, Language and State Building, S. 20. 
tungsgerichtshof in Wien in einer Entscheidung aus dem Jahre 1894 die Möglichkeit verneinte, die Umgangssprache als Indiz für die Nationalität zu erachten. ${ }^{26}$ Durch die statistische Erfassung der Umgangssprache wurde die Sprache $» z u$ einem erstrangigen Aspekt einer öffentlichen und politischen Identität «. ${ }^{27}$ Weil die Angaben zur Umgangssprache dementsprechend als Ausdruck vom subjektiven Bekenntnis zu einer »Nation« (miss)verstanden werden konnten, entstanden nationalistische Ansprüche auf Territorien, die somit als »nationaler Besitz« galten. ${ }^{28}$

\begin{tabular}{lrr}
$1890^{318}$ & \\
\hline Deutsch & 5.904 & $1.90 \%$ \\
Slowenisch & 44.418 & $14.33 \%$ \\
Serbisch / Kroatisch & 140.713 & $45.39 \%$ \\
Italienisch / Ladinisch & 118.027 & $38.07 \%$ \\
& & \\
$1900^{319}$ & & \\
\hline Deutsch & 7.076 & $2.11 \%$ \\
Slowenisch & 47.717 & $14.20 \%$ \\
Serbisch / Kroatisch & 143.057 & $42.58 \%$ \\
Italienisch / Ladinisch & 136.191 & $40.53 \%$ \\
& & \\
& & \\
1910 & & \\
Deutsch & 12.735 & $3.30 \%$ \\
Slowenisch & 55.134 & $14.27 \%$ \\
Serbisch / Kroatisch & 168.184 & $43.52 \%$ \\
Italiensich / Ladinisch & 147.417 & $38.15 \%$ \\
& & \\
Tabelle 1: Verbreitung der wichtigsten Umgangssprachen in \\
Istrien, 1890-1910
\end{tabular}

Die vorhandene, lokal erlebte und praktizierte Vielfalt wurde nach konstruiert nationalen Kategorien geordnet, wo besonders der Sprache als einem vermeintlich nationalen Merkmal eine übergeordnete Bedeutung beigemes-

26 Zitiert Wiggermann, K. u. K. Kriegsmarine und Politik, S. 45.

27 Wolfgang GöDERLE, Zensus und Ethnizität. Zur Herstellung von Wissen über soziale Wirklichkeiten im Habsburgerreich zwischen 1848 und 1910, Göttingen 2016, S. 266.

28 Pieter Judson, Inventing Germans. Class, Nationality and Colonial Fantasy at the Margins of the Hapsburg Monarchy, in: Social Analysis 33 (1993), S. 47-67, hier S. 55. 
sen wurde. Somit wurde der nationalistische Diskurs, auch wenn dieser nur einen Bruchteil der damaligen Öffentlichkeit repräsentierte, übernommen und festgeschrieben. ${ }^{29}$

Die sozial bedingte und ethnisch-national markierte Kluft zwischen »italienischer" Stadt und »südslawischem « Land $^{30}$ wurde allerdings während des 19. Jahrhunderts immer kleiner, die Interaktionen zwischen den zwei "Welten« wurden immer häufiger. Viele Dorfbewohner zogen wegen neuer Arbeitsmöglichkeiten in die Städte, die ländliche Bevölkerung konnte sich gleichzeitig (etwa dank der eigenen Kreditinstitute) wirtschaftlich von der italienischsprachigen, urbanen Elite immer mehr loslösen. Das städtische Alltagsleben blieb allerdings - trotz der großen Zahl zugezogener, südslawischer Menschen - weiterhin italienischsprachig geprägt und in politischer Hinsicht italienisch-nationalliberal dominiert. ${ }^{31}$

Die ethnische Vielfalt war freilich auch innerhalb der katholischen Kirche vorhanden. Die katholische Mehrheit der Halbinsel (1890: $99.65 \%,{ }^{32}$ 1900: $99.64 \%,{ }^{33} 1910: 99.08 \%{ }^{34}$ ) war ethnisch-national sehr heterogen zusammengesetzt. Diese Vielfalt erzeugte eine Situation, in der die katholische Kirche sowohl als Treffpunkt als auch als Kampfplatz unterschiedlicher Völker erscheinen konnte. Innerhalb der Städte schaffte vor allem die katholische Kirche der südslawischen Präsenz einen Raum. Das istrianische Südslawentum wurde im »Kronprinzenwerk«, wie dem folgenden Zitat zu entnehmen ist, mit dem ländlichen, katholischen Hinterland identifiziert: Die südslawische Bevölkerung der istrianischen Halbinsel sei tief religiös, bildungsfern und es lebe in kleinen Dörfern:

Wenn auch die meisten [von den Südslawen - P. T.] sehr weit zur Kirche haben, so kommen sie doch jeden Sonn- und Feiertag zur Messe. Rein und sauber, so gut als möglich angezogen, mit Blumensträußchen auf der Brust, auf der Kappe oder in der Hand, sieht man sie aus ihren zerstreut stehenden Weilern zur Pfarrkirche eilen. Vor und nach dem Gottesdienst begrüßen sie sich, Männer wie Frauen, gegenseitig mit Worten oder (besonders in Süd-Istrien) auch mit Händedruck und Kuß. In der Kir-

29 Simon, Kulturelle Hybridität als Bedrohung?, S. 54.

30 Zur Entstehung der dichotomischen Raumimaginationen in und um Triest, siehe auch Francesco ToNCICH, Narrazioni e pratiche politiche antislave a Trieste tra città e campagna (1850-1871) [Antislawische politische Narrative und Praxen in Triest zwischen Stadt und Land (1850-1871)], in: Acta Histriae 25 (2017), S. 539-562.

31 Elke-Nicole Kappus, Regionale Identität in Istrien - oder: Auf der Suche nach der Istrianität, in: Manfred Bornewasser/Roland WAKenhut (Hg.), Ethnisches und nationales Bewußtsein - zwischen Globalisierung und Regionalisierung, Frankfurt a. M. u. a. 1999, S. 85-99, hier S. 87f.

32 Daten aus: Die Ergebnisse der Volkszählung vom 31. Dezember 1890, S. XVIII.

33 Daten aus: Die Ergebnisse der Volkszählung vom 31. Dezember 1900, S. XXXIII.

34 Daten aus: Die Ergebnisse der Volkszählung vom 31. Dezember 1910, S. 54. 
che wohnen sie andächtig dem Gottesdienst bei, hören mit besonderer Befriedigung die Epistel und das Evangelium, in einigen Gegenden auch Alles, was der Geistliche »nach uralter Sitte« in altslawischer, beziehungsweise kroatischer Sprache singt; sie merken auf die Predigt, die Vielen, besonders den Bejahrten beinahe die einzige geistige Nahrung ist. ${ }^{35}$

Die zitierte Passage zeigt indirekt die Bereiche auf, die Konfliktpotenzial bargen. Einerseits erzeugte die starke südslawische Präsenz im lokalen Kirchenleben - was sich in der großen Zahl südslawischer Priester manifestierte - eine Lage, die die Kirche als »südslawischen Raum« erscheinen ließ. In Europa war überall zu beobachten, dass der Katholizismus zum Volkscharakter bestimmter ländlicher Regionen stilisiert wurde. ${ }^{36}$ Im ethnischsprachlich durchmischten Istrien konnte eine solche "räumliche« Zuteilung der katholischen Kirche nur auf der mental map erfolgen. Eine solche narrative Raummarkierung ermöglichte sowohl nationalistisch motivierte Ansprüche (seitens südslawischer Akteure) als auch nationalistisch motivierte Kirchenkritik (seitens italienischsprachiger Akteure). Andererseits verursachte die altslawische (oder sogar kroatische/slowenische) Liturgiesprache innerkirchliche Spannungen, die für außen-kirchliche (sogar antikirchliche) Ziele instrumentalisiert werden konnten.

Die räumliche Zuteilung, die Ethnisierung des ländlichen Hinterlandes bzw. der katholischen Kirche verschleierten die sozialen Dynamiken zwischen ländlichen und urbanen Räumen, zwischen südslawischen und italienischsprachigen Bevölkerungsteilen, zwischen lokalen Kirchengemeinden und kirchlichen Obrigkeiten. Diese Dynamiken wurden in der Historiographie lange einseitig nur als »nationales Erwachen« (»narodni preporod«) der ländlichen (meist südslawischen) Bevölkerung wahrgenommen. Dabei wurde aber nicht auf die sozialen Strukturen und Machtverhältnisse eingegangen, sondern es wurde die Herausbildung angeblich getrennter "nationaler Identitäten« und »nationaler Räume« hervorgehoben. Eine solche Erklärung verkennt die Abhängigkeiten, in denen sich die Menschen in den zu schildernden Konfliktfällen befanden.

35 Alois SpINčıć, Volksleben der Slawen in Istrien, in: Die österreichisch-ungarische Monarchie in Wort und Bild, S. 215f.

36 Manuel Borutta, Antikatholizismus. Deutschland und Italien im Zeitalter der europäischen Kulturkämpfe, Göttingen 2010, S. 357. 


\subsubsection{Konfliktgeschichten: Angegriffene Priester, zerstrittene Kirchengemeinden}

Als Bischof Giovanni Battista Flapp an einem Sonntag Ende Oktober 1896 die Kirche der westistrianischen Ortschaft Visinada/Vižinada verließ, erschallten Rufe unter den versammelten Menschen. Einige riefen dem italienischsprachigen Bischof italienisches »Evviva« oder kroatisches »Živio«, also "Lebe hoch" zu. Nicht weniger Menschen waren allerdings gegen den Bischof und schrien beleidigende Sprüche wie etwa »Morte ai Croati«, also »Tod den Kroaten $\ll .{ }^{37}$ Der Bischof von Pola/Pula und Parenzo/Poreč war auf einer Reise durch sein Bistum, er wollte mehrere Kirchengemeinden aufsuchen. In Visinada / Vižinada war er zur Firmung mehrerer Kinder eingeladen.

Die antikroatischen Rufe würden einen Nationalitätenkonflikt nahelegen. Im Ort gaben die meisten Menschen das Italienische als ihre Umgangssprache an: Im Jahre 1900 lebten 2.231 Menschen in Visinada/Vižinada, wovon 2.138 italienisch-, 89 kroatisch- und nur 2 slowenischsprachig waren. Im Gerichtsbezirk, zu dem auch die ländliche Umgebung gehörte, war der Anteil der kroatischsprachigen Einwohner höher, wenn auch ebenso in der Minderheit: Von 3.978 Menschen waren 3.043 italienisch-, 866 kroatischund 61 slowenischsprachig. ${ }^{38}$ Die zwei "Welten« trafen in der Kirche von Visinada/Vižinada aufeinander. Das dortige Kirchenleben war insofern von einer ethnisch-sprachlichen und sozialen Vielfalt geprägt: In den Kirchenbänken saßen die kroatisch- oder slowenischsprachigen Bauern neben den italienischsprachigen Bürgern. Der soziale und kulturelle Unterschied ließ sich in nationale Gegensätze übersetzen. Nationalsprachliche »Identitäten " waren aber in Istrien nicht klar zu trennen: Alle Bewohner hatten Biographien, Familiengeschichten, in denen sich mehrere ethnische Elemente bzw. unterschiedliche Sprachen mischten. Viele italienischsprachige Bürger hatten etwa südslawische Familiennamen, ${ }^{39}$ und die Mehrsprachigkeit war sehr verbreitet. ${ }^{40}$

37 Bericht der Bezirkshauptmannschaft von Parenzo/Poreč (22. Oktober 1896), in: AST, Luogotenenza, AP, b. 190, fasc. 4.2.1., 1896/2123.

38 Daten aus: K.K. Statistische Zentralkommission (Hg.), Gemeindelexikon der im Reichsrathe vertretenen Königreiche und Länder. Bearbeitet auf Grund der Ergebnisse der Volkszählung vom 31. Dezember 1900, Wien 1906, Bd. VII: ÖsterreichischIllyrisches Küstenland (Triest, Görz und Gradiska, Istrien), S. 76.

39 D’Alessio, Croatian Urban Life and Political Sociability in Istria, S. 136.

40 Ders., Dall' Impero d'Austria al Regno d'Italia. Lingua, stato e nazionalizzazione [Vom Kaiserreich Österreich bis zum Königreich Italien. Sprache, Staat und Nationalisierung], in: Lorenzo BertuCELli / Mila OrLić (Hg.), Una storia balcanica. Fascismo, comunismo e nazionalismo nella Jugoslavia del Novecento [Eine balkanische Geschichte. Faschismus, Kommunismus und Nationalismus im Jugoslawien des 20. Jahrhunderts], Verona 2008, S. 31-71, hier S. 31. 
Beim bischöflichen Besuch war die Kirche von Visinada/Vižinada bis auf den letzten Platz besetzt. Als Zeichen des interethnischen Respektes und des supranationalen Selbstverständnisses der römisch-katholischen Kirche wandte sich Bischof Flapp an die italienisch- und kroatischsprachigen Kirchgänger in beiden Sprachen. Für viele italienischsprachige Menschen war das aber ein Skandal - oder zumindest ein Vorwand, einen Skandal provozieren zu können. Mehrere Personen standen mitten in der Predigt auf und verließen mit großem Lärm die Kirche. Sie riefen noch in der Kirche, beim Verlassen, "Tod den Kroaten " und andere Beschimpfungen. ${ }^{41}$ Als Bischof Flapp nach dem Gottesdienst aus der Kirche trat, beschimpften sie ihn weiter unter anderem als $»$ kroatischen Schweinebischof ${ }^{42}{ }^{42}$ obwohl Flapp bekanntermaßen italienischer Abstammung war. So löste die kroatischsprachige Predigt die heftigsten Gegenreaktionen aus. Der Besuch fand von Anfang an in einer verfeindeten Stimmung statt: Bischof Flapp wurde abgelehnt, bevor er überhaupt etwas gesagt hatte. Einige Menschen, die den Bischof hassten, brauchten insofern nicht einmal den Gottesdienst zu besuchen, um ihm etwa »kroatische« Sympathien vorzuwerfen. Schon bei dessen Ankunft in Visinada/Vižinada warteten sie auf die bischöfliche Kutsche, und riefen dem Bischof »Merda per i Croati«, das heißt »Scheiße den Kroaten «, zu. Sie bejubelten gleichzeitig irredentistische und antiklerikale Vereine wie die Unione ${ }^{43}{ }^{3}$

Angesichts der angespannten Lage verzichteten Bischof Flapp und seine Gäste auf das geplante gemeinsame Mittagessen im Ort. Die eingeladenen Menschen aus der Ortschaft fürchteten sich vor Provokationen und möglichen Angriffen. ${ }^{44}$ Auch wenn es nicht zu physischer Gewalt kam, wollte Bischof Flapp so schnell wie möglich mit einer Kutsche in die nächste Ortschaft weiterfahren. Ihm wurde aber keine Kutsche in Visinada/Vižinada bereitgestellt. Alle, die eine Kutsche hatten, verweigerten dem Bischof ihre Hilfe. Daher verzögerte sich die Abfahrt, bis eine Kutsche für den Bischof aus einem anderen Dorf gefunden werden konnte. ${ }^{45}$ Als Bischof Flapp wegfuhr, konnte er noch immer die schreienden Menschen hören. Sie beleidigten

41 Bericht der Bezirkshauptmannschaft von Parenzo/Poreč (22. Oktober 1896), in: Državni Arhiv u Pazinu (Staatsarchiv in Pisino/Pazin, weiter: DAP), Kotarsko poglavarstvo (Kapetanat) u Poreču (Bezirkshauptmannschaft von Parenzo/Poreč, weiter: Kapetanat Poreč), Opči Spisi (Allgemeine Schriften, weiter: Op.Sp.), kutija (kut.) 60, fasc. I/9, 1896/10365.

42 Zeugenaussage über einen Tatverdächtigen (ohne Datum), in: Ebd. [übersetzt aus dem Italienischen von mir].

43 Protokolle über einen Tatverdächtigen (ohne Datum), in: Ebd., 1896/10365 [übersetzt aus dem Italienischen von mir].

44 Bericht des Landes-Gendarmarie-Commando (28. Oktober 1896), in: Ebd., kut. 53, fasc. D/1, 7215 - 98 - D1.

45 Bericht des Landes-Gendarmarie-Commando (19. Oktober 1896), in: Ebd., kut. 60, fasc. I/9, 1896/10365. 
jedoch nicht nur die »Kroaten«, sondern auch alle, die den Bischof würdig verabschieden wollten: Als ein italienischsprachiger Mann seinen Hut vor der Kutsche des Bischofs abnahm, wurde er von den lärmenden Menschen barsch zur Rede gestellt. ${ }^{46}$ Eine Großzahl der Leute, die sich am Platz und entlang der Straße versammelten, stand mit abgesetzten Hüten schweigsam da und schaute der wegfahrenden Kutsche in würdevoller Weise nach. ${ }^{47}$

In Visinada/Vižinada war das Verhältnis zwischen einigen Bewohnern und der Kirche seit einer gewissen Zeit schlecht: Die Entscheidung des örtlichen Pfarrers, kroatische Predigten in der Kirche einzuführen, verursachte Empörung unter einigen italienischsprachigen Einwohnern. Trotzdem wurde daraufhin an den Sonn- und Feiertagen immer auch auf Kroatisch in der Stadtkirche gepredigt. Die Messe um 7 Uhr in der Früh wurde für die Landbevölkerung zelebriert. Der Vorwurf der italienisch-nationalistischen Kreise, dass die kroatische Predigt von Bischof Flapp ein ungewöhnlicher Akt in der Kirche von Visinada / Vižinada gewesen sei, stimmte also nicht: In der Kirche wurde regelmäßig auf Kroatisch gepredigt. ${ }^{48}$ Italienischsprachige Menschen besuchten öfters diese Gottesdienste, obwohl Gottesdienste mit italienischer Predigt ebenso gelesen wurden. Für viele stellte die kroatische Predigt aber eine gute Gelegenheit dar, ihrer Missbilligung demonstrativ Ausdruck zu verleihen. Es kamen also immer wieder ähnliche Szenen in der Kirche vor wie während des bischöflichen Besuches: Wie die örtliche Gendarmarie berichtete, verließen »die von der italienischen Partei« während der kroatischen Predigten fast jeden Sonntag die Kirche. ${ }^{49}$

Das Kirchenleben war in den polizeilichen Berichten so dargestellt, als ob die Kirchgänger in zwei Parteien, die "slawische« und die »italienische« gespalten gewesen wären. Der Hass der »italienischen Partei«, die das Stadtmagistrat von Visinada/Vižinada dominierte, richtete sich jedenfalls nicht (nur) gegen die kroatische Predigt oder die kroatischsprachigen Kirchgänger (»die kroatische Partei«). Die eigentlichen Positionen der »italienischen Partei« gingen über das »nationale« Thema hinaus. Sie lehnten grundsätzlich die katholische Kirche als solche ab. Der barsche Empfang für den Bischof seitens einiger italienischsprachiger Einwohner und des nationalliberal dominierten Magistrates lässt sich nur mit nationalen Gegensätzen und purem Nationalismus nicht erklären. Bischof Flapp war der italienischfreundlichste Bischof im Österreichischen Küstenland, der etwa die altslawische Liturgiesprache,

46 Ebd.

47 Bericht des Landes-Gendarmarie-Commando (28. Oktober 1896), in: Ebd., kut. 53, fasc. D/1, $7215-98-\mathrm{D} 1$.

48 Bericht der Bezirkshauptmannschaft von Parenzo/Poreč (22. Oktober 1896), in: AST, Luogotenenza, AP, b. 190, fasc. 4.2.1., 1896/2123.

49 Bericht des Landes-Gendarmarie-Commando (28. Oktober 1896), in: DAP, Kapetanat Poreč, kut. 53, fasc. D/1, 7215 - 98 - D1. 
also eine Forderung der kroatisch-nationalistischen Kreise, in seinem Bistum entschieden bekämpfte. ${ }^{50}$ Er galt als Verfechter des lateinischen Charakters der lokalen Kirche. ${ }^{51}$ Auch Don Angelo Palaoro, der als Missionar aus Visignano/Višnjan beim bischöflichen Empfang in Visinada/Vižinada mitgeholfen hatte, war italienischer Abstammung. Einige Jahre zuvor war er aus dem italienischsprachigen Teil von Tirol nach Istrien gekommen. In Istrien kritisierte er die altslawischen Tendenzen in der katholischen Kirche. ${ }^{52}$ Insofern wären Anfeindungen gegen Bischof Flapp oder Don Palaoro eher von den kroatischsprachigen Kirchgängern zu erwarten gewesen. Der Magistrat und einige italienischsprachige Bewohner von Visinada / Vižinada nahmen diese Geistlichen dennoch als »kroatisch « wahr. »Kroatisch « bedeutete in diesem Falle nicht (nur) eine nationale Zuschreibung - die im Falle von Monsignore Flapp und Don Palaoro nicht einmal objektiv stimmte -, sondern vielmehr stand es für »klerikal«. Die Kirche galt in der nationalliberalen, italienischsprachigen Öffentlichkeit Istriens als ein »kroatischer« Raum. Diese nationale Markierung ermöglichte gleichzeitig eine nationale Kaschierung antiklerikaler Positionen.

Beim bischöflichen Besuch in Visinada/Vižinada zeigte sich die antiklerikale Ausrichtung der angeblich nur »antikroatischen" Protestaktionen. Der Magistrat nahm etwa die Ortsflagge vom Rathaus bei der Ankunft des Bischofes ab - als Zeichen dafür, dass er in Visinada/Vižinada kein willkommener Gast war. Auf die Nachfrage will der Magistrat nur wegen des andauernden Regens die Flagge eingezogen haben. Die ganze Nacht vor dem Besuch regnete es tatsächlich, aber der Magistrat holte die Flagge erst am Vormittag, also während des Besuches des Bischofs, ein, als das Wetter viel besser geworden war. Don Palaoro berichtete außerdem darüber, dass eine gelb-weiße päpstliche Fahne, die er zur Begrüßung des Bischofs ausgehängt hatte, in der Nacht vor dem Besuch entfernt worden sei. Ein solcher Akt lässt sich nicht mit innerkatholischen, vermeintlich national motivierten Spannungen erklären - er richtete sich nicht bloß gegen Katholiken anderer Muttersprache, sondern auch gegen die ganze Kirche und ihre Repräsentanten wie den örtlichen Pfarrer, den Bischof und letztendlich die päpstliche Macht. Die Wiener christlich-soziale Tageszeitung Reichspost nahm die Ereignisse in Visinada/Vižinada dementsprechend - entgegen dem Haupttenor der anderen Zeitungen - nicht als nationalistischen, sondern als antikirchlichen

$50 \mathrm{Zu}$ Flapps Position bezüglich der altslawischen Liturgiesprache siehe Gotтsmann, Rom und die nationalen Katholizismen, S. 72f.

51 Blasina, Die Kirche und die nationale Frage, S. 184ff.

52 Milanović, Hrvatski narodni preporod u Istri, S. 330. 
Vorfall wahr: »hinter der nationalen Flagge« habe der liberal gesinnte Magistrat eigentlich »seine feindliche Gesinnung gegen Kirche und Religion" verschleiert. ${ }^{53}$

Die Vermutung liegt daher nahe, dass diejenigen, die die Kirche während der kroatischsprachigen Predigten (nicht nur beim bischöflichen Besuch) in Visinada/Vižinada mit Lärm verließen, eigentlich nur den Skandal suchten, um die Autorität der Kirche zu schwächen. Ihnen ging es zuvorderst nicht darum, in ihrer eigenen Muttersprache (das heißt im Italienischen) die Predigten hören zu können - diese Möglichkeit hätten sie während der anderen Gottesdienste gehabt, die nicht für die Landbevölkerung zelebriert wurden -, sondern um die Störung des kirchlichen Lebens. Sie wussten, dass eine nationalpolitische Spaltung die gesellschaftliche Position der Kirche massiv untergräbt. Die objektive Tatsache, dass die örtliche Kirchengemeinde in Visinada/Vižinada ethnisch-sprachlich gemischt war, stellte insofern nicht den Konfliktgrund, sondern den Konfliktvorwand für einige Menschen dar die eigentlich nationalliberal (und demnach antiklerikal) eingestellt waren -, um die Kirche und ihre Repräsentanten kritisieren und die kirchlichen Zeremonien stören zu können.

Die Behauptung, dass die Kirche in Istrien »südslawisch « geprägt sei, hatte allerdings auch objektive Gründe. Die katholische Kirche in Istrien war stark von einem südslawischen Klerus geprägt, der die klerikalen Ziele mit dem sozialen Aufstieg der südslawischen Bevölkerung verband. ${ }^{54}$ Nicht nur die antiklerikalen Kreise bedienten sich also eines nationalistischen Vokabulars und verorteten die kirchlichen Akteure - unabhängig von ihrer tatsächlichen nationalen Zugehörigkeit oder Muttersprache - als »kroatisch", sondern viele südslawischen Priester akzeptierten die antiklerikale Tendenz, die Kirche den »Südslawen« zuzuschreiben. Politische und soziale Gegensätze wurden somit national markiert.

Die lange Konfliktgeschichte innerhalb - oder vielmehr: bezüglich der katholischen Kirche auf den Kvarner-Inseln zeigte mehrere Facetten von solchen Frontlinien- und Diskursüberlappungen auf: Im Mikrokosmos einer insularen Welt verdichteten sich vorhandene, persönlich motivierte, lokal verwurzelte Konflikte, die von antiklerikalen oder nationalistischen Ideen angestachelt werden konnten. Alois Lasciac, der zwischen 1887 und 1889 Bezirkshauptmann in Lussin/Lošinj war, beschrieb die Inselbewohner als eine »in langjährigen nationalen Kämpfen gefeite, streitlustige Bevölkerung «. ${ }^{55}$ Die innerkirchlichen Konflikte gelangten in die makropo-

53 Reichspost, 28. Oktober 1896.

54 Trogrlić, Katolička crkva u Istri, S. $95 f$.

55 Alois Lasciac, Erinnerungen aus meiner Beamtencarrière in Österreich in den Jahren 1881-1918, Trieste 1939, S. 14. 
litischen Diskurse. Daher beschäftigte sich sogar der Hl. Stuhl mit diesen lokalen Fällen in den kleinen Ortschaften. ${ }^{56}$ Im Folgenden kommen daher einige Beispiele von diesen Inseln.

An einem Sonntag Ende September 1895 zelebrierte ein Franziskanermönch, Padre Smolje, die übliche feierliche Sonntagsmesse in der Kathedrale der kleinen Ortschaft Neresine/ Nerezine auf der Insel Lussin/Lošinj. Zum ersten Mal seit Jahren ertönte die sog. altslawische Sprache in der Kirche: Padre Smolje sang den ersten Teil der Gottesdienste in der altslawischen Sprache gemäß des alten Privilegs einiger ostadriatischen Bistümer. Die meisten Menschen standen sofort auf und verließen die Kirche aus Protest. Als italienischsprachige Kirchgänger verstanden sie die andere Sprache nicht. Sie sahen darin einen Affront gegen den lateinischen Charakter ihrer Pfarrgemeinde und der katholischen Kirche. Der Franziskanermönch bekam die Unzufriedenheit nach dem Gottesdienst gewaltig zu spüren. Fünfzehn Männer warteten auf ihn und verfolgten ihn stundenlang in den kleinen Gassen der idyllischen Ortschaft: Als sie ihn einholten, bedrohten und schüttelten sie ihn. ${ }^{57}$ Der Bürgermeister (podestà) von Ossero / Osor, zu dem auch Neresine/ Nerezine gehörte, bemerkte, dass der Hass gegen den Franziskanermönch sehr groß sei. ${ }^{58}$ Auch der örtliche Bezirkshauptmann warf dem kroatischsprachigen, jungen Franziskanermönch vor, die Traditionen, etwa bezüglich der bisher lateinisch gelesenen Gottesdienste, außer Acht gelassen zu haben. Damit trage er zur Vertiefung der politischen Spannungen innerhalb der Bevölkerung bei. ${ }^{59}$ Der damalige Bischof von Veglia/ Krk, dem die Insel Lussin / Lošinj unterstellt war, Andrej Marija Šterk führte die Drohungen und Angriffe gegen den Franziskanermönch auf die Debatten zwischen den zwei »Parteien«, der »kroatischen« und der »italienischen«, zurück, die ihre politische Feindschaft auf das Kirchenleben übertragen hätten. ${ }^{60}$

Obwohl Bischof Šterk betonte, dass die altslawische Liturgie in Neresine/ Nerezine keine aufgedrängte Neuigkeit, sondern die Wiederbelebung einer jahrhundertelang bestehenden lokalen Tradition darstelle, ${ }^{61}$ ermahnte er dennoch den Franziskanermönch: Er solle mit der altslawischen Liturgiesprache den öffentlichen Frieden in der Ortschaft nicht aufs Spiel setzen. ${ }^{62}$

56 Andreas Gottsmann arbeitete in seiner Monographie die makrogeschichtliche Wahrnehmung vieler Fälle aus der Insel Lussin / Lošinj auf, siehe GotTsmanN, Rom und die nationalen Katholizismen, S. 177-190.

57 Bericht der Bezirkshauptmannschaft von Lussin/Lošinj (23. September 1895), in: AST, Luogotenenza, AP, b. 256, fasc. 4.1.5., 1895/2198.

58 Brief des Bürgermeisters (23. September 1895), in: Ebd., 1896/16.

59 Brief des Bezirkshauptmannes an den Bischof von Veglia/ Krk (27. September 1895), in: Ebd., 1895/2216.

60 Brief des Bischofes (15. Oktober 1895), in: Ebd., 1895/2325.

61 Ebd.

62 Brief des Bischofes (31. Oktober 1895), in: Ebd., 1895/2490. 
Neresine/Nerezine war mehrheitlich italienischsprachig: Von den 1.308 Einwohnern gaben 997 Menschen das Italienische und 306 Menschen das Kroatische als ihre Umgangssprache (bei der Volkszählung von 1900) an. ${ }^{63}$ Bischof Šterk meinte, dass die ganze Debatte um die Liturgiesprache als Vorwand für antikirchliche Positionen italienischsprachiger politischer Akteure diene: Die lateinische Sprache sei dabei »ein Mittel für politische Zwecke«. ${ }^{64}$

Die Spannungen wirkten bis in das Leben einzelner Menschen auf der lokalen Ebene hinein - und in diesen konkreten Fällen nahmen die Menschen ihre Situation oft durch eine nationalisierte Brille wahr. Für viele italienischsprachige Katholiken, auch wenn sie die nationalliberale Deutungshoheit ablehnten, stellten die südslawischen Priester eine Bedrohung dar. Viele jüngeren, südslawischen Priester forderten nicht nur die nationalliberale Elite, sondern auch die italienischsprachigen Gläubigen innerhalb der Kirche heraus. Im April 1897 meldete etwa der Bürgermeister von Ossero / Osor, dass die kroatischsprachigen Priester in Neresine/ Nerezine mehreren Kindern die in lateinischer Sprache zu erteilende Taufe verweigert hätten. ${ }^{65}$ Ein neugeborenes, krankes Mädchen verstarb im Februar 1896, ohne getauft zu werden: Don Trinajstić habe die kleine Marcella nur in altslawischer Sprache taufen wollen, was die Eltern aber ablehnten. Der Vater, Dominico Cavedoni, stellte ein paar Monate später am Grab seiner verstorbenen Tochter ein eineinhalb Meter großes Holzkreuz auf. Es wurde »der Seele unserer allerliebsten Marcella" gewidmet, »der verneint wurde, den Fleck der Erbsünde in einer Zeremonie der lateinischen Liturgie wegzuwaschen«. Der Vater ließ dem Text - wie eine fiktive Aussage des Mädchens gegen den Priester - hinzufügen: „Von der Spitze des Himmels bete ich für diejenigen, die das Gut der Vernunft verloren haben. ${ }^{66}$

Im Bischofsitz von Veglia / Krk folgte inzwischen der slowenischsprachige Antun Mahnič auf den kroatischsprachigen Šterk, der als Bischof nach Triest ging. Fälle, in denen Kinder auf der Insel Lussin/Lošinj wegen der Sprache kirchlich nicht begraben oder getauft wurden, ereigneten sich auch unter ihm immer wieder. ${ }^{67}$ Hinter den nationalen Gegensätzen schienen jedoch

63 Daten aus: Gemeindelexikon der im Reichsrathe vertretenen Königreiche und Länder, S. 62.

64 Brief des Bischofes (31. März 1896), in: AST, Luogotenenza, AP, b. 256, fasc. 4.1.5., 1896/745 [übersetzt aus dem Italienischen von mir].

65 Brief des Bürgermeisters (7. April 1897), in: Ebd., 1897/22.

66 Bericht des Bezirks-Gendarmarie-Commandos von Lussinpiccolo/Mali Lošinj (4. Juni 1897), in: Ebd., 1897/5440 [übersetzt aus dem Italienischen von mir].

67 Siehe etwa Bericht der Bezirkshauptmannschaft von Lussin / Lošinj (7. Februar 1898), in: Ebd., 1898/307 oder Bericht der Bezirkshauptmannschaft von Lussin/Lošinj (7. Februar 1898), in: Ebd., b. 223, fasc. 4.1.15., 1899/2284. [Etwa wollte Bischof Mahnič im Jahre 1906 das Begräbnis nach lateinischer Zeremonie erlauben, aber der örtliche Kaplan behauptete, das Telegramm darüber erst nach dem Begräbnis erhalten zu haben - deswegen entstand zuerst wiederum eine Streitigkeit zwischen 
oft andere Unterschiede hindurch: Im Jahre 1904 warf etwa eine italienischsprachige Familie dem kroatischsprachigen Pfarrer in Lussinpiccolo/Mali Lošinj, Don Bonefačić, vor, aus nationalistischen Gründen ihren verstorbenen Verwandten nicht begraben zu wollen. Don Bonefačić rechtfertigte seine Weigerung hingegen damit, dass weder die Familie noch der Verstorbene die Gottesdienste besucht hätten und dass der Sterbende die letzten Sakramente ausdrücklich abgelehnt hätte. ${ }^{68}$ Die priesterliche Entscheidung, dem Begräbnis nicht beizuwohnen, wäre demnach von einer konservativen, streng klerikalen Einstellung motiviert gewesen. ${ }^{69}$ Bischof Mahnič war der Ansicht, dass den meisten Beschwerden antiklerikale, politische Ziele zugrunde lägen. Auch im Falle eines anderen Begräbnisses, wo der Familie die gewünschte lateinische Zeremonie nicht erteilt wurde, bemerkte Bischof Mahnič, dass die Familie mit dem Konflikt gegen ihn und die katholische Kirche demonstrieren wollte: »nun aber kann ich als Bischof zu antikirchlichen und politischen Demonstrationen meine Hand nicht herleihen ${ }^{70}$ Er stand unter zweifachem Druck. Einerseits wollten einige kroatischsprachige Priester aus dem niederen Klerus die Präsenz der kroatischen Sprache im Kirchenleben verstärken, was viele italienischsprachige Katholiken von der Kirche zu entfremden drohte. Andererseits nutzten die antiklerikalen Akteure die angespannte Situation in der Kirche aus, indem sie die ethnisch-sprachlichen Differenzen für politische Ziele intensivierten. Bischof Mahnič musste alle Versuche abwehren, die den innerkirchlichen Frieden aufgrund ethnischnationaler Ausgrenzungen gefährdet hätten.

Die Sprachenfrage betraf auf den Inseln auch den schulischen Religionsunterricht. Auch wenn die Schulen, bis auf die privaten, von den Kommunen, die in Istrien meistens italienisch-nationalliberal regiert waren, bestimmt wurden, ermöglichte der Religionsunterricht es dem jeweiligen lokalen Priester, sich als Religionslehrer in die schulischen Curricula und die Sprachenfrage einzumischen, indem er etwa in den italienischsprachigen, kommunalen Schulen kroatisch- oder slowenischsprachigen Religionsunterricht hielt. In mehreren Schulen (wie etwa ab 1898 in der italienischsprachigen

einer kirchlichen Person und einer italienischsprachigen Familie, und der Tote musste ohne priesterliche Assistenz begraben werden; vgl. Brief von Bischof Mahnič (24. Dezember 1906), in: Ebd., b. 307, fasc. 19b, 1906/1778].

68 Bericht der Bezirkshauptmannschaft von Lussin / Lošinj (24. Oktober 1904), in: AST, Luogotenenza, Atti presidiali riservati (Reservierte Präsidialakten, weiter: AP ris.), b. 5, fasc. 5.6.1., 1904/4112.

69 Brief von Don Bonefačić an Bischof Mahnič (24. Dezember 1904), in: Ebd.

70 Brief von Bischof Mahnič (28. September 1899), in: Bericht der Bezirkshauptmannschaft von Lussin/Lošinj (7. Februar 1898), in: AST, Luogotenenza, AP, b. 223, fasc. 4.1.15., 1899/2404. 
Volkschule in Neresine/Nerezine und 1904 in Cherso/Cres ${ }^{71}$ oder ebenso 1904 in Unie/Unije) ${ }^{72}$ wurde der Religionsunterricht eingestellt, weil die dortigen Priester ihn nur in kroatischer Sprache zu erteilen willens gewesen wären. Alle betroffenen Orte waren jedoch ethnisch-national sehr gemischt: Im Gerichtsbezirk von Cherso/Cres waren 5.863 Menschen kroatisch- und 2.039 Menschen italienischsprachig, auch in der Stadt Cherso/Cres stellten die kroatischsprachigen Menschen die Mehrheit: Von 4379 Einwohnern waren sie $2.269 .{ }^{73}$ In Unie/ Unije lebten 446 italienisch- und 250 kroatischsprachige Menschen.$^{74}$ In welcher Sprache der Religionsunterricht in solchen Orten zu erteilen sei, war schwer zu bestimmen. Bischof Mahnič behauptete jedenfalls, dass die Kinder die italienische Sprache nicht verstünden ${ }^{75}$ insofern betrachtete er den kroatischsprachigen Religionsunterricht in den eigentlich italienischsprachigen Volksschulen als gesellschaftliche Emanzipation gegenüber herrschenden Strukturen wie etwa den Sprachenordnungen der Schulen. In vielen Aktionen lokaler, kroatischsprachiger Priester, die auf die Stärkung der kroatischen Sprache in der Kirche und im Religionsunterricht abzielten, erblickte der Wiener Nuntius, Emidio Taliani, aber einen rein südslawischen Nationalismus. ${ }^{76}$ Bischof Mahnič gab zwar zu, dass er und sein Klerus das kroatische Volk "gegen viele Unterdrückungen" verteidige - aber nicht aus Nationalismus, sondern aus christlicher Liebe. ${ }^{77}$

Bischof Mahnič verortete die Konflikte ungern im Kontext der »Nationalitätenkonflikte«, weil eine solche Perspektive die Kirche spalten und schwächen konnte. Stattdessen stellte er die Konflikte einerseits als Teil der Kämpfe zwischen Klerikalen und Antiklerikalen dar, um eine kirchliche Einheit gegen die Kritiker hervorheben und stärken zu können. Andererseits nahm er die Konflikte als Folge sozial bedingter Ungleichheiten zwischen einer italienischsprachigen, städtischen Elite und der kroatischsprachigen, ländlichen Bevölkerung wahr. Er sprach deswegen meistens nicht von »Ita-

71 Bericht der Bezirkshauptmannschaft von Lussin/Lošinj (25. September 1906), in: Državni Arhiv u Rijeci (Staatliches Archiv in Fiume/ Rijeka, weiter: DAR), Kotarsko poglavarstvo / kapetanat Lošinj (Bezirkshauptmannschaft von Lussin / Lošinj, weiter: Kapetanat Lošinj), kutija (kut.) 3, fasc. D3, 84 - 906 - D3.

72 Brief von Bischof Mahnič (10. Februar 1904), in: Ebd., D3 - 193 - 506/I.S.

73 Daten aus: Gemeindelexikon der im Reichsrathe vertretenen Königreiche und Länder, S. 60.

74 Ebd., S. 62.

75 Brief von Bischof Mahnič (29. März 1904), in: DAR, Kapetanat Lošinj, kut. 3, fasc. D3 [ohne weitere Nummerierung].

76 Brief vom Wiener Nuntius Taliani an Bischof Mahnič (12. März 1899), in: Archivio Apostolico Vaticano (Vatikanisches Apostolisches Archiv, weiter: AAV), Archivio della Nuntiatura di Vienna (Archiv der Nuntiatur von Wien, weiter: ANV), busta (b.) 693 , fasc. 7 , fol. 356 .

77 Brief von Bischof Mahnič an den Wiener Nuntius Taliani (7. November 1898), in: AAV, ANV, b. 693, fasc. 7, fol. 342. 
lienern « und »Kroaten«, sondern von »Herren«, denen die »Bauern" gegenübergestanden hätten: »die Bauern [sehen] von Tag zu Tag besser [ein], wie sie von der herrschenden Clique hinters Licht geführt und in schnödester Weise missbraucht werden ${ }^{78}$

Bischof Mahnič erkannte die Gewalt nicht in den physischen Handlungen kroatischsprachiger Bauern. Seiner Auffassung nach war die kroatischsprachige, ländliche Bevölkerung solchen Ungleichheitsstrukturen ausgesetzt. Dabei verschwieg er, dass vertikale, sozial bedingte Konflikte nicht nur im "weltlichen« Raum, das heißt zwischen der städtischen (meist italienischsprachigen) Elite und der ländlichen (meist südslawischen) Bevölkerung bestanden, sondern auch im kirchlichen Raum zwischen den Kirchgängern und den kirchlichen Obrigkeiten (Pfarrern, Bischöfen). In den ethnischsprachlich heterogenen Gebieten konnten diese vertikalen Konflikte national gedacht und bedient werden - auch wenn die Konfliktgründe vordergründig nicht von den ethnisch-nationalen Differenzen (als horizontaler Konfliktpotenzialität), sondern den vertikalen Machtstrukturen bedingt waren.

Im Folgenden werden einige Fallbeispiele aus der istrianischen Halbinsel - vor allem aus dem sehr gemischt bewohnten west- und nordistrianischen Teil - geschildert, die zwar die nationale Polarisierung des Kirchenlebens und die nationale Positionierung der Priester beweisen könnten, aber eigentlich andere Konfliktgründe aufwiesen: persönliche Animositäten zwischen den Priestern und den Kirchgängern. Weil mehrere Sprachen vor Ort vorhanden waren, verdeckten die sprachlichen Unterschiede als vermeintlicher Konfliktgrund die Komplexität der lokalen Ebene.

Im westistrianischen San Giovanni di Sterna / Sv. Ivan od Šterne verließen die Menschen ab 1897 immer öfters sehr empört die Kirche, wenn der tschechischstämmige Pfarradministrator, ${ }^{79}$ Josip Ptašinski, predigte. Das Dorf gehörte zum mehrheitlich italienisch bewohnten Gerichtsbezirk von Visignano/Višnjan, hatte aber eine südslawische Mehrheit: Von den 1.153 Einwohnern gaben 907 das Kroatische als ihre Umgangssprache bei der Volkszählung von 1900 an. ${ }^{80}$ Trotz der Präsenz der großen italienischsprachigen Minderheit waren die Predigten von Don Ptašinski meistens Wutausbrüche gegen die »Italiener«, die er etwa - im Sinne der nationalen Markierung

78 Brief vom Bischof Mahnič (27. Mai 1902), in: AST, Luogotenenza, AP, b. 267, fasc. 1.2.3., 1902/1321.

79 Im Sinne einer slawischen Brüderlichkeit gingen einige tschechische Priester aus den Kronländern Böhmen und Mähren nach Istrien, darüber siehe Ivan BARTOLIĆ, Češki i Moravski svećenici u Istri od 1890. do 1930. [Tschechische und mährische Priester in Istrien vom 1890 bis 1930], in: Pazinski memorijal 19 (1995), S. 107-120.

80 Daten aus: Gemeindelexikon der im Reichsrathe vertretenen Königreiche und Länder, S. 76. 
politischer Positionen - als »Freimaurer« (»Farmasonen«) bezeichnete. ${ }^{81}$ Don Ptašinski gehörte zu den slawischen Priestern, die gleichzeitig klerikal und slawisch-nationalistisch eingestellt waren. Indem sie die »Italiener« als antiklerikal markierten, konnten sie nationale Abneigungen gegenüber den "Italienern" und klerikale Ideen verbinden. Weil sie aber dadurch die italienischsprachigen Katholiken ebenso provozierten, trugen sie zur nationalen Spaltung der Kirche - insofern zur Schwächung kirchlicher Position - bei. Das Verhältnis der italienischsprachigen Einwohner mit dem Pfarramt war in San Giovanni di Sterna/Sv. Ivan od Šterne schon unter dem Vorgänger von Don Ptašinski, dem ebenso antiitalienisch eingestellten Don Ante Nedved, angespannt gewesen: Gegen ihn gab es sogar nächtliche Demonstrationen im Mai 1895 vor seinem Pfarrhaus. ${ }^{82}$

Don Ptašinski agitierte besonders während der Wahlkämpfe gegen »die italienische Partei « ${ }^{83}$ Das war die Partei der antiklerikalen Nationalliberalen, die überwiegend aus italienischsprachigen Bürgern bestand - insofern wurde diese Partei in den Predigten einfach als »Italiener« beschimpft. Er hob somit den nationalen Gegensatz statt des politischen hervor. Italienischsprachige Katholiken, die die Gottesdienste von Don Ptašinski besuchten, lehnten zwar - als gute Katholiken und loyale Staatsbürger - die antiklerikalen, nationalliberalen Ideen ab. Es entstanden aber innerhalb der Kirche auch Spannungen wegen der nationalen Zuschreibungen politischer Positionen. Einerseits trug Don Ptašinski antiliberale Ideen, die in der Kirche in ganz Europa anzutreffen waren, mit einem nationalen Vokabular vor, als ob alle »Italiener« liberale Ideen unterstützt hätten. Andererseits glaubte er, die Kirche vor den liberalen Ideen dadurch zu schützen, dass die »kroatische« Prägung der Kirche verstärkt werden solle. »Italienisch" war insofern für ihn verdächtig. Don Ptašinski geriet infolgedessen nicht nur mit der »italienischen «, das heißt nationalliberalen, Partei in Konflikt -, sondern letztendlich mit allen italienischsprachigen Mitgliedern seiner Kirchengemeinde. Er hätte ihnen sogar einmal gesagt: »Die Slawen waren, die Slawen sind und bleiben, und ihr [Italiener - P. T.] werdet alle zum Teufel gehen«. Dass sein Verhältnis mit der Kirchengemeinde konfliktbeladen war, hatte andere Ursachen. ${ }^{84}$

81 Bericht des Landes-Gendarmarie-Commandos von San Lorenzo/Sveti Lovreč (9. April 1897), in: DAP, Kapetanat Poreč, Op.Sp., kut. 63, fasc. D1.

82 Bericht an den Bürgermeister von Grisignana/Grožnjan (ohne Datum), in: Ebd., kut. 50, fasc. I/9, 4800/1895.

83 Bericht der Bezirkshauptmannschaft von Parenzo/Poreč (2. Mai 1897), in: Ebd., kut. 63, fasc. D1, $269-97$ - D1.

84 Zitiert im Bericht des Landes-Gendarmarie-Commandos von San Lorenzo/Sveti Lovreč (9. April 1897), in: Ebd., 2908 - 97 - L6. 
Dass sein Verhältnis mit der Kirchengemeinde konfliktbeladen war, hing jedoch nicht nur mit seinen politischen Ideen zusammen. Wegen seines Lebensstils stand er nämlich in ständiger Kritik. Eine persönliche Schwäche kam ins Spiel, die das Verhältnis zwischen dem Priester und der Gemeinde belastete: Alkoholprobleme. Er trank zu viel: Seine Wutausbrüche gegen die "Italiener" mögen sogar damit zusammengehangen haben. Als das Bistum ihn für seinen Alkoholkonsum rügte, erwiderte er: »Er soll mich entlassen, wann er will, ich werde dann Schnaps fabricieren. ${ }^{85}$ Zum Alkoholproblem gesellten sich finanzielle Unklarheiten. Don Ptašinski soll eine große Summe Schulden bei den Kirchgängern angehäuft haben. Er wurde dabei bezichtigt, Gelder zu veruntreuen. Er wollte etwa eine Pilgerfahrt nach Rom organisieren und fing eine Spendenaktion an - aber das eingesammelte Geld soll er für persönliche Zwecke abgezweigt haben. ${ }^{86}$ Schließlich waren Don Ptašinskis Wutpredigten gegen die »Italiener» (als »Freimaurer») und sein Lebensstil (besonders sein Trinken) für das Bistum nicht mehr tolerierbar. Er wurde daher in ein anderes Dorf, Montreo/Muntrilj, versetzt. Er stand mit der kirchlichen Obrigkeit ebenso im Konflikt, welche die nationalen Positionen und den unmoralischen Lebensstil des Pfarrers als Gefahr für den innerkirchlichen Frieden erkannte.

Der neue Pfarradministrator in San Giovanni di Sterna / Sv. Ivan od Šterne, Don Marek, wurde von den Menschen keineswegs positiv aufgenommen. Die Kirchgänger lehnten zwar einige Verhaltensweisen von Don Ptašinski ab. Sie erlebten dennoch seine Absetzung als Einmischung in ihr gewohntes Leben. In diesem Widerstandsmoment zeigt sich, dass innerkirchliche Konflikte stark antihierarchisch bestimmt waren. Das Bistum beklagte sich öfters über den "Geist des Ungehorsams gegenüber der kirchlichen Autorität«, der seit einigen Jahren unter den Katholiken von San Giovanni di Sterna/Sv. Ivan od Šterne zu beobachten gewesen sei. ${ }^{87}$ So wie Don Ptašinski pflegte die kleine Welt des dörflichen Mikrokosmos ein anderes Leben als es von oben her vorgestellt und befürwortet gewesen wäre. Während viele Menschen früher gegen Don Ptašinski waren, bekundeten sie plötzlich ihre Solidarität mit dem abgesetzten Pfarradministrator. Einen hierarchischen Eingriff wollten sie anscheinend nicht akzeptieren. Viele Kirchgänger hätten sich sogar bereit erklärt, die Schulden von Don Ptašinski zu übernehmen - damit er doch in der Kirchengemeinde bleiben könne. ${ }^{88}$ Solange der Konflikt zwischen Don Ptašinski und den Kirchgängern auf der lokalen Ebene verblieb, waren viele

85 Bericht der Bezirkshauptmannschaft von Parenzo/Poreč (2. Mai 1897), in: Ebd., $269-97-\mathrm{D} 1$.

86 Ebd.

87 Bericht des Bischofs (17. August 1898), in: Ebd., kut. 68, fasc. D1, 172 - D1 [übersetzt aus dem Italienischen von mir].

88 Ebd. 
Kirchgänger gegen ihn, aber sobald sich die kirchliche Obrigkeit in diesen Mikrokosmos einmischte, war den Kirchgängern wichtiger, diesen obrigkeitlichen Eingriff abzulehnen, als ihren problematischen Pfarrer loszuwerden.

Als später ein Konkurs für die Pfarrerwahl ausgeschrieben wurde, bewarb sich Don Ptašinski ${ }^{89}$ der die Menschen auf Versammlungen für sich - und indirekt gegen die kirchliche Obrigkeit - mobilisierte. ${ }^{90}$ Don Ptašinski konnte sich jedoch nicht durchsetzen, er musste in Montreo/Muntrilj bleiben, wo er seine ethnographischen Forschungen ${ }^{91}$ fortsetzte sowie sich weiter dem politischen Ziel der südslawischen Emanzipation widmete. Er engagierte sich etwa für den kroatisch- und slowenischsprachigen Journalismus in Istrien. ${ }^{92}$ Nach dem Ersten Weltkrieg ging er in die Vereinigten Staaten, wo er in Cleveland als Pfarrer einer kroatischsprachigen Gemeinde tätig war. ${ }^{93}$

Die südslawisch-nationale Einstellung von Priestern führte auch in anderen Ortschaften in Istrien zu Unstimmigkeiten. In der nordistrianischen Ortschaft Sdregna/Zrenj erlaubte etwa Don Vranjac ab 1898 kroatische und slowenische Predigten. Das Dorf hatte eine größere slowenischsprachige Minderheit: Von den 915 Einwohnern gaben 242 Menschen im Jahre 1900 das Slowenische als ihre Umgangssprache an. ${ }^{94}$ Neben der Liturgiesprache entstand auch hier besonders um den Religionsunterricht ein Konflikt. Don Vranjac weigerte sich, in der privaten Schule des italienischsprachigen, in vieler Hinsicht antiklerikalen Privatvereins »Lega Nazionale« katholischen Religionsunterricht auf Italienisch zu erteilen. Er stellte stattdessen das Pfarrhaus für eine slowenischsprachige Privatschule zur Verfügung. Einige Kirchgänger blieben daraufhin aus Protest von den Gottesdiensten fern, weil sie die "politische Agitation" des Priesters, welche er besonders während der Wahlkämpfe betrieben habe, ablehnten. ${ }^{95}$ Don Vranjac stand mit dem italienischsprachigen Teil der Pfarrgemeinde auf Kriegsfuß, er klagte mehrere Menschen von ihnen sogar wegen Religionsstörung bzw. Ehrenbeleidigung an. Die Bezirkshauptmannschaft warf ihm dabei vor, gerade »Personen, die zu den angesehensten im Ort gehören «, beleidigt oder strafrechtlich ange-

89 Bericht des Bischofs (23. August 1899), in: Ebd., 172 - D1.

90 Bericht des Landes-Gendarmarie-Commando in San Giovanni/Sv. Ivan (17. Oktober 1899), in: Ebd., 172 - D1.

91 Josip MilićEvić, Etnografski rad Josipa Ptašinskog [Etnographische Arbeit von Josip Ptašinski], in: Istarska danica 1992, S. $92 \mathrm{f}$.

92 Naša Sloga, 5. Oktober 1899.

$93 \mathrm{Zu}$ seinem Leben siehe Luka ŠEšo, Ptašinski, Josip, in: Istarska Enciklopedija [Istrianische Enzyklopädie], URL: <http://istra.lzmk.hr/clanak.aspx?id=2257> (15.10.2019).

94 Daten aus: Gemeindelexikon der im Reichsrathe vertretenen Königreiche und Länder, S. 76.

95 Bericht der Bezirkshauptmannschaft von Parenzo / Poreč (7. August 1898), in: DAP, Kapetanat Poreč, kut. 63, fasc. D1, 7970 - 98 - D1. 
zeigt zu haben. ${ }^{96}$ Diese Personen bildeten wahrscheinlich die städtische Elite, die einer gesellschaftlichen Emanzipation der südslawischen Bevölkerungsteile im Wege stand. ${ }^{97}$ Die Spannungen zwischen Don Vranjac und der Pfarrgemeinde seien jedoch - ähnlich zum Fall von Don Ptašinski - nicht nur nationalpolitisch motiviert gewesen. Finanzielle Unklarheiten hätten dabei auch eine Rolle gespielt. Die Vorwürfe lauteten: Don Vranjac habe niemandem Einsicht in die Kirchenbücher gewährt; außerdem habe er ein persönliches Darlehen auf das Kirchenvermögen aufgenommen, das er nicht zurückgezahlt habe. ${ }^{98}$

Persönliche Abneigungen, Streitigkeiten oder antiklerikale Einstellungen ließen sich hinter dem allgemeinen Vorwurf verbergen, die Priester oder die Kirche stünden nur dieser oder jener Nationalität nahe. Ähnlichen Vorwürfen war etwa Don Antonio (Ante) Ragusin in Grisignana/Grožnjan ausgesetzt. Kaum war er in der nordwestistrianischen Ortschaft als neuer Kirchenadministrator im Mai 1899 angekommen, wachte er eines Nachts durch ein schreckliches Geräusch auf: In sein Zimmer, dessen Fenster zur Straße lagen, wurde ein ca. $1 \mathrm{~kg}$ schwerer Stein eingeworfen. Der Pfarrer wurde dabei nicht verletzt, aber Möbel im Zimmer wurden beschädigt. ${ }^{99}$ Don Ragusins Leben war bereits früher von ständigen, meist verbalen Attacken geprägt. Er beschwerte sich bei Bischof Flapp über Beleidigungen, die er seit seiner Ankunft in Grisignana / Grožnjan zu erdulden hatte. Ihm wurden etwa weitere Gewaltakte angedroht, damit er sich nicht einmal tagsüber auf die Straße zu gehen traue. Er berichtete darüber, dass er wegen seiner angeblichen kroatischen Abstammung (oder Sympathie) auf der Straße als »kroatisches Schwein « beschimpft worden sei. ${ }^{100}$ In einer langen Anzeige listete er mehrere Fälle auf, wo ihm unterschiedliche antikroatische Beleidigungen zugerufen wurden: "Kroaten sind Schweine, vom ersten bis zum letzten" oder »Schweine der Sklaven sind Sie, hier befehlen wir, venezianischen Blutes, italienischen Blutes «. ${ }^{101}$

Bericht der Bezirkshauptmannschaft von Parenzo/ Poreč (18. Oktober 1898), in: Ebd., 8335 - D1.

97 Zur Einstellung dieser Elite siehe u. a. ArA, Fra nazione e impero, S. 263.

98 Bericht der Bezirkshauptmannschaft von Parenzo/Poreč (14. Oktober 1898), in: DAP, Kapetanat Poreč, Op.Sp., kut. 63, fasc. D1, 7970 - 98 - D1.

99 Bericht des Landes-Gendarmarie-Commandos in Buje (12. August 1899), in: Ebd., 5817 - 99 - D1.

100 Brief von Don Ragusin an das Bistum (14. Juli 1900), in: Ebd., 190 - D1. Die Beleidigungen wurden im kroatischsprachigen Bericht auf Italienisch zitiert [übersetzt aus dem Italienischen von mir].

101 Bericht des Landes-Gendarmarie-Commandos in Buje über die eingetroffene Anzeige des Priesters (3. August 1900), in: Ebd., kut. 68, Op.Sp., fasc. D1, 190 - D1. Die Beleidigungen wurden im deutschsprachigen Bericht auf Italienisch zitiert [übersetzt aus dem Italienischen von mir]. 
Ob Don Ragusin - der eigentlich einen typisch venezianisch-istrianischen Nachnamen trug - kroatischer Abstammung war, ist den Quellen - außer den Beschimpfungen, denen aber italienischsprachige Priester anderswo ebenso ausgesetzt wurden - nicht eindeutig zu entnehmen. Der italienisch und nationalliberal eingestellte Magistrat von Grisignana/Grožnjan rechnete ihn jedenfalls den »Kroaten« zu, weil er kroatische Predigten einführte und für die kroatischsprachige Landbevölkerung in einer Privatkapelle auf dem Land eigene Gottesdienste zelebrierte. ${ }^{102}$ Die südslawische Bevölkerung musste zuvor aus den kleineren Dörfern in die größere Ortschaft gehen, um dort an einem lateinisch gelesenen Gottesdienst teilzunehmen. Insofern stellte die priesterliche Initiative, den ländlichen und südslawischen Bauern die Gottesdienste räumlich wie sprachlich näherzubringen, einen Beitrag zur sozialen Emanzipation dar - trotz der bizarren Behauptung des Stadtmagistrates, dass die Bauern die von Don Ragusin eingeführten kroatischen Predigten in der Messe nicht einmal verstanden hätten. ${ }^{103}$

Don Ragusin wurde seitens des nationalliberalen Stadtmagistrates bezichtigt, »einen stillen Krieg gegen das zivile Element des Landes« zu führen und dabei Hass unter den kroatischsprachigen Bauern "gegen die Italiener" $\mathrm{zu}$ schüren. ${ }^{104}$ Er wurde in eine kroatisch-nationalistische Ecke gestellt, als ob er - wie ein Protestbrief des Bürgermeisters (podestà) gegen ihn formulierte "mehr eine politisierende kroatische Person, als Gottes Diener" gewesen sei. ${ }^{105}$ Der Bürgermeister bezeichnete Don Ragusin als "fanatischen kroatischen Agitator «. Dabei verwickelte sich der Bürgermeister jedoch in Widersprüche. Er meinte, dass sein Protest gegen den Pfarrer unpolitisch gewesen sei - gleichzeitig betonte er ein politisches Argument, die angebliche Notwendigkeit, die italienische Kultur der Gegend zu schützen. ${ }^{106}$ Dieser Aspekt war eindeutig nationalpolitisch. Bischof Šterk meinte hingegen, dass die Mehrheit der Pfarrgemeinde kroatischsprachig sei und nur eine kleine italienischsprachige Minderheit die kroatischsprachigen Predigten ablehne. ${ }^{107}$ Die Zahlen zeigen aber eine andere Realität: Nach der Volkszählung von 1900 benutzte eine überwiegende Mehrheit der Bevölkerung das Italienische als Umgangssprache. Im ganzen Gerichtsbezirk von Grisignana/Grožnjan gaben 3.669 Menschen das Italienische als ihre Umgangssprache an, daneben

102 Protestbrief des Stadtmagistrates gegen den Pfarrer an die Statthalterei in Triest (30. Juni 1900), in: Ebd., 1776/1900.

103 Ebd.

104 Ebd. [übersetzt aus dem Italienischen von mir].

105 Protestbrief des Bürgermeisters (podestà) gegen Don Ragusin (23. September 1901), in: Ebd., kut. 74, fasc. D1, 366 - 01 - D1 [übersetzt aus dem Italienischen von mir].

106 Brief des Bürgermeisters von Grisignana/Grožnjan an die Wiener Nuntiatur (30. Juli 1901), in: AAV, ANV, b. 692, fasc. 7 (XIII), fol. 327f.

107 Brief vom Bischof Šterk an die Wiener Nuntiatur (13. April 1901), in: Ebd., fol. 325. 
waren 40 Menschen slowenischer und 70 Menschen kroatischer Umgangssprache. In der Ortschaft gab es elf Menschen, die das Slowenische angaben, die weiteren 1.561 Einwohner benutzten das Italienische. ${ }^{108}$

Der Konflikt war aber angeblich nicht nur von Tendenzen wie sozialer Emanzipation oder einem nationalpolitisch inszenierten $» S t a d t \ll-» L a n d \ll-$ Kampf bestimmt. Das örtlich zuständige Landes-Gendarmarie-Commando meinte angesichts der ständigen Angriffe und Beleidigungen gegen Don Ragusin, dass »[n]icht nur die Nationalität der Grund dieser Ausschreitungen " gewesen sei. ${ }^{109}$ Der Bericht vermutete eher - wie es in San Giovanni di Sterna/Sv. Ivan od Šterne oder Sdregna/Zrenj bereits der Fall war - persönliche Querelen im Hintergrund: Einige Bewohner hätten bei dem Pfarrer Schulden gehabt, die sie ihm nicht zurückzahlen wollten. ${ }^{110}$ Viele Kirchgänger hatten also sehr profane Motive für einen Konflikt mit dem Pfarrer, aber solche finanziellen Interessen ließen sich im nationalpolitischen Kontext öffentlichkeitswirksamer vortragen.

Das Bistum erkannte das Problem, und es wurde ein Konkurs für einen neuen Pfarrer ausgeschrieben. Dabei bewarben sich mehrere Personen um den Posten. Obwohl Don Ragusin als Kirchenadministrator seine Kandidatur zurückgezogen hatte, lehnte der Stadtmagistrat, dem ein Mitspracherecht zugesichert war, alle Kandidaten ab, die angeblich kroatischer Abstammung waren. ${ }^{111} 1902$ wurde letztendlich Don Vittorio Vasselli, ein italienischsprachiger Priester, zum Pfarrer ernannt. Er entsprach den Vorstellungen des nationalliberalen Stadtmagistrates, weil er die kroatischen Predigten und die Gottesdienste in den Dörfern abschaffte. Die Bauern, die sich an die Situation unter Don Ragusin (kroatische Predigt, Gottesdienst auf dem Land) gewöhnt hatten, griffen den neuen Pfarrer an: Nach einem Gottesdienst sei Don Vasselli laut einem Bericht des nationalliberalen Bürgermeisters von Bauern vor der Kirche sogar verletzt worden (der konkrete Vorgang wurde aber nicht geschildert). ${ }^{112}$

Wie den bisher geschilderten Fällen zu entnehmen ist, bestimmten nationale Zuschreibungen die wahrgenommenen Positionen und Rollen in den Konflikten. Nationale Markierungen ermöglichten eine schematische Erzählung. Die gleiche Person konnte allerdings dabei unterschiedlichen "nationalen« » Gruppen« zugeordnet werden, damit er im Narrativ des »Nati-

108 Daten aus: Gemeindelexikon der im Reichsrathe vertretenen Königreiche und Länder, S. 74.

109 Bericht des Landes-Gendarmarie-Commando von Buie / Buje (12. August 1899), in: DAP, Kapetanat Poreč, Op.Sp., kut. 63, fasc. D1, 5817 - 99 - D1.

110 Ebd.

111 Protestbrief des Bürgermeisters (podestà) (29. Mai 1902), in: Ebd., kut. 81, fasc. D1, 3863 - 02 - D1.

112 Bericht des Bürgermeisters (podestà) (21. August 1902), in: Ebd., 9718 - 02 - D1. 
onalitätenkonfliktes« als das "nationale Andere« verortet werden könne. So einen Fall stellte etwa die Konfliktgeschichte aus Torre/Tar dar. Der Streit zwischen Don Giuseppe Corazza (Josip Koraca) und der Kirchengemeinde der west-istrianischen Ortschaft wurde widersprüchlich wahrgenommen. Der Konflikt entstand auch hier um die Frage, welche Sprache während des Gottesdienstes zu benutzen sei. Don Corazza wollte kroatischsprachige Predigten und Gesänge einführen. Als er etwa Anfang 1898 in der Kirche nach vorn trat und am Altar ein kroatisches Kirchenlied zu singen anfing, antwortete ihm der Chor auf Latein. Don Corazza sah darin einen Affront gegen seine Person und die katholische Kirche, und er beschimpfte daraufhin einige italienischsprachige Kirchgänger, denen er Antiklerikalismus unterstellte. ${ }^{113}$ Die italienischsprachige Bevölkerung bezichtigte den Pfarrer prokroatischer Voreingenommenheit: Don Corazza habe einige italienischsprachige Familien in seinen kroatischsprachigen Predigten zuvor immer wieder beleidigt. Auch die italienischsprachige, nationalistische Presse hetzte gegen den Pfarrer, dem sie Verrat an seiner angeblich italienischen Abstammung unterstellte. Das Blatt La Provincia dell'Istria bemerkte bereits 1887 bissig, dass Don Corazza - »obwohl geboren aus dem italienischen Visignano [Višnjan] « - seinen Namen ab und zu nach kroatischer Schreibweise (als Korazza oder sogar Korača) angebe. ${ }^{114}$ In den Augen der nationalistischen Agitatoren galt er deswegen als national indifferent, das heißt verräterisch. Von einem angeblich italienischstämmigen Pfarrer hätten die italienischsprachigen, nationalistisch eingestellten Kreise mehr nationale Exklusivität erwartet, als ob sich ein ethnisch-sprachliches Bewusstsein nur nationalistisch-antikroatisch erleben ließe. Die Bezirkshauptmannschaft stellte insofern fest, dass Don Corazza »bei der italienisch gesinnten Bevölkerung von Torre [Tar] sehr verhasst« sei. ${ }^{115}$ Was unter »italienisch gesinnt« gemeint war, darf allerdings nicht mit italienischer Abstammung verwechselt werden: Einerseits umfasste es diejenigen, die ihrer ethnisch-nationalen Abstammung eine politische Bedeutung im Sinne nationalistischer Selbstverortung beimaßen; andererseits bedeutete eine »italienische Gesinnung « oft Antiklerikalismus, weil in mehreren Quellen die nationalliberale, antiklerikale Partei unter der »italienische[n] Partei« gemeint war.

Während Don Corazza in der Ortschaft Torre/Tar in nationalpolitisch aufgeladene Querelen geriet, genoss er in den umliegenden, kleineren Dörfern wie etwa Fratta / Frata und Abrega/Vabriga immer noch einen hohen Respekt. ${ }^{116}$ Im Rahmen seiner Tätigkeit als Priester besuchte er die kleineren

113 Über den konkreten Konfliktfall siehe L' Istria, 1. Januar 1898.

114 La Provincia dell' Istria, 1. Februar 1887 [übersetzt aus dem Italienischen von mir].

115 Bericht der Bezirkshauptmannschaft von Poreč/Parenzo [ohne Datum], in: AST, Luogotenenza, AP, b. 223, fasc. 4.2.1., 1899/885.

Ebd. 
Dörfer ebenso und hielt dort kroatischsprachige Predigten. Dies bedeutete für die dortige ländliche Bevölkerung eine soziale Aufwertung zumindest innerhalb der katholischen Kirche. Die Kirche bot dieser südslawischen Bevölkerung einen Raum an. Infolgedessen konnte sich nationalistisch-antikroatische und antiklerikale Kritik dagegen überlappen: In beiden Perspektiven erschien Don Corazza als politischer Feind - entweder weil er kroatischsprachige Gottesdienste zelebrierte oder wegen seiner Tätigkeit als Priester. In den Vorwürfen gegen Don Corazza, antiitalienisch zu sein, seinen Namen nach kroatischer Schreibweise anzugeben sowie unter der ländlichen, meist südslawischen Bevölkerung kroatischsprachige Predigten zu halten, zeigten sich die allgemeinen Vorstellungen, die in der städtischen Öffentlichkeit über die katholische Kirche vorherrschten: Infolge der Raumimaginationen gehörte ein Pfarrer, auch wenn er etwa italienischer Abstammung war, zum »südslawischen « »Lande«. Die italienischsprachige, nationalliberale, urbane Elite sah in der katholischen Kirche einen Raum, in dem und durch den sich die ländliche, südslawische Bevölkerung emanzipieren könne.

Das Narrativ des innerkatholischen »Nationalitätenkonfliktes« ging von der Annahme aus, dass sich ethnisch-sprachlich homogene, geschlossene Gruppen (und die diesen Gruppen zugehörigen Menschen) in den Konflikten gegenübergestanden hätten. Diese gruppenfixierten Gegensätze wurden allerdings erst durch Erklärungen konstruiert, welche etwa Don Corazza als national indifferenten »Italiener" oder (infolge der nationalen Markierung des kirchlichen Raumes) als »Kroate« beschrieben. Die Bezirkshauptmannschaft stellte zuerst fest, dass Don Corazza zwar »der Gesinnung nach « »Kroate « sei, aber bis jetzt keinerlei nationalistische Agitation ausgeübt habe. ${ }^{117}$ Wie fluid solche Identitätszuschreibungen sein konnten, beweist ein späterer Bericht derselben Bezirkshauptmannschaft: Dort galt Don Corazza als »ein eifriger Parteigänger der Italiener «. ${ }^{118}$ Die Bezirkshauptmannschaft gab in beiden Fällen verbreitete Meinungen aus der lokalen Ebene wieder. Zwischen diesen zwei Bemerkungen über den Pfarrer von Torre/Tar verging nur ein halbes Jahr. Die Unsicherheit bezüglich der national-sprachlichen Zuordnung des Pfarrers rührte auch daher, dass sich italienische und südslawische Elemente in der örtlichen Kultur oder den persönlichen Biographien nicht klar voneinander trennen ließen. ${ }^{119}$ Die ethnisch-nationalen, sprach-

117 Bericht der Bezirkshauptmannschaft von Poreč/ Parenzo (21. Januar 1899), in: Ebd., $1899 / 51$.

118 Bericht der Bezirkshauptmannschaft von Poreč/Parenzo (24. Juli 1899), in: Ebd., $1899 / 1852$.

119 Marta Verginella, Radici dei conflitti nazionali nell'area alto-adriatico. Il paradigma dei »nazionalismi opposti« [Wurzel der nationalen Konflikte im oberadriatischen Raum. Das Paradigma der "gegenseitigen Nationalismen«], in: Alessandro 
lichen Differenzen erlangten erst in ihrer Politisierung konfliktbeladene Bedeutungen. ${ }^{120}$

Gruppenkonstruktionen waren unter anderem deswegen möglich, weil das Verhältnis zwischen Don Corazza und der Kirchengemeinde in Torre/ Tar angespannt war - aber nicht aus nationalen Gründen. Mit seiner Kirchengemeinde geriet der eigenbrötlerische Don Corazza nicht nur aufgrund nationaler Differenzen in Konflikt: Nicht die Sprache, sondern das Gesagte verursachte die Spannungen. Das innerkirchlich erlebte Hauptproblem bestand darin, dass Don Corazza den Altar als Bühne für seine seltsamen Ideen und pseudowissenschaftlichen Forschungen benutzte, was in der Kirchengemeinde Irritationen auslöste. Im August 1897 berichtete das italienisch-nationalistische Blatt Istria etwa darüber, wie Don Corazza in der Kirche von Torre/Tar mal zoologische, mal politisch-ökonomische »Vorträge « statt wahrer Predigten gehalten habe. ${ }^{121}$ Das Bistum von Pola/Pula und Parenzo / Poreč zeigte sich ebenso kritisch angesichts solcher Nachrichten: Bischof Flapp sprach etwa von »einer unglücklichen Pfarrgemeinde«, die in vielen Hinsichten "sehr demoralisiert " sei. ${ }^{122}$ Wegen des Priestermangels konnte er keinen neuen Geistlichen nach Torre/ Tar schicken. ${ }^{123}$

Während Don Corrazza außerhalb der Kirche wegen seiner Aktionen zugunsten der sozialen und sprachlichen Emanzipation südslawischer, ländlicher Bevölkerungsteile kritisch beäugt wurde, geriet er innerkirchlich wegen seiner fragwürdigen Predigten unter Druck. In beiden Fällen war also nicht die vermeintliche nationale Zugehörigkeit des Pfarrers entscheidend, sondern das vertikale (inner- wie außenkirchliche) Verhältnis - einerseits zwischen der städtischen Elite und der ländlichen Bevölkerung, andererseits zwischen einem normabweichenden, eigensinnigen Pfarrer und der kirchlichen Obrigkeit.

Diese zwei "Schienen« vertikaler Konflikte ließen sich in den anderen, geschilderten Konfliktfällen erkennen: Konkurrenz um die Deutungshoheit über den kirchlichen Raum vor Ort bzw. normabweichende Handlungen und kirchen-obrigkeitliche Einmischungen. Die fragmentiert und anekdotisch aufgezeigten Fälle in Istrien zeigen exemplarisch, wie persönliche,

Magherini (Hg.), Dall' impero austro-ungarico alle foibe. Conflitti nell' area altoadriatico [Vom österreichisch-ungarischen Reich bis zur Vertreibung. Konflikte im oberadriatischen Raum], Torino 2009, S. 11-18, hier S. 11.

120 Vanni D’ Alessio, Istrians, Identifications and Habsburg Legacy, in: Acta Historiae 14 (2006), S. 15-39, hier S. $17 \mathrm{ff}$.

121 L' Istria, 21. August 1897.

122 Brief des Bischofs (3. November 1899), in: AST, Luogotenenza, AP, b. 223, fasc. 4.2.1., 1899/2616 [übersetzt aus dem Italienischen von mir].

123 Letztendlich ersuchte Don Corazza im Sommer 1900 um seine Pensionierung; vgl. Bericht der Statthalterei von Triest (7. August 1900), in: DAP, Kapetanat Poreč, Op.Sp., kut. 68, fasc. 190-D1, 5846 - 00 - D1. 
parteipolitische oder gesellschaftliche (usw.) Konfliktlinien national markiert und beschrieben wurden - auch in einer Region wie Istrien, wo die Selbst- und Fremdwahrnehmungen ethnisch-national gesehen, wie im Falle von Don Corazza zu betrachten war, stark variierten oder sich überlappten. Damit wird freilich nicht die Präsenz nationalpolitischer Konfliktpotenzialität verneint. Im Gegenteil: Die lokale Ebene war von ethnischen Differenzen und dem diesbezüglichen Bewusstsein der Menschen geprägt. In den konkurrierenden Ansprüchen - etwa hinsichtlich der Liturgiesprache oder der Person des Priesters - artikulierten sich aber vielmehr die soziale Emanzipation der ländlichen (meist südslawischen) Bevölkerung oder der Machterhaltungswille der herrschenden (meist italienischsprachigen) Elite.

\subsubsection{Konfliktanalyse: Nationalisierbare Konfliktlinien}

Nachdem einige Beispiele an Konflikten aus dem lokalen Kirchenleben istrianischer Ortschaften - von der Halbinsel und den Kvarner-Inseln - geschildert wurden, wird die Kontextualisierung dieser Fälle angestrebt. Wieso wurden die Konfliktgründe sowie die Konfliktparteien national markiert? Welche Frontlinien versteckten sich hinter den nationalistisch wahrgenommenen und wahrnehmbaren Positionen einiger Priester und Kirchgänger? In diesem Unterkapitel werden daher Tendenzen herausgearbeitet, die in den geschilderten Fällen anzutreffen waren bzw. die die Gründe der Nationalisierung der Konflikte erklären können: (1) soziale Emanzipation der südslawischen Bevölkerungsteile, was eine Herausforderung für die bisherigen Machtpositionen der italienischsprachigen Elite darstellte; (2) Zuwanderung bäuerlicher Elemente in die Städte, was die ethnisch-nationale Heterogenität urbaner Räume - und auch der dortigen kirchlichen Räume - erhöhte und somit einen nationalistisch bedienten »Stadt«-»Land«-Konflikt ermöglichte; sowie (3) unterschiedliche politische Einstellungen der italienischsprachigen (nur weltlichen) und der kroatischsprachigen (oft klerikalen) Elitenakteure, was eine Gleichsetzung nationaler Gegensätze (»italienisch" vs. »kroatisch») mit politischen Meinungsgegensätzen (»liberal« vs. »klerikal«) ermöglichte. Diese letzte Tendenz kam sowohl den nationalistisch eingestellten, südslawischen Klerikalen als auch den nationalistisch eingestellten, italienischsprachigen Antiklerikalen zugute. Gleichzeitig verinnerlichten sogar italienischsprachige Klerikale dieses vorherrschende Vokabular, in dem kirchenpolitische Positionen (»klerikal«, »antiklerikal«) national markiert wurden (»kroatisch «, »italienisch «). All diese Tendenzen erzeugten ein gesteigertes Konfliktpotenzial, das infolge lokal verwurzelter, persönlicher, unpolitischer Streitigkeiten oder Missstände aktiviert und bedient werden konnte. 
Die italienischsprachige Elite fühlte sich in ihrer bisherigen Machtposition und wirtschaftlichen Lage bedroht, weil die soziale Mobilität marginalisierter Bevölkerungsteile die Konkurrenz um wirtschaftliches oder kulturelles Kapital, also die gesellschaftlichen Ressourcen erhöhte. Diese Konkurrenz bestimmte das ganze Küstenland, unabhängig von nationalen und räumlichen Markierungen: Die italienischsprachige, liberale Elite wollte den Bauern die Aufstiegsmöglichkeiten ebenso erschweren wie den italienischsprachigen Arbeitern. ${ }^{124}$ Was aber die soziale Mobilität südslawischer Bevölkerungsteile anders erscheinen ließ, war ihre nationalpolitische Instrumentalisierbarkeit. In ihrem Fall drückten die sozio-wirtschaftlichen Positionen auch nationale Differenzen (»Italiener«, »Südslawen«) aus. ${ }^{125}$

Auch der »Stadt«-»Land «-Gegensatz wurde national- und kirchenpolitisch bedient, um den bestehenden politischen Konflikten eine Raumdimension zu verleihen. ${ }^{126}$ Der ethnische Unterschied ließ sich durch angeblich sichtbare Grenzen - wie etwa zwischen "Stadt" und "Land « - noch mehr veranschaulichen. ${ }^{127}$ Es stellt sich aber die Frage, ob dieser Gegensatz eine tatsächliche räumliche Trennung widerspiegelte. Räume sind nicht bloße geographische Entitäten, sie entstehen nämlich in gesellschaftlichen Prozessen. ${ }^{128}$ "Stadt« und »Land « stellten dementsprechend Gegensätze vor allem auf der mentalen Karte dar: Mental maps beschreiben die kulturellen Unterschiede, die divergierenden Wahrnehmungen innerhalb desselben Raumes. ${ }^{129}$ Indem etwa nationalliberale Magistrate in mehreren istrianischen Ortschaften die kroatische Sprache - als Sprache des umliegenden, dörflichen Hinterlandes - von den jeweiligen Stadtkirchen fernhalten wollten, untermauerten sie den Unterschied zwischen »Stadt» und "Land « mit angeblich eindeutigen, nationalen Differenzen zwischen den zwei »Welten«. Die kroatische oder slowenische Sprache in der Kirche bedeutete für sie eine Bedrohung für die bis dahin bestandene, italienischsprachige Deutungsmacht über den städti-

$124 \mathrm{Zu}$ Triest, wo die Lage diesbezüglich ähnlich war, siehe Rutar, Kultur - Nation Milieu, S. 54ff.

125 Jože Pirjevic, Serbi, croati, sloveni. Storia di tre nazioni [Serben, Kroaten, Slowenen. Geschichte von drei Nationen], Bologna 2015, S. 118.

126 Marco Bellabarba, Italiani d' Austria tra Otto e Novecento [Österreichs Italiener zwischen 19. und 20. Jahrhundert], in: Mazohl / Pombeni (Hg.), Minoranze negli imperi, S. 397-439, hier S. 431.

127 Andreas Wimmer, Ethnische Grenzziehungen. Eine prozessorientierte Mehrebenentheorie, in: Marion Müller / Zifonun Dariuš (Hg.), Ethnowissen. Soziologische Beiträge zu ethnischer Differenzierung und Migration, Wiesbaden 2010, S. 99-152, hier S. 111f.

128 Vgl. Hannes Grandits u.a., Phantomgrenzen im östlichen Europa. Eine wissenschaftliche Positionierung, in: Dies., Phantomgrenzen. Räume und Akteure in der Zeit neu denken, Göttingen 2015, S. 13-56, hier S. 20.

129 Fritjhof Benjamin Schenk, Mental Maps, in: Geschichte und Gesellschaft 28 (2002), S. 493-514, hier S. 504. 
schen - und im Besonderen: den kirchlichen - Raum. Durch die Sprachen entstanden nationalistische Vorstellungen, die einen Raum (wie etwa die "Stadt«) als »nationalen Besitz« nur einem Volk zuschrieben. ${ }^{130}$

Dem nationalpolitisch aufgeladenen »Stadt«-»Land «-Konfliktnarrativ wohnten insofern auch kolonisatorische Ansprüche und Sichtweisen inne, ${ }^{131}$ denn dieses Narrativ begründete kulturrassistische, nationalistische Ansprüche auf die Ganzheit eines imaginierten Raumes. ${ }^{132}$ Der postkolonialen Kritik solcher Raumimaginationen liegt aber die Annahme zugrunde, dass sich in der Machtfrage und den Machtkämpfen nationale Unterschiede und Konkurrenz manifestiert hätten. ${ }^{133}$ Die Machtkämpfe um die Deutungshoheit über den Raum waren aber weniger national, sondern durch die Frage der politischen und gesellschaftlichen Positionen und die dadurch bedingten Zugangsmöglichkeiten bestimmt. ${ }^{134}$ Daher sollen eher die Macht- und nicht die nationalen Verhältnisse im Vordergrund stehen. Kategorien wie (auf der einen Seite) »urban«, »liberal« und »italienisch sowie (auf der anderen Seite) »ändlich«, »klerikal« und »südslawisch« überlappten sich zwar oft, ${ }^{135}$ aber wenn sie sich in den öffentlichen Diskursen zu klaren Frontlinien verdichteten, verschleierten sie die wahren Machtstrukturen. Diese waren nicht national bedingt - sondern nur als Teil einer theatralisierten Politik national inszeniert oder national interpretiert. ${ }^{136}$

Der nationalen Markierung (und dementsprechend der nationalen Beanspruchung) gewisser Räume lag ein Vokabular zugrunde, in dem die nationalen Zuschreibungen politische und kulturelle Eigenschaften und Positionen abdeckten. "Italiener « und »Kroaten « bedeuteten in den inner- oder antikirchlichen Diskussionen keine objektiven Beschreibungen nationaler Zugehörigkeit, sondern sie standen für politische Positionen oder kulturelle Eigenschaften. Die südslawischen Bauern betrachteten etwa die »Italiener»

$130 \mathrm{Zu}$ den Vorstellungen des "nationalen Besitzes« siehe u.a. Mark Cornwall, The Struggle on the Czech-German Language Border, 1880-1940, in: The English Historical Review 109 (1994), S. 914-951, hier S. 919.

131 Verginella, Il paradigma città / campagna, S. 790f. Zur postkolonialen Analyse der innerhabsburgischen Machtverhältnisse siehe u. a. Heidemarie UHL, Zwischen "Habsburgischem Mythos« und (Post-)Kolonialismus. Zentraleuropa als Paradigma für Identitätskonstruktionen in der (Post-)Moderne, in: FeICHTinger u.a. (Hg.), Habsburg postcolonial, S. 45-54, hier S. 48f.

132 Johannes Feichtinger/Gary B. Cohen, Introduction. Understanding Multiculturalism. The Habsburg Central European Experience, in: Dies. (Hg.), Understanding Multiculturalism, S. 1-14, hier S. 6.

133 Jan Surman, Postkolonialismus, in: Feichtinger / Uhl (Hg.), Habsburg neu denken, S. 181-187, hier S. 181ff.

134 Peter Niedermüller, Der Mythos des Unterschieds. Vom Multikulturalismus zur Hybridität, in: Feichtinger u. a. (Hg.), Habsburg postcolonial, S. 69-81, hier S. 79.

135 Milo, Trieste 1830-1870, S. 77.

136 Judson, L' Autriche-Hongrie était-elle un empire?, S. 586. 
als kirchenfeindliche, von der »unmoralischen" städtischen Kultur »verseuchte « Menschen. ${ }^{137}$ Diese Tendenz ging bis auf das revolutionäre Jahr von 1848 sowie die österreichischen Kulturkämpfe der 1860er und 1870er Jahre zurück, als südslawische Klerikale und Kirchgänger auf der Seite des Klerikalismus standen. ${ }^{138}$ Damals verfestigte sich das Bild, dass die »Italiener" antiklerikal und die »Südslawen« klerikal seien (und zu sein hätten).

Besonders unter den jungen, slawischen (nicht nur kroatischsprachigen, sondern zum Beispiel aus Böhmen und Mähren stammenden) Priestern war die Idee verbreitet, die südslawische (soziale, sprachliche) Emanzipation in Istrien mit den Mitteln, die einem Geistlichen zur Verfügung standen, voranzutreiben. Sie wollten die Herrschaft der italienischsprachigen, nationalliberalen Elite durch die Stärkung der Schicht des bäuerlichen, ländlichen Südslawentums herausfordern. In anderen Gebieten der Habsburgermonarchie war ebenso zu beobachten, wie sich die katholische Kirche mit ländlichen Katholiken gegen die liberale Elite, die einer anderen Nationalität angehörte, verbündete. ${ }^{139}$ Auch Wien war daran interessiert - im Gegensatz zu Budapest -, die Präsenz der katholischen Südslawen auf Kosten des italienischsprachigen, säkularen Nationalliberalismus zu stärken. ${ }^{140}$ Als beispielweise nach einem Nachfolger des deutschösterreichischen Franz Xaver Nagl 1910 für den Bischofssitz in Triest gesucht wurde, betonte die Triestiner Statthalterei explizit - obwohl das mehrheitlich italienischsprachige Bistum nach 1831 (bis auf Nagl) nur südslawische Bischöfe hatte ${ }^{141}$-, dass »wir die Wahl eines Slowenen für den Bischofssitz der eines Italieners aus Rücksicht für das slowenische Interesse vorzuziehen meinen. $"{ }^{142}$ Wien unterstützte dabei aber nicht den einen Nationalismus gegen den anderen, sondern es hoffte auf die staatsintegrative Kraft des südslawischen Katholizismus (oder umgekehrt: eines katholischen Südslawentums).

137 Pietro Zovatto, Stampa cattolica slovena ed italiana [Slowenische und italienische katholische Presse], Trieste 1987, S. 16.

138 Cattaruzza, I conflitti nazionali a Trieste, S. 139f.

139 Zum Südkärnten siehe etwa Andreas Moritsch/Gerhard Baumgartner, The Process of National Differentiation within Rural Communities in Southern Carinthia and Southern Burgenland 1850-1940, in: Ellen Wiegand u. a. (Hg.), Roots of Rural Ethnic Mobilisation. Comparative Studies on Governments and Non-Dominant Ethnic Groups in Europe. 1850-1940, Vol. VII, New York 1992, S. 99-143, hier S. 117f.

140 Robin Oкеу, Austrian-Hungarian Diplomacy and the Campaign for a Slavonic Liturgy in the Catholic Church. 1881-1914, in: The Slavonic and East European Review 70 (1992), S. 258-283, hier S. 278.

141 Zovatto, Cattolicesimo a Trieste, S. 9.

142 Brief des Statthalters an den österreichischen Cultus- und Unterrichtsminister (23. Juni 1910), in: AST, Luogotenenza, AP ris., b. 6, fasc. 34, 1910/14 [Hervorhebung von $\mathrm{mir}]$. 
Sogar italienischsprachige Priester konnten sich in dem Diskurs der nationalisierten kirchenpolitischen Positionen verorten. Sie hetzten gegen die "Italiener", auch wenn sie eigentlich die Politik der nationalliberalen Elite der istrianischen Städte oder des italienischen Königreiches meinten. Anfang 1892 beschwerte sich der italienische Konsul in Triest in einem Brief an den Bürgermeister (podestà) der westistrianischen, überwiegend italienisch bewohnten ${ }^{143}$ Stadt Rovigno/Rovinj über den italienischsprachigen Stadtpfarrer Bernardo Malusa, der in seinen italienischsprachigen Predigten mehrmals »die Italiener « beleidigt habe. ${ }^{144}$ Selbst der nationalliberale Bürgermeister musste auf die Proteste des Konsuls hin zugeben, dass Don Malusa nicht alle Italiener, sondern die aktuelle, antipäpstliche Politik der italienischen Regierung und die antiklerikalen Kreise der österreichischen Küstenstadt kritisierte. ${ }^{145}$ Die Tendenz, die »Italiener« mit der lokalen, nationalliberalen Elite oder dem italienischen Königreich gleichzusetzen, war auch unter vielen italienischsprachigen Katholiken vorhanden. ${ }^{146}$

Italienischsprachige Priester konnten demnach den Antiklerikalismus, den Hass auf die katholische Kirche, den »Italienern« zuschreiben, womit sie zur Nationalisierung eigentlich parteipolitischer oder sozial bedingter Konfliktlinien beitrugen. Als Steine im westistrianischen Verteneglio/ Brtonigla im Oktober 1907 in die Wohnung des italienischsprachigen Pfarrers Don Pietro Vascon eingeworfen worden waren, ${ }^{147}$ bezichtigte er die »Italiener «, hinter dem Gewaltakt gestanden zu haben. Die Ortschaft nahe der Adriaküste war aber fast ausschließlich italienisch bewohnt: Von den 1.734 Einwohnern waren nur acht slowenischsprachig, alle anderen gaben 1900 das Italienische als ihre Umgangssprache an. ${ }^{148}$ Insofern erscheint ein solcher Vorwurf auf den ersten Blick unverständlich. Er suggeriert, dass die »Italiener« nur einen kleinen Teil der überwiegend italienischsprachigen Bevöl-

143 Von den 10.302 Stadtbewohnern waren 9.716 italienisch-, 201 deutsch- und nur 41 kroatischsprachig; Daten aus: Gemeindelexikon der im Reichsrathe vertretenen Königreiche und Länder, S. 50.

144 Brief des italienischen Konsuls (10. Januar 1892), in: AST, Luogotenenza, AP, b. 154, fasc. 4.2.1., 1892/126.

145 Brief des Bürgermeisters (podestà) von Rovigno/Rovinj an die Statthalterei (13. Januar 1892), in: Ebd.

146 Ein Teil der italienischsprachigen, katholischen Öffentlichkeit war besonders antiitalienisch ausgeprägt, ihr Hass richtete sich nicht nur gegen den Irredentismus, sondern an sich gegen die italienischen Einwanderer, die sie als wirtschaftliche Belastung für den Wohlstand und als politische Gefahr für Österreich erachteten; vgl. dazu u. a. Apollonio, La »belle époque« e il tramonto dell' Impero asburgico, S. 127f.; sowie Tеснет, Imperiale Loyalität unter den italienischsprachigen Katholiken, S. 312f.

147 Bericht des Pfarrers Don Pietro Vascon (14. Oktober 1907), in: DAP, Kapetanat Poreč, Op.Sp., kut. 115, fasc. I/1, $13544-07$ - I/1.

148 Daten aus: Gemeindelexikon der im Reichsrathe vertretenen Königreiche und Länder, S. 74. 
kerung darstellten. In der priesterlichen Meinung, dass die »Italiener« ihn angegriffen hätten, wurden die »Italiener in der Tat nicht national, sondern politisch gemeint. Don Vascon meinte mit dieser Zuschreibung die antiklerikale, italienischsprachige Partei. ${ }^{149}$

Dass die »Italiener « mit Antiklerikalismus identifiziert wurden, ermöglichte gleichzeitig der italienischen Elite die Verwendung des Vokabulars der "Nationalitätenkonflikte«, auch in Bezug auf den eigentlich nationsunabhängigen Gegensatz zwischen Klerikalismus und Antiklerikalismus. Einerseits wollte diese Elite die katholische Kirche durch die "Nationalitätenkonflikte» polarisieren und schwächen (antiklerikales Ziel). Die italienischsprachigen Liberalen konnten somit das Feindbild »katholische Kirche« mit antislawischen Affekten aufladen. ${ }^{150}$ Andererseits wollte diese Elite die italienischsprachige Öffentlichkeit vollkommen beherrschen und aus ihr alle alternativen Diskurse (etwa den italienischsprachigen Klerikalismus) ausschließen (hegemoniales Ziel). Indem die antiklerikalen Kreise eine "südslawische« Dominanz des kirchlichen Raumes suggerierten, versuchten sie, die italienischsprachige Bevölkerung von der Kirche zu entfremden. Solange das allgemeine Männerwahlrecht in Österreich nicht eingeführt wurde (1907), half das restriktive Wahlrecht den national-liberalen Kreisen, ihre Macht über den politischen Raum des Österreichischen Küstenlandes aufrechtzuerhalten.

Es gab viele südslawische (oder böhmische, mährische) Priester in Istrien, die die politisch und sozial bedingten Konflikte mit der italienischsprachigen, städtischen Elite nationalisierten. Die Worte und Taten etwa von Don Ptašinki (in San Giovanni di Sterna/Sv. Ivan od Šterne), Don Ragusin (in Grisignana / Grožnjan), Don Vranjac (in Sdregna / Zrenj) oder mehreren kroatischsprachigen Priestern auf der Insel Lussin / Lošinj spitzten den Konflikt zwischen »italienischer« »Stadt« und »südslawischem« »Land« zu. Die Einführung muttersprachlicher Predigten auf den ländlichen Gebieten lässt sich als Beitrag zur sozialen Emanzipation der dortigen Bevölkerung verstehen und als solche rechtfertigen. Wenn sich Protest dagegen erhob, zeigte sich die Angst der herrschenden, italienischsprachigen Elite, ihre Macht über soziale Ressourcen bzw. die Deutungshoheit über den kirchlichen Raum verlieren zu können. Als die (süd)slawischen Priester alle »Italiener« beleidigten oder ihnen muttersprachliche Predigten, Taufen, Begräbnisse oder Religionsunterrichtsstunden verweigerten, agierten sie selbst als nationalistische

Bericht des Pfarrers Don Pietro Vascon (8. August 1907), in: DAP, Kapetanat Poreč, Op.Sp., kut. 115, fasc. I/1, $13544-07$ - I/1.

150 Ernst Bruckmüller, Österreich - eine »katholische« Nation?, in: Altermatt / Metzer (Hg.), Religion und Nation, S. 69-93, hier S. 86. 
Akteure. Ihr Ziel bestand darin, die kirchlichen Räume für nationalistische Homogenitäts- und Einheitsimaginationen - als ob die katholische Kirche ein »nationaler Besitz« der »Südslawen« wäre - zu beanspruchen.

Das kirchliche Feld schien für die soziale und nationale Emanzipation ein geeigneter Raum zu sein: Einerseits waren die südslawischen Priester in einer eindeutigen Mehrzahl in Istrien, und auch die mehrheitlich italienischsprachigen Ortschaften hatten oft einen südslawischen Priester. Andererseits konnten die südslawischen Bauern ihre Identität im Katholizismus einfacher und selbstbewusster erleben als etwa die italienischsprachigen Katholiken, deren politische Öffentlichkeit (die italienischsprachige Öffentlichkeit der Küstenstädte) liberal und antiklerikal eingestellt war. Während ein nationalistisch gefärbter, italienischsprachiger Katholizismus widersprüchlich gewesen wäre - auch im neu entstandenen Königreich Italien verhielten und äußerten sich die dortigen klerikalen Kreise lange sehr skeptisch gegenüber dem italienischen Nationalismus -, ließen sich nationale und klerikale Ideen bezüglich des ländlichen »Südslawentums" einfacher verbinden. Einerseits war die Meinung, dass der Katholizismus die wesentliche Identität der "Slowenen « und der »Kroaten" ausmache, auch in südslawisch-nationalistischen (sogar unter nationalliberalen) Kreisen - im Gegensatz zu den meist antiklerikalen, italienisch-nationalistischen Kreisen der österreichischen Küstenstädte - weit verbreitet. Andererseits ließ sich der südslawische Nationalismus - wie etwa der Triestiner Sozialist, Angelo Vivante, bemerkte - auch innerhalb des katholischen, imperialen Staatsgedankens und Rahmens gut erleben.

Klerikalismus und Austroloyalismus [austriacantismo], die die Verbreitung des nationalen Bewusstseins unter den Italienern verhinderten oder zumindest nicht förderten, erfüllen andere Funktionen unter den Slawen. [...] Der slawische Priester [...] erreichte mit den gleichen Mitteln andere Ergebnisse, weil das slawische, nationale Bewusstsein mit dem katholischen nicht im Widerspruch steht, und es entwickelte sich besser als das italienische auch im dynastischen oder staatlichen Umfeld. ${ }^{151}$

151 Angelo Vivante, Irredentismo adriatico [Adriatischer Irredentismus], Trieste 1984 [Firenze 1912], S. 200 [übersetzt aus dem Italienischen von mir]. 


\subsubsection{Historischer Kontext: Supranationales Selbstverständnis der Kirche}

Wie verhielt sich eine solche klerikal-nationale Symbiose mit der universalistischen Idee der katholischen Kirche? Gerade in Gebieten, wo die katholische Bevölkerung ethnisch-sprachlich heterogen war, bestand die Gefahr, dass Priester eine ethnisch-sprachliche "Gruppe« bevorzugten. Im Interesse der gesamten Kirche stand vielmehr eine katholisch begründete Überwindung ethnisch-sprachlicher Polarisierungen. Im Folgenden wird kurz aufgezeigt, wie die katholische Obrigkeit und Teile der katholischen Öffentlichkeit in Istrien auf die innerkatholischen, nationalisierenden Tendenzen der lokalen Ebene reagierten.

Die katholische Religion ist - wie schon ihr Name zeigt - universalistisch und supranational konzipiert und nicht von nationalen Gruppenidentitäten, sondern vom individuellen Glauben von Menschen unterschiedlicher Herkunft bestimmt. ${ }^{152}$ Aber diese Individuen, die vor der Kirche als Gottes einheitliches Volk stehen, haben nicht nur eine religiöse Zugehörigkeit, sondern auch andere Zugehörigkeiten, die sie jenseits und unterhalb des katholischen Universalismus in partikularen, tradierten Mitgliedschaften, Identitäten, Zugehörigkeiten und Gegebenheiten verwurzeln ließen. Eine davon war die national-sprachliche Selbstbestimmung. Die »Nationen «, die seit der Mitte des 19. Jahrhunderts in der Habsburgermonarchie eine immer größere, öffentlichkeitsgenerierendere Bedeutung gewannen, waren zwar elitäre Konstrukte, die der lokalen Ebene erst aufgezwungen werden mussten - aber diese Konstrukte konnten sich auf vorhandener faktischer Basis entwickeln. ${ }^{153}$ Solch eine Basis bildete die Sprache. In Gesellschaften, die jahrhundertelang in mehreren Sprachen miteinander kommunizieren konnten, entstanden Vorstellungen von »sprachlichen Grenzen«, die die gelebte Plurikulturalität in einen negativen Multikulturalismus, das heißt in ein getrenntes Nebeneinander (statt Miteinander) unterschiedlicher Völker verwandelten. ${ }^{154} \mathrm{Im}$ fast homogen katholischen Istrien konnten deswegen innerkirchliche Konflikte zwischen katholischen Pfarrern und ihren Gemeinden entstehen. Die italienischsprachigen und die südslawischen Menschen waren nicht durch die Konfession voneinander getrennt - wie es etwa zwischen Kroaten und Serben im Ungarisch-Kroatischen Küstenland der Fall war (Kapitel 4.1.2) -, insofern beanspruchten nationalistische Akteure denselben kirchlichen

152 Christine Alix, Le Saint-Siège et les nationalismes en Europe 1870-1960, Sirey 1962, S. 32.

153 Karl F. BAнм, Beyond the Bourgeoisie. Rethinking Nation, Culture, and Modernity in Nineteenth-Century Central Europe, in: Austrian History Yearbook 29 (1998), S. 19-35, hier S. 33.

154 Judson, Do Multiple Languages Mean a Multicultural Society?, S. 70. 
Raum. ${ }^{155}$ Wenn die Religion für nationale Absonderung mobilisiert wird, wird die Beseitigung der bestehenden, tradierten Pluralitäten wie der sprachlichen Vielfalt angestrebt. ${ }^{156}$

Die kirchliche Obrigkeit verpflichtete sich allerdings weiterhin der Idee der katholischen Supranationalität. Insofern lehnten die Bischöfe im Österreichischen Küstenland, egal ob sie in Triest, Pola/Pula oder Veglia/Krk saßen, wie auch egal ob sie italienischer, kroatischer, slowenischer oder deutscher Abstammung waren, die nationalistischen Tendenzen außerhalb und innerhalb der katholischen Kirche dezidiert ab. Sie empfanden jegliche nationalistische Tendenzen als Schwächung der kirchlichen Position in der Öffentlichkeit. In den bischöflichen Korrespondenzen lässt sich diese Sorge nachlesen, auch wenn die einzelnen Bischöfe bei der Frage, wer für die aufgewühlten nationalen Gefühle vor Ort verantwortlich sei, unterschiedliche Akzente setzten und unterschiedliche Erklärungen lieferten.

Dieser Unterschied ließ sich nicht mit einer nationalpolitischen Voreingenommenheit, sprich: der ethnisch-nationalen Zugehörigkeit der jeweiligen Bischöfe, erklären, sondern vielmehr mit ihren kirchenpolitischen Intentionen. Der eine war politischer, ultramontaner, klerikaler eingestellt, der andere begnügte sich hingegen vielmehr mit der rein pastoralen Arbeit. Der eine ließ mehr abweichende Partikularität auf der lokalen Ebene etwa in der Liturgie zu, der andere wollte das Kirchenleben von oben her vereinheitlichen. Ihr Ziel bestand aber darin, die Kirche als internationalen Raum und als Verbündete des österreichischen Staatsgedankens bewahren zu können. In diesem Sinne hielt es der slowenischsprachige Bischof von Triest, Ivan Nepomuk Glavina, für unabdingbar, dass die Priester die Sprachen der örtlichen Völker zu erlernen haben. Deswegen wies er 1891 den Pfarrer des nordistrianischen Carcauzze/Krkavče, Don Jakob Ladavac, darauf hin - nachdem Don Ladavac den kroatischen Gesang in der Kirche des zwar mehrheitlich slowenischsprachigen, aber von italienischsprachigen Menschen ebenso bewohnten Dorfes ${ }^{157}$ eingeführt hatte -, »daß nicht das Volk des Priesters wegen, sondern der Priester des Volkes wegen da ist, und daß daher dem Seelsorger die Gewissenspflicht obliegt, die Sprache des Volkes zu erlernen. $\aleph^{158}$

155 Trogrlić, Katolička crkva u Istri, S. 217; Wiggermann, K. u. K. Kriegsmarine und Politik, S. 144.

156 Chris Hann, The Limits of Galician Syncretism. Pluralism, Multiculturalism, and the Two Catholicisms, in: Ders. / Magocsi (Hg.), Galicia, S. 210-237, hier S. 213.

157 Im Jahre 1900 lebten im Dorf 518 slowenischsprachige und 85 italienischsprachige Menschen; Daten aus: Gemeindelexikon der im Reichsrathe vertretenen Königreiche und Länder, S. 54.

158 Glavinas Brief an Don Ladavac (17. August 1891), beigefügt als Beilage zum Bericht von Glavina an die Triestiner Statthalterei (17. August 1891), in: AST, Luogotenenza, AP, b. 147, fasc. 4.1.5., 1891/1647. 
Der Triestiner Bischof, der auf Glavina folgte, Andrej Marija Šterk, - der sich in einem Hirtenbrief als "weder italienischer noch slawischer noch deutscher, sondern ausschließlich katholischer Bischof « bezeichnete ${ }^{159}$ - beklagte 1898 in seinem Brief an den Wiener Nuntius, Emidio Taliani, dass einige Priester leider nicht mehr Gott, sondern die Nation anhimmeln würden: »hr Gott ist die Nation. ${ }^{160}$ Eine solche nationale Positionierung schadete der katholischen Kirche. Nicht zufällig gerieten nationalistisch eingestellte Priester, wie in den einzelnen Fallbeispielen zu sehen war, mit der kirchlichen Obrigkeit und ihren jeweiligen Bischöfen, egal welcher Nationalität sie angehörten, in Konflikt.

Die nationalistischen Tendenzen verurteilte auch der Bischof von Veglia/Krk, Antun Mahnič, in alle Richtungen, egal ob »in Nerezine [Neresine] die sog. »italienische « Partei« oder »in Veglia [Krk] oder Lussinpiccolo [Mali Lošinj] die kroatische Partei« dahinter stünden. ${ }^{161}$ Er wusste, dass diese Parteien nicht mit der ethnisch-sprachlichen Zugehörigkeit gleichzusetzen waren: Sie waren nationalistische Parteien, deren Ziele notwendigerweise jenen der kirchlichen Obrigkeit entgegenliefen. Die kirchliche Obrigkeit wollte den nationalistischen Akteuren, auch wenn sie Priester waren, den kirchlichen Raum nicht überlassen. Bischof Mahnič machte in diesem Sinne den Wiener Nuntius Emidio Taliani, der den bischöflichen Erzählungen bezüglich der innerkirchlichen Konflikte keinen Glauben schenkte, darauf aufmerksam, dass die katholische Kirche vor Ort von allen nationalistischen Seiten, von »italienischen" wie auch »südslawischen«, herausgefordert und bekämpft werde: »Mons Flapp, der Bischof von Pola [Pula] und Parenzo [Poreč] ist von den Slawen gehasst, der Bischof von Triest [Mons. Šterk] ist von den Italienern gehasst und verfolgt... « ${ }^{162}$ Bischof Mahnič verstand sich und die Kirche infolgedessen nicht als »Täter«, sondern vielmehr als »Opfer« der »Nationalitätenkonflikte«. In diesem Sinne verurteilte der Triestiner Bischof Franz Xaver Nagl im Februar 1903 mit einem Hirtenbrief an die Gläubigen den exklusiven (Sprach-)Nationalismus, der auch innerhalb der Kirche, unter einigen Priester und Kirchgängern, anzutreffen war:

159 Hirtenbrief vom Bischof Šterk (8. April 1898), in: AAV, ANV, b. 692, fasc. 7 (XIII), fol. 199f. [übersetzt aus dem Italienischen von mir].

160 Brief vom Bischof Šterk an Taliani (4. April 1898), in: Ebd., fol. 181ff. [übersetzt aus dem Italienischen von mir].

161 Bischof Mahnič an den Statthalter (28. September 1899), in: AST, Luogotenenza, AP, b. 223, fasc. 4.1.5., 1899/2404.

162 Brief vom Bischof Mahnič an den Wiener Nuntius Taliani (23. März 1899), in: AAV, ANV, b. 693, fasc. 7, fol. 373. 
Halte den Frieden auch mit Deinem Nebenmenschen. Auch das gilt allen, und ist besonders wichtig dort, wo der unvernünftige Nationalitätenhader die Gemüter erregt, ja geradezu erbittert. Gewiss hast Du das Recht und die Pflicht, Deine Nation und Deine Muttersprache zu lieben und zu pflegen. Du bist aber nicht allein auf der Welt; dein anderssprachiger Nächster hat dasselbe Recht und wo ihr beide zusammenkommt, gilt euch das Wort des heiligen Geistes: »Was du nicht willst, das Dir geschehe, das tue auch einem anderen nicht. ${ }^{163}$

Im nationalistischen Vokabular wurde die lokale Komplexität auf klare Trennlinien entlang nationaler Unterschiede reduziert. Auf die Konfliktparteien wurde danach als »die Südslawen« und »die Italiener« referiert, als ob die Konflikte nur aufgrund nationaler Differenzen entstanden wären. »Südslawen « und »Italiener" waren allerdings dabei nur diejenigen, die sich nationalistisch positionierten. Insofern sind sie nicht mit allen gleichzusetzen, die sich zwar ihrer ethnisch-nationalen Zugehörigkeit und ihrer Muttersprache bewusst waren, ihnen aber keine politische, geschweige denn ausschließende/ausschließliche Bedeutung beimaßen. ${ }^{164}$ Als etwa italienischsprachige Frauen in mehreren Kirchen in der Umgebung von Parenzo/Poreč im Jahre 1911 die heilige Jungfrau von Pompei mit einer Anspielung auf Italien, wo Pompei liegt, anbeteten, erachteten es einige südslawische Priester aus dem niederen Klerus - angestachelt von der kroatischsprachigen, nationalistischen Zeitung Naša Sloga ${ }^{165}$ - als irredentistisch-nationalistisch. Es handelte sich aber um einen religiösen Akt, wo nicht Italien, sondern die Mutter Gottes im Vordergrund stand. Die Frauen mögen zwar dabei auch ein italienisches Bewusstsein gehabt haben, aber ihnen fehlte jegliche nationalistische Intention. ${ }^{166}$ Es war jedoch in den nationalistischen Diskursen möglich, aus dem religiösen Akt eine angeblich nationalistische Handlung herauszulesen.

Während die kirchliche Obrigkeit die Vielfalt der lokalen Ebene und die Akzeptanz der Mehrsprachigkeit innerhalb der Kirchengemeinden betonte,

163 Hirtenbrief vom Bischof Nagl (15. Februar 1903), in: AST, Luogotenenza, Atti Generali (Allgemeine Schriften, weiter: AG), b. 1262, fasc. 42.2, 1903/5482. (Der Hirtenbrief wurde in italienischer, deutscher und slowenischer Sprache verfasst, damit erwies sich die Kirche toleranter und offener, als etwa die liberale Stadtverwaltung in Triest, die der slowenischen Sprache die ihr aufgrund der demographischen Zusammensetzung von Triest gebührende öffentliche Verwendung - trotz der diesbezüglichen österreichischen Vorschriften - verweigerte).

164 Dazu, warum Nation und Nationalismus nicht gleichzusetzen sind, siehe Rogers BrUbaker, Nationalism reframed. Nationhood and the national question in the New Europe, Cambridge 1996, S. 16f.

165 Naša Sloga, 5. Oktober 1911.

166 Brief vom Bischof Flapp an die Bezirkshauptmannschaft von Parenzo/Poreč (24. November 1911), in: AST, Luogotenenza, AP, b. 360, fasc. 19b, 1911/1954. 
versuchte sie gleichzeitig, besonders unter dem Triestiner Bischof Franz Xaver Nagl, die lokalen Partikularitäten bezüglich religiöser Rituale, Praktiken (usw.) zu verdrängen, was ebenso zu Konflikten führen konnte.

\subsection{Kirchenstreit im ländlichen Hinterland der Hafenstadt Triest}

\subsubsection{Ricmanje: Slowenischsprachiges Dorf an der sprachkulturellen Grenze zu Triest}

Ein junger, slowenischsprachiger Priester wurde im Herbst 1906 in ein winziges Dorf unweit der österreichischen Adriametropole Triest entsandt, um die dortige aufbegehrende Bevölkerung zu beruhigen und mit der katholischen Kirche zu versöhnen. Was er aber an Weihnachten diesen Jahres erleben musste, übertraf sogar seine schlimmsten Befürchtungen. Jakob Ukmar wollte alle Häuser in Ricmanje ${ }^{167}$ und im benachbarten Log besuchen: In den meisten Familien stieß er auf Ablehnung. Mal wurde er als »hässlicher Zigeuner», mal als »Teufel» beschimpft. In einigen Häusern schlugen die Menschen die Türe zu: Sie hätten keinen katholischen Priester gebraucht, weil »ein orthodoxer Geistlicher uns segnen kommt «. ${ }^{168}$ Don Ukmar war traurig und enttäuscht nach einem solchen Tag:

Endresultat: Soviel Hohn und Spott, wie an dem Tag [der Weihnachten] werde ich wohl ein ganzes Jahr in Ricmanje nicht mehr einstecken. [...] In vielen Häusern wies man mir unter Fluch und Schimpf die Tür, in einigen Häusern lachten sie mich aus, in einigen Häusern blieb die Familie auf meinen Gruß stumm, wieder andere antworteten höflich, in neun Fällen wurde ich sehr freundlich aufgenommen und segnete die Wohnung ein. ${ }^{169}$

167 Das Dorf war ausschließlich slowenisch bewohnt, daher ist es angebracht, nur den slowenischen Namen - statt des italienischen San Giuseppe della Chiusa - zu benutzen. Auch die zeitgenössischen italienischsprachigen Dokumente, Zeitungsartikel, Berichte benutzten nur den slowenischen Namen des Dorfes, ab und zu wurde Rizmanje - nach deutscher Rechtschreibung - geschrieben. Auch bezüglich der anderen im Text vorkommenden Nachbardörfer (Dolina, Boljunec, Log usw.) verwende ich ihre slowenischsprachigen Namen. Die italienischsprachigen Namen wurden erst während und nach dem italienischen Faschismus durchgesetzt. Weil die Gegend bis heute slowenischsprachig geprägt ist, haben die Dörfer um Triest das Recht, die slowenischen Ortsnamen - nebst den italienischen - anbringen zu dürfen.

168 Eintrag am 24. Dezember 1906 im Annales Ricmanienses (weiter: Annales), in: Župnijski arhiv v Ricmanjih/Archivio parocchiale di Ricmanje (Pfarrarchiv in Ricmanje, weiter: ŽAR) [übersetzt aus dem Slowenischen von mir]. Brief von Don Ukmar (28. Dezember 1906), in: ADT, GP, 1906/82. 
Die große Dorfkirche stand die ganze Zeit, nicht nur zu Weihnachten, fast leer: Die Menschen gingen nicht in die Kirche, sie meldeten sich sogar konfessionslos an. Der junge Priester schickte dem Triestiner Bischof, dem deutschsprachigen Franz Xaver Nagl, in seinen ersten zwei Dienstmonaten mehrere Briefe, in denen er immer wieder beteuerte, wie glücklich und froh er die Herausforderung wahrnehme, in einem Dorf wie Ricmanje seelsorgerische Aufgaben zu erfüllen: "Ich bin in Ricmanje vollkommen zufrieden und danke Gott und Ihnen, dass Sie mich hierher schickten. ${ }^{170}$ Die Zustände, die er aber in seinen Briefen schilderte - vom Kaplanhaus, das auch nach der Meinung des antikirchlich eingestellten Dorfvorstehers wie »ein Schweinestall« aussah ${ }^{171}$ bis zu den feindseligen Bewohnern und Kindern, die gegen den neuen Priester Steine warfen und sein Leben erschwerten -, unterschieden sich kaum von den Beschwerden eines anderen, früheren Kaplans, Jožef Krančič, der zuvor wegen der Gewaltakte sogar aus dem Dorf fliehen musste. Auch ein anderer Vorgänger, ein gewisser Dr. Anton Požar, konnte sich nicht lange in Ricmanje halten, aber im Gegensatz zu Don Krančič und Don Ukmar war er nicht vom Dorf, sondern von der kirchlichen Obrigkeit verdrängt worden. Unter ihm begann die Streitigkeit mit dem Triestiner Bistum, die fast zehn Jahre lang andauerte und als Paradebeispiel eines national motivierten, innerkatholischen Konfliktes galt. Der Fall kam und kommt immer wieder als Beispiel der nationalen Selbstverortung slowenischsprachiger Katholiken in der späteren Historiographie vor. ${ }^{172}$

Im Folgenden geht es darum, diesen Konflikt - der bis jetzt nur sporadisch erforscht und dargestellt wurde - von der mikrogeschichtlichen Ebene her zu rekonstruieren. ${ }^{173}$ Dabei stellt sich die Frage, ob und wie der Kampf eines slowenischsprachigen Dorfes mit seinen slowenischsprachigen Priestern, Pfarrern und dem »slowenisch« markierten Triestiner Bistum als »Nationalitätenkonflikt« gelten konnte. Im Mittelpunkt der Analyse stehen die unterschiedlichen Konfliktebenen, die einer mehrdimensionalen Erklärung bedürfen. Die nationalpolitischen Debatten um die Rolle der lokalen Kirche stellen zwar den diskursiven Hintergrund dar. Hatte aber der Konflikt in Ric-

170 Brief von Don Ukmar an Bischof Nagl (25. November 1906), in: Ebd.

171 Don Ukmar zitiert in seinem Brief den Dorfvorsteher Ivan Berdon; vgl. Don Ukmars Brief an Bischof Nagl (25. November 1906), in: ADT, GP, 1906/82.

172 Vgl. u. a. Valdevit, Chiesa e lotte nazionali, S. 197ff.; Tomaž Simčıč, Jakob Ukmar (1878-1971). Sto let slovenstva in krščanstva v Trstu [Jakob Ukmar (1878-1971). Hundert Jahre Slowenentum und Christentum in Triest], Gorica 1986, S. 50ff.; Alojz Rebula, Jakob Ukmar, Pordenone 1992, S. 10ff.; Angel Kosmač, Ricmanje - včeraj in danes [Ricmanje - gestern und heute], Trst [Triest] 1997; GotTsmann, Rom und die nationalen Katholizismen, S. 158ff.

173 Teilergebnisse meiner Forschung über den Kirchenstreit wurden schon veröffentlicht, vgl. Péter Tеснет, Gewaltmomente unter ländlichen Katholiken in der späten Habsburgermonarchie. Kirchenstreit in Ricmanje bei Triest, in: Bouwers (Hg.), Glaubenskämpfe, S. 117-138. 
manje nationalpolitische Gründe? War die Kirche im Hinterland von Triest "slowenisch" geprägt? Anhand des Kirchenstreites von Ricmanje lassen sich die gängigen Annahmen von einer nationalpolitisch umkämpften Kirche sowie eines "slowenisch « und »ländlich " geprägten Katholizismus prüfen.

Ricmanje war ein kleines Dorf in der bergig-karstigen Umgebung der kosmopolitischen, aber politisch-kulturell von einer italienischsprachigen, liberalen Elite dominierten Hafenstadt Triest. ${ }^{174}$ Nach der Volkszählung von 1900 lebten 617 Menschen in Ricmanje, von denen 616 römisch-katholisch und davon 609 slowenischsprachig waren. ${ }^{175}$ Die Frage, ob der in der Habsburgermonarchie seit der Mitte des 19. Jahrhunderts voranschreitende Prozess der ethnisch-nationalen Selbstverortung als Grundlage des Kirchenstreites in Ricmanje zu betrachten ist, ${ }^{176}$ erfährt infolge der geographischen Lage des Dorfes eine besondere Relevanz. Ricmanje befand sich an der sprachkulturellen Grenze zwischen dem slowenischsprachigen ländlichen Raum und der italienisch dominierten, aber mehrsprachigen Hafenstadt Triest. Die politische Aufwertung der Sprachenfrage erklärt sich aus der Gleichzeitigkeit geographischer Nähe bei ethnisch-sprachlicher Ferne zu Triest.

In Triest herrschte eine nationalliberale Hegemonie über das politische und kulturelle Leben, die allen anderen gesellschaftlichen und politischen Gruppen die gleichberechtigte Teilhabe verwehrte. Dies betraf besonders die slowenischsprachige Bevölkerung. Seit Mitte des 19. Jahrhunderts wanderten viele (meistens slowenischsprachige) Menschen aus den umliegenden, ländlichen Gegenden ein. ${ }^{177}$ Erst ab Ende des 19. Jahrhunderts formierten sie sich als eigenständige Gruppe (»Volk») in Triest. ${ }^{178} \mathrm{Um}$ die südslawische Präsenz vom urbanen Raum fernzuhalten oder - wenn diese schon im urbanen Raum angekommen war - als »ländlich «, »fremd « zu stigmatisieren, wurde in den nationalliberalen Diskursen eine starke Kontrastierung zwischen »Stadt" und »Land « bedient. Der Konflikt spielte sich insofern nicht nur innerhalb eines Dorfes wie Ricmanje ab, sondern im Kontext (im »Hintergrund«) der »Nationalitätenkonflikte«, die das öffentliche Leben in der benachbarten Adriametropole Triest prägten.

174 Zur Raumbeschreibung des Triestiner Hinterlandes siehe Andreas MoRitsch, Das nahe Triester Hinterland. Zur wirtschaftlichen und sozialen Entwicklung vom Beginn des 19. Jahrhunderts bis zur Gegenwart, Wien u.a. 1969.

175 Daten aus: Gemeindelexikon der im Reichsrathe vertretenen Königreiche und Länder, S. 52.

176 Die ethnisch-nationale Selbstverortung übertönte ab der Mitte des 19. Jahrhunderts in den habsburgischen Gebieten immer mehr die anderen Identitäten, vgl. CLEWING, Staatensystem und innerstaatliches Agieren im multiethnischen Raum, S. 505f.

177 Vgl. Marina Cattaruzza, Population Dynamics and Economic Change in Trieste and Its Hinterland 1850-1914, in: Richard Lawton/Robert LeE (Hg.), Population and Society in Western European Port-Cities c. 1650-1939, Liverpool 2002, S. 185-191.

Vgl. Cattaruzza, Sloveni e italiani a Trieste, S. 33. 
Der Konflikt in Ricmanje brach aber nicht wegen der Nähe zu Triest oder der dortigen politischen Debatten aus. Streitigkeiten bestanden seit Langem zwischen der slowenischsprachigen Pfarrei Dolina und den ihr unterstellten Filialen wie Ricmanje. Die Zugehörigkeit zur Pfarrei Dolina war aus finanziellen Gründen nachteilig für die Dorfbewohner, weil sie Geld und andere materielle Beiträge (etwa Wein) an den dortigen Pfarrer zu zahlen hatten. ${ }^{179}$ Wie der damalige, kroatischsprachige Triestiner Bischof, Andrej Marija Šterk, 1900 bemerkte, »[s]eit längerer Zeit macht sich eine Gärung« in den Kaplaneien infolge der an den Pfarrer von Dolina zu entrichtenden Leistungen »fühlbar«. Bischof Šterk meinte, dass die kirchenrechtliche Verselbstständigung dieser Dörfer - indem etwa eigene Pfarreien für sie gegründet würden - eine mögliche Lösung sei. ${ }^{180}$ Auch aus Prestigegründen empfand die Dorfgemeinschaft in Ricmanje die Zugehörigkeit zu Dolina als erniedrigend. Ricmanje hatte eine große Kirche, die seit dem 18. Jahrhundert als Pilgerfahrtort weit über das Tal hinaus bekannt war, über dem das Dorf lag. Die S. Giuseppe/Sv. Jožef Kirche befand sich an einem Pilgerfahrtweg, und sie war ein beliebtes Ziel für Pilger aus Istrien. ${ }^{181}$ Im Gegensatz dazu war die Kirche in Dolina viel unbedeutender.

In diesem Kapitel stelle ich zuerst anhand bisher in der Forschung nicht oder kaum beachteter staatlicher und kirchlicher Quellen sowie Zeitungsberichten die lange Konfliktgeschichte vor (Kapitel 3.2.2). In einem zweiten Schritt werden die Konfliktmomente analysiert, in denen sich die Dorfbewohner situativ identifizierten. Statt der Frage, welche »Identität« die Dorfbewohner bewegte, stellt sich vielmehr die Frage nach den konkreten Situationen, in denen sich die Dorfbewohner zu verorten hatten (Kapitel 3.2.3). Den historischen Kontext zum Fallbeispiel bildete der damalige kirchliche Versuch, Einheitlichkeit auf der lokalen Ebene - im Sinne einer klerikalen Kirchenpolitik - durchzusetzen und gegen die Partikularitäten und die normabweichenden Praxen härter vorzugehen. Im letzten Unterkapitel wird daher dieses kirchliche Ziel erörtert (Kapitel 3.2.4).

179 Vgl. etwa den Bericht der Triestiner Statthalterei über die Lage in Ricmanje und Log (29. November 1899), in: AST, Luogotenenza, AG, b. 791, fasc. 4.2.5, 1899/27286.

180 Brief vom Bischof Šterk an die Statthalterei (6. Februar 1900), in: AST, Luogotenenza, AG, b. 791, fasc. 4.2.5, 1900/4442.

181 Petra Kavrečıč, Turizem v Avstrijskem primorju. Zdravilišča, kopališca in kraške jame (1819-1914) [Tourismus im Österreichischen Küstenland. Heilbäder, Strände und Karsthöhlen], Koper 2015, S. 35. 


\subsubsection{Konfliktgeschichte: Vom Kampf um die Pfarrei bis zum Kampf gegen die Kirche}

Im September 1898 kam ein neuer Kaplan in Ricmanje an: Dr. Anton Požar (1861-1933) (siehe Abbildung 3) diente zuvor als Pfarrer im nordost-istrianischen Dorf Passo / Paz. In Ricmanje trat der in Graz promovierte Jurist eine Kaplanstelle an, ${ }^{182}$ was als Karriererückgang zu betrachten ist.

Laut einem späteren Bericht habe Don Požar nach seinem Ankommen in Ricmanje die Gottesdienste sofort »in slawischer Sprache« zu lesen angefangen. ${ }^{183} \mathrm{Ob}$ damit die altslawische oder die moderne slowenische Sprache gemeint war, ist nicht klar. Er konnte immerhin die Wortführer in Ricmanje für das Thema gewinnen: Schon im März 1900 trugen sie in einem Brief den Wunsch vor, altslawische Messen zu haben. ${ }^{184}$ Ihr Wunsch wurde aber nicht beachtet, und das Bistum von Triest erlaubte ihnen nicht - zumindest offiziell - die Verwendung der altslawischen oder slowenischen Sprache in der Liturgie. Im August 1900 erreichte ein slowenischsprachiges Schreiben aus Ricmanje das Triestiner Bistum: Mit der Unterschrift von einem gewissen Peter Herščak - dessen Unterschrift vom Schreibstil des ganzen Textes abweicht; es ist also zu vermuten, dass nicht er den Text niederschrieb wurde mitgeteilt, dass die Dörfer Ricmanje und Log »aus dem römischkatholischen Ritus« ausgetreten seien. Das Schreiben betonte, dass es nur um einen Wechsel des Ritus ginge: "wir bleiben ansonsten in der heiligen katholischen Kirche, aber wir treten in die griechisch-katholische Kirche über«. ${ }^{185}$

Die griechisch-katholische Kirche ist eine mit Rom unierte Kirche. Auch wenn ihre religiösen Praktiken mit jenen der Orthodoxie nahezu identisch sind, stellt die griechisch-katholische Kirche einen Ritus innerhalb der katholischen Kirche dar. Sie ist von Rom nicht losgelöst. In der Habsburgermonarchie gehörten größere Teile der ukrainisch- und rumänischsprachigen Bevölkerung zu dieser Kirche. Ein uniertes Bistum existierte im kroatischen Križevci. ${ }^{186}$ Kroatien gehörte zwar staatsrechtlich zur ungarischen Reichshälfte der Habsburgermonarchie, weswegen der dortige Bischof aus der

182 Seinen tabellarischen Lebenslauf siehe in: ŽAR, Fascicoli di sacerdoti: Angel Kosmač (Dossiers der Pfarrer: Angel Kosmač, weiter: Kosmač), fasc. 6 [keine weitere Nummerierung].

183 Bericht des Landes-Gendarmarie-Commandos von Boljunec über die Vorgeschichte des Konfliktes an die Bezirkshauptmannschaft von Capodistria/Koper (17. Februar 1906), in: AST, C.d. Capodistria, Culto, b. 170, fol. 468.

184 Slowenischsprachiger Brief der Dorfbewohner Peter Herščak, Ivan Zerjan und Josip Mavers an das österreichische Kultusministerium (eingetroffen am 7. März 1900), in: Ebd., b. 170, fol. 624ff.

185 Brief aus Ricmanje an das Bistum (8. August 1900), in: ADT, Gestione Ordinare (Allgemeine Verwaltung, weiter: GO), 1900/2139 [übersetzt aus dem Slowenischen von mir].

186 Zur Geschichte des Bistums von Križevci, siehe auch Pirigy István, A magyarors- 


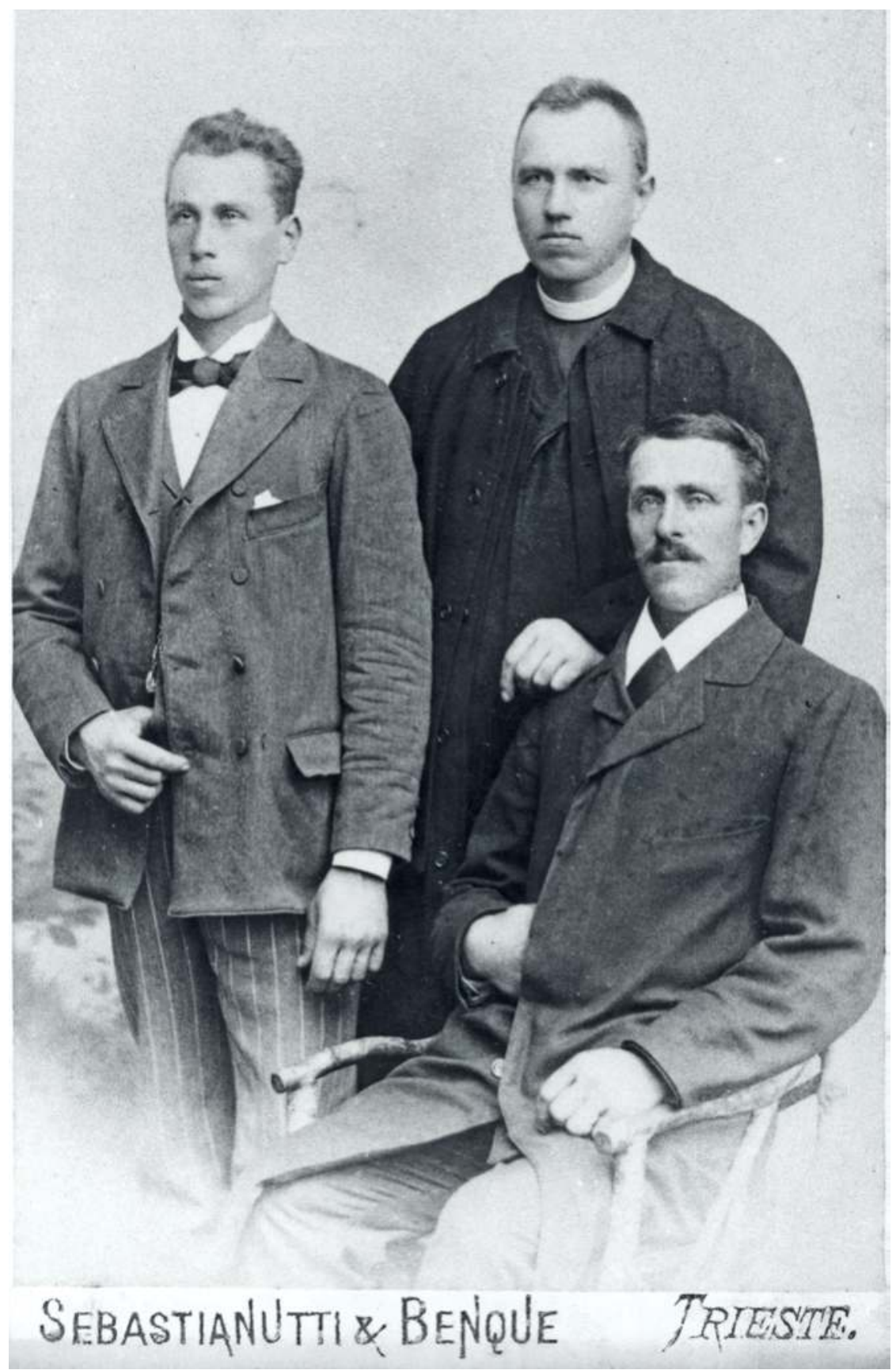

Abbildung 3: Dr. Anton Požar (in der Mitte) mit seinen Brüdern (ohne Datum) 
österreichischen Makroperspektive sogar als »ausländischer Bischof « galt. ${ }^{187}$ Den Dorfbewohnern in Ricmanje wird er aber - wegen der geographischen, geistigen und sprachlichen Nähe - keinesfalls »ausländisch " vorgekommen sein. Die Dörfer unterwarfen sich einseitig der Jurisdiktion dieses griechischkatholischen (unierten) Bistums.

Dem Schreiben war eine Liste mit den unterstützenden Bewohnern beigefügt. Die Unterschriften wurden nach Familien gezählt: 132 Familien aus Ricmanje und 29 aus Log. Insgesamt waren das somit 524 Menschen aus Ricmanje und 131 aus Log. Darunter gab es viele Kinder, einige waren zur Zeit des »Unterstützens« nur wenige Monate alt. ${ }^{188}$ Don Požar, der Kaplan von Ricmanje, kam weder im Schreiben noch in der Liste vor. Er wurde nicht einmal erwähnt. Das Bistum nahm den Übertritt - wie es in einer Notiz zum Brief anmerkte - als traurige Konsequenz »d[er] brennende[n] Frage betreffend die Theilung der Pfarre Dolina« wahr, welche »einer ehebaldigen Erledigung « bedürfe. ${ }^{189}$ Gemäß den Gesetzen gehörten die Austritt- sowie Übertrittangelegenheiten zur Kompetenz weltlicher Behörden, und daher meldeten die Dorfbewohner ihren Aus- und Übertritt bei der vor Ort zuständigen Bezirkshauptmannschaft von Capodistria/Koper an. ${ }^{190}$ In ihrem Brief an die Triestiner Statthalterei fasste die Bezirkshauptmannschaft die Ereignisse zusammen und schob die Verantwortung dem Kaplan Don Požar zu: Er habe »die Abneigung der in religiösen Dingen ohnehin indifferenten Bevölkerung jener Gegenden gegen den Pfarrer von Dolina« ausgenutzt und mobilisiert. ${ }^{191}$

Als Beweis für die Agitation von Don Požar erzählte das Landes-Gendarmarie-Commando von Capodistria/Koper die Geschichte eines gewissen Ivan Valentič, der aus der römisch-katholischen Kirche austreten wollte und daher den Kaplan von Ricmanje besuchte. Don Požar habe ihm daraufhin ein vorgefertigtes Schreiben zum Unterschreiben vorgelegt, wonach er aus

zági görögkatolikusok története. II. Rész [Die Geschichte der Griechisch-Katholiken in Ungarn, Bd. 2], Nyíregyháza 1990, S. 14-23.

187 Bischof Drohobeczky protestierte dagegen, Brief von Bischof Drohobeczky an das österreichische Kultusministerium (29. Dezember 1900), in: AST, Luogotenenza, AP, b. 265, fasc. 4.1.5., 1900/3427.

188 Als im Frühjahr 1901 die slowenischsprachigen Katholiken in der Pfarrgemeinde des Triestiner Vorortes Roiano/Rojan gegen den dortigen italienischsprachigen Pfarrer, Giuseppe Iurizza, einen Brief verfassten, bemerkte die italienischsprachige, katholische Zeitung La Ricreazione bissig, dass viele der »Unterschreibenden « eigentlich Analphabeten oder Kinder gewesen seien; vgl. La Ricreazione, 1. Mai 1901.

189 Notiz des Bistums zum Brief aus Ricmanje (8. August 1900), in: ADT, GO, 1900/2139.

190 Abschrift der Anmeldung aus Ricmanje (2. August 1900), in: AST, C.d. Capodistria, Culto, b. 170, fol. 204.

191 Bericht der Bezirkshauptmannschaft von Capodistria/Koper an die Statthalterei von Triest (23. August 1900), in: Ebd., fol. 493f. [Hervorhebung von mir]. 


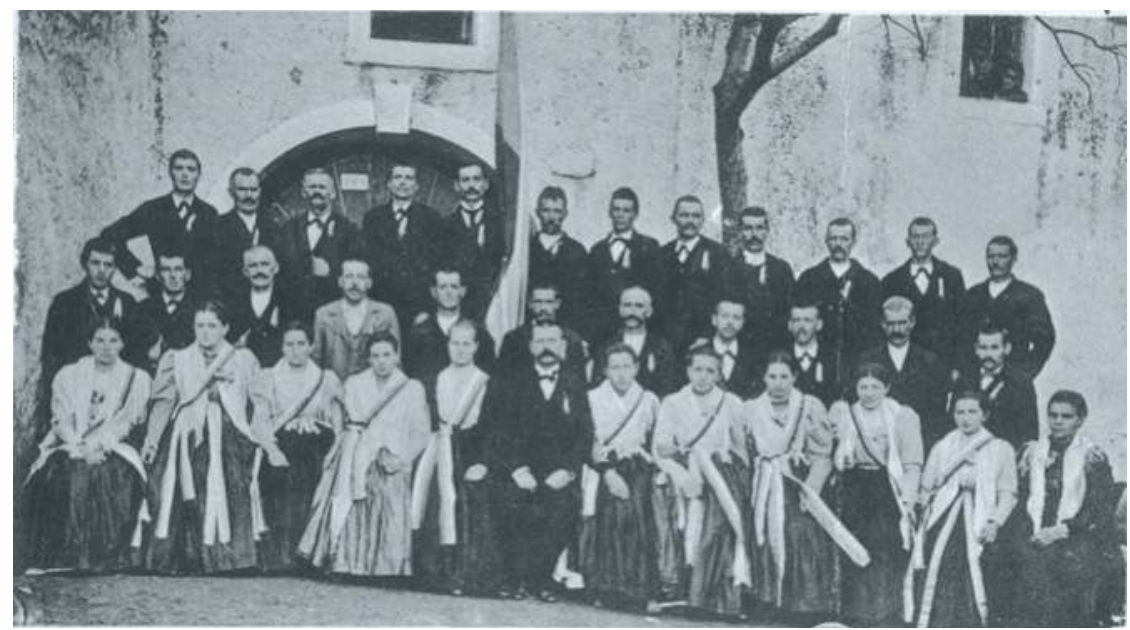

Abbildung 4: Lese- und Gesangsverein in Ricmanje zur Zeit des »Übertrittes in den griechisch-katholischen Ritus«

der Kirche austreten wolle, weil die Messe nicht in slowenischer Sprache zelebriert sei. Don Požar habe ihm erklärt, dass es außer der verwendeten Liturgiesprache keinen Unterschied zwischen den zwei Riten des Katholizismus, dem römischen und dem griechischen, gebe. Valentič sagte außerdem, dass Peter Herščak die Dorfbewohner schon Anfang Juli 1900 in einem Gasthaus in Ricmanje zusammengerufen habe, um sie zum Übertritt zu überreden. Bis auf zwanzig Personen hätten alle Teilnehmer aus Ricmanje und Log an diesem Abend dem Austritt aus der römisch-katholischen Kirche zugestimmt. Unter den Anwesenden sei nur eine sechzigjährige Witwe, eine gewisse Uršula Hrvatič, der römisch-katholischen Kirche treu geblieben: Dreimal hätten ihr Bruder Peter Hrvatič sowie Don Požar versucht, sie zum Übertritt $\mathrm{zu}$ bewegen, aber sie habe sich geweigert. ${ }^{192}$

Die Bezirkshauptmannschaft von Capodistria/Koper vermutete persönliche Ziele hinter der Agitation von Don Požar, der den lange bestehenden Konflikt zwischen Ricmanje und Dolina geschickt für seine Zwecke instrumentalisiert habe. Don Požar sei seit zwei Jahren mit einer Frau zusammen gewesen, das uneheliche Paar habe schon zwei Kinder gehabt. Don Požar habe also - laut der Bezirkshauptmannschaft - deswegen in die griechisch-

192 Abschrift des Berichtes des K.K. Landes-Gendarmerie-Commandos an die Bezirkshauptmannschaft von Capodistria/Koper (15. August 1900), in: ADT, GO, $1900 / 2340$. 
katholische Kirche übertreten wollen, weil er dort als griechisch-katholischer Geistlicher seine Freundin endlich heiraten könne. ${ }^{193}$ Schon Ende Juni 1900 berichtete Ugo Mioni, ein italienischsprachiger Priester und Verleger in Triest, dem Wiener Nuntius Emidio Taliani über die »korrupte Moral« von Don Požar. ${ }^{194}$ Don Mioni glaubte zu wissen, dass Don Požar in einem »Konkubinat« lebe: Um seine Geliebte heiraten zu können, habe Don Požar die Ignoranz des lokalen Volkes ausgenutzt und zum Übertritt bewegt. ${ }^{195}$ Der Vorwurf bezüglich des Privatlebens von Don Požar tauchte jedoch später nie wieder in den Quellen auf. Auch der griechisch-katholische Bischof, den er wegen der Aufnahme des Dorfes ansuchte, ernannte nicht ihn zum neuen griechisch-katholischen Kaplan von Ricmanje. Don Požar wandte sich später dem zivilen Beruf eines Journalisten zu.

Die negative Meinung über Don Požar übermittelte Nuntius Taliani an Kardinal Rampolla. Don Taliani verkannte dabei die griechisch-katholische Kirche, in deren kroatisches Bistum Ricmanje und Log übertreten wollten: Er bezeichnete fälschlicherweise den griechisch-katholischen (also mit Rom unierten) Bischof von Križevci als "schismatisch", als ob er orthodox gewesen wäre. ${ }^{196}$ Den Dorfbewohnern war der Unterschied zwischen den Riten ebenso nicht klar, aber die kirchenrechtlichen und theologischen Unterschiede spielten für sie keine große Rolle. Die Motivationen für den Übertritt waren vielmehr pragmatisch bestimmt - wie es mehreren Polizeiprotokollen zu entnehmen ist. Der bereits zitierte Ivan Valentič erklärte seinen Schritt mit dem sozialen Druck: Weil alle anderen im Dorf übergetreten seien, habe er sich dieser Tendenz nicht entziehen können und wollen. Petar Hrvatič fand den zu zahlenden Beitrag zu hoch, und deswegen wollte er aus der römischkatholischen Kirche - und insofern aus der Pfarrei von Dolina - austreten. Beide betonten aber, dass sie "katholisch" bleiben wollten; Ivan Valentič glaubte sogar, dass der griechisch-katholische Ritus älter sei als der lateinische. ${ }^{197}$ Nur ein einziger Befragter, Andrej Kuret aus Log, erwähnte, dass er übergetreten sei, weil ihm versprochen wurde: »wir werden so slowenischen Gottesdient haben«. Er beteuerte aber wie alle anderen Befragten, mit Don Požar nie über die Übertritte geredet zu haben. ${ }^{198}$

Bericht der Bezirkshauptmannschaft von Capodistria/Koper an die Statthalterei von Triest (23. August 1900), in: AST, C.d. Capodistria, Culto, b. 170, fol. 493 f.

194 Brief von Don Mioni an Msgr. Taliani (27. Juni 1900), in: AAV, ANV, b. 692, fol. $273 \mathrm{f}$. [übersetzt aus dem Italienischen von mir].

195 Brief von Don Mioni an Msgr. Taliani (3. Dezember 1900), in: Ebd., fol. 286.

196 Don Taliani an Msgr. Rampolla (1. Dezember 1900), in: AAV, ANV, b. 692, fol. 282 [übersetzt aus dem Italienischen von mir].

197 Protokolle über die Aussagen von Ivan Valentič und Petar Hrvatič (10. September 1900), in: ADT, GO, 1900/2385.

198 Protokolle über die Aussagen von Ivan Žuljan und Andrej Kuret (14. September 1900), in: Ebd. [übersetzt aus dem Slowenischen von mir]. 
Die Dorfbewohner von Ricmanje ersuchten Bischof Julij Drohobeczky bereits im Mai 1900 -noch vor der offiziellen Ankündigung des Übertrittes mit der Bitte, die Kirchengemeinde in seine Jurisdiktion zu übernehmen und ihnen einen griechisch-katholischen Priester zu schicken. ${ }^{199}$ Bischof Drohobeczky hatte zwar einen typisch multiethnischen Lebenslauf, ${ }^{200}$ aber er sympathisierte auch mit dem Gedanken, das sprachliche und nationale »Erwachen" der Kroaten und Slowenen kirchlich zu unterstützen. Beim ersten Ansuchen im Mai 1900 versuchte Bischof Drohobeczky zunächst, die Sache mit der Hoffnung hinzuzögern, dass sich die Menschen in Ricmanje und Log beruhigen würden - was aber nicht eintrat: »unserem Bemühen zum Trotze ließ sich das Volk nicht von seinem Vorhaben abzuleiten [sic!] «. ${ }^{201}$

Warum kam er der Bitte aus den Dörfern nach? Bischof Drohobeczky erwähnte die schleichende Gefahr der Orthodoxisierung slowenischsprachiger Bewohner von Triest und der Umgebung. Tatsächlich liebäugelten nationalistische, slowenischsprachige Kreise mit der Idee, in die serbische Orthodoxie überzutreten, weil ihnen diese Kirche nationaler vorkam als der betont supranationale Katholizismus. ${ }^{202}$ Ein slowenischsprachiger Agitator der Orthodoxisierung, ein gewisser Ivan Jajčič - der aus der Stadt Triest schon zuvor ausgewiesen worden war -, wurde tatsächlich in Ricmanje gesichtet. ${ }^{203}$ Drohobeczky erklärte es daher zur »Pflicht» seines Bistums, »unsere Maueren zu befestigen und Thürme auf den exponierten Posten aufzustellen und namentlich das slowenische Element zu bewahren dem die Gefahr [der Orthodoxisierung] am meisten droht «. Drohobeczky rechtfertigte seine Entscheidung, die Kirchengemeinden von Ricmanje und Log zu übernehmen, mit dem Ziel, »die Einwohner aus Ricmanje und Log aus den Garnen dieser

Vgl. den Brief von Msgr. Drohobeczky an das österreichische Kultusministerium über die Vorgeschichte der Übernahme (29. Dezember 1900), in: AST, Luogotenenza, AP, b. 265, fasc. 4.1.5, 1900/3427.

200 Msgr. Drohobeczky wurde in einer ruthenischsprachigen Familie im ostungarischen ungarisch-, rumänisch-, ukrainisch- und jiddischsprachigen Dorf Karácsonyfalva geboren; seit 1891 war er griechisch-katholischer (unierter) Bischof im kroatischen Križevci. Zu seinem Lebensweg siehe Ivan Pekilić, Život i djelo križevačkoga biskupa Julija Drohobeckog [Das Leben und das Werk des Bischofs von Križevci, Julij Drohobeczky], in: Podravina 3 (2004), S. 71-88, hier S. 71f.

201 Brief von Bischof Drohobeczky an das österreichische Kultusministerium (29. Dezember 1900), in: AST, Luogotenenza, AP, b. 265, fasc. 4.1.5., 1900/3427.

202 Über einige slowenischsprachige Familien in Triest, die wegen der italienischsprachigen Predigten in ihren katholischen Kirchen in die (serbische oder russische) Orthodoxie übertreten würden, siehe Bericht der Triestiner Statthalterei (25. November 1893), in: AST, Luogotenenza, AP, b. 161, fasc. 4.1.5, 1893/2047; sowie Bericht der Statthalterei (20. April 1894), in: AST, Luogotenenza, AP, b. 169, fasc. 4.1.5, 1894/165.

203 Brief des Landes-Gendarmerie-Commandos von Boljunec an die Bezirkshauptmannschaft von Capodistria/Koper (6. Mai 1901), in: AST, Luogotenenza, AP, b. 137, fasc. 4.1.5, 1901/1001. 
[orthodoxen] Agitatoren - die sie bereits zu umschlingeln versuchten - zu befreien und sie der heil. kathol. Kirche zu erhalten ${ }^{204}$ Er meinte daher, dass eine Ablehnung des Übertrittes die Lage vor Ort nur verschlechtern würde.

Bischof Drohobeczky nahm im November 1900 die Anforderung aus Ricmanje und Log positiv entgegen und erklärte sich bereit, die dortige Kirche in sein Bistum als eigenständige Pfarrei aufzunehmen: Er teilte die neue griechisch-katholische Kirchengemeinde in das dalmatinische Vikariat des Bistums ein und ernannte Šandor Abodić zum neuen Pfarrer. ${ }^{205}$ Don Požar wurde nicht zum griechisch-katholischen Priester, wie in den Gerüchten um sein Privatleben öfters erzählt wurde. Die bischöfliche Entscheidung bedurfte aber der päpstlichen Zusage - und diese kam nicht. Der Hl. Stuhl stimmte dem Übertritt des Dorfes nicht zu.

Der Fall erreichte schnell die österreichischen Medien: Die liberalen Zeitungen behandelten ihn im Kontext des »Nationalitätenkonfliktes«. Das Neue Wiener Tagblatt meldete etwa am 6. November 1900, dass »[s]ämtliche Bewohner sich für den griechisch-katholischen Ritus ausgesprochen [haben], und zwar aus nationalen Gründen, um die Einführung der slawischen Liturgie zu erreichen «. ${ }^{206}$ Für die Tageszeitung war der Grund klar: innerkirchlicher Nationalismus. Andere Töne schlug die katholische Presse an, die eine Nationalisierung des Kirchenlebens vermeiden wollte. Die italienischsprachige, katholische Zeitung aus Triest, La Ricreazione, betonte die Tatsache, dass die Einwohner von Ricmanje auch nach einem eventuellen Übertritt in die griechisch-katholische Kirche mit dem Papst vereint blieben. ${ }^{207}$ Die Zeitung wollte vermeiden, dass die Einheit der katholischen Völker im Küstenland durch ähnliche Nachrichten und Fälle gefährdet und zerstört werde (vgl. Kapitel 3.1.4). Don Mioni, der Herausgeber der katholischen Zeitung L'Amico aus Triest, machte jedoch auch die südslawenfreundliche Politik des Hl. Stuhls für den Übertritt verantwortlich. ${ }^{208}$ Im Falle von Ricmanje griff der Hl. Stuhl aber entschieden durch. Papst Leo XIII ließ weder den Rituswechsel (das heißt den Übertritt in das Bistum von Križevci) noch den altslawischen Usus innerhalb des lateinischen Ritus zu, und er erlaubte nur den slowenischsprachigen Gesang in der Kirche von Ricmanje. Der Hl. Stuhl

204 Brief vom Bischof Drohobeczky an das österreichische Kultusministerium (29. Dezember 1900), in: AST, Luogotenenza, AP, b. 265, fasc. 4.1.5., 1900/3427.

205 Brief vom Bischof Drohobeczky an die Triestiner Statthalterei (16. November 1900), in: AST, Luogotenenza, AG, b. 791, 1900/26479.

206 Neues Wiener Tagblatt, 6. November 1900 [Hervorhebung von mir].

207 La Ricreazione, 16. Dezember 1900.

208 Brief von Don Mioni an Msgr. Taliani (3. Dezember 1900), in: AAV, ANV, b. 692, fol. 286. 
forderte außerdem das Bistum von Triest auf, »den Gemeinden eine entsprechende Belehrung zu ertheilen «. ${ }^{209}$

Neben der Pfarreifrage stellte Don Požar immer mehr die Liturgiesprache in den Vordergrund. Die Sprachenfrage war ein Thema, mit dem die katholischen Kirchengemeinden auch in anderen Ortschaften nationalpolitisch umkämpft, beansprucht und gespalten werden konnten. Der damalige Bischof von Triest, Andrej Marija Šterk, nahm die volkssprachlichen Messen schweigend zur Kenntnis. Er vertrat die Meinung, dass abweichende, sogar eigentlich illegale Praxen auf der lokalen Ebene zu erdulden seien, falls somit Ruhe und Frieden gewährleistet werden konnten. ${ }^{210}$ Das österreichische Kultusministerium rügte daher »die wenig energische Haltung « von Bischof Šterk gegenüber den normabweichenden Tendenzen in Ricmanje. ${ }^{211}$

Im September 1901 starb Bischof Šterk. In der bischöflichen Vakanz intensivierte Don Požar seine Tätigkeit im Interesse der altslawischen oder slowenischsprachigen Messen. Als er vom Bistum aufgefordert wurde, zur lateinischen Liturgiesprache zurückzukehren, drohte er für diesen Fall mit »Unruhen und Chaos« im Dorf, wofür er keine Verantwortung übernehmen würde. ${ }^{212}$ Als promovierter (Kirchen-)Jurist wusste Don Požar sehr wohl, dass eine Kirchengemeinde - gemäß den diesbezüglichen Entscheidungen des Hl. Stuhls ${ }^{213}$ - das alte Privileg der altslawischen Liturgiesprache erst dann in Anspruch nehmen durfte, wenn dieser Usus auch in der Vergangenheit - mindestens seit 30 Jahren - erwiesenermaßen praktiziert wurde. Daher war es für ihn wichtig, ein altslawisches Messbuch aus dem Jahre 1483, das sich eigentlich im Besitz der Kirche von Ricmanje befand, aus dem bischöflichen Archiv von Triest zurückzufordern. ${ }^{214}$ Mit diesem Messbuch glaubte er, belegen zu können, dass die altslawische Sprache in Ricmanje seit Jahrhunderten verbreitet gewesen sei. Die Nachricht, dass Don Požar in Ricmanje altslawische Gottesdienste lese, sprach sich in der Gegend rasch herum. Don Požar betrieb in den umliegenden Dörfern Agitation für die

209 Das österreichische Kultusministerium übermittelt der Triestiner Statthalterei die päpstliche Entscheidung (18. Februar 1901), in: AST, Luogotenenza, AP, b. 265, fasc. 4.1.5, 1901/393.

210 Blasina, Santa Sede, vescovi e questioni nazionali, S. 490.

211 Brief des österreichischen Kultusministers an den österreichisch-ungarischen Außenminister (23. Dezember 1901), in: ÖStA, HHStA, Slawische Liturgie V/7.

212 Brief von Don Požar an das Bistum von Triest (7. Januar 1902), in: ADT, GO, 1902/40 [übersetzt aus dem Slowenischen von mir].

213 Nach einem Dekret aus dem Jahre 1898 wurde die altslawische Liturgiesprache nur den konkreten Kirchen erlaubt, in denen ein seit mindestens 30 Jahren kontinuierlicher Usus historisch belegt werden konnte. (Über die kirchlichen Dekrete bezüglich der Verwendbarkeit der altslawischen Liturgiesprache siehe Gotтsмann, Rom und die nationalen Katholizismen, S. 58ff.).

214 Brief von Don Požar an das Bistum über den Erhalt des Messbuches (16. Dezember 1901), in: ADT, GO, 1901/3806. 
altslawische Liturgiesprache und den Übertritt in die griechisch-katholische Kirche, in der auch die volkssprachlichen Gottesdienste erlaubt waren. Er lud im September 1901 den griechisch-katholischen Bischof Julij Drohobeczky nach Ricmanje ein, obwohl dem Bischof bereits vor einem Jahr die Übernahme der Dorfgemeinschaft verboten worden war. Die bischöfliche Vakanz schien für Don Požar eine Zeit zu sein, in der er sich über frühere kirchliche Vorschriften, etwa bezüglich der Liturgiesprache, hinwegsetzen konnte.

Bischof Drohobeczky traf am 14. September 1901 im Dorf ein und ging sofort zu Don Požar. Als seine Ankunft im Dorf bekannt wurde, versammelte sich eine kleine Menge, um ihn mit kroatischen »Živio!«-Rufen (»Es lebe!«) zu begrüßen. ${ }^{215}$ In Ricmanje wurden ein Denkblatt mit einem slowenischsprachigen Gedicht sowie ein Bild vom Bischof mit seinem kurzen, slowenischsprachigen Lebenslauf unter den anwesenden Menschen verteilt. Am 15. September 1901 um 10 Uhr und um 16 Uhr zelebrierten Bischof Drohobeczky und Don Požar kroatischsprachige Gottesdienste in der Kirche von Ricmanje. Auch aus den Nachbardörfern kamen viele Menschen zu den Messen. 200 slowenischsprachige Katholiken reisten sogar aus Roiano/Rojan, einem Vorort von Triest, an, ${ }^{216}$ wo sich die slowenischsprachige Gemeinde seit Langem wegen der Sprache der Predigten im offenen Streit mit dem italienischsprachigen Pfarrer, Don Iurizza, befand. ${ }^{217}$ Die slowenischsprachigen Katholiken drohten dort ebenso mit dem Übertritt in die griechisch-katholische Kirche, weil sie die italienischsprachigen Predigten und Gesänge in ihrer Kirche ablehnten. ${ }^{218}$

Der bischöfliche Besuch blieb nicht folgenlos. Im Winter 1901 / 1902 meldeten mehrere Menschen ihre Austritte aus der römisch-katholischen Kirche an. Diesmal nicht nur in Ricmanje, sondern auch in einer anderen Gemeinde aus der Pfarrei von Dolina, dem ebenso ausschließlich slowenischsprachig bewohnten Boljunec. Die Bezirkshauptmannschaft von Capodistria/Koper befragte einige Menschen bezüglich ihrer Austrittsgründe. Ihnen ging es darum, endlich eine eigene Pfarrei zu haben und an den Pfarrer von Dolina keine Beiträge mehr zahlen zu müssen. Sonst betonten fast alle, dass sie sich katholisch fühlten und zwischen den verschiedenen Riten des Katholizismus

215 Bericht des Landes-Gendarmarie-Commandos von Capodistria/Koper an die Bezirkshauptmannschaft von Capodistria/ Koper über den Besuch (16. September 1901), in: AST, Luogotenenza, AP, b. 265, fasc. 4.1.5, 1901/2096.

216 Ebd.

217 Zum Kirchenstreit in Roiano/Rojan, wo Don Iurizza 1901 einen slowenischsprachigen Kirchenverein verbot, siehe u. a. VALDEvit, Chiesa e lotte nazionali, S. 200.

218 Vgl. Polizeibericht an die Triestiner Statthalterei über die Übertritterwägungen (18. Mai 1901), in: AST, Luogotenenza, AP, b. 244, fasc. 4.1.5, 1901/1078; sowie Polizeibericht an die Triestiner Statthalterei über die Übertritterwägungen (4. November 1901), in: Ebd., 1901/2555. 
keinen wesentlichen Unterschied kennen würden. ${ }^{219}$ Es gab Menschen, die nicht nur keinen Unterschied zwischen den Riten kannten, sondern überhaupt nicht wussten, worum es in dem, was sie unterschrieben, ging: Sie hätten nur mitgemacht, weil alle es getan hätten. ${ }^{220}$ Eine gewisse Maria Jabec rechtfertigte ihren Austritt etwa mit dem väterlichen Wille: »was mein Vater gewollt hat, das will ich «. ${ }^{221}$ Ein anderer Bewohner, Jožef Zohec, räumte ein, dass er nicht wisse, welcher Religion Bischof Drohobeczky angehöre, aber er sei der Einzige, der Boljunec einen Priester versprochen habe. ${ }^{222}$ Einen wichtigen Grund zum Übertritt stellte die Forderung nach einer eigenen Pfarrei, also der kompletten Verselbstständigung von Dolina dar. ${ }^{223}$ Die Verselbstständigung hätte die Dorfbewohner finanziell entlastet. Johanna Zohec beklagte sich vor allem über die jährlich an den Pfarrer von Dolina zu entrichtenden Beiträge. Sie musste zum Beispiel allein vom Wein jährlich 24 Liter an die Pfarrei abgeben. Außer der finanziellen Entlastung sah sie keinen Unterschied zwischen den zwei Riten. ${ }^{224}$ Einige, wie etwa Ivan Ota, erwähnten jedoch die Sprache als einzigen Unterschied. ${ }^{225}$ Wie ein gewisser Miha Žerjav sagte, kenne er nur den Unterschied, »daß der griech. Bischof, wie ich in Ricmanje gesehen habe, die Messe in slowenischer Sprache hielt «. ${ }^{226}$ Der Besuch von Bischof Drohobeczky in Ricmanje im September 1901 beeinflusste also auch die Einwohner von Boljunec, wobei der Bischof die Messe in der Kirche nicht in slowenischer, sondern kroatischer Sprache las.

Ähnlich diverse Motivationen ließen sich bei den Einwohnern von Ricmanje erkennen, die Anfang 1902 - nochmals - ihre Austritte aus der römisch-katholischen Kirche anmeldeten. ${ }^{27}$ Die italienischsprachige, christ-

219 Protokoll der Bezirkshauptmannschaft Capodistria/Koper (23. Januar 1902), in: AST, C.d. Capodistria, Culto, b. 170, fol. 48.

220 Zum Beispiel Jože Maver; vgl. Protokoll bei der Bezirkshauptmannschaft Capodistria / Koper (14. Februar 1902), in: Ebd., fol. 32.

221 Protokoll der Bezirkshauptmannschaft Capodistria/Koper (23. Januar 1902), in: Ebd., fol. 48.

222 Protokoll der Bezirkshauptmannschaft Capodistria/Koper (31. Januar 1902), in: Ebd., fol. 50.

223 Zum Beispiel betonte Jozef Zerjal explizit, dass er keine andere Absicht mit dem Übertritt habe; vgl. Protokoll der Bezirkshauptmannschaft Capodistria/Koper (28. Februar 1902), in: Ebd., fol. 36; Franc Lampe, vgl. Protokoll bei der Bezirkshauptmannschaft Capodistria / Koper (7. März 1902), in: Ebd., fol. 42; oder Andreja Žerjav, vgl. Protokoll bei der Bezirkshauptmannschaft Capodistria/Koper (7. März 1902), in: Ebd., fol. 44.

224 Protokoll der Bezirkshauptmannschaft Capodistria/Koper (31. Januar 1902), in: Ebd., fol. 52.

225 Protokoll bei der Bezirkshauptmannschaft Capodistria/Koper (14. Februar 1902), in: Ebd., fol. 27.

226 Ebd., fol. 30.

227 Protokoll der Bezirkshauptmannschaft Capodistria / Koper (Januar / Februar 1902), in: Ebd., fol. 668ff. 
lich-soziale Zeitung aus Triest, L'Avennire, verbreitete gleichzeitig das Gerücht, dass sich eine russische Prinzessin in der Nähe von Ricmanje aufhalte. ${ }^{228}$ Das Blatt wollte damit suggerieren, dass die Austritte in Ricmanje und Boljunec mit einer russischen Agitation zu erklären seien.

Ende März 1902 wurde die bischöfliche Vakanz beendet. Mit Franz Xaver Nagl, dem neuen Bischof, schickte der Hl. Stuhl seit mehr als 70 Jahren den ersten nicht südslawischen Bischof in die sonst überwiegend italienischsprachige Hafenstadt. ${ }^{229}$ Das italienischsprachige, katholische Blatt in Triest, $L a$ Ricreazione, betonte, dass der neue Bischof zwar deutschösterreichischer Abstammung sei, aber auch die italienische Sprache sehr gut beherrsche. ${ }^{230}$ Bischof Nagl traf erst im August 1902 in Triest ein. In seiner ersten, lateinischen Predigt begrüßte er »omnes Italos et Slavos «. ${ }^{231}$ Wie das italienischnationalistische Blatt L'Istria bemerkte: Er habe seine Stelle »in einer sehr kritischen Zeit« angetreten, als »ein krasser Antagonismus [...] zwischen dem italienischen und dem slawischen Teil des Klerus « bestanden habe. ${ }^{232}$ Bischof Nagl stand jenseits dieser Antagonismen: Er wollte - wie im Kapitel 3.1.4 angedeutet wurde - das Kirchenleben von den »Nationalitätenkonflikten « fernhalten. Gleichzeitig vertrat er die Ansicht, dass der Gehorsam gegenüber den päpstlichen Entscheidungen eindeutiger einzufordern sei.

Die auch von Nagl vorangetriebene Supranationalisierung (im Sinne von Klerikalisierung/Ultramontanisierung) der katholischen Kirche war mit einer starken Rückbesinnung auf Rom möglich. ${ }^{233}$ Als Bischof veröffentlichte Nagl alle früheren päpstlichen Dekrete bezüglich der altslawischen Liturgiesprache, welche sein Vorgänger, Bischof Šterk, aus Angst vor nationalistischen Konflikten in seinem Bistum bewusst verschwiegen hatte. Bischof Nagl griff entschieden gegen die normabweichenden Realitäten durch. Nach der Information des kroatisch-nationalistischen Blattes Istriens, Naša Sloga, hätte Bischof Nagl mit dem italienischsprachigen Bischof von Pola/Pula, Giovanni Battista Flapp, vereinbart, härter gegen die altslawische Liturgiesprache in den Kirchen vorzugehen. Das Blatt warnte daher »den nationalen [volksnahen] Klerus« vor »einem tödlichen Schlag «. ${ }^{234}$ Bischof Nagl erzwang

228 L' Avvenire, 14. März 1902 [übersetzt aus dem Italienischen von mir].

229 Zovatto, Cattolicesimo a Trieste, S. 9.

230 La Ricreazione, 1. Mai 1902.

231 Zitiert in Katarina Košuta, L' episcopato triestino di Franz Xaver Nagl (1902-1910). Tesi di laurea in storia contemporanea [Die Triestiner Bischofszeit von Franz Xaver Nagl (1902-1910). Diplomarbeit in Zeitgeschichte], Trieste 2002 [unveröff. Diplomarbeit], S. 31.

232 L' Istria, 30. August 1902 [übersetzt aus dem Italienischen von mir].

233 Adolf M. Birke, Nation und Konfession. Varianten des politischen Katholizismus in Europa des 19. Jahrhunderts, in: Historisches Jahrbuch 116 (1996), S. 395-416, hier S. 397.

234 Naša Sloga, 11. Dezember 1902 [übersetzt aus dem Kroatischen von mir]. 
zwar von der Zeitung eine Richtigstellung, als ob die zwei Bischöfe so eine Vereinbarung nicht getroffen hätten, ${ }^{235}$ aber seine Politik entsprach in der Tat einer klerikalen Linie, welche nationale oder andere Abweichungen nicht mehr zu erdulden willens war. Im Naša Sloga meinte Bischof Nagl, dass er »als katholischer Bischof innerhalb und außerhalb der Kirche Frieden« wolle. ${ }^{236}$ Frieden bedeutete für ihn die Beseitigung der lokalen Partikularismen und der normabweichenden Situationen, auch wenn sie bisher schweigsam toleriert wurden.

Er akzeptierte dementsprechend den Übertritt von Ricmanje und Log in die griechisch-katholische Kirche nicht. Im November 1902 verbot er außerdem jegliche Verwendung altslawischer oder slowenischsprachiger Messen. Er wollte die Dörfer nicht nur in die römisch-katholische Kirche, sondern auch in die normgemäße Praxis der Latinität zurückzwingen. Konsequenterweise enthob Bischof Nagl im Dezember 1902 Don Požar seiner Kaplanstelle in Ricmanje. ${ }^{237}$ Damit fing der Konflikt an. Eine Karikatur der slowenischsprachigen Satirezeitschrift aus Triest, Škrat, machte sich über den Namen des Bischofs lustig: In den Stein von Ricmanje werde der "Deutsche» den neuen Nagel (also Dr. Nagl) doch nicht einschlagen können - Ricmanje erweise sich härter (siehe Abbildung 5).

Der neue Kaplan in Ricmanje wurde Jožef Krančič, bis dahin Kaplan in Vatovlje, einem kleinen Dorf nahe der istrianisch-krainischen Grenze. Don Požar hätte schon vor dem Jahresende 1902 dem neuen Kaplan die Kirche und die Kaplanwohnung in Ricmanje übergeben sollen, aber er kooperierte weder mit der Pfarrei von Dolina noch mit dem neuen Kaplan Don Krančičč. ${ }^{238}$ Auch der Dorfvorsteher Ivan Berdon wollte die Übergabe vereiteln. ${ }^{239}$ Don Požar wurde im Januar 1903 wegen seines Widerstandes sogar vom Priestertum suspendiert. In seinen späteren Briefen an Papst Pius X prangerte er Bischof Nagl mit kritischen Worten an: Der Bischof sei »ein Mensch ohne Gewissen und ohne Herz« gewesen, und »ein Mensch, der ständig bereit ist, zu lügen $\ll{ }^{240}$ Er meinte, dass er unter der Jurisdiktion des griechisch-katholischen Bistums von Križevci stehe und insofern Entscheidungen aus Triest

235 Ebd., 25. Dezember 1902 [übersetzt aus dem Kroatischen von mir].

236 Ebd., 25. Dezember 1902.

237 Absetzungsurkunde (7. Dezember 1902), in: ADT, GO, 1902/4275.

238 Protokoll über den ersten misslungenen Versuch, die Kirche und die Wohnung in Ricmanje zu übernehmen (29. Dezember 1902), in: ADT, GO, 1902/4275.

239 Kopie des Briefes der Triestiner Statthalterei an die Bezirkshauptmannschaft von Capodistria/Koper darüber, dass der Schlüssel vom Dorfvorsteher Ivan Berdon evtl. auch mit Zwang weggenommen werden darf (30. Januar 1903), in: Ebd., 1903/395.

240 Brief von Dr. Požar an den Papst Pius X. (2. August 1907), in: ŽAR, Kosmač, fasc. 4 [keine weitere Nummerierung] [übersetzt aus dem Italienischen von mir]. 


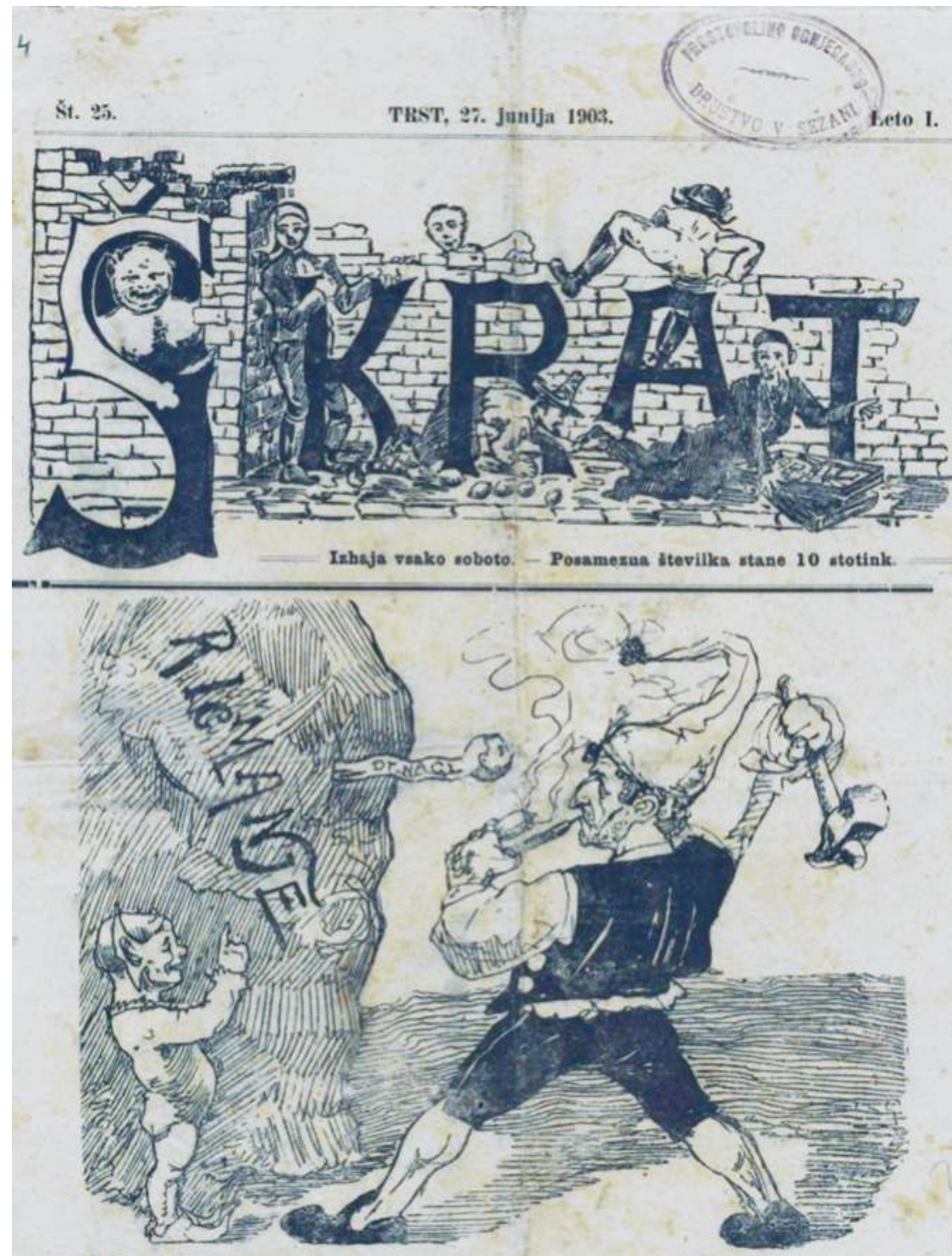

Nembki Mihel: Saperlot nazaj, že dve leti zabijam ta żebelj’) a -nikakor noče naprej. Začel se mi je že zvijati.

\$krat: Le korajžno naprej, mu vsaj odbiješ glavo.

7) Zebell we zore po semilko Nogh.

Abbildung 5: Karikatur über Bischof Nagl als »Nagel« (1903) 
keinen Gehorsam zu leisten habe. ${ }^{241}$ Er beschwerte sich beim Hl. Stuhl, dass er seit Januar 1903 keine finanzielle Unterstützung mehr erhalte: »mir [bleibt] daher nichts übrig als entweder nach Amerika auszuwandern oder zur Advokatur überzutreten «. ${ }^{242}$ Don Požar wurde inzwischen auch bezichtigt, Wertsachen aus der Ricmanjer Kirche gestohlen zu haben. Ein gewisser Domenico Fabris hatte 1900 der dortigen Kirche einen großen Fußteppich hinterlassen. Der Teppich verschwand irgendwann plötzlich aus der Kirche. Einige hätten ihn mit anderen Wertsachen aus der Dorfkirche in der Triestiner Privatwohnung von Don Požar gesehen. ${ }^{243}$ Don Požar wurde später von den Vorwürfen freigesprochen. 1907 beantragte er seine Pensionierung, ${ }^{244}$ was ihm ab 1910 zugesprochen wurde. ${ }^{245}$

Der anfängliche Konflikt um den suspendierten Dr. Požar erlangte die Aufmerksamkeit der deutschnationalen, antiklerikalen Öffentlichkeit Österreichs, die ihn als Opfer des Klerikalismus feierte. Das deutschnationale, protestantische, antiklerikale Grazer Tagblatt veröffentlichte Anfang April 1903 eine längere Reportage über ihn und Ricmanje: Ein Journalist aus der steierischen Landeshauptstadt besuchte Ricmanje, dessen slowenischsprachige Bewohner er »im Gegensatze zu vielen ihrer Stammesgenossen in anderen wendischen [slowenischen - P.T.] Gegenden" als viel offener empfand. Als Don Požar ihm die Türe aufmachte, erinnerte er den Journalisten sogar an Martin Luther. Don Požar verglich selbst »die heutige Gährung unter den Südslawen« mit den Kämpfen der deutschen Reformation. Das Blatt sah Ähnlichkeiten zwischen dem dörflichen Widerstand und der deutschnationalen Los-von-Rom-Bewegung. ${ }^{246}$ Für die antiklerikale, deutschnationale

241 Brief von Don Požar an das Bistum von Triest (27. Dezember 1902), in: ADT, GO, 1903/1.

242 Kopie des Briefes von Don Požar an den Hl. Stuhl (31. Dezember 1903), in: ŽAR, Kosmač, fasc. 4 [keine weitere Nummerierung].

243 Brief von Maria Senizza an das Triestiner Bistum (19. Dezember 1903), in: ADT GP, 1903/3982. Die Bezirkshauptmannschaft von Capodistria/Koper bemerkte in ihrem Bericht, dass auch andere wertvolle Sachen aus der Kirche in der Triestiner Privatwohnung von Dr. Požar gesehen worden seien; vgl. Kopie des Berichtes der Bezirkshauptmannschaft von Capodistria/Koper (16. März 1904), in: ADT, GO, $1903 / 3982$.

244 Brief von Dr. Požar (20. Juni 1907), in: Ebd., 1907/1715.

245 Brief der Triestiner Statthalterei an das Bistum von Triest (3. Mai 1910), in: Ebd., 1909/307.

246 Die »Los-von-Rom«-Bewegung war eine antikatholische, antihabsburgische, deutschnationale, meist protestantisch geprägte Strömung in Österreich, welche die Habsburgermonarchie und ihre tolerante Nationalitätenpolitik sowie den supranationalen Katholizismus ablehnte und einen politischen wie geistigen Anschluss der Deutschösterreicher an das Deutsche Reich und den deutschen Protestantismus forderte. Die Bewegung stand den antisemitischen Kreisen ebenso nahe. Über die Bewegung siehe Karl-Reinhart Trauner, Die Los-von-Rom-Bewegung. Gesellschaftspolitische und kirchliche Strömung in der ausgehenden Habsburgermonarchie, Szentendre 1999. 
Zeitung war es nicht ungewohnt, einen südslawischen (ehemaligen) Priester zu loben: Die zwei »Nationen«, die »Deutschen« und die "Slowenen«, hätten sich - nach dem diesbezüglichen nationalistischen Narrativ - im Heimatland der Zeitung, der Steiermark, einander eigentlich bekämpfen sollen. Der Journalist bemerkte es jedoch am Ende des Treffens: »Aufrichtig und ehrlich konnten wir uns zum Abschiede die Rechte geben, trotzdem wir nationale Gegner sind. ${ }^{247}$

Die steirische Zeitung kritisierte die Politik von Bischof Nagl hart: Er sei ein Bischof, der "mit Kugeln und Bajonetten das "Christentum« lehren wolle ${ }^{248}$ Diese Bemerkung war eine Anspielung darauf, dass Bischof Nagl seine Entscheidung, Don Požar aus dem Dorf zu entfernen, in der Tat mit polizeilicher Gewalt durchsetzen wollte. Anfang des Jahres 1903 wurde Ricmanje mehrmals von bewaffneten Gendarmen besetzt: Am 20. Januar 1903 kam der neue Kaplan, Don Krančič, mit mehreren Gendarmen im Dorf an, um die Kirche und die Kaplanwohnung zu übernehmen. ${ }^{249}$ Die Dorfbewohner akzeptierten ihn keineswegs: Sie gingen nicht mehr in die Kirche. Als am 10. Februar 1903 eine alte Frau als einzige an dem von Don Krančič in lateinischer Sprache zelebrierten Gottesdienst teilnahm, wurde sie nach der Messe in der Straße von anderen Frauen, die vor der Kirche auf sie gewartet hatten, als »Hure « beschimpft und mit Steinen angegriffen. ${ }^{250}$ Ende März 1903 berichtete Don Krančič dem Bistum über andere schwerwiegende Vorfälle: Kinder hätten ihn auf der Straße beschimpft, verflucht, und sie hätten Steine nach ihm geworfen. Im April 1903 wurde Don Krančič an seinem rechten Arm von einem Stein, den ein Kind nach ihm warf, verletzt. ${ }^{251}$ Wenn die Kinder in die Kirche gingen, dann nur, um sich über den Priester lustig zu machen: Eines Tages hätten sie den Beichtstuhl in der Kirche besetzt und das Beichten lachend nachgeahmt. ${ }^{252}$ Als im Juni 1903 Menschen aus dem slowenischsprachigen Triestiner Vorort, Servola / Ščedna, nach Ricmanje pilgerten und am Gottesdienst teilnahmen, wurden die angereisten Frauen von den Dorfkindern schikaniert und beschimpft. Die Männer, die statt in die Kirche in die Kneipen gingen, wurden in Ruhe gelassen. ${ }^{253}$ Dem Kirchengebäude wurden auch materielle Schäden zugefügt. Anfang März 1903, als

247 Grazer Tagblatt, 3. April 1903 [Hervorhebung von mir].

248 Ebd.

249 Edinost, 20. Januar 1903; Slovenski Narod, 23. Januar 1903.

250 Bericht des Landes-Gendarmarie-Commandos von Boljunec (12. Februar 1903), in: AST, Luogotenenza, AP, b. 265, fasc. 4.1.5, 1903/396 [übersetzt aus dem Slowenischen von mir].

251 Bericht der Bezirkshauptmannschaft von Capodistria/Koper an die Triestiner Statthalterei (16. Mai 1903), in: Ebd., 1903/912.

252 Brief von Don Krančič an den Bischof Nagl (30. März 1903), in: ADT, GO, 1903/1088.

253 Bericht des Landes-Gendarmarie-Commandos von Boljunec (6. Juni 1903), in: AST, Luogotenenza, AP, b. 265, fasc. 4.1.5, 1903/1224. 
der Messediener die Türe zum Kirchenturm (bewusst oder nicht) zu verschließen vergaß, stiegen einige Dorfbewohner hinauf und schnitten sämtliche Seile der Glocken ab. Der Bericht des Landes-Gendarmarie-Commandos beschrieb angesichts solcher Gewaltakte die Dorfbewohner als ein »bösartiges Volk «. ${ }^{254}$ Am 29. März 1903 sei sogar während des von fast niemandem besuchten Gottesdienstes Kot in die Kirche geworfen worden. ${ }^{255}$

Bischof Nagl versuchte bereits Ende Januar 1903, die Bevölkerung zu belehren. Am 25. Januar - am Fest der Heiligen Familie - wandte er sich wie die österreichische, katholische Tageszeitung Das Vaterland schrieb - mit einem »liebevollen, offenen, wenn auch kurzen" Hirtenbrief an die Dorfgemeinde. ${ }^{256}$ Der dem Hirtenbrief angeschlossene Kommentar vom Vaterland drückte sich diesbezüglich pathetisch aus, indem es sich fragte: „Was hat Jesus Christus, unser Erlöser der nur eine heiligmachende Kirche gestiftet hat, den Bewohnern von Ricmanje und Log denn zuleide gethan, daß sie ihn so schnöde verlassen wollen? ${ }^{257}$ Bischof Nagl sprach in seinem Hirtenbrief selbst von "einem Schisma", als ob das Dorf nicht nur einen Rituswechsel, das heißt den Übertritt in einen anderen katholischen Ritus gewünscht hätte: "Tief ins Herz hinein hat es mich betrübt, als ich schon vor Monaten und auch jetzt wieder hörte, daß einige von Euch ihre Mutter, die katholische Kirche, die da ist, die allein seligmachende Kirche, verlassen und zum Schisma übertreten wollen. « $^{258}$

Der gewünschte Übertritt zur griechisch-katholischen Kirche hätte kein Schisma dargestellt, weil sie ebenso dem Papst unterstellt ist. Don Požar drohte aber schon früher damit, dass ein Verbot des Übertrittes zur griechisch-katholischen Kirche in der Tat zum Schisma, das heißt zum Übertritt in die Orthodoxie, führen könne. ${ }^{259}$ Anfang April 1903 entschlossen sich einige Dorfbewohner in Ricmanje, die Aufnahme in die Orthodoxie beim serbisch-orthodoxen Bischof in Zara/Zadar zu beantragen. Die Delegation von fünf Männern aus Ricmanje, die sich in die dalmatinische Stadt aufmachten, trug die Absicht vor, in die Orthodoxie überzutreten, um im Dorf altslawische oder muttersprachliche Gottesdienste einführen zu können. Der serbisch-orthodoxe Bischof von Zara/Zadar zeigte aber wenig Interesse an der Sache und lehnte das Ansuchen mit dem Argument ab, keinen Geistli-

254 Bericht des Landes-Gendarmarie-Commandos von Boljunec (3. März 1903), in: Ebd., 1903/552.

255 Brief von Don Krančič an den Bischof Nagl (30. März 1903), in: ADT, GO, 1903/1088.

256 Edinost, 28. Januar 1903.

257 Das Vaterland, 4. Februar 1903.

258 Deutsche Übersetzung des Hirtenbriefes, in: Ebd., 4. Februar 1903.

259 Kopie vom Brief von Don Požar an den Hl. Stuhl (20. September 1902), in: ŽAR, Kosmač, fasc. 4 [keine weitere Nummerierung]. 
chen aus seinem Bistum nach Ricmanje schicken zu können. ${ }^{260}$ Er erkannte, dass die Übernahme der Kirchengemeinde das interkonfessionelle Verhältnis zwischen Katholizismus und Orthodoxie belasten bzw. den Interessen von Wien entgegenlaufen würde.

Im Frühjahr 1903 meldeten daraufhin mehrere Dorfbewohner aus Ricmanje und Log ihre Austritte aus der römisch-katholischen Kirche wieder an. Fast alle rechtfertigten diesmal ihren Schritt mit dem Wunsch, Gottesdienste in der eigenen Muttersprache hören zu wollen. Die Sprachenfrage übertönte immer mehr den Konflikt. Wie etwa die Dorfbewohnerin Marija Žuljan sagte: »Ich will den eigenen Gott in der eigenen Sprache anbeten ${ }^{261}$ Jože Dariž drückte sich auf die Frage, warum er übertreten will, einfacher aus: "Ich will meine Muttersprache ${ }^{262}$ Außer der verwendeten Sprache erkannten die Dorfbewohner aber weiterhin keinen Unterschied zwischen den Riten des Katholizismus bzw. zwischen dem Katholizismus und der Orthodoxie, weil der Gott - wie etwa Uršula Pregarc aus Ricmanje betonte »der selbe« sei: »Wir sind dieselben, die wir zuvor waren; wir glauben an den selben Gott, an den wir davor geglaubt hatten. Lateinisch können wir nicht, wir wollen slowenische Messe. $\aleph^{263}$

Die Ablehnung gegenüber der institutionalisierten Kirche zeigte sich etwa darin, dass ab März 1903 Begräbnisse ohne priesterliche Assistenz stattfanden (siehe Abbildung 6). Die Menschen riefen Don Krančič, den neuen Kaplan, weder zu den Taufen noch den Begräbnissen, die daher »zivil« erledigt wurden. Ähnliche Fälle traten in einem anderen Kirchenstreit zwischen 1908 und 1910 in Drenova auf der ungarischen Seite (Kapitel 4.2) auf. Das LandesGendarmarie-Commando beschrieb ein solches Begräbnis am 25. März 1903 ziemlich detailliert: An der Spitze des Leichenzuges marschierten ein alter Mann und ein Junge mit je einem großen Holzkreuz, ihnen folgten die Gäste aus der ganzen Gegend (ca. 1600 Menschen) und eine slowenische Musikkapelle. Beim Grab hielt der Dorfvorsteher Ivan Berdon eine Rede, und danach warf er dreimal Erde auf den Sarg. Er benahm sich wie ein Geistlicher, er war sogar priestermäßig angekleidet. Den Gästen aus den anderen, umliegenden Ortschaften soll das »zivile« Begräbnis so gut gefallen haben, dass sie es daheim einführen würden. ${ }^{264}$ In Ricmanje verbreitete sich diese Pra-

260 Bericht der Bezirkshauptmannschaft von Zara/Zadar an die Triestiner Statthalterei (2. April 1903), in: AST, Luogotenenza, AP, b. 265, fasc. 4.1.5, 1903/753.

261 Protokoll über den Austritt von Marija Žuljan (29. Januar 1903), in: AST, C.d. Capodistria, Culto, b. 170, fol. 70 [übersetzt aus dem Slowenischen von mir].

262 Protokoll über den Austritt von Jože Dariž (3. Februar 1903), in: Ebd., fol. 69 [übersetzt aus dem Slowenischen von mir].

263 Protokoll über den Austritt von Ursula Pregerc (24. März 1903), in: Ebd., fol. 678 [übersetzt aus dem Slowenischen von mir].

264 Bericht des Landes-Gendarmarie-Commandos von Boljunec an die Bezirkshauptmannschaft von Capodistria/Koper (26. März 1903), in: AST, Luogotenenza, AP, 


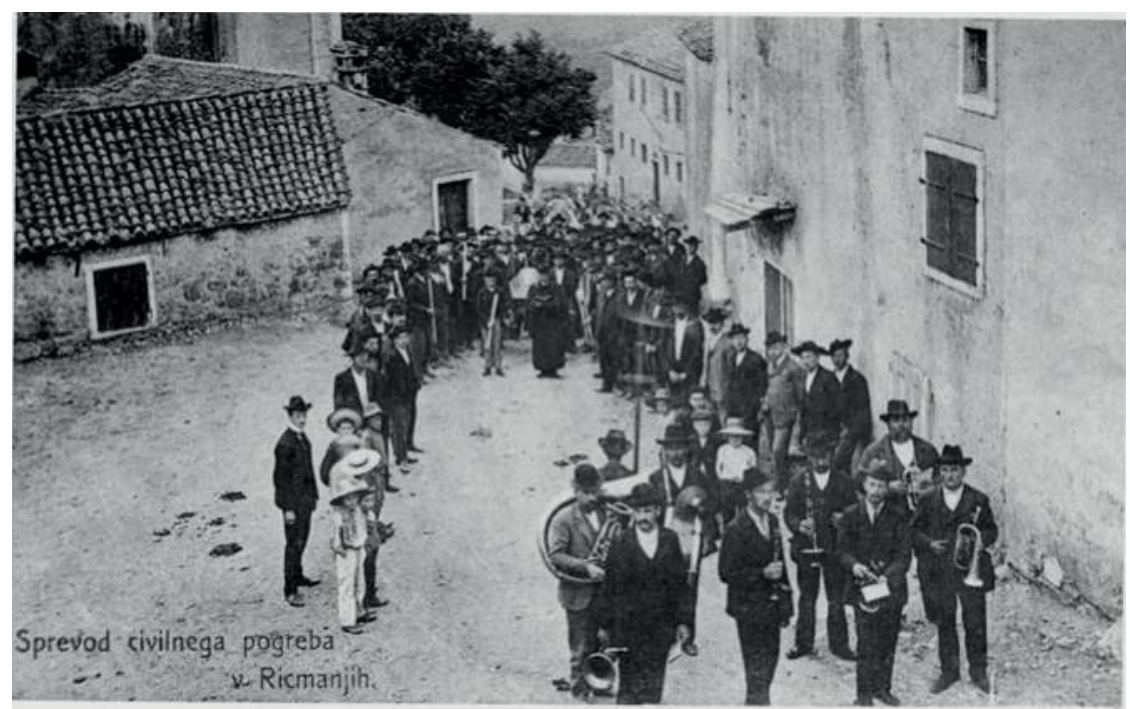

Abbildung 6: Postkarte vom Zivilbegräbnis in Ricmanje (ohne Datum)

xis, in der sich eine eindeutige und performative Ablehnung der Amtskirche zeigt. Dieser Ablehnung lagen allerdings keine säkularen oder freidenkerischen Ansätze zugrunde, da die Dorfbewohner anscheinend die religiösen (das heißt katholische Praxen und Formalitäten nachahmenden) Zeremonien dennoch brauchten. Die Zeremonien waren nicht im säkularen Sinne "zivil«, auch wenn sie sowohl von der Bezirkshauptmannschaft als auch den Dorfbewohnern so benannt wurden. Die »zivilen« Begräbnisse und Taufen lösten die institutionalisierten Formen des religiösen Lebens ab. Ende 1904 berichtete die nationalliberale, slowenischsprachige Tageszeitung aus Triest, Edinost, triumphierend, dass in den letzten zwei Jahren in Ricmanje ca. 30 "zivile« Beerdigungen stattfanden und ca. 70 ungetaufte, uneheliche Kinder geboren wurden - für das Blatt »ein phänomenaler Erfolg «. ${ }^{265}$

Nicht nur die Begräbnisse und Taufen, sondern auch die Ehen wurden nicht mehr kirchlich (das heißt institutionell-kirchlich) begangen. Die örtliche Bezirkshauptmannschaft behauptete sogar, dass der Dorfvorsteher Ivan Berdon den Leuten im Dorf vom Heiraten abgeraten habe. Er habe ihnen ein-

b. 265 , f. 4.1.5, 1903/717. (Über das »Zivile« Begräbnis von Josip Pregarac und Ana Kuret berichtete auch Edinost, 26. März 1903).

265 Edinost, 29. Dezember 1904 [übersetzt aus dem Slowenischen von mir]. 


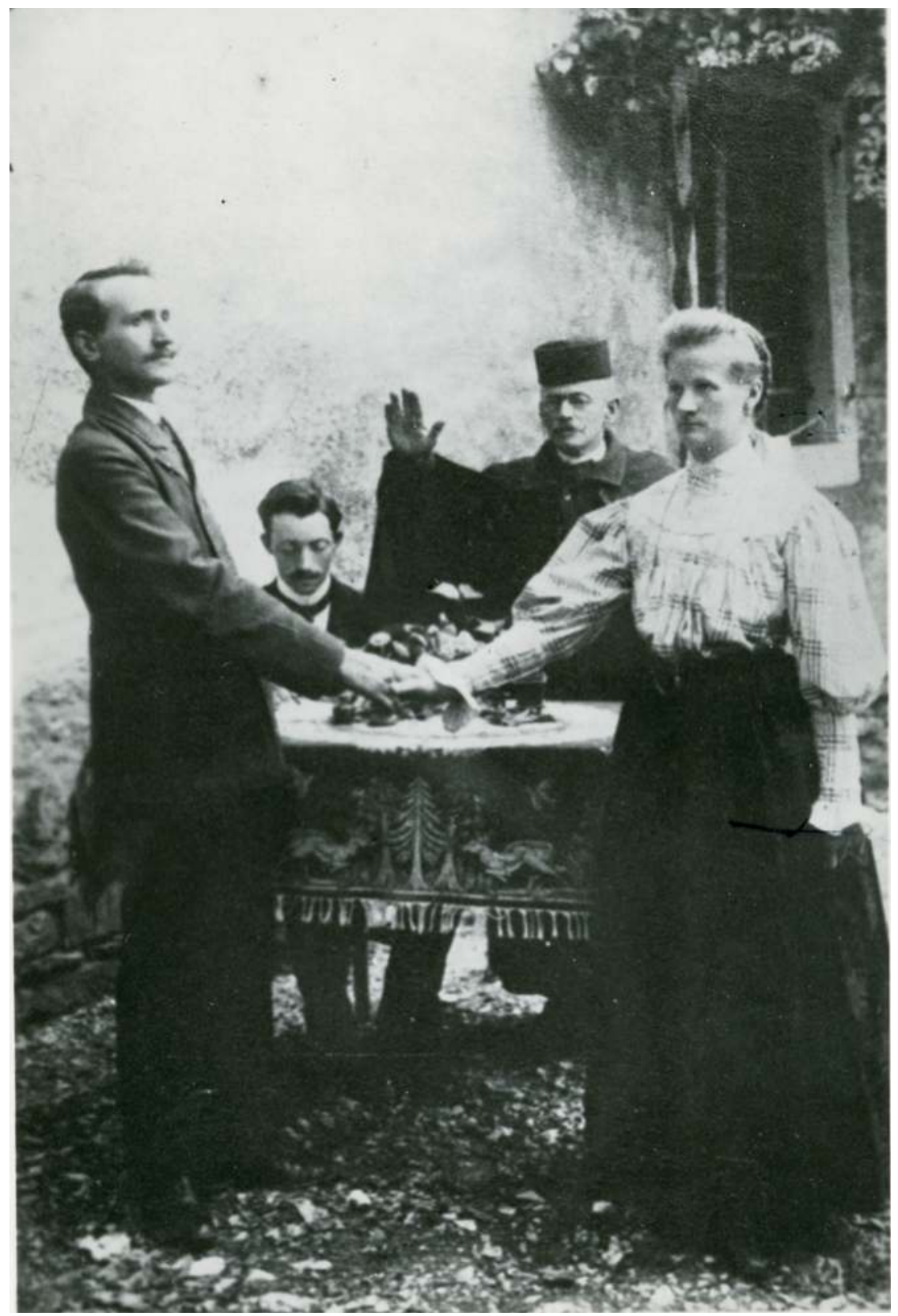

Abbildung 7: Postkarte von einer zivilen Trauung in Ricmanje mit Ivan Berdon, dem Dorfvorsteher (ohne Datum) 
getrichtert: »sie sollen lieber so zusammenleben gehen, als heiraten« ${ }^{266}$ Für die Paare, die dennoch heiraten wollten, führte Berdon - manchmal mithilfe des suspendierten, aber immer noch im Dorf lebenden Dr. Požar - Zeremonien ein, die den katholischen Trauungen ähnelten (siehe Abbildung 7). ${ }^{267}$

Bei einer Beerdigung zu Weihnachten 1905 wies Berdon darauf hin, dass das Dorf seinen Glauben nicht verlassen, sondern in seiner eigenen Muttersprache erleben und praktizieren wolle. Dabei erwähnte er das Beispiel von Jesus Christus, der seine Jünger mit der Anforderung in die Welt geschickt hatte, "allen Völkern in ihren eigenen Sprachen « zu predigen. ${ }^{268}$ Aus diesem Grunde forderte er im Namen des Dorfes das Recht ein, slowenischsprachige Gottesdienste einführen zu dürfen. Die Dorfbewohner wollten die muttersprachlichen Gottesdienste nicht deswegen einführen, um sich nationalistisch gegenüber anderen Völkern (im Sinne eines "Nationalitätenkonfliktes«) abzuschotten, sondern um ihren Glauben sprachlich besser ausdrücken und verstehen zu können. Diese Forderung war aber keine Reaktion - im Sinne von Beibehaltung bestehender Praktiken -, sondern ein bewusstes, proaktives Handeln, mit dem die kirchlichen und weltlichen Obrigkeiten herausgefordert wurden. Der Selbstbehauptungswille zeigte sich auch darin, dass sich Ricmanje - im Gegensatz zum ungarischen Drenova (Kapitel 4.2) - nach außen hin bewusst als rebellisches Dorf inszenierte. Die Zeremonien der «zivilen« Begräbnisse, Taufen oder Trauungen von Ricmanje wurden ab 1907 als Postkartenmotive festgehalten und bewahrt. Das slowenischsprachige, nationalliberale Blatt Slovenski Narod forderte "alle nationalen Händler, alle nationalen Trafiks« auf, diese Postkarten zum Ankauf anzubieten. ${ }^{269}$ Das Blatt bemerkte stolz, dass sogar im russischen Parlament, der Duma, die Abgeordneten diese Postkarten "von Hand zu Hand « gereicht hätten. ${ }^{270}$ Auf einer Postkarte (siehe Abbildung 8) bezeichnete sich Ricmanje als »erste slowenische Gemeinde der heiligen katholischen Kirche griechischen Ritus mit altslawischer Liturgiesprache«. Dazu wurde ein Zitat von Bischof Drohobeczky ausgewählt, in dem er die Dorfbevölkerung beruhigte, »in wahrem katholischen Glauben" geblieben zu sein. Damit wollte er sagen, dass der Übertritt zur griechisch-katholischen Kirche keinen Austritt aus dem Katholizismus bedeute: »Ein Körper, eine Seele... Ein Gott, ein Glauben, ein Christentum.« Eine solche Selbstdarstellung kann wiederum - wie

266 Bericht des Landes-Gendarmarie-Commandos von Boljunec (26. Oktober 1904), in: AST, C.d. Capodistria, Culto, b. 170, fol. 1236.

267 Bericht des Landes-Gendarmarie-Commandos von Boljunec (2. Dezember 1904), in: Ebd., fol. 1233.

268 Slovenski Narod, 30. Dezember 1905 [übersetzt aus dem Slowenischen von mir].

269 Slovenski Narod, 6. November 1907 [übersetzt aus dem Slowenischen von mir].

270 Ebd., 3. November 1907 [übersetzt aus dem Slowenischen von mir]. 


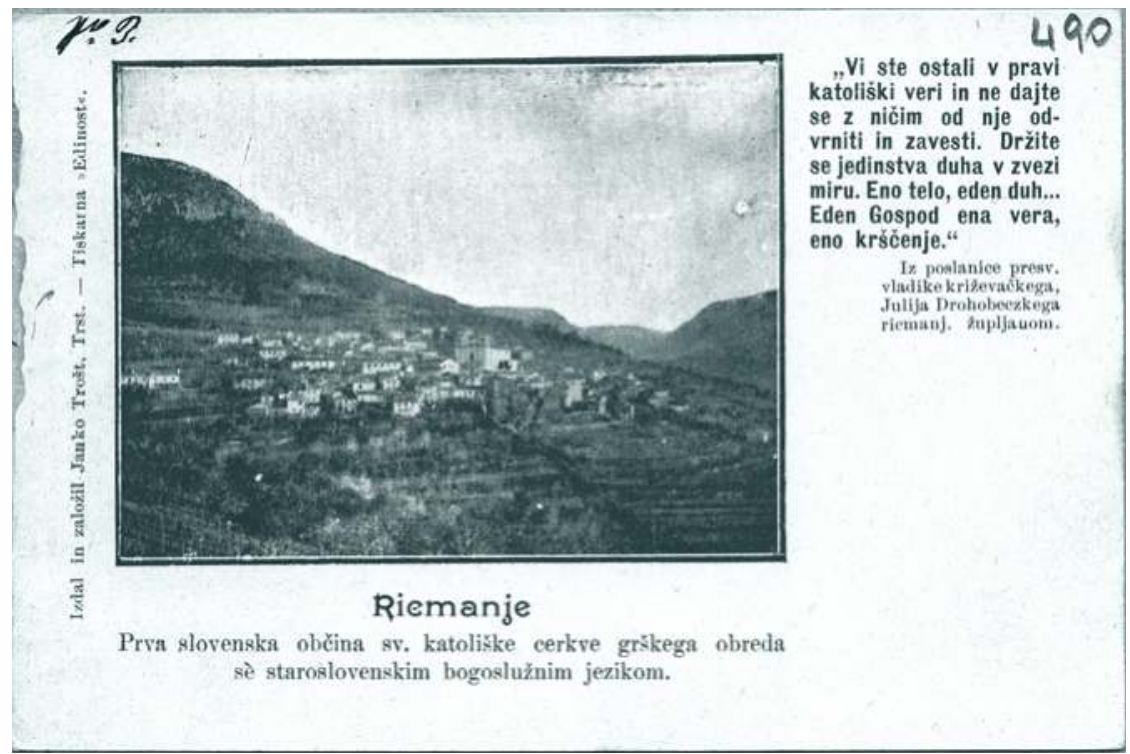

Abbildung 8: Postkarte aus Ricmanje (ohne Datum)

die »zivilen« Zeremonien - einerseits als Provokation gegen die Amtskirche, andererseits als Ausdruck des Wunsches, weiterhin katholisch zu bleiben, verstanden werden.

Den Dorfbewohnern wurde jedoch religiöse Indifferenz und kirchliches Unwissen unterstellt: dass sie nicht gewusst hätten, was sie eigentlich wollten bzw. dass sie willenlos einem rebellischen Priester ausgesetzt seien. Die Bezirkshauptmannschaft beschrieb schon am Anfang der Konfliktgeschichte die Bevölkerung als »in religiösen Dingen ohnehin indifferent ; $^{271}$ der Wiener Nuntius Emidio Taliani berichtete in seinen Briefen an Kardinal Rampolla von der »ignoranten « Dorfbevölkerung; ${ }^{272}$ und die italienischsprachigen, katholischen Blätter aus Triest schrieben über »arme Bauern ohne jegliche Kultur ${ }^{273}$ oder »verblendete, arme Dorfbewohner $«,{ }^{274}$ die unter rus-

271 Bericht der Bezirkshauptmannschaft von Capodistria/Koper an die Statthalterei von Triest (23. August 1900), in: AST, C.d. Capodistria, Culto, b. 170, fol. $493 f$.

272 Brief von Nuntius Taliani an Kardinal Rampolla (1. Dezember 1900), in: AAV, ANV, b. 692 , fol. 282.

273 L' Amico, 25. Januar 1903.

274 La Ricreazione, 16. Februar 1903. 
sischem Einfluss gestanden hätten. ${ }^{275}$ Auch wenn sich die Dorfbewohner in den theologischen und kirchenrechtlichen Differenzen zwischen den katholischen Riten bzw. zwischen dem Katholizismus und der Orthodoxie nicht vollkommen auskannten - diesbezügliches Wissen war beim Wiener Nuntius auch nicht immer vorhanden ${ }^{276}$-, wussten sie, was sie vor Ort erreichen wollten: die muttersprachliche Liturgie und eine eigene Pfarrei.

Die slowenischsprachigen, klerikalen Kreise hatten allerdings Angst vor säkularisierenden Tendenzen. Ihre Zeitung Slovenec behauptete daher hoffnungsvoll, dass mehrere Dorfbewohner weiterhin zur Messe gegangen und die Kinder nach römisch-katholischem Ritus getauft worden seien - in Triest oder anderen, benachbarten Ortschaften, wo die Wortführer von Ricmanje keine Macht mehr besäßen. Im Dorf sei »der Terrorismus noch im Gange« gewesen. ${ }^{277}$ Nicht nur auf den Einfluss von Berdon ließ sich die Eskalation zurückführen, sondern auch auf die Präsenz von Don Požar, der trotz seiner Suspendierung und Absetzung noch eine Weile im Dorf blieb. ${ }^{278}$ Er und seine Anhänger seien sehr geschickt darin gewesen, in einer Situation, in der einige Dorfbewohner zur römisch-katholischen Kirche gern zurückgekehrt wären, »die Leute auf ihre Seite wiederzugewinnen «. ${ }^{279}$ Anfang 1904 berichtete die zuständige Bezirkshauptmannschaft daher mit großer Erleichterung über die angeblich endgültige Abreise von Dr. Požar nach Triest - wo er in der Redaktion der nationalliberalen, slowenischsprachigen Tageszeitung Edinost arbeiten würde -, was eine Wende zuungunsten der »Berdon-Partei« ermöglicht hätte. ${ }^{280}$ Solche Hoffnungen erwiesen sich aber als unbegründet. Der Konflikt schien längst nicht beendet zu sein. Die Gewaltakte gegen den Dorfkaplan Don Krančič setzten sich ebenso fort. Er konnte letztendlich die Zustände in Ricmanje nicht mehr aushalten. Im Juni 1903 wurde er zuerst

275 L’Avvenire, 14. März 1902. Die Zeitung berichtete über den angeblichen Besuch einer russischen Prinzessin in der Gegend.

276 Nuntius Taliani schrieb etwa über den griechisch-katholischen Bischof Drohobeczky als "schismatischen Bischof", obwohl ein griechisch-katholischer Bischof dem Papst unterstellt (und insofern keinesfalls schismatisch) ist; vgl. Brief von Nuntius Taliani an Kardinal Rampolla (1. Dezember 1900), in: AAV, ANV, b. 692, fol. 282.

277 Slovenec, 12. Mai 1903 [übersetzt aus dem Slowenischen von mir].

278 Im Oktober 1903 schien er endgültig nach Triest umzuziehen, aber dann kam er wenige Tage später doch nach Ricmanje zurück. Es stellte sich auch heraus, dass er eigentlich nicht in Triest, sondern in der ungarischen Hafenstadt Fiume/Rijeka war; vgl. Bericht der Bezirkshauptmannschaft von Capodistria / Koper an die Triestiner Statthalterei (17. Oktober 1903), in: AST, Luogotenenza, AP, b. 265, fasc. 4.1.5, $1903 / 2397$

279 Bericht des Landes-Gendarmarie-Commandos von Boljunec [ohne Datum], in: AST, C.d. Capodistria, Culto, b. 170, fol. 657f.

280 Bericht des Landes-Gendarmarie-Commandos von Boljunec (24. Februar 1904), in: Ebd., fol. 474ff. 
für mehrere Monate beurlaubt, dann Anfang 1904 in ein anderes Dorf versetzt. Mehr als ein Jahr lang hatte das Dorf keinen eigenen Kaplan vor Ort. ${ }^{281}$ Erst am Ostersonntag 1905 wurde verkündet, dass Josip Stržinar, der Pfarrer von Cattinara/Katinara, mit der seelsorgerischen Aufgabe in Ricmanje beauftragt werde, ohne dass er in das Dorf umziehen müsse. ${ }^{282}$ Die Wortführer in Ricmanje waren keineswegs zufrieden: 21 Einwohner wandten sich mit einem slowenischsprachigen Protestbrief an Bischof Nagl. ${ }^{283}$ Sie wollten eine eigene Pfarrei, die zum griechisch-katholischen Ritus gehört. Bei der Übernahme der Kirche erschien niemand aus dem Dorf, nur eine schwarze Fahne hing an einem Maulbeerbaum vor der Kirche, mit der slowenischen Anschrift: »Der Pfarrer aus Katinara [Cattinara] ist ein Lump «. ${ }^{284}$ Trotz der allgemeinen Ablehnung zelebrierte Don Stržinar ab Mitte Mai 1905 jeden Sonn- und Feiertag Gottesdienste. Nur aus den umliegenden Ortschaften kamen jedoch einige Menschen in die Kirche von Ricmanje. Während der Gottesdienste mussten die Gendarmen das Dorf besetzen, um die Sicherheit des Kaplans zu gewährleisten.

Der Widerstand zeigte sich jedoch zuerst nicht öffentlich, aber das Kirchengebäude wurde immer wieder heimlich beschädigt: Im Juni 1905 etwa konnte Don Stržinar öfters nicht in die Kirche hinein, weil das Schloss der Kirchentüre mit kleinen Eisenstückchen und Nägeln verstopft worden war. Die Täter konnten nicht gefunden werden, weil - wie die örtliche Bezirkshauptmannschaft traurig feststellte - »keiner in der Ortschaft jemanden verraten tut $\ll{ }^{285}$ Die Bezirkshauptmannschaft erklärte die Ablehnung gegenüber Don Stržinar jedoch nicht mit politischen oder religiösen Gründen, sondern nur mit der Natur des neuen Pfarrers. Er sei »als ein sehr grober und abstossender Geistlicher« »sehr verhasst« gewesen:

281 »Res Ricmanjenses« [ohne Datum], in: Župnijski in dekanijski arhiv Dolina / Archivio parocchiale e decanato di San Dorligo della Valle (Pfarr- und Dekanatsarchiv von Dolina/San Dorligo della Valle; weiter: ŽDAD), Knjige, škatla 49 (Bücher, Box 49; weiter: Knjige 49), Kronika županije 1900-1984 (Chronik der Pfarrei; weiter: Kronika) [keine weitere Nummerierung].

282 Slovenec, 29. April 1905.

283 Protestbrief aus Ricmanje (2. Mai 1905), in: ADT, GO, 1905/1634. Auch an Papst Pius X schrieben sie einen Brief, in dem sie gegen die Errichtung einer römischkatholischen Pfarrei protestierten; vgl. Brief aus Ricmanje an Papst Pius X (10. [12.] Mai 1905), in: ŽAR, Kosmač, fasc. 4 [keine weitere Nummerierung].

284 Bericht der Bezirkshauptmannschaft von Capodistria/Koper (30. Juni 1905), in: AST, Luogotenenza, AG, b. 1263, 1905/20165 [übersetzt aus dem Slowenischen von $\mathrm{mir}]$.

285 Ebd. 
Ich bin daher der Ansicht, dass durch die Ernennung beziehungsweise Anstellung eines eigenen Pfarrers, welcher es verstehen würde in liebenswürdiger, geduldiger und zugleich konzilianter Weise auf die erregten Gemüter einzuwirken, die Ortsbewohner von Ricmanje doch eines Besseren belehrt werden könnten und vielleicht wieder in den Schoss der römisch-katholischen Kirche zurückkehren würden. ${ }^{286}$

Ricmanje wurde inzwischen zu einem religiös/kirchlich neu besetzbaren Raum. Da über den Kirchenstreit in der ganzen Donaumonarchie berichtet wurde, kamen mehrere Agitatoren nach Ricmanje, die das Dorf für protestantische, altkatholische oder orthodoxe Ideen gewinnen wollten. Im Sommer 1905 besuchte etwa der böhmische, protestantische Theologe Anton Chráska, der seit einiger Zeit in Ljubljana/Laibach lebte, das Dorf, um die Bewohner zum Übertritt in eine protestantische Kirche zu überzeugen. ${ }^{287}$ Einige Dorfbewohner trafen sich in Triest im Café Balkan mit einem Gesandten der Prager altkatholischen Gemeinde. 91 Familienväter seien in Ricmanje angeblich bereit gewesen, eine altkatholische Gemeinde - unter der Obhut der Prager Gemeinde - zu gründen. ${ }^{288}$ Nicht nur religiöse Agitatoren entdeckten die Möglichkeit, Ricmanje für ihre Ideen zu gewinnen. Auch antiklerikal-atheistische Kreise wollten den Widerstand für ihre Ziele fruchtbar machen - sie dachten, dass Ricmanje im Kontext des Kulturkampfes gegen die katholische Kirche verortet werden könne. Ein gewisser Emil Frauer wollte im Dorf sogar »ein Zentrum einer antikatholischen Bewegung« ins Leben rufen. ${ }^{289}$ Die Dorfbewohner schienen nicht nur den Katholizismus, sondern allmählich auch die Religiosität abzulehnen. 1906 meldeten sich mehrere von ihnen als konfessionslos an, ${ }^{290}$ womit der Kirchenstreit einen neuen Höhepunkt (oder Tiefpunkt) erreichte. Die Forderung nach einer Pfarrei entwickelte sich immer mehr zu einem Kampf gegen jegliche Abhängigkeiten. Die Dorfgemeinschaft war aber an radikal-säkularen oder freidenkerischen Tendenzen nicht interessiert. Die Abkehr von der Kirche war eine Reaktion und keineswegs das ursprüngliche und eigentliche Hauptziel des dörflichen Widerstandes. Die Dorfbewohner unterschieden insofern zwischen der Amtskirche und dem römisch-katholischen Glauben - dem letzteren wollten sie, solange es möglich war, treu bleiben.

286 Ebd.

287 Bericht des Landes-Gendarmerie-Commando von Boljunec (13. Juli 1905), in: AST, C.d. Capodistria, Culto, b. 170, fol. 1249; sowie Bericht des Landes-GandermarieCommando von Boljunec (15. Juli 1905), in: Ebd., fol. 1247.

288 Bericht des Triestiner Polizei-Präsidiums (30. Dezember 1905), in: Ebd., fol. 1263.

289 Bericht der Triestiner Polizei-Direktion (30. März 1906), in: Ebd., fol. 47.

290 Anmeldungen in: Ebd., fol. 232, 243, 251-356, 374, 382ff., 406, 461ff. 
Im Herbst 1906 erhielt das Dorf einen neuen Priester, der sogar bereit war, aus Triest in das Dorf umzuziehen. Er hieß Jakob Ukmar. Don Ukmar war ein slowenischsprachiger Priester aus Triest, der mit seinen klerikalen, christlich-sozialen, austro-loyalen Ideen den politischen und kirchlichen Zielen von Bischof Nagl sehr nahestand. ${ }^{291}$ Die slowenischsprachige, liberale Tageszeitung Slovenski Narod nannte ihn deswegen kritisch den »erste[n] Klerikaler von Triest und Umgebung «. ${ }^{292}$ Sowohl Bischof Nagl als auch Don Ukmar unterstützten einen Katholizismus, der fähig wäre, sich jenseits der nationalistischen Polarisierungen als eigenständige, supranationale, proösterreichische, soziale Kraft zu behaupten. In der Kirchenpolitik forderten sie daher klerikale Rom-Treue, also eine ultramontane Einstellung, ein. In der Innenpolitik verpflichteten sie sich der Idee eines supranationalen und katholischen Österreichs, in dem nationale und religiöse Identität sowie imperiale Loyalität einander ergänzen und stärken und nicht ausschließen. Don Ukmar wusste, dass die Nationalisierung des Kirchenlebens - wie der Fall in Ricmanje zeigte - die Positionen der römisch-katholischen Kirche letztendlich untergraben würde. Seine Aufgabe als neuer Pfarrer in Ricmanje bestand dementsprechend darin, die aufgewühlte Dorfgemeinschaft zu beruhigen und in die römisch-katholische Kirche "zurückzuholen«. Als slowenischsprachiger und junger Priester, der in die lokalen Verhältnisse nicht verwickelt war, schien er für diese Aufgabe besser aufgestellt zu sein als ältere Geistliche aus der Umgebung.

Don Ukmar trat seine Stelle im November 1906 an. Obwohl er von Anfang an im Dorf skeptisch beäugt wurde, reagierte er entweder mit unerwarteter Freundlichkeit oder gar nicht auf die Provokationen und Schikanen, denen seine Vorgänger ausgesetzt gewesen waren. An seinem ersten Tag Ende November 1906 wurde er vom Dorfvorsteher Ivan Berdon in Ricmanje empfangen. Berdon entschuldigte sich zwar für die schlimmen Zustände der Pfarrerwohnung: »[D]aran ist der verfluchte deutsche Bischof [Nagl] schuld $\ll{ }^{293}$ Er stellte aber sofort klar, dass er gegen die Idee sei, in Ricmanje einen römisch-katholischen Priester zu haben: »Wir brauchen keinen Priester und können ganz ruhig auch so leben und sterben. Schauts diese nicht getauften erwachsenen Kinder. Ich lasse ihn nimmer taufen. So lange ich ein Vater bin, geht er mir nicht in die Kirche... $\aleph^{294}$ Einige Frauen, die dem Dorfvorsteher zugehört hatten, taten kund, dass ihnen die Lage von Don Ukmar

291 Edinost, 25. November 1906.

292 Slovenski Narod, 18. Dezember 1906 [übersetzt aus dem Slowenischen von mir].

293 Zitiert auf Deutsch im Brief von Don Ukmar an Bischof Nagl (25. November 1906), in: ADT, GP, 1906/82 (Don Ukmar fügt in seinem Brief an Bischof Nagl hinzu: »Hier ging ein ganzes Gewitter auf Ihre Exzellenz los ...«).

294 Ebd. 
leidgetan habe: »Ach, der Arme [Don Ukmar] erbarmt uns, er ist ja doch unschuldig an der Sache, aber wir brauchen ihn nicht, wir wünschen nur eine Erledigung unserer Sache, aber selbst dafür ist es jetzt zu spät...« $\aleph^{295}$

Don Ukmar erzählte von einer Frau, die als einzige die Gottesdienste besucht hatte. Wegen der Drohungen ihres Mannes hätte sie sich aber nicht mehr getraut, in die Kirche zu gehen. ${ }^{296}$ Er betonte, dass die Leute nett seien, wenn man sich ihnen annähere. Er verglich deswegen seine Arbeit mit jener eines Missionars, der »die Zivilisation « in ein wildes Dorf bringen solle: »Das sind so Freuden eines Missionärs. Freilich haben die Kinder von europäischer Kultur so viel wie nichts. Er machte einige Wortführer im Dorf für die Lage verantwortlich: „Verführt sind die armen Leute vom Gott abgefallen und werden von einigen gottlosen Anführern in diesem traurigen Zustande gehalten. ${ }^{297}$ Er zitierte einen älteren Dorfbewohner: Drei Viertel der Menschen hätten laut ihm Angst vor einer aggressiven Minderheit. ${ }^{298}$ Don Ukmar schilderte in einem Brief an Bischof Nagl sein Gespräch mit einem Tischler, der in der Priesterwohnung die Fenster reparierte. Als sie auf den Kirchenstreit zu sprechen kamen, bemerkte der Tischler, dass das Dorf in der Frage, ob es römisch-katholisch bleiben wolle oder nicht, sehr gespalten sei: »Jetzt sind unter uns zwei Parteien, und ich weiß nicht, wie das am Ende ausfällt. $^{299}$ Don Ukmar schienen die Dorfbewohner »in der Lage des verlorenen Sohnes zu sein«. Er bemerkte diesbezüglich das zwiespältige Verhältnis vieler Dorfbewohner gegenüber dem Glauben. An den Zeremonien der institutionalisierten Religiosität nahmen sie weiterhin nicht teil; die Gottesdienste waren praktisch von niemandem besucht. Viele Männer seien aber tagsüber für eine kurze Zeit in die Kirche geschlichen, um vor dem Altar kniend zu beten. Don Ukmar schrieb von einem »Katakombenleben $«:^{300}$ Viele Dorfbewohner trauten sich nicht, sich öffentlich zur katholischen Religion zu bekennen, aber sie wollten und konnten der Religiosität nicht komplett entsagen. Don Ukmar beschrieb die Kinder, die ihn auf der Straße mit geballten Fäusten begrüßten: »Ich liebe sie sehr und spreche liebevoll mit ihnen, dann werden sie milder und lächeln über mich«. Er meinte im Allgemeinen, dass die Dorfbewohner mit seinem ruhigen und konzilianten Stil nichts anfangen könnten: »Die Terroristen wissen nicht, was sie mit mir eigentlich machen sollen. Es ergeht ihnen ungefähr so wie der jetzigen französischen Regierung, die der unerwarteten Ruhe und Entschlossenheit der Kirche rat-

295 Ebd.

296 Brief von Don Ukmar an Bischof Nagl (15. Dezember 1906), in: Ebd.

297 Brief von Don Ukmar an Bischof Nagl (25. November 1906), in: Ebd.

298 Eintrag am 21. Dezember 1906 im Annales, in: ŽAR.

299 Zitiert auf Deutsch im Brief von Don Ukmar an Bischof Nagl (6. Dezember 1906), in: ADT, GP, 1906/82.

300 Ebd. 
los gegenübersteht. ${ }^{301}$ Den Widerstand verortete er somit nicht im Narrativ der »Nationalitätenkonflikte", sondern des europaweit (in Frankreich wie angeblich auch im winzigen Ricmanje) zutage tretenden »Kulturkampfes«.

Er interessierte sich für die weiterhin fortgesetzten »zivilen« Begräbnisse. ${ }^{302}$ Als er Mitte Dezember 1906 erfuhr, dass jemand gestorben war, ging er in das Haus, wo er am Bett der gestorbenen Frau betete. Don Ukmar bot dem Ehemann Hilfe an, aber er lehnte den Priester barsch ab: „Wir haben aus unserem Hause schon drei so [also ohne Priester - P. T.] bestattet und werden die da auch so beerdigen, wie es bei uns Sitte ist. Einen Priester brauchen wir nicht. ${ }^{303}$ Don Ukmar begann zwar nicht, mit dem Mann zu diskutieren, aber er akzeptierte die Ablehnung nicht. Zur Überraschung aller tauchte er plötzlich bei der Beerdigung auf: Als Priester angekleidet (mit Stola usw.) gesellte er sich zum Leichenzug. Einige hätten ihn ausgelacht, andere beschimpft. Er war sich jedoch sicher, dass die meisten deswegen stumm auf ihn reagierten, weil sie »voll einer hl. Scheu« gewesen seien. Er ließ sich nicht verjagen und ging mit den ca. 400 Menschen auf den Friedhof, wo die Zeremonie pseudoreligiöse Züge hatte. Don Ukmar nahm daran teil, kniete nieder und betete wie alle anderen. Am Ende trat er sogar nach vorn ans Grab und segnete es. Die Menschen hätten ihm schweigend nur zugeschaut. ${ }^{304}$

Die Bewohner reagierten nicht immer so ruhig auf ihn. Don Ukmar musste physische Gewalt erleben wie die vorherigen Kapläne in Ricmanje ebenso. Im Februar 1907 wurde er etwa von einigen Kindern mit Steinen beworfen, und sie riefen ihm »Weg mit dem Pfarrer« nach. ${ }^{305}$ Noch im selben Frühjahr gab es ähnliche Fälle. ${ }^{306}$ Am 18. März 1907 kamen mehrere Pilger in Ricmanje an, die Dorfkinder strömten währenddessen in die Kirche ein und benahmen sich dort wild. ${ }^{307}$ In der Kirche las Don Ukmar mit drei anderen Priestern eine Messe für die eingetroffenen Pilger. ${ }^{308}$ Einer der Priester wurde im Dorf auf der Straße daraufhin als »Bastard « beschimpft. ${ }^{309}$ Trotz solcher Schikanen genoss Don Ukmar seine »Mission«. Er bat noch im März

301 Brief von Don Ukmar an Bischof Nagl (15. Dezember 1906), in: Ebd.

302 Das erste »zivile« Begräbnis, das Don Ukmar miterlebte, fand am 2. Dezember 1906 statt; vgl. Eintrag am 2. Dezember 1906, in: ŽAR, Annales.

303 Zitiert auf Deutsch im Brief von Don Ukmar an Bischof Nagl (15. Dezember 1906), in: ADT, GP, 1906/82 (zitiert auch im Kirchenbuch; vgl. 12. Dezember 1906, in: ŽAR, Annales).

304 Brief von Don Ukmar an Bischof Nagl (15. Dezember 1906), in: ADT, GP, 1906/82.

305 Eintrag am 19. Februar 1907 im Annales, in: ŽAR [übersetzt aus dem Slowenischen von mir].

306 Einträge am 7. März 1907, 14. März 1907, 21. März 1907, 25. März 1907, 26. März 1907, 11. April 1907, 15. April 1907, in: Ebd.

307 Eintrag am 18. März 1907, in: Ebd.

308 Eintrag am 20. März 1907, in: Ebd.

309 Eintrag am 21. März 1907, in: Ebd. [übersetzt aus dem Slowenischen von mir]. 
1907 Bischof Nagl darum, ihn nicht aus Ricmanje zu entfernen. ${ }^{310}$ Ihm gefiel die Herausforderung, ein feindseliges Dorf zu bekehren. Zu Ostern war die Stimmung im Dorf jedoch so aufgewühlt und feindselig, dass die liberale Zeitung Slovenski Narod sarkastisch bemerkte: »Wir wissen nicht, ob Christus in Ricmanje auferstanden ist, oder nicht. ${ }^{311}$ Kurz danach, Ende April 1907, wechselte Don Ukmar in die Triestiner Innenstadt-Kirche Sant' Antonio vecchio/Sv. Anton stari. ${ }^{312}$ Offiziell blieb er zwar weiterhin Kaplan von Ricmanje, ${ }^{313}$ aber Bischof Nagl wollte ihn nicht mehr dem dortigen feindseligen Zustand aussetzen. Als er das Dorf verließ, sagte ihm der Dorfvorsteher Ivan Berdon, dass »die Menschen Sie nicht so behandelten, wie es sich mit einem Priester gehört«. Berdon habe sich nicht wohl mit der Lage gefühlt, die »leider so« sei. ${ }^{314}$

Nach Don Ukmar blieb das Dorf ohne Priester. Der böhmische Vorsitzende des Prager Freidenkerkongresses, Karl Palent, lobte daraufhin Ricmanje als "Mustergemeinde", "welche bei uns den Mut hatte, mit Rom abzurechnen und welche praktisch die Trennung von Staat und Kirche durchgeführt hat «. ${ }^{315}$ Plötzlich wurde der Konflikt nicht (nur) im Kontext des "Nationalitätenkonfliktes", sondern in jenem des "Kulturkampfes" gesehen. Die Wiener Neue Freie Presse bezeichnete das bäuerliche Ricmanje als »Freidenkergemeinde ${ }^{316}$ Das slowenischsprachige, klerikale Blatt Slovenec warf hingegen den slowenischen nationalistischen Kreisen in Triest vor, Lügen im Dorf zu verbreiten, wo die Bewohner deswegen »ohne Priester, ohne Taufe, ohne Gesetz, ohne den letzten Trost als völlig heidnische Gemeinde« leben würden. ${ }^{317}$

Im Dorf führte der Widerstand zu einer Situation, welche das lokale Leben und die menschlichen Beziehungen, etwa zu den anderen slowenischsprachigen Gemeinden, immer mehr belastete. Das Dorf entfremdete sich nicht nur vom Bistum und der katholischen Religion, sondern auch von seiner slowenischsprachigen Umgebung. Ein konfessionsloses Dorf mag einigen antiklerikalen Zeitungen beispielhaft vorgekommen sein, aber die Katholiken der Umgebung, die alle slowenischsprachig waren, reagierten mit Unverständnis und Empörung auf die Ereignisse in Ricmanje. Daher schaltete sich der kroatischsprachige Reichsratsabgeordnete aus Wien, Matija Laginja, in die Affäre ein: In seinem Brief an das österreichische Kultusministerium forderte er

310 Brief von Don Ukmar an Bischof Nagl (5. März 1907), in: ADT, GP, 1907/14.

311 Slovenski Narod, 20. April 1907 [übersetzt aus dem Slowenischen von mir].

312 Slovenec, 23. April 1907.

313 SimČıč, Jakob Ukmar, S. 52.

314 Eintrag am 29. April 1907 im Annales, in: ŽAR [übersetzt aus dem Slowenischen von $\mathrm{mir}]$.

315 Zitiert in Neue Freie Presse, 28. August 1907.

316 Ebd.

317 Slovenec, 23. September 1907 [übersetzt aus dem Slowenischen von mir]. 
im Sommer 1908 eine rasche Lösung für den Fall: »mehr als Hundert nicht getaufte Kinder christlicher Eltern, Dutzende von Familien ohne gesetzlich eingegangene, somit ungültige Ehen, der Abgang jedweden kirchlichen Unterrichten und religiösen Funktionen im Dorfe. ${ }^{318}$ Der gesellschaftliche Ausnahmezustand in Ricmanje, der sich etwa in der entschlossenen und radikalen Ablehnung der kirchlichen Obrigkeit und in den aufgelockerten Lebensumständen (hohe Zahl unehelicher Kinder, Zusammenleben ohne Heirat usw.) manifestierte, stimmte die Dörfer in der Gegend um. Anscheinend ging die Radikalisierung in Ricmanje für die umliegenden, ebenso slowenischsprachigen Dorfgemeinschaften zu weit. Die Bewohner in Ricmanje bekamen die Isolation immer mehr zu spüren. Die Statthalterei in Triest berichtete im Oktober 1908, dass

der jetzt 8 Jahre währende, ganz exzeptionelle Zustand bei der Bevölkerung Rizmanje’s schliesslich das Bestreben erzeugt hat, in den Schoss der römisch-katholischen Kirche zurückzukehren. Wie ich aus verlässlicher Quelle erfahre [...], ist die Bevölkerung Rizmanje's darüber besorgt, dass der Ort infolge der Ungebundenheit der jeden sittlichen Einflusses entzogenen Jugend immer mehr gemieden wird; dass daher die öffentlichen Lokale sich keines Zuspruches mehr erfreuen; dass mit den als konfessionslos zu betrachtenden Jünglingen und Mädchen des Ortes Niemand aus der Umgebung mehr eine Ehe eingehen will, u. dgl. m. ${ }^{319}$

In der Sache der Liturgiesprache meldete Laginja im Februar 1909, dass diese nach der mündlichen Absprache mit dem Triestiner Bistum »als erledigt $\mathrm{zu}$ betrachten ist «. ${ }^{320}$ Insofern blieb nur die Pfarreifrage zu lösen. Es mussten eine Errichtungsurkunde ausgestellt und die Pfarrerwahl festgelegt und ausgeschrieben werden. Die finanzielle Lage musste, etwa infolge der seit mehreren Jahren nicht mehr entrichteten Zahlungen an die Pfarrei von Dolina, ebenso abgeklärt werden. ${ }^{321}$ Am 29. April 1909 wurde die Pfarreierrichtungs- und Donationsurkunde angenommen. Infolgedessen endete die Verpflichtung der Dorfbewohner in Ricmanje und Log, dem Pfarrer in Dolina weitere Zahlungen leisten zu müssen. Das Patronat über die Kirche übernahm Ricmanje, alle männlichen Pfarrinsassen durften somit an der Pfarrerwahl teilnehmen.

318 Kopie des Briefes von Matija Laginja (28. Juli 1908), in: ADT, GP, 1908/54.

319 Brief des Triestiner Statthalters an das österreichische Kultusministerium (4. Oktober 1908), in: ÖStA, Allgemeines Verwaltungsarchiv (weiter: AVA), Unterricht und Kultus: Katholischer Kultus (weiter: KK), 455: Pfarren im Küstenland: R (weiter: 455, R), 455.3 Signatur 42: Ri - Rizmanje (weiter: 455.3, 42: Ri).

320 Erklärung von Matija Laginja, beigefügt der Ricmanje-Akte (11. Februar 1909), in: Ebd.

321 Brief des Triestiner Statthalters an das Bistum von Triest (9. November 1909), in: ADT, GP, 1908/54. 
Bezüglich der Liturgiesprache stellte das österreichische Kultusministerium fest, dass es sich um eine innerkirchliche Angelegenheit handele: In diesem Sinne wurde Ricmanje "prinzipiell als zum lateinischen Ritus gehörig« anerkannt, in dem die Sprache der Liturgie gemäß den Vorschriften des Hl. Stuhls festzustellen sei. ${ }^{322}$ Das Bistum stimmte diesbezüglich schon vorher den Vorschlägen von Matija Laginja zu, nach denen »in der Pfarrkirche von Ricmanje die lateinische als liturgische Sprache zu gelten hat", auch wenn die slawische Sprache ebenso seinen Platz in der Liturgie haben dürfe. ${ }^{323}$ Der Hl. Stuhl verfolgte nicht mehr wie noch unter Leo XIII eine südslawophile Linie, sondern setzte immer mehr das fast ausnahmslose Primat des lateinischen Usus durch. ${ }^{324}$ Wien erkannte aber die heikle Situation im Bistum von Triest, wo sich ein innerkatholischer Frieden - wie es der Fall von Ricmanje bewies - nicht mit einem strikten Verbot, sondern nur mit einem geduldigeren Vorgehen aufrechterhalten ließ. Daher bat der österreichische Kultusminister - auch hinsichtlich des Kompromisses von Ricmanje - den Hl. Stuhl und das Triestiner Bistum um »die Notwendigkeit eines vorsichtigen Vorgehens «. ${ }^{325}$

Bischof Nagl wechselte zum 1. Januar 1910 als Koadjutor des Erzbischofs nach Wien. ${ }^{326}$ Ein Jahr lang konnten sich Wien und der Hl. Stuhl auf keinen neuen Bischof verständigen; auch die heikle Nationalitätsfrage musste in Betracht gezogen werden. Wien und der Hl. Stuhl unterstützten eher einen südslawischen Kandidaten. ${ }^{327}$ Der neue, slowenischsprachige Bischof, Andrej Karlin, trat seine Stelle in der Adriametropole im Februar 1911 an. Er folgte nicht der aktiven, klerikal-politischen Linie seines Vorgängers. Bischof Karlin wollte die Kirche nicht mehr als klerikale Akteurin im öffentlichen, politischen Leben positionieren. Er begnügte sich damit, sich auf das religiöse, pastorale Leben, das heißt die Förderung der religiösen Frömmigkeit, zu konzentrieren, und lehnte infolgedessen jegliche politischen Aktionen ab. ${ }^{328}$

Ab dem Frühjahr 1909 war Ricmanje - diesmal auch kirchenrechtlich vollständig - eine eigene Pfarrei. Es stellte sich nunmehr die Frage, wer als Pfarrer in das rebellische Dorf gehen sollte. Don Ukmar wäre gern in das

322 Regelung der Pfarrverhältnisse in Ricmanje (5. Mai 1909), in: ÖStA, AVA, KK, 455, R, 455.3, 42: Ri.

323 Brief von Dr. Laginja an den Bischof von Triest (23. Juli 1908), in: ADT, GP, 1908/54.

324 Über das Dekret von 1906, mit dem der Usus der altslawischen Liturgiesprache praktisch eingedämmt wurde, siehe u. a. Gottsmann, Rom und die nationalen Katholizismen, S. 73ff.

325 Brief des österreichischen Kultusministers an die Triestiner Statthalterei (21. März 1910), in: AST, Luogotenenza, AP ris., b. 6, fasc. 34, 1910/6.

326 Mitteilung des österreichischen Kultusministers an die Triestiner Statthalterei (3. Januar 1910), in: Ebd.

327 Brief des österreichischen Kultusministers an die Triestiner Statthalterei (30. Oktober 1910), in: Ebd.

328 Valdevit, Chiesa e lotte nazionali, S. 239f. 
Dorf zurückgekehrt, die Dorfbewohner stimmten jedoch für einen anderen Kandidaten, einen gewissen Frančišek Jedrejčič. ${ }^{329}$ Er blieb nach seiner Ernennung im Februar $1910^{330}$ nur kurz im Dorf. Im September 1910 wurde Ivan Zega zum neuen Pfarrer ernannt. ${ }^{331}$ Mit ihm zeigte sich die slowenischsprachige, nationalistische Presse zufrieden: Die nationalliberale Edinost sprach im Winter 1910 sogar davon, dass Don Zega im Dorf »Wunder« bewirkt habe. ${ }^{332}$ Damit waren neue Kommunionen und Taufen gemeint. Am 20. November 1910 fand eine große Kirchenfeier mit Gottesdienst in Ricmanje statt, wo 46 Menschen - als Zeichen der Aussöhnung zwischen dem Dorf und der römisch-katholischen Kirche - vom Erzbischof aus Görz, Frančišek Borgia Sedej, getauft wurden. ${ }^{333}$ Auf einmal schien der zehnjährige Konflikt beendet zu sein - zumindest für die große Politik und die kirchliche wie imperiale Öffentlichkeit.

Über Pfarrer Zega, der im Herbst 1910 die neu gegründete Dorfpfarrei übernommen hatte, wurde später berichtet, dass er seit dem Frühjahr 1912 zur lateinischen Liturgiesprache zurückgekehrt sei. Im April 1912 kam es daher erneut zu einem direkten Konflikt mit der Kirchengemeinde: In einer Messe, die Don Zega in lateinischer Sprache sang, antwortete ihm der Chor in slowenischer Sprache. Nachdem der Pfarrer daraufhin als Rache stille Messen eingeführt hatte, besuchten viele Dorfbewohner die Kirche nicht mehr. ${ }^{34}$ Im Februar 1915 räumte Bischof Karlin ein, dass »die Hartnäckigkeit» der Dorfbewohner keinesfalls nachgelassen habe. ${ }^{335}$ Das Dorf lehnte auch den nächsten Pfarrer, Don Križman, ab, der auf Don Zega folgte. Gleichzeitig entstand ein Konflikt zwischen dem alten Pfarrer Don Zega und dem Bistum. Don Zega war mit seiner Absetzung nicht einverstanden, und hetzte daher das Dorf gegen das Bistum auf. Dabei unterstützte ihn der örtliche Pfarradministrator, der wegen der bischöflichen Kritik »über seine Lebensweise punkto Trinkens « beleidigt und aufgebracht gewesen sei. ${ }^{336}$ Neben der Liturgiesprache sorgten die moralischen Predigten des neuen Pfarrers, Don Križman, für Empörung im Dorf. Die Moralvorstellungen von Don Križman entsprachen keinesfalls der gelebten Lebensweise der Dorfbewohner. Nach einer Predigt, in welcher der Pfarrer die Frauen von Ricmanje wegen ihrer zu

329 SiмČič, Jakob Ukmar, S. 53.

330 Zur Ernennung siehe Slovenec, 19. Februar 1910.

331 Edinost, 17. September 1910.

332 Ebd., 18. November 1910 [übersetzt aus dem Slowenischen von mir].

333 Slovenski Narod, 22. November 1910.

334 Bericht des Landes-Gendarmarie-Commandos von Boljunec (26. Mai 1912), in: AST, Luogotenenza, AP, b. 370, fasc. 19b, 1912/1076.

335 Brief des Bischofs (26. Februar 1915), in: AST, C.d. Capodistria, Culto, b. 170, 1915/4430 [übersetzt aus dem Italienischen von mir].

336 Bericht der Bezirkshauptmannschaft von Capodistria/Koper an den Bischof Karlin (13. März 1915), in: ADT, GP, 1915/18. 
engen Röcke anprangerte, blieben viele Dorfbewohner der Kirche fern. Die örtliche Bezirkshauptmannschaft bemerkte dabei, dass jede erzkonservative, die Sexualmoral betreffende Predigt »bei verrohtem Volke«, »bei der lockeren Moralität in Ricmanje« als Angriff empfunden werde. ${ }^{337}$

Auf der lokalen Ebene war die Stimmung weiterhin in der Kirchengemeinde zwischen den Menschen und ihren Priestern schlecht - nur das makropolitische Interesse ließ nach. Die Konflikte nach 1910/1911 erreichten nicht die gleiche Aufmerksamkeit wie die Konfliktgeschichte davor, als sich die lokale Angelegenheit in kirchen- und nationalpolitische Makrodiskurse einbetten ließen.

\subsubsection{Konfliktanalyse: Situative Identifizierungen auf mehreren Konfliktebenen}

Nach der Darlegung der Konfliktgeschichte in Ricmanje, versuche ich im folgenden Unterkapitel, die unterschiedlichen Konfliktebenen jenseits der öffentlichen Wahrnehmung und Inszenierung des Konfliktes herauszuarbeiten. Dabei steht die Frage im Mittelpunkt, wogegen sich die Ereignisse im Dorf richteten.

Der Konflikt in Ricmanje dauerte mehr als zehn Jahre - zumindest stand das Dorf so lange im medialen Rampenlicht des öffentlichen Interesses. Viele Erzählungen fokussierten dabei auf ein einziges Konfliktmoment: die Forderung nach muttersprachlichen Gottesdiensten. Herausgerissen aus ihrem lokalen Kontext wurde diese Forderung für die starre These eines nationalpolitisch gespaltenen Kirchenlebens herangezogen. Dabei wurde sogar behauptet, dass Ricmanje gegen eine angebliche »Italianisierung « des Kirchenlebens Widerstand geleistet habe. Der böhmische Priester und Publizist, Rudolf Vrba, meinte 1903 etwa, dass »[d]er Name »Ricmanje« sich allmälig als Fachbezeichnung für den Widerstand gegen die Italianisierung der katholischen Kirche im Küstenlande ein[bürgert]. (338 $^{338}$ Vrba projizierte nationale Gegensätze (und damit nationale Kategorien) in den Konflikt hinein, die objektiv in einem homogen slowenischsprachigen Dorf nicht vorhanden waren und sein konnten. Diese Darstellung war aber typisch auf der makrogeschichtlichen Ebene: Ricmanje galt in diesen Diskursen als Beispiel für eine angeblich national-ethnisch gespaltene katholische Kirche auf der lokalen Ebene. Zwischen 1900 und 1910 war der Name des Dorfes nicht nur in den größeren österreichischen und ungarischen Blättern, sondern auch in diplomati-

337 Ebd.

338 Rudolf Vrba, Oesterreichs Bedränger. Die Los-von-Rom Bewegung. Studien über politische, religiöse und sociale Zustände der Gegenwart, Prag 1903, S. 395. 
schen Korrespondenzen zwischen Wien und dem Hl. Stuhl zu lesen. Mit den weniger als tausend Einwohnern, von denen viele die Abhängigkeit von einer anderen Pfarrei und die Zahlungen an den dortigen Pfarrer nicht mehr hatten erdulden wollen und daher ihren Austritt aus der römisch-katholischen Kirche erklärten, beschäftigte sich also auch die »hohe Politik«. Weil sich das Dorf in der Nähe des nationalpolitisch umkämpften Triest befand, geriet der lokale Wunsch, sich gegenüber der örtlichen, ebenso slowenischsprachigen Pfarrei behaupten zu können, in einen nationalpolitischen Kontext. Ricmanje wurde dadurch zu einem Inbegriff des nationalen Widerstandes. Immer wieder wurde das Dorf in diesem Sinne als drohende Gefahr heraufbeschwört. Ein Beispiel dafür: Nachdem Papst Pius X Ende Dezember 1906 mit einem Dekret die früheren Zugeständnisse an die altslawische Liturgiesprache praktisch im ganzen oberadriatischen Raum beseitigt hatte, formulierte ein Brief, der Anfang 1907 aus der dalmatinischen Landeshauptstadt Zara/Zadar das österreichische Außenministerium erreichte, die folgende Drohung: »[Dieses Attentat auf unser Heiligthum] könnte, wie ich befürchte, schwere Folgen für Rom und Wien haben. Es könnte ganz Dalmatien in Ricmanje verwandeln. ${ }^{339}$ Ein einfacher Hinweis auf den Dorfnamen genügte, den makrogeschichtlichen Kontext der "Nationalitätenfrage», besonders bezüglich der katholischen Kirche, zu aktivieren.

Ricmanje und seine Geschichte lassen sich aber nicht aus einem einzigen, sogar entkontextualisierten Konfliktmoment wie etwa der Forderung nach muttersprachlichen Gottesdiensten verstehen. Wie sich die Dorfbewohner verorteten, kann nicht anhand äußerlicher Zuschreibungen beantwortet werden - sondern nur aus der Komplexität verschiedener Momente, in denen der Wille, sich zu behaupten, zum Ausdruck kam. Dieser Wille formulierte sich nicht entlang dem nationalen Gegensatz zwischen »Slowenen« und Italienern«. Einerseits war die lokale Forderung nach muttersprachlichen Messen eher pragmatisch motiviert: Nicht eine »nationale« »Zugehörigkeit«, sondern die territorial-lokale Selbstverortung drückte sich darin aus. Die Loslösung von einer anderen slowenischsprachigen Pfarrei sowie der Wunsch, die katholischen Messen statt in einer toten Sprache (wie der lateinischen) in der eigenen slowenischen Muttersprache beten und singen zu können, waren keineswegs nationalistisch motivierte Forderungen.

Im ländlichen Kampf um die Sprache fehlte andererseits der konkrete "nationale« Gegner. Es ist der zweite Grund, warum Ricmanje nicht als Teil des »Nationalitätenkonfliktes« zu betrachten ist. Die Frontlinien bezüglich und innerhalb des Kirchenstreites in Ricmanje verliefen nicht zwischen den

339 Brief aus Zara/Zadar (24. Februar 1907) [ohne Hinweis auf Autor], in: ÖStA, HHStA, PA XI 261, Slawische Liturgie V/7, fol. 43 [übersetzt in deutscher Sprache vom Außenministerium]. 
»Italienern « und den »Slowenen « - sondern unter den »Slowenen«, die unterschiedliche kirchenpolitische Ansichten hatten. Was als "Nationalitätenkonflikt« bekannt ist, waren oft eher intraethnische Konflikte, in denen um die Deutungshoheit über den eigenen "nationalen" »Raum«, aber nicht gegen eine andere Nationalität, gerungen wurde. ${ }^{340}$ Der Widerstand in Ricmanje erfreute sich dementsprechend - trotz des nationalistischen Diskurses, der den Fall für den Kampf des ganzen "Slowenentums« beanspruchte - keiner einheitlichen Unterstützung und Sympathie in der slowenischsprachigen Öffentlichkeit Österreichs. Das slowenischsprachige, klerikale Blatt Slovenec hielt den Dorfbewohnern vor, dass $» H 1$. Kyrill und Method mit solchen »Unierten « [Griechisch-Katholiken - P. T.] kaum zufrieden wären «. ${ }^{341}$ Die christlich-soziale Slowenische Volkspartei (»Slovenska Ljudska Stranka») nannte die Vorfälle in Ricmanje sogar eine "Schande des ganzen slowenischen Volkes «. ${ }^{342}$ Die slowenischsprachigen klerikalen Kreise erkannten darin die Gefahr, dass die nationalpolitische Instrumentalisierung der Sprachenfrage die Bande der slowenischsprachigen ländlichen Bevölkerung mit der katholischen Kirche lockern könne.

Der Fall in Ricmanje lässt sich aus den folgenden zwei Gründen nicht als "Nationalitätenkonflikt» begreifen: Die Sprachenfrage stellte eine lokale und keine nationalpolitische Forderung seitens der Dorfbevölkerung dar, und selbst die slowenischsprachige Öffentlichkeit war - zwischen nationalliberalen und klerikalen Kreisen - gespalten. Die lokalen Gegebenheiten in Ricmanje erhielten dennoch mittels eines nationalistischen Vokabulars neue Bedeutungen. So entstand das Bild eines slowenischsprachigen Dorfes, das sich im Interesse ihrer Nationalität und Sprache der katholischen Kirche und einer »italienisch" dominierten Öffentlichkeit widersetzte.

Vier Ebenen/Momente asymmetrischer Konflikte zeichneten sich in Ricmanje ab: gegenüber der Pfarrei, dem Bistum, der römisch-katholischen Kirche und der institutionalisierten Religiosität. Im Grunde ging es in allen vier Konfliktebenen und -momenten um die aktive Selbstbehauptung eines kleinen Dorfes innerhalb des kirchlichen Raumes. Dabei wurde Ricmanje von außen her immer wieder unterschiedlich - weil nur punktuell - wahrgenommen: Mal als ein trotziges Dorf (gegen die Pfarrei in Dolina), mal als ein slowenisch-nationalistisches Dorf (gegen das Bistum), mal als ein religiös non-konformes Dorf (gegen die Kirche), mal als ein unreligiöses Dorf (gegen die Religiosität).

Auf den vier Konfliktebenen handelten die Dorfbewohner - zwar für dasselbe Ziel (die Selbstbehauptung), aber - mit unterschiedlichen Mitteln und

340 Judson, Guardians of the Nation, S. 68.

341 Slovenec, 27. März 1903 [übersetzt aus dem Slowenischen von mir].

342 Ebd., 27. September 1907 [übersetzt aus dem Slowenischen von mir]. 
Feindbildern: (1) Im Konflikt mit der örtlichen Pfarrei ging es um soziale und wirtschaftliche Abhängigkeiten: Ricmanje war kirchenrechtlich Dolina, einem anderen Dorf, unterstellt, und die Dorfbewohner hatten dem dortigen Pfarrer hohe Beiträge zu erbringen. Sie forderten eine eigene Pfarrei, um die wirtschaftlich belastende Abhängigkeit beenden zu können. Die Zugehörigkeit zur Pfarrei von Dolina war allerdings nicht nur wirtschaftlich schädlich. Es war auch hinsichtlich des Selbstwertgefühls des Dorfes als Gemeinschaft problematisch. Ricmanje war ein Pilgerort mit einer großen, bedeutenden Kirche, dennoch war das Dorf einem anderen Ort unterstellt. (2) Im Konflikt mit dem Bistum stand die Sprachenfrage im Fokus, was dem Fall eine nationalpolitische "Sichtbarkeit» verlieh. Auch wenn es sich bei der Sprachenfrage um eine pragmatische Forderung handelte, wurde sie im Kontext der "Nationalitätenkonflikte» artikuliert. Das Vokabular der »Nationalitätenkonflikte«, die Verwendung nationalistischer Sprache, ermöglichte vielen Konfliktfällen auf dem Land eine breitere öffentliche Wahrnehmung. (3) Weil das Bistum die lokalen Ansprüche sowohl in der Liturgiesprachen- als auch in der Pfarreifrage ablehnte, entfremdeten sich die Bewohner immer mehr von der römisch-katholischen Kirche als Institution. Daher kündigten sie ihren Übertritt zum griechischen Katholizismus an. Da dieser Übertritt seitens der katholischen Hierarchie nicht erlaubt wurde, versuchten die Dorfbewohner, in die serbisch-orthodoxe Kirche überzutreten. Wegen den Übertritten (oder besser gesagt: wegen den Übertrittsversuchen) konnte das Dorf als unkatholisches Dorf dargestellt werden, das seinen Glauben verlassen würde. Dem Übertrittswunsch lag aber keine Kritik am katholischen Glauben zugrunde, sondern nur der Wunsch, eine eigene Pfarrei zu bekommen und die Gottesdienste im Slowenischen zelebrieren zu können. (4) Weil den Dorfbewohnern ihre Forderungen innerhalb der institutionalisierten Religion verweigert wurden, entstand ein Konflikt zwischen ihrer sprachlichen und religiösen Zugehörigkeit: Es stellte sich die Frage, welchem Inhalt sie größere Bedeutung beimaßen. ${ }^{343}$ Die Dorfbewohner hoben diese Frage insofern dialektisch auf, als dass sie ihre Sprache in einer privatisierten und entkirchlichten Religiosität weiterhin erleben konnten und wollten - wie die Akte priesterlos begangener, pseudo-religiöser Zeremonien zeigten. In diesem Sinne spricht Thomas Luckmann von einer "unsichtbaren Religion", welche keines institutionalisierten Rahmens bedürfe. ${ }^{344}$

343 Über den Bedeutungszuwachs der Sprache gegenüber der privatisierbaren Religion siehe u. a. Brubaker, Language, Religion, and the Politics of Difference, S. 99.

344 Über die Problematik der Gleichsetzung von Entkirchlichung und Unreligiosität sowie von Entkirchlichung und Sekularität siehe Thomas Luckmann, The Invisible Religion. The Problem of Religion in Modern Society, New York/London 1967, S. $22 \mathrm{f}$. 
Die Konfliktebenen folgten in gewisser Hinsicht chronologisch und dynamisch aufeinander: Je weniger Gehör die ursprünglichen, pragmatisch und territorial bestimmten Forderungen fanden, desto mehr entfremdete sich das Dorf von seiner Kirche. Auf den einzelnen Konfliktebenen kamen immer neue Abhängigkeiten zum Vordergrund, die durch den Widerstand infrage gestellt wurden - insofern zeichnete sich letztendlich eine multiple Unterdrückungsmatrix ab, welcher sich die Dorfbewohner entzogen.

\subsubsection{Historischer Kontext: Lokaler Widerstand gegen kirchliche Vereinheitlichung}

Die Geschichte vom Kirchenstreit war von zwei starken Persönlichkeiten geprägt: dem Dorfkaplan Dr. Anton Požar und dem Triestiner Bischof Franz Xaver Nagl. In der Person von Nagl traf Don Požar auf einen Gegenpart, der den Konflikt um die Liturgiesprache nicht verschweigen, sondern selbstbewusst angehen wollte. Ihr konfliktbeladenes Verhältnis lässt sich nicht mit persönlichen Motiven erklären: Sie kannten einander vorher nicht. Sie standen aber innerhalb der Kirche für zwei Wege, welche dem Konflikt eine makropolitische Bedeutung verliehen bzw. zugleich die zwei radikalen Gegenpositionen innerhalb der römisch-katholischen Kirche vertraten: Entweder beharrten die kirchlichen Akteure auf einer supranationalen-universalen Position (wie etwa Bischof Nagl), oder sie verschrieben sich nationalistischpartikularen Zielen (wie etwa Don Požar). Mit Bischof Nagl »betrat« also der Klerikalismus - ein anderes modernes Phänomen nebst dem Nationalismus $^{345}$ - die Bühne von Ricmanje. Die Ideen von Bischof Nagl entsprachen der Linie des neuen Papstes Pius X, der von der südslawenfreundlichen Voreingenommenheit seines Vorgängers Leo XIII zurückruderte. ${ }^{346}$ Pius X vertrat eine viel strengere Linie gegenüber jeglichen lokalen, normabweichenden Realitäten, ${ }^{347}$ insofern verstärkte sich die Politik des Hl. Stuhls gegen die altslawische Liturgiesprache, ${ }^{348}$ die nur noch in begrenzten Fällen zugelassen werden durfte. Der Konflikt in Ricmanje fing unter Leo XIII an, aber die Lage eskalierte unter den neuen Richtlinien, die sowohl der neue Papst

345 Über den ultramontanen Klerikalismus als modernes, transnationales Phänomen siehe u.a. Christopher Clark, The European Culture Wars, in: Clark/KaISER (Hg.), Culture Wars, S. 1-10, hier S. 3ff.

346 VALDEvit, Chiesa e lotte nazionali, S. $215 f$.

347 Siehe dazu u. a. Gottsmann, Rom und die nationalen Katholizismen, S. 73ff.

348 Deswegen begrüßte die nationalliberale, italienischsprachige Presse Istriens den neuen Papst, siehe u. a. L' Istria, 15. August 1903. 
als auch der neue Bischof in Triest vorgaben: mehr Disziplin auf der lokalen Ebene und unter dem Klerus, Beseitigung der lokalen Partikularitäten, keine Voreingenommenheit gegenüber katholischen Südslawen.

Der Konflikt in Ricmanje entstand nicht von selbst - er wurde von Don Požar in Gang gesetzt, der in der pragmatisch bestimmten und lokal-partikular verwurzelten Sprachenfrage das Potenzial eines nationalpolitisch instrumentalisierbaren Streites erblickte. Mehreren Berichten ist zu entnehmen, dass die slowenische Sprache in der Kirche von Ricmanje wahrscheinlich schon früher praktiziert worden ist. Diese illegale Praxis wurde im Interesse des innerkirchlichen Friedens kirchlicherseits toleriert. Die früheren Bischöfe von Triest wie Glavina und Šterk verkündeten nicht einmal die päpstlichen Vorschriften bezüglich der Begrenzung altslawischer, geschweige denn volkssprachlicher Liturgiepraxis, weil sie einen solchen Konflikt befürchteten, der später in Ricmanje aufflammte. Don Požar versuchte, diese stillschweigende Praxis öffentlich zu machen, um somit einen Konflikt mit der kirchlichen Obrigkeit anzustacheln. Indem Nagl hart dagegen durchgriff, traf Don Požar auf einen Gegenpart, der fähig und willens war, den Konflikt öffentlich auszutragen. Während die früheren Bischöfe die normabweichenden Partikularitäten stillschweigend geduldet hatten, griff Bischof Nagl dagegen härter durch. In diesem Sinne verurteilte er alle nationalisierenden Tendenzen.

Der kirchliche Wunsch unter Bischof Nagl, einheitliche Struktur und Praxis auf der lokalen Ebene, etwa in Ricmanje, durchzusetzen, kann im Kontext der »Klerikalisierung « verstanden werden: In Europa etablierte sich ein neues kirchliches Selbstverständnis. Dazu gehörte die Vereinheitlichung der kirchlichen Strukturen, Formen, Riten und Inhalte. Die Kirche konnte sich als eigenständiger Akteur behaupten, wenn sie sich von nationalen, partikularen Interessen sowie abweichenden Praxen loslöste. Die Klerikalisierung zielte - wie Urs Altermatt und Franziska Metzger zusammenfassen - auf die Hierarchisierung und Homogenisierung des Kirchenlebens ab. ${ }^{349}$ Eigensinnige Lebenswege und Lebensweisen wurden daher immer weniger toleriert. Gehorsamkeit gegenüber der Kirchenhierarchie und eine Vereinheitlichung des Kirchenlebens wurden immer stärker eingefordert. Wie Metzger betont, vereinheitliche die katholische Kirche überall in Europa die bisherige heterogene "Frömmigkeitskultur«. Sie versteht es als "Ultramontanisierung" des Kirchenlebens, die eine elitäre, "von oben her« betriebene, erzwungene

349 Urs Altermatt / Franziska Metzger, Religious Institutes as a Factor of Catholic Communities of Communication, in: Jan De Maeyer/dies. (Hg.), Religious Institutes and Catholic Culture in 19th- and 20th-Century Europe, Leuven 2014, S. 11-20, hier S. $16 f$. 
Homogenisierung der kirchlichen Praxen, Ritualen und Symbole bedeute. ${ }^{350}$ Diese Tendenz manifestierte sich meistens supra- und transnational, indem die katholische Kirche über die nationalen Partikularismen hinweg eine gewisse Homogenität etablierte. Mittels einer hierarchisierten Kirchenstruktur und eines homogenisierten, transnational standardisierten Kirchenlebens (vom Vereinsleben bis hin zu den Riten) konnte sich die Kirche gleichzeitig den nationalistischen Hegemonieansprüchen entziehen.

Bischof Nagl vertrat die Idee, der katholischen Kirche ein einheitlicheres, selbstbewussteres »Erscheinungsbild« zu verpassen. Dieses Ziel ermöglichte die "Professionalisierung der Religion": Abweichende, heterogene Praktiken wurden nicht mehr zugelassen. ${ }^{351}$ Dies ging mit einer Symbolkontrolle einher. ${ }^{352}$ Das Verbot muttersprachlicher Liturgien sowie anderer partikularen Formen einer lokalen Frömmigkeitskultur diente also der Verstärkung kirchlicher Kontrolle über die Inhalte, Formen und Modi der katholischen Religionsausübung. Die katholische Kirche erhob mit der Vereinheitlichung der Liturgiesprache - ob entlang der lateinischen oder der altslawischen Sprache, ist hier nebensächlich ${ }^{353}$ - einen Deutungshoheitsanspruch bezüglich der Symbole und ihrer Bedeutungen. Die Kirchenhierarchie wollte ihre Deutungshoheit über den kirchlichen Raum wiederherstellen, indem sie alle normabweichenden Partikularismen verbot. Die Deutungshoheit wollte die Kirche - im Sinne eines straffer strukturierten und hierarchisierten Kirchenlebens - weder den nationalistischen Agitatoren noch den lokalen Akteuren überlassen. Bischof Nagl forderte daher mehr Disziplin vom Klerus und von den Kirchgängern ein: Diese Forderung richtete sich aber nicht nur gegen die nationalistischen Tendenzen, sondern auch jegliche Partikularitäten des örtlichen Kirchenlebens.

Die Kirche entfremdete sich dadurch aber von der lokalen Ebene. Je ungleicher die religiös-institutionelle Repräsentation ist, desto mehr besteht die Möglichkeit einer religiösen Entfremdung. ${ }^{354}$ Auch Ricmanje fühlte sich immer weniger innerhalb der katholischen Kirche repräsentiert. Don Požar

350 Metzger, Religion, Geschichte, Nation, S. 21.

351 Ebd., S. 22.

352 Burkhard Gladigow, Symbole und Symbolkontrolle als Ergebnis einer Professionalisierung von Religion, in: Rudolf SCHLÖGL u. a. (Hg.), Die Wirklichkeit der Symbole. Grundlagen der Kommunikation in historischen und gegenwärtigen Gesellschaften, Konstanz 2004, S. 159-172, hier S. 163ff.

353 Wie im Unterkapitel 4.1.4 zu zeigen sein wird, konnte sich der klerikale Deutungshoheitsanspruch nicht nur gegenüber, sondern auch in der generellen Einführung der altslawischen Liturgiesprache manifestieren: Das kroatische Bistum Senj wollte das lokale Kirchenleben gerade mittels der allgemeinen Verbreitung der altslawischen Liturgiesprache vereinheitlichen und von normabweichenden Partikularitäten »bereinigen «.

354 Luckmann, The Invisible Religion, S. 65. 
und andere nationalistische oder antiklerikale Agitatoren konnten diese Situation ausnutzen, um das Dorf institutionell von der katholischen Kirche abzukoppeln. Die Klerikalisierung verfehlte insofern ihr Ziel.

\subsection{Fazit: Konkurrierende und proaktive Selbstbehauptung ländlicher Katholiken}

Rogers Brubaker spricht bezüglich der Religionen von einer »Pluripotentialität«: Die Religion kann gleichzeitig als integrativer und unterscheidender (polarisierender) Faktor wirken, weil die Andersartigkeit durch die Religion sowohl aufgehoben als auch erst recht konstruiert werden kann. ${ }^{355}$ Die Gleichzeitigkeit mehrerer katholischer Völker im Österreichischen Küstenland hätte einen religiös begründeten Nationalismus - also eine religiös begründete Andersartigkeit - eigentlich nicht zugelassen. Eine narrative Konstruktion solcher Andersartigkeit war dennoch möglich, indem sich etwa die »Kroaten" und die »Slowenen« - im Gegensatz zu den liberalen »Italienern" - als die katholischen Völker der Region inszenierten. Der kroatische und slowenische Nationalismus vertrat die Ansicht, dass die katholische Religion das unabdingbare Wesen des Kroatentums/Slowenentums ausmache, weil der Liberalismus nur den bereits dominierenden »Italienern « das "nationale Erwachen« garantiere. Die kleineren Völker sollten sich gemäß dieser Auffassung mehr auf ihre religiöse Zugehörigkeit als kohäsives Element der Nation berufen, auch wenn ihre Religion eigentlich universalistisch war. ${ }^{356}$

Je nachdem, ob sich die lokale Ebene behaupten oder gegenüber den Selbstbehauptungen von oben beschützen wollte, lässt sich die Gewalt, welche die lokalen Konflikte innerhalb der katholischen Kirche begleitete, kategorisieren. Charles Tilly unterscheidet zwischen konkurrierenden, reaktiven und proaktiven Ansprüchen, die sich in den kollektiven Handlungen manifestieren konnten. ${ }^{357}$ Im österreichischen Teil waren vor allem konkurrierende und proaktive Ansprüche in den lokalen Kirchengemeinden anzutreffen: Konkurrierende Aktionen erheben den »Anspruch auf Ressourcen, die ebenfalls von anderen Gruppen beansprucht werden ${ }^{358}$. Die »Ressourcen«, um welche in den geschilderten Konfliktfällen ab und zu sogar gewalttätig konkurriert wurde, stellten der Raum, die Sprache und die Autorität der Kirche dar. Auch die nationalistischen Agitatoren maßen all diesen "Gegenständen« hohe Bedeutung bei: Die Kirche konnte für die nationalpolitische

355 Brubaker, Religious Dimensions of Political Conflict, S. 8.

356 STrecha, »Sve za vjeru i domovinu«, 1996, S. 97.

357 Charles Tilly, Hauptformen kollektiver Aktionen in Westeuropa 1500-1975, in: Geschichte und Gesellschaft 3 (1977), S. 153-163, hier S. 153ff.

Ebd., S. 153. 
Vereinnahmung einer Gesellschaft instrumentalisiert werden. Wem gehört der kirchliche Raum? Welche Sprache ist in der Kirche zu verwenden? Durch solche Fragen ließ sich die Kirche - sowohl ideell (in Bezug auf den Katholizismus), als auch materiell (in Bezug auf den konkreten kirchlichen Raum) beanspruchen. Um die Kirche als Raum, die Sprache als Gegenstand oder den Priester als Funktion konkurrierten die Akteure in den Kirchengemeinden (Kapitel 3.1). Sie benutzten dabei - wie gezeigt - oft das nationale Vokabular, auch wenn der Konkurrenzkampf nicht (nur) national, sondern vielmehr sozial bedingt war. Ein Konkurrenzkampf beinhaltet stets gleichzeitig proaktive und reaktive Elemente: Die eine Seite beschützt ihre bisherige Situation, die andere Seite fordert diese Situation aktiv heraus. In einer Kirchengemeinde, in der die südslawische Bevölkerung sozial benachteiligt und marginalisiert war und jahrzehntelang jeden Sonntag die lateinischen Gottesdienste nicht oder kaum verstehen konnte, prallten proaktive Ansprüche dieser Bevölkerung auf die reaktiven Ansprüche der italienischsprachigen Bevölkerung, die die "Slawisierung" des Kirchenlebens - sprich: die Öffnung der Kirche gegenüber den marginalisierten südslawischen Bevölkerungsteilen - aufhalten wollte.

In Ricmanje, wo keine ethnisch-sprachlichen Differenzen vorlagen, zeigte sich eindeutig, dass der Konkurrenzkampf um den kirchlichen Raum weder ethnisch-national noch horizontal geprägt war (Kapitel 3.2). Die Dorfgemeinschaft wollte sich proaktiv innerhalb der bestehenden vertikalen Strukturen behaupten, und dabei geriet sie mit ihren Priestern und dem Bistum in Konflikt.

Nur in seltenen Fällen wurden aber solche Interessenskonflikte und Gewaltakte jenseits der nationalisierenden Verortungen wahrgenommen. So ein Fall war etwa der Angriff auf den Priester in Corridico/Kringa. Als im Juni 1906 im fast ausschließlich kroatisch bewohnten, ${ }^{359}$ mittel-istrianischen Dorf das Pfarrhaus nächtlich - wie es im Polizeibericht stand - "mit Steinen förmlich bombardiert« wurde, konnte die Polizei den Akt mit nichts anderem als der "Natur" des Volkes erklären, die "wild und gewaltsüchtig« sei. ${ }^{360}$ So einfach war es aber nicht. Der dortige Konflikt zwischen dem Pfarrer und der Kirchengemeinde bestand vor allem in den divergierenden Moralvorstellungen: Der Pfarrer lehnte viele Gewohnheiten des kleinen Mikrokosmos ab (er bezeichnete die Bewohner öfter in seinen Predigten als

359 Im Jahre 1900 gaben 1.201 von den 1.205 Einwohnern das Kroatische als ihre Umgangssprache an; Daten aus: Gemeindelexikon der im Reichsrathe vertretenen Königreiche und Länder, S. 68.

360 Vorfallens-Bericht der Bezirkshauptmannschaft Pisino/ Pazin (16. Juni 1906), in: AST, Luogotenenza, AP, b. 305, fasc. 11b, 1906/5261. 
»Diebe«), und vor allem bezüglich der Sexualmoral hatten der Priester und die Dorfgemeinschaft verschiedene Auffassungen. Dabei zeigte sich der vertikale Konflikt zwischen Kirchgängern und kirchlicher Obrigkeit.

In vielen ähnlichen Fällen wurden die Konflikte jedoch nationalpolitisch dargestellt. Es stand aber nicht nur im Interesse nationalistischer Agitatoren, sondern auch in jenem der lokalen Akteure. "Doing ethnicity « war in Österreich eine mögliche ritualisierte, visualisierte, verbalisierte Performance sozialer Selbstbehauptungen innerhalb von Ungleichheitsstrukturen. Akteure verwenden die Sprache, die Symbole, die Referenzen, welche sie zuvor gehört oder beobachtet hatten, um sich und ihre Interessen nach außen verständlicher - und überhaupt: interessanter - zu machen. ${ }^{361}$ Der "Nationalitätenkonflikt» war eine Performance und eine Sprache, derer sich lokale Akteure bedienen konnten, um alltägliche (oder parteipolitisch motivierte) Konflikte öffentlichkeitswirksamer gestalten und benennen zu können. ${ }^{362}$ Die Konflikte entstanden aber nicht (nur) wegen der Sprache. Diese konnte allerdings als Konfliktvorwand herangezogen werden, wenn andere Gründe, die Streitigkeiten zwischen Pfarrern und Kirchgängern hervorrufen konnten, bereits vorlagen. Konfliktauslöser konnten einerseits persönliche, oft profane Momente sein, ${ }^{363}$ die entlang vermeintlicher oder tatsächlicher nationaler Gegensätze erzählt werden. ${ }^{364}$ Andererseits wirkten politische Ideologien wie der nationalistisch kaschierte Antiklerikalismus einiger italienischsprachiger Kreise bzw. der kirchenpolitisch kaschierte Nationalismus einiger südslawischer Klerikalen destabilisierend auf die lokalen Kirchengemeinden.

361 McAdam u.a., Dynamics of Contention, Cambridge 2004, S. 138.

362 Dazu, warum auch alltägliche Konflikte in einer routinierten Performance verliefen, siehe ebd., S. 140.

363 Konkurrierenden Aktionen liegen oft banale Motive zugrunde; vgl. Charles Tilly u. a., The Rebellious Century 1830-1930, Cambridge MA 1975, S. 284.

364 Judson, Marking National Space, S. 125. 


\title{
4. Ungarisch-Kroatisches Küstenland
}

\author{
»...tu ga ulazi hrvatsvo, taljanstvo u obće politike, \\ koliko i Pilato u vjerovanje... «1 \\ (Riječki Novi List, 11. August 1908)
}

Das katholische Grazer Volksblatt aus Österreich bot seinen Lesern immer wieder Reiseberichte aus den verschiedenen Städten und Regionen der Donaumonarchie. Als ein Journalist der Zeitung 1892 die ungarische Hafenstadt Fiume/Rijeka besuchte, zeigte er sich gleichzeitig verwundert und berührt ob des Gesehenen und Gehörten in der katholischen Kirche:

»Der Gottesdienst frappierte mich gewaltig. Kleidung und Ritus waren ganz römisch, aber die Sprache verstand ich nicht. Ich horchte anfangs und glaubte sogar, mein Gehör habe Noth gelitten. Aber ich überzeugte mich bald, daß die Sprache in der heiligen Messe nicht lateinisch, sondern slawisch war. [...] Rührend war, wie das Volk und hauptsächlich die armen Kroaten, die als solche an ihrer Kleidung leicht kennbar waren, in beständiger Procession um den Altar herumgiengen und nicht nur das Kreuz zu den Füßen des Altars, sondern den Altar selbst küßten. ${ }^{2}$

Obwohl Fiume/Rijeka öfters als eine wenig religiöse Stadt beschrieben wurde und wird ${ }^{3}$ - was etwa in den kirchlichen Zeitungen als Vorwurf, in den antiklerikalen Diskursen als Selbstbestätigung anklang -, stellte das zitierte österreichische Blatt ein lebendiges religiöses Leben dar. Auch wenn eine solche Schilderung mit der katholischen Überzeugung der Zeitung zusammenhängen mag, schickten zwei (vielleicht sogar unbewusste) Bemerkungen im Bericht die Probleme immerhin voraus, die das Kirchenleben und besonders das Verhältnis der städtischen und staatlichen Politik mit

1 Auf Deutsch: »...Kroatentum, Italienertum kamen zur allgemeinen Politik wie Pilatus ins Credo..." [übersetzt aus dem Kroatischen von mir].

2 Grazer Volksblatt, 12. Juni 1892.

3 Fried, Emlékek városa, S. 28; Zucconi, Una città cosmopolita, S. 108.

4 Das städtische katholische Blatt Il Risveglio beklagte sich etwa 1914 (obwohl die Stimmung unter den klerikalen Kreisen auch früher nicht viel anders war), dass »Fiume [Rijeka] bestimmt eine der am antiklerikalsten und antireligiössten Städte der Monarchie« sei; vgl. Il Risveglio, 16. März 1914 [übersetzt aus dem Italienischen von mir]. 
der örtlichen kirchlichen Obrigkeit in Fiume/Rijeka und der Region stark belasteten: die Debatten um die Liturgiesprache (was nicht nur eine innerkirchliche, organisatorische Angelegenheit blieb) sowie die starke kroatischsprachige Präsenz im Kirchenleben. ${ }^{5}$ Beide Debatten drückten der Kirche vor Ort eine »kroatische" Prägung sowohl in den Augen der italienisch- als auch der kroatisch-nationalen Kreise auf.

$\mathrm{Zu}$ diesen nationalpolitischen Diskursen, die auch in der österreichischen Hälfte den kirchlichen Raum nach nationalen Bezeichnungen markierten, gesellte sich ein weiteres, spezielles Problem in Fiume/Rijeka. Es geht um die kirchenrechtliche Zugehörigkeit der Region: Fiume/Rijeka und das Ungarisch-Kroatische Küstenland gehörten zum kroatischen Bistum von Senj. Infolgedessen waren die Bischöfe - im Unterschied zu den Bistümern in der österreichischen Reichshälfte - immer kroatischer Abstammung, und der Klerus wurde im kroatischsprachigen Seminar in Senj ausgebildet. Besonders in der Stadt Fiume/Rijeka - wie es noch im Kapitel 4.2 näher erörtert wird - eröffnete diese Konstellation eine staatspolitische Dimension der inner- und antikatholischen Diskurse, weil die Stadt staatsrechtlich unmittelbarer Teil von Ungarn war. Die kroatisch-nationale Ausrichtung des örtlichen Klerus wurde in Fiume / Rijeka italienischer- und ungarischerseits öfters beklagt und eine kirchenrechtliche Verselbstständigung angestrebt. Tatsächliche Konflikte zwischen dem Klerus und der lokalen Ebene entstanden aber überraschenderweise nicht im urbanen, multiethnischen Milieu der Hafenstadt, sondern auf der ländlichen, meist kroatischsprachigen Ebene, als etwa das Bistum die altslawische Liturgiesprache einführte (Kapitel 4.1) oder einen vor Ort beliebten Pfarrer absetzte (Kapitel 4.2).

In diesem Kapitel stehen zwei lokale, innerkatholische Konflikte im Mittelpunkt. Es geht um kroatischsprachige Dörfer, die mit kirchlichen und staatlichen Einmischungen konfrontiert waren. Im südlichen Teil des Bistums Senj rebellierten 1894 die Bewohner in mehreren überwiegend kroatischsprachigen Dörfern gegen die angeordnete altslawische Liturgiesprache. Im ländlichen Hinterland von Fiume/Rijeka wehrten sich die Bewohner einer kroatischsprachigen Untergemeinde zwischen 1908 und 1910 gegen die vom Bistum erzwungene Absetzung ihres beliebten Priesters. Im ersten Fall richtete sich die Wut gegen die lokalen Geistlichen, im zweiten Fall manifestierte sie sich im Interesse eines lokalen Priesters. In beiden Fällen zeigte sich die lokale Ablehnung gegenüber den äußerlichen Einmischungen. Um die Gründe für die lokalen Widerstände zu erkennen, ist es angebracht, sich der lokalen Konsequenzen der nationalisierenden Diskurse anzunehmen.

5 Die starke kroatische Präsenz hing auch damit zusammen, dass die Kirche den kroatischsprachigen, etwa bäuerlichen Schichten, Ausstiegsmöglichkeiten bot, derer die italienischsprachige Bevölkerung nicht bedurfte; vgl. Fried, Emlékek városa, S. $92 \mathrm{f}$. 
War etwa die altslawische Liturgiesprache eine Forderung von unten, wie die kroatisch-nationalistischen Agitatoren behaupteten und die italienisch- oder ungarischsprachigen Politiker in Fiume/ Rijeka und Budapest befürchteten? Verorteten sich die lokalen Akteure entlang der »nationalen« Gegensätze, wie die nationalistischen Presseberichte die Konflikte darstellten? Fügten sich die kroatischsprachigen Bauern vor Ort der katholischen Kirche als einem »kroatischen Raum«, wie ihnen dieser in den städtischen Diskursen zugeschrieben wurde? Kurz gefragt: Wie reagierte die lokale Ebene auf die nationalistischen bzw. kirchlichen Erwartungen von oben?

In den folgenden zwei Unterkapiteln untersuche ich Gewaltmomente, die bis jetzt kaum oder überhaupt nicht in der Forschung thematisiert wurden. Die ganze Region ist in der Historiographie wenig erforscht. Das Ungarisch-Kroatische Küstenland kommt in der Forschung meistens im Kontext der Stadtgeschichte von Fiume/Rijeka, ${ }^{6}$ der sog. Militärgrenze und ihrer Abschaffung ${ }^{7}$ sowie der immer wieder ausgebrochenen Bauernaufstände vor. ${ }^{8}$ Das Bistum Senj wird etwa in den Studien über die mittelalterliche Entstehung der altslawischen Liturgiesprache und der damit verbundenen glagolitischen Schrift erwähnt, ${ }^{9}$ während die Adriaküste der sog. Militärgrenze vor allem für die Periode der Piratenkämpfe ${ }^{10}$ oder der osmanischen Eroberungen sowie der österreichischen Befreiung gewissermaßen erforscht ist. $^{11}$ Die südliche Adriaküste der Region sowie das ländliche Hinterland

6 Zur Sekundärliteratur über die Stadtgeschichte von Fiume/ Rijeka siehe Kapitel 1.1.4.

7 Zur Militärgrenze siehe u.a. Gunther E. Rothenburg, The Military Border in Croatia 1740-1881. A Study of an Imperial Institution, London / Chicago 1966; Hans Sokol, Die k.k. Militärgrenze, Wien 1967; Mirko Valentić, Hrvatsko-slavonska Vojna Krajina 1790-1881 [Kroatisch-slawonische Militärgrenze 1790-1881], in: Fedor MoAČın / ders., Vojna Krajina u Hrvatskoj [Militärgrenze in Kroatien], Zagreb 1981, S. 42-77; Karl KasER, Freier Bauer und Soldat. Die Militarisierung der agrarischen Gesellschaft an der kroatisch-slawonischen Militärgrenze (1535-1881), Wien 1997; Catherine Horel, Soldaten zwischen nationalen Fronten. Die Auflösung der Militärgrenze und die Entwicklung der königlich-ungarischen Landwehr (Honvéd) in Kroatien-Slawonien 1868-1914, Wien 2009; Spannenberger/VArga (Hg.), Ein Raum im Wandel.

8 Siehe u.a. Stefano Petrungaro, Pietre e fucili. La protesta sociale nelle campagne croate di fine Ottocento [Steine und Gewehre. Der soziale Protest auf dem kroatischen Land im späten 19. Jahrhundert], Roma 2009.

9 Siehe u.a. Mile Bogović, Povijest biskupije Senjske i Modruške ili Krbavske [Geschichte des Bistums von Senj und Modruš oder Krbava], in: Fontes. Izvori za hrvatsku povijest 7 (2001), S. 20-32; Luc OrešKović, Un diocèse des Alpes Dinariques. La rencontre des influences italienne et germanique (XVIIe-XVIIIe siècles), in: Histoire des Alpes - Storia delle Alpi - Geschichte der Alpen 12 (2007), S. 183-200; ders., Le diocèse de Senj-Modruš en Croatie habsbourgeoise de la Contre-Réforme aux Lumières (1650-1770), Turnhout 2008; Bogović, Senjska glagoljška baština.

10 Catherine Bracewell, The Uskoks of Senj. Piracy, Banditry, and Holy War in the Sixteenth-Century Adriatic, Ithaca NY 1992.

11 Karl KaSer, Freier Bauer und Soldat; Horel, Soldaten zwischen nationalen Fronten; Catherine Horel, Die Entmilitarisierung der kroatisch-slawonischen Militärgrenze 
der ungarischen Hafenstadt - wo die Fallbeispiele herkommen - wurden bis jetzt nur sporadisch in lokalgeschichtlichen Studien erfasst. Ich stütze mich primär auf bisher kaum erfasste Quellen-Korpora. Zum einen benutze ich die zeitgenössischen (italienisch-, kroatisch-, ungarisch- und deutschsprachigen) Zeitungsartikel, in denen der nationalistische Diskurs bezüglich des kirchlichen Raumes und der innerkatholischen Konflikte zum Ausdruck kam. Diese Berichte werden zum anderen mit den Polizei- und innerkirchlichen Berichten und Korrespondenzen, einem ebenso bis jetzt fast unberührten Quellencorpus, konfrontiert.

\subsection{Konflikte um und gegen die altslawische Liturgiesprache im Bistum Senj}

\subsubsection{Einführung der altslawischen Liturgiesprache in der ehemaligen Militärgrenze}

An einem Sonntag Ende Mai 1894 blickten sich die Menschen in der Kirche von Kriviput, einem größeren Dorf in der Nähe des Bischofsitzes Senj, verwundert und entsetzt an. Die Messe wurde in einer anderen Sprache gelesen, als sie es gewohnt waren. Besonders bei dem Gebet »Vaterunser« wurde es in der Kirche plötzlich unruhig. Als der Priester für »unser Brot« betete, das täglich gegeben werden solle, benutzte er nicht wie bislang das kroatische Wort "kruh", sondern ein anderes: Er sagte »hleb«, was auf Serbisch Brot heißt. Einige Wörter der sog. altslawischen Sprache waren mit den serbischen identisch. Dass der Pfarrer die Messen in dieser alten Sprache zu lesen hatte, war ihm und anderen römisch-katholischen Pfarrern der Gegend erst kürzlich bischöflich angeordnet worden. Die Menschen reagierten trotzig: Als der Priester für »naš hleb « (»unser Brot») betete, antworteten sie ihm »naš kruh«. Auch am Ende des Gebetes, als der Priester »Dein Reich« auf Serbisch (eigentlich auf Altslawisch) heraufbeschwor (»carstvo Tvoje«), sagten die Menschen es dennoch auf Kroatisch: »kraljstvo Tvoje«. ${ }^{12}$ Ähnliche Szenen hatten sich zuvor in Lipice, einem kleineren Dorf in der Nähe, abgespielt. ${ }^{13}$

(1868-1881) im ungarischen Kontext, in: Laurence Cole u. a. (Hg.), Glanz - Gewalt Gehorsam. Militär und Gesellschaft in der Habsburgermonarchie (1800 bis 1918), Essen 2011, S. 153-176.

12 Über die katholische Messe am 29. Mai 1894 im Dorf Kriviput siehe den Bericht der Bezirksverwaltung (kotarska oblast) von Senj (29. Mai 1894), in: Hrvatski Državni Arhiv, Zagreb (Kroatisches Staatsarchiv, weiter: HDA), Zemaljska Vlada, Predsjedništvo 1869-1921 (Landesregierung, Präsidium; weiter: ZV, Pr.), kutija (kut.) 487, 1962/1894, broj (Nr.) 2845.

13 Bericht der Bezirksverwaltung (kotarska oblast) in Brinje (6. Juni 1894), in: Ebd., broj 20/Pr. 


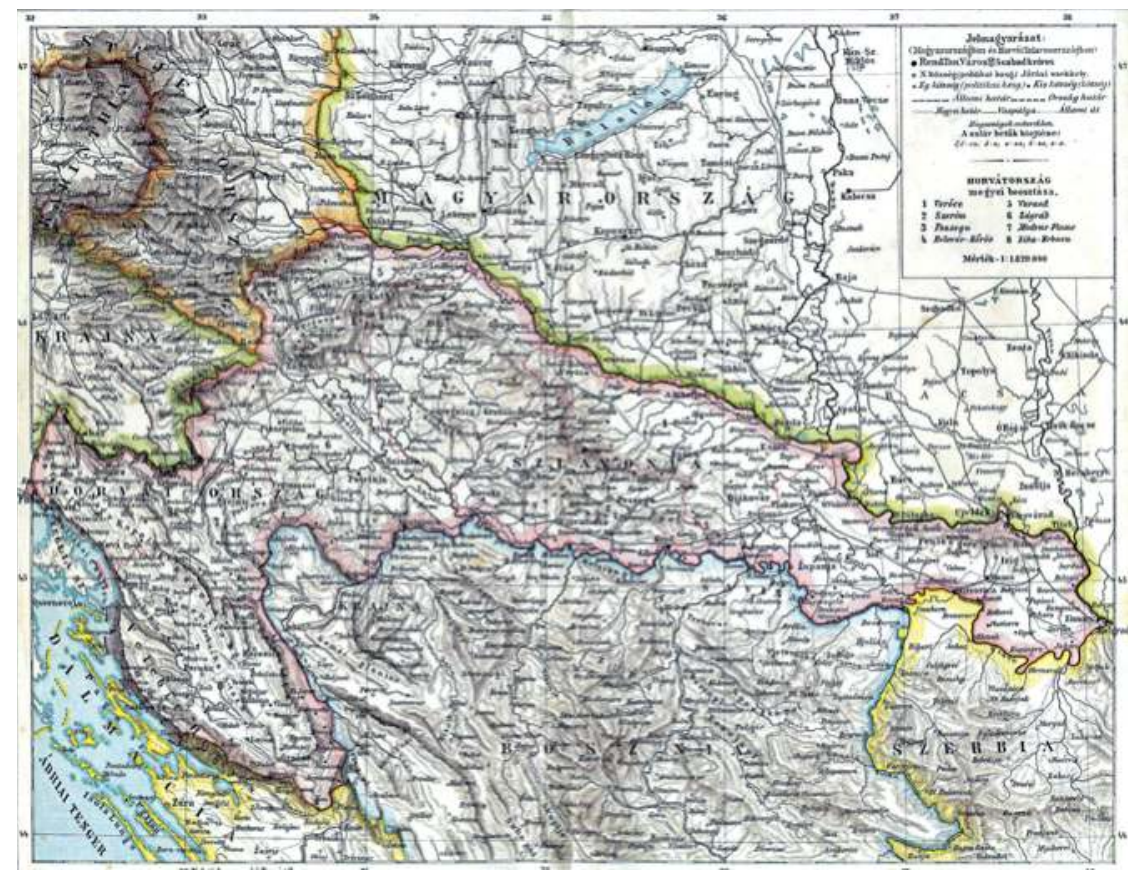

Abbildung 9: Karte von Kroatien-Slawonien (1897)

Wegen der regelmäßigen Verwendung des altslawischen Wortes für Brot (das auf Serbisch gleich klingt: »хлеб«/»hleb«) konnte der Eindruck bei den Menschen entstanden sein, dass die Priester die Messe auf Serbisch lesen würden. ${ }^{14}$ Die Menschen verstanden diese Wörter, weil sie seit Jahrhunderten in der Nähe von orthodoxen Serben lebten. An diesem Maisonntag standen sie jedoch, bis auf wenige, auf und verließen mit Lärm die Kirche. Sie hatten Angst, dass ihr Kirchenleben künftig serbisch-orthodox gestaltet würde. Sie warteten vor der Kirche, bis der Pfarrer die altslawische (oder wie sie sagten: "vlachische«) Messe beendete. Danach wollten sie die Kirche sofort zusperren, damit der Pfarrer nicht die katholischen Bilder durch orthodoxe Ikonen ersetzen könnte - was sie befürchteten. Die Frauen wollten sogar gehört haben, dass russische Agitatoren die Priester in der Gegend

14 Über die sprachliche Verwirrung infolge der altslawischen (glagolitischen) Liturgiesprache siehe u. a. Josip Burić, Pobjeda »šćaveta«. Posebni otisak iz »Novog Života« [Sieg vom »Šćavet«. Sonderdruck aus »Novi Život«], Rim [Rom] 1966, S. 255. 
bestochen hätten: Ihr Ziel sei die Orthodoxisierung einer sonst katholischen und kroatischsprachigen Gemeinschaft wie jener in Kriviput gewesen. ${ }^{15}$

Der Dorfpfarrer Konrad Modrčin hatte den Einwohnern zuvor vergeblich erklärt, dass die neue Sprache, in der die Gottesdienste von nun an zelebriert werden müssten, nicht Serbisch oder Vlachisch, sondern Altslawisch sei - eine Sprache, welche als nationales Privileg des kroatischen, katholischen Volkes galt. Es handelte sich um ein kirchenrechtliches Privileg aus dem Mittelalter, das es einigen römisch-katholischen Bistümern im östlichen Adriaraum erlaubte, die Gottesdienste in altslawischer Sprache zu lesen. In vielen Pfarreien der Region, besonders im Bistum Senj, hatte sich aber seit Langem eine kirchenrechtlich illegale Praxis, die volkssprachliche Liturgie, durchgesetzt, welche kroatische und lateinische Elemente vereinigte. Diese volkssprachliche Variation hieß "Sćavet oder $" S c h i a v e t t i \ll .{ }^{16}$ Im Zeitalter des Nationalismus entdeckten nationalistische Kreise das Thema der altslawischen Liturgiesprache als eine mögliche Form der nationalpolitischen Beherrschung der katholischen Kirche. Die altslawische Liturgiesprache wurde in den kroatisch-nationalistischen Diskursen so dargestellt, als ob sie eine Forderung der lokalen Ebene gewesen sei. Das Volk in Kriviput und später während des Sommers 1894 in anderen Dörfern im südlichen Teil vom Bistum Senj rebellierte gegen eine Sprache, auf welche es - nach den nationalistischen Diskursen - eigentlich hätte stolz sein sollen. Die Menschen in Kriviput spürten jedoch statt des Stolzes Verunsicherung: Sie waren verzweifelt darüber, dass ihr gewohntes Kirchenleben verändert wurde.

Der ungarische Kultusminister, Ágoston Trefort, stellte bereits 1889 - als die Frage der altslawischen Liturgiesprache hochzukommen begann - fest, dass sie im Gebiet des Bistums Senj immer noch im Usus sei. ${ }^{17}$ Die ungarische Politik hoffte darauf, dass das Volk diese Liturgiesprache nicht akzeptieren würde. Der ungarische Ministerpräsident, Gyula von Szapáry, berichtete 1891 etwa darüber, dass

15 Bericht der Bezirksverwaltung (kotarska oblast) von Senj (29. Mai 1894), in: HDA, ZV, Pr., kut. 487, 1962/1894, broj 2845.

16 Antonio Benvin, Il glagolitico nella liturgia nella regione di Fiume [Das Glagolitische in der Liturgie in der Region von Fiume/Rijeka], in: Giornata di studio sugli aspetti di vita cattolica, S. 46.

17 Trefort an den K.K. Außenminister Heinrich von Haymerle (28. Juni 1889), in: ÖStA, HHStA, Akten zur »Slawischen Liturgie«, PA XI 260, V/1-4 (weiter: Slawische Liturgie, V/1-4), fol. 44. 
die Agitation der Geistlichkeit der Zengger [Senjer] Diöcese zu Gunsten der slawischen Liturgie immer größere Dimensionen annehme, und obwohl vorderhand nicht $z u$ befürchten sei, daß dieselbe auch in breiteren Schichten der Bevölkerung eindringe, dies doch nicht ausgeschlossen sei. ${ }^{18}$

Die altslawische Liturgiesprache drang jedoch nicht von unten in die Öffentlichkeit ein: Es war nicht die Forderung der Kirchgänger vor Ort. Das Bistum Senj und der dortige kroatischsprachige Klerus engagierten sich für die Einführung dieser Praxis. Sie werden wohl gedacht haben, dass die kroatischsprachigen Katholiken darauf positiv reagieren würden - es fehlte der nationale Gegner innerhalb der lokalen Kirchen, die die altslawische Liturgiesprache aus nationalistischen Gründen abgelehnt hätten, wie es der Fall etwa in den österreichischen Bistümern des Küstenlandes war. Dort führte die altslawische Liturgiesprache - infolge der ethnisch-nationalen Heterogenität der dortigen katholischen Kirchengemeinden - zu innerkatholischen Querelen und Streitigkeiten (Kapitel 3.1). Das Bistum Senj, dessen Kirchengemeinden bis auf die Hafenstadt Fiume/Rijeka nur kroatischsprachig und ländlich geprägt waren, schien ein idealer Raum für die altslawische Liturgiesprache zu sein.

Ein diplomatisches Ereignis zwischen dem Hl. Stuhl und dem kürzlich unabhängig gewordenen Montenegro ermöglichte den Druck neuer Messbücher, die in den betreffenden Pfarreien seit Langem fehlten. Infolge des vatikanisch-montenegrinischen Konkordates (1886) wurde dem katholischen Erzbistum Bar / Antivari in Montenegro erlaubt, altslawische Messbücher zu verwenden. ${ }^{19}$ Zuerst war geplant, dass die Messbücher in kyrillischer Schrift verfasst werden sollten, aber später rückte der Hl. Stuhl von dieser Idee ab, welche besonders in Wien wegen ihrer panslawisch-prorussisch bedienbaren Richtung auf vollkommene Ablehnung stieß - die Messbücher wurden mit glagolitischen Buchstaben, das heißt einer längst "ausgestorbenen « Schrift, angefertigt. $^{20}$ Die katholische Bevölkerung des montenegrinischen Erzbistums war aber mehrheitlich nicht slawischer (montenegrinischer), sondern albanischer Abstammung. Auch die Priester waren italienisch- oder albanischsprachig, insofern benötigten sie das Privileg der altslawischen Sprache

18 Szapáry an den K. K. Minister, Gustav von Kálnoky (10. Dezember 1891), in: ÖStA, HHStA, Akten zur »Slawischen Liturgie«, PA XI 261, Liasse Rom V/6 (weiter: Slawische Liturgie, V/6), fol. 162 [Hervorhebung von mir].

19 Über das Konkordat mit Montenegro siehe u.a. Andreas Gottsmann, Papst Leo XIII und die »jugoslawische« Versuchung. Montenegro, San Girolamo und die südslawische Frage in der Diplomatie des Hl. Stuhls, in: Römische Historische Mitteilungen 49 (2007), S. 457-510, hier S. 458ff.

20 Ebd., S. $472 \mathrm{ff}$. 
nicht. ${ }^{21}$ Daher wurden die 1893 neu gedruckten Messbücher nicht in Montenegro, sondern in den dalmatinischen, westkroatischen und istrianischen Bistümern verwendet. ${ }^{22}$ Der ungarische Banus von Kroatien-Slawonien, Károly von Khuen-Héderváry, berichtete, dass im Bistum Senj ca. 100 altslawische Messbücher aus Montenegro aufgekauft worden seien. ${ }^{23}$ Ähnliche Ankaufswellen wurden aus anderen Bistümern im Küstenland und Dalmatien gemeldet. Der österreichisch-ungarische Botschafter am Hl. Stuhl, Friedrich Revertera von Salandra, sprach diesbezüglich sogar vom "Mißbrauch" (des Konkordates), was seiner Meinung nach "vorauszusehen " gewesen sei. ${ }^{24}$ Einige Messbücher gelangten nicht einmal nach Montenegro, sondern wurden schon auf dem Weg dorthin abgezweigt. Das vatikanisch-montenegrinische Konkordat eröffnete somit ungewollt und ungeplant die Möglichkeit der Wiederbelebung der in altslawischer Liturgiesprache gehaltenen Gottesdienste in den »südslawischen Bistümern $\aleph^{25}$ der Donaumonarchie. Auch in den Dörfern von Lika-Krbava konnten die Pfarrer mit diesen neugedruckten Messbüchern mit der altslawischen Lesung der Messen anfangen.

Im April 1894 hatte Jurij Posilović, der damalige Bischof von Senj, die altslawische Liturgiesprache in vielen dem Bistum angehörenden Pfarreien «als schönes Geschenk [des Papstes] « eingeführt, bevor er als Erzbischof nach Zagreb wechselte. ${ }^{26}$ Damit wurde eine vergessene Tradition im Interesse national- und kirchenpolitischer Ziele auf bischöfliche Anordnung wiederbelebt. Auch wenn die altslawische Liturgiesprache eine lange Tradition in der Region hatte, ${ }^{27}$ war sie allmählich zugunsten der gemischten, mit volkssprachlichen und lateinischen Elementen gehaltenen Messe verschwunden. Indem Bischof Posilović in seinem Bistum die altslawische Liturgiesprache anordnete, wollte er diese illegale Praxis mit dem kirchenrechtlich anerkannten Privileg der glagolitischen Messe ablösen und gleichzeitig das natio-

21 Smežık, The Glagolitic or Roman-Slavonic Liturgy, S. 116; Gottsmann, Papst Leo XIII und die »jugoslawische" Versuchung, S. 467ff.

22 Gottsmann, Rom und die nationalen Katholizismen, S. 56.

23 Notiz über den Bericht von Khuen-Héderváry aus Zagreb (10. Dezember 1893), in: ÖStA, HHStA, Slawische Liturgie, V/6, fol. 300.

24 Brief von Revertera an den gemeinsamen Außenminister, Gustav von Kálnoky (25. November 1893), in: Ebd., fol. 253.

25 Die betreffenden Bistümer wurden in den diplomatischen sowie päpstlichen Berichten einfach als »südslawische Bistümer« beschrieben, wogegen Budapest öfters protestierte, Ungarn wollte auch den kleinsten Eindruck vermeiden, dass einige Gebiete der Donaumonarchie den Südslawen »zugesichert« wären; vgl. u. a. Brief vom ungarischen Kultusminister György Lukács [nur Namensverwandtschaft mit dem Philosophen György Lukács] an den gemeinsamen Außenminister Agenor Graf Goluchovski (1. Dezember 1905), in: Ebd., Slawische Liturgie V/7, fol. $104 \mathrm{f}$.

26 Hirtenbrief von Bischof Jurij Posilović, in: Katolički List, 26. April 1894 [übersetzt aus dem Kroatischen von mir].

27 Bogović, Povijest biskupije Senjske i Modruške, S. 23. 
nale Bewusstsein der kroatischsprachigen, katholischen Einwohner stärken: Nationalisierung und Klerikalisierung (im Sinne von Vereinheitlichung der kirchlichen Praxen) zeichneten sich dabei als Intentionen $a b .^{28}$ Diese Entscheidung betraf auch den lokalen Klerus, von dem viele das glagolitische Alphabet kaum beherrschten. ${ }^{29}$ Bischof Posilović räumte in seinem Hirtenbrief im April 1894 ein, dass die altslawische Sprache zuerst zu erlernen sei, weil die glagolitische Schrift "nicht einfach [...] und nicht schnell« gelesen werden könne. ${ }^{30}$ Er wies darauf hin, dass das Kirchenvolk auf diese Umstellung - das heißt auf die Umstellung von der bisherigen volkssprachlichen oder lateinischen Praxis auf die Einführung der altslawischen Liturgiesprache - gut vorbereitet sein solle. Er befürchtete sogar, dass es zu Unruhen und Aufständen unter dem Volk kommen könne, falls die Gottesdienste in einer ähnlichen Sprache gelesen werden würden, die das Volk bisher nur in der serbisch-orthodoxen Kirche hören konnte. ${ }^{31}$

Das Gebiet, wo die altslawische Liturgiesprache eingeführt wurde, war vom Erlebnis konfessioneller Unterschiede sowie von der Erinnerung osmanischer Fremdherrschaft und militärischer Tugenden geprägt. Große Teile des Bistums Senj gehörten bis 1881 zur sog. Militärgrenze (Vojna Krajina). Die Militärgrenze wurde ab dem 16. Jahrhundert als Puffer- und Abwehrzone gegen das Osmanische Reich in kroatischen und slawonischen Gebieten, mit serbischen, kroatischen oder valachischen Kämpfern unterschiedlicher Privilegien (besonders für die vlachische Bevölkerung ${ }^{32}$ ), errichtet. Die »Grenzer» - die Bewohner dieser Gebiete - fühlten sich gegenüber den Bewohnern der zivil verwalteten Gebiete überlegen, die über keine Privilegien

28 Bischof Posilović galt übrigens in der kroatischen Kirchenhierarchie - etwa im Gegensatz zu Strossmayers Kreisen - eher als ungarnfreundlich, weil er im »Pazmaneum ", dem ungarischen Priesterseminar in Wien studiert hatte; vgl. ders., Senjsko-modruška ili krbavska biskupije. Izvješća biskupa svetoj stolici (1602-1919) [Bistum von Senj-Modruš oder Krbava. Berichte des Bistums an den Hl. Stuhl (16021919)], Zagreb 2003, S. 79f.

29 Die altslawische Liturgiesprache war der serbischen sehr ähnlich, in den orthodoxen Kirchen wurden also die Messen praktisch in dieser altslawischen Sprache gelesen. Der wesentliche Unterschied bestand in der Schrift: Die altslawischen, katholischen Messbücher wurden mit dem glagolitischen Alphabet geschrieben, das nicht mit der kyrillischen Schrift der serbischen Orthodoxen zu verwechseln ist.

30 Hirtenbrief vom Bischof Jurij Posilović, in: Katolički List, 26. April 1894 [übersetzt aus dem Kroatischen von mir].

31 Opreze pri uvadjanju staroslavenske liturgije [Vorsichtsmaßnahmen für die Einführung der altslawischen Liturgie], 6. Juni 1894, in: Okružnice biskupskoga Ordinarijata senjskoga i modruškoga ili krbavskoga [Rundschreiben des bischöflichen Ordinariates von Senj und Modrus / Modruš oder Krbava], Senj 1892-1897, S. 16.

$32 \mathrm{Zu}$ den Privilegien der Vlachen siehe u.a. Ekkehard VöLKL, Militärgrenze und "Statuta Vlachorum«, in: Gerhard ERnst (Hg.), Die österreichische Militärgrenze. Geschichte und Auswirkungen, Regensburg 1982, S. 9-24. 
verfügten. ${ }^{33}$ Viele Bewohner wurden für militärische Zwecke in die Region mit Privilegien "gelockt " und dort angesiedelt - so entstand eine ethnische und religiöse Vielfalt mit gleichzeitigen Ausgrenzungen und Überlappungen der Identitäten. ${ }^{34}$ In der Militärgrenze wurde die Religion immer mehr zum wichtigsten Unterscheidungsmerkmal, anhand dessen sich die Bewohner unterschiedlich verorten konnten. Hier lässt sich also - als Gegentendenz zur Nationalisierung der Selbstwahrnehmungen - eine "Konfessionalisierung" der Identitäten beobachten. Der Unterschied zwischen den »Kroaten« und den "Serben« drückte sich immer stärker nur konfessionell aus. ${ }^{35}$ Auch die ungarischen Volkszählungen machten keinen Unterschied zwischen kroatischer und serbischer Sprache/ Nationalität, daher wurde die Konfession zum einzigen Indikator für nationale Selbstverortung und Fremdwahrnehmung.

Nach der Volkszählung von 1891 lebten 190.978 Menschen in der Gespanschaft Lika-Krbava, wovon 93.313 katholisch und 97.649 orthodox waren. ${ }^{36}$ Nach der Eingliederung dieser Gebiete in die zivile Verwaltung von Kroatien-Slawonien (1881) verlor die dortige Bevölkerung ihre Vorrechte. Insofern war die Stimmung unter den früher militarisierten Bauern gegenüber den kirchlichen und zivilen Obrigkeiten angespannt: Im Jahre 1883 brach der erste Bauernaufstand nach der Eingliederung aus. Auch die spätere Aufstandswelle von 1897 war unter anderem von der Erinnerung an die weggefallenen Privilegien stark geprägt. ${ }^{37}$ Weil sich die Bewohner der ehemaligen Militärgrenze als Kämpfer betrachteten, reagierten sie rebellisch, wenn ihnen Privilegien - nach der Eingliederung der Militärgrenze in die zivile Verwaltung Kroatiens - entzogen wurden. ${ }^{38}$

Alle Katholiken der Region waren - im Gegensatz zu den anderen Teilen des Küstenlandes (Fiume/Rijeka, Istrien, Triest) - kroatischsprachig: Ethnisch-nationale Gegensätze polarisierten nicht die örtlichen Kirchengemein-

33 Horel, Die Entmilitarisierung der kroatisch-slawonischen Militärgrenze, S. 156.

34 Die unklaren, verflochtenen Strukturen und Identitäten wirkten in diesem Gebiet bis ins 21. Jahrhundert, etwa infolge des Jugoslawienkrieges und der Vertreibungen, hinein; vgl. Bernhard SтRUCK, Grenzregionen, in: Europäische Geschichte Online (EGO), hg. v. Leibniz-Institut für Europäische Geschichte (IEG), URL: <http://iegego.eu/de/threads/crossroads/grenzregionen> (15.10.2019).

35 KASER, Freier Bauer und Soldat, S. 608.

36 Daten aus: Országos Királyi Magyar Statisztikai Hivatal (Hg.), A Magyar Korona Országaiban az 1891. év elején végrehajtott népszámlálás eredményei. I. rész: Általános népleírás [Die Ergebnisse der am Anfang des Jahres 1891 in den Ländern der Ungarischen Krone durchgeführten Volkszählung. Teil I: Allgemeine Volksbeschreibung], Budapest 1893, S. 104 f.

37 Petrungaro, Pietre e fucili, S. 44f.

38 Über die Auflösung der kroatischen Militärgrenze siehe Rothenburg, The Military Border in Croatia, S. 180ff.; Mirko Valentić, Vojna Krajina i pitanje njezina sjedinjenja s Hrvatskom 1849-1881 [Militärgrenze und die Frage ihrer Vereinigung mit Kroatien 1849-1881], Zagreb 1981; sowie Horel, Die Entmilitarisierung der kroatisch-slawonischen Militärgrenze. 
den wie anderswo. Eine Rebellion innerhalb der katholischen Kirche wäre in solchen ethnisch-sprachlich homogenen Kirchengemeinden am wenigsten zu erwarten gewesen. Die kirchliche Obrigkeit in Kroatien und die nationalistischen Agitatoren gingen davon aus, dass gerade homogen kroatischsprachige Gemeinden wie jene in Lika-Krbava (siehe Abbildung 10) ${ }^{39}$ die altslawische Liturgiesprache als nationale Errungenschaft begrüßen würden.

Wollten sich die kroatischsprachigen Katholiken wirklich mittels der altslawischen Liturgiesprache national - das heißt als Teil einer einheitlichen »kroatischen, katholischen Nation" - verorten? War die altslawische Liturgiesprache in der Tat ihre Forderung? Anhand des folgenden Fallbeispiels aus Lika-Krbava lässt sich erforschen, wie die lokale Ebene darauf reagierte und wie die nationalistischen Diskurse diese Reaktionen rezipierten. Ziel dieses Unterkapitals ist die Analyse der lokalen Widerstände in mehreren Dörfern in der Gespanschaft Lika-Krbava. Diese Widerstände wurden in den städtischen Diskursen - meiner Hypothese nach fälschlicherweise - im Kontext der »Nationalisierung « oder der »Nationalitätenkonflikte« wahrgenommen. Diese Narrative wirken in der gegenwärtigen kroatischen Historiographie nach: Während verschiedene ländliche Aufstände gegen die staatlichen Obrigkeiten zumindest quellenmäßig gut dokumentiert und geschildert sind, ${ }^{40}$ sind die Aufstände gegen die altslawische Liturgiesprache aus dem Jahre 1894 kaum erwähnt. ${ }^{41}$ Diese würden das nationale Narrativ relativieren, in dem die bäuerlichen Aufstände in Kroatien-Slawonien (1883, 1897,

39 Historisch waren auch die katholischen Gemeinden der ehemaligen Militärgrenze sehr gemischt: Einige folgten seit jeher einer altslawisch-katholischen Linie, einige waren lateinisch geprägt (v. a. diejenigen, die aus anderen Teilen der Donaumonarchie hinzogen), einige waren "neuchristlich" (»novokrštenike«), weil sie im 17. und 18. Jahrhundert vom Islam zum Katholizismus konvertierten. Über die multireligiöse und multiethnische Zusammensetzung der Mikroregion siehe u.a. Damjan PEŠUt, Etnička i konfesionalna podjela nakon oslobođanja Like od Turaka [Ethnische und konfessionelle Teilung nach der Befreiung von Lika von den Türken], in: Senjski Zbornik 24 (1997), S. 85-128.

40 Die Wellen der Aufstände wurden bis jetzt nicht vergleichend und kritisch dargestellt, nur einzelne Teile wurden - und zwar oft nach einer heroisierenden, nationalen Historiographie - behandelt; zum Aufstand von 1883 siehe Dragutin PavličEvić, Narodni pokret 1883. u Hrvatskoj [Nationale Bewegung von 1883 in Kroatien], Zagreb 1980; zum Aufstand von 1897 siehe Matкović, Afirmacija Khuenove autokracije; zum Aufstand 1903/1904 siehe Vaso BogDANov, Hrvatski narodni pokret 1903./ 1904. [Kroatische nationale Bewegung von 1903/1904], Zagreb 1961; Stefano Petrungaros italienischsprachiges (und auch ins Kroatische übersetztes) Buch über die Aufstände von 1897 gehört zu den ersten Versuchen, eine Aufstandswelle, jene im Jahre 1897, in ihren sozialwirtschaftlichen Kontexten, jenseits nationaler Heroisierungen zu analysieren (Petrungaro, Pietre e fucili).

41 Die Rebellion gegen die altslawische Liturgiesprache in einigen Dörfern von LikaKrbava wird nur kurz erwähnt bei Oкey, Austrian-Hungarian Diplomacy and the Campaign for a Slavonic Liturgy, S. 277; Bogović, Hrvatsko glagoljsko tisućljeće, S. 127ff.; ders., Senjska glagoljška baština, S. 23. 


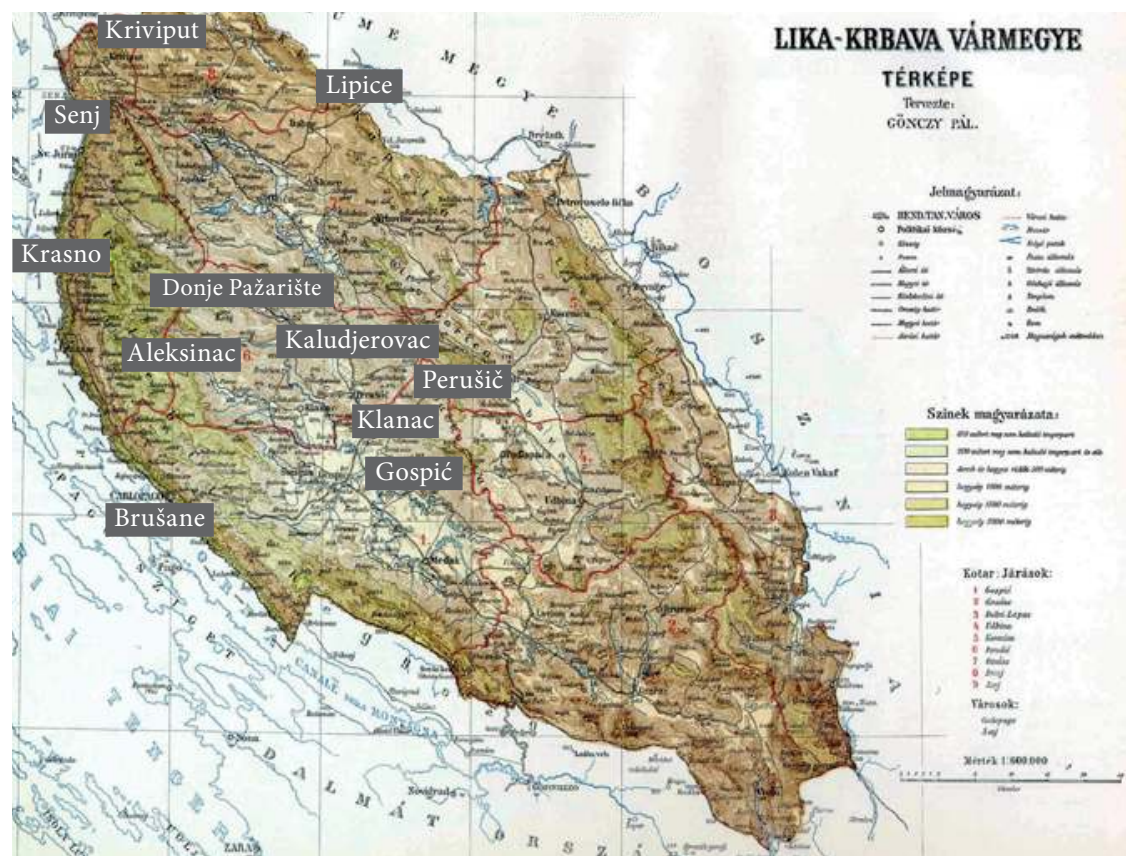

Abbildung 10: Karte der ungarisch-kroatischen Gespanschaft Lika-Krbava

1903 / 1904) als "Aufwachmomente« der »kroatischen Nation" gelten. In diesem Kapitel liegt der Fokus auf zwei Elementen der Ereignisse: Einerseits wird der Vorgang der öfters gewalttätig ausgetragenen lokalen Widerstände gegen die altslawische (glagolitische) Liturgiesprache beschrieben (4.1.2). Andererseits steht die mediale Rezeption der Konflikte im Mittelpunkt (4.1.3): Daran lässt sich die Diskrepanz zwischen lokaler Eigenständigkeit und nationalistischen Diskursen und Erwartungen erkennen.

\subsubsection{Konfliktgeschichte: Lokaler Widerstand gegen die altslawische Liturgiesprache}

Obwohl Bischof Posilović erst ab August 1895 angeordnet hatte, die altslawische Liturgiesprache einzuführen, fingen einige Priester sofort nach der Veröffentlichung des diesbezüglichen Hirtenbriefes im Frühjahr 1894 an, die Messen in altslawischer Sprache zu lesen. Die kroatischsprachigen Einwohner in einigen Dörfern in der Gespanschaft Lika-Krbava reagierten darauf aller- 
dings nicht den Erwartungen der Kirchenhierarchie entsprechend. Bereits im Mai 1894 kamen die ersten Nachrichten aus Kriviput, einem größeren Dorf in der Nähe des Bischofsitzes Senj, darüber, dass sich die Bewohner als Erstes gegen die »neue« Liturgiesprache auflehnten. Der örtliche Pfarrer, Konrad Modrčin, berichtete der Bezirkshauptmannschaft Ende Mai 1894, dass er wegen der Einführung der neuen Liturgiesprache bedroht worden sei. In ihrem Bericht an die Landesregierung in Zagreb meinte die Gespanschaftssverwaltung, dass die Aufstände entweder deswegen ausbrachen, weil die Menschen die neue Liturgiesprache schlechthin nicht verstünden - oder weil »einige fanatische[...] Gläubige[...]« das Volk zuvor »gegen die geistliche und weltliche Macht« aufgehetzt hätten. ${ }^{42}$

Was war passiert? Am 24. Mai 1894 in der Früh bereitete sich Don Modrčin auf die Messe und die darauffolgende Fronleichnamsprozession vor, welche er in altslawischer Liturgiesprache abhalten wollte. Noch davor suchten ihn mehrere Menschen aus dem Dorf und der Gegend bei der Pfarrerwohnung auf, um zu erfahren, ob die Messe "nach altem Gebrauch", das heißt volkssprachlich oder in altslawischer Sprache, gelesen werden würde. ${ }^{43}$ Es ist dabei auffällig, dass die Dorfbewohner die altslawische Liturgie, eine aus dem Mittelalter stammende Praxis, als etwas Neues empfanden, und dass demgegenüber die bisherige Praxis der volkssprachlichen oder lateinischen Liturgie in ihren Augen »den alten Gebrauch" darstellte. Die altslawische Liturgiesprache war für sie eine fremde, unbekannte Angelegenheit, welche sie rein sprachlich an die orthodoxen Gottesdienste der serbischen Bevölkerung erinnerte. Daher nannten sie die altslawische Sprache »vlachisch", womit sie eigentlich »serbisch (also in der Region: serbisch-orthodox) meinten. Es ist jedoch nicht klar, ob der in den Quellen anzutreffende Begriff „Vlache« national oder religiös zu verstehen war. $^{44}$

Don Modrčin antwortete den aufgeregten Menschen in Kriviput, dass er sich an das halten müsse, was ihm sein Bischof vorgeschrieben habe. Die Menschen wollten aber unbedingt verhindern, dass am Feiertag des Fronleichnams eine altslawische Messe in der Dorfkirche gelesen werden würde. Daher verwehrten sie dem Pfarrer den Zugang in die Kirche. Mehrere Dorf-

42 Bericht der Gespanschaftsverwaltung (županski oblast) von Lika-Krbava (31. Mai 1894), in: HDA, ZV, Pr., kut. 487, 1962/1894, broj 668ž [übersetzt aus dem Kroatischen von mir].

43 Bericht der Bezirksverwaltung (kotarska oblast) von Senj über die Mitteilung des Pfarrers von Kriviput (25. Mai 1894), in: Ebd., broj 2818 [übersetzt aus dem Kroatischen von mir].

44 Die Vlachen, als ein eigenständiges, ursprünglich rumänisches Volk, wanderten ab dem 15. Jahrhundert vom südlichen Teil des Balkans in die nördlicheren Gebiete, zuerst nach Bosnien und von dort aus nach Lika-Krbava; dazu siehe u. a. Karl KASER, Familie und Verwandtschaft auf dem Balkan. Analyse einer untergehenden Kultur, Wien u. a. 1995, S. 104ff. 
bewohner versammelten sich drinnen, Don Modrčin konnte von draußen nur dabei zusehen, wie sie die Kirche zusperrten. Ein Dorfbewohner nahm den Kirchenschlüssel an sich. Don Modrčin versprach den Bewohnern verzweifelt, die Messe "nach altem Gebrauch" (das heißt volkssprachlich-lateinisch) zu lesen, aber er bekam den Schlüssel nicht zurück, insofern blieb das Dorf am Fest des Fronleichnams ohne Gottesdienst. ${ }^{45}$ Die katholische Bevölkerung war überzeugt, dass die altslawische Liturgiesprache nur der erste Schritt zum erzwungenen Übertritt in die orthodoxe Religion sei. Die serbischsprachige, orthodoxe Bevölkerung machte sich deswegen sogar über die kroatischsprachigen Katholiken lustig.

Gerüchte spielten in den bäuerlichen Aufständen und Krawallen vielerorts in Kroatien eine wichtige Rolle; sie verliehen den Ereignissen eine gewisse Eigendynamik. ${ }^{46}$ Ein solches Gerücht in der Gegend war, dass einige katholische Priester - um heiraten und Bart tragen (!) zu können - mit ihren Kirchengemeinden in die Orthodoxie übertreten würden. Einige Dorfbewohner glaubten dabei zu wissen, dass der russische Zar höchstpersönlich die lokalen katholischen Priester bestochen hätte, damit sie dem Volk den orthodoxen Glauben aufzwangen. ${ }^{47}$ In den späteren Prozessen sagten die angeklagten Frauen aus Kriviput vor dem Gerichtshof aus: Sie hätten in der Tat Angst davor gehabt, dass der Pfarrer Don Modrčin heimlich das Bild der Hl. Maria in der Kirche durch eine orthodoxe Ikone ersetzen würde. ${ }^{48}$ Kriviput war bekannt für seinen Kult um die Hl. Maria: Ihr Bild und ihre Statue erfreuen sich bis heute einer großen Verehrung in der Region. ${ }^{49}$ Damit erklärt sich, warum die Dorfbewohner in Kriviput die Kirche sofort zusperrten, als sie von der Einführung der altslawischen Liturgiesprache erfuhren. Sie dachten, dass eine drohende Orthodoxisierung nicht nur die Liturgiesprache, sondern auch die materielle Einrichtung der Kirche (samt Gemälden, Statuen usw.) beträfe.

Don Modrčin besaß keinen anderen Schlüssel, daher konnte er die Kirche nicht mehr betreten. ${ }^{50}$ Nachdem aber bewaffnete Gendarmen in Kriviput angekommen waren, nahmen sie zwei Männer fest, die den Schlüssel bei sich

45 Bericht der Bezirksverwaltung (kotarska oblast) von Senj über die Mitteilung des Pfarrers von Kriviput (25. Mai 1894), in: HDA, ZV, Pr., kut. 487, 1962/1894, broj 2818.

46 Petrungaro, Pietre e fucili, S. 88.

47 Bericht der Gespanschaftsverwaltung (županski oblast) von Lika-Krbava (29. Mai 1894), in: HDA, ZV, Pr., kut. 487, 1962/1894, broj 6589 (solche Gerüchte kursierten auch im österreichischen Ricmanje während des dortigen Kirchenstreites zwischen 1900 und 1910; siehe Kapitel 3.2).

48 Über den Prozess wurde berichtet u.a. in: Agramer Zeitung, 18. Mai 1895.

49 Vgl. Marija Kulıšıć/Ivana Vuković, Majka Božja Snježna u pučkoj pobožnosti na področju Krivoga Puta [Die Verehrung der Schnee Gottesmutter in der Volksfrömmigkeit auf dem Gebiet von Krivi Put], in: Senjski Zbornik 31 (2004), S. 239-260.

50 Bericht der Bezirksverwaltung (kotarska oblast) von Senj über die Mitteilung des Pfarrers von Kriviput (25. Mai 1894), in: HDA, ZV, Pr., kut. 487, 1962/1894, broj 2818. 
hielten. Später forderten ca. 200 Menschen vor dem Gemeindehaus die Rückgabe des Schlüssels und die Entlastung der festgenommenen Personen. ${ }^{51}$ Don Modrčin erhielt die Schlüssel zurück, die Kirche konnte wieder geöffnet werden - auch wenn die Einwohner dagegen waren. Nachdem Don Modrčin die Schlüssel wiedererhalten hatte, war es den Menschen noch wichtiger, das Kirchengebäude Tag und Nacht zu »beschützen«. In den folgenden Tagen kamen Hunderte aus dem Dorf und der Gegend vor der Kirche und dem Pfarrhaus zusammen - sie seien »sehr aufgeregt" gewesen, wie ein staatlicher Bericht feststellte. ${ }^{52}$ Als Ende Mai 1894 der Sekretär des Großgespans von Lika-Krbava das Dorf besuchte, beschrieb er, wie sich vor der Kirche »in überwiegender Mehrheit Frauen « versammelten: Sie tanzten dabei Kolo, den typischen kroatischen Volkstanz. ${ }^{53}$

Zur gleichen Zeit kam der Gesandte von Bischof Posilović, ein gewisser Don Srdoc, aus dem Nachbardorf Brinje nach Kriviput, um die Gemüter zu beruhigen und dem Volk nochmals die bischöfliche Entscheidung zu erläutern. Er war zuvor 17 Jahre lang Pfarrer in Kriviput gewesen und erfreute sich immer noch hoher Beliebtheit unter den Einwohnern. ${ }^{54}$ Das Verhältnis zwischen den kroatischen Bauern und ihren Priestern war vielerorts zwiespältig: geprägt von hoher, fast mystischer Achtung und gleichzeitigem Unverständnis gegenüber den neuen (klerikalen oder nationalen) Ideen. ${ }^{55}$ Weil Don Srdoc in seinem Dorf die Fronleichnamsprozession noch in kroatischer Sprache zelebriert hatte, begrüßten ihn die Bewohner in Kriviput zuerst als »unseren wahren Priester, der den Gottesdienst nicht glagolitisch [altslawisch] liest $«{ }^{56}$ Auch wenn einige Dorfbewohner die Kirche wieder zugesperrt hatten, konnte Don Srdoc sie mit seinem Schlüssel aufmachen. Eine große Menschenmenge folgte ihm hinein. Sie machten aber sofort klar, dass sie keine "vlachische" Messe wollten, sondern eine Messe »in kroatischer Sprache wie bis jetz $«^{57}{ }^{57}$ Als Don Srdoc vor der Messe die bischöfliche Anordnung über die altslawische Liturgiesprache verkündete, verließen fast alle lärmend die Kirche. Nur fünf Dorfbewohner nahmen schließlich am von Don Modrčin in altslawischer Sprache gelesenen Gottesdienst teil. Vor der Kirche versuchte Don Srdoc vergeblich, den aufgeregten Bewohnern noch einmal zu erklären, dass die neue Liturgiesprache nicht »vlachisch« sei.

51 Bericht der Bezirksverwaltung (kotarska oblast) von Senj (29. Mai 1894), in: Ebd., broj 2845 .

52 Ebd. [übersetzt aus dem Kroatischen von mir].

53 Ebd., broj 6589 [übersetzt aus dem Kroatischen von mir].

54 Ebd., broj 2845.

55 Petrungaro, Pietre e fucili, S. 160f.

56 Bericht der Gespanschaftsverwaltung (županski oblast) von Lika-Krbava (29. Mai 1894), in: HDA, ZV, Pr., kut. 487, 1962/1894, broj 6589 [übersetzt aus dem Kroatischen von mir].

57 Ebd., broj 2845 [übersetzt aus dem Kroatischen von mir]. 
Sie glaubten ihm nicht und meinten verzweifelt und traurig, dass Don Srdoc »bestochen" worden sei. ${ }^{58}$ Die Menschen verhielten sich den Geistlichen gegenüber immer aggressiver. Bewaffnete Gendarmen sorgten dafür, dass die zwei Priester an diesem Tag nicht angegriffen wurden. Wie ein Bericht schrieb: »bis auf einige Frauen und Mädchen« gingen alle Dorfbewohner letztendlich ruhig nach Hause. ${ }^{59}$

Anfang Juni 1894 wurde über weitere Vorfälle aus Kriviput berichtet. Am ersten Junisonntag versammelten sich 400 Menschen in der Kirche, aber sobald Don Modrčin den Raum betrat, verließen alle das Gebäude. Die Menschen warteten draußen, solange die altslawische Messe gelesen wurde. Nach dem Ende der Messe kehrten sie in die Kirche zurück - vielleicht um zu kontrollieren, ob die heiligen Bilder noch da waren -, und erst nach einer gewissen Zeit gingen sie heim. Die Kirche war während der Messe nicht nur leer, sondern auch still, da einige Dorfbewohner dem Glöckner zuvor mit dem Tod gedroht hatten, falls er an der altslawischen Messe als Meßner teilnehmen würde. ${ }^{60}$ Der Glöckner hatte schon zuvor Drohungen erhalten: Nach den Informationen der national-klerikal eingestellten Tageszeitung Agramer Tageblatt hätten die Bauern den Glöckner schon früher, Ende Mai, halbtot geschlagen. ${ }^{61}$ Der Bericht der örtlichen Bezirkshauptmannschaft bemerkte diesbezüglich, dass »die Lage weiterhin ernst ist «. ${ }^{62}$ Am 25. Juni 1894 rückten weitere bewaffnete Kräfte in Kriviput zur »Unterdrückung des Aufstandes« ein. ${ }^{63}$ Don Modrčin bangte ernsthaft um sein Leben. Die Polizeiberichte schrieben vom persönlich motivierten Hass, der die Beziehung der Bevölkerung untereinander und zu ihrem Pfarrer belastet habe: In Kriviput habe Don Modrčin zuvor den Friedhof zugesperrt, was ihm mehrere Dorfbewohner, vor allem die Frauen, nicht hätten verzeihen können. ${ }^{64}$ Die Gründe dafür sind den Quellen nicht zu entnehmen, es kann aber vermutet werden, dass Don Modrčin und einige Frauen schon zuvor ein konfliktbeladenes Verhältnis hatten und das Zusperren des Friedhofes einen Racheakt des Priesters gegen diese Frauen darstellte. Die staatlichen Behörden empfahlen dem Bistum von Senj, einen neuen Priester nach Kriviput zu schicken, weil Don Modrčin - unabhängig von der altslawischen Liturgiesprache - »bei allen

58 Ebd., broj 6589.

59 Ebd. [übersetzt aus dem Kroatischen von mir].

60 Bericht der Bezirksverwaltung (kotarska oblast) von Senj (4. Juni 1894), in: Ebd., broj 2924.

61 Agramer Tagblatt, 31. Mai 1894.

62 Bericht der Bezirksverwaltung (kotarska oblast) von Senj (4. Juni 1894), in: Ebd. [übersetzt aus dem Kroatischen von mir].

63 Bericht der Bezirksverwaltung (kotarska oblast) von Senj (29. Mai 1894), in: Ebd., broj 2845 [übersetzt aus dem Kroatischen von mir].

64 Ebd., broj 6589. 
Einwohnern verhasst« sei. ${ }^{65}$ Stimmt aber ein so pauschalisierendes Urteil über ein ganzes Dorf? Die Frage, wie die Bewohner die altslawische Liturgiesprache aufnehmen sollten, spaltete die lokale Gemeinde in Kriviput. Don Modrčin meinte etwa, dass viele Menschen die altslawische Liturgiesprache akzeptiert hätten, ${ }^{66}$ aber einige Wortführer, die in den priesterlichen Briefen oder polizeilichen Berichten immer namentlich erwähnt wurden, bestimmten im Dorf die Ereignisse: Die Menschen seien laut einem Bericht des national-oppositionellen Blattes Hrvatska gegeneinander aufgehetzt worden. Ein Bauer, der sich für Don Modrčin Partei zu ergreifen traute, sei von anderen Bauern auf der Straße angespuckt worden. ${ }^{67}$

Nur mit örtlich bedingtem, persönlichem Hass lässt sich der Widerstand in Kriviput aber nicht erklären. Das dortige Ereignis blieb keinesfalls ein Einzelfall. Aus einem weiteren Dorf, Krasno, meldete der dortige Pfarrer noch im Juni 1894, dass mehrere Menschen mit Drohungen und Gewalt auf die altslawische Liturgiesprache reagiert hätten. Ein alter Mann riet dem Pfarrer davon ab, das neue, altslawische Messbuch weiterhin am Altar liegen zu lassen, weil die Menschen es als Provokation wahrgenommen hätten. Als der Pfarrer am 10. Juni 1894 die Messe in altslawischer Sprache zu lesen begann, riefen viele »Raus! Raus!« und verließen die Kirche. ${ }^{68}$ Wie der Priester schrieb: "Die Menschen schrien und machten Lärm «. ${ }^{69}$ Vor der Kirche eskalierte die Situation. Einige Kirchenbesucher attackierten einen Mitarbeiter des Pfarramtes. Nachdem der Pfarrer das Kirchentor zugesperrt hatte, bewarfen sie es mit Steinen. Der Pfarrer bat die Gendarmarie um Hilfe, um »den größten Skandal« zu vermeiden. ${ }^{70}$ Das Steinewerfen hatte keine biblische oder theologische Konnotation - es war eine übliche Gewaltform in der Region, wie sie auch im österreichischen Istrien zu sehen war (3.1.). Gerade in der steinigen Gegend von Lika-Krbava, den karstigen, hohen Gebirgen von Velebit, boten sich die Steine als "Waffen« an.

Die Angst vor einer Orthodoxisierung sprach sich in der Gegend rasch herum. Die serbisch-orthodoxe Bevölkerung schürte die Befürchtungen der Katholiken ebenso. In Kriviput berichteten die katholischen Einwohner darüber, dass einige Orthodoxe aus der Gegend sie wegen der altslawischen Liturgiesprache ausgelacht hätten. Die Orthodoxen hätten etwa behaup-

65 Bericht der Gespanschaftsverwaltung (županijska oblast) von Gospić an das Bistum Senj (10. Juni 1894), in: Ebd., broj 695 [übersetzt aus dem Kroatischen von mir].

66 Bericht der Bezirksverwaltung (kotarska oblast) von Senj über die Mitteilung des Pfarrers von Kriviput (25. Mai 1894), in: Ebd., broj 2818.

67 Hrvatska, 30. Mai 1894.

68 Bericht der Bezirksverwaltung (kotarska oblast) von Senj (15. Juni 1894), in: HDA, ZV, Pr., kut. 487, 1962/1894, broj 3080 [übersetzt aus dem Kroatischen von mir].

69 Ebd. [übersetzt aus dem Kroatischen von mir].

70 Bericht der Bezirksverwaltung (kotarska oblast) von Senj (15. Juni 1894), in: Ebd. [übersetzt aus dem Kroatischen von mir]. 
tet, dass sich die Katholiken künftig "nicht einmal so bekreuzigen werden wie bis jetzt, sondern mit drei Fingern", wie es in der Orthodoxie üblich war. $^{71}$ Solche Meinungen verstärkten die katholische Bevölkerung in ihren Ängsten, die katholische Religion (samt Liturgiesprache, religiöser Praxen, kirchlichen Einrichtungen usw.) verlieren zu müssen. Ein anonym gebliebener katholischer Priester beschwerte sich im national-oppositionellen Blatt Hrvatska darüber, dass sich die Orthodoxen in vielen Dörfern über die Katholiken wegen der altslawischen Liturgiesprache ständig lustig machen würden. ${ }^{72}$ Überall, wo die altslawische Liturgiesprache eingeführt wurde, dachten die Menschen, dass sie serbisch (»vlachisch «) werden müssten. ${ }^{73}$ Die Angst schlug aber besonders in den ausschließlich oder mehrheitlich katholisch bewohnten Dörfern in Gewaltakte um. Nie wurde die serbische Bevölkerung, sondern die kirchlichen und staatlichen Obrigkeiten (Pfarrer, Dorfvorsteher, Gendarmen usw.) angegriffen. Die Menschen schrieben ihnen, die selbst katholisch und kroatisch waren, und nicht den serbischsprachigen Orthodoxen die angeblichen orthodoxisierenden Tendenzen zu. Im Spätsommer 1894 wollten die Einwohner auch in weiteren Ortschaften wie etwa in Perušič, Klanac oder Aleksinac die Einführung der altslawischen Liturgiesprache mit Gewalt verhindern. Diese Dörfer lagen ebenso in der ehemaligen Militärgrenze - und sie hatten eine ähnliche Demographie hinsichtlich der konfessionellen Zusammensetzung wie Kriviput: Orthodoxe lebten zwar in der Umgebung, aber nicht (oder nur kaum) in den betreffenden Ortschaften.

Am 16. August 1894, dem Tag vom Heiligen Rochus, kam es zu Gewaltakten, als der Pfarrer in Perušič, Franjo Kovačić, vor der Kirche ankam, um sich in der Sakristei auf die altslawisch zu lesende Messe vorzubereiten. Die aus der Gegend versammelten drei- bis viertausend Menschen warfen Steine auf den Pfarrer. ${ }^{74}$ Viele Bewohner umzingelten die Kirche und bewarfen alle, die hineinwollten, mit Steinen. ${ }^{75}$ Die Messe konnte letztendlich nicht gehalten werden, da Don Kovačić in seine Wohnung fliehen musste. Er hatte zu Hause weitere Pfarrer aus der Umgebung zu Gast, unter anderem den Pfarrer von Klanac, Don Lovro Vidaš, der in seiner Kirche später ebenso mit den antialtslawischen Protesten konfrontiert wurde. Don Vidaš war nach Perušić gekommen, um die geplante altslawische Messe mit Don Kovačić gemeinsam

71 Bericht der Bezirksverwaltung (kotarska oblast) von Senj (29. Mai 1894), in: Ebd., broj 2845 [übersetzt aus dem Kroatischen von mir].

72 Hrvatska, 5. Juni 1894.

73 Siehe etwa den Bericht des Pfarrers von Aleksinac, Ante Lukša (22. August 1894), in: HDA, ZV, Pr., kut. 487, 1657/1894, broj 149.

74 Bericht des Bezirksvorstehers in Perušič (18. August 1894), in: Ebd., broj 42/pres., fol. $7 \mathrm{f}$.

75 Agramer Tagblatt, 22. August 1894. 
zu lesen. ${ }^{76}$ In Perušić schaltete sich die Polizei sofort ein und verhinderte die gewalttätige Eskalation des Konfliktes. Wegen der Unruhen in Kriviput im Mai 1894 waren die Gendarmen auf mögliche weitere gewalttätige Vorfälle in der Region vorbereitet. Mehrere Menschen wurden vor Ort sofort festgenommen. Die aus den anderen Ortschaften eingetroffenen Gendarmen bewachten den ganzen Tag das Pfarrhaus, um die Sicherheit von Don Kovačić und seinen Gästen im aufgewühlten Dorf zu garantieren. Der polizeiliche Einsatz stellte aber eine ähnlich externe Einmischung in das Leben der Dorfbewohner dar wie die kirchliche Entscheidung bezüglich der altslawischen Liturgiesprache: Zuerst wollte das Bistum ihnen eine nicht gewollte Änderung der Liturgiesprache aufzwingen, und als sie dagegen protestierten, wurde ihr Dorf vom Staat polizeilich besetzt. In einer Region, wo die zivile Verwaltung erst seit wenigen Jahren (seit 1881) aufgebaut wurde, war der nötige Respekt gegenüber den staatlichen Organen nicht immer vorhanden.

Am 18. August 1894 marschierten 400-500 Menschen aus Perušić nach Gospić, dem Gespanschaftssitz von Lika-Krbava, um für die Freilassung der festgenommenen Personen zu demonstrieren. ${ }^{77}$ Im Dorf ereigneten sich daraufhin spektakuläre Brandfälle. Das Feuer flammte auch andernorts sowohl als Gewaltakt als auch als reinigendes Symbol in den bäuerlichen Aufständen Kroatiens und Slawoniens auf. ${ }^{78}$ Nach den ersten Unruhen in Perušić wurde zuerst das Haus des örtlichen Försters, eines gewissen Murgić, in der Nacht vom 16. auf den 17. August in Brand gesetzt. Das Forstwesen war ein strittiges Thema in der ehemaligen Militärgrenze: Während die Bauern früher das Recht gehabt hatten, die umliegenden Wälder (land)wirtschaftlich zu nutzen, wurde ihnen dieses Privileg nach der Eingliederung der Gebiete in Kroatien immer mehr weggenommen. Besonders die ungarische Zentralregierung zog die Kontrolle über das Forstwesen an sich, weil sie die Holzindustrie für die neuen, staatlichen Projekte wie die Bahn brauchte. ${ }^{79}$ Insofern galt auch ein Förster im Dorf »ungarisch« gebrandmarkt. Er war nicht der Einzige, der im Visier einiger Dorfbewohner stand. Nach seinem Haus brannte etwa der Stall des Bürgermeisters Ivan Sokolić komplett aus. In der Nacht vor dem ungarischen Nationalfeiertag, dem 20. August, zündeten Dorfbewohner die

76 Bericht des Bezirksvorstehers in Perušič (18. August 1894), in: Ebd., broj 42/pres., fol. 8 .

77 Bericht des Sekretärs des Großgespans von Lika-Krbava (19. August 1894), in: Ebd., broj 42/pres., fol. 8 f.

78 Zur Rolle des Feuers bei den kroatischen Bauernaufständen vgl. Stefano PetrunGARO, Fire and Honor. On the Comparability of Popular Protests in Late 19th Century Croatia-Slavonia, in: Sabine Rutar (Hg.), Beyond the Balkans. Towards an Inclusive History of Southeastern Europe, Münster 2013, S. 247-263, hier S. 261ff.

79 Horel, Soldaten zwischen nationalen Fronten, S. 84ff. 
Kartoffel- und Haferfelder von Don Kovačić an. ${ }^{80}$ Repräsentanten der lokalen Macht wurden mit den Brandanschlägen attackiert. Der Protest war insofern nicht national motiviert (serbische Opfer gab es keine), sondern richtete sich gegen die lokalen Machthaber, die als Repräsentanten der sich einmischenden kirchlichen und staatlichen Obrigkeiten angesehen und als solche abgelehnt wurden. Der antihierarchische Charakter des dörflichen Widerstandes zeigte sich darin, dass die Menschen am 20. August auf den Straßen tanzten, anstatt in die Kirche zu gehen. ${ }^{81}$

Die regierungsnahe Tageszeitung aus Zagreb, Narodne Novine, betonte angesichts des Benehmens der Dorfbevölkerung, dass der »Mob«»vom Schnaps angetrunken« auf den Straßen in Perušić randaliert habe. ${ }^{82}$ Alkoholkonsum spielte eine wichtige Rolle in den anderen Bauernaufständen in Kroatien und Slawonien: Es schaffte Gemeinschaftlichkeit unter den Beteiligten und lockerte die Hemmungen. ${ }^{83}$ Nur mit Alkoholkonsum lässt sich aber die Rebellion in Perušič und den umliegenden Dörfern nicht erklären. Die Menschen pöbelten nicht ziellos herum, auch wenn sie ab und zu nicht nüchtern waren. Sie wussten genau, wovor sie Angst haben und was sie bekämpfen müssen. Auch wenn dieser Angst, der Angst vor der Orthodoxisierung, irrationale Gerüchte und Falschmeldungen zugrunde lagen, handelten die Menschen ihrem Erfahrungs- und Wissenshorizont nach "rational« und verständlich.

Die Bewohner in Perušić lehnten die Gottesdienste von Don Kovačić vollkommen ab, weil er diese weiterhin altslawisch zelebrierte. Am ersten Septembersonntag erschienen nur ein älterer Mann und eine Frau in der Dorfkirche. ${ }^{84}$ Die Gottesdienste wurden auch später nur von wenigen Leuten besucht. ${ }^{85}$ Alle anderen gingen nicht mehr in Perušić zur Messe, sondern in einem anderen Dorf, Kaludjerovac, wo der Pfarrer Nikola Gršković - trotz des bischöflichen Hirtenbriefes - weiterhin kroatischsprachige Gottesdienste zelebrierte. Seine trotzige Reaktion sprach sich rasch in der Gegend herum: Nicht nur aus Perušić, sondern auch aus anderen Ortschaften, wo die altslawische Liturgiesprache eingeführt worden war, wanderten viele Menschen jeden Sonntag in das winzige, an einem pittoresken See liegende Dorf

80 Bericht des Bezirksvorstehers in Perušič (22. August 1894), in: HDA, ZV, Pr., kut. 487, 1657/1894, broj 44/pres., fol. $22 \mathrm{ff}$.

81 Ebd.

82 Narodne Novine, 28. August 1908 [übersetzt aus dem Kroatischen von mir].

83 Zur Rolle des Schnaps (rakija) bei den kroatischen Bauernaufständen siehe u.a. Petrungaro, Pietre e fucili, S. 76.

84 Bericht des Vorstehers (predstojnik) von Perušić (3. September 1894), in: HDA, ZV, Pr., kut. 487, 1657/1894, broj 6114, fol. 43.

85 Am 9. September 1894 wohnten etwa 16 Menschen der Messe bei; vgl. Bericht des Bevorsteher (predstojnik) von Perušić (10. September 1894), in: Ebd., broj 6348, fol. 61. 
Kaludjerovac. Diese Abwanderung aus den Kirchen - und somit aus den eigenen "Herrschaftsgebieten" - zeigt interessante Ähnlichkeiten mit dem frühneuzeitlichen »Auslaufen« auf, das heißt einer Praxis, bei der bestimmte Personen ihre eigenen Orte verließen, um anderswo religiöse Rituale (meistens nach einer anderen Konfession) auszuüben. ${ }^{86}$ Obwohl die Menschen, die in Kaludjerovac zur Messe gingen, ihre Konfession nicht verließen (sie blieben weiterhin römisch-katholisch), wollten sie sich der bischöflichen Entscheidung, in allen Kirchen der Gegend altslawische Messen hören zu müssen, entziehen. Dass sie dabei weder ihre konfessionelle Zugehörigkeit noch die kirchenrechtliche Aufteilung der Pfarreistruktur infrage stellten - wie es etwa im österreichischen Ricmanje letztendlich passierte (Kapitel 3.2) -, zeigt die lokale Verbundenheit der Menschen mit ihrer katholischen Religion, die sie nach ihren bisherigen Gewohnheiten und Traditionen in der bisher benutzten Sprache erleben und praktizieren wollten. Ihr "Auslaufen" war also kein aktives Handeln gegen die römisch-katholische Kirche bzw. die katholische Religion an sich, sondern ein reaktiver Schutzmechanismus.

Der Pfarrer in Kaludjerovac, Don Gršković, stand mit der weltlichen Macht auf Kriegsfuß: Wie der oppositionelle Parteiführer, Mile Starčević, noch im Dezember 1893 im Zagreber Parlament (Sabor) beklagte, sei der Geistliche aus Gospić auf Initiative des Obergespanns von Lika-Krbava in eine andere "kleinere Ortschaft» verbannt worden, ${ }^{87}$ womit wahrscheinlich Kaludjerovac gemeint war. Don Grškovic war ein eindeutiger Anhänger der nationalistischen Opposition. Während Don Kovačić aus dem Wahlkreis von Perušić für die ungarnfreundliche Regierungspartei, die Volkspartei (»Narodna Stranka«), im Sabor saß, gehörte Don Gršković - als einfaches Mitglied - der oppositionellen »Partei des Rechtes« (»Stranka Prava») an. Er wurde daher in den Polizeiberichten als »pravaši» (»Rechtler»), das heißt Anhänger der Rechtspartei, bezeichnet. ${ }^{88}$ In der Gegend repräsentierte die "Stranka Prava" die antiungarische und regierungskritische Opposition, das Küstenland war eine Hochburg dieser oppositionellen Fraktion. ${ }^{89}$ Viele Priester, besonders aus dem niederen Klerus, schlossen sich dieser Partei und nicht der vom hohen Klerus (etwa von Bischof Josip Jurij Strossmayer) geprägten anderen Oppositionskraft, der Unabhängigen Volkspartei (»Neovisna Narodna Stranka«), an. ${ }^{90}$ Die altslawische Liturgiesprache wurde eher

86 Über das »Auslaufen« siehe etwa Benjamin J. Kaplan, Cunegonda's Kidnapping. A Story of Religious Conflict in the Age of Enlightenment, New Haven/London 2014, S. 79f.

87 Agramer Zeitung, 21. Dezember 1893.

88 Bericht des Großgespanns von Lika-Krbava (19. August 1894), in: HDA, ZV, Pr., kut. 487, 1657/1894, broj 1104, fol. 6.

89 Gross, Povijest pravaške ideologije, S. 206.

90 Ebd., S. 265f. 
von dieser letzten Partei lautstark gefordert; die offizielle Linie der »Stranka Prava« hingegen war skeptischer hinsichtlich jeglicher proserbischer, jugoslawischer Annäherungsversuche, und insofern auch der altslawischen Liturgiesprache. Im Falle von Don Gršković lässt sich zeigen, wie unterschiedlich und gespalten selbst das nationalistisch-oppositionelle »Lager« auf die altslawische Liturgiesprache in der kroatischen Öffentlichkeit reagierte. ${ }^{91}$ Gleichzeitig lassen sich dabei innerkirchliche Unstimmigkeiten zwischen dem höheren und dem niederen Klerus erkennen. Don Gršković änderte aber später seine Meinung: 1901 wanderte er in die USA aus - infolge von Streitigkeiten mit der kirchlichen Obrigkeit -, wo er sich als nationalistischer Journalist und Priester betätigte. ${ }^{92}$ In der dortigen kroatischen Diaspora unterstützte er eindeutig - gegenüber den prohabsburgischen Auswanderern - die jugoslawische Idee. ${ }^{33}$

Die Tatsache, dass Menschen von einem regierungsnahen Priester zu einem oppositionellen abwanderten (»auslaufen«), ermöglichte eine nationalistische Erklärung der Vorfälle. Die dominierende nationalistische Presse (Agramer Tagblatt, Hrvatska, Obzor) versuchte, den antialtslawischen Widerstand in einen antiungarischen umzuinterpretieren. Die antialtslawischen Aufstände erstreckten sich aber auch auf Dörfer wie Klanac oder Alexinac, ${ }^{94}$ wo die Pfarrer keine Anhänger der Regierungspartei waren. Weil der Pfarrer in Klanac, Don Vidaš, die altslawischen Messen unterstützte - er hätte in Perušič gemeinsam mit Don Kovačić die Messe lesen sollen -, stieß er in seiner Kirchengemeinde ebenso auf Ablehnung. Ihm wurde der Zugang zur Kirche verweigert, damit er in der Ortskirche nicht mit den altslawischen Messen anfangen könnte. ${ }^{95}$ Mehrere Bewohner marschierten zum Pfarrhaus, um den Kirchenschlüssel einzufordern. Danach versammelten sie sich vor der Kirche. Sie wollten die Kirche zusperren, um weitere altslawische Messen im Dorf zu verhindern - wie sie dem Pfarrer Don Vidaš verkündeten: »Wir

91 Günter Schödl meint immerhin, dass die zwei Hauptströmungen des kroatischen Nationalismus (Jugoslawismus und Kroatismus) einander eigentlich nicht ausschlossen, weil sie ähnliche Ziele hatten: die innen- oder außerhabsburgische Verselbstständigung der kroatischsprachigen Länder bzw. die Emanzipierung von den magyarisierenden Tendenzen; vgl. Günther SсHöDL, Kroatische Nationalpolitik und »Jugoslavenstvo«. Studien zu nationaler Integration und regionaler Politik in Kroatien-Dalmatien am Beginn des 20. Jahrhunderts, München 1990, S. 67.

92 Matjaž Klemenčič, Croats and Croatian Americans, 1870-1940, in: Elliot Robert BARKan (Hg.), Immigrants in American History. Arrival, Adaptation and Integration. Vol. 1, Santa Barbara u. a. 2014, S. 291-300, hier S. 299.

$93 \mathrm{Zu}$ seinem Leben siehe Srećko LjubLJANović, Niko Gršković, in: Hrvatski Biografski Leksikon [Kroatisches Biographisches Lexikon], URL: <http://hbl.lzmk.hr/clanak. aspx?id=28> (15.10.2019).

94 Narodne Novine, 27. August 1894.

95 Bericht des Vizegespans von Lika-Krbava (23. August 1894), in: HDA, ZV, Pr., kut. 487, 1657/1894, broj 39, fol. 21f. 
geben unsere Kirche nicht her, und Sie werden uns keine Messen auf Vlachisch lesen $«{ }^{96}$ Die Bewohner von Klanac vermieden ihre Kirche, und sie gingen - ähnlich wie die Menschen aus Perušić oder Aleksinac - nach Kaludjerovac zur Messe. ${ }^{97}$ Der Vizegespan meinte, dass die Bewohner in Klanac ihren Pfarrer nicht (nur) wegen der altslawischen Liturgiesprache, sondern auch »seines angeblich unmoralischen Lebens wegen « abgelehnt hätten ${ }^{98}$ diese Bemerkung wurde aber im Bericht nicht weiter erläutert.

In Aleksinac war der Pfarrer, Ante Lukša, wegen des ständigen Lärms der Bewohner vor dem Pfarrhaus um sein Leben besorgt. Ein alter Mann empfahl ihm: »Herr, Sie dürfen nicht mehr so [altslawisch] die Messen lesen, weil das Volk Sie ermorden wird «. ${ }^{99}$ Don Lukša zelebrierte auch in anderen Dörfern die Messen. In Donje Pazarište waren die Angst und die Empörung wegen der altslawischen Messe so groß, dass ein Kirchgänger dem Pfarrer, als er das altslawische »Vaterunser« zu lesen begann, zurief: »Soll der Teufel das beten, ich werde es nicht beten « ${ }^{100}$ Don Lukša berichtete über Gerüchte, die sich schon im Mai 1894 in Kriviput verbreitet hatten: die angebliche Orthodoxisierung der katholischen Bevölkerung. Er machte dafür die orthodoxe Bevölkerung verantwortlich. Aleksinac liegt nicht weit weg von Gospić, dem kroatisch und serbisch bewohnten Hauptort der Gespanschaft. Die Menschen aus Aleksinac gingen öfters dorthin zum Markt. Ihnen hätten die orthodoxen Menschen dort erzählt: »die Katholiken kehrten in ihren [orthodoxen] Glauben zurück «. ${ }^{101}$ Infolgedessen befürchteten die katholischen Menschen, dass sie mit der neuen Liturgie serbisch/orthodox werden müssten. Im Herbst 1894 kamen weitere Nachrichten über Vorfälle infolge der altslawischen Liturgiesprache. Im September wurde das neue altslawische Messbuch aus der katholischen Kirche in Gospić in der Nacht gestohlen. ${ }^{102}$ Im November bedrohten die Einwohner in Brušane den örtlichen Pfarrer mit dem Tod, falls er weiterhin altslawische Messe lesen würde. ${ }^{103}$ Die Menschen in diesem Dorf nahe der südlichen Adriaküste von Lika-Krbava waren dabei stark

96 [übersetzt aus dem Kroatischen von mir].

97 Bericht des Vizegespans von Lika-Krbava an das Vikariat von Senj (28. August 1894), in: Biskupski Arhiv Senj (Bischöfliches Archiv Senj, weiter: BAS), Spisi (Schriften, weiter: Spisi), broj (Nr.) 132.

98 Bericht des Vizegespans von Lika-Krbava (28. August 1894), in: HDA, ZV, Pr., kut. 487, 1657/1894, broj 10749, fol. 17f. [übersetzt aus dem Kroatischen von mir].

99 Brief von Don Lukša (22. August 1894), in: Ebd., broj 149, fol. 32f. [übersetzt aus dem Kroatischen von mir].

100 Ebd. [übersetzt aus dem Kroatischen von mir].

101 Ebd., fol. 31 [übersetzt aus dem Kroatischen von mir].

102 Bericht des Vizegespans in Gospić (14. September 1894), in: Ebd., broj 11455.

103 Bericht der Bezirksverwaltung (kotarska oblast) in Gospić (13. November 1894), in: HDA, ZV, Pr., 1962/1894, broj 10056. 
angetrunken. Die »schon mit Schnaps übermäßig belustigten" Einwohner brüllten in der Kirche herum, als das "Vaterunser « nicht kroatisch, sondern altslawisch gebetet wurde. ${ }^{104}$

Die oft gewalttätigen Handlungen ähnelten sich zwar (Sperrung der Kirche, Wache vor der Kirche, Steinwürfe gegen die Priester, Lärm und Geschrei in der Kirche oder vor dem Pfarrhaus usw.). Sie folgten aber keiner einheitlichen »Regie«. Die Dorfbewohner traten nicht gemeinsam gegen die kirchliche oder staatliche Obrigkeit auf, aber sie blieben auch keine isolierten Einzelfälle. Einerseits verbanden die Ängste die Menschen untereinander: Überall verbreiteten sich die gleichen Gerüchte, welche die Ängste vor dem Verlust der katholischen Religion schürten. Andererseits kannten die Dorfbewohner die Ereignisse aus der gesamten Gegend, und sie reagierten darauf. Sie wussten etwa, dass Don Srdoc, der im Mai 1894 Kriviput besuchte, in seinem Dorf die altslawische Liturgiesprache noch nicht eingeführt hatte. Oder die Bewohner von Klanac: Als sie erfuhren, dass ihr Pfarrer im Nachbarort Perušić die Messe mit dem dortigen Pfarrer Don Kovačić auf Altslawisch lesen wollte, hinderten sie ihn daran, in Klanac die Kirche zu betreten. Auch die Tatsache, dass die Messen in Kaludjerovac, einem Dorf, wo weiterhin kroatischsprachige Messen gelesen wurden, von Kirchgängern aus mehreren anderen Dörfern besucht wurden, zeigt ebenso, wie die Menschen in ihren Ängsten und ihrem reaktiven Widerstand miteinander kommunizierten und aufeinander reagierten. Die Vorfälle ereigneten sich dennoch lokal, punktuell und spontan. Statt als organisierter Aufstand lassen sich die Ereignisse als spontane Widerstandmomente beschreiben, in denen die Gewalt nicht im Interesse jeglicher Änderungen, sondern des Beibehaltens der bestehenden Ordnung angewendet wurde.

Diese Abwehr- und Widerstandsmomente ebbten aber in der Region rasch $a b$, und die Bevölkerung gewöhnte sich an die "neue" Liturgiesprache. Dazu trug auch die staatliche Macht von Kroatien bei: ${ }^{105}$ Sie sorgte einerseits mit mehreren rasch eingesetzten Gendarmarie-Einheiten vor Ort für die Wiederherstellung der Ordnung. Andererseits wurden Dutzende Wortführer festgenommen und vor Gericht gestellt. Aus Kriviput wurden 40 Menschen, überwiegend Frauen, wegen öffentlicher Gewalttätigkeit, Ruhestörung, Beleidigung einer gesetzlich anerkannten Kirche und Zusammenrottung angeklagt. ${ }^{106}$ Die Urteile fielen mild aus: Einige Männer wurden für fünf

104 Ebd. [übersetzt aus dem Kroatischen von mir].

105 In der inneren Angelegenheit genoss Kroatien-Slawonien innerhalb der ungarischen Reichshälfte eine gewisse Autonomie, insofern war die Polizei der Landesregierung in Zagreb unterstellt; vgl. 2.1.2.

106 Es handelt sich um die offiziellen Bezeichnungen der betreffenden Tatbestände, wie sie im ungarischen Strafgesetzbuch, dem sog. Csemeghy-Kódex (Gesetzesartikel $1878-\mathrm{V})$, benannt wurden. 
Wochen strengen Arrestes verurteilt, die meisten Angeklagten wurden aber freigesprochen. ${ }^{107}$ Der Staat war in jeder Hinsicht an der Wiederherstellung der lokalen Ruhe interessiert: Daher griff er konsequent vor Ort gegen die Rebellion durch. Härtere Urteile hätten aber die wiederkehrende Ruhe weiter aufgewühlt, daher entsprachen die milden Urteile dem staatlichen Interesse, in der Region keine weiteren Irritationen auszulösen.

\subsubsection{Konfliktanalyse: Nationale Indifferenz oder antiserbischer Hass?}

Die Tatsache, dass die altslawische Liturgiesprache gerade in homogen kroatischen Kirchengemeinden abgelehnt wurde, versetzte die nationalistischen Agitatoren in große Erklärungsnot. Ihr vorläufiges "Scheitern" versuchten sie mit zwei Diskursen zu rechtfertigen. Einerseits gingen sie davon aus, dass die kroatischsprachigen Bauern im Bistum Senj die Wichtigkeit der altslawischen Liturgiesprache noch nicht erkannt hätten. Andererseits versuchten sie, die späteren, sommerlichen Aufstände umzuinterpretieren und im Kontext eines antiungarischen oder antiserbischen »Nationalitätenkonfliktes« zu verorten, als ob die Bauern mit ihren Gewaltakten gegen die lokalen Priester im nationalen Sinne gehandelt hätten. Die zwei Wellen der Aufstände (im Mai in Kriviput und im August in der Gegend von Perušić) wurden dementsprechend unterschiedlich rezipiert, obwohl die Situation in beiden Fällen die gleiche war: Kroatischsprachige Bauern griffen kroatischsprachige Priester wegen der Einführung der altslawischen Liturgiesprache an. Im Folgenden geht es um die Erklärungsstrategien der nationalistischen, städtischen Öffentlichkeit.

Über die ersten Nachrichten aus Kriviput im Mai 1894 war die nationalklerikale, oppositionelle Öffentlichkeit Kroatiens, die die altslawische Liturgiesprache als gesamtkroatische Forderung darstellte, schockiert. Die national-oppositionellen Blätter Hrvatska sowie Agramer Tagblatt bezeichneten den angegriffenen Don Modrčin als einen "tapferen und geachteten « ${ }^{108}$ sowie »allgemein geachteten « Priester. ${ }^{109}$ Die Zeitungen bekundeten eindeutig ihre Sympathien mit ihm - trotz seines angeblich schlechten Rufes unter der Bevölkerung -, und sie verurteilten vielmehr das Benehmen der Bewohner. Die national-oppositionellen Blätter betonten, dass das Volk zu beleh-

107 Agramer Zeitung, 18. Mai 1895.

108 Hrvatska, 30. Mai 1894 [übersetzt aus dem Kroatischen von mir].

Agramer Tagblatt, 31. Mai 1894. 
ren sei ${ }^{110}$ weil es die nationale Bedeutung und Wichtigkeit der altslawischen Liturgiesprache noch nicht begriffen habe:

Die Wiedereinführung der Glagoljica in der katholischen Kirche in Kroatien ist im Interesse der kroatischen Nation gelegen und man kann es nur unpatriotisch bezeichnen, wenn das Volk gegen diese Errungenschaft haranguirt wird, auf welche die Kroaten als die einzigen unten den Katholiken der Welt mit Stolz verweisen können. ${ }^{111}$

Die regierungsnahe Presse (Agramer Zeitung, Narodne Novine) wies hingegen schadenfreudig darauf hin, dass das "einfache« Volk den national-klerikalen Erwartungen und Forderungen wenig Verständnis entgegenbringe:

Wir constatieren demnach zunächst, daß die Opposition stets behauptet, die ganze Nation stehe hinter ihr und bekenne sich zu ihren Grundsätzen;... [...] Und statt dessen, was sehen wir nun? Die Bevölkerung eines Landestheiles, in welchem die Erinnerung an den Gottesdienst in der slawischen Sprache noch nicht erloschen sein kann, widersetzt sich der Wiedereinführung desselben in seiner reinen Form auf das Entschiedenste und verlangt die lateinische Messe, wodurch sie eclatant beweist, daß sie dieser national wichtigen Maßregel, zu deren alleinigem Fürsprecher die Opposition sich, im Gegensatz zu der "magjaronischen" Partei, stets aufgeworfen hat, absolut nicht das geringste Verständnis entgegenbringt... [...] Dem Volke die hohe Wichtigkeit und die nationale Bedeutung des altslawischen Gottesdienstes klar zu machen, das waren sie [die Opposition] nicht im Stande, daran war ihnen auch offenbar sehr wenig gelegen; aber dazu Schlagwort von dem magjaronischen Landesverrath und dem Serbenhass, die haben sie glücklich in das Volk geschmuggelt. ${ }^{112}$

Die regierungsnahe Tageszeitung betonte mit Recht, dass die kroatischsprachige lokale Ebene nicht den nationalistischen Erwartungen entsprechend auf die Forderungen der nationalistischen Kreise reagiere. Obwohl die altslawische Liturgiesprache in der politischen Öffentlichkeit - nicht nur in Kroatien, sondern auch im ganzen Habsburgerreich - als Ausdruck lokaler nationaler Selbstverortungen wahrgenommen und dargestellt wurde, scheiterten die kroatisch-nationalistischen Agitatoren mit der altslawischen Liturgiesprache gerade in einer Region, wo die Kirchengemeinden homogen kroatischsprachig waren und die altslawische Liturgiesprache zumindest eine gewisse historische Tradition hatte. Das Blatt hebt ebenso mit Recht hervor, dass die nationalistischen Kräfte die blamierende Ablehnung der altslawischen Liturgiesprache mit antiserbischer Hetzerei und Angstmache-

110 Hrvatska, 30. Mai 1894.

111 Agramer Tagblatt, 31. Mai 1894.

112 Agramer Zeitung, 25. August 1894. 
rei übertönen wollten. Die Agramer Zeitung verschwieg aber dabei, dass der Aufstand nicht im Interesse der lateinischen, sondern der kroatischsprachigen Messen ausbrach. Dieses Detail ist deswegen wichtig, weil es eindeutig zeigt: Die lokale Ebene war nicht national indifferent - wie die nationalistisch-oppositionellen Kräfte behaupteten oder die regierungsnahen (ungarnfreundlichen, madjaronen) Zeitungen hofften -; die Menschen wollten aber ihre kroatische Sprache und katholische Religion eigensinnig - weder den nationalistischen noch den madjaronen Diskursen entsprechend - erleben und beibehalten.

Bezüglich des nationalistischen Vorwurfes, die lokale Bevölkerung sei rückständig gewesen, ist es auffallend, wie dabei die Präsenz der Frauen hervorgehoben wurde. Dies war nicht nur eine Deskription, sondern gleichzeitig eine Bewertung der Aufstände. In Europa war die Tendenz in den antiklerikalen Diskursen anzutreffen, die katholische Kirche zu feminisieren und dadurch zu marginalisieren. ${ }^{113}$ Im Falle der Aufstände in Lika-Krbava stellten aber gerade die Gegner des Klerus in den Augen der nationalistischen Agitatoren die "vor-moderne" Seite dar, welche die nationale Wichtigkeit der altslawischen Liturgiesprache und überhaupt die Idee einer einheitlichen Nation noch nicht verstanden habe. Die altslawische Liturgiesprache ließ sich in der "modernen " Tendenz der Nationalisierung verorten. Die Betonung der Beteiligung von Frauen und Mädchen an den Widerstandsmomenten war insofern ein diskursives Mittel, die Widerstände als Ausdruck ländlicher Rückständigkeit darzustellen. Die Präsenz der Frauen stand für emotionsgeleitetes Unwissen. Ingrid Bauer spricht bezüglich ähnlicher Phänomene von der »Provinzialisierung der Frauen $« .{ }^{114}$ Umgekehrt könnte die Rede von einer gewissen Feminisierung der Provinz sein - die Provinz galt als rückständig und wurde daher marginalisiert.

Die betonte Rückständigkeit übersetzte sich in den Berichten der nationalistischen Zeitungen in die Aufforderung, das Volk zu belehren. Die national-oppositionelle Presse (Agramer Tagblatt, Obzor, Hrvatska) betonte im August 1894, dass »[d] as Volk belehrt werden [muß]«, weil es noch nicht eingesehen habe, »daß es mit der glagolitischen Liturgie einen Vorzug vor allen anderen katholischen Völkern der Welt erlangt hat. ${ }^{115}$ Diese Bemerkungen implizierten nationale Indifferenz. Diese bedeutet - wenn man sie nicht als analytische Kategorie (vgl. Kapitel 1.1.3), sondern anhand der nati-

113 Zur Feminisierung des Katholizismus, welcher nicht antifeministische Tendenzen, sondern ein bestimmtes Bild von Frauen, der katholischen Kirche und ihrer Zuneigung zueinander zugrunde lagen, siehe u. a. Borutta, Antikatholizismus, S. 372ff.

114 Ingrid Bauer, Welche Zentren? - Welche Peripherien? Frauen - Arbeiter - Provinz. Oder: Über eine gezielte Abweichung vom Thema, in: Österreichische Zeitschrift für Geschichtswissenschaften 4 (1993), S. 305-313, hier S. $306 f$.

Agramer Tagblatt, 29. August 1894. 
onalistischen Vorwürfe (praktisch als Quellenbegriff) verstehen will ${ }^{116}$ verspätete Modernisierung. Diesem Gedanken wohnt die Dichotomie zwischen "moderner Nation« und »rückständiger, noch zu modernisierender Gemeinschaft« inne. ${ }^{117}$ Nach dieser Auffassung sei die nationale Indifferenz das vormoderne Nichtverstehen eines modernen Diskurses: der nationalen Argumentation. Dieses Unverständnis ergebe sich demnach aus einer negativ beeinträchtigten Kommunikation zwischen nationalen Agitatoren und dem zu überzeugenden »Publikum«. Die Kommunikation sei in einem modernistisch-nationalisierenden Diskurs zwischen den Diskursakteuren und den Rezipienten - wie Peter Haslinger schreibt - negativ beeinträchtigt, »wenn sich diskursive Barrieren parallel zu potenziellen gesellschaftlichen Bruchlinien etablieren «. ${ }^{118} \mathrm{Im}$ Kontext ländlicher Gegenden könnte eine gesellschaftlich erklärbare Diskursbarriere zwischen der ländlichen Bevölkerung und den nationalistischen Agitatoren (die meistens aus dem städtischen Milieu stammten) erkannt werden. Bedeutet es, dass die Menschen die nationalistischen Diskurse nicht verstehen konnten? Oder hätten sie es gekonnt - aber nicht gewollt? Ich gehe davon aus, dass die nationale Indifferenz in diesem Falle ein Nicht-Verstehen-Wollen der nationalistischen Diskurse, das heißt eine reaktive (aber bewusste) Ablehnung nationalistischer Einmischungen und Erwartungen, bedeutet.

Die nationalistische Forderung, die Menschen ob ihrer »wahren«»Identität« zu belehren, würde die konstruktivistische These gut unterstützen, nach der die nationalistischen Ideen immer Produkte elitärer Diskurse seien, die oft kontrafaktuell durchgesetzt worden seien. ${ }^{119}$ Bezüglich des Endresultates hat der Konstruktivismus aber keinen Unterschied zum Primordialismus, nur die Geburt der Nation wird anders erzählt. ${ }^{120}$ Der konstruktivistische Ansatz stellt den Zusammenhang zwischen Nation und Nationalismus nicht infrage. ${ }^{121}$ Die Nation ist aber - wie Rogers Brubaker betont - nie Träger des Nationalismus: Der Nationalismus wird als Idee nur von den nationalistischen Agitatoren, einem kleineren Teil der Nation, getragen. ${ }^{122}$ Der Vorwurf der nationalen Indifferenz gegenüber Menschen, die sich nicht nationalistisch verorten, ergibt sich also aus der falschen Idee, Nation (als kulturellsprachliche Größe) und Nationalismus (als politische Idee, Ideologie) gleich-

116 Pieter Judson, Nationalism and Indifference, in: Feichtinger / Uhl (Hg.), Habsburg neu denken, S. 148-155, hier S. 151.

117 Kritisch darüber u. a. Zahr A, Imagined Noncommunities, S. 98f.

118 Haslinger, Nation und Territorium, S. 29.

119 Siehe u.a. Gellner, Nations and Nationalism, S. 55f.

120 Ashutosh Varshney, Ethnicity and Ethnic Conflict, in: Carles Borx/Susan C. Stokes (Hg.), The Oxford Handbook of Comparative Politics, Oxford 2009, S. 274-294, hier S. 288.

121 Zahra, Kidnapped Souls, S. $6 f$.

122 Brubaker, Nationalism reframed, S. 19ff. 
zusetzen. Die kroatische Nation als Einheit war nicht nur unterschiedlich - je nach den verschiedenen, elitären Parteien - konzipiert, ${ }^{123}$ sondern sie war auch eine Idee von oben, der sich weite Teile der kroatischsprachigen Gebiete der Donaumonarchie erst im Laufe des 20. Jahrhunderts anschlossen. ${ }^{124}$ Der Nationalismus - oder im kroatischen Falle besser gesagt: die verschiedenen innernationalen Nationalismen - dürfen nicht mit der Nation gleichgesetzt werden: Menschen können ein Zugehörigkeitsgefühl haben, ohne sich dabei nationalistisch zu verorten.

Ihrer nationalen Zugehörigkeit waren sich die Bauern in Lika-Krbava bewusst. ${ }^{125}$ Die Dorfbewohner stellten im Dorf Klanac im Sommer 1894 der Einführung der altslawischen Liturgiesprache die klare Forderung entgegen: »Wir wollen nichts anderes, als das Kroatische ${ }^{126}$ Statt nationaler Indifferenz stellen sich daher vielmehr die Fragen, was die Bewohner vor Ort mit ihrem »Kroatisch-Sein « meinten und wovor sie Angst hatten. Sie erlebten die Einführung der altslawischen Liturgiesprache als Affront gegen ihre Identität und Sprache. ${ }^{127}$ Sprachlich waren sie keineswegs indifferent.

Jenseits der elitären Diskurse bedeutete das Bewusstsein, kroatisch und katholisch zu sein, auf der lokalen Ebene eine starke Bindung an das gewohnte Leben. Die ländliche Abwehr formierte sich nicht national, sondern territorial. Denn die »Nation« (d.h. eine Gemeinschaft von voneinander weit gelegenen »Nationsbrüdern«) blieb für die lokale Ebene eine eher fremde, abstrakte Idee. ${ }^{128}$ Der Erfahrungs- und Erwartungshorizont, nach dem die Bauern die externen Einmischungen zu verstehen versuchten, war begrenzt. Die Begrenztheit lässt sich darin erkennen, dass die Einwohner ihre Dörfer als die »Welt« wahrnahmen. Ein gewisser Toma Faljević aus Perušić forderte

123 Die kroatische Nation hatte vollkommen unterschiedliche Bedeutungen in den Diskursen der Illyristen, der Jugoslawisten, der Partei des Rechtes (pravaštvo), der Bauernpartei und der Sozialdemokratie; vgl. Mirjana Gross, Croatian NationalIntegrational Ideologies from the End of Illirism to the Creation of Yugoslavia, in: Austrian History Yearbook 15 (1979), S. 2-33, hier S. 4.

124 Mirjana Gross, O integraciji hrvatske nacije [Von der Integration der kroatischen Nation], in: Dies. (Hg.), Društveni razvoj u Hrvatskoj, S. 175-190, hier S. 180ff.

125 Darüber, dass unterschiedliche Nationskonzepte in den ländlichen Gegenden der Habsburgermonarchie kursierten, siehe am Beispiel von Galizien u.a. STAUTERHalsted, Nation in the Village, S. 8, $185 f$.

126 Bericht des Gemeindevorstehers von Klanac (20. August 1894), in: HDA, ZV, Pr., kut. 487, 1657/1894, broj 3437 [übersetzt aus dem Kroatischen von mir].

127 Wie noch in diesem Kapitel zu zeigen sein wird, konnten die kroatisch-nationalistischen Diskurse die lokale Angst vorm Verlust der kroatischen und katholischen Identität - sprich: die Angst vor Orthodoxisierung/Serbisierung - stärken, weil einige kroatisch-nationalistische Ideen die Nähe an das orthodoxe Serbentum betonten.

128 Pieter Judson, Nationalizing Rural Landscapes in Cisleithania, 1880-1914, in: Nancy M. Wingfield (Hg.), Creating the Other. Ethnic Conflicts and Nationalism in Habsburg Central Europe, New York 2003, S. 127-148, hier S. 130. 
im August 1894 den kroatischen Banus Károly von Khuen-Héderváry »im Namen der Perušićer Welt" auf, Don Kovačić abzusetzen und die wegen der Unruhen festgenommenen sechs Personen freizulassen. ${ }^{129}$ Die Bezeichnung »Welt« (»svjet«) zeigte die geschlossene Selbstwahrnehmung der Dorfbewohner, die sich nicht als Teil einer abstrakten "Nation", sondern vordergründig lokal, in ihrem eigenen, eigenständigen Mikrokosmos verorteten. ${ }^{130}$ Das familiäre und dörfliche Netzwerk stellte für sie den wichtigsten (und vielleicht sogar den letztmöglichen) Erwartungs- und Wahrnehmungshorizont dar. Die Menschen verteidigten ihre »Welt«. Deswegen wollten sie die kroatischsprachigen Gottesdienste so beibehalten, wie sie sie gewohnt waren.

Das nationalistische Narrativ über ein zu belehrendes Volk, das einen anständigen Priester angreift, widerspricht der Idee, dass der Nationalismus dem Willen des Volkes entsprungen sei. Die kroatisch-nationalistische Presse benötigte daher andere Erklärungsstrategien, in denen dieser Widerspruch aufgehoben werden konnte. Diese neue Erklärung wurde bezüglich des Widerstandes im August 1894 in Perušić und den anderen Dörfern der Gegend "gefunden". Als sich die Rebellion gegen den dortigen Pfarrer, Don Kovačić, richtete, schilderte die nationalistische Presse den Konflikt anders, damit dieser nicht mehr nach einem antialtslawischen, sondern einem antiungarischen / antiserbischen Aufstand - in diesem Sinne als Ausdruck einer "richtig " nationalen Selbstverortung der lokalen Ebene - aussah. Im Falle von Kriviput räumten die nationalistischen Zeitungen ein, dass ihr Nationalismus auf der lokalen Ebene vorerst gescheitert sei, und sie machten dafür das »Unwissen", die »nationale Indifferenz«, des Volkes verantwortlich. Im Falle von Perušić von August 1894 konnten sie dieses "Scheitern« in einem anderen Narrativ neu kontextualisieren - und dadurch sogar als Erfolg verbuchen.

Wie war das möglich? Im Gegensatz zu Don Modrčin, dem Pfarrer von Kriviput, bekleidete der angegriffene Don Kovačić auch politische Ämter. Er saß, wie oben erwähnt, für die ungarnfreundliche Regierungspartei im kroatischen Parlament. Dieses Detail ermöglichte den nationalistischen Blättern, den Fall im Kontext der »Nationalitätenkonflikte« zu verorten, als ob die kroatischsprachigen Bauern Don Kovačić (nur) wegen seiner angeblichen ungarnfreundlichen (das heißt »madjaronen«) Ansichten angegriffen hätten. Das oppositionelle Blatt Hrvatska betonte in seinem Bericht, dass die Dorfbevölkerung in Perušić eben davor Angst gehabt habe, von einem »magjaronen Priester« »vlachisiert«, das heißt zu orthodoxen Serben gemacht zu

129 Telegramm von 18. August 1894, in: HDA, ZV, Pr., kut. 487, 1962/1894 [übersetzt aus dem Kroatischen von mir].

130 Zur Bedeutung der Selbstbezeichnung als »Welt« siehe Petrungaro, Pietre e fucili, S. 71f. 
werden. ${ }^{131}$ Dieser Vorwurf hatte in Kroatien und besonders in Lika-Krbava eine stark nationalpolitische Konnotation. Die serbische Minderheit galt als ungarnfreundlich und - aus einer national-kroatischen Perspektive »verräterisch «. ${ }^{132}$

Indem die national-klerikalen Blätter die Aufstände gegen die altslawische Liturgiesprache mit antiserbischem Hass zu erklären versuchten, konnten sie die Ereignisse in den Kontext der »Nationalitätenkonflikte « zwischen »Kroaten« und »Ungarn« sowie »Kroaten« und »Serben« rücken. Das national-oppositionelle Agramer Tagblatt betonte deswegen in seinen Berichten aus Perušić den "Antagonismus«, der zwischen den Katholiken und den Orthodoxen in Lika-Krbava bestanden habe, und behauptete, dass sich die katholische Bevölkerung zurückgedrängt fühle. ${ }^{133}$ Die nationalistische Diskursstrategie zielte diesmal darauf ab, die lokalen Widerstände als Ausdruck nationalistischen Bewusstseins darzustellen. Mit der Fokussierung auf das interkonfessionelle Spannungsverhältnis zwischen katholischen und orthodoxen Bevölkerungsteilen ließ sich der Stellenwert der altslawischen Liturgiesprache im Sinne eines national-kroatischen Narratives uminterpretieren, als ob die kroatischsprachigen Katholiken nicht die altslawische Liturgiesprache, sondern die serbische Bevölkerung abgelehnt hätten.

Die Angst der lokalen Bevölkerung vor einer »Orthodoxisierung« lässt sich allerdings nicht (nur) als Zeichen antiungarischer oder antiserbischer Selbstverortung verstehen. Die »Gefahr» der »Orthodoxisierung« wurde nicht den serbischsprachigen Bevölkerungsteilen zugeschrieben. Die jugoslawische Idee, das kroatische und das serbische Volk als Einheit zu denken, oder die Einführung der altslawischen Liturgiesprache wurden nicht serbischerseits propagiert und vorangetrieben - sondern seitens einiger Teile der

131 Hrvatska, 21. August 1894 [übersetzt aus dem Kroatischen von mir].

132 Besonders der ungarische Banus von Kroatien-Slawonien, Károly von KhuenHédervary, der zwischen 1883 und 1903 in Zagreb an der Macht war, regierte mithilfe der ungarnfreundlichen kroatischen (sog. »madjaronen«) und der serbischen Abgeordneten des Zagreber Parlaments, wo der Anteil der serbischen Abgeordneten - dank des restriktiven Wahlrechts - überrepräsentiert war. Daneben organisierte sich aber auch eine serbische Opposition (Nationale Unabhängigkeitspartei, Radikale Partei usw.), die sich vor allem auf das "Parlament« der serbischen Minderheit der ganzen ungarischen Reichshälfte (also auch aus Vojvodina), den sog. National-Kirchlichen Kongress konzentrierte, der sich als Sprachrohr der serbischen Nationalität und der serbisch-orthodoxen Religion in der Donaumonarchie verstand. Bis zum sog. "Neuen Kurs" (1903), als serbische und kroatische nationalliberale Kräfte eine kurzlebige antiösterreichische, proungarische Allianz in der "Fiumaner Resolution" eingingen, wurde die serbische Öffentlichkeit durch Budapest als Gegenpol zu kroatischen nationalen Forderungen benutzt; zum proungarischen Verhalten serbischer Politik unter Khuen-Héderváry siehe u.a. Nicholas J. Miller, Between Nation and State. Serbian Politics in Croatia before the First World War, Pittsburgh 1997, S. 36ff.

Agramer Tagblatt, 29. August 1894. 
kroatisch-nationalistischen Öffentlichkeit. Ein Teil der kroatisch-nationalistischen Opposition im Küstenland neigte sogar zur Idee, die Orthodoxie als "nationale Religion« aller Südslawen zu akzeptieren. Sie erkannten den möglichen Widerspruch zwischen dem supranationalen Katholizismus und der Nationalisierung des katholischen Kirchenlebens. Nach einem Bericht des national-oppositionellen Blattes Obzor erwogen national-kroatische Kreise um den Fiumaner kroatischsprachigen Politiker Erazmo Barčić bereits 1889, in die (serbische) Orthodoxie überzutreten, weil ihnen die katholische Kirche nicht südslawisch genug vorkam. ${ }^{134}$ Sie zogen der katholischen Religion die per definitionem südslawisch-national konzipierte (serbische) Orthodoxie vor. Auch in der österreichischen Hälfte erwogen nationalistisch eingestellte, kroatisch- oder slowenischsprachige Personen, in die Orthodoxie überzutreten, ${ }^{135}$ und die dortige slowenisch-nationalistische Presse betrieb Agitation für einen Übertritt. ${ }^{136}$ Einige slowenisch- oder kroatischsprachige, nationalistische Kreise verstanden die »Kroaten " (mitunter auch die "Slowenen«) und die "Serben« als Teil einer zu schaffenden jugoslawischen Nation. In der katholischen Kirche war diese Einstellung besonders um Bischof Strossmayer anzutreffen. ${ }^{137} \mathrm{Ihm}$ wurde sogar eine gewisse Vorliebe für die (serbische) Orthodoxie nachgesagt. ${ }^{138}$ Theoretisch hätte die serbische Orthodoxie der kirchenpolitischen und religiösen Untermauerung des

134 Der Bericht von Obzor zitiert in Vaterland, 3. August 1889.

135 Polizeibericht über einige slowenische Familien in Triest, die einen Übertritt erwägen würden (5. September 1893), in: AST, Luogotenenza, AP, b. 161, fasc. 4.1.5, $1630 / 1893$.

136 Bericht des slowenischsprachigen Bischofs von Triest, Ivan Nepomuk Glavina darüber (31. Oktober 1893), in: Ebd., 1957/1893.

137 Über die jugoslawischen Ideen von Strossmayer und seinem »Ideologen«, Franjo Rački siehe u. a. Egidio Ivetic, Jugoslavia sognata. Lo jugoslavismo delle origini [Das erträumte Jugoslawien. Der Jugoslawismus seit seinen Ursprüngen], Milano 2012, S. 119ff. (Strossmayer sprach aber der kroatischen Sprache und Kultur die Führungsrolle im Jugoslawismus zu - ähnlich dazu, wie er die kirchliche Vereinigung auf Basis der katholischen Religion forderte -, was dem Serbokroatismus und besonders der Expansions- und Kulturpolitik von Belgrad sowie der serbischorthodoxen Kirche vollkommen entgegenlief; vgl. dazu Auburger, Grundzüge der kroatischen und südslawischen Kulturpolitik, S. 35.

138 Klaus Buchenau, Svetosavlje und Pravoslavlje. Nationales und Universales in der serbischen Orthodoxie, in: Schulze Wessel (Hg.), Nationalisierung der Religion und Sakralisierung der Nation, S. 203-232, hier S. 208. (Strossmayer stellte aber fest, dass die serbische Seite die Annäherungsversuche feindselig beäugte, und auch wenn Strossmayer die serbische Kultur weiterhin unterstützte, musste er nüchtern zugeben, dass Serbien und die serbisch-orthodoxe Kirche eigentlich andere Ziele verfolgten als eine jugoslawische und katholische Vereinheitlichung aller Südslawen, die er anstrebte; zu Strossmayers zwiespältigem Verhältnis zum Serbentum siehe u. a. Auburger, Grundzüge der kroatischen und südslawischen Kulturpolitik, S. 39ff.). 
südslawischen, nationalen »Erwachens« besser entsprechen können als der Katholizismus.

Demnach kann die lokale Angst vor einer »Serbisierung« nicht nur auf antiungarische Gefühle, sondern auch auf die Ablehnung jugoslawischer Ideen unter dem Volk zurückgeführt werden. Auch der nationalpolitisch motivierte Hass auf den vermeintlich madjaronen Don Kovačić in Perušić ${ }^{139}$ kann insofern keinesfalls als alleinige Ursache der Aufstände herangezogen werden: Es war eher eine lokale Bedingtheit, die dem kroatisch-nationalistischen Diskurs als Ausrede zugutekam. Die altslawische Liturgiesprache war nicht die Forderung der ungarnfreundlichen kroatischen oder der serbischen Öffentlichkeit, insofern kann auch ihre Ablehnung nicht als antiungarischer oder antiserbischer Protest verstanden werden.

Zusammenfassend lässt sich festhalten, dass die nationalistische Öffentlichkeit mit den Aufständen nicht gut umgehen konnte. Dieselben Dorfbewohner galten mal als zu belehrende, national indifferente Fälle, und mal als Bauern, die sich nicht gegen die altslawische Liturgiesprache, sondern die serbische (orthodoxe) Bevölkerung bzw. die ungarnfreundliche Regierung aufgelehnt hätten. Diese Erklärungen, die sich einander klar widersprachen, zeigten die mentale Ferne zwischen den städtischen Diskursen und den ländlichen Realitäten. Meiner These nach lassen sich die ländlichen Konflikte daher nicht in der Dichotomie "nationale Indifferenz oder exklusiver Nationalismus « verstehen. Diese Bezeichnungen wurden der lokalen Ebene von außen her aufgedrückt. Der Widerstand gegen die altslawische Liturgiesprache erklärt sich vielmehr als Abwehrmoment einiger Gemeinden, die sowohl ihren katholischen Glauben als auch ihre kroatische »Identität« eigensinnig leben und praktizieren wollten. Die Dorfbewohner verorteten sich jenseits des Lagerdenkens der elitären Diskurse. Sie wehrten sich gegen jegliche Einmischungen, egal ob diese die lokale Ebene belehren (wie etwa im Falle von Kriviput) oder für einen antiserbischen-antimagyarischen Nationalismus preisen wollten (wie etwa im Falle von Perušić).

\subsubsection{Historischer Kontext: Altslawische Sprache als nationales Thema}

Der Konflikt in Lika-Krbava entstand infolge der altslawischen Liturgiesprache: Während die Makroebene über die Einführung diskutierte - Budapest war dagegen, die nationalistischen und viele kirchliche Akteure dafür (Kapitel 2.2.2) -, lehnte die lokale Ebene jegliche Veränderung ab. Die alt- 
slawische (glagolitische) Liturgiesprache darf zwar nicht - im Sinne von Eric Hobsbawm ${ }^{140}$ - als »erfundene Tradition « betrachtet werden, weil sie in der Vergangenheit tatsächlich praktiziert worden war. ${ }^{141}$ Ihre Wiedereinführung in den kroatisch bewohnten Teilen des oberadriatischen Raumes stellte aber eine künstliche, von oben her angeordnete Wiederbelebung einer vielerorts schon vergessenen und von der lokalen Ebene nicht erwünschten Praxis dar. In vielen Ortschaften hatte die Volkssprache im Alltag längst die altslawische Liturgiesprache ersetzt oder zumindest ergänzt. ${ }^{142}$ Im kirchlichen Bereich etablierte sich - wie Predrag Bukovec schreibt - »eine faktische Dreisprachigkeit«: Neben der altslawischen und der rein lateinischen Messe gab es Messen, in denen der Priester sein Brevier lateinisch betete, aber die Sakramente in kroatischer Sprache verteilte. ${ }^{143}$ Bereits 1495 wurde ein Messbuch zu dieser volkssprachlichen Variation in Venedig gedruckt, welches in Fiume/Rijeka 1889 nochmals verlegt wurde. ${ }^{144} 1634$ wurde die Verwendung der aus dem lateinischen Messbuch wortwörtlich übertragenen volkssprachlichen Messen erlaubt, die somit ein Usus innerhalb des lateinischen Ritus darstellten. ${ }^{145}$ Eine Messe, wo alles volkssprachlich gebetet wurde, war jedoch nicht zugelassen. ${ }^{146}$

Auch wenn der Hl. Stuhl die volkssprachliche Praxis zurückdrängen wollte, beäugte er kritisch und skeptisch die Entscheidung von Bischof Posilović, sie 1894 per Dekret mit der altslawischen Liturgiesprache in allen Kirchen des Bistums zu ersetzen. Die Ritenkongregation des Hl. Stuhles erlaubte mit einer Entscheidung von 1892 die altslawische Liturgiesprache als kirchenbezogenes Privileg: Nur in den Kirchen hätten die Priester die

140 Eric Hobsbawm, Inventing Traditions, in: Ders./Terence Ranger, The Invention of Tradition, Cambridge 1992, S. 1-14.

141 Die altslawische sowie kroatischsprachige Liturgie bestimmte das Kirchenleben im Bistum Senj vor dem 19. Jahrhundert; vgl. OrešKović, Un diocèse des Alpes Dinariques, S. 188.

142 Okey, Austro-Hungarian Diplomacy and the Campaign for a Slavonic Liturgy, S. 274.

143 Bukovec, Der glagolitische Usus, S. 104f.

144 Gottsmann, Rom und die nationalen Katholizismen, S. 40f.

145 Bukovec, Der glagolitische Usus, S. 104.

146 Es ist immerhin bemerkenswert, dass ein generelles Verbot volkssprachlicher Messen in der katholischen Kirche infolge des Privilegiums westkroatischer, dalmatinischer Pfarreien, die Messen in altslawischer oder (teilweise) kroatischer Sprache lesen zu dürfen, nie explizit und kategorisch festgelegt werden konnte, was kirchenrechtlich die spätere, während des Zweiten Vatikanischen Konzils erfolgte Öffnung der katholischen Kirche hin zur volkssprachlichen Liturgie ermöglichte; vgl. ders., S. 103. (Es war der damalige Bischof von Senj, der das Konzil von Trient im 16. Jahrhundert auf das bestehende Privileg der altslawischen Liturgiesprache, insofern auf die Unmöglichkeit eines generellen Verbotes der nichtlateinischen Messen aufmerksam machte, vgl. Smežıx, The Glagolitic or Roman-Slavonic Liturgy, S. 113). 
Gottesdienste altslawisch lesen dürfen, in denen es in der Vergangenheit als Privileg praktiziert wurde. Diese Entscheidung richtete sich einerseits gegen eine generelle Einführung der altslawischen Liturgiesprache, andererseits gegen die Meinung, dass das Privileg personenbezogen sei und dass ein »altslawischer Priester» deswegen in allen Kirchen die Messe altslawisch lesen dürfe. ${ }^{147}$

Warum löste die altslawische Liturgiesprache gerade unter den Kroaten in Lika-Krbava einen reaktiven Widerstand aus - und nicht etwa unter den istrianischen Kroaten? Milo Bogović erblickt darin einen Beweis dafür, dass die altslawische Liturgiesprache in den zwei Hälften einen unterschiedlichen Stellenwert gehabt habe. In Istrien waren die Kirchengemeinden ethnischnational heterogen, insofern hätte sich die altslawische Liturgiesprache als Möglichkeit für die kroatisch- oder slowenischsprachigen Katholiken angeboten, sich dadurch innerhalb der eigenen katholischen Kirchengemeinde behaupten zu können. Mit der Forderung nach altslawischen Gottesdiensten konnte die Latinität herausgefordert werden. In Lika-Krbava, wo der Unterschied zwischen Kroaten und Serben nicht in der Sprache, sondern in der Konfession bestand, habe die altslawische Liturgiesprache aber - wie Mile Bogović schreibt - eine andere Bedeutung gehabt: die Gefahr der Orthodoxisierung/Serbisierung der kroatischsprachigen Katholiken. Der Aufstand der kroatischsprachigen Katholiken in Lika-Krbava gegen die altslawische Liturgiesprache ließe sich daher - Bogović zufolge - aus derselben nationalen/nationalistischen Selbstverortung wie der (angebliche) Kampf der ebenso kroatischsprachigen Katholiken in Istrien für dieselbe Liturgiesprache erklären. Angesichts der unterschiedlichen Differenzierungsangebote (mal sprachlich gegen die »Italiener", mal konfessionell gegen die »Serben«) habe demnach die altslawische Liturgiesprache unterschiedliche Reaktionen auf der lokalen Ebene hervorgerufen. ${ }^{148}$

Bogović weist dabei richtigerweise darauf hin, dass die lokale Ebene - wie gezeigt wurde - nicht national indifferent war und die lokale Wahrnehmung der altslawischen Liturgiesprache dementsprechend neu gedacht, erforscht werden müsse. Es ist aber pauschalisierend zu behaupten, dass sich die kroatisch- oder slowenischsprachige Bevölkerung in Istrien die altslawische Liturgiesprache den nationalistischen Ideen entsprechend gewünscht habe. In beiden Teilen des Küstenlandes ging es letztendlich darum, die Gottesdienste zu verstehen. In den ethnisch-sprachlich heterogenen Kirchengemeinden führte dieser Wunsch zu innerkatholischen Kollisionen (vgl. Kapi-

147 Über das Dekret von 1892 siehe u. a. Gottsmann, Rom und die nationalen Katholizismen, S. 58ff. (Das Dekret war aber voll von inneren Widersprüchen, welche verschiedene, sehr weit gefasste Interpretationsräume eröffneten).

Bogović, Hrvatsko glagoljsko tisućljeće, S. 128ff. 
tel 3.1): Die italienischsprachigen Katholiken in Istrien konnten eine Messe, die nur für die kroatisch- und slowenischsprachigen Katholiken verständlich war, nicht akzeptieren. In einem solchen Kontext konnten die kroatisch- und slowenischsprachigen Katholiken ihre Forderungen nur proaktiv vortragen. Auch in Istrien wollten die kroatisch- oder slowenischsprachigen Katholiken, wie das Konfliktbeispiel aus Ricmanje zeigte (Kapitel 3.2), muttersprachliche (und nicht altslawische) Gottesdienste einführen. In Lika-Krbava hingegen verstanden die kroatischsprachigen Katholiken ihre Messen. Diese wurden in kroatischer Sprache zelebriert, die Kirchgänger brauchten kein neues Privileg. Daher verteidigten sie ihre bestehende Situation reaktiv. Die unterschiedliche Haltung gegenüber der altslawischen Liturgie erklärt sich also nicht aus der ethnisch-sprachlichen Zusammensetzung einer Region, sondern aus der Taktik, ob die kroatisch- oder slowenischsprachigen Katholiken die muttersprachlichen Gottesdienste proaktiv verlangen (mit Hinweis auf die altslawische Liturgie "herausprovozieren") oder reaktiv beschützen mussten.

Bogović versucht, die Akzeptanz oder die Ablehnung der altslawischen Liturgiesprache unter kroatischsprachigen Katholiken des oberadriatischen Raumes im Kontext des »Nationalitätenkonfliktes« zu erklären, als ob sich die diesbezüglichen unterschiedlichen Positionen der kroatischsprachigen Katholiken von der Perspektive eines »nationalen Anderen «, dem gegenüber sie sich verortet hätten, erklären lassen. Diese Erklärung ist aber zweifach problematisch. Einerseits forderten die kroatisch- (oder slowenisch-)sprachigen Katholiken in Istrien nicht die Einführung altslawischer Liturgien, sondern jene der muttersprachlichen Gottesdienste. Was in Lika-Krbava schon erreicht worden war (die kroatischsprachigen Gottesdienste), musste in Istrien noch erkämpft werden. Dabei - und es ist meine zweite Gegenthese stellte nicht die andere Nationalität, sondern die (oft ebenso kroatisch- oder slowenischsprachige) kirchliche Obrigkeit den Gegenpart dar. Sowohl in Istrien als auch in Lika-Krbava war die kirchliche Obrigkeit, auch wenn ein Bischof slowenischer oder kroatischer Abstammung war, gegen die verlangte oder bereits praktizierte muttersprachliche Liturgie auf der lokalen Ebene. In beiden ländlichen Teilen des Küstenlandes ging es um die muttersprachliche (und nicht die altslawische) Liturgie, die gegenüber der kirchlichen Obrigkeit proaktiv erkämpft (Istrien) oder reaktiv beibehalten (Lika-Krbava) werden musste.

Entsprechend der Richtung der Ansprüche - ob sie proaktiv oder reaktiv erhoben wurden -, konnten sie freilich im Kontext der "Nationalitätenfrage " - entweder als Nationalismus (Istrien) oder als nationale Indifferenz (Lika-Krbava) - (miss)verstanden werden (darüber siehe Kapitel 5.1.2). In einer solchen Erklärung werden jedoch die Abhängigkeiten sowie die Interessen der lokalen Akteure verkannt. Insofern ging es den lokalen Akteuren 
einerseits nicht um die altslawische Liturgiesprache (sondern um die muttersprachliche Liturgie). Andererseits war die Frage, ob die südslawischen Katholiken proaktiv oder reaktiv handeln mussten, nicht vom Vorhandensein inner- oder außerkirchlicher, nationaler Differenzen, also nicht horizontal, sondern von der jeweiligen Politik der kirchlichen und staatlichen Obrigkeit, also vertikal, bedingt.

Bezüglich der altslawischen Liturgiesprache dominierten bisher zwei Annahmen: Einerseits wurde besonders in den nationalistischen Blättern der damaligen Zeit angenommen, dass diese Liturgiesprache eine Forderung »der kroatischen Nation" (das heißt, der lokalen Ebene) sei. Andererseits wird in der Historiographie heutzutage öfters angenommen, dass innerkatholische Konflikte höchstens in den national-ethnisch heterogenen Kirchengemeinden - also in der Konstellation religiöser Homogenität und ethnisch-nationaler Heterogenität - entstanden seien: Dort stellte die Sprache - nicht nur in der Kirche, sondern auch in der Schule - ein umkämpftes Feld dar. Die rein kroatischsprachigen Kirchengemeinden hätten demnach die altslawische Liturgiesprache problemlos praktizieren können und wollen - es hätte sich letztendlich um ihre Forderung gehandelt. Die Widerstände in Lika-Krbava widerlegen jedoch diese Annahmen. Weder die erste Annahme (dass diese Liturgiesprache eine Forderung von unten gewesen sei) noch die zweite (dass Konflikte daraus nur in den ethnischnational heterogenen Kirchengemeinden entstehen könnten) lassen sich für diese kroatischsprachige Mikroregion bestätigen. Die kroatischsprachigen, katholischen Bewohner von Lika-Krbava hatten zwar ein ausgeprägtes kroatisches Bewusstsein (insofern waren sie nicht national indifferent), aber sie erlebten ihre Zugehörigkeit nicht im Kontext und Sinne nationalistischer Vorstellungen städtischer Diskurse. Insofern waren sie nicht nationalistisch eingestellt.

\subsection{Kirchenstreit im ländlichen Hinterland der Hafenstadt Fiume / Rijeka}

\subsubsection{Drenova: Kroatischsprachige Gemeinde in einem multiethnischen Raum}

An einem sonnigen Vormittag Ende Oktober 1908 hörte man schreiende Frauenstimmen vor einer Baustelle in der Innenstadt von Fiume/Rijeka. Weinende Frauen standen entsetzt neben einigen erschrockenen Kapuzinern herum: Ihre dunkelbrauen Kutten waren schmutzig, und die kroatischsprechenden Frauen versuchten, sie so gut wie möglich zu reinigen. Einige Maurer hatten die Kapuziner zuvor von oben her mit Mörtel überschüttet, als 
die Mönche unter ihrem Baugerüst vorbeiflanierten. Die Frauen hatten dem Vorgang zugesehen und eilten ihnen sofort zu Hilfe. ${ }^{149}$

Den lachenden Arbeitern und den weinenden Frauen war in diesem Moment wahrscheinlich nicht bewusst, dass sie der "Nationalitätenkonflikte« teilhaftig wurden. Drei marginalisierte Gruppen (Kapuziner, Arbeiter, Frauen) trafen aufeinander - in einer Stadt, deren Öffentlichkeit von einer italienischsprachigen, großbürgerlichen, liberalen, antiklerikalen, männlichen Elite dominiert war. Die ungarischsprachige (mit der italienischsprachigen Elite verbundene) Tageszeitung der Stadt, Fiumei Estilap, behauptete, dass die italienischsprachigen Maurer die kroatischsprachigen Kapuziner »aus Rache« attackierten, um »ihre Antipathie gegen die großkroatisch fühlenden Priester zu zeigen $\ll .{ }^{150}$ Was die Arbeiter wirklich dachten, ist unbekannt. Sie waren nur Objekte in einem nationalistischen Diskurs, der einen vielleicht eher persönlich oder antiklerikal motivierten Vorfall zwischen Arbeitern und Kapuzinern auf der mental map der städtischen Elite verortete. Nach der Raumimagination der städtischen Elite waren alle Konflikte national motiviert. Daher schien es dem Blatt wichtig zu sein, die Frauen, die Arbeiter und die Kapuziner national-sprachlich zu markieren. Damit ließ sich ein nationales Lagerdenken aufrechterhalten, in dem die vermeintliche nationale Abstammung/Muttersprache das Parteiergreifen in allen Konflikten bestimmt hätte.

Die städtische Öffentlichkeit in Fiume/Rijeka war im Sommer und Herbst 1908 besonders aufgeregt. Am 31. Juli 1908 meldete A Tengerpart, eine ungarischsprachige Tageszeitung der Hafenstadt, dass »ein kleiner Nationalitätenskandal die Einwohner von Drenova, einer Untergemeinde von Fiume [Rijeka] in Spannung hält«. ${ }^{151}$ Die italienisch- und ungarischsprachigen Zeitungen waren nach August 1908 voller Artikel über diesen Fall. Im Mittelpunkt stand Drenova, dessen Bewohner mit dem Klerus in Fiume / Rijeka sowie dem Bistum von Senj in Konflikt gerieten, nachdem das Bistum den vor Ort beliebten Priester entfernt hatte. Das Bistum schickte zwar neue Priester in das hoch gelegene Dorf, aber da ihnen das Stadtmagistrat die Dorfkirche nicht zur Verfügung stellte, wurde das Kirchenleben in Drenova unmöglich gemacht. Immer wieder kamen neue Nachrichten über kroatischsprachige Priester, die die örtliche Bevölkerung "terrorisieren" würden. Ein Angriff von italienischsprachigen Arbeitern auf kroatischsprachige Priester in der Stadt ließ sich daher gerade zu dieser Zeit gut in diesem Kontext der Streitigkeit darstellen. Die »kroatisch«markierte Kirche und die

149 Fiumei Estilap, 29. Oktober 1908.

150 Ebd. [übersetzt aus dem Ungarischen von mir].

151 A Tengerpart, 31. Juli 1908 [übersetzt aus dem Ungarischen und Hervorhebung von mir]. 
»italienisch" dominierte Stadt standen seit langer Zeit im Konflikt miteinander: Die altslawische Liturgiesprache oder die umstrittene kirchenrechtliche Zugehörigkeit der Hafenstadt waren Themen, die dieses Verhältnis stark belasteten. Der lokale Fall in Drenova geriet in den städtischen Zeitungen in ein Diskursfeld, in dem er als neues Unterkapitel dieser nationalpolitischen Konfliktgeschichte wahrgenommen wurde.

Drenova war eine der drei Untergemeinden der ungarischen Hafenstadt. ${ }^{152}$ Fiume/Rijeka war - im Gegensatz zu Lika-Krbava (Kapitel 4.1) - unmittelbarer Teil von Ungarn, was sich in der Bezeichnung "corpus separatum « ausdrückte. ${ }^{153}$ Was war damit ursprünglich gemeint? Maria Theresia inkorporierte die Stadt mit dem kaiserlichen Patent vom 23. April 1779 als »separatum sacrae Regni Coronae Hungariae adnexum corpus« in das Königreich Ungarn. ${ }^{154}$ Bis zum ungarisch-kroatischen Ausgleich von 1868 änderte sich die staatsrechtliche Lage öfters - auch infolge der napoleonischen Kriege und der darauf folgenden restaurativen Neuordnung Europas. Der Ausgleich von 1868 konnte dafür nur eine provisorische Lösung finden, ${ }^{155}$ welche jedoch Budapest die unmittelbare Herrschaft über die Stadt sowie der italienischsprachigen Elite die lokale Deutungshoheit bis 1918 gewährte. ${ }^{156}$ Das »Gefühl

152 Die Hafenstadt Fiume / Rijeka hatte drei Untergemeinden: Drenova, Cosala / Kozala, Plasse / Plase. Sie durften Abgeordnete ins Rathaus schicken und hatten vor Ort je einen Dorfrichter.

Über die staatsrechtliche Lage der Stadt und ihre Interpretationsmöglichkeiten siehe Dorottya ANDRÁsı, Fiume államjogi helyzetének rendezése és jelentősége a XIX. század második felében a jogforrások tükrében [Die Regelung und Bedeutung der staatsrechtlichen Lage von Fiume / Rijeka in der zweiten Hälfte des 19. Jahrhunderts im Lichte der Rechtsquellen], in: Jogtörténeti Szemle 7 (2005), S. 17-22.

154 CApuzzo, L' autonomia della città di Fiume, S. $13 \mathrm{ff}$.

155 HekA, A magyar-horvát államközösség, S. 166.

156 Während Kroatien-Slawonien innerhalb von Ungarn (besser gesagt: innerhalb den "Ländern der Ungarischen Heiligen Krone«) weitgehende Autonomie zugesichert war - weshalb die Kroaten den Status einer eigenen politischen Nation hatten -, blieb Fiume/ Rijeka unmittelbarer Teil von Ungarn. Nach der kroatischen Historiographie hätte aber Budapest die Regelung bezüglich der staatsrechtlichen Zugehörigkeit von Fiume/Rijeka im Text des ungarisch-kroatischen Ausgleichs gefälscht. Die ungarischen Regierungskreise hätten mit Tricks erreichen können, dass König Franz Joseph I. letztendlich nicht den vom kroatischen Parlament (Sabor), sondern den vom ungarischen (Országgyülés) verabschiedeten Text sanktionierte. Der so in Kraft getretene Text sei aber bezüglich der staatsrechtlichen Lage von Fiume/ Rijeka wesentlich vom ursprünglichen Text abgewichen, welchen die ungarischen und kroatischen Partner zuvor ausgehandelt hätten. Um diese juristische »Fälschung" $\mathrm{zu}$ vertuschen, wurde auf den kroatischen (und demnach gültigen) Text die sanktionierte (d.h. in Kraft getretene) Version des Paragraphen 66 (über Fiume/Rijeka) einfach aufgeklebt. Die ungarische Interpretation der staatsrechtlichen Lage von Fiume/Rijeka wäre somit dem ursprünglichen Text des ungarisch-kroatischen Ausgleichs wortwörtlich aufgedrückt worden. (Über diese kroatische Interpretation des Textes siehe u. a. Maja Polić, »Riječka krpica« 1868. godine i uvjeti za njezino naljepljivanje na Hrvatsko-ugarsku nagodbu [Das »Fiumaner Blättchen« vom Jahre 1868 und die Bedingungen für ihr Aufkleben auf den kroatisch-ungarischen 
der Besonderheit«, das die Einstellung der Stadtbewohner charakterisierte, ${ }^{157}$ wies zwar starke lokale Züge auf - daher war etwa der italienische Nationalismus / Irredentismus in der Stadt kaum vorhanden ${ }^{158}$-, aber der kulturell-sprachlich verstandene »italienische Charakter« wurde sowohl seitens der lokalen, italienischsprachigen Elite als auch der ungarischen Regierung und ihrem Repräsentanten vor Ort, dem jeweiligen Gouverneur, affirmativ betont. ${ }^{159}$ Zwischen den freisinnigen Regierungen in Budapest und der italienischsprachigen liberalen Elite in Fiume / Rijeka bestand eine Allianz - nicht zuletzt gegenüber Kroatien und den Kroaten. ${ }^{160}$

Die Untergemeinden der Hafenstadt standen lange Zeit mit ihrer ländlichen und kroatischen Prägung im Kontrast zu den städtischen Milieus. Die Mehrheit der Bewohner dieser Untergemeinden gehörte bis $\mathrm{zu}$ den 1880er-Jahren fast ausschließlich der kroatischen Nationalität an. ${ }^{161}$ Diese Lage veränderte sich aber rasch mit dem wirtschaftlichen und demographischen Aufschwung der Hafenstadt, ${ }^{162}$ weil viele Italiener und Ungarn nach

Ausgleich], in: Rijeka, 2010/1, S. 77ff.; William Klinger meint aber, dass nur die (nicht rechtsbindende) kroatische Übersetzung überklebt worden, aber dass dem kroatischen Sabor der vom König Franz Joseph I. sanktionierte Text vorgelegt worden sei, in dem Fiume / Rijeka als unmittelbarer Teil von Ungarn festgelegt worden war, siehe KLINGER, Negotiating the Nation, S. 121.

157 KARPOWICZ, Riječki Corpus separatum, S. 14.

158 Catherine Horel, Trieste et Fiume, deux aspects de l'irredentisme italien 18671914, in: Vojislav G. Pavlović (Hg.), Italy's Balkan Strategies. 19th and 20th Century, Belgrade 2014, S. 121-136, hier S. 129.

159 Der ungarische Gouverneur Sándor Nákó stellte etwa in seiner italienischen Amtsantrittsrede am 26. Juni 1906 in Fiume/Rijeka Folgendes fest: »ich bin in diese schöne Meeresstadt gekommen - wo die jahrhundertelange Vereinigung der uralten, vorwiegend lateinischen Kultur und Moral mit der ungarischen Kraft und Begabung stattfindet«; zitiert in: Budapesti Hírlap, 27. Juni 1906 [Hervorhebung und übersetzt aus dem Ungarischen von mir].

160 Tеснет, Verzahnung kirchen- und nationalpolitischer Frontlinien in Fiume/ Rijeka, S. $296 f$.

161 Deswegen wurden zuerst nur kroatischsprachige Grundschulen in diesen Untergemeinden gegründet, von denen aber nur die Grundschule in Drenova das Kroatische als Unterrichtssprache - neben dem Italienischen - beibehielt. So existierte die einzig kroatisch-italienische, zweisprachige Grundschule der Region in Drenova; vgl. Milivoj Čop, Riječko školstvo (1848-1918.) [Das Fiumaner Schulwesen (1848-1918)], Rijeka 1988, S. 51ff. (Laut Ilona Fried hätten die kroatischsprachigen Familien 1899 in Drenova abgelehnt, eine nur kroatischsprachige Schule zu haben, weil sie sich eher »illyrisch", fiumanerisch und nicht kroatisch gefühlt hätten; vgl. FRIED, Emlékek városa, S. 69).

162 Unter der ungarischen Herrschaft erlebte die Stadt einen wirtschaftlichen Aufschwung, der sich auch demographisch niederschlug. Aus den Statistiken lässt sich ein großer Bevölkerungszuwachs ablesen (1891: 29.494 Einwohner; 1910: 49.806) auch wenn die Größe der Stadt jene von Triest nicht einmal annähernd erreichte -, was einerseits der ungarischen Ansiedlungspolitik, andererseits italienischer (und in geringerem Maße: südslawischer) Zuwanderung aus Istrien, Kroatien-Slawonien, Dalmatien, der Krain wie auch aus dem Königreich Italien zuzurechnen war. 
Plasse / Plase oder Cosala / Kozala zogen. Diese zwei Untergemeinden (besonders Cosala / Kozala) wuchsen infolgedessen als Vororte mit den innenstädtischen Teilen der Hafenstadt zusammen. Drenova hingegen war geographisch gesehen die entfernteste Untergemeinde, die sich in der bergigen Umgebung, in einem verkehrsmäßig schwer erreichbaren Gebiet, befand. ${ }^{163}$ Aber auch auf der mental map vieler Fiumaner befand sich Drenova "weit weg« vom städtischen Leben. Im Gegensatz zu den zwei anderen Untergemeinden blieb Drenova bis zum Ende der Habsburgermonarchie ausschließlich katholisch und überwiegend kroatisch bewohnt: Laut der Volkszählung von 1910 lebten 1.156 Menschen im Dorf, wovon 1.000 kroatischer und 156 »sonstiger" (das heißt italienischer ${ }^{164}$ ) Nationalität waren, und nur 13 Menschen waren der ungarischen Sprache mächtig. ${ }^{165}$ Drenova konnte seine ursprüngliche demographische und soziokulturelle Struktur am ehesten bewahren, weil das Dorf von den urbanisierenden Veränderungen und der (überwiegend magyarischen) Einwanderung kaum betroffen war. Im Bezirk von Fiume / Rijeka

Der Anteil der ungarischen Bevölkerung vervielfachte sich binnen zwanzig Jahren (1891: 3.60 \%; 1910: $13.04 \%$ ), die meisten Bürger waren bei staatlichen Einrichtungen angestellt. Stellen bei der Post oder der Staatsbahn (MÁV) wurden fast nur von (ethnischen oder assimilierten) Magyaren besetzt; Daten aus: Országos Királyi Magyar Statisztikai Hivatal (Hg.), A Magyar Korona Országaiban az 1891. év elején végrehajtott népszámlálás eredményei. I. rész: Általános népleírás [Die Ergebnisse der am Anfang des Jahres 1891 in den Ländern der Ungarischen Krone durchgeführten Volkszählung. Teil I: Allgemeine Volksbeschreibung], Budapest 1893, S. 30, 122; sowie Magyar Királyi Központi Statisztikai Hivatal (Hg.), A Magyar Szent Korona Országainak 1910. évi népszámlálása. Első rész: A népesség főbb adatai községek és népesebb puszták, telepek szerint [Die Volkszählung der Länder der Ungarischen Heiligen Krone im Jahre 1910. Erster Teil: Die Hauptdaten der Bevölkerung in den Gemeinden und bevölkerungsreicheren Puszten, Siedlungen], Budapest 1912, S. 26, 459.

163 Das Gouverneursamt wies in der Debatte, ob Priester aus Fiume/Rijeka die Seelsorge in Drenova von der Stadt aus wahrnehmen könnten, darauf hin, dass die Dorfkirche in Drenova von der Stadtpfarrei von Fiume/Rijeka (also praktisch von der Innenstadt der Hafenstadt) "auf gut eine oder eineinhalb Stunde Spaziergang" liege; vgl. Brief an den ungarischen Kultus- und Bildungsminister (25. August 1908), in: Magyar Nemzeti Levéltár, Országos Levéltár (Ungarisches Nationales Archiv, Staatsarchiv; weiter: MNL OL), Miniszterelnökség (Ministerpräsidium; weiter: ME), Fiumei ügyek K26 (Fiumaner Angelegenheiten; weiter: FÜ K26), 1908/3897 [übersetzt aus dem Ungarischen von mir].

164 Die ungarische Statistik erfasste die Italiener nicht separat, weil sie - außer Fiume/Rijeka - in Ungarn vollkommen irrelevant waren; sie wurden also unter "Sonstigen" gefasst, was aber im Falle von Fiume/ Rijeka - angesichts der Tatsache, dass alle anderen Nationalitäten / Nationalitätssprachen von Ungarn separat aufgelistet wurden - praktisch nur die Italiener abdeckte.

165 In Plasse/Plase lebten zur selben Zeit 8046 Menschen, davon u.a. 4.280 Italiener, 2.729 Kroaten und 1.232 Ungarn (und insgesamt 1.312 Menschen sprachen Ungarisch); in Cosala/Kozala lebten 6.219 Menschen, davon u.a. 3.954 Italiener, 1.507 Kroaten und 795 Ungarn (und insgesamt 942 Menschen sprachen Ungarisch); Daten aus: A Magyar Szent Korona Országainak 1910. évi népszámlálása, S. 629. 
(dem sog. "Corpus Separatum«) stellte Drenova somit ein dörfliches Milieu dar, das eher dem istrianischen und kroatischen, ländlichen Hinterland als der multikulturellen Hafenstadt (und den zwei anderen, urbanisierten Untergemeinden) ähnlich war.

Im Folgenden geht es darum, zuerst den Kirchenstreit in Drenova zu rekonstruieren, der bis jetzt in der Forschung noch nie von der mikrogeschichtlichen Ebene her dargestellt worden ist (4.2.2). ${ }^{166}$ In einem zweiten Schritt wird die mediale Rezeption des Falles im Kontext der bestehenden national- und kirchenpolitischen Frontlinien analysiert: Dabei werden einerseits die Interpretationsstrategien der verschiedenen Blätter untersucht (4.2.3), andererseits werden die Konfliktfelder (altslawische Liturgiesprache, Bistumsfrage) geschildert, die in Fiume/Rijeka die Wahrnehmung kirchlicher Angelegenheiten bestimmten (4.2.4).

\subsubsection{Konfliktgeschichte:}

\section{Abwehr kirchlicher Einmischungen}

Drenova bekam die Konsequenzen des Konfliktes zu spüren, der seit Langem zwischen der italienischsprachigen, liberalen Stadtführung und der kroatischsprachigen Kirchenhierarchie bestand. Die selbstständige Dorfpfarrei in Drenova hatte deswegen keinen eigenen Pfarrer, weil sich die Stadt Fiume / Rijeka - die die Herrschaftsrechte über die Dorfkirche ausübte - mit dem Bistum Senj auf keinen Pfarrer einigen konnte. Nachdem der frühere Dorfpfarrer, Fabiano Sirola, pensioniert worden war, ${ }^{167}$ lehnte die Stadt die ihr vorgestellten Pfarrerkandidaten konsequent ab, weil sie - wie der autonomistische Bürgermeister Francesco Vio beteuerte - "politische Agitatoren" und »hart gegenüber den Bürgern von Fiume« seien. ${ }^{168}$ Die Ernennung eines

166 Der Kirchenstreit in Drenova wurde bis jetzt nur bei Andreas Gottsmann kurz im Kontext der diplomatischen Korrespondenz zwischen Wien/Budapest und dem Hl. Stuhl erwähnt, vgl. Gottsmann, Rom und die nationalen Katholizismen, S. 113f.

167 Mit Fabiano Sirola waren die ungarischen und italienischen politischen Akteure zufrieden, weil er die Pfarrei - wie ihn der ungarische Parlamentsabgeordnete, Tivadar von Batthyány, 1911 im ungarischen Landtag lobte - nicht im Sinne "anti-ungarischer und anti-italienischer, kroatischer Propaganda " geführt hätte, Batthyány bemerkte dabei, dass »die Situation [in Drenova und Fiume/Rijeka] damals noch aushaltbar war«. Siehe Rede von Tivadar von Batthyány im ungarischen Landtag (Országgyülés), am 5. April 1911, in: Az 1910. évi június hó 21-ére hirdetett Országgyűlés Képviselőházának Naplója. Hatodik Kötet [Protokolle des für den 21. Juni 1910 berufenen Abgeordnetenhauses des Landtages. Sechster Bd.], Budapest 1911, S. 468 [übersetzt aus dem Ungarischen von mir].

Brief des Bürgermeisters Vio an den ungarischen Ministerpräsidenten Wekerle 
Pfarrers bedurfte - wie auch in der Stadt - der städtischen Zustimmung, ohne die das Bistum nur Administratoren nach Drenova schicken konnte. ${ }^{169}$

Im Jahre 1906 wählte das Bistum Pavel Zigar aus, ${ }^{170}$ der zuvor - nach beruflichen Stationen im kroatischsprachigen Gymnasium in Sušak und im Priesterseminar in Senj - in der kroatischen Stadt Ogulin als Kaplan tätig gewesen war. ${ }^{171}$ Fiume/Rijeka begrüßte damals - wie sich der Bürgermeister Dr. Vio 1907 zurückerinnerte - die bischöfliche Entscheidung, einen in Fiume / Rijeka geborenen Priester zum Administrator in Drenova zu ernennen. ${ }^{172}$ Don Zigar trat somit als ein Priester seine Stelle an, der sich nicht nur der Unterstützung der kroatischen Kirchenobrigkeit, sondern auch jener der italienischsprachigen Stadtführung erfreute. Diese Idylle dauerte aber nicht lange an. Was war passiert?

Am 7. Februar 1908 starb Antun Maurović, der Bischof von Senj, dessen Sitz bis 1910 vakant blieb. In diesem Interregnum ergriffen die »italienischen « wie auch die »kroatischen« nationalistischen Kreise die Initiative, die lokale Kirchenpolitik nach ihren Interessen zu beeinflussen. Schon im April 1908 veröffentlichte das kleine, irredentistische Blatt von Fiume/Rijeka, Giovine Fiume, einen besorgten Artikel über die angebliche »kroatische Propaganda» in den Fiumaner Untergemeinden. Dabei wurde explizit Drenova erwähnt, wo »kroatische Agitatoren« aus dem istrianischen (also schon österreichischen) Hinterland einen »Lesekreis« zu gründen geplant hätten. ${ }^{173}$ Die $»$ Lesekreise« (čitaonice) bildeten den intellektuellen Raum für die südslawische nationale Emanzipation. ${ }^{174}$ Auch wenn sie meistens keine direkte politische

(31. August 1908), in: MNL OL, ME, FÜ K26, 1908/4230 [übersetzt aus dem Italienischen von mir].

169 Brief des Stadtrates von Fiume/ Rijeka an den Gouverneur Sándor Nákó (30. August 1908), in: DAR, Kraljevskij Gubernij za Rijeku i Ugarsko-Hrvatsko Primorje (Königlicher Gouverneur für Fiume / Rijeka und das Ungarisch-Kroatische Küstenland, weiter: Gubernij), Prezidijalni Spisi (Präsidialschriften, weiter: Pr.Sp.), kutija (kut.) 34, 1908/172.

170 Mitteilung von Stadtpfarrer Kukanić an den Magistrat über die Ernennung von Don Zigar (2. Mai 1906), in: DAR, Gradsko poglavarstvo Rijeka / Magistrato civico di Fiume (Stadtmagistrat von Fiume/Rijeka; weiter: Magistrato), Opći spisi (Allgemeine Schriften; weiter: Op.Sp.), D-57-1897 - 8410.

171 Zur Biographie siehe: "Pavel Zigar« (1878-1947), in: BAS, R22: Album svećenika senjske i modruške biskupije u dva sveska (Album der Priester des Bistums von Senj-Modruš in zwei Bde.; weiter: R22 Album) [ohne weitere Nummerierung].

172 Brief von Bürgermeister Dr. Vio an Stadtpfarrer Kukanić (5. November 1907), in: DAR, Magistrato, Op.Sp., D-57-1897 - 22002.

173 Giovine Fiume, 26. April 1908 [übersetzt aus dem Italienischen von mir].

174 Über die istrianischen Lesekriese - meist nach einem national-historiographischen Narrativ - siehe u. a. F. SLOKović, Narodne čitaonice u Istri [Nationale Lesekreise in Istrien], in: Bruno Dobrić/Antun Hek (Hg.), Hrvatska čitaonička društva u Istri u 19. i početkom 20. stoljeća [Kroatische Leserkreis-Gesellschaften in Istrien im 19. Jahrhundert und Anfang des 20. Jahrhunderts], Pula / Pazin 1993, S. 89-101; Bruno DoBRIĆ, Kultura čitanja i nacionalni pokreti. Čitalačka društva i knjižnice 
Tätigkeit ausübten, sondern vielmehr einer mehrheitlich analphabetischen, südslawischen Bevölkerung das Lesen und Schreiben beibringen wollten freilich in kroatischer oder slowenischer Sprache -, empfand die italienischsprachige, liberale Elite das als eine national- wie auch sozial-politische Provokation. Die kroatischsprachige Tageszeitung Riječki Novi List rechtfertigte die Pläne eines »Lesekreises « hingegen mit der (vor allem in kultureller Hinsicht) "verlassenen « Situation der Drenovaer: Sie seien »ein sehr verlassenes Volk" gewesen, die "seit Jahren nicht einmal ein Krümelchen vom reichen Tisch der Hochkultur« abbekommen hätten. ${ }^{175}$ Pavel Zigar soll sich jedoch als Kirchenadministrator in Drenova diesen Gründungsplänen eines »Lesekreises « widersetzt haben, woraufhin er vom Bistum Senj seines Kirchenamtes im Sommer 1908 enthoben und in das kroatische Küstendorf Ledenice versetzt wurde.

Zumindest nach der Erzählung des autonomistischen Bürgermeisters (podestà) von Fiume/Rijeka, Francesco Vio, fing damit der Konflikt in der Untergemeinde an. Dieser Erklärung schlossen sich die Presse- und Gouverneursberichte vorbehaltlos an:

Und weil der Geistliche Don Paolo Zigar für seine Pflicht als guter Priester und guter Fiumaner erachtete, sich in diese Machenschaften [die Gründung eines kroatischen Lesekreises - P. T.] nicht einzumischen, und weil er hingegen die Einheit unter den Menschen und die Liebe gegenüber der Stadt Fiume [Rijeka] und ihrer Union mit Ungarn verkündete, bekam er an einem schönen Tag eine Anordnung vom Bischof aus Zengg [Senj], die ihn in ein kleines Dorf in Kroatien versetzte. ${ }^{176}$

Die Behauptung, dass Don Zigar wegen seiner vermeintlichen Weigerung, bei der Gründung einer Čitaonica mitzuhelfen, entlassen worden sei, sollte aber infrage gestellt werden. Denn auch, wenn im italienischsprachigen, nationalliberalen Diskurs ein kausaler Zusammenhang zwischen den Gründungsversuchen eines "Lesekreises « und der Absetzung von Don Zigar hergestellt wurde, war die Absetzung schon zuvor erwogen worden. Bereits im Herbst 1907 unternahm das Bistum Senj Maßnahmen, um Don Zigar aus dem Dorf zu entfernen. Damals gab Bischof Maurović den Protesten aus der Stadt und

u Puli u drugoj polovici 19. i prvoj polovici 20. stoljeća [Lesekultur und nationale Bewegungen. Lesegesellschaft und Bibliothek in Pula in dem späten 19. und frühen 20. Jahrhundert], Pula 2003.

175 Riječki Novi List, 20. Februar 1909 [übersetzt aus dem Kroatischen von mir].

176 Brief des Bürgermeisters Dr. Vio an den ungarischen Ministerpräsidenten Sándor Wekerle (31. August 1908), in: MNL OL, ME, FÜ K26, 1908/4230 [übersetzt aus dem Italienischen von mir]. Die Beschreibung stimmt schon daher nicht, weil Zigar die Anordnung nicht vom Bischof, dessen Sitz vakant war, sondern dem Vikar der kroatischen Kleinstadt Novi, Matej Cvetko, erhielt, der in der bischöflichen Vakanz stellvertretend agierte. 
dem Dorf gegen die Absetzung jedoch nach, »nicht weil [Zigar] nicht schuldig sei«, sondern weil der Bischof anhaltende Unruhen in Drenova befürchtete. ${ }^{177}$ Die kirchlichen Berichte erwähnten dabei nirgendwo die Weigerung bezüglich der Gründung einer Čitaonica. Als Matej Cvetko, der als Vikar der adriatischen Kleinstadt Novi während der bischöflichen Vakanz handeln durfte, im Sommer 1908 Don Zigar seines Amtes enthob, ${ }^{178}$ wies er darauf hin, dass der Entlassungsgrund genau derselbe sei wie im Herbst 1907:

Das Bischöfliche Ordinariat von Senj-Modruš hat denselben [Zigar] schon voriges Jahr versetzt, aber unter dem Druck der Umstände gab [das Bistum] nach und ließ ihn weiterhin auf der gleichen Stelle, unter der Bedingung, dass er sofort versetzt würde, falls er denselben Fehlern anheimfällt. Nachdem das Vikariat gesehen hatte, dass sich Pavel Zigar nicht verbesserte, musste es seine Pflicht tun und ihn absetzen. ${ }^{179}$

Was war der »Fehler«, den Don Zigar anscheinend zum wiederholten Mal begangen hatte? Don Cvetko benannte in seinem Brief an den Wiener Nuntius Anfang 1909, als er ihm den Fall erläuterte, »[Zigars] unwürdiges priesterliches Benehmen" als Absetzungsgrund. ${ }^{180}$ Die Weigerung, einen »Lesekreis« zu unterstützen, wird Don Cvetko nicht als »Fehler« oder »unwürdiges Benehmen « beschrieben haben. Diese Worte ließen andere Gründe vermuten. In seinem offiziellen Brief an Jurij Posilović, den Zagreber Erzbischof, rechtfertigte Don Cvetko seine Entscheidung mit unpolitischen Ursachen: Don Zigar habe »die Pfarrei [in Drenova] völlig vernachlässigt« und die meiste Zeit »in den Kneipen und Cafés von Fiume/Rijeka mit allen möglichen Leuten " verbracht. ${ }^{181}$ Neben den angesprochenen persönlichen Problemen deuteten die Kirchenverwalter in ihren späteren Berichten - schon nach der Absetzung - auch finanzielle Unklarheiten an: Don Zigar habe sich geweigert, ihnen die Rechnungen, samt Erklärungen, zur Verfügung zu

177 Brief von Vikar Rocco Vučić an den Bürgermeister Francesco Vio (27. November 1907), in: DAR, Magistrato, Op.Sp, D-57-1897 - 23041 [übersetzt aus dem Kroatischen von mir].

178 Mitteilung von Stadtpfarrer Kukanić an den Magistrat bezüglich der Entscheidung von Cvetko (30. Juli 1908), in: DAR, Magistrato, Op.Sp., D-57-1897 - 17349.

179 Brief von Matej Cvetko an den ungarischen Kultus- und Bildungsminister (1. September 1908), in: DAR, Gubernij, Pr.Sp., kut. 34, 1908/161 [übersetzt aus dem Kroatischen von mir].

180 Matej Cvetko an den Wiener Nuntius über die Absetzung (18. Februar 1909), in: AAV, ANV, b. 741, fasc. XIII, fol. 37 [übersetzt aus dem Italienischen von mir].

181 Brief von Matej Cvetko an Jurij Posilović (6. Februar 1909), in: Nadbiskupski Arhiv u Zagrebu (Erzbischöfliches Archiv in Zagreb; weiter: NbAZ), Ostavština Jurija Posilovića (Vermächtnis von Jurij Posilović; weiter: Posilović), Prezidijalni spisi / Acta praes. (Präsidialschriften, weiter: AP), kutija 4, broj 112 [übersetzt aus dem Kroatischen von mir]. 
stellen, ${ }^{182}$ insofern hätten sie überhaupt nicht feststellen können, »wo und wie [Zigar] das Geld verwendete «. ${ }^{183}$

Die kroatischsprachigen Dorfbewohner zeigten sich solidarisch ihrem abgesetzten Priester gegenüber. Ende Juli 1908 meldete die italienischsprachige, politisch wenig voreingenommene Tageszeitung Il Corriere, dass die Dorfbewohner gegen die Absetzung von Don Zigar protestierten. ${ }^{184}$ In Drenova war er in der Tat beliebt: Daher befürchtete Bischof Maurović schon im Herbst 1907 Unruhen infolge einer möglichen Versetzung.

Die kirchliche Obrigkeit nahm den Widerstand zuerst nicht ernst und schickte einen neuen Priester, Balaž Petrović, als Nachfolger nach Drenova. ${ }^{185}$ Am 31. Juli 1908 hätte Don Zigar ihm die Kirche übergeben sollen. Der Magistrat von Fiume/Rijeka ließ vorher die Dorfkirche zusperren, um die Übergabe zu vereiteln. Dass die Kirche in Drenova keinem anderen Priester als Don Zigar übergeben werden würde, war zu erwarten, nachdem der Stadtmagistrat vorher verkündet hatte: Die kirchliche Entscheidung, einen neuen Priester für Drenova zu ernennen, nehme »zahlreichen christlichen Familien von Drenova die priesterliche Präsenz« weg. ${ }^{186}$ Die Seelsorge war jedoch nicht infolge der Ernennung eines neuen Priesters, sondern durch die Schließung der Kirche gefährdet, auch wenn die Dorfbevölkerung den neuen Priester ablehnte. Mate Polić, der spätere Kirchenadministrator von Drenova, bemerkte im Sommer 1911 im Drenovaer Kirchenbuch - auf die Affäre zurückblickend -, dass die Dorfbevölkerung zu diesen Zeiten keinen anderen Priester außer Pavel Zigar zu akzeptieren willens gewesen sei: »entweder Zigar kehrt nach Drenova zurück oder überhaupt kein Pfarrer«, so fasste Don Polić die damalige Meinung der Dorfbewohner zusammen. ${ }^{187}$

Am Tag des angesetzten Übergabetermins versammelte sich eine kleinere Menge - hauptsächlich Frauen - schon in der Früh am Hauptplatz von Drenova, um gegen den neuen Kirchenadministrator Don Petrović zu demonstrieren. ${ }^{188}$ Die kirchliche Obrigkeit änderte daraufhin ihre Entscheidung: Statt eines neuen Administrators habe sich der Stadtpfarrer von

182 Brief der Kirchenverwalter an den Stadtmagistrat (9. September 1908), in: DAR, Magistrato, Op.Sp., D-67-1908 - 20377.

183 Brief der Kirchenverwalter an den Stadtmagistrat (3. Oktober 1908), in: Ebd., D-671908 - 22360 [übersetzt aus dem Italienischen von mir].

184 Il Corriere, 30. Juli 1908.

185 Brief des Stadtpfarrers von Fiume/Rijeka, Ivan Kukanić an die Stadtverwaltung (27. Juli 1908), in: DAR, Magistrato, Op.Sp., D-57-1897 - 17177.

186 Brief des Magistrates an den Stadtpfarrer von Fiume/ Rijeka, Ivan Kukanić (31. Juli 1908), in: Ebd., D-57-1897 - 17349 [übersetzt aus dem Italienischen von mir].

187 Notiz von Mate Polić (11. Juni 1911), in: Arhiv Župe na Drenovi (Archiv der Pfarrei in Drenova, weiter: AŽD), Liber Insertionis Historiae neoerectae parochiae Drenovensis ab anno 1837 (weiter: Liber Insertionis), fol. 21 [übersetzt aus dem Kroatischen von mir].

188 La Bilancia, 31. Juli 1908. 
Fiume/Rijeka, Ivan Kukanić, um die Seelsorge des Dorfes zu kümmern. ${ }^{189}$ Wegen des andauernden Widerstands im Dorf und der Tatsache, dass die Stadt die Kirchenschlüssel bei sich hielt, konnte Don Kukanić jedoch keine seelsorgerischen Aufgaben in Drenova wahrnehmen. Die Dorfbewohner sperrten Don Zigar - seiner Sicherheit halber - im Pfarrhaus ein, und vor seinem Haus wurde sogar eine Wache organisiert, weil befürchtet wurde, dass die kirchliche Obrigkeit ihre Entscheidung, ihn aus dem Dorf zu entfernen, mit Gewalt durchsetzen werde. ${ }^{190}$ Vikar Cvetko machte für die eskalierte Situation die städtische Presse verantwortlich, die das Dorf gegen die Kirche aufgehetzt habe:

die Drenovaer Gläubigen, ein sonst ruhiges und frommes Volk, angestachelt von den lügnerischen und tendenziös verzerrten Berichten auf den Versammlungen und in den Zeitungen, bedrohen den Geistlichen und hindern ihn an seiner priesterlichen Pflicht... ${ }^{191}$

Aus dem Dorf reiste eine Delegation in die Stadt, um persönlich gegen die Absetzung zu demonstrieren. Im Rathaus überreichten die Gesandten dem Bürgermeister Francesco Vio und dem Budapester Parlamentsabgeordneten der Stadt, Riccardo Zanella, einen Protestbrief, der von den Politikern der »Autonomistischen Partei« freilich wohlwollend entgegengenommen wurde. Danach wollten die Dorfbewohner Stadtpfarrer Kukanić aufsuchen. Sie marschierten daher zum Stadtdom San Vio/Sv. Vid, vor das Pfarrhaus, wo einige den Zaun vor der Pfarrei entfernten und ins Pfarrhaus einbrechen wollten. Einige Fiumaner Passanten schlossen sich der Demonstration an und skandierten beleidigende Sprüche gegen Don Kukanić. Die liberale Tageszeitung Riječki Novi List bemerkte, dass die anwesenden Dorfbewohner Don Kukanić »in reinem Kroatischen verfluchten ${ }^{192}$ Obwohl die kroatischsprachige Tageszeitung mit diesem Halbsatz die »italienischen« Ansprüche bezüglich des Dorfes relativieren wollte - worin sie Recht hatte -, zeigt diese Situation, wo »kroatische" Bauern in kroatischer Sprache gegen einen »kroatischen" Priester demonstrieren, dass sich der Konflikt nach nationalen Kategorien weder verstehen noch erklären lässt.

189 Don Kukanić teilt die diesbezügliche Entscheidung dem Stadtmagistrat mit (4. August 1908), in: DAR, Magistrato, Op.Sp., D-57-1897 - 17762.

190 La Voce del Popolo, 8. August 1908; La Bilancia, 10. August 1908.

191 Brief von Matej Cvetko an den ungarischen Kultus- und Bildungsminister (1. September 1908): DAR, Gubernij, Pr.Sp., kut. 34, 1908/161 [übersetzt aus dem Kroatischen von mir].

192 Riječki Novi List, 11. August 1908 [übersetzt aus dem Kroatischen von mir]. 
Nach der städtischen Demonstration begab sich Don Zigar letztendlich nach Ledenice, ${ }^{193}$ einem kleinen Dorf an der kroatischen Adriaküste neben Novi, wo er angeblich mit Demonstrationen erwartet worden sei. ${ }^{194}$ Diese Nachricht hätte wiederum das nationale Narrativ des Konfliktes betonen sollen: Wenn die Erzählung »kroatisches Dorf gegen national indifferenten Priester « in Drenova nicht wirkte, hätte es zumindest in Ledenice, einem nicht nur kroatisch bewohnten, sondern zu Kroatien gehörenden Dorf, funktionieren sollen. Aber gerade die Tageszeitung Riječki Novi List - oder besser gesagt: ein Leser der Zeitung - dementierte diese Nachricht in einem Leserbrief: "gegen diesen Žigar oder Cigar oder wie er sonst heißt« habe es in Ledenice keine Demonstration gegeben, weil »die Ledeniceaner ruhige und anständige Bauern sind «. ${ }^{195}$ Nachdem Don Zigar weggegangen war, blieb das Dorf ohne Priester. Die liberale Tageszeitung La Bilancia wunderte sich heuchlerisch ob der so entstandenen Situation in einem sonst tiefreligiösen Dorf:

Drenova ist heute ohne Priester. In einer hoch entwickelten und ziemlich atheistisch eingestellten Stadt würde ein solcher Zustand, ehrlich gesagt, kein großes Problem darstellen, aber in unserer Untergemeinde, wo das religiöse Gefühl noch lebendig ist, wo der Glaube an die Unsterblichkeit der Seele und an die Existenz einer jenseitigen Welt noch gelebt ist, ist so ein Zustand nicht weniger als eine Ungeheuerlichkeit. ${ }^{196}$

Mitte August 1908 fand die traditionelle Prozession der Drenovaer statt: Die Dorfbewohner reisten wie jedes Jahr in die Stadt. Diesmal wurden sie aber dort von niemandem aus der katholischen Kirche empfangen. Die Kirchenglocken läuteten nicht, und keine Messe wurde im Dom zelebriert. Nach den Informationen von La Bilancia habe Don Kukanić allen Priestern in der Stadt angeordnet, der Prozession nicht beizuwohnen. Die traurigen Dorfbewohner gingen letztendlich in eine andere Kirche oberhalb der Stadt, wo sie allein den Rosenkranz beteten. ${ }^{197}$ Die sonst antiklerikale Tageszeitung der Autonomisten, La Voce del Popolo, zeigte sich über die verletzten religiösen Gefühle der Dorfbewohner paternalistisch besorgt. Das Blatt erkannte die Möglichkeit, den Fall - statt eindeutig antiklerikal - "nur« antikroatisch zu behandeln, um sich sogar als Schützer wahrer religiöser Gefühle gegenüber der »kroatischen" Kirche positionieren zu können: »Unsere guten Bauern können religiöse Tröstung nicht nur in Drenova, sondern auch in Fiume

193 Zigar teilte seine am 12. August 1908 erfolgte Abreise dem Stadtmagistrat mit (13. August 1908), in: DAR, Magistrato, Op.Sp., D-57-1897 - 18486.

194 Budapesti Hírlap, 18. August 1908.

195 Riječki Novi List, 29. August 1908 [übersetzt aus dem Kroatischen von mir].

196 La Bilancia, 12. August 1908 [übersetzt aus dem Italienischen von mir].

197 Ebd., 17. August 1908. 
nicht finden. [...] [D]er kroatische Klerus betrachtet die Drenovaer als rechtlos und er behandelt sie tatsächlich wie Hunden in der Kirche. ${ }^{198}$

Die kroatischsprachigen Zeitungen machten sich dagegen darüber lustig, wie sich die antiklerikalen Kreise plötzlich im Interesse eines Priesters, des »armen, elenden Don Zigar«, betätigten. ${ }^{199}$ Als sich der antiklerikale Politiker Zanella für die Gläubigen im Dorf einsetzte, ${ }^{200}$ bezeichnete ihn das kroatischsprachige Riječki Novi List sarkastisch als »frischgebackene[n] große[n] Katholik[en] und Missionar «. ${ }^{201}$ Die irredentistische, antiklerikale Giovine Fiume war hingegen offener und ehrlicher in seinem Antiklerikalismus: Die Zeitung fand, bei dem Fall um Don Zigar handele es sich um »eine dumme Angelegenheit«, weil »es eigentlich um einen Priester geht «. ${ }^{202}$ Das Blatt räumte ein, dass es keine Sympathie für irgendwelche kirchlichen Personen hegen könne und dass es sich in einer kirchlichen Angelegenheit ungern positioniere - auch wenn der Fall nationale Konnotationen hervorrufen könne.

Auch wenn die Dorfgemeinschaft in Drenova den »klerikalen« Erwartungen nicht entsprach, wurde der katholische Glaube im Dorf nicht abgelehnt, sondern ohne kirchliche Mitwirkung weiter praktiziert. Die Dorfbewohner übernahmen einige kirchliche Aufgaben wie etwa Taufen: Es wurde - ähnlich wie in Ricmanje (Kapitel 3.2.2) - "zivil« (aber nicht religionslos) getauft. ${ }^{203}$ Während die Amtskirche ein polizeiliches, sogar mit Gewalt durchzusetzendes Verbot der angekündigten »Ziviltaufen« forderte, vertrat Budapest die Linie, dass die »Ziviltaufen « zwar politisch motiviert $^{204}$ und gesetzwidrig, ${ }^{205}$

198 La Voce del Popolo, 19. August 1908 [übersetzt aus dem Italienischen von mir].

199 Riječki Novi List, 8. August 1908 [übersetzt aus dem Kroatischen von mir].

200 Zanella wurde dadurch im Dorf nicht beliebter, wie sich etwa aus dem Vorfall in der Wahlkampagne von 1911 zeigte, als er als Kandidat der Autonomistischen Partei während seines einzigen Versuchs, auch in Drenova eine Wahlveranstaltung abzuhalten, von der Menge, die in die Kirche ging, ausgepfiffen und verjagt wurde; vgl. Agramer Zeitung, 6. März 1911.

201 Riječki Novi List, 1. September 1908 [übersetzt aus dem Kroatischen von mir].

202 Giovine Fiume, 22. August 1908 [übersetzt aus dem Italienischen von mir].

203 Vikar Cvetko informierte Gouverneur Nákó im Voraus über die geplanten Ziviltaufen; vgl. Telegramm von Cvetko (22. August 1908), in: DAR, Gubernij, Pr.Sp., kut. 34, 1908/161.

204 Gouverneur Nákó verortete die Nachricht - also den Wunsch der Dorfbevölkerung, auch ohne Priester den religiösen Ritualen treu zu bleiben - entlang nationalpolitischer Frontlinien. Er verstand die Ziviltaufe nicht etwa als (pseudo)religiöse Handlung unpolitischen Charakters, sondern als politischen Akt gegen die kroatischen Priester: "Die Abhaltung der zivilen Taufe hat meiner Meinung nach rein politischen Protestcharakter gegen den der kroatischen Propaganda dienenden Klerus in Senj, dessen gnadenlose und taktlose Vorgehensweise [...] die Empörung verursachte«; vgl. Brief des Gouverneurs an den ungarischen Minister für Kultur und Bildung (31. August 1908), in: Ebd., 1908/168 [übersetzt aus dem Ungarischen von $\mathrm{mir}]$.

205 Staatssekretär Tóth an den Gouverneur Nákó (25. August 1908), in: Ebd., 1908/166. 
aber mit Gewalt nicht zu verhindern seien. ${ }^{206}$ Gouverneur Nákó meinte bezüglich einer möglichen Gewaltanwendung, »dass die polizeiliche Gewalt die Gemüter noch mehr vergiften würde ${ }^{207}$ Er machte sich Sorgen, dass die katholische Kirche in der Stadt auf tiefere Ablehnung stoßen würde, falls man sogar die Polizei gegen die Bevölkerung in Drenova einsetzen würde. Deswegen schloss er jegliche polizeiliche Gewalt aus. ${ }^{208}$

La Bilancia bemerkte bezüglich der "zivilen« Taufen sarkastisch, dass sie beweisen würden: »es geht wunderbar auch ohne Priester «, weil »Gott überall ist ${ }^{209}$ Die sozialdemokratische Tageszeitung aus Budapest, Népszava, hoffte ob der "Ziviltaufen" sogar auf eine antireligiöse Wende in der Fiumaner Untergemeinde: »[D]ie Gläubigen sehen ein, dass sie für diesen Hokuspokus nicht mehr zu zahlen haben. Zuerst bewältigen sie es selber umsonst, dann werden sie sich die Zeremonien ganz abgewöhnen. ${ }^{210} \mathrm{Um}$ den Fall als vollkommene Ablehnung der bestehenden (religiösen, kirchlichen) Ordnung darstellen zu können, berichtete die antiklerikale Zeitung La Voce del Popolo der Autonomisten triumphierend darüber, dass angeblich ein Übertritt zur calvinistischen (reformierten) Kirche in Drenova erwogen worden sei. ${ }^{211}$ Auch das liberale Budapesti Hírlap aus der ungarischen Hauptstadt will von einer solchen Initiative erfahren haben: Don Zigar sei demnach im Dorf aufgefordert worden, zum Calvinismus überzutreten, damit er als reformierter Pastor ins Dorf zurückkehren könne. ${ }^{212}$ Somit hätte die Geschichte eine ähnliche Wende genommen wie in Ricmanje. Eine solche Initiative kommt aber in keinen Quellen vor, nur die italienisch- und ungarischsprachigen Blätter verbreiteten dieses Gerücht. Die Dorfbewohner wollten nicht proaktiv eine neue Ordnung etablieren - sondern reaktiv die alte Lage, das heißt ihren alten Pfarrer, zurückhaben.

Bereits im August 1908 gab es Versuche, in Drenova wieder katholische Messen abzuhalten: Don Luigi Torcoletti fuhr aus Fiume/Rijeka nach Drenova, um in der Kirche eine Messe zu lesen, aber als er ankam, versammelte sich eine größere Menge - wie die italienischsprachigen Zeitungen der Stadt berichteten -, die ihn auspfiff und verjagte. Don Torcoletti suchte zuerst bei der örtlichen Gendarmerie Zuflucht, und später - nachdem er sich getraut

206 Staatssekretär Tóth an den Gouverneur Nákó (29. August 1908), in: MNL OL, ME, FÜ K26, 1908/3897.

207 Gouverneur Nákó an den ungarischen Minister für Kultus und Bildung (28. August 1908), in: DAR, Gubernij, Pr.Sp., kut. 34, 1908/166 [übersetzt aus dem Ungarischen von $\mathrm{mir}]$.

208 Kopie des Briefes des Gouverneurs an den Vikar von Novi (4. September 1904), in: Ebd., 1908/187.

209 La Bilancia, 14. August 1908 [übersetzt aus dem Italienischen von mir].

210 Népszava, 23. August 1908 [übersetzt aus dem Ungarischen von mir].

211 La Voce del Popolo, 19. August 1908.

212 Budapesti Hírlap, 26. August 1908. 
hatte, die Gendarmerie-Stelle zu verlassen - fuhr er zurück in die Stadt. ${ }^{213}$ "Fäuste und Stöcke« hätten sich gegen Don Torcoletti im Dorf erhoben, wie das Budapesti Hírlap berichtete. Die liberale Zeitung aus der ungarischen Hauptstadt bezeichnete den Priester sogar als »Vertreter des kroatischen Klerus ${ }^{214}$ Er war aber im Gegenteil eher »italienisch « gesinnt, ${ }^{215}$ er engagierte sich - etwa mit der von ihm redigierten, italienischsprachigen, katholischen Tageszeitung Il Faro del Quarnero - für die Stärkung des italienischen Charakters der örtlichen katholischen Kirche. ${ }^{216}$ Die Bemerkung, ihn dennoch dem »kroatischen Klerus« zuzuordnen, diente gleichzeitig zwei antikirchlichen Vorstellungen. In diesen Vorstellungen überlappten sich national- wie kirchenpolitische Argumente. ${ }^{217}$ Don Torcoletti wurde einerseits als »kroatischer Priester« beschrieben, weil eine solche Etikettierung der Erzählung entsprach, nach der sich Drenova nur den kroatischen Priestern widersetzte. Hier manifestierte sich ein nationalpolitisches Argument. Andererseits war Torcoletti auch deswegen »kroatisch « markiert, weil die katholische Kirche auf der mental map als südslawischer Raum galt. Hier zeigte sich eine kulturrassistisch aufgeladene, antikirchliche Haltung.

Dass sich das Dorf einem italienischen Priester wie Don Torcoletti widersetzte, beweist hingegen die diesbezügliche »nationale Indifferenz« der Dorfbewohner. Sie unterstützten den abgesetzten Don Zigar nicht als einen italienischen oder kroatischen, sondern als ihren Priester. Ihnen ging es nicht um die Ablehnung einer Nationalität oder der katholischen Kirche, sondern um den Erhalt ihres gewohnten (Kirchen-)Lebens. Der Widerstand richtete sich nicht gegen die (vermeintliche) ethnisch-nationale Zugehörigkeit der Priester (wie es im Narrativ des »Nationalitätenkonfliktes« erzählt wurde), ebensowenig gegen die katholische Religion (wie es sich einige antiklerikalen Blätter in Fiume / Rijeka oder Budapest erhofften). Die Dorfbewohner waren einfach nur wütend darüber, dass sich die kirchliche sowie die städtische Obrigkeit in die ihren lokalen Angelegenheiten einmischen wollten. Als die Stadt Fiume/Rijeka - um Unruhen im Dorf zu vermeiden - neue Gendarmen »hochschickte«, erlebten sie eine ähnlich strikte Ablehnung seitens vie-

213 La Bilancia, 25. August 1908 [übersetzt aus dem Italienischen von mir].

214 Budapesti Hírlap, 27. August 1908 [übersetzt aus dem Ungarischen von mir].

215 »Kroatische« Kreise bezichtigten ihn sogar des Irredentismus; darüber siehe Lina Blau Remorino, Associazionismo religioso a Fiume [Religiöses Vereinsleben in Fiume], in: Giornata di studio sugli aspetti di vita cattolica, S. 85-94, hier S. 88f.

216 Über Torcolettis Rolle in der Etablierung einer italienischsprachigen, christlichsozialen Öffentlichkeit in Fiume/Rijeka siehe u.a. Bogović, Crkvena povijest Rijeke, S. 26.

217 Dazu, wie sich national- und kirchenpolitische Argumente in Fiume/ Rijeka überlappen konnten, siehe Tеснет, Verzahnung kirchen- und nationalpolitischer Frontlinien in Fiume/ Rijeka, S. 306ff. 
ler Dorfbewohner wie die Priester. Im Januar 1909 mussten die Gendarmen dem Widerstand sogar nachgeben und wegen der aufgewühlten Menschen in die Hafenstadt zurückkehren. ${ }^{218}$

Das gewohnte Kirchenleben in Drenova war aber nicht nur von den kirchlichen und städtischen Einmischungen - also der Absetzung von Don Zigar sowie dem Zusperren der Dorfkirche - gestört, sondern auch von inneren Spannungen. Der gewaltsame Widerstand war im Dorf höchst umstritten: Einige Dorfbewohner wünschten sich ein »normales« Kirchenleben zurück und hätten sich mit anderen Priestern abfinden können und wollen. Dabei zeichneten sich die inneren Frontlinien innerhalb der Gemeinde ab. Es wäre daher pauschalisierend zu behaupten, dass alle Dorfbewohner den Priestern aus Fiume/Rijeka feindlich gegenübergestanden hätten. Priester wurden nicht nur verjagt, sondern von einigen Dorfbewohnern eingeladen, heimlich im Dorf in einigen Privathäusern Gottesdienste zu lesen. Das Dorf war also bezüglich des Widerstandes gespalten. Die Zeitung La Voce del Popolo sprach im September 1908 darüber, dass es in Drenova, »einem friedlichen Ort«, neulich praktisch »tagtäglich « $\mathrm{zu}$ »Streitigkeiten und Tumulten « gekommen sei. $^{219}$ In einer Osteria seien die Gäste - wegen einer politischen Streitigkeit im September 1908 gewalttätig aufeinander losgegangen. ${ }^{20}$

Im September 1908 lud ein Maurer aus Drenova, ein gewisser Giuseppe (Josip) Scrobogna Don Bujan, einen Priester aus Fiume ein. Die Messe konnte letztendlich aber nicht stattfinden. Als die beiden Männer im Dorf eintrafen, versammelten sich 70-80 Menschen gegen sie. Don Bujan kehrte sofort in die Stadt zurück. Der erwähnte Maurer floh vor dem Zorn seiner Mitbewohner in die Wachstelle der örtlichen Gendarmerie. Erst nach einer Stunde traute er sich heimzugehen. ${ }^{21}$ Die italienischsprachige Presse sprach bezüglich des Vorfalles von »einer winzigen Fraktion von kroatischen Einwohnern", welche den Priester eingeladen habe. ${ }^{222}$ Mit dieser Bemerkung ließ sich das Narrativ des "Nationalitätenkonfliktes" aufrechterhalten und sogar in die inneren Verhältnisse einer sonst homogen kroatischen Gemeinde wie Drenova projizieren.

Es war nicht das erste oder das letzte Mal, dass einige Dorfbewohner Priester aus der Hafenstadt nach Drenova holten oder riefen. Nach den Informationen der Hauptstadtzeitung Budapesti Hírlap hätten »die Kroaten" Ende Dezember 1908 den Kirchenschlüssel, der in der Priesterwohnung aufbewahrt wurde, sogar stehlen wollen: Sie hätten versucht, in die Wohnung

218 Il Popolo, 5. Januar 1909.

219 La Voce del Popolo, 8. September 1908 [übersetzt aus dem Italienischen von mir].

220 Il Corriere, 8. September 1908.

221 Bericht der Sicherheitswacht (6. September 1908), in: DAR, Magistrato, Op.Sp., D-67-1908 - 20993.

222 Il Popolo, 13. September 1908 [übersetzt aus dem Italienischen von mir]. 
zu kommen. Als sie aber schon ein Fenster eingebrochen hätten, hätten sich andere Einwohner versammelt und die Einbrecher aus dem Dorf verjagt. Der Stadtmagistrat ließ den Kirchenschlüssel danach nicht mehr im Dorf aufbewahren, sondern er versteckte ihn im Rathaus. Was meinte aber die Zeitung damit, dass »die Kroaten« den Kirchenschlüssel haben wollten? Das Dorf war fast ausschließlich kroatischsprachig, insofern war diese Bezeichnung wiederum ein Versuch, die inneren Spaltungen, die mit nationalen Identitäten nichts zu tun hatten, in nationalpolitische Gegensätze umzudeuten.

Nicht die Nationalität, sondern die Frage, ob und wie das katholische Leben wiederhergestellt werden könne, polarisierte das Dorf. Hätten die Dorfbewohner die Rückkehr zu ihrem gewohnten Leben von der Öffnung der Kirche oder von der Beharrung auf den Widerstand erwarten können? Einige betrachteten die gesperrte Kirche als Chance, endlich Druck auf die kirchliche Obrigkeit auszuüben; andere hätten die Öffnung der Kirche begrüßt, weil das Kirchenleben des Dorfes sonst vernachlässigt werde. Im Dezember 1908 erreichten zwei Briefe den Stadtmagistrat in Fiume/Rijeka. Im ersten Brief forderten 63 Einwohner die Wiedereröffnung der Kirche, weil die Schließung "schweren Nachteil für unsere religiösen Gefühle« mit sich zöge; ${ }^{223}$ im zweiten Brief sprachen sich 158 Einwohner dafür aus, dass die Kirche weiterhin geschlossen bleibe, »solange die kirchlichen Fragen nicht endgültig gelöst sind . $^{224}$

Im Januar 1909 berichtete das Il Popolo darüber, dass einige Dorfbewohner - nachdem ihnen der Stadtmagistrat den Kirchenschlüssel nicht ausgehändigt hatte - einem Fiumaner Priester ein Privathaus in Drenova zur Verfügung gestellt hätten, damit er eine Messe zelebrieren könne. ${ }^{25}$ Ein paar Tage später sei ein anderer Priester, Don Petrović, nach Drenova gegangen, um im selben Privathaus wieder eine Messe zu zelebrieren. Dieses Mal hätten sich die Menschen nicht versteckt - im Gegenteil: Drenova sei sogar mit ungarischen und Fiumaner Farben beflaggt worden, um den Priester zu begrüßen. ${ }^{26}$ Nach der Messe habe Don Petrović zwei Kinder katholisch getauft. ${ }^{27}$ Die Gottesdienste waren freilich meistens nicht so öffentlichkeitswirksam gestaltet. Im September 1909 habe eine heimliche Messe sogar nur um Mitternacht stattfinden können, damit die Mehrheit des Dorfes davon nichts erfahre. Die italienischsprachigen Zeitungen der Hafenstadt rechne-

223 Brief (9. Dezember 1908), in: DAR, Magistrato, Op.Sp., D-67-1908 - 27022 [übersetzt aus dem Italienischen von mir].

224 Brief [ohne Datum, wahrscheinlich kurz nach dem ersten Brief], in: Ebd., D-671908 - 27108 [übersetzt aus dem Italienischen von mir].

225 Il Popolo, 2. Januar 1909.

226 Ebd., 6. Januar 1909.

227 La Bilancia, 7. Januar 1909. 
ten diese Initiative - gemäß des Narratives des »Nationalitätenkonfliktes« wiederum der »kroatischen Partei« im Dorf zu. ${ }^{228}$

Drenova hatte gleichzeitig wegen seines Widerstandes einen schlechten Ruf - ähnlich wie Ricmanje - in seiner Umgebung. Im September 1908 kehrte ein Kutscher aus Dražice in eine Kneipe von Drenova ein und habe die Dorfbewohner betrunken wegen ihres antikirchlichen Benehmens beleidigt: Mehrere Einheimische seien daraufhin aufgestanden und hätten den fremden Gast verprügelt. ${ }^{22}$ In den kroatischsprachigen Zeitungen gab es auch Leserbriefe, in denen sich Bewohner aus den umliegenden Nachbardörfern über den vermeintlich antikirchlichen und national indifferenten Widerstand in Drenova aufregten - wie etwa im Herbst 1908 in der Riječki Novi List:

Sprecht ihr italienisch, oder sprecht ihr dieselbe Sprache, wie unsere Brüder in Grobnik, Trsat, Podvežica, Kostrena? Und wenn ihr also [dieselbe Sprache sprecht], könntet ihr Italiener sein? Hand auf die Brust, Drenovaer, und klug im Kopf. Reißt euch zusammen und denkt über diese Frage nach. ${ }^{230}$

Was in Drenova passierte, blieb keinesfalls eine lokale Angelegenheit. Die Streitigkeit beschäftigte auch die »hohe Politik«. Budapest, Wien und der Hl. Stuhl verfolgten mit großem Interesse die Ereignisse. Die mikrogeschichtlichen Prozesse in Drenova gelangten somit in einen makrogeschichtlichen Kontext: die innenpolitischen und diplomatischen Debatten um die "Nationalisierung" des Kirchenlebens in der Donaumonarchie. Der autonomistische Parlamentsabgeordnete Riccardo Zanella traf sich mit dem ungarischen Ministerpräsidenten Sándor Wekerle schon Mitte August 1908, um die Drenova-Affäre - als eine negative Folge der zu lösenden »Bistumsfrage«, das heißt der kirchenrechtlichen Zugehörigkeit der Hafenstadt, - zu besprechen. ${ }^{231}$ Mitte November 1908 ging eine Kommission, angeführt von Zanella, nach Rom, ${ }^{232}$ aber sie wurden von Papst Pius X - wegen seiner Krankheit nicht empfangen. Der Hl. Stuhl interessierte sich von Anfang an für den Fall. Pignatelli di Belmonte, der Nuntius in Wien, warnte vor einer Überdimensionierung des Falles: Er erwartete von der Ernennung eines neuen Bischofs

228 Il Popolo, 19. September 1909 [übersetzt aus dem Italienischen von mir].

229 La Voce del Popolo, 8. September 1908.

230 Riječki Novi List, 25. August 1908 (Die erwähnten Orte sind kroatische Dörfer in der Nähe von Fiume/ Rijeka) [übersetzt aus dem Kroatischen von mir].

231 Agramer Zeitung, 22. August 1908.

232 Fiumei Estilap, 21. November 1908 (Das ungarisch-nationalistische Anti-ZanellaBlatt, A Tengerpart, meinte aber, dass dieser Besuch überflüssig sei; vgl. A Tengerpart, 21. November 1908). 
in Senj die Beruhigung der Gemüter. ${ }^{233}$ Diese Bemerkung des Nuntius zeigt, dass ihm das Phänomen des nationalpolitisch aktiven, niedrigeren Klerus bekannt war: Während der höhere Klerus das supranationale Selbstverständnis der katholischen Kirche vertrat (wie es in Istrien zu beobachten war, vgl. Kapitel 3.1.4), setzten sich Priester aus dem niederen Klerus öfters für nationalistische Ziele ein. ${ }^{234}$ Der Wiener Nuntius hoffte daher auf die Einwirkung der kirchlichen und politischen Elite. Vonseiten des höheren Klerus schaltete sich Árpád Lipót Várady, der ungarischsprachige Titularbischof des dalmatinischen Sebenico/Šibenik, in die Affäre ein: Anfang Februar 1909 besuchte er Don Cvetko in Novi, um einen Kompromiss zwischen ihm und der Stadt Fiume/Rijeka herbeizuführen. Don Cvetko willigte ein, dass ein Pfarrer regelmäßig Drenova besuchen dürfe. ${ }^{235}$ Es wurde mit der Stadt vereinbart, dass ein gewisser Don Regalati - ohne zum Kirchenadministrator ernannt zu werden - ab Februar 1909 jeden Sonntag Gottesdienste in Drenova lesen solle, wofür ihm die Stadt die bisher geschlossene Dorfkirche zur Verfügung stellen werde. ${ }^{236}$

Die Lage normalisierte sich dadurch aber keinesfalls. Don Kukanić bemerkte ein Jahr später, dass die bisherigen Gottesdienste im Dorf von niemandem besucht worden seien und dass er - trotz der diesbezüglichen Aufforderungen des Stadtmagistrates - keine Priester mehr in die Untergemeinde schicken wolle:

Die Kirche [in Drenova] war gewöhnlich leer, ohne von irgendjemandem besucht zu werden. Währenddessen begann das Volk, der religiösen Indifferenz anheimzufallen, und die Jugend der Sittenlosigkeit, wie es die erhöhten Zahlen der unehelichen Kinder beweisen. ${ }^{237}$

Don Kukanić meinte außerdem, dass keinem Priester in Fiume/Rijeka zuzumuten sei, jeden Sonntag nach Drenova, in diese weit entfernt gelegene Untergemeinde, zu fahren, daher schlug er als möglichen ständigen Pfarrer

233 Brief des Wiener Nuntius an den Hl. Stuhl, mit der Bemerkung "Affari Fiume (Croazia)« (obwohl Fiume/Rijeka Ungarn angehörte) (21. September 1908), in: AAV, ANV, b. 741, fasc. XIII, fol. 35.

234 Rudolf JawOrsKi, Konfession als Faktor nationaler Identifikationsprozesse in Ostmitteleuropa im 19. und zu Beginn des 20. Jahrhunderts, in: CsÁKY / ZEYRINGER (Hg.), Pluralitäten, Religionen und kulturelle Codes, S. 131-147, hier S. 138.

235 Privatbrief von Cvetko an den Zagreber Erzbischof Posilović über den Besuch am 3. Februar 1909 (12. Februar 1909), in: NbAZ, Posilović, AP, kut. 4 [ohne weitere Nummerierung].

236 Kopie des Briefes des Gouverneurs Nákó an den Wiener Nuntius (3. Februar 1909), in: AAV, ANV, b. 741, fasc. XIII, fol. 70.

237 Brief des Stadtpfarrers Kukanić an den Bürgermeister Vio (21. Februar 1910), in: DAR, Magistrato, D-57-1897 - 4946 [übersetzt aus dem Italienischen von mir]. 
den bisherigen Kaplan im kroatischen Crkvenica, Ivan Kumbatović, vor. ${ }^{238}$ Die Stadt lehnte ihn ab, weswegen der ungarische Kultusminister Albert von Apponyi in seinem Brief an Gouverneur Nákó im Mai 1910 bemerkte, dass »der Fall der Pfarrei von Drenova wieder giftig zu werden droht «. ${ }^{239}$ Erst der neue Bischof konnte Bewegung in den erstarrten Konfliktfall bringen.

Im Mai 1910 wurde der Bischofssitz - nach mehr als zweijähriger Vakanz mit Rocco Vučić besetzt. ${ }^{20}$ Er kannte die Geschichte, weil er parteiisch darin involviert gewesen war, nachdem er bereits 1907 noch als Vikar in Senj daran mitgewirkt hatte, Pavel Zigar aus Drenova zu entfernen. Viele im Dorf wollten sich jedoch weiterhin mit keinem anderen Pfarrer als dem abgesetzten Don Zigar abfinden: 160 Dorfbewohner wandten sich mit einer Petition an den neuen Bischof von Senj, dass er die Rückkehr von Don Zigar ermöglichen möge. ${ }^{241}$ Bischof Vučić bemerkte aber in seinem Brief an den Stadtpfarrer Kukanić, dass er die Unterschriftenaktion der Dorfbewohner »im Allgemeinen als Forderung nach einem Geistlichen « verstehe. ${ }^{242}$ Letztendlich wurde ein Konkurs für die Administratorenstelle ausgeschrieben. Auch Pavel Zigar aus Ledenice bewarb sich um den Posten. Ausgewählt wurde aber ein anderer Priester. Bischof Vučić ernannte im September 1910 den bisherigen Kaplan in Novi, Mate Polić, zum neuen Kirchenadministrator in Drenova. Die zwei weiteren Kandidaten waren für den Posten nicht geeignet: Im Falle von Don Zigar bestanden »die genannten Gründe" seiner Absetzung immer noch, ${ }^{243}$ während der andere Kandidat, Pavao Oršić, der italienischen Sprache nicht mächtig war. ${ }^{244}$ Es dauerte bis zum 11. April 1911, bis Mate Polić seine Stelle in Drenova antreten und die Kirchenschüssel vom Stadtma-

238 Ebd.

239 Brief vom Minister Apponyi an Gouverneur Nákó (7. Mai 1910), in: DAR, Gubernij, Pr.Sp., kut. 37, 1910/130 [übersetzt aus dem Ungarischen von mir].

240 Der ungarische Ministerpräsident, Sándor Wekerle, legte im Herbst 1910 dem österreichisch-ungarischen Außenministerium einen Protestbrief vor, in dem er sich darüber beschwerte, dass Rocco Vučić ohne vorherige Absprache mit der ungarischen Regierung und ohne ihre vorherige Einwilligung ernannt worden sei, wofür er vom Hl. Stuhl eine Entschuldigung und die Feststellung der Einmaligkeit erwartete; vgl. Brief von Wekerle (20. November 1908), in: MNL OL, ME, FÜ K26, 1910/457.

241 Unterschriftenliste (eingetroffen am 23. Juli 1910 beim Gouverneur), in: DAR, Gubernij, Pr.Sp., kut. 37, 1910/223.

242 Brief von Bischof Vučić an Stadtpfarrer Kukanić (21. Juli 1910), in: Ebd. [übersetzt aus dem Italienischen von mir].

243 Note von Mate Polić (11. Juni 1911), in: AŽD, Liber Insertionis, fol. 22 [übersetzt aus dem Kroatischen von mir].

244 Ebd. (Dass die italienische Sprache für die Stelle vorausgesetzt war, kann sowohl als sprachliche Toleranz der katholischen Kirche als auch eine städtische Anforderung angesehen werden. Angesichts der Tatsache, dass die Kirchenhierarchie die sprachliche Vielfalt andernorts ebenso respektierte - etwa in Triest oder Istrien wurden alle bischöflichen Hirtenbriefe mehrsprachig verkündet, auch wenn die lokale welt- 
gistrat erhalten durfte. Der neue Administrator wurde zwar in Drenova mit Fahnen feierlich empfangen, aber er musste zugeben, dass einige Bewohner immer noch auf die Rückkehr von Don Zigar hofften. ${ }^{245}$ Gegenüber der Stadt meinte Don Polić dennoch - als Rechtfertigung seiner Ernennung -, dass im Dorf allgemeine Zufriedenheit herrsche: »Das Volk von Drenova ist nach der Meinung des Unterschriebenen [Mate Polić] - zufrieden, dass es nach so vielen Zeiten einen Priester kriegte, der unter ihnen, tags und nachts wohnt... ${ }^{246}$ Nach mehr als zweieinhalb Jahren schien sich das Dorf endlich zu beruhigen. Drenova hatte nicht nur wieder einen Kirchenadministrator, der bis zum Ende der Donaumonarchie im Dorf blieb, ${ }^{247}$ sondern auch einen »Lesekreis«. Schon fast ein Jahr zuvor, am 20. Februar 1909, war dieser mit einem großen Volksfest eröffnet worden. ${ }^{248}$ Don Zigar konnte ins Dorf jedoch nicht mehr zurückkehren. Nach Stationen in kroatischen Gemeinden (zuerst als Administrator in Ledenice, dann Brinje und Starigrad sowie ab 1912 als Pfarrer in Starigrad, inzwischen wurde er in Theologie in Budapest promoviert) lehnte er 1918 einen Ruf als Pfarrer nach dem kleinen Dorf Lipice ab, weswegen er letztendlich im Sommer 1918 »ab officio et beneficio« aus der Priesterstelle suspendiert wurde. Er starb im Jahre 1947 im jugoslawischen Fiume / Rijeka. ${ }^{249}$

\subsubsection{Konfliktanalyse:}

Nationalistische Erwartungen aus der Stadt

Wie in Ricmanje und anderen istrianischen Ortschaften schien der Konflikt auch in Drenova ursprünglich unpolitische, persönliche Ursachen zu haben - oder zumindest auch solche zu haben. Ob der angeblich unmoralische Lebensstil von Don Zigar oder der Neid des Fiumaner Stadtpfarrers Don

liche Macht die sprachliche Toleranz nicht immer praktizierte und erwartete -, kann auch in diesem Falle vermutet werden, dass die Kirche die Mehrsprachigkeit von ihren Priestern erwartete).

245 Ebd.

246 Brief von Polić an den Stadtmagistrat (21. April 1911), in: DAR, Magistrato, Op.Sp., D-57-1897 - 10844 [übersetzt aus dem Italienischen von mir].

247 Gegen Mate Polić beschwerte sich später die Stadtpolizei, weil er sich unhöflich gegenüber den Polizisten benommen habe, und - wie der damalige Gouverneur, István von Wickenburg meinte - »der ähnliche Vorgang des Geistlichen könnte auch die verpflichtende Achtung der [...] Gläubigen gegenüber der staatlichen Polizei nachteilig beeinflussen«, vgl. Brief vom Gouverneur an den Stadtpfarrer Kukanić (31. Januar 1918), in: DAR, Gubernij, Pr.Sp., kut. 61, 1918/138 [übersetzt aus dem Ungarischen von mir].

248 Riječki Novi List, 22. Februar 1909.

249 Zur Biographie siehe »Pavel Zigar«, in: BAS, R22: Album. 
Kukanić wegen Don Zigars Beliebtheit ${ }^{250}$ bei der kirchlichen Entscheidung als Argument überwogen, ist nebensächlich. Die Ursache der Absetzung, also die Einmischung seitens der kirchlichen Obrigkeit in das Kirchenleben eines Dorfes (sowohl in Ricmanje als auch in Drenova), ermöglichte eine nationalund kirchenpolitische Instrumentalisierung des Falles über das Dorf hinaus. Die tendenziöse Erzählung der Vorgeschichte gab die Konfliktnarrative vor. Drenova und die Absetzung des örtlichen Priesters galten dabei als ein weiteres Kapitel der "Nationalitätenkonflikte«, die das Verhältnis zwischen der »italienischen « Hafenstadt und dem »kroatischen« Bistum bestimmten. Das autonomistische La Voce del Popolo meinte etwa, dass die lokale katholische Kirche »auch den Teufel« zum Pfarrer in Drenova ernennen würde, falls dieser »ein guter kroatischer Agitator « wäre. ${ }^{251}$ So war der Tenor in allen italienisch- und ungarischsprachigen Zeitungen der Hafenstadt. In die städtischen Diskurse konnten die persönlichen Gründe, zum Beispiel Don Zigars angebliche regelmäßige Kneipenbesuche und sein nichttransparentes Umgehen mit dem Kirchenvermögen nicht durchdringen. Nicht einmal die kroatischsprachige Presse, die an der »Entmythisierung« von Don Zigars Opferrolle Interesse hätte haben sollen, erwähnte andere Motive als die nationalpolitischen. Die Riječki Novi List bezeichnete Don Zigar dementsprechend als »Muttersöhnchen/Liebling" der italienischsprachigen, städtischen Elite. ${ }^{252}$ Das Narrativ der »Nationalitätenkonflikte« dominierte also komplett die öffentliche Wahrnehmung des Konfliktes. Die Stärke der gruppenbildenden Vorstellungen zeigte sich auch darin, wie verwundert etwa die städtische ungarischsprachige Tageszeitung $A$ Tengerpart darauf reagierte, dass Drenova als ein »kroatisches« Dorf nicht nach den Erwartungen - das heißt der nationalistischen Logik entsprechend - handelte:

»Drenova ist bekannterweise eine Untergemeinde von Fiume [Rijeka], von deren Bewohnern wir bisher nur wussten, dass sie Kroaten sind. Jetzt stellt sich aber heraus, dass ihr Symbol doch nicht der slawische Geier ist. ${ }^{253}$ Von einem kroatischsprachigen Dorf wurde erwartet, dass es den kroatischsprachigen Klerus unterstützt - weil der Klerus selbst »kroatisch" markiert war. Die Ethnizität/Nationalität erscheint in diesen Vorstellungen als eine substanzielle, starre Gruppeneigenschaft. Ethnizität/ Nationalität ist aber nicht etwas, das existiert, sondern etwas, das geschieht. ${ }^{254}$ Die Ethnizität/ Nationa-

250 Gouverneur Nákó meinte, dass Don Kukanić nur aus purem Neid die negativen Gerüchte über Don Zigar verbreiten würde; vgl. Brief vom Gouverneur Nákó an den ungarischen Ministerpräsidenten Wekerle (14. August 1908), in: MNL OL, ME, FÜ K26, 1908/3795.

251 La Voce del Popolo, 31. Juli 1908 [übersetzt aus dem Italienischen von mir].

252 Riječki Novi List, 1. August 1908 [übersetzt aus dem Kroatischen von mir].

253 A Tengerpart, 14. August 1908 [übersetzt aus dem Ungarischen und Hervorhebung von mir].

254 Brubaker, Nationalism reframed, S. 19ff. 
lität beschreibt also nicht eine kulturelle Eigenschaft einer immerwährenden, geschlossenen Gruppe, sondern sagt viel mehr über die Interpretations- und Diskursmacht (als Ereignis) aus, in der (und mit der) die Ethnizität/ Nationalität diskursiv hergestellt und als etwas Vorhandenes gedacht wird. ${ }^{255}$

Daher ist die wichtigste Frage bezüglich der ländlichen Konflikte, wer die Akteure identifizierte. Wer besaß die Macht, die Diskurse herzustellen und somit die Akteure in den Dörfern zu kategorisieren? Die Riječki Novi List meinte, dass »Menschen, die in Rijeka [Fiume] die Macht in ihren Händen hatten, hatten es nach dem Recht auch in Drenova «. ${ }^{256}$ Damit waren freilich »die Italiener" und »die Ungarn" gemeint, denen gegenüber »die kroatische [Kultur] [sowohl in Fiume/Rijeka als auch in Drenova - P. T.] ihren Platz sucht, der ihr rechtlich zusteht ${ }^{257}$ Auch wenn die Machtinhaber in der Stadt tatsächlich meistens italienischer oder ungarischer Abstammung waren, nationalisierte die kroatischsprachige Zeitung diese sozial bedingte Machtstruktur. Die Machtverhältnisse lassen sich nicht nach dieser nationalistischen Logik beschreiben, weil ihnen nicht primär nationale, sondern soziokulturelle Unterschiede zugrunde lagen. Bezüglich des Dorfes hatten etwa nicht nur »die Italiener" und »die Ungarn« die definitorische Macht inne, sondern auch die kroatisch-nationalistischen Agitatoren bzw. der örtliche (überwiegend kroatischsprachige) Klerus.

Weil Drenova nicht nach den nationalistischen Erwartungen und Annahmen handelte, nahm besonders die kroatisch-nationalistische Presse die Geschichte als Beispiel eines national indifferenten, rückständigen Dorfes wahr, das praktisch - wie es während der antialtslawischen Aufstände in Lika-Krbava ebenso gefordert wurde - ob seiner nationalen »Identität« noch belehrt werden müsse. In der nationalistischen Auffassung galten die Dorfbewohner als "national indifferent«, also rückständig. Die kroatisch-nationalistischen Agitatoren machten den Drenovaern in diesem Sinne mehrmals zum Vorwurf, nicht nach den nationalistischen Erwartungen zu handeln. Die istrianische, kroatischsprachige Zeitung Naša Sloga stellte empört der Dorfgemeinschaft folgende Frage: „Wir sind immer das, was wir waren, aber wo stehen sie [die Dorfbewohner - P. T.]? [...] [I]hr seid keine Italiener, und ihr werdet es nie sein. [...] Renegaten sind diejenigen, [...] die nicht einmal wissen, was sie sind. Traurig für ihre Heimat! « ${ }^{258}$ Dass sich die Dorfbewohner in Drenova anders identifizierten, weil sie ihre »Identität« eigensinnig erlebten, kam den kroatisch-nationalistischen Agitatoren sogar wie ein Versuch vor, »Italiener« oder »Ungarn« werden zu wollen: »In Rijeka [Fiume]

255 Göderle, Zensus und Ethnizität, S. $28 \mathrm{f}$.

256 Riječki Novi List, 20. Februar 1909 [übersetzt aus dem Kroatischen von mir].

257 Ebd. [übersetzt aus dem Kroatischen von mir].

258 Naša Sloga, 20. August 1908 [übersetzt aus dem Kroatischen von mir]. 
passiert so was, was nirgendwo in der Welt [passiert]: Menschen werden von kroatischen Müttern geboren, ihre Muttersprache ist Kroatisch, aber sie würden lieber irgendwelche Italiener, irgendwelche Ungar sein. ${ }^{259}$ Die kroatische Presse bezichtigte auch Don Zigar des Identitätswandels. Das kroatischsprachige Blatt Riječki Novi List bemerkte etwa, dass Don Zigar seine Stelle in Drenova 1906 noch als "großer Kroate, Frankianer ${ }^{260}$ angetreten habe. In der Behauptung, dass er sich dann in Drenova zu einem "großen Italiener und Autonomisten " entwickelt habe, ${ }^{261}$ schimmerte der Versuch durch, ihn unbedingt einem narrativ erzeugten Lager (»Kroatentum«, »Italienertum«) zurechnen zu wollen. In den Quellen ist übrigens nicht eindeutig festzustellen, was für eine nationale »Identität« Zigar überhaupt hatte. In den Berichten wurde er mal als "pan-italienischer Agitator ${ }^{262}$ - als ob er nur italienisch-nationalen Interessen dienen würde -, mal als »[kroatischer] Renegat ${ }^{263}$ - als ob er »entgegen« seiner kroatischen Abstammung handeln würde - beschrieben. Bekannt ist, dass er in Fiume/ Rijeka geboren war, und dass er - bevor er zum Administrator in Drenova ernannt wurde - unter anderem als Kaplan in Ogulin, einer rein kroatischen Kirchengemeinde, gedient hatte. Auch nach seiner Absetzung in Drenova war er in anderen homogen kroatischsprachigen Kirchengemeinden (Ledenice, Starigrad, Brinje) tätig. ${ }^{264}$ Sein Lebensweg lässt eher vermuten, dass ihm eine »italienische « Abstammung oder Sympathie - mal negativ, mal positiv konnotiert nur deswegen unterstellt worden waren, weil er nicht dem nationalistisch vorgestellten Idealtyp eines »kroatischen Priesters « entsprach.

Mit solchen Vorwürfen war auch der kroatischsprachige Stadtpfarrer Don Kukanić konfrontiert - in seinem Falle italienischerseits. Das autonomistische La Voce del Popolo bemerkte bissig, dass Don Kukanić die »italienischen« Hoffnungen bei seiner Wahl 1897 zwar geweckt, aber später nicht erfüllt habe. Das Blatt glaubte, das daran festmachen zu können, dass Don Kukanić seinen Namen später nach kroatischer Schreibweise anzuführen angefangen habe: «Nachdem er zum Pfarrer gewählt worden war, wandelte sich der »Cucanich« bald und zum Erstaunen aller in »Kukanich«, um vor

259 Ebd., 20. August 1908 [übersetzt aus dem Kroatischen von mir].

260 Frankianer (»frankovci«) waren die Anhänger der von Josip Frank gegründeten, klerikal-nationalen, proösterreichischen, antiungarischen Reinen Partei des Rechtes; über die Partei siehe u.a. Stjepan Matković, Čista stranka prava 1895.-1903. [Reine Partei des Rechtes 1895-1903], Zagreb 2001.

261 Riječki Novi List, 11. August 1908 [übersetzt aus dem Kroatischen von mir].

262 Etwa in der ungarischen Tageszeitung in Fiume/Rijeka, A Tengerpart; siehe A Tengerpart, 18. August 1908 [übersetzt aus dem Ungarischen von mir].

263 Etwa im Leserbrief, wo Zigar als Renegat bezeichnet wird, siehe Riječki Novi List, 29. August 1908.

264 Zur Biographie siehe »Pavel Zigar«, in: BAS, R22: Album. 
kurzem einfach zum »Kukanic« [eigentlich: Kukanić - P.T.] zu werden. ${ }^{265}$ Multiple Selbstverortungen, komplexe Identifizierungen wurden dementsprechend als »Identitätswechsel«, »Wechsel des Lagers«, sogar als »Renegatentum« angeprangert. Daher wurden auch die Dorfbewohner in Drenova aufgefordert, nach den normativen Erwartungen nationaler Kategorisierungen zu handeln. Nationalisierung bedeutet die Eindimensionierung eines eigentlich vielfältigen Raumes. ${ }^{266}$

Als einige Journalisten der Riječki Novi List im Dezember 1908 - also fünf Monate nach dem Ausbruch des Konfliktes - in das Dorf hochfuhren, um sich dort umzuschauen, stellten sie fest, dass »alle, die wir trafen, küstenländischen kroatischen Dialekt sprachen ${ }^{267}$ Die kroatischsprachigen Journalisten glaubten, anhand der gesprochenen Sprache die nationale »Identität« der Dorfbewohner feststellen zu können. Dabei wurde Sprache einerseits mit nationaler »Identität« gleichgesetzt. Andererseits wurde angenommen, dass die Sprachen- und Identitätsfrage nach der nationalistischen EntwederOder-Logik zu entscheiden sei. Die elitären Diskurse und die dörfliche Realität verstanden jedoch unter der nationalen »Identität « nicht das gleiche. ${ }^{268}$ Besonders die Ausschließlichkeit der nationalistischen Diskurse und Imaginationen waren einem ländlichen Mikrokosmos fremd. ${ }^{269}$ Die Gleichsetzung der Sprache und einer daraus abzuleitenden, eindeutigen, exklusiven nationalen »Identität« war auf der lokalen Ebene unbekannt, aber die nationalistischen Agitatoren wollten die lokale Bevölkerung dennoch von dieser Gleichsetzung überzeugen. ${ }^{270}$

\subsubsection{Historischer Kontext: Staat/Stadt-Kirche-Konflikt in und um Fiume / Rijeka}

Die Konflikte in Drenova erfuhren auch deswegen eine größere Aufmerksamkeit, weil das Verhältnis zwischen den zwei Hauptakteuren, die den Konflikt auslösten, der städtischen Führung und dem Bistum, zu der Zeit sehr angespannt war. Die weltliche Macht strebte sogar die kirchenrechtliche Verselbstständigung der Hafenstadt an: Fiume/Rijeka war einem kroatischen

265 La Voce del Popolo, 14. August 1908 [übersetzt aus dem Italienischen von mir].

266 Alberto Mario Banti, Conclusions. Performative Effects and "Deep Images" in National Discourse, in: Cole (Hg.), Different Paths to the Nation, S. 221.

267 Riječki Novi List, 1. Dezember 1908 [übersetzt aus dem Kroatischen von mir].

268 Laurence Cole, Differentiation or Indifference? Changing Perspectives on National Identification in the Austrian Half of the Habsburg Monarchy, in: VAN GinderACHTER / Beyen (Hg.), Nationhood from Below, S. 96-119, hier S. 114.

269 Judson, Inventing Germans, S. 53.

270 Ders., Beyond Nations. Rethinking the History of Habsburg Central Europe, in: Berlin Journal (2011), S. 29-33, hier S. 31. 
Bistum unterstellt. Der Konflikt in Drenova wurde in den italienisch- und ungarischsprachigen Zeitungen und Berichten dementsprechend als Beispiel für die dringende Notwendigkeit einer kirchenrechtlichen Abtrennung vom Bistum Senj angeführt. Dabei wurde impliziert, dass sich die Dorfbewohner, die Don Zigar zurückforderten, aus national- und kirchenpolitischen Gründen den bischöflichen Entscheidungen widersetzt hätten. Die italienischsprachige Elite der Hafenstadt und die ungarische Regierung aus Budapest behaupteten, dass die Kirche in Fiume/ Rijeka - infolge ihrer Zugehörigkeit zum kroatischen Bistum Senj - nur »kroatischen « Interessen diene. Die italienischsprachige Elite der Hafenstadt betrachtete dementsprechend die Kirche in Fiume/ Rijeka als einen Raum der »kroatischen« Propaganda.

Im Folgenden wird aufgezeigt, wie der kirchliche Raum in Fiume/Rijeka staats- und nationalpolitisch umkämpft wurde bzw. wie die diesbezüglichen Diskurse die Wahrnehmung und den Verlauf des lokalen Konfliktes in Drenova vergrößerten.

Die Kirche wurde nicht nur italienischer- und ungarischerseits national markiert. Nachdem die ungarische Macht ab den 1880er-Jahren alle anderen kroatischen Institutionen (kroatisches Gymnasium, Gespanschaftsverwaltung von Modrus-Fiume / Modruš-Rijeka) aus der Stadt verbannt hatte, ${ }^{271}$ sah die kroatischsprachige Bevölkerung der Hafenstadt in der städtischen Kirche - besonders unter dem Stadtpfarrer Don Kukanić - ihre letzte nationale "Bastion «, welche Fiume / Rijeka institutionell noch mit Kroatien verband. ${ }^{272}$ Die kroatisch-nationalistischen Kreise betonten die nationalpolitische Bedeutung der bestehenden kirchenrechtlichen Lage. Als kroatischsprachige Priester im Februar 1909 eine Versammlung in Buccari/Bakar gegen die Abtrennungspläne abhielten, begründeten sie ihre Ablehnung mit dem nationalpolitischen Argument, dass »die Kirche von Rijeka [Fiume] gegenwärtig die einzige Beziehung ist, die Rijeka [Fiume] mit Kroatien verbindet «. ${ }^{273}$ Selbst das liberale, kroatischsprachige Blatt der Stadt, Riječki Novi List, wies darauf hin, dass dem kroatischen Volk in Fiume/Rijeka "nichts anderes übrig blieb als die Einheit in kirchlichen und priesterlichen Angelegenheiten [mit Kroatien - P. T. $\ll^{274}$

Die Aversion der italienischsprachigen, liberalen Elite gegenüber der »kroatischen" Kirche kam auch der ungarischen Regierung zugute. Im lokalen

271 Zoran Grijak, Odnos Hrvata prema problemu odvajanja Riječke župe od senjskomodruške biskupije [Verhältnis der Kroaten gegenüber dem Problem der Lostrennung der Fiumaner Pfarrei vom Bistum von Senj-Modruš], in: Bernardin Nikola Škrivanić i njegovo vrijeme, S. 61-92, hier S. 68.

272 Butorac u.a., Povijest Rijeke, S. 235.

273 Memorandum an Jurij Posilović (10. Februar 1909), in: NbAZ, Posilović, AP, kut. 4 [ohne weitere Nummerierung] [übersetzt aus dem Kroatischen von mir].

274 Riječki Novi List, 6. Dezember 1908 [übersetzt aus dem Kroatischen von mir]. 
Kampf um die Deutungshoheit über den kirchlichen Raum unterstützte Budapest die italienische Forderung, in Fiume/ Rijeka entweder ein eigenes Bistum zu gründen oder die Stadt einem ungarischen Bistum wie etwa jenem in Pécs/Fünfkirchen anzuschließen. ${ }^{275}$ Budapest verfolgte dabei freilich nur politische Ziele, wie der damalige Wiener Nuntius es gut erkannte, ${ }^{276}$ denn die kirchliche Verselbstständigung der Hafenstadt war aus religiösen und kirchlichen Interessen nicht nötig. Der ungarische Staat wollte aber seine Macht schon seit den 1880er-Jahren auf den kirchlichen Raum in der Hafenstadt ausdehnen. Die italienischsprachige Elite der Hafenstadt stellte dabei eine wichtige Verbündete dar. ${ }^{277}$ Theodor Veiter weist darauf hin, dass zwischen den "Ungarn « und den »Italienern « in der späten Habsburgermonarchie eine "frappante Ideenübereinstimmung " bestanden habe, ${ }^{278}$ weil beide Völker in ihren nationalen Elitendiskursen liberale, säkulare Politik und Ziele verfolgten, im Gegensatz zu den Südslawen, die sich als »katholische Völker« verstanden und deshalb viel selbstverständlicher innerhalb des katholischen Österreich politisch verorten konnten.

Budapest strebte die Verstärkung der ungarischen Staatsmacht bzw. die ungarisch-magyarische Hegemonie über die Hafenstadt an, was die Verdrängung der »kroatischen « Präsenz aus Fiume/ Rijeka voraussetzte. Ágost von Zichy, ein früherer Gouverneur von Fiume/Rijeka, schrieb schon 1884 hinsichtlich der umstrittenen Bistumsfrage, dass die Kirche in der Hafenstadt den Interessen der ungarischen Regierung zu dienen habe:

für das Ziel der Verfestigung der ungarischen Staatsidee nicht nur wünschenswert, sondern auch nötig ist, dass in Fiume [Rijeka] auch in diesem Bereich [das heißt in der Kirche - P. T.] nichts anderes, als der Einfluss der ungarischen Regierungen gelten darf. ${ }^{279}$

$275 \mathrm{Zu}$ den Plänen siehe u.a. Notiz vom ungarischen Ministerpräsidenten Sándor Wekerle über die Bistumsfrage (20. September 1908), in: MNL OL, ME, K26 FÜ, 1908/2158 [Der ungarische Kultus- und Bildungsminister war aber der Meinung, dass dem Anschluss der Stadt an ein ungarisches Bistum die Gründung eines unabhängigen Bistums für die Stadt - aus Rücksicht auf die italienischsprachige Bevölkerung, die weder einem kroatischen noch einem ungarischen Bistum gerne unterstellt sei - vorzuziehen ist; vgl. Brief des ungarischen Kultus- und Bildungsministers, Albert von Apponyi (30. Oktober 1908), in: Ebd., 1908/4230].

276 Brief des Wiener Nuntius an den Hl. Stuhl (21. September 1908), in: AAV, ANV, b. 741, fasc. XIII, fol. 35 .

277 Über die zweckrationale Allianz der italienischsprachigen, liberalen Elite der Hafenstadt und der ungarischen Regierung siehe VolPI, Fiumani, ungheresi, italiani, S. 51ff.

278 Theodor Veiter, Die Italiener in der Österreichisch-Ungarischen Monarchie. Eine volkspolitische und nationalitätenrechtliche Studie, München 1965, S. 9.

279 Brief des Gouverneurs Ágost von Zichy an das ungarische Kultus- und Unterrichtsministerium (10. Juli 1884), in: DAR, Gubernij, Pr.Sp., kut. 15, 1884/96 [übersetzt aus dem Ungarischen von mir]. 
Diese Einstellung nationalisierte das Kirchenleben und die kirchlichen Angelegenheiten "von oben her «. Ungarisch-magyarische Priester, die aus Ungarn nach Fiume/Rijeka gingen, empfanden ihre Aufgabe dementsprechend als eine staatspolitische Mission, in der die Kirche als ein Mittel und Raum für die Propagierung der ungarischen Staatsidee und der kulturellen Magyarisierung zu fungieren hatte. Als Gyula Csóbor 1881 als ungarischer Kaplan und Religionslehrer von Budapest nach Fiume/Rijeka geschickt wurde, bekannte er sich zum ungarischen Nationalismus, und er verstand seine kirchliche Aufgabe vor allem als Dienst im Interesse der ungarischen Nation:

In politischer Hinsicht wird immer die ungarische Staatsidee maßgebend für mich sein. [...] Ja, ich verstehe in politischer Hinsicht vollkommen meinen erhobenen Beruf, der zuvorderst darin besteht, dass ich die Interessen der ungarischen Nation unter feindlichen Elementen [das heißt in einem kroatischen Bistum - P.T.], trotz meiner geringen Kraft, vorantreibe. ${ }^{280}$

In Csóbors Worten schimmerte die ungarische Einstellung durch, Fiume/ Rijeka für den aufzubauenden ungarischen Nationalstaat mit kirchlicher Hilfe zu »kolonisieren«. Für die Analyse der lokalen Machtkonstellation zwischen den "Italienern" und den "Kroaten" in Fiume/Rijeka sowie der Einstellung von Budapest gegenüber »seiner« Hafenstadt bietet sich die postkoloniale Lesart ansatzweise gut an. ${ }^{281}$ Budapest betrachtete die Stadt als Prestigeprojekt im Interesse des ungarischen Nationalstaates. ${ }^{282}$ Das imperiale Zentrum Budapest hatte infolgedessen nicht nur Präferenzen im lokalen »Nationalitätenkonflikt« wie etwa Wien, sondern es verfolgte in »seiner« Hafenstadt - nach einer kolonialen Logik - eine eindeutig ungarischnationale, auf eine imperiale Beherrschung und nationale Homogenisierung abzielende Linie, welcher sich die örtliche Kirche unterwerfen sollte.

Im Kielwasser der Drenova-Affäre intensivierten die ungarische Regierung und die italienischsprachige Elite der Hafenstadt wiederum ihre Aktivitäten im Interesse der Lostrennung der Hafenstadt vom Bistum Senj. Die konkrete Frage der Drenova-Affäre, ob der frühere Priester, Don Zigar, in die Untergemeinde zurückkehren darf, aktivierte längst bestehende nationalpolitische Diskurse und Ansprüche. Wem gehört der kirchliche Raum? Welche Sprache soll in der Liturgie dominieren? Wie hat sich ein »kroatischer« oder

280 Csóbors Brief an das Kultus- und Unterrichtsministerium in Budapest (13. Juli 1883), in: DAR, Gubernij, Op.Sp., kut. 69, 1881/1138 [übersetzt aus dem Ungarischen und Hervorhebung von mir].

281 Zur allgemeinen postkolonialen Herangehensweise in der habsburgischen Historiographie siehe u.a. Feichtinger, Habsburg (post-)colonial, S. 13.

282 ZuCCONI, Una città cosmopolita, S. 90. 
»italienischer« Priester zu verhalten? Diese Fragen dominierten die öffentliche Wahrnehmung des Kirchenstreites. Für die kroatisch-nationalistischen Kreise stellte Drenova ein Beispiel nationaler Indifferenz dar, der mit einer stärkeren kroatischen Prägung der Kirche begegnet werden solle; für die italienisch- oder ungarisch-nationalistischen Kreise war Drenova ein Beweis dafür, warum die Hafenstadt vom angeblich zu kroatisch geprägten Bistum Senj losgelöst sein müsse. Gouverneur Sándor Nákó von Nagyszentmiklós schilderte die Affäre als eine beispielhafte Zuspitzung des Konflikts, der zwischen den Fiumanern und dem Bistum längst bestanden habe. Er meinte, dass »die Ereignisse in Drenova es [die Problematik der ungelösten Bistumsfrage - P.T.] am prägnantesten illustrieren «. ${ }^{283}$ Gouverneur Nákó befürchtete diesbezüglich sogar einen »Kulturkampf«, was hier vielmehr national-, als kirchenpolitische Konflikte bedeutet hätte:

Die seit Jahrzehnten gegen den slawischen Klerus gerichtete Antipathie brach im Falle des Drenovaer Pfarrers mit elementarer Kraft hervor. Die ganze Gemeinschaft [in Drenova] bezog einmütig Stellung gegen die kroatischen Priester, und wenn es in diesen Angelegenheiten nicht rasch geholfen wird, steht uns ein radikaler Kulturkampf bevor. ${ }^{284}$

Ein solches Narrativ ermöglichte sogar, dass die nationalpolitisch motivierten Verselbstständigungsforderungen so vorgetragen werden konnten, als ob eine Lostrennung letztendlich im Interesse der katholischen Religion stünde. Gouverneur Nákó hob gerade mit Hinweis auf die Affäre in Drenova hervor, dass der kroatischsprachige, im Priesterseminar von Senj ausgebildete Klerus der Aufgabe, in einem multiethnischen Umfeld zu wirken, nicht gerecht werden könne:

Die Hafenstädte sind bekanntlich die unmoralischsten Orte, deren ganzes inneres Leben nur dann auf einem gewissen Niveau zu halten ist, wenn die ernsthafte Religiosität gepflegt wird. Wenn aber die Bevölkerung mit Recht im ständigen Streit [mit der Kirche] lebt, dann entfernen sich die Gläubigen vollkommen von der Religion. Der kroatische Klerus ist national betrachtet so vollkommen intolerant, dass ihm Gläubige anderer Nationalität nicht anvertraut werden dürfen. ${ }^{285}$

283 Brief des Gouverneurs Nákó an den Ministerpräsidenten Wekerle (31. August 1908), in: MNL OL, ME, FÜ K26, 1908/3795 [übersetzt aus dem Ungarischen von mir].

284 Ebd. [übersetzt aus dem Ungarischen und Hervorhebung von mir].

285 Note vom ungarischen Ministerpräsidenten Sándor Wekerle über die Bistumsfrage (20. September 1908), in: Ebd., 1908/2158 [übersetzt aus dem Ungarischen von mir]. 
Den städtischen Diskursen und Konflikten um die katholische Kirche in Fiume/Rijeka lagen zwei Annahmen zugrunde. Was den Konflikt zwischen der »Stadt" und der »Kirche» anbetraf, wurde angenommen, dass der überwiegend kroatischsprachige Klerus in Fiume/Rijeka und seiner Untergemeinde Drenova infolge des multiethnischen Charakters der Stadt und seiner Umgebung auf Ablehnung in der Bevölkerung gestoßen wäre. Die Kirche wurde dementsprechend als nationaler Akteur wahrgenommen: Wegen der Zugehörigkeit der Stadt zum Bistum Senj wurde die Kirche - und dies ist die zweite Annahme der damaligen Diskurse - »kroatisch" und »ländlich" markiert. In den städtischen Diskursen ließen sich mehrere Debatten finden, wo diese Unterschiede bedient und betont wurden.

Der in diesem Kapitel geschilderte und analysierte Streit zwischen dem Dorf hoch oben in den Bergen und dem Bistum unten am Meer widerlegte aber diese Annahmen. Das Bistum stand nicht (nur) mit der städtischen Öffentlichkeit im Konflikt, sondern auch mit einem kroatischsprachigen Dorf. Dies beweist gleichzeitig, dass sich die Kirche nicht eindeutig »ländlich" und »kroatisch" markieren lässt - weil sie gerade in einer ländlichen und kroatischsprachigen Gegend wie Drenova auf Ablehnung stieß. Der Fall von Drenova kann infolgedessen nicht als Beispiel des makrogeschichtlichen "Nationalitätenkonflikts" zwischen einer (»italienischen«) Stadt und der (»kroatischen«) Kirche, sondern als Fall des Selbstschutzes eines eigenständigen Mikrokosmos gelten. Die Dorfbewohner lehnten jegliche Einmischung in ihre eigenständige Lebensweise ab. Wie ein Leserbrief eines Dorfbewohners in der Fiumaner Tageszeitung Il Popolo zeigte, fühlten sich die Drenovaer von beiden Seiten (dem Bistum ebenso wie der Stadt) ausgenutzt:

Wir, die Pfarrgemeinde in Drenova sind seit vier Monaten ohne Pfarrer. [...] In diesem Kampf sind wir, Drenovaer diejenigen, die leiden. Für die Taufen müssen wir nach Fiume [Rijeka] gehen. Wer zahlt die Kutsche? Weder die Priester noch der Stadtmagistrat, sondern wir. ${ }^{286}$

\subsection{Fazit:}

Reaktiver Selbstschutz ländlicher Katholiken

Die Konflikte in dem ländlichen Hinterland Lika-Krbava sowie der ländlichen Peripherie städtischer Räume wie Drenova lassen sich schematisch als ein Aufeinandertreffen lokaler Lebensweisen und externer, kontrafaktueller Erwartungen zusammenfassen: Kroatischsprachigen Bauern wurden Entscheidungen aufgebürdet - mal die Einführung einer nicht gewollten

286 Il Popolo, 25. Dezember 1908 [übersetzt aus dem Italienischen von mir]. 
Liturgiesprache, mal die Absetzung eines gewollten Priesters -, die ihren Lebensweisen und Interessen nicht entsprachen. Die kirchliche Obrigkeit traf jeweils die Entscheidungen, aber diese wurden auch von den nationalistischen Diskursen mitgetragen. Die rebellierenden Dörfer identifizierten sich nicht nach fremdbestimmten Gruppenkategorien, das heißt den Vorstellungen nationaler und klerikaler Kreise. Sie verfügten jedoch nicht über die Möglichkeit und die Ressourcen, den von außen her wahrgenommenen Inhalt ihrer kollektiven »Identität« zu bestimmen. Der Konflikt zwischen den Narrativen des Zentrums und der Eigenständigkeit der Peripherie bestand insofern in einem Spannungsverhältnis zwischen Anspruch und Praxis, ${ }^{287}$ die auf der lokalen Ebene aufeinanderprallten.

In den ländlichen Konfliktfällen aus den Dörfern von Lika-Krbava und der Fiumaner Untergemeinde Drenova wehrte sich die Bevölkerung gegen die Einmischungen und die Erwartungen von außen. Sie lehnten die altslawische Liturgiesprache (Kriviput, Perušić usw.) oder die neuen Priester (Drenova) nicht aus nationaler oder religiöser Indifferenz ab, sondern als Zeichen lokalen Selbstschutzes. Der Widerstand der lokalen Ebene in der ungarischen Hälfte war nicht aktiv - wie die Selbstbehauptungsversuche in Istrien oder Ricmanje (Kapitel 3.3) -, sondern reaktiv. Im österreichischen Ricmanje stellten die Dorfbewohner sogar die kirchenrechtliche Abhängigkeit aktiv infrage (Kapitel 3.2): organisatorisch, indem sie sich von der örtlichen Pfarrei institutionell loslösen wollten und sogar aus der römisch-katholischen Kirche austraten, sowie inhaltlich, indem sie eine andere Liturgiesprache einforderten. Im Gegensatz dazu wollten die Dörfer in Lika-Krbava oder Drenova bei Fiume/Rijeka in der bisherigen Situation (im Sinne des "Eigenen«) verbleiben, ohne politische Forderungen gestellt zu haben. Sie schützten ihre eigene Lebensweise und kirchliche Praxis. Das »Eigene» ist - wie Alf Lüdtke schreibt - eine konkrete Handlung, welcher aber keine politische Motivation, sondern eine situative Logik zugrunde liegt:

Das Eigene ist nicht das Ergebnis einer politischen Organisierung oder einer gesellschaftlichen Bewegung; es ist die Frucht dieser oder jener Aktivität, die einzelne Personen entwickeln, durchsetzen und aller meistens ohne großes Getöse einfach tun. ${ }^{288}$

Im ungarisch-kroatischen Teil erhob die lokale Ebene keine proaktiven Ansprüche: Die Konflikte entstanden weder in den Dörfern von Lika-Krbava noch im Fiumaner Hinterland infolge interethnischer Konkurrenz oder pro-

287 Hans-Christian Maner, Zentrum und Grenzregion in der Habsburgermonarchie im 18. und 19. Jahrhundert. Eine Einleitung, in: Ders. (Hg.), Grenzregionen der Habsburgermonarchie, S. 9-24, hier S. 18.

288 Alf LüDTKE, Eigen-Sinn. Fabrikalltag, Arbeitererfahrungen und Politik vom Kaiserreich bis in den Faschismus. Neuauflage, Münster 2015, S. 14. 
aktiver Forderungen. Eine proaktive Handlung unterstützt Ansprüche, »die zuvor noch nicht erhoben wurden $«{ }^{289}$ Die Bewohner in den Dörfern von Lika-Krbava oder in Drenova wollten aber keine neue Situation herbeiführen - sie wollten die bestehende Lage beschützen. Sie wehrten sich gegen die konkurrierenden oder proaktiven Ansprüche der »hohen Politik«. Der Konkurrenzkampf war nicht auf der lokalen Ebene anzutreffen. Was im österreichischen Teil auf der lokalen Ebene ausgetragen wurde, die Konkurrenzkämpfe um die lokale Deutungshoheit, verortete sich im ungarischkroatischen Teil eine Ebene "höher«, unter den Akteuren der staatlichen, städtischen oder kirchlichen Obrigkeiten. Sie konkurrierten von oben um die lokale Deutungshoheit, während sich die lokale Ebene aktiv gegen diese Ansprüche wehrte.

Ich begreife insofern den lokalen Widerstand der Bauern in Perušić, Kriviput, Klanac (usw.) oder Drenova gegenüber den Homogenisierungen ihres Kirchenlebens nicht als nationale Indifferenz oder vormoderne Rückständigkeit, sondern als Abwehrreaktion eines ländlichen Mikrokosmos, der seine nationale »Identität«, Muttersprache, Religion (usw.) nicht nach den externen Erwartungen und Normen der kirchlichen oder staatlichen Obrigkeit oder der nationalen Agitatoren erleben wollte. Die Dorfbewohner in Kriviput, Perušić (usw.) oder Drenova strebten im Konflikt nicht die Änderung der Herrschaftsstrukturen (oder der Herrschaftsdiskurse) an. Daher lässt sich das Konzept des opportunistischen »Eigensinns« der deutschen Arbeiter, wie Alf Lüdtke es entwickelte, auch auf die lokale »Welt» (svjet) gut anwenden. Im Falle des bäuerlichen Widerstands handelte es sich ebenso um "Anstrengungen zur Distanz gegenüber Zumutungen »von oben « wie von »nebenan««. ${ }^{290}$ Der Wunsch, keine Änderungen erdulden zu müssen, war nicht nationaloder kirchenpolitisch motiviert - indem sich aber der Wunsch gegen national- und kirchenpolitische Vorstellungen der "großen Politik" richtete, geriet er in ein Diskursfeld, in dem die lokalen Lebensweisen nach externen Kategorien bezeichnet wurden. In diesem Moment wurden die Dorfbewohner zu einfachen Objekten unterschiedlicher städtischer Elitediskurse. Die Dorfbewohner waren nicht in der Machtposition, sich und ihre Wünsche dagegen zu artikulieren: Ihr Kirchenleben war von kirchlichen Entscheidungen bestimmt (etwa mit der Einführung einer nicht gewollten Liturgiesprache) und von nationalistischen Diskursen (etwa mit den Vorwürfen, national indifferent zu sein) beschrieben.

289 Tilly, Hauptformen kollektiver Aktionen, S. 156.

290 Alf LÜDTKE, Wo blieb die »rote Glut«? Arbeitererfahrungen und deutscher Faschismus, in: Ders. (Hg.), Alltagsgeschichte. Zur Rekonstruktion historischer Erfahrungen und Lebensweisen, Frankfurt a. M. / New York 1989, S. 224-282, hier S. 262. 
Nach einer dichotomischen Logik des Nationalismus erschienen solche eigensinnigen, unentschiedenen "Grauzonen" oder »In-Between «-Situationen als indifferente, rückständige, nichtreflektierte, vormoderne Haltungen und Handlungen. ${ }^{291}$ Stefano Petrungaro zeigt jedoch in seinen Fallstudien zu den kroatischen Bauernaufständen auf, dass Momente, welche als Ambivalenz, Indifferenz oder sogar Unwissen etwa bezüglich der nationalen Symbolik galten, nur aus der Perspektive des »Zentrums« unverständlich waren. ${ }^{292}$ Indem die Menschen religiös oder national indifferent beschrieben werden, wird ihnen das Recht abgesprochen, auf ihre Art und Weise kroatisch und katholisch sein zu dürfen. Wie die Dorfbewohner ihr Kroatischund Katholisch-Sein in Lika-Krbava und Drenova erlebten, entsprach nicht den klerikalen oder nationalistischen, normativen, mit Macht ausgestatteten Vorstellungen und Erwartungen. Eigenständige Lebensweisen wurden mit dem Vorwurf, nicht katholisch genug und/oder nicht kroatisch genug zu sein, marginalisiert und stigmatisiert. In den Konflikten gegen die kirchliche/ staatliche Obrigkeit lässt sich eine lokale Ebene erkennen, die sich ihrer nationalen und religiösen Zugehörigkeit zwar bewusst war, sich aber nach nationalistischen Kategorien oder klerikalen Erwartungen nicht verorten und verändern wollte.

Wenn allerdings ein bestehender Zustand schon gewalttätig verteidigt werden muss, ist es kein gutes Zeichnen für die Erfolgschancen der Ansprüche: ${ }^{293}$ Die Gewalt ist in dieser Hinsicht vielmehr ein Zeichen der Verzweiflung und der Marginalisierung. Auch im Falle der Dörfer in Lika-Krbava oder von Drenova konnte sich der reaktive Anspruch nicht durchsetzen: Die altslawische Liturgiesprache wurde letztendlich eingeführt bzw. der beliebte Priester Don Zigar konnte nicht nach Drenova zurückkehren - in allen Fällen ebbten die gewaltvollen Proteste rasch ab. Der proaktive Anspruch der kirchlichen Obrigkeit, die altslawische Liturgiesprache in Lika-Krbava einzuführen bzw. einen neuen Priester nach Drenova zu schicken, erwies sich als stärker und effizienter. Wie in Kapitel 5.2.1 zu zeigen sein wird: Die Erfolglosigkeit lässt sich mit der in Ungarn vorherrschenden Machtstruktur erklären.

291 Darüber, dass eine gewisse nationale Einstellung von Bauern nach den nationalistischen Diskursen urbaner Akteure als indifferent erscheinen kann, siehe an lateinamerikanischen Beispielen Florencia E. MaLlon, Peasant and Nation. The Making of Postcolonial Mexico and Peru, Berkeley u. a. 1995, S. 3ff.

292 Stefano Petrungaro, Popular Protest against Hungarian Symbols in Croatia (1883-1903). A Study in Visual History, in: Cultural and Social History 13 (2016), S. 503-520, hier S. 508.

293 Tilly u.a., The Rebellious Century, S. 284. 


\section{Konfliktdynamiken: \\ Nationale Nonkonformität und religiöse Peripherie}

"Man glaubt gar nicht, wie schwer es oft ist,
eine Tat in einen Gedanken umzusetzen! « ${ }^{1}$

(Karl Kraus)

In den dargestellten Fallbeispielen aus dem ländlichen Hinterland sowie der ländlichen Peripherie urbaner Räume untersuchte ich Konflikte, die sich in den katholischen Kirchengemeinden ereigneten. Viele davon waren von Gewaltmomenten begleitet: Die katholische Kirche - als Organisation und Gemeinde - sowie der gemeinsame Glaube schienen die Menschen nicht davon abzuhalten, gegen ihre Priester (also hierarchiedestruktiv) mit Gewalt bzw. Androhung der Gewalt oder sonstigen verbalen Verletzungen vorzugehen. In fast allen Fällen spielten die vermeintliche Nationalität der Akteure und ihre Sprachen eine wichtige Rolle (zumindest in der Wahrnehmung der Ereignisse).

Eine mikrohistorisch fokussierte Untersuchung der Hintergründe zeigte aber, dass sich tiefere, lokale Konflikte hinter der Nationalitäten- bzw. der Sprachenfrage verbargen, oder dass diese Frage erst in den städtischen Interpretationen auftauchte. Das nationale Vokabular, mit dem die Konflikte vorgetragen und besonders in den städtischen Diskursen gedeutet wurden, stellte in vielen Fällen eine Strategie dar, mit der den eigentlichen Konflikten öffentlichkeitswirksam mehr Gehör verschafft werden konnte. Die lokalen Akteure bedienten sich des nationalen Vokabulars, um dadurch andere Konflikte auszutragen. In anderen Fällen wurde das nationale Vokabular von außen her der lokalen Ebene aufgedrückt: Daher erwies es sich den dortigen Akteuren oft als fremd und irrelevant.

Im letzten Kapitel wird eine abschließende Analyse der geschilderten Konfliktfälle angestrebt - mit dem Ziel, die konkreten Konfliktfälle auf einer abstrakteren Ebene zu analysieren und somit für andere Konflikte, die ebenso kirchenbezogen und durch soziale Macht- und Teilhabepositionen

1 Karl Kraus, Aphorismen. Sprüche und Widersprüche. Pro domo et mundo. Nachts, Frankfurt a. M. 1986, S. 162. 
bedingt sind, fruchtbar zu machen. Weil die ethnisch-sprachlichen Differenzen als Gründe für die Konflikte in den städtischen Diskursen herangezogen wurden, wird zuerst in diesem Kapitel untersucht, wie und warum politisierte Konflikte aus möglichen Differenzen hervortreten können (Kapitel 5.1.1). Dabei steht das Phänomen der »Nationalitätenkonflikte« im Mittelpunkt: Lassen sich die geschilderten Fälle damit erklären? Waren die sog. "Nationalitätenkonflikte überhaupt von den ethnisch-nationalen Differenzen und nicht eher von sozialen und parteipolitischen, das heißt primär nationsunabhängigen Konfliktlinien bestimmt? Indem die »Nationalitätenkonflikte« hinterfragt werden, lassen sich andere Gründe der geschilderten Konflikte erarbeiten. Die Betonung der nationalen Differenzen verdeckte sowohl interethnische Konflikte als auch gesellschaftliche Dynamiken.

Im Weiteren stellt sich die Frage, ob sich das Ergebnis der Arbeit und die Dekonstruktion der nationalistischen Erklärungen in der Erkenntnis zusammenfassen lässt, die Handlungen der lokalen Akteure im Sinne von Tara Zahra als Beispiele "nationaler Indifferenz« zu beschreiben (Kapitel 5.1.2). Lässt sich der Diskurs der »Nationalitätenfrage« nur durch die Verneinung nationaler Differenzen und ihrer handlungsbestimmenden Wirkung relativieren? Oder bestimmten ethnisch-nationale Differenzen das alltägliche Leben? Es gilt dabei, nicht nur eine Überdimensionierung der "Nationalitätenfrage«, sondern auch ihre Bagatellisierung zu vermeiden.

Weil der oberadriatische Raum staatsrechtlich innerhalb der Donaumonarchie zweigeteilt war, ist es auch von großer Relevanz, wie sich makrohistorische Unterschiede zwischen den zwei Staaten Österreich und Ungarn auf der lokalen Ebene auswirkten (Kapitel 5.2.1). Trotz der verschiedenen Rahmenbedingungen in den zwei Hälften des Küstenlandes wird abschließend versucht, eine gemeinsame, von der lokalen Perspektive aus gedachte Erklärung für die Konfliktfälle zu finden (Kapitel 5.2.2).

\subsection{Nationalitätenkonflikt?}

\subsubsection{Intraethnische Konflikte}

Wie die Parteienforschung feststellte, verliefen die Konfliktlinien, die die europäischen Länder im 19. Jahrhundert bestimmten, entlang der Differenzen zwischen Staat und Kirche, Stadt und Land, Arbeit und Kapital bzw. Zentrum und Peripherie. ${ }^{2}$ Diese Differenzen, wie in den Fallbeispielen teil-

2 Seymour M. Lipset / Stein Rokkan, Cleavage Structures, Party Systems, and Voter Alignments, in: Dies. (Hg.), Party Systems and Voters Alignments. Cross-National Perspectives, New York/ London 1967, S. 1-64, hier S. 47f. 
weise aufgezeigt wurde, waren auch im oberadriatischen Raum vorhanden. Sie wurden aber - und darin besteht der Unterschied zu den Staaten, die ethnisch-national homogen sind - vom Konfliktnarrativ der "Nationalitätenkonflikte« überdeckt, in dem die verschiedenen Pole der jeweiligen Konfliktparteien ethnisch beschrieben oder markiert wurden: »südslawische« Kirche, »italienische« Stadt, »südslawisches« Dorf usw. Die Konflikte und die Gewaltakte auf der lokalen Ebene wurden entweder von den lokalen Akteuren oder in den städtischen Diskursen somit "verständlicher« gemacht - als Teil einer politischen Kommunikation, in und mit welcher sich die Ereignisse in den Gedanken der vermeintlichen »Nationalitätenkonflikte« umwandeln ließen. Heinz-Gerhard Haupt definiert Gewalt als politische Kommunikation, die daher in ihren "politische[n] Deutungsund Wirkungszusammenhänge[n] « zu verorten sei. ${ }^{3}$ Weil die Öffentlichkeit in der Habsburgermonarchie vom Narrativ der "Nationalitätenkonflikte« dominiert war, wurden auch die Gewaltmomente, die ich in dieser Arbeit untersuchte, ständig als deren Teil rezipiert.

Bei vielen Fällen aus dem österreichischen und ungarisch-kroatischen Teil des Küstenlandes war allerdings auffallend, dass die verbal oder physisch angegriffenen Menschen in den Konfliktbeispielen derselben Nationalität angehörten wie ihre Angreifer. Siehe etwa die Beispiele des italienischstämmigen Bischofs Flapp in Visinada/Vižinada (Kapitel 3.1.2), der slowenischsprachigen Priester in Ricmanje (Kapitel 3.2.2), der kroatischsprachigen Priester in den Dörfern von Lika-Krbava (Kapitel 4.1.2) oder Drenova (Kapitel 4.2.2). In all diesen Fällen wurde zwar das nationale Vokabular zur Beschreibung der Konfliktgründe und der Konfliktparteien bedient, aber es lagen vor Ort keine ethnischen Differenzen unter den Akteuren vor.

In den politischen Konflikten ging es oft darum, welche Elitengruppe das jeweilige Volk zu repräsentieren beanspruchte. Diese Strategie der städtischen Akteure wurde von außen her in die ländlichen Gebiete getragen, die städtische Öffentlichkeit war von ihr eindeutig geprägt. Besonders in der italienischsprachigen Öffentlichkeit, die im Österreichischen Küstenland einen ideologisch wie strukturell klar ausgeprägten parteipolitischen Pluralismus (Nationalliberale, Klerikale, Sozialisten usw.) aufwies, konnten die nationalistischen Akteure mit einem Rekurs auf eine homogene "Nation« die Sympathisanten anderer Strömungen aus der so vorgestellten nationalen community ausschließen.

3 Heinz-Gerhard Haupt, Gewalt und Politik im Europa des 19. und 20. Jahrhunderts, Göttingen 2012, S. 7f. 
Wie diese Strategie funktionierte, zeigt folgendes Beispiel: In der fast ausschließlich italienischsprachigen, west-istrianischen Küstenstadt Rovigno/ Rovinj ereignete sich Ende August 1908 ein großer Angriff antiklerikaler Akteure auf die Teilnehmer und Teilnehmerinnen der in der Stadt tagenden Versammlung der italienischsprachigen, christlich-sozialen Partei. ${ }^{4}$ Beide Seiten waren italienischsprachig. Die Klerikalen, die aus Triest und anderen Ortschaften Istriens angereist waren, wurden angegriffen, verprügelt, einige sogar an der Teilnahme gehindert. ${ }^{5}$ Die italienischsprachigen Liberalen stellten die Aktion als Teil des "Nationalitätenkonfliktes« dar. In diesem Sinne wurden die italienischsprachigen Klerikalen der "nationalen Indifferenz«, des »Renegatentums" oder sogar der »südslawischen Sympathie« bezichtigt. Die italienischsprachigen Liberalen beteuerten, dass die italienischsprachigen Klerikalen in Rovigno/Rovinj einem südslawischen Reichsratsabgeordneten, Matko Laginja, sogar auf Kroatisch - also mit »Živio«-Rufen - zugejubelt hätten. ${ }^{6}$ Die italienischsprachige, klerikale Zeitung L'Amico wies jedoch darauf hin, dass die italienischsprachigen Katholiken (das »Volk») überzeugt seien, »sich keine schlimmeren Herrscher als einige Signorotti [Herrschaften; Bezeichnung für die Liberalen - P. T.] geben zu können«.? Die katholische Zeitung hob damit die Interessenskonflikte hervor, die nicht entlang der nationalen Differenzen, sondern vielmehr vertikal innerhalb der italienischsprachigen Öffentlichkeit vorlagen.

Der »Nationalitätenkonflikt« verschleierte einen Kampf um die Deutungsmacht zwischen den politischen Seiten oder unter den gesellschaftlichen Schichten. Nur diejenigen konnten den Nationalismus aktivieren, die die politische Deutungshoheit dafür besaßen. ${ }^{8}$ Auf der ländlichen Ebene wollten die südslawisch-nationalistischen Agitatoren die südslawischen Bewohner ob ihrer nationalen Zugehörigkeit belehren, weil sich die ländliche Bevölkerung dem Nationalismus, wie ihn sich die nationalistischen Agitatoren vorstellten, nicht immer fügten. Daher wurden etwa die kroatischsprachigen Bauern in Lika-Krbava oder in Drenova von den kroatischsprachigen Nationalisten der "nationalen Indifferenz«, des »Verrates« (o.ä.) bezichtigt. Aber auch Priester, die nicht nach den Vorstellungen nationalistischer Akteure handelten wie

$\mathrm{Zu}$ den Vorfällen siehe die Polizeiberichte sowie die Briefe des örtlichen Pfarrers, in: AST, Luogotenenza, AP, b. 322, fasc. 10c, 1908/1505.

5 Protokolle über die Taten siehe in DAP, Općina Rovinj (Gemeinde Rovigno / Rovinj, weiter: Rovinj), Opći Spisi (Allgemeine Schriften, weiter: Op.Sp.), kutija (kut.) 658, No. 5210; No. 5238; No. 5283; No. 5314; No. 5352; No. 5363; No. 5376; No. 5379; No. 5380; No. 5401; No. 5402; No. 5507; No. 5587.

6 Il Processo di Rovigno per I fatti del 30 agosto 1908. Supplemento al periodico L’ Amico [Der Prozess von Rovigno/Rovinj wegen der Taten vom 30. August 1908. Beiheft zur Zeitung L'A mico], Trieste 1909, S. $82 \mathrm{f}$.

7 Ebd., S. 109 [übersetzt aus dem Italienischen von mir].

8 BRUBAKer, Nationalism reframed, S. 17. 
etwa Bischof Flapp in Istrien, Don Corazza in Torre/Tar oder Don Zigar in Drenova, wurden nationalistisch beschuldigt. Der Rekurs auf die "Nation" war also ein gut bespielbares Diskursmittel der intraethnischen Auseinandersetzungen. ${ }^{9}$ Die Handlungen nationalistischer Akteure richteten sich dabei nicht gegen Menschen anderer Nationalität, sondern vielmehr - wie Pieter Judson und Tara Zahra feststellen - gegen die große Mehrheit von Menschen, die sich nicht nach den Erwartungen nationalistischer Agitatoren verorteten und verhielten. ${ }^{10}$

Die Konflikte bestanden insofern nicht zwischen den »Völkern«, also zwischen den "nationalen Zugehörigkeiten" - davon zeugt auch die Tatsache, dass es in keinem der geschilderten Konfliktfälle zu interethnischen Gewaltakten kam -, sondern zwischen den lokalen Selbstverortungen und den makropolitischen Diskursen, die diese Selbstverortungen von oben her und von außen her deuteten. Auch wenn etwa Istrien oder das Ungarisch-Kroatische Küstenland als Kampfplatz nationaler Positionierungen galt - zwischen »Italienern« und »Kroaten «/»Slowenen« in Istrien oder zwischen »Kroaten« und »Serben« in Lika-Krbava -, trugen sich die geschilderten Konflikte nicht unter den Bewohnern unterschiedlicher Muttersprache / Nationalität aus. Die italienischsprachigen Katholiken in Istrien lehnten zwar einige südslawische Priester - aufgrund ihres persönlichen Lebensstils oder ihrer politischen Einstellung $-a b$, aber sie attackierten nicht, wie es der Logik eines "Nationalitätenkonfliktes« entspräche, die südslawischen Kirchgänger, mit denen sie übrigens oft dieselbe Kirche und / oder denselben Gottesdienst besuchten. Die Konflikte waren daher vertikal: zwischen der lokalen Ebene und den Priestern / der kirchlichen Obrigkeit. Ähnliches lässt sich im Ungarisch-Kroatischen Küstenland erkennen: Auch wenn die kroatischsprachigen Kirchgänger in Lika-Krbava Angst vor einer Orthodoxisierung hatten, griffen sie nicht die serbischsprachigen Orthodoxen an, sondern die kroatischsprachigen, katholischen Vertreter der staatlichen und kirchlichen Obrigkeit. Und auch die kroatischsprachigen Bewohner von Drenova gerieten nicht mit der italienischsprachigen Stadtbevölkerung in Konflikt, sondern vielmehr mit Klerikalen, die kroatischsprachig waren.

9 Nancy M. Wingfield, Introduction, in: Dies. (Hg.), Creating the Other, S. 4; Pieter Judson, Constructing Nationalities in East Central Europe. Introduction, in: Ders. / Marsh L. Rozenbilt (Hg.), Constructing Nationalities in East Central Europe, Oxford / New York 2005, S. 1-16, hier S. 3.

10 Ders. / Tara Zahra, Introduction, in: Austrian History Yearbook 43 (2012), S. 21-27, hier S. 25. 


\subsubsection{Nationale und/ oder religiöse Indifferenz?}

Nationalistische Agitatoren erkannten freilich die Diskrepanz zwischen der behaupteten "nationalen Einheit" und den intraethnischen, sozial und politisch bedingten Konflikten. Sie beschrieben daher die Akteure der geschilderten Konfliktfälle oft als »national indifferent«. Der Begriff der »nationalen Indifferenz« kommt dort als Vorwurf, sogar als Beschimpfung vor: Er bedeutet "Renegatentum « (ein in den nationalistischen Zeitungen oft verwendetes Wort), nationalen »Verrat«. Besonders diejenigen wurden damit beschuldigt, die den nationalistischen Erwartungen nicht entsprachen und sich den nationalistischen Gruppenkategorien nicht fügten: Priester oder Bischöfe in Istrien, die sich nicht entlang ethnisch-nationaler Frontlinien verorteten; Kirchgänger in Lika-Krbava, die »trotz« ihrer kroatischen Nationalität keine altslawischen Gottesdienste wollten; Kirchgänger in Drenova, die den Priester nicht nach den nationalen/nationalistischen Kriterien ablehnten oder unterstützten; Priester in Drenova oder Fiume/Rijeka, von denen nationalistische Kreise andere Handlungen erwartet hätten.

Auch wenn die südslawisch-nationalen Akteure dem Katholizismus eine positive Bedeutung beimaßen, weil Teile des katholischen (vor allem niederen) Klerus, wie in den Konfliktbeispielen gezeigt wurde, die nationale und sprachliche Emanzipation der streng religiösen südslawischen Bevölkerung unterstützten und förderten, stießen südslawisch-nationalistische Ideen auch unter den südslawischen Katholiken in den ländlichen Gebieten oft auf Unverständnis oder sogar Ablehnung. Daher wurde der Vorwurf, national indifferent zu sein, auch seitens südslawisch-nationalistischer Akteure gegenüber kroatisch- oder slowenischsprachigen Katholiken erhoben. Dies ging mit der Aufforderung einher, sie ob ihrer ethnisch-nationalen Zugehörigkeit belehren zu müssen. Der Quellenbegriff der nationalen Indifferenz ist also eindeutig nationalistisch belastet: Alle Menschen und Handlungen, welche den Erwartungen nationalistischer Akteure und Diskurse nicht entsprachen, wurden mit diesem Begriff - und seinen Synonymen - belegt.

Indifferenz gegenüber den Nationalismen, den »nationalen« Themen, die in vielen Konfliktfällen vorzufinden war, ist jedoch nicht gleich nationaler Indifferenz. ${ }^{11}$ Wenn die "Nation « nicht als geschlossene Gruppe, sondern als heterogene, widersprüchliche Ereignisse aufgefasst wird (vgl. Kapitel 1.2.2), werden auch die Akteure erfasst, die sich zwar einer ethnisch-national verstandenen "Gruppe« zugehörig fühlten, aber außerhalb und jenseits des herrschenden, hegemonialen "nationalen Narratives " standen. ${ }^{12}$ In diesem Sinne verstehen Maarten Van Ginderachter und Jon Fox die "nationale

11 Stourzh, The Ethnicizing of Politics and »National Indifference», S. 302.

12 EgrY, Etnicitás, identitás, politika, S. 34f. 
Indifferenz« als »a local distrust of outsiders $« .{ }^{13}$ Die Indifferenz der lokalen Akteure manifestierte sich insofern nicht gegenüber ihren ethnisch-nationalen »Identitäten «, derer sie sich bewusst waren, sondern vielmehr gegenüber den externen Erwartungen und Einmischungen. Diese Einstellung lässt sich im Sinne des arbeits- und alltagsgeschichtlichen Konzepts von Alf Lüdtke als »eigensinnig « beschreiben; ${ }^{14}$ die Eigensinnigkeit der lokalen Akteure drückte sich auch in Bezug auf ihre religiösen und nationalen Praktiken, Identifizierungen aus. Eigensinniges Handeln geht nicht aus eindeutigen, gruppierbaren und klar kategorisierbaren Eigenschaften (»südslawisch", »katholisch«) hervor, sondern es stellt eine Praxis dar, welche gleichzeitig (angesichts der Erwartungen) normabweichend, (angesichts der sozialen Dynamik) proaktiv/ reaktiv und (angesichts ihrer Wirkung) punktuell-momentan ist. ${ }^{15}$

Die eigensinnigen Akteure konnten sich gleichzeitig je nach den unterschiedlichen Situationen imperial, religiös, national, sprachlich, lokal, parteipolitisch und/oder klassenbestimmt verorten. ${ }^{16}$ Auch die Ethnizität ist eine historisch bestimmte, situativ anwendbare $"$ mutable strategy ${ }^{17}$ wie alle anderen »Identitätsangebote«, welche die lokalen Akteure je nach ihrem Interesse situativ und strategisch-opportun einsetzen bzw. benutzen konnten. Nationalismus und nationale Indifferenz waren Elemente, die auf der lokalen Ebene gleichzeitig das Alltagsleben charakterisieren konnten. Jakub Beneš stellt bezüglich der ethnisch-nationalen Züge der böhmischen Arbeiterbewegung fest, dass sich die Arbeiter und Arbeiterinnen weder ständig politisch (national) bewusst noch ständig politisch (national) indifferent identifizierten. ${ }^{18}$ Die Binarität der nationalen Indifferenz (»entweder nationalistisch oder national indifferent«) lässt sich demzufolge in einer Gradualität auflösen, welche die unterschiedlichen Akzeptanz- und Ablehnungsstufen gegenüber externen Erwartungen hervorhebt. ${ }^{19}$

13 VAn Ginderachter/Fox, Introduction, S. 8.

14 Zum Konzept siehe u. a. LüDTKe, Eigen-Sinn, S. 9-14.

15 Belinda Davis u.a., Einleitung, in: Dies. (Hg.), Alltag, Erfahrung, Eigensinn. Historisch-anthropologische Erkundungen, Frankfurt a. M./ New York 2008, S. 11-28, hier S. 18.

16 Daher lassen sich konkrete Handlungen nicht in der Frage nach einer starren Identität, sondern vielmehr in der Frage nach der wechselbaren und situativen Loyalität erfassen und beschreiben; vgl. Jana Osterkamp / Martin Schulze Wessel, Texturen von Loyalität. Überlegungen zu einem analytischen Begriff, in: Geschichte und Gesellschaft 46 (2016), S. 553-573, hier S. 560, 565ff.

17 Jeremy MacClancy, At Play with Identity in the Basque Language Arena, in: Sharon MacDonald (Hg.), Inside European Identities. Ethnography in Western Europe, Providence RI 1993, S. 84-97, hier S. 85.

18 BENEš, Workers and Nationalism, S. 243.

19 EGRY, Etnicitás, identitás, politika, S. 36f. 
Nicht nur national, sondern auch religiös indifferent wurden einige Taten lokaler Akteure wahrgenommen. Wenn sich Kirchgänger in den Dörfern von Lika-Krbava weigerten, altslawische Messen zu besuchen, oder wenn die katholischen Dorfbewohner in Drenova Taufen ohne Priester organisierten, oder wenn mehrere Menschen in Ricmanje, Log und Boljunec aus der römisch-katholischen Kirche austraten, wurden sie als "religiös indifferent" oder sogar "antireligiös«, "antikatholisch" beschrieben. In Drenova oder stärker in Ricmanje erfreuten sich die Dorfbewohner deswegen einer fragwürdigen Beliebtheit in den antiklerikalen, sogar atheistischen Diskursen, die die Akte der Dorfbewohner (besonders die "zivil" gehaltenen, "religiös" gemeinten Zeremonien oder die Über- und Austritte) als Zeichen einer lokalen Säkularisierung, als Abkehr von der Religiosität verstanden und lobten. Diesen Diskursen lag ebenso eine dichotomische Logik zugrunde wie der Bipolarität »Nationalismus oder nationale Indifferenz«: Entweder seien die Menschen "gute Katholiken" (falls sie den klerikalen Erwartungen der kirchlichen Obrigkeiten folgten), oder sie seien »religiös indifferent«/»säkularisiert«/»antikatholisch"/»atheistisch" (falls sie von diesen klerikalen Erwartungen abwichen). In einer solchen Perspektive geht aber gerade die eigentliche Intention der lokalen Akteure verloren, die weder die klerikalen Erwartungen hundertprozentig erfüllen noch den katholischen Glauben aus antiklerikalen oder ähnlichen Gründen verlassen wollten.

Wie lassen sich aber die priesterlos durchgeführten, »religiös« gemeinten Zeremonien in Ricmanje oder Drenova begreifen? Bedeuteten sie nicht eine klare Abkehr von der Religiosität, also eine Art Säkularisierung der ländlichen Ebene? Mit den "zivilen« Zeremonien wurde die Religion - im Sinne von Niklas Luhmann ${ }^{20}$ - privatisiert, das heißt einer breiteren Auslegung freigegeben. Ich begreife - in Anlehnung an die diesbezügliche Theorie von Christoph Kleine - die "zivilen«, pseudo- oder semireligiösen Zeremonien als non-konforme Handlungen, die sich zwar religiös verstanden, aber keinen Normen einer institutionalisierten Religiosität (das heißt einer Kirche) fügten. Kleine führt die Begrifflichkeit von »religiöser Nonkonformität« und »religiösem Nonkonformismus« ein. Während die »religiöse Nonkonformität« normabweichendes Handeln innerhalb einer akzeptierten Ordnung bedeutet, definiert Kleine den »religiösen Nonkonformismus« als wertrationale Gesinnung oder Handlung, die die bestehende Ordnung ablehne oder sie sogar beseitigen wolle. ${ }^{21}$ Der »religiöse Nonkonformismus« leugnet also die Legitimität der bestehenden Ordnung. ${ }^{22}$ Im Gegensatz zum »religi-

20 Luhmann, Die Religion der Gesellschaft, S. 224.

21 Christoph KLEINE, "Religiöser Nonkonformismus« als religionswissenschaftliche Kategorie, in: Zeitschrift für Religionswissenschaft 23 (2015), S. 3-34, hier S. $11 f$.

22 Ebd., S. 17. 
ösen Nonkonformismus« stellt die »religiöse Nonkonformität« zwar selbst eine Normbrechung dar, aber nicht mit der Intention, die ganze Ordnung zu ersetzen. ${ }^{23}$

Die «zivilen« Zeremonien in Ricmanje und Drenova können demnach als religiös nonkonforme Normbrechung betrachtet werden. Sie zielten nicht auf die wertrational motivierte Beseitigung der katholischen Religion - sie waren vielmehr zweckrational bestimmt: Weil die proaktiven oder reaktiven Ansprüche innerhalb der bestehenden Ordnung (»Kirche«) nicht erreicht werden konnten, bedienten sich die lokalen Akteure non-konformer Formen, ohne dabei die bestehende Ordnung wertrational abgelehnt zu haben. Die »zivilen« Begräbnisse und Taufen forderten zwar die Deutungshoheit, die Autorität der kirchlichen Obrigkeit heraus, indem sie der Kirche etwa die Macht über den Körper entzogen. ${ }^{24}$ Aber die Zeremonien waren nicht »zivil« im Sinne von einer Religionslosigkeit oder Antireligiosität. Statt von Säkularisierung kann die Rede vielmehr - im Sinne einer »Entkirchlichung « - von »Profanierung« sein. Wie Giorgio Agamben die Profanierung beschreibt: Während die Säkularisierung die Machtgrundlage verweltlicht, macht die Profanierung sie allen zugänglich. ${ }^{25}$ Nicht die religiöse Lehre, sondern die Machtstellung des Klerus wurde durch die dörflichen Handlungen wie etwa die Zivilbegräbnisse oder zivile Taufen infrage gestellt.

Indem Laien in Ricmanje und Drenova priesterliche Aufgaben und Formen ausübten, profanierten sie - im Agambenschen Sinne - ein Machtverhältnis: Sie gaben es einem allgemeinen Gebrauch zurück. Die (zumindest ursprünglich formulierten) Ansprüche der Menschen auf der lokalen Ebene bestanden also nicht darin, die katholische Kirche, geschweige denn den katholischen Glauben, verlassen zu wollen, sondern sie wollten ihr lokales Kirchenleben (sowohl was die Pfarreistruktur als auch die Liturgiesprache anbetraf) selbst bestimmen und gestalten dürfen. Erst nachdem die kirchliche Obrigkeit diesen proaktiven oder reaktiven Ansprüchen nicht nachgekommen war, handelten die Menschen in Ricmanje und Drenova zweckrational non-konform, indem sie sich immer mehr der katholischen Kirche entfremdeten.

Als Analogie zur "religiösen Nonkonformität«, das heißt der zweckrationalen Abweichung innerhalb einer bestehenden Ordnung, lässt sich auch die vermeintliche, oben beschriebene "nationale Indifferenz« eher als "nationale Nonkonformität« begreifen. Die nationalistischen Diskurse gaben vor, was als »Italiener« oder »Kroate« oder »Slowene« - im Sinne einer nationalen

23 Ebd., S. 7.

24 Zum biopolitischen Konzept der Macht über den nackten Körper siehe u. a. Giorgio Agamben, Homo sacer. Die Souveränität der Macht und das nackte Leben, Frankfurt a. M. 2002, S. 127f.

25 Ders., Profanierungen, Frankfurt a. M. 2015, S. 74f. 
Konformität - zu gelten hatte. ${ }^{26}$ Die lokalen Akteure erlebten aber ihre nationale Zugehörigkeit - ähnlich zu ihrer religiösen - nicht normkonform.

In den "national indifferent« oder »religiös indifferent" wahrgenommenen Handlungen artikulierte sich eine lokale Ebene, die sich ihrer ethnischsprachlichen und religiösen Zugehörigkeit zwar bewusst war, diese aber nicht den äußeren (nationalistischen und/oder klerikalen) Vorstellungen und Erwartungen entsprechend praktizierte. Gesellschaftliche Schichten, die in den bestehenden Machtstrukturen vielschichtig marginalisiert wurden, erlebten sowohl ihren religiösen Glauben als auch ihre ethnisch-nationale Zugehörigkeit jenseits der erwarteten und angebotenen Diskurse und Artikulationskanäle.

\subsection{Erfolgschancen der lokalen Akteure}

\subsubsection{Interessenartikulation in Österreich und Ungarn}

Was die konkreten Fallbeispiele anbetrifft, besteht die interessante Frage darin, in welchen Situationen sich Menschen auf der lokalen Ebene »national« verorteten, das heißt sich des vorhandenen Instrumentariums des nationalen Vokabulars bedienten: Wann erscheint die "Nation « auf der lokalen Ebene? ${ }^{27}$ Zwischen Österreich und Ungarn, also den zwei Reichshälften, deren Grenze den oberadriatischen Raum durchzog und ihn daher makrogeschichtlichstrukturell bestimmte, lässt sich ein gravierender Unterschied bezüglich der Frage feststellen, auf welcher Ebene (Handlungs- oder Beobachtungsebene) das nationale Vokabular bedient wurde. In Österreich verortete die Handlungsebene (das heißt die proaktiven Akteure der Konflikte) ihre eigenen Konflikte mit einem nationalen Vokabular, auch wenn diesen keine politischen, geschweige denn nationalpolitischen Motive zugrunde lagen. In den Kirchengemeinden von Istrien und den Kvarner-Inseln bedienten sich Kirchgänger oder Priester problemlos des nationalen Vokabulars, wenn sie eigene (private) oder sozial bedingte Ziele in einer öffentlichkeitswirksamen Art und Weise kommunizieren wollten. In Ricmanje lässt sich gut erkennen, wie sich lokale Ziele wie etwa der unpolitische Wunsch nach einer eigenen Pfarrei oder slowenischsprachigen Gottesdiensten in nationalpolitisch konnotierten Kategorien (»Muttersprache«, »Nation«, »Slowenentum«) äußerten.

26 Darüber, dass die »nationalen« Bewegungen die »nationale Kultur» bestimmten und somit politische Forderungen im Namen der von ihnen bestimmten "Nation« stellten, siehe u. a. Laurence CoLE, Introduction. Re-examining National Identity in Nineteenth-Century Central Europe and Italy. 1830-1870, in: Ders. (Hg.), Different Paths to the Nation, S. 9.

27 Fox / Miller-Idriss, Everyday Nationhood, S. 540. 
Im Gegensatz dazu erschien das nationale Vokabular (also die nationalpolitische Interpretation der Fälle) im ungarisch-kroatischen Küstenland erst auf der Beobachtungsebene, das heißt unter den städtischen, kirchlichen, staatlichen Akteuren, die die Konflikte von außen her (von oben her) beobachteten. In den Kirchengemeinden von Lika-Krbava reagierte die lokale Ebene auf die "Nationalisierung" nicht den Erwartungen entsprechend: Die Menschen verorteten sich außerhalb des nationalen Vokabulars, auch wenn sie sich gleichzeitig ihrer nationalen Abstammung und Muttersprache bewusst waren. In Drenova verwendeten die lokalen Akteure keine national konnotierten Kategorien, sie wehrten sich dagegen, durch solche Kategorien "von außen her" wahrgenommen und beschrieben zu werden.

War das Österreichische Küstenland also national bewusster? Waren die ethnisch-sprachlichen Differenzen auf der lokalen Ebene dort ausgeprägter, während sie im ungarisch-kroatischen Teil nur Elitendiskurse bzw. gescheiterte Versuche darstellten, die lokale Ebene für diese Diskurse zu gewinnen? Mit einem modernistischen Ansatz, der die voranschreitende Nationalisierung als lineare Modernisierung versteht, ${ }^{28}$ wäre dieser Unterscheid mit verzögerten Entwicklungsetappen, einem »Verzögerungszusammenhang sozial-struktureller und kollektiv-mentaler Art als Antithese gegenüber der nationalen Emanzipations- und Reformtendenz « zu erklären. ${ }^{29}$ Eine solche Perspektive würde zur Annahme führen, dass etwa das österreichische, ländliche Istrien national bewusster (und dadurch »moderner«) gewesen wäre als das ländliche Hinterland der ungarischen Hafenstadt Fiume / Rijeka.

Meine Annahme weist allerdings in die andere Richtung. Ich gehe davon aus, dass die lokale Ebene, trotz der Grenze zwischen Österreich und Ungarn, eigentlich (sozial, religiös, ethnisch-national) ähnlich strukturiert und bedingt war. Wieso erschien dann das nationale Vokabular im österreichischen Teil stärker auf der Handlungsebene, das heißt unter den konkret agierenden Menschen? Wieso bedienten sie sich eines Vokabulars, das im ungarisch-kroatischen Teil anscheinend eher in den Elitendiskursen anzutreffen war? Die Frage, wieso sich ähnliche Konflikte in den zwei Teilen einer ähnlichen Region unterschiedlich äußerten, lässt sich, meiner Annahme nach, durch den Bedeutungsunterschied der »Nationalitätenkonflikte«, die Zugangsmöglichkeiten zur politischen Öffentlichkeit und die dadurch bedingten Artikulationsmöglichkeiten in Österreich und Ungarn erklären.

28 Dieser Ansatz geht von einer verzögerten "nationalen Emanzipation« und insofern einer verzögerten Modernisierung unter den bäuerlichen Bevölkerungsteilen aus, vgl. dazu u. a. Horst Haselsteiner u.a., Zum Begriff des Nationalismus und zu seinen Strukturen in Südosteuropa im 19. Jahrhundert und zu Beginn des 20. Jahrhunderts, in: Österreichische Osthefte 20 (1978), S. 58.

29 SCHÖDL, Kroatische Nationalpolitik und »Jugoslavenstvo«, S. 19. 
In Österreich richteten sich die »Nationalitätenkonflikte« nicht gegen den imperialen Rahmen, sie wurden erst von diesem sowohl juristisch als auch gesellschaftlich ermöglicht. ${ }^{30}$ Der Staat schuf sogar die juristischen und politischen Voraussetzungen für die "Nationalitätenkonflikte«, ohne sich daran beteiligen zu wollen. Im Sinne von Carl Schmitt, der den politischen Konflikt, das heißt die Freund-Feindgruppierung im internationalen (zwischenstaatlichen) Verhältnis verortete, ${ }^{31}$ sei der österreichische "Nationalitätenkonflikt « nicht einmal politisch gewesen. Dieser erreichte keine Intensität, welche die Staatlichkeit (als maßgebende Einheit des Politischen ${ }^{32}$ ) infrage gestellt oder zerstört hätte. Erst im Sinne von Chantal Mouffe lässt sich der österreichische "Nationalitätenkonflikt« als politischer (innenpolitischer) Konflikt verstehen. Sie setzt die Agonistik (statt der Antagonistik) der Politik als Bedingung für ein dynamisches, politisches Leben voraus. ${ }^{33}$ Somit lässt sich die Politik auch in einer heterogenen (von Gegensätzlichkeiten geprägten) Gesellschaft aufrechterhalten. ${ }^{34}$ Die »Nationalitätenkonflikte» in der österreichischen Reichshälfte stellten insofern keine Gefahr für das ganze Imperium dar, sondern sie waren die im Mouffe'schen Sinne gemeinte Voraussetzung für eine lebendige politische Öffentlichkeit. Die "nationale« Rhetorik stand als bedienbare Vorlage für unterschiedliche Interessen zur Verfügung - daher artikulierten sich auch lokale Interessen aus dem ländlichen Hinterland in diesem Kontext.

Der "Nationalitätenkonflikt« war insofern in Österreich eine Selbstbehauptung von unten, welche der lokalen Ebene einen allgemein verstehbaren Kommunikationsrahmen darbot. Daher spricht Jana Osterkamp bezüglich der österreichischen »Nationalitätenkonflikte« vom »Verteilungskampf um die Öffentlichkeit«, das heißt um die Aufmerksamkeit in der Öffentlichkeit. ${ }^{35}$ Ricmanje erfreute sich etwa nur deswegen einer großen Aufmerksamkeit, weil sich die Dorfbewohner (oder zumindest die vor Ort bestimmenden Akteure) im Narrativ der "Nationalitätenkonflikte « verorteten, obwohl die Angelegenheit um die Errichtung einer eigenen Pfarrei lokal und banal war. Nachdem dieses Narrativ durch die Rückkehr in den Schoß der römisch-

30 Judson, L' Autriche-Hongrie était-elle un empire?, S. 568.

31 Carl Schmitt, Der Begriff des Politischen, München 1932, S. 41ff.

32 Ebd., S. 31.

33 Mouffe, Über das Politische, S. 27ff.; dies., Agonistik. Die Welt politisch denken, Frankfurt a. M. 2014, S. 29f.

34 Oliver Marchart, Die politische Differenz. Zum Denken des Politischen bei Nancy, Lefort, Badiou, Laclau und Agamben, Frankfurt a. M. 2010, S. 42.

35 Jana Osterkamp, Zur Geschichte von »Vielfalt und Verteilung«. Einleitung, in: Vielfalt und Verteilung. Regionale, nationale und konfessionelle Verteilungsfragen in Europa. Historische Sozialkunde. Geschichte - Fachdidaktik - Politische Bildung 45 (2015), S. 2. 
katholischen Kirche 1910 / 1911 aufgegeben worden war, richtete sich weniger Aufmerksamkeit auf das kleine Dorf, obwohl sich Gewaltmomente wie davor weiterhin ereigneten.

In Ungarn hingegen stellte der »Nationalitätenkonflikt« nicht die Basis für eine dynamische politische Öffentlichkeit. Ungarn bot keinen Raum für die Artikulation nationaler oder sozialer Interessen, die ungarische Politik war von einer ungarisch-magyarischen Elite bestimmt, die nicht nur die Nationalitäten, die bis 1900 die Mehrheit der Gesamtbevölkerung ausmachten, sondern auch weite Teile der ungarischsprachigen Bevölkerung (Arbeiter, Bauern) bis zum Ende der Donaumonarchie etwa durch die dezidierte Ablehnung jeglicher Öffnung des Wahlrechts aus dem politischen Leben ausschloss. ${ }^{36}$

Diese Strategie hing auch damit zusammen, dass sich der Staat in Ungarn aktiv an der »Nationalisierung « der Öffentlichkeit beteiligte. In einem solchen Kontext wurden die "Nationalitätenkonflikte» nicht um die lokale Macht »ausgefochten", die im zentralisierten Ungarn sowieso kaum Bedeutung hatte. In den lokalen »Nationalitätenkonflikten" ging es nicht um die lokale Machtstruktur und Deutungsmacht, sondern vielmehr um die lokale Wahrnehmung (Akzeptanz oder Ablehnung) der ungarischen Staatsidee. Gegen die nationalisierenden staatlichen Elitendiskurse formierten sich die Elitendiskurse der Nationalitäten. Innerhalb einer »nationalen« Öffentlichkeit stellten diese nationalistischen Elitendiskurse das »Zentrum« dar. Der "Nationalitätenkonflikt« war insofern nur eine Strategie der jeweiligen Zentren - sei es die magyarische Staatselite oder die nationalistischen Agitatoren der jeweiligen Nationalitäten -, sich von oben her zu behaupten. Die lokale Ebene wehrte sich reaktiv dagegen - wie es sich in den Konflikten in LikaKrbava oder Drenova beobachten ließ -, und deswegen zeigte sich vollkommenes Unverständnis und Desinteresse dem nationalistischen Vokabular gegenüber, was von den nationalistischen Akteuren als Beweis für die »nationale Indifferenz« der ländlichen Bevölkerung herangezogen werden konnte.

\subsubsection{Antihierarchische (soziale) Gewalt}

Wie lassen sich die entstandenen gewaltbefrachteten Konflikte - als Handlungen und nicht von ihrer Wahrnehmung her - charakterisieren? Einerseits waren sie sehr unterschiedlich. Was diese Fälle zu einem »historischen Phänomen« zusammenfügte, waren die externen (zeitgenössischen wie historiographischen) Erklärungen. Erst in diesen erschienen all die Konflikte als »Unterkapitel« desselben Phänomens: der ethnisch-nationalen Spaltung des

36 Cohen, Nationalist Politics, S. 275. 
katholischen Kirchenlebens. In den mikrohistorischen Perspektiven zeigten sich aber dann die Unterschiede, die zwar eine allgemeine Erklärung für all diese Fälle von Drenova bis zu Visinada/Vižinada, von der Gespanschaft Lika-Krbava bis zur Insel Lussin / Lošinj schwierig macht. So kommt aber die lokale Komplexität zum Vorschein.

Andererseits erklären sich viele Unterschiede in den Handlungen und besonders bezüglich der Erfolgschancen aufgrund der staatsrechtlichen Lage, das heißt der unterschiedlichen Rahmenbedingungen für die Handlungen und Beobachtungen. Die Gewaltmomente waren auf der österreichischen Seite (also in Istrien und Ricmanje) proaktiv und staatsindifferent. Die lokalen Konfliktakteure handelten proaktiv, indem sie Forderungen stellten. Dabei gerieten sie aber nicht mit dem Staat, sondern nur mit der kirchlichen Obrigkeit - meistens mit den örtlichen Priestern - in Konflikt. Im Gegensatz dazu waren die Gewaltmomente auf der ungarisch-kroatischen Seite (also in Lika-Krbava und Drenova) reaktiv und antistaatlich. Die lokalen Konfliktakteure handelten reaktiv, indem sie auf externe Einmischungen - etwa die bischöflichen Entscheidungen, altslawische Liturgiesprache einzuführen oder einen Priester aus dem Dorf zu entfernen - reagierten. Ihr Ziel war nicht die Veränderung der bestehenden Lage wie etwa im österreichischen Ricmanje, sondern ihre Beibehaltung. Gleichzeitig handelten sie - im Gegensatz zu den Konfliktakteuren auf der österreichischen Seite - nicht nur gegen die Amtskirche, sondern auch gegen die - in ihrem Falle: ungarische oder kroatische - Staatsmacht.

Die Frage der Pro- oder Reaktivität wie auch die Einstellung gegenüber der staatlichen Macht hingen mit dem unterschiedlichen Staats- und Nationskonzept in den zwei Reichshälften zusammen: In Ungarn-Kroatien bewegten sich die staatliche Macht und die kirchlichen Obrigkeiten in einem bewusst "nationalen« Kontext; in Österreich hingegen waren die staatliche Macht wie auch die kirchlichen Obrigkeiten bemüht, national interpretierbare Konflikte abzumildern. Die Erfolgschancen der Gewaltakte waren dadurch wesentlich vorbestimmt. Wie etwa der Konflikt in Ricmanje zeigte, wo die Forderungen (wenn auch zum Beispiel im Falle der Liturgiesprache nur stillschweigend) am Ende akzeptiert wurden, war es anscheinend einfacher, auf der österreichischen Seite (und in der österreichischen katholischen Kirche) Forderungen nach mehr lokaler Selbstbestimmung durchzusetzen als auf der ungarisch-kroatischen Seite. Ricmanje war letztendlich eine lokale Erfolgsgeschichte, während sich die Bevölkerung in Drenova in einem in vieler Hinsicht ähnlichen Streit nicht durchsetzen konnte.

Was verbindet aber die zwei Teile des Küstenlandes? Dafür muss die lokale Ebene - und nicht die Makrostrukturen - wieder in den Blick genommen werden. In beiden Hälften des oberadriatischen Raumes ging es um Konflikte zwischen den homogenisierenden Ansprüchen des kirchlichen oder (natio- 
nal-)politischen »Zentrums« und den lokalen, eigensinnigen, abweichenden Praktiken der »Peripherie«. Niklas Luhmann weist darauf hin, dass die Differenz zwischen »Zentrum « und »Peripherie« auch bezüglich und innerhalb der Religion erscheint und reflektiert wird: »diese Differenz bildet selbst eine strukturelle Kopplung zwischen Religion und übriger Gesellschaft, ohne in dieser Funktion ein Thema religiösen Glaubens zu sein. ${ }^{37}$ Was als Nationalisierung des lokalen Kirchenlebens (das heißt Nationalisierung der Religion) bewertet wird, lässt sich in diesem Sinne vielmehr als innerkirchliche, lokale Reflexion und Einholung der Zentrum-Peripherie-Differenz verstehen.

In diesem Sinne - und so meine Hauptthese - verstand ich die in meiner Arbeit analysierten innerkirchlichen Konfliktfälle - trotz der wichtigen Unterschiede - als gewaltbefrachtete Ausdrücke sozialen Emanzipationsanspruches marginalisierter, ländlicher, eigensinniger Katholiken innerhalb der katholischen Kirche. Die lokalen Akteure wollten im Sinne der »kulturellen Souveränität ${ }^{38}{ }^{8}$ ihre Lebensart - etwa bezüglich der religiösen Praktiken - selbst bestimmen und gestalten können. Sie forderten damit die kirchlichen und die weltlichen Obrigkeiten heraus. Die Gewaltereignisse waren dementsprechend nicht horizontal. Sie richteten sich gegen die Amtskirche und ihre lokalen Repräsentanten bzw. (vor allem im "nationalstaatlichen" Ungarn) gegen den Staat - mit dem Ziel, ein selbstbestimmtes Kirchenleben vor Ort reaktiv zu erhalten oder proaktiv zu erkämpfen.

37 Luhmann, Die Religion der Gesellschaft, S. 287.

38 Zum Konzept der kulturellen Souveränität siehe Gregor Feindt u.a., Kulturelle Souveränität. Zur historischen Analyse von Deutungs- und Handlungsmacht jenseits des Staates, in: Dies. (Hg.), Kulturelle Souveränität. Politische Deutungs- und Handlungsmacht jenseits des Staates im 20. Jahrhundert, Göttingen 2017, S. 9-46, hier S. 13. 


\section{Ausblick}

$»$ Penso alle mie lontane origini sconosciute... $\ll^{1}$

(Scipio Slataper)

In der Arbeit bestand mein Ziel darin, national erzählte, innerkatholische, lokale Konfliktgeschichten und Gewaltmomente aus unterschiedlichen Perspektiven zu beleuchten. Dabei stellte sich heraus, dass ethnisch-nationale Differenzen zwar auf der lokalen Ebene im Bewusstsein der Akteure vorhanden waren (insofern lässt sich die lokale Ebene nicht als "national indifferent« beschreiben), diese aber noch keine Ursache für Konflikte und Gewaltmomente darstellten. Diese Differenzen wurden jedoch für politische oder andere Zwecke instrumentalisiert: Entweder benutzten die Akteure während der konkreten Konfliktfälle auf dem Land ein nationales Vokabular, oder die Konfliktfälle wurden in den städtischen Diskursen für nationalpolitische Ziele verwendet.

Auch wenn andere Motive als die nationalen historiographisch herauszuarbeiten und zu erkennen sind, setzte sich politisch letztendlich der "Nationalitätenkonflikt» durch: Die Habsburgermonarchie zerfiel nach dem Ersten Weltkrieg entlang nationaler Raumimaginationen. In den neu entstandenen "Nationalstaaten" setzten sich die "Nationalitätenkonflikte» staatlich, von oben her (in Form von Assimilierung, Vertreibung oder Massenmord) viel brutaler fort als in der als »Völkerkerker« verrufenen Habsburgermonarchie. Der nationalen Nonkonformität, den multiplen Identifizierungen sowie den lokalen Identitäten räumten die posthabsburgischen Nachfolgestaaten, die sich auf der Vorstellung einer homogen nationalen Einheit organisierten und organisieren, oft kaum mehr Platz im öffentlichen Leben ein. Die demokratischen Nationalstaaten legitimieren sich viel mehr durch die Ethnisierung der Gesellschaft als die Imperien. ${ }^{2}$ Grauzonen werden dabei nach klaren $»$ Farben $"$ geordnet: Die Menschen wurden

1 Auf Deutsch: »Ich denke an meine ferne, unbekannte Herkunft...«; zitiert aus der Ausgabe: Scipio Slataper, Il mio carso. Prefazione e note a cura di Anna Storti, Trieste 2015 [1912], S. 8. (Deutsche Übersetzung zitiert aus der Ausgabe: Ders., Mein Karst. Mit einer Auswahl autobiographischer Prosa. Hg., aus dem Italienischen übertr. und mit einem Nachwort von Ilse Pollack, Klagenfurt 2000, S. 12).

2 Wimmer, Ethnische Grenzziehungen, S. 120. 
gezwungen, sich ethnisch-national eindeutig zu positionieren - und zwar im Rahmen einer Nationalstaatlichkeit, wo diese Positionierung mit staatlichen Vor- oder Nachteilen, sogar möglichen Repressionen, gesellschaftlichen Ausgrenzungen und Stigmatisierungen einherging und einhergeht. Menschen, die sich in ihren multiplen Identitäten im imperialen Rahmen der Habsburgermonarchie gut verorten konnten, gerieten somit in Situationen, in denen ihre Lebensweise immer mehr von staatlicher Seite infrage gestellt und bedroht wurde. Auch wenn Robert Musil das Habsburgerreich sarkastisch als »ein Land für Genies" auffasste und den Grund seines Scheiterns eben darin erblickte, ${ }^{3}$ konnten sich viele »einfache « Menschen in seinem Rahmen einrichten. Die in dieser Arbeit dargestellten Konflikte zeigten ebenso gesellschaftliche Dynamiken, welche durch das Imperium vielmehr ermöglicht als erstickt wurden.

Die Geschichte von Menschen, die sich in lokalen Konfliktfällen und Gewaltmomenten behaupteten oder bewährten, ist eher eine Geschichte der Verlierer. Nicht ihre Interessen und Ziele, sondern jene der in der Arbeit kritisierten nationalistischen Agitatoren bestimmten das 20. Jahrhundert. Die Geschichte wird, besonders im posthabsburgischen Ostmitteleuropa, oft als Geschichte der Nationen und ihrer Siege rückwärts erzählt. ${ }^{4}$ Dabei stellt sich die Frage, wo die Akteure meiner Arbeit vorzufinden sind. Einige gelangten freilich in das Pantheon der jeweiligen Nationen, weil die von ihnen angestachelten Konflikte als »Erwachen der Nation« erinnert und erzählt werden. All die Menschen jedoch, die ihren Glauben oder ihre Muttersprache im imperialen Rahmen erleben konnten und die in ihren Konflikten die lokalen, aber nicht die staatlichen Verhältnisse verändern wollten, werden dabei ausgeklammert und vergessen. Siege werden erinnerungs- und geschichtspolitisch aufrechterhalten - insofern gehört die von Siegern geschriebene Geschichte in die Politik. In der longue durée zeigen sich Aspekte, die in einem konkreten historischen Moment als überholt erscheinen, aber "aus der Geschichte« dennoch nicht wegzuschaffen sind. ${ }^{5}$ Verlierer können in der Geschichte wieder zu Wort kommen. ${ }^{6}$ In der Historiographie sowie der Erinnerungspolitik der posthabsburgischen Gesellschaften - eher auf den gesellschaftlichen, als auf den staatlichen Ebenen - erscheinen die vergessenen

3 Zitiert nach der Ausgabe: Robert MusiL, Der Mann ohne Eigenschaften. Erstes und Zweites Buch, Hamburg 2014, S. 35.

4 Corine Defrance / Catherine Horel, Réalités, perceptions et usages de la défaite en Europe, in: Dies. u.a. (Hg.), Vaincus! Histoires des défaites, Paris 2016, S. 9-28, hier S. $16 f$.

5 Reinhard Koselleck, Erfahrungswechsel und Methodenwechsel. Eine historischanthropologische Skizze, in: Ders., Zeitschichten. Studien zur Historik. Mit einem Beitrag von Hans-Georg Gadamer, Frankfurt a. M. 2003, S. 27-77, hier S. $67 f f$.

6 Matthieu Jestin / François-Xavier Nérard, Le temps des défaites, in: Defrance u. a., Vaincus!, S. 311-326, hier S. 325f. 
oder besiegten Erzählungen wieder. Auch die Geschichtswissenschaft widmet sich der Habsburgermonarchie und ihrer lokalen Ebene immer stärker aus der Perspektive des Verlorenen, was in besonderer Weise den multiethnischen Raum der adriatischen Teile der ehemaligen Habsburgermonarchie betrifft - wie Dominique Reill Kirchner schreibt: »By reintroducing the more complicated history of Adriatic multi-nationalism into the master narrative of the nineteenth century, we can see that where we find ourselves today is as much a product of what did not happen as what did «?

Das Gebiet wurde nach dem Ersten und Zweiten Weltkrieg unter mehreren Nationalstaaten aufgeteilt, die sich mit Vertreibungen und Massenmorden in ihren jeweiligen Teilen eine gewisse ethnisch-sprachliche Homogenität herzustellen anschickten. ${ }^{8}$ Die ehemalige Plurikulturalität (oder wie Dominique Reill Kirchner schreibt: der »adriatische Multikulturalismus«)

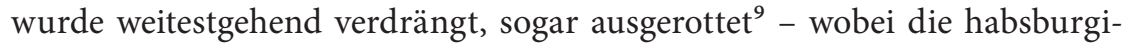
sche Vergangenheit in der letzten Zeit historiographisch und erinnerungspolitisch vor Ort immer mehr als eine Zeit friedlichen Zusammenlebens und sozio-ökonomischer Prosperität dargestellt wird. ${ }^{10}$ Die supranationale, imperiale Idee - die besonders in der österreichischen Reichshälfte aufrecht-

7 Reill Kirchner, Nationalists Who Feared the Nation, S. 243.

8 Zum Überblick der konfliktbeladenen Geschichte der Region siehe u.a. Glenda Sluga, The Problem of Trieste and the Italo-Yugoslav Border. Difference, Identity, and Sovereignty in Twentieth-Century Europe, Albany NY 2001; Giampaolo VAlDEvit, Trieste. Storia di una periferia insicura [Triest. Geschichte einer unsicheren Peripherie], Milano 2004; Wörsdörfer, Krisenherd Adria; Pamela Ballinger, History's »Illegibles«. National Indeterminacy in Istria, in: Austrian History Yearbook 43 (2012), S. 116-137; sowie die Aufsätze aus Borut KlaBJAN (Hg.), Borderlands of Memory. Adriatic and Central European Perspectives, Oxford u. a. 2019.

9 Reill Kirchner, Nationalists Who Feared the Nation, S. 241ff.; zu nationalistischen Raumimaginationen bezüglich des nordöstlichen Adriaraumes siehe Borut KLABJAN, »Jadran je naš«. Nacionalno prisvajanje Jadranskega morja pred prvo svetovno vojno in po njej [»Die Adria gehört uns«. Nationale Aneignung der Adria vor und nach dem Ersten Weltkrieg], in: Annales 21 (2011), S. 43-54.

10 Im Allgemeinen über die posthabsburgischen Nostalgien und grenzüberschreitenden Kontinuitäten siehe u.a. Helga Mitterbauer/Carrie Smith-Prei, Introduction. Crossings and Encounters, in: Dies. (Hg.), Crossing Central Europe. Continuities and Transformations. 1900 and 2000, Toronto 2017, S. VII-XVIII; über die erinnerungspolitische Bedienung der imperialen Geschichte des oberadriatischen Raumes siehe u. a. Emilio Cocco, Borderlands Mimicry. Imperial Legacies, National Stands and Regional Identity in Croatian Istria after the Nineties, in: Narodna umjetnost 47 (2010), S. 7f.; JoHLER, »Hibridismus«, S. 5; über den diesbezüglichen "Mythos Triest" siehe u.a. Pamela Ballinger, Imperial Nostalgia. Mythologizing Habsburg Trieste, in: Journal of Modern Italian Studies 8 (2003), S. 99; über den diesbezüglichen »Mythos Fiume« siehe Fried, Fiume, S. 293f., sowie Péter Techet, Post-habsburgische Erinnerungspolitik als unreflektierte Nostalgie oder als antinationalistisches Gegennarrativ im heutigen Rijeka?, in: Zibaldone - Zeitschrift für italienische Kultur der Gegenwart 68 (2019), S. 119-131. 
erhalten blieb - prägte auch nachwirkend die europäische Geschichte, indem sich imperiale Ideen nach dem Zusammenbruch der europäischen Imperien in die europäischen Einigkeitsideen übertrugen. ${ }^{11}$

Wo befindet sich heutzutage das Küstenland? Auf der historiographischen Topographie der europäischen (und besonders der deutschsprachigen) Geschichtswissenschaft kann es nicht problemlos verortet werden. Weil sich das Konzept vom "Zentraleuropa ${ }^{12}{ }^{2}$ - als einem posthabsburgischen Zwischenraum zwischen West- und Osteuropa - in der deutschsprachigen Geschichtswissenschaft kaum durchsetzte, scheint der (post)habsburgische Raum inmitten der klassischen Ost-West-Aufteilung Europas zu liegen. ${ }^{13}$ Dass große Teile des ehemaligen Habsburgerreiches zu Ostmitteleuropa (Südosteuropa) gehören, ist kaum umstritten. ${ }^{14}$ Es stellt sich aber die Frage, welchem Raum etwa das heutige Österreich oder das heute italienische Triest (und somit Teile meines Untersuchungsraumes) zuzurechnen sind. Gehören sie $\mathrm{zu}$ »Westeuropa", also nicht demselben historischen Großraum wie die anderen Teile der ehemaligen Donaumonarchie? In meiner Arbeit deckte ich folglich eine Mikroregion ab, die sich in der Gegenwart auf der mentalen Grenze zwischen »Westeuropa« und »Osteuropa« (»Ostmitteleuropa«, »Südosteuropa«) befindet. ${ }^{15}$ Johannes Feichtinger plädiert aber weiterhin für das

11 Siehe u.a. Dina Gusejnova, European Elites and Ideas of Empire, 1917-1957, Cambridge 2019.

12 Siehe zu diesem Konzept u.a. Csáky, Die Ambivalenz des kulturellen Erbes, S. 27-49; sowie ders., "Was man Nation und Rasse heißt, sind Ergebnisse und keine Ursachen «. Zur Konstruktion kollektiver Identitäten in Zentraleuropa, in: Wolfgang Müller-Funk u.a. (Hg.), Kakanien revisited. Das Eigene und das Fremde (in) der österreichisch-ungarischen Monarchie, Tübingen / Basel 2002, S. 33-49; zur zusammenfassenden Überlegung im Hinblick auf »Zentraleuropa« siehe Moritz CsÁKY, Das Gedächtnis Zentraleuropas. Kulturelle und literarische Projektionen auf eine Region, Wien 2019.

13 Zur Frage der historiographischen Verortung von Ostmitteleuropa siehe u. a. Philipp Ther, Von Ostmitteleuropa nach Zentraleuropa. Kulturgeschichte als Area Studies, in: Clio-Online. Themenportal Europäische Geschichte, URL: <http://www.europa. clio-online.de/essay/id/artikel-3307> (15.10.2019).

$14 \mathrm{Zu}$ den Verortungsproblemen des ostmitteleuropäischen Zentraleuropas siehe u.a. Catherine Horel, Cette Europe qu' on dit centrale. Des Habsbourg à l'intégration européenne 1815-2004, Paris 2009, S. 13f., 262ff.; sowie zum konkreten Verortungsproblem der Stadt Triest siehe KlabJan, Nicht Ost, nicht West.

15 Zum Verschwinden und gleichzeitigen metageographischen, erinnerungspolitischen Heraufbeschwören von Zentraleuropa (Mitteleuropa) siehe Balázs TrencsénYI, Central Europe, in: Diana Mishkova/ders. (Hg.), European Regions and Boundaries. A Conceptual History, New York/ Oxford 2017, S. 166-187, hier S. $172 \mathrm{ff}$. 
Konzept von Zentraleuropa, weil alle anderen Konzepte (wie Ost- oder Westeuropa) in dieser Region Produkte der postimperialen, nationalstaatlichen Aufteilung waren:

Wird von Zentraleuropa gesprochen, so wird die Aufmerksamkeit verstärkt wieder auf übergreifende Interaktionsprozesse und diachrone Verschichtungen gezwungen, um das sichtbar zu machen, was in der Vergangenheit von nationalen bzw. nationalstaatlichen Narrativen verdeckt bzw. verleugnet wurde. ${ }^{16}$

Was das innerkatholische Leben der lokalen Ebene betrifft, lässt sich erkennen, wie aus Niederlagen - etwa der Ablehnung der ländlichen, religiösen Nonkonformitäten - Siege hervortreten konnten. Joseph Schumacher betont, dass die innerkatholischen Spannungen und Gegensätze, wegen derer die katholische Kirche sogar des Synkretismus bezichtigt werden kann, nicht kontradiktorischer, sondern konträrer (und dadurch komplementärer) Natur seien: Sie lassen sich in der katholischen Kirche gleichzeitig erleben. ${ }^{17}$ In Bezug auf die Muttersprache gelang der katholischen Kirche diese Einsicht erst beim Zweiten Vatikanischen Konzil. Die in der Arbeit geschilderte, direkte Kommunikation mit der kirchlichen Obrigkeit und die aktiven oder reaktiven Ansprüche - auch wenn sie zuerst nicht gehört, geschweige denn erlaubt wurden - drängten die katholische Obrigkeit und die Priesterschaft letztendlich dazu, den Laienbedürfnissen nachzukommen. Die damaligen Forderungen südslawischer Kirchgänger nach muttersprachlichen Liturgien wurden so nach dem Zweiten Vatikanischen Konzil erlaubt und eingeführt. Was zu den habsburgischen Zeiten als Zeichen von nationaler wie religiöser Indifferenz, aber auch vom Nationalismus missverstanden und bedient werden konnte, gilt heutzutage als Normalität des Kirchenlebens einer Kirche, die durch die Anerkennung lokaler Partikularitäten und muttersprachlicher Liturgien ihre Supranationalität nicht einbüßen musste. Andreas Gottsmann meint daher mit Recht, dass viele Konflikte der habsburgischen Zeit durch eine kirchliche Toleranz etwa in der Liturgiesprachenfrage - das heißt gegenüber der »religiösen Peripherie« (Niklas Luhmann) - hätten abgemindert, sogar vermieden werden können. ${ }^{18}$

16 Feichtinger, Wissenschaft als reflexives Projekt, S. 79.

17 Joseph Schumacher, Die Identität des Katholischen, Heimbach / Eifel 2016, S. 26.

18 Gottsmann, Rom und die nationalen Katholizismen, S. 318. 
Die Supranationalität wird in der katholischen Kirche nicht zwangsweise als Homogenität der Rituale, Praktiken und Symbole verstanden und erlebt, als ob alle Abweichungen »religiöse Indifferenz« darstellen würden und als solche beseitigt werden sollten. Die katholische Kirche lässt sich - in vielen Hinsichten infolge ihres "römischen " (imperialen) Erbes - als complexio oppositorum, das heißt als Einheit der Gegensätze, verstehen, ${ }^{19}$ in dem - wie selbst der protestantische Theologe Paul Tillich bemerkt - vieles seinen Platz zu finden habe:

Das Prädikat der intensiven Universalität hält die Kirchen offen - offen, wie das Leben selbst ist. Nichts, was geschaffen und darum essentiell gut ist, ist vom Leben der Kirchen und ihrer Glieder ausgeschlossen. Das ist der Sinn des Prinzips der complexio oppositorum, auf das die römisch-katholische Kirche mit Recht stolz ist. ${ }^{20}$

Insofern lassen sich die innerkatholischen Konflikte auch im ländlichen Hinterland des Küstenlandes - im Sinne von Max Weber - letztendlich als

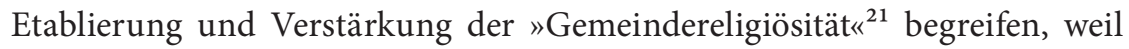
die lokalen Akteure immer mehr Einfluss und Gestaltungsraum bezüglich ihrer Kirche und ihres religiösen Lebens - ohne dabei den katholischen Glauben verlassen zu wollen - einforderten. Auch wenn ihre nationale Nonkonformität in den nationalstaatlichen Strukturen immer weniger beachtet und geduldet wurde, brachte die römisch-katholische Kirche der religiösen Peripherie letztendlich Verständnis und Akzeptanz entgegen.

19 Carl Sснмітт, Römischer Katholizismus und politische Form, Stuttgart 2002, S. 11ff.

20 Paul Tillich, Systematische Theologie III. Hg. und eingeleitet von Christian Danz, Berlin / Boston 2017, S. 648 [Hervorhebung im Orig.].

21 Zur »Gemeindereligiösität« siehe Max Weber, Wirtschaft und Gesellschaft. Herrschaft, Tübingen 1972, S. 278. 


\section{Quellen- und Literaturverzeichnis}

\section{Archivmaterial}

\section{Wien:}

AVA: Allgemeines Verwaltungsarchiv des Österreichischen Staatsarchivs

- Unterricht und Kultus, Kultus, Neuer Kultus, Katholischer Kultus, 455: Pfarren im Küstenland

HHStA: Haus-, Hof- und Staatsarchiv des Österreichischen Staatsarchivs

- Akten zur slawischen Liturgie

\section{Budapest:}

MNL OL: Magyar Nemzeti Levéltár, Országos Levéltár Budapest [Ungarisches Nationalarchiv, Staatsarchiv Budapest]

- Miniszterelnökség, K26: Fiumei Ügyek [Ministerpräsidium, Fiumaner Angelegenheiten]

\section{Vatikanstadt:}

AAV: Archivio Apostolico Vaticano [Vatikanisches Apostolisches Archiv]

- Archivio della Nunziatura di Vienna [Archiv der Nuntiatur in Wien]

\section{Zagreb:}

HDA: Hrvatski Državni Arhiv Zagreb [Kroatisches Staatsarchiv Zagreb]

- HR-HDA-78 Zemaljska vlada, Predsjedništvo 1869-1921 [Landesregierung, Präsidium]

NbAZ: Nadbiskupski Arhiv u Zagrebu [Erzbischöfliches Archiv in Zagreb]

- Ostavština Jurija Posilovića, Acta Praesidiae [Vermächtnis von Jurij Posilović, Präsidialakten]

\section{Triest:}

ADT: Archivio Diocesano di Trieste [Bischöfliches Archiv von Triest]

- Gestione ordinare [Allgemeine Verwaltung]

- Gestione particolare [Besondere Verwaltung]

AST: Archivio di Stato di Trieste [Staatsarchiv Triest]

- Capitanato distrettuale di Capodistria, Culto [Bezirkshauptmannschaft von Capodistria/ Koper, Kultus]

- Imperial Regia Luogotenenza, Atti generali [Kaiserlich-Königliche Statthalterei, Allgemeine Akten]

- Imperial Regia Luogotenenza, Atti presidiali [Kaiserlich-Königliche Statthalterei, Präsidialakten]

- Imperial Regia Luogotenenza, Atti presidiali riservati [Kaiserlich-Königliche Statthalterei, Reservierte Präsidialakten]

- Polizia, Atti presidiali riservati [Polizei, Reservierte Präsidialakten] 
NŠKT OZ: Narodna in študijska knjižnica v Trstu - Odsek za zgodovino [Volks- und Studienbibliothek in Triest - Abteilung für Geschichte]

- H-HI Kultura, kraji, fasc. 4.: Ricmanje

- HP-HI Kraji: HA-HH Ricmanje

\section{Ricmanje:}

ŽAR: Župnijski arhiv v Ricmanjih / Archivio parocchiale di Ricmanje [Pfarrarchiv in Ricmanje]

- Annales Ricmanienses

- Fascicoli di sacerdoti: Angel Kosmač [Hefte der Pfarrer: Angel Kosmač]

\section{Dolina:}

ŽDAD: Župnijski in dekanijski arhiv Dolina/ Archivio decanato e parocchiale di Dolina [Pfarrund Dekanatsarchiv in Dolina]

- Kronika županije 1900-1984 [Chronik der Pfarrei], in: Knjige - škatla 49

- Župnijski akti in dopisi 1909 [Pfarrakten und Schriften], in: Knjige - škatla 47 (Župnijski akti in dopisi 1906-1914)

\section{Pisino / Pazin:}

DAP: Državni Arhiv u Pazinu [Staatsarchiv in Pazin/ Pisino]

- HR-DAPA-28 Kotarsko poglavarstvo (kapetanat) u Poreču, Opči Spis [Bezirkshauptmannschaft von Parenzo / Poreč, Allgemeine Schriften]

- HR-DAPA-41 Općina Rovinj, Opči Spisi [Gemeinde Rovigno / Rovinj, Allgemeine Schriften]

\section{Fiume/Rijeka:}

AŽD: Arhiv Župe na Drenovi [Archiv der Pfarrei in Drenova]

- Liber Insertionis Historiae neoerectae Parochiae Drenovensis ab anno 1837

DAR: Državni Arhiv u Rijeci [Staatsarchiv in Fiume/Rijeka]

- HR-DARI-22: Gradsko Poglavarstvo Rijeka (Magistrato civico di Fiume), Opći Spisi [Stadtmagistrat von Fiume / Rijeka, Allgemeine Schriften]

- HR-DARI-16: Kotarsko poglavarstvo Lošinj, Opči Spisi [Bezirkshauptmannschaft von Lussin/ Lošinj, Allgemeine Schriften]

- HR-DARI-7: Kraljevskij gubernij za Rijeku i Ugarsko-Hrvatsko Primorje, Prezidijalni Spisi [Königlicher Gouverneur für Fiume/Rijeka und das Ungarisch-Kroatische Küstenland, Präsidialschriften]

- HR-DARI-7: Kraljevskij gubernij za Rijeku i Ugarsko-Hrvatsko Primorje, Opči Spisi [Königlicher Gouverneur für Fiume/Rijeka und das Ungarisch-Kroatische Küstenland, Allgemeine Schriften]

\section{Senj:}

BAS: Biskupski Arhiv Senj [Bischöfliches Archiv Senj]

- R 22: Album svećenika senjske i modruške biskupije u dva sveska [Album der Pfarrer des Bistums von Zengg-Modrus in zwei Jahrhunderten]

- Spisi (1894) [Schriften] 


\section{Bibliotheken}

Wien:

- Österreichische Nationalbibliothek

Budapest:

- Országgyülési Könyvtár [Parlamentsbibliothek]

- Országos Széchenyi Könyvtár [Széchenyi Staatsbibliothek]

\section{Zagreb:}

- Nacionalna i Sveučilišna Knjižnica [Nationale und Universitäre Bibliothek]

\section{Rom:}

- Archivio-Museo Storico di Fiume [Historisches Archiv-Museum von Fiume]

- Biblioteca del' Istituto Luigi Sturzo [Bibliothek des Institutes Luigi Sturzo]

- Bibliothek des Österreichischen Historischen Institutes

\section{Triest:}

- Biblioteca Civica Attilio Hortis [Stadtbibliothek Attilio Hortis]

- Biblioteca del Seminario vescovile di Trieste [Bibliothek des Bischöflichen Seminars von Triest]

- Biblioteca Statale di Trieste [Staatsbibliothek von Triest]

\section{Fiume/Rijeka:}

- Knjižnica Teologije Katoličkog bogoslovnog fakulteta u Rijeci Sveučilišta u Zagrebu [Bibliothek der Theologie der Katholischen Theologischen Fakultät in Fiume / Rijeka der Universität Zagreb]

- Sveučilišna Knjižnica u Rijeci [Universitätsbibliothek von Fiume/Rijeka]

\section{Florenz:}

- Library of European University Institute [Bibliothek des Europäischen Hochschulinstitutes, EUI]

\section{Zeitungen}

\section{Budapest:}

- Budapesti Hírlap [Budapester Tagesblatt]

- Népszava [Volksstimme]

- Pester Lloyd 
Wien und Österreich:

- Die Presse

- Grazer Tagblatt

- Grazer Volksblatt

- Neue Freie Presse

- Reichspost

- Vaterland

Zagreb und Kroatien-Slawonien:

- Agramer Tagblatt

- Agramer Zeitung

- Hrvatska [Kroatien]

- Katolički List [Katholisches Blatt]

- Narodne novine [Volkszeitung]

- Obzor [Horizont]

- Okružnice biskupskoga Ordinarijata senjskoga i modruškoga ili krbavskoga [Rundschreiben des bischöflichen Ordinariates von Senj und Modrus / Modruš oder Krbava] (Senj)

- $\operatorname{Trn}[$ Dorn]

Triest:

- Edinost [Einheit]

- Il Popolo [Das Volk]

- L'Amico [Der Freund]

- L'Avvenire [Die Zukunft]

- La Ricreazione [Die Erholung]

- Škrat [Zwerg]

Istrien und Krain:

- L' Avvenire [Die Zukunft]

- L'Istria [Das Istrien]

- La Provincia dell’ Istria [Die Provinz von Istrien]

- Naša Sloga [Unsere Eintracht]

- Slovenec [Der Slowene]

- Slovenski Narod [Slowenische Nation]

Fiume/Rijeka:

- A Tengerpart [Die Seeküste]

- Fiumei Estilap [Fiumaner Abendblatt]

- Giovine Fiume [Jugendliches Fiume]

- Il Corriere [Der Kurier]

- Il Popolo [Das Volk]

- Il Risveglio [Das Erwachen]

- La Bilancia [Die Bilanz]

- La Voce del Popolo [Die Stimme des Volkes]

- Magyar Tengerpart [Ungarische Seeküste]

- (Riječki) Novi List [(Fiumaner) Neues Blatt] 


\section{Digitale Sammlungen}

Arcanum Digitális Tudománytár [Arcanum Digitale Wissenssammlung]: URL: <https://adtplus. arcanum.hu/hu/> (15.10.2019).

Digitalna Knjižnica Slovenije [Digitatale Bibliothek von Slowenien]: URL: <https://www.dlib.si/> (15.10.2019).

Hrčak - Portal znanstvenih časopisa Republike Hrvatske [Hamster - Portal der wissenschaftlichen Aufsätze der Republik Kroatien]: URL: <https://hrcak.srce.hr/> (15.10.2019).

MAPIRE - The Historical Map Portal: URL: <https://mapire.eu/de/> (15.10.2019).

Österreichische Nationalbibliothek, Austrian Newspapers Online: URL: <http://anno.onb.ac.at/>.

SiStory.si - Zgodovina Slovenije [SiStory.si - Geschichte von Slowenien]: URL: <http://www. sistory.si/> (15.10.2019).

\section{Zeitgenössische Literatur}

L'Amico (Hg.), Il Processo di Rovigno per i fatti del 30 agosto 1908. Supplemento al periodico L'Amico, Trieste 1909.

Bureau der K. K. Statistischen Central-Commission (Hg.), Die Ergebnisse der Volkszählung vom 31. Dezember 1890 in den im Reichsrathe vertretenen Königreichen und Ländern. 1. Heft: Die summarischen Ergebnisse der Volkszählung, Wien 1892.

Bureau der K. K. Statistischen Central-Commission (Hg.), Die Ergebnisse der Volkszählung vom 31. Dezember 1900 in den im Reichsrathe vertretenen Königreichen und Ländern. 1. Heft: Die summarischen Ergebnisse der Volkszählung, Wien 1900.

Bureau der K. K. Statistischen Zentralkommission (Hg.), Die Ergebnisse der Volkszählung vom 31. Dezember 1910 in den im Reichsrathe vertretenen Königreichen und Ländern. 1. Heft: Die summarischen Ergebnisse der Volkszählung, Wien 1912.

Jellinek, Georg/Pliverić, Josip, Das rechtliche Verhältnis Kroatiens zu Ungarn, Agram 1885.

Ders., Über Staatsfragmente, Heidelberg 1896.

K.K. Statistische Zentralkommission (Hg.), Gemeindelexikon der im Reichsrathe vertretenen Königreiche und Länder. Bearbeitet auf Grund der Ergebnisse der Volkszählung vom 31. Dezember 1900, Wien 1906, Bd. VII.: Österreichisch-Illyrisches Küstenland (Triest, Görz und Gradiska, Istrien).

Klodić, Anton, Slawische Sprache und Literatur, in: Erzherzog Rudolf (Hg.), Die österreichisch-ungarische Monarchie in Wort und Bild. Das Küstenland (Görz, Gradiska, Triest und Istrien). Auf Anregung und unter Mitwirkung weiland Seiner kaiserl. und königl. Hoheit des Kronprinzen Erzherzog Rudolf begonnen, fortgesetzt unter dem Protectorate Ihrer kaiserl. und königl. Hoheit der durchlauchtigsten Frau Kronprinzessin-Witwe Erzherzogin Stephanie, Wien 1891, S. 231-249.

LASCIAC, Alois, Erinnerungen aus meiner Beamtencarrière in Österreich in den Jahren 1881-1918, Trieste 1939.

Magyar Királyi Központi Statisztikai Hivatal (Hg.), A Magyar Szent Korona Országainak 1910. évi népszámlálása. Első rész: A népesség főbb adatai községek és népesebb puszták, telepek szerint, Budapest 1912.

Országos Királyi Magyar Statisztikai Hivatal (Hg.), A Magyar Korona Országaiban az 1891. év elején végrehajtott népszámlálás eredményei. I. rész: Általános népleírás, Budapest 1893.

Palacký, Franz, Eine Stimme über Österreichs Anschluß an Deutschland. An den FünfzigerAusschuß zu Handen des Herren Präsidenten Soiron in Frankfurt a. M., in: Ders., Oesterreichs Staatsidee, Prag 1866.

Slataper, Scopio, Il mio Carso, Trieste 2015 [1912].

Spinčić, Alois, Volksleben der Slawen in Istrien, in: Erzherzog Rudolf (Hg.), Die österreichisch-ungarische Monarchie in Wort und Bild. Das Küstenland (Görz, Gradiska, Triest 
und Istrien). Auf Anregung und unter Mitwirkung weiland Seiner kaiserl. und königl. Hoheit des Kronprinzen Erzherzog Rudolf begonnen, fortgesetzt unter dem Protectorate Ihrer kaiserl. und königl. Hoheit der durchlauchtigsten Frau Kronprinzessin-Witwe Erzherzogin Stephanie, Wien 1891, S. 208-230.

TeChet, Carl, Vom toten Österreich, Leipzig 1922.

Vivante, Angelo, Irredentismo adriatico, Trieste 1984 [1912].

VRBA, Rudolf, Oesterreichs Bedränger. Die Los-von-Rom Bewegung. Studien über politische, religiöse und sociale Zustände der Gegenwart, Prag 1903.

\section{Sekundärliteratur}

ADRIÁNYi, Gábor, Fünfzig Jahre ungarischer Kirchengeschichte, 1895-1945, Mainz 1974.

Ders., Die katholische Kirche und die Nationalitätenfrage in Ungarn im 19. und 20. Jahrhundert, in: Der Donauraum 20 (1975), S. 47-57.

Agamben, Giorgio, Homo sacer. Die Souveränität der Macht und das nackte Leben. Übersetzt aus dem Italienischen von Hubert Thüring, Frankfurt a. M. 2002.

Ders., Profanierungen. Übersetzt aus dem Italienischen von Marianne Schneider, Frankfurt a. M. 2015.

Alix, Christine, Le Saint-Siège et les nationalismes en Europe 1870-1960, Sirey 1962.

Altermatt, Urs, Religion und Nation - Die Rolle der Religion bei der Nationalstaatenbildung Europas im 19. und 20. Jahrhundert, in: Ruloff, Dieter (Hg), Religion und Politik, Chur/ Zürich 2001, S. 27-52.

Ders., Katholizismus und Nation. Vier Modelle in europäisch-vergleichender Perspektive, in: Ders. / Metzger, Franziska (Hg.), Religion und Nation. Katholizismen im Europa des 19. und 20. Jahrhunderts, Stuttgart 2007, S. 15-31.

Ders., Konfession, Nation und Rom. Metamorphosen im schweizerischen und europäischen Katholizismus des 19. und 20. Jahrhunderts, Frauenfeld 2009.

Ders. / Metzger, Franziska, Religious Institutes as a Factor of Catholic Communities of Communication, in: De MAeYer, Jan u. a. (Hg.), Religious Institutes and Catholic Culture in 19th- and 20th-Century Europe, Leuven 2014, S. 11-20.

Anderson, Benedict, Imagined Communities. Reflections on the Origin and Spread of Nationalism, London 2006.

ANDrÁsI, Dorottya, Fiume államjogi helyzetének rendezése és jelentősége a XIX. sz. második felében a jogforrások tükrében, in: Jogtörténeti Szemle 7 (2005), S. 17-22.

Apollonio, Almerigo, La "Belle Époque« e il tramonto dell'Impero asburgico sulle rive dell' Adriatico. I: Gli anni prebellici (1902-1914), Trieste 2014.

Appiah, Kwame Anthony, The Lies That Bind. Rethinking Identity, New York/ London 2019.

Ara, Angelo / Magris, Claudio, Trieste. Un' identità di frontiere, Torino 2007.

Ders., Fra nazione e impero. Trieste, gli Asburgo, la Mitteleuropa, Milano 2009.

AUBURger, Leopold, Grundzüge der kroatischen und südslawischen Kulturpolitik von Josip Juraj Strossmayer, in: Zeitschrift für Balkanologie 48 (2012), S. 22-50.

Aust, Martin / Schenk, Frithjof Benjamin (Hg.), Imperial Subjects. Autobiographische Praxis in den Vielvölkerreichen der Romanovs, Habsburger und Osmanen im 19. und frühen 20. Jahrhundert, Wien u. a. 2015.

Babejová, Eleonóra, Fin-de-siècle Pressburg. Conflict and Cultural Coexistence in Bratislava 1897-1914, Boulder 2003.

BABERowski, Jörg, Gewalt verstehen, in: Zeithistorische Forschungen/Studies in Contemporary Studies 5 (2008), S. 5-17.

Ders., Einleitung. Ermöglichungsräume exzessiver Gewalt, in: Ders. / Metzler, Gabriele (Hg.), Gewalträume. Soziale Ordnungen im Ausnahmezustand, Frankfurt a. M./New York 2012, S. 7-27. 
Ders., Der Sinn der Geschichte. Geschichtstheorien von Hegel bis Foucault, München 2014.

Ders., Räume der Gewalt, Bonn 2016.

BАнм, Karl F., Beyond the Bourgeoisie. Rethinking Nation, Culture, and Modernity in NineteenthCentury Central Europe, in: Austrian History Yearbook 29 (1998), S. 19-35.

BAldus, Manfred, Hapsburgian Multiethnicity and the »Unity of the State«. On the Structural Setting of Kelsen's Legal Thought, in: Diner, Dan/Stolleis, Michael (Hg.), Hans Kelsen and Carl Schmitt. A Juxtaposition, Gerlingen 1999, S. 13-23.

BAllinger, Pamela, Imperial Nostalgia. Mythologizing Habsburg Trieste, in: Journal of Modern Italian Studies 8 (2003), S. 84-101.

Dies., History’s »Illegibles«. National Indeterminacy in Istria, in: Austrian History Yearbook 43 (2012), S. 116-137.

BAnAC, Ivo, Hrvati i Crkva. Kratka povijest hrvatskog katoličanstva u modernosti, Zagreb 2013.

Banti, Alberto Mario, Conclusions. Performative Effects and »Deep Images in National Discourse, in Cole, Laurence (Hg.), Different Paths to the Nation. Regional and National Identities in Central Europe and Italy, 1830-70, New York 2007, S. 220-229.

Baran-SzoŁtys, Magdalena/Dvoretska, Olena u.a. (Hg.), Galizien in Bewegung. Wahrnehmungen - Begegnungen - Verflechtungen, Göttingen 2018.

Baric, Daniel, Von Fiume bis Rijeka, in: Serrier, Thomas (Hg.), Die Aneignung fremder Vergangenheiten in Nordosteuropa am Beispiel plurikultureller Städte, in: Nordost-Archiv. Zeitschrift für Regionalgeschichte 15 (2006), S. 324-334.

Ders., Entre construction juridique, tensions nationales et modernisation. Le compromis hungaro-croate de 1868, in: Ducange, Jean-Numa/Lajarrige, Jacques (Hg.), L'empire austrohongrois. Les enjeux de la présence allemande en Europe centrale (1867-1918), in: Austriaca 73 (2011), S. 31-48.

Ders., Langue allemande, identité croate. Au fondement d' un particularisme culturel, Paris 2013.

Bartolić, Ivan, Češki i Moravski svećenici u Istri od 1890. do 1930., in: Pazinski memorijal 19 (1995), S. 107-120.

BAuer, Ingrid, Welche Zentren? - Welche Peripherien? Frauen - Arbeiter - Provinz. Oder: Über eine gezielte Abweichung vom Thema, in: Österreichische Zeitschrift für Geschichtswissenschaften 4 (1993), S. 305-313.

BECK, Ulrich, The Cosmopolitan Society and Its Enemies, in: Theory, Culture \& Society 19 (2002), S. 17-44.

Ders./Grande, Edgar, Jenseits des methodologischen Nationalismus. Außereuropäische und europäische Variationen der Zweiten Moderne, in: Soziale Welt 61 (2010), S. 187-216.

Bedorf, Thomas, Das Politische und die Politik - Konturen einer Differenz, in: Ders. / Röttgers, Kurt (Hg.), Das Politische und die Politik, Frankfurt a. M. 2010, S. 13-37.

Bellabarba, Marco, Italiani d'Austria tra Otto e Novecento, in: Mazohl, Brigitte/ Pombeni, Paolo (Hg.), Minoranze negli imperi. Popoli fra identità nazionale e ideologia imperial, Bologna 2012, S. 397-439.

Beller, Steven, What is Austrian about Austrian Culture?, in: Diem-Wille, Gertraud/NagL, Ludwig/STAdLER, Friedrich (Hg.), Weltanschauungen des Wiener Fin de Siècle 1900/2000. Festgabe für Kurt Rudolf Fischer zum achtzigsten Geburtstag, Frankfurt a. M. 2002, S. 25-41.

Ders., What Has the Empire Ever Done for Us? The Surprising Legacies of the Habsburg Monarchy, and the Lessons for Today's European Union, in: Eurozine, 3. November 2017, URL: <http:// www.eurozine.com/what-has-the-empire-ever-done-for-us/> (15.10.2019).

Beneš, Jakub S., Workers and Nationalism. Czech and German Social Democracy in Habsburg Austria, 1890-1918, Oxford 2017.

Benvin, Anton [Antonio], Prenošenje glagoljske tradicije u liturgiji, in: Croatica Christiana Periodica 4 (1980), S. 124-135.

Ders., Il glagolitico nella liturgia nella regione di Fiume, in: Società di Studi Fiumani/Lega Fiumana di Roma (Hg.), Giornata di studio sugli aspetti di vita cattolica nella storia di Fiume. Roma, 26 gennaio 1985, Roma 1988, S. 37-51.

Berecz, Ágoston, Recepciótörténeti széljegyzet Tara Zahra tanulmányához, in: Regio 25 (2017), S. $43-50$. 
Ders., Empty Signs, Historical Imaginaries. The Entangled Nationalization of Names and Naming in a Late Habsburg Border Region, New York 2020.

Berger, Stefan / Miller, Alexei, Building Nations in and with Empires - A Reassesment, in: Dies., Nationalizing Empires, Budapest 2015, S. 1-30.

BertošA, Miroslav, Mletačka Istra u XVI i XVII stoljeću. I.: Kolonizacija (Teme i problemi), Pula 1986.

Beyen, Marnix/Van Ginderachter, Maarten, General Introduction. Writing the Mass into a Mass Phenomenon, in: Dies. (Hg.), Nationhood from Below. Europe in the Long Nineteenth Century, New York / Basingstoke 2012, S. 3-22.

BeŽAnIĆ-Roknić, Andrea / LeIDeck, Markus, Rijeka und Liburnien während der österreichischen Herrschaft, in: Stojić, Aneta/Pintarić Pavić, Anita (Hg.), Kroatiens Küste im Lichte der Habsburgermonarchie, Wien 2017, S. 55-78.

BILlig, Michael, Banal Nationalism, Los Angeles 1995.

BINDER, Harold, Galizien in Wien. Parteien, Wahlen, Fraktionen und Abgeordnete im Übergang zur Massenpolitik, Wien 2008.

Birke, Adolf M., Nation und Konfession. Varianten des politischen Katholizismus in Europa des 19. Jahrhunderts, in: Historisches Jahrbuch 116 (1996), S. 395-416.

BJork, James, Neither German nor Pole. Catholicism and National Indifference. Catholicism and National Indifference in a Central European Borderland, Ann Arbor 2008.

BJork, Jim, "I Have Removed the Boundaries of Nations". Nations switching and the Roman Catholic Church during and after the Second World War, in: Van Ginderachter, Maarten / Fox, Jon, National Indifference and the History of Nationalism in Modern Europe, London / New York 2019, S. 204-224.

Blasina, Paolo, Santa Sede, vescovi e questioni nazionali. Documenti vaticani sull'espiscopato di A.M Sterk a Trieste (1896-1901), in: Rivista di Storia e Letteratura religiosa 24 (1988), S. 471-502.

Ders., Die Kirche und die nationale Frage in den adriatischen Gebieten 1870-1914, in: ArA, Angelo/KolB, Eberhard (Hg.), Grenzregionen im Zeitalter der Nationalismen, Berlin 1998, S. 177-199.

Blau Remorino, Lina, Associazionismo religioso a Fiume, in: Società di Studi Fiumani/Lega Fiumana di Roma (Hg.), Giornata di studio sugli aspetti di vita cattolica nella storia di Fiume. Roma, 26. gennaio 1985, Roma 1988, S. 85-94.

BogDanov, Vaso, Hrvatski narodni pokret 1903./1904., Zagreb 1961.

Bogović, Mile, Crkvena povijest Rijeke od 1889.-1924, in: Hrvatska, Matica/ Ograna, Rijeke (Hg.), Bernardin Nikola Škrivanić i njegovo vrijeme. Zbornik radova, Rijeka 1997, S. 7-42.

Ders., Hrvatsko glagoljsko tisućljeće, in: Senjski Zbornik 25 (1998), S. 1-140.

Ders., Povijest biskupija Senjske i Modruške ili Krbavske, in: Fontes. Izvori za hrvatsku povijest 7 (2001), S. 20-32.

Ders., Senjsko-modruška ili krbavska biskupije. Izvješća biskupa svetoj stolici (1602-1919), Zagreb 2003.

Ders., Senjska glagoljska baština, in: Senjski zbornik 35 (2008), S. 11-26.

Ders., Hrvatsko glagoljaštvo kao inkulturacijski proces, in: Riječki teološki časopis 23 (2015), S. 317-324.

BoncodDo, Marco, Alba e tramonto di un sogno mitteleuropeo. Gli anni dell'»idillio fiumanomagiaro«, Messina 2014 / 2015 [unveröff. Doktorarbeit].

Bosetti, Gilbert, Les limites de la pluriculturalité. Le cas de Trieste et de Rijeka / Fiume sous les Habsbourg, in: Chroniques allemandes 11 (2006/2007), S. 203-217.

Borutta, Manuel, Antikatholizismus. Deutschland und Italien im Zeitalter der europäischen Kulturkämpfe, Göttingen 2011.

Bouwers, Eveline G., Glaube und Gewalt. Ein Beziehungsgeflecht auf dem Prüfstand, in: Dies., Glaubenskämpfe. Katholiken und Gewalt im 19. Jahrhundert, Göttingen 2019, S. 13-38.

Dies., Die Wandlungen im Verhältnis von Glaube und Gewalt im 19. Jahrhundert, in: Dies. (Hg.), Glaubenskämpfe. Katholiken und Gewalt im 19. Jahrhundert, Göttingen 2019, S. 337-345. 
Boyer, John W., Religion and Political Development in Central Europe around 1900. A View from Vienna, in: Austrian History Yearbook 25 (1994), S. 13-57.

Bozanić, Anton, Biskup Antun Mahnič i hrvatski katolički pokret - inicijative i ostvarenja u javnom životu, in: Riječki teološki časopis 18 (2010), S. 511-532.

Bracewell, Catherine W., The Uskoks of Senj. Piracy, Banditry, and Holy War in the SixteenthCentury Adriatic, Ithaca NY 1992.

Bremer, Thomas, Religion and Conceptual Boundary in Central and Eastern Europe. Introductory Remarks, in: Ders. (Hg.), Religion and Conceptual Boundary in Central and Eastern Europe, New York 2007, S. 1-15.

Brubaker, Rogers/Cooper, Frederick, Beyond »identity«, in: Theory and Society 29 (2000), S. 1-47.

Ders., Nationalism reframed. Nationhood and the National Question in the New Europe, Cambridge 1996.

Ders., Ethnicity without Groups, Cambridge 2004.

Ders., Religion and nationalism. Four approaches, in: Nation and Nationalism 18 (2012), S. 2-20.

Ders., Language, Religion, and the Politics of Difference, in: Ders., Grounds for Difference, Cambridge MA/London 2015, S. 85-101.

Ders., Religious Dimensions of Political Conflict and Violence, in: Sociological Theory 33 (2015), S. 1-19.

Bruckmüller, Ernst, Österreich - eine »katholische« Nation?, in: Altermatt, Urs / Metzger, Franziska (Hg.), Religion und Nation. Katholizismen im Europa des 19. und 20. Jahrhunderts, Stuttgart 2007, S. 69-93.

Buchen, Tim/Rolf, Malte (Hg.), Eliten im Vielvölkerreich. Imperiale Biographien in Russland und Österreich-Ungarn, Berlin / Boston 2015.

Buchenau, Klaus, Orthodoxie und Katholizismus in Jugoslawien 1945-1991. Ein serbischkroatischer Vergleich, Wiesbaden 2004.

Ders., Katholizismus und Jugoslawismus. Zur Nationalisierung der Religion bei den Kroaten, 1918-1945, in: Geyer, Martin/Lehmann, Hartmut (Hg.), Religion und Nation. Nation und Religion, Göttingen 2004, S. 225-254.

Ders., Svetosavlje und Pravoslavlje. Nationales und Universales in der serbischen Orthodoxie, in: Schulze Wessel, Martin (Hg.), Nationalisierung der Religion und Sakralisierung der Nation im östlichen Europa, Stuttgart 2006, S. 203-232.

Bucur, Maria / Wingfield, Nancy M. (Hg.), Staging the Past. The Politics of Commemoration in Habsburg Central Europe, 1848 to the Present, West Lafayette 2001.

Bukovec, Predrag, Der glagolitische Usus des römischen Ritus, in: Ostkirchliche Studien 64 (2015), S. 96-129.

Burić, Josip, Pobjeda »šćaveta«. Posebni otisak iz »Novog Života«, Rim [Rom] 1966.

Butorac, Franjo / Antić, Vinko/Klen, Danilo, Povijest Rijeke, Rijeka 1988.

CAPuzzo, Ester, L' autonomia della città di Fiume, in: Dies., Dall' Austria all' Italia. Aspetti istituzionali e problemi normativi nella storia di una frontera, Roma 1996, S. 7-32.

Catalan, Tullia, La comunità ebreica di Trieste 1781-1914, Trieste 2000.

Cattaruzza, Marina, Sloveni e italiani a Trieste. La formazione dell' identità nazionale, in: Clio, rivista trimestrale di studi storici 25 (1989), S. 27-58.

Dies., I conflitti nazionali a Trieste nell' ambito della questione nazionale nell' impero asburgico. 1850-1914, in: Quaderni Giuliani di Storia 10 (1989), S. 131-148.

Dies., Trieste nell' Ottocento. Le trasformazioni di una società civile, Udine 1995.

Dies., Population Dynamics and Economic Change in Trieste and Its Hinterland 1850-1914, in: Lawton, Richard/ Lee, Robert (Hg.), Population and Society in Western European Port-Cities c. 1650-1939, Liverpool 2002, S. 176-211.

Dies., Sozialisten an der Adria. Plurinationale Arbeiterbewegung in der Habsburgermonarchie, Berlin 2011.

Čepulo, Dalibor/Krešić, Mirela, Hrvatsko-ugarska nagodba. Institucije i stvarnost, in: ŠoKČEvić, Dinko [Sokcsevits, Dénes] (Hg.), »Mint nemzet a nemzettel...«. Tudományos konferencia a magyar-horvát kiegyezés 140. évfordulója emlékére/ »Kao narod s narodom...« Konferencija u spomen 140. obljetnici Hrvatsko-ugarske nagodbe, Budapest 2011, S. 141-155. 
Cetnarowicz, Antoni, Narodni preporod u Istri (1860-1907). Übersetzt aus dem Polnischen von Magdalena Najbar-Agičić, Zagreb 2014.

Christ, Michaela/ Gudehus, Christian, Gewalt - Begriffe und Forschungsprogramme, in: Dies. (Hg.), Gewalt. Ein interdisziplinäres Handbuch, Stuttgart 2013, S. 1-16.

Clayer, Nathalie/Grandits, Hannes / Pichler, Robert (Hg.), Conflicting Loyalities in the Balkans. The Great Powers, the Ottoman Empire and Nation Building, London 2011.

Clewing, Konrad, Staatlichkeit und nationale Identitätsbildung. Dalmatien in Vormärz und Revolution, München 2001.

Ders., Staatensystem und innerstaatliches Agieren im multiethnischen Raum. Südosteuropa im langen 19. Jahrhundert, in: Ders. / Schмiтt, Oliver Jens (Hg.), Geschichte Südosteuropas. Vom frühen Mittelalter bis zur Gegenwart, Regensburg 2011, S. 432-553.

Clark, Christopher, The European Culture Wars, in: Ders./Kaiser, Wolfram (Hg.), Culture Wars. Secular-Catholic Conflict in Nineteenth-Century Europe, Cambridge 2003, S. 1-10.

Cocco, Emilio, Borderlands Mimicry. Imperial Legacies, National Stands and Regional Identity in Croatian Istria after the Nineties, in: Narodna umjetnost 47 (2010), S. 7-28.

Cohen, Gary B., The Politics of Ethnic Survival. Germans in Prague, 1861-1914, Princeton 1981.

Ders., Nationalist Politics and the Dynamics of State and Civil Society in the Habsburg Monarchy, 1867-1914, in: Central European History 40 (2007), S. 241-278.

Cole, Laurence, »Für Gott, Kaiser und Vaterland«. Nationale Identität der deutschsprachigen Bevölkerung Tirols 1860-1914, Frankfurt a. M. / New York 2000.

Ders., Der Habsburger-Mythos, in: Brix, Emil/Bruckmüller, Ernst/Stekl, Hannes (Hg.), Memoria Austriae I. Menschen, Mythen, Zeiten, Wien 2004, S. 472-504.

Ders., Introduction. Re-examining National Identity in Nineteenth-Century Central Europe and Italy, in: Ders. (Hg.), Different Paths to the Nation. Regional and National Identities in Central Europe and Italy. 1830-1870, New York 2007, S. 1-15.

Ders., Differentiation or Indifference? Changing Perspectives on National Identification in the Austrian Half of the Habsburg Monarchy, in: VAN Ginderachter, Maarten/Beyen, Marnix (Hg.), Nationhood from Below. Europe in the Long Nineteenth Century, New York/Basingstoke 2012, S. 96-119.

Ders., Military Culture and Popular Patriotism in Late Imperial Austria, Oxford 2014.

Collins, Randall, Violence. A Micro-sociological Theory, Princeton / Oxford 2008.

Conzemius, Victor, Kirchen und Nationalismen im Europa des 19. Jahrhunderts und 20. Jahrhunderts, in: LANGNer, Albrecht (Hg.), Katholizismus, nationaler Gedanke und Europa seit 1800, Paderborn u. a. 1985, S. 11-50.

Čop, Milivoj, Riječko školstvo (1848.-1918.), Rijeka 1988.

Cornwall, Mark, The Struggle on the Czech-German Language Border, 1880-1940, in: The English Historical Review 109 (1994), S. 914-951.

Crenshaw, Kimberle, Demarginalizing the Intersection of Race and Sex. A Black Feminist Critique of Antidiscrimination Doctrine, Feminist Theory and Antiracist Policies, in: University of Chicago Legal Forum (1989), S. 139-167.

Dies., Mapping the Margins. Intersectionality, Identity Politics, and Violence against Women of Color, in: Stanford Law Review 43 (1991), S. 1241-1299.

CsÁky, Moritz, Der Kulturkampf in Ungarn. Die kirchenpolitische Gesetzgebung der Jahre 1894/ 1895, Graz u.a. 1967.

Ders., Historische Reflexionen über das Problem einer österreichischen Identität, in: WoLfRAM, Herwig/Pohl, Walter (Hg.), Probleme der Geschichte Österreichs und ihrer Darstellung, Wien 1991, S. 29-47.

Ders., Die Vielfalt der Habsburgermonarchie und die nationale Frage, in: Altermatt, Urs (Hg.), Nation, Ethnizität und Staat in Mitteleuropa, Wien u. a. 1996, S. 44-64.

Ders., Ideologie der Operette und Wiener Moderne. Ein kulturhistorischer Essay zur österreichischen Identität, Wien u. a. 1996.

Ders., Die Ambivalenz des kulturellen Erbes, Zentraleuropa. Moderne und/oder postmoderne Befindlichkeit, in: Ders./Zeyringer, Klaus (Hg.), Ambivalenz des kulturellen Erbes. Vielfachcodierung des historischen Gedächtnisses. Paradigma: Österreich, Innsbruck u.a. 2000, S. 27-49. 
Ders., Paradigma Zentraleuropa. Pluralitäten, Religionen und kulturelle Codes. Religion - Mythos - Nation. Einführende Überlegungen, in: Ders./ZEYringer, Klaus (Hg.), Pluralitäten, Religionen und kulturelle Codes. Religion-Mythos-Nation, Innsbruck u. a. 2001, S. 9-17.

Ders., »Was man Nation und Rasse heißt, sind Ergebnisse und keine Ursachen«. Zur Konstruktion kollektiver Identitäten in Zentraleuropa, in: MüLler-Funk, Wolfgang/Plener, Peter/RuthNER, Clemens (Hg.), Kakanien revisited. Das Eigene und das Fremde (in) der österreichischungarischen Monarchie, Tübingen / Basel 2002, S. 33-49.

Ders., Mitteleuropa / Zentraleuropa. Ein komplexes kulturelles System, in: Österreichische Musikzeitschrift 60 (2005), S. 9-16.

Ders., Culture as a Space of Communication, in: Feichtinger, Johannes / Cohen, Gary B., Understanding Multiculturalism. The Habsburg Central European Experience, New York/Oxford 2014, S. 187-208.

Ders., Die Stadt in Zentraleuropa - ein hybrider Kommunikationsraum, in: STIEgLER, Bernd/Werner, Sylwia (Hg.), Laboratorien der Moderne. Orte und Räume des Wissens in Mittel- und Osteuropa, Paderborn 2016, S. 31-59.

Ders., Das Gedächtnis Zentraleuropas. Kulturelle und literarische Projektionen auf eine Region, Wien 2019.

Ćutić Gorup, Maja, Istrien zur Zeit der österreichischen Herrschaft, in: StojIĆ, Aneta / Pintarić Pavić, Anita (Hg.), Kroatiens Küste im Lichte der Habsburgermonarchie, Wien 2017, S. 41-53.

D’ Alessio, Vanni, Il cuore conteso. Il nazionalismo in una comunità multietnica. L'Istria asburgica, Napoli 2004.

Ders. Croatian Urban Life and Political Sociability in Istria from the 19th to the Early 20th Century, in: Jahrbücher für Geschichte und Kultur Südosteuropas 8 (2006), S. 133-152.

Ders., Istrians, Identifications and Habsburg Legacy, in: Acta Historiae 14 (2006), S. 15-39.

Ders., From Central Europe to the Northern Adriatic. Habsburg Citizens between Italians and Croats in Istria, in: Journal of Modern Italian Studies 13 (2008), S. 237-258.

Ders., Dall' Impero d' Austria al Regno d' Italia. Lingua, stato e nazionalizzazione, in: BERTUCELLI, Lorenzo/ OrLić, Mila (Hg.), Una storia balcanica. Fascismo, comunismo e nazionalismo nella Jugoslavia del Novecento, Verona 2008, S. 31-71.

Davis, Belinda/Lindenberger, Thomas/Wildt, Michael, Einleitung, in: Dies. (Hg.), Alltag, Erfahrung, Eigensinn. Historisch-anthropologische Erkundungen, Frankfurt a. M. / New York 2008, S. 11-28.

Defrance, Corine/Horel, Catherine, Réalités, perceptions et usages de la défaite en Europe, in: Dies. / Nérard, François-Xavier (Hg.), Vaincus! Histoires des défaites, Paris 2016, S. 9-28.

Doвin, Lois C., The Port Jews of Habsburg Trieste. Absolutist Politics and Enlightenment Culture, Stanford 1999.

DoвRIĆ, Bruno, Kultura čitanja i nacionalni pokreti. Čitalačka društva i knjižnice u Puli u drugoj polovici 19. i prvoj polovici 20. stoljeća, Pula 2003.

Domonkos, László, A kicserélt város. Fiume. Volt és van, Budapest 2010.

Dragostinova, Theodora/Hashamova, Yana, Introduction. Beyond Mosque, Church, and State. Alternative Narratives of the Nation in the Balkans, in: Dies. (Hg.), Beyond Mosque, Church, and State. Alternative Narratives of the Nation in the Balkans, Budapest/New York 2016, S. 1-27.

Dutoit, Jan / Previšić, Boris, Stammesdenken und internationale Solidarität. Bradstvo im Ersten und Zweiten Jugoslawien, in: Zimmermann, Tanja (Hg.), Brüderlichkeit und Bruderzwist. Mediale Inszenierung des Aufbaus und des Niedergangs politischer Gemeinschaften in Ost- und Südosteuropa, Göttingen 2014, S. 73-98.

Dvořak, Johann, Politik und Kultur der Moderne in der späten Habsburgermonarchie, Innsbruck/Wien 1997.

EGRY, Gábor, Etnicitás, identitás, politika. Magyar kisebbségek regionalizmus és nacionalizmus között Csehszlovákiában és Romániában 1918-1944, Budapest 2015.

Ders., Beyond Politics. National Indifference as Everyday Ethnicity, in: VAN Ginderachter, Maarten / Fox, Jon, National Indifference and the History of Nationalism in Modern Europe, London/New York 2019, S. 145-160. 
Engel-Janosi, Friedrich, The Church and the Nationalities in the Habsburg Monarchy, in: Austria History Yearbook 3 (1967), S. 67-82.

Engemann, Iris, Die Slowakisierung Bratislavas. Universität, Theater und Kultusgemeinden 1918-1948, Wiesbaden 2012.

Evans, Robert J., Der ungarische Nationalismus im internationalen Vergleich, in: HirschHAUSEN, Ulrike von/LeonhaRD, Jörn (Hg.), Nationalismen in Europa. West- und Osteuropa im Vergleich, Göttingen 2001, S. 291-305.

Ders., Language and State Building. The Case of the Habsburg Monarchy, in: Austrian History Yearbook 35 (2004), S. 1-24.

Fejtö, François, Requiem pour un empire défunt. Histoire de la destruction de l'AutricheHongrie, Paris 1993.

Feichtinger, Johannes, Habsburg (post-)colonial. Anmerkungen zur Inneren Kolonialisierung in Zentraleuropa, in: Ders./ Prutsch, Ursula/Csáky, Moritz (Hg.), Habsburg postcolonial. Machtstrukturen und kollektives Gedächtnis, Innsbruck u.a. 2003, S. 13-31.

Ders., Wissenschaft als reflexives Projekt. Von Bolzano über Freud zu Kelsen. Österreichische Wissenschaftsgeschichte 1848-1938, Bielefeld 2010.

Ders., Zwischen Mittel- und Zentraleuropa. Oder: Vom politisch überformten Raum zum heuristischen Konzept, in: Lajarrige, Jacques/Schmitz, Walter/Zanasi, Giusi (Hg.), »Mitteleuropa«. Geschichte eines transnationalen Diskurses im 20. Jahrhundert, Dresden 2011, Bd. 1, S. 53-73.

Ders. / Cohen, Gary B., Introduction. Understanding Multiculturalism. The Habsburg Central European Experience, in: Dies., Understanding Multiculturalism. The Habsburg Central European Experience, New York/ Oxford 2014, S. 1-14.

Feindt, Gregor/Gissibl, Bernhard/Paulmann, Johannes, Kulturelle Souveränität. Zur historischen Analyse von Deutungs- und Handlungsmacht jenseits des Staates, in: Dies. (Hg.), Kulturelle Souveränität. Politische Deutungs- und Handlungsmacht jenseits des Staates im 20. Jahrhundert, Göttingen 2017, S. 9-46.

Fellerer, Jan/Pyrah, Robert/Turda, Marius (Hg.), Identities In-between in East-Central Europe, London/ New York 2019.

FERrari, Liliana, Liturgia paleoslava. Il revival del XIX secolo, in: Quaderni Giuliani di Storia 36 (2015), S. 23-34.

Finzi, Roberto/Panjek, Giovanni (Hg.), Storia economica e sociale di Trieste. Vol. 1: La città dei gruppi 1719-1918, Trieste 2001.

Fox, Jon E. / Miller-Idriss, Cynthia, Everyday Nationhood, in: Ethnicities 8 (2008), S. 536-563.

Ders. / Van Ginderachter, Maarten, Introduction. Everyday Nationalism's Evidence Problem, in: Nations and Nationalism 24 (2018), S. 546-552.

Frank, Alison Fleig, Oil Empire. Visions of Prosperity in Austrian Galicia, Cambridge MA 2007.

FrIEd, Ilona, Emlékek városa. Fiume, Budapest 2001.

Dies., Fiume, Budapest 2004.

Galtung, Johan, Strukturelle Gewalt. Beiträge zur Friedens- und Konfliktforschung, Reinbek bei Hamburg 1979.

Gammerl, Benno, Untertanen, Staatsbürger und andere. Der Umgang mit ethnischer Heterogenität im britischen Weltreich und im Habsburgerreich 1867-1918, Göttingen 2010.

Gellner, Ernest, Nations and Nationalism, Oxford 1983.

Ders., Language and Solitude. Wittgenstein, Malinowski and the Habsburg Dilemma, Cambridge 2004.

Geréby, György, A népek angyalai, avagy lehetséges-e nemzeti kereszténység?, in: Pannonhalmi Szemle 16 (2008), S. 35-55.

Geyer, Martin/Lehmann, Hartmut (Hg.), Religion und Nation. Nation und Religion, Göttingen 2004.

Ginzburg, Carlo/ Poni, Carlo, Il nome e il come. Scambio ineguale e mercato storiografica, in: Quaderni storici 14 (1979), S. 181-190.

Gladigow, Burkhard, Symbole und Symbolkontrolle als Ergebnis einer Professionalisierung von Religion, in: Schlögl, Rudolf/Giesen, Bernhard/Osterhammel, Jürgen (Hg.), Die Wirk- 
lichkeit der Symbole. Grundlagen der Kommunikation in historischen und gegenwärtigen Gesellschaften, Konstanz 2004, S. 159-172.

Gottsmann, Andreas, Papst Leo XIII. und die »jugoslawische« Versuchung. Montenegro, San Girolamo und die südslawische Frage in der Diplomatie des Hl. Stuhls, in: Römische Historische Mitteilungen 49 (2007), S. 457-510.

Ders., Rom und die nationalen Katholizismen in der Donaumonarchie. Römischer Universalismus, habsburgische Reichspolitik und nationale Identitäten 1878-1914, Wien 2010.

GöDERLE, Wolfgang, Zensus und Ethnizität. Zur Herstellung von Wissen über soziale Wirklichkeiten im Habsburgerreich zwischen 1848 und 1910, Göttingen 2016.

Grad, Héctor/Rojo, Luisa Martín, Identities in Discourse. An Integrative View, in: Dolón, Rosana/Todolí, Júlia (Hg.), Analysing Identities in Discourse, Amsterdam/Philadelphia 2008, S. 3-28.

Grandits, Hannes, Familie und sozialer Wandel im ländlichen Kroatien (18.-20. Jahrhundert), Wien u.a. 2002.

Ders., Herrschaft und Loyalität in der spätosmanischen Gesellschaft. Das Beispiel der multikonfessionellen Herzegowina, Wien u. a. 2008.

Ders./Hirschhausen, Béatrice von/Kraft, Claudia/Müller, Dietmar/Serrier, Thomas, Phantomgrenzen im östlichen Europa. Eine wissenschaftliche Positionierung, in: Dies., Phantomgrenzen. Räume und Akteure in der Zeit neu denken, Göttingen 2015, S. 13-56.

Griesebner, Andrea/Hehenberger, Susanne, Intersektionalität. Ein brauchbares Konzept für die Geschichtswissenschaften?, in: Kallenberg, Vera/Meyer, Jennifer/Müller, Johanna M. (Hg.), Intersectionality und Kritik. Neue Perspektiven für alte Fragen, Wiesbaden 2013, S. $105-124$.

Griffante, Andrea, Between Empire and Nation State. Urban Space and Conflicting Memories in Trieste (19th- Early 20th Century), in: Journal of Architecture and Urbanism 39 (2015), S. 17-27.

Grijak, Zoran, Odnos Hrvata prema problemu odvojanja riječke župe od senjsko-mudruške biskupije (1891.-1925.), in: Matica Hrvatska/Ograna Rijeke (Hg.), Bernardin Nikola Škrivanić i njegovo vrijeme. Zbornik radova, Rijeka 1997, S. 61-92.

Groenemeyer, Alex, Kulturelle Differenz, ethnische Identität und die Ethnisierung von Alltagskonflikten. Ein Überblick sozialwissenschaftlicher Thematisierungen, in: Ders./ MANSEL, Jürgen (Hg.), Die Ethnisierung von Alltagskonflikten, Wiesbaden 2013, S. 11-46.

Gross, Mirjana, Povijest pravaške ideologije, Zagreb 1973.

Dies., Croatian National-Integrational Ideologies from the End of Illirism to the Creation of Yugoslavia, in: Austrian History Yearbook 15 (1979), S. 2-33.

Dies., O integraciji hrvatske nacije, in: Dies. (Hg.), Društveni razvoj u Hrvatskoj, Zagreb 1981, S. $175-190$.

Dies., Anfänge des modernen Kroatien, Wien u.a. 1993.

Grunert, Heiner, Glauben im Hinterland. Die Serbisch-Orthodoxen in der habsburgischen Herzegowina 1878-1918, Göttingen 2016.

Gusejnova, Dina, European Elites and Ideas of Empire, 1917-1957, Cambridge 2019.

Habermas, Jürgen, Inklusion - Einbeziehen oder Einschließen? Zum Verhältnis von Nation, Rechtsstaat und Demokratie. Für Hans-Ulrich Wehler zum 65. Geburtstag, in: Ders., Die Einbeziehung des Anderen. Studien zur politischen Theorie, Frankfurt a. M. 1999, S. 154-184.

Hajdarpasic, Edin, Whose Bosnia? Nationalism and Political Imagination in the Balkans, 1840-1914, Ithaca/ London 2015.

Hann, Chris, The Limits of Galician Syncretism. Pluralism, Multiculturalism, and the Two Catholicisms, in: Ders. / Magocsi, Paul Robert (Hg.), Galicia. A Multicultured Land. Toronto, 2005, S. 210-237.

HÁrs, Endre/Müller-Funk, Wolfgang/Reber, Ursula/Ruthner, Clemens, Zentren peripher. Vorüberlegungen zu einer Denkfigur, in: Dies. (Hg.), Zentren, Peripherien und kollektive Identitäten in Österreich-Ungarn, Tübingen / Basel 2006, S. 1-15.

Haselsteiner, Horst/Plaschka, Richard G. / Suppan, Arnold, Zum Begriff des Nationalismus und zu seinen Strukturen in Südosteuropa im 19. Jahrhundert und zu Beginn des 20. Jahrhunderts, in: Österreichische Osthefte 20 (1978), S. 48-78. 
HASLINGER, Peter, Sprachenpolitik, Sprachendynamik und imperiale Herrschaft in der Habsburgermonarchie 1740-1914, in: Zeitschrift für Ostmitteleuropa-Forschung 57 (2008), S. 81-111.

Ders., Nation und Territorium im tschechischen politischen Diskurs 1880-1938, München 2010.

Haupt, Heinz-Gerhard, Religion and Nation in Europe in the 19th Century. Some Comperative Notes, in: Estudos avançados 22 (1998), S. 77-94.

Ders., Gewalt und Politik im Europa des 19. und 20. Jahrhunderts, Göttingen 2012.

Heitmayer, Wilhelm/Soeffner, Hans-Georg, Einleitung. Gewalt. Entwicklungen, Strukturen, Analyseprobleme, in: Dies. (Hg.), Gewalt. Entwicklungen, Strukturen, Analyseprobleme, Frankfurt a. M. 2004, S. 11-17.

HeKA, László, A magyar-horvát államközösség alkotmány- és jogtörténete, Szeged 2004.

Henschel, Frank, "Das Fluidum der Stadt ... « Urbane Lebenswelten in Kassa/Košice/ Kaschau zwischen Sprachenvielfalt und Magyarisierung 1867-1918, Göttingen 2017.

HirschHAusen, Ulrike von, Citizenship in Austria-Hungary 1867-1923 between Imperial Inclusion and National Exclusion, in: European Review of History 16 (2009), S. 551-573.

Новзвашм, Eric, Nations and Nationalism since 1780. Programme, Myth, Reality, Cambridge 1990.

Ders., Inventing Traditions, in: Hobsbawm, Eric/Ranger, Terence, The Invention of Tradition, Cambridge 1992, S. 1-14.

Hоск, Beata, Kulturelle Dimensionen der Transnationalen Verflechtungen Ostmitteleuropas 1870er Jahre bis 1914, in: Hadler, Frank / Middell, Matthias (Hg.), Handbuch einer transnationalen Geschichte Ostmitteleuropas, Göttingen 2017, Bd. I: Von der Mitte des 19. Jahrhunderts bis zum Ersten Weltkrieg, S. 189-255.

Dies., Forschungen zur kulturellen Dimension transnationaler Verflechtungen Ostmitteleuropas von den 1870er Jahren bis 1914, in: Hadler, Frank/Middell, Matthias (Hg.), Handbuch einer transnationalen Geschichte Ostmitteleuropas, Göttingen 2017, Bd. I: Von der Mitte des 19. Jahrhunderts bis zum Ersten Weltkrieg, S. 489-523.

Horel, Catherine, Cette Europe qu' on dit centrale. Des Habsbourg à l'intégration européenne 1815-2004, Paris 2009.

Dies., Soldaten zwischen nationalen Fronten. Die Auflösung der Militärgrenze und die Entwicklung der königlich-ungarischen Landwehr (Honvéd) in Kroatien-Slawonien 1868-1914, Wien 2009.

Dies., Die Entmilitarisierung der kroatisch-slawonischen Militärgrenze (1868-1881) im ungarischen Kontext, in: Cole, Laurence/Hämmerle, Christa/Scheutz, Martin (Hg.), Glanz Gewalt - Gehorsam. Militär und Gesellschaft in der Habsburgermonarchie (1800 bis 1918), Essen 2011, S. 153-176.

Dies., Trieste et Fiume, deux aspects de l'irrédentisme italien 1867-1914, in: PAvlović, Vojislav (Hg.), Italy's Balkan Strategies 19th-20th Century, Belgrade 2014, S. 121-136.

Hormel, Ulrike/SCHERr, Albert, Was heißt »Ethnien« und »ethnische Konflikte« in der modernen Gesellschaft?, in: Groenemeyer, Alex/Mansel, Jürgen (Hg.), Die Ethnisierung von Alltagskonflikten, Wiesbaden 2003, S. 47-66.

НвомјÁк, Ĺuboslav, Hrvati i Crkva slovacca dalle origini fino alla prima metà del Novecento, in: JAKIR, Aleksandar/Trogrlić, Marko, Klerus und Nation in Südosteuropa vom 19. bis zum 21. Jahrhundert, Frankfurt a. M. 2014, S. 15-48.

Huber, Florian, Grenzkatholizismen. Religion, Raum und Nation in Tirol 1830-1848, Göttingen 2016.

Islamov, Tofik M., From Natio Hungarica to Hungarian Nation, in: RudolPh, Richard L. / Good, David F. (Hg.), Nationalism and Empire. The Habsburg Empire and the Soviet Union, New York 1992, S. 159-183.

IvanišEvić, Alojz, Die Bemühungen Josip Juraj Strossmayers um die slawische Liturgie aus der Sicht der österreichisch-ungarischen Zentralbehörden und des Vatikans, in: Österreichische Osthefte 37 (1995), S. 423-445.

Ders., Katholizismus und die nationale Identität der Kroaten von der Mitte des 19. Jahrhunderts bis 1918, in: Moser, Alois (Hg.), „Gottes auserwählte Völer«. Erwählungsvorstellungen und kollektive Selbstfindung in der Geschichte, Frankfurt a. M. 2001, S. 217-232. 
Ivetic, Egidio, La popolazione dell' Istria nell' eta moderna, Rovigno 1997.

Ders. (Hg.), Istra kroz vrijeme. Pregled povijesti Istre sa osvrtom na grad Rijeku, Rovinj / Rovigno 2009.

Ders., Jugoslavia sognata. Lo jugoslavismo delle origini, Milano 2012.

JászI, Oscar, The Dissolution of the Habsburg Monarchy, Chicago 1961 [1929].

JAWORSKI, Rudolf, Konfession als Faktor nationaler Identifikationsprozesse in Ostmitteleuropa im 19. und zu Beginn des 20. Jahrhunderts, in: Csáky, Moritz/Zeyringer, Klaus (Hg.), Pluralitäten, Religionen und kulturelle Codes. Religion-Mythos-Nation, Innsbruck u. a. 2001, S. 131-147.

JeLIČIĆ, Ivan, Nell'ombra dell' autonomismo. Il movimento socialista a Fiume 1901-1921, Trieste 2015/2016 [unveröff. Doktorarbeit].

Jestin, Matthieu/Nérard, François-Xavier, Le temps des défaites, in: Defrance, Corine/ Horel, Catherine/ ders. (Hg.), Vaincus! Histoires des défaites, Paris 2016, S. 311-326.

Jobst, Kerstin S. / Obertreis, Julia/Vulpius, Ricarda, Neue Imperiumsforschung in der Osteuropäischen Geschichte. Die Habsburgermonarchie, das Russländische Reich und die Sowjetunion, in: Comparativ. Zeitschrift für Globalgeschichte und Gesellschaftsordnung 18 (2008), S. 27-56.

JOHLER, Reinhard, »Hibridismus«, Istrien, die Volkskunde und die Kulturtheorie, in: Zeitschrift für Volkskunde 108 (2012), S. 1-21.

Johnston, William M., The Austrian Mind. An Intellectual and Social History 1848-1938, Berkely 1972.

Ders., Zur Kulturgeschichte Österreichs und Ungarns 1890-1938. Auf der Suche nach verborgenen Gemeinsamkeiten, Wien u. a. 2015.

Judson, Pieter, Inventing Germans. Class, Nationality and Colonial Fantasy at the Margins of the Hapsburg Monarchy, in: Social Analysis 33 (1993), S. 47-67.

Ders., Nationalizing Rural Landscapes in Cisleithania, 1880-1914, in: Wingfield, Nancy M. (Hg.), Creating the Other. Ethnic Conflicts and Nationalism in Habsburg Central Europe, New York 2003, S. 127-148.

Ders., Constructing Nationalities in East Central Europe. Introduction, in: Ders./ RozenbiLT, Marsh L. (Hg.), Constructing Nationalities in East Central Europe, Oxford/New York 2005, S. 1-17.

Ders., Guardians of the Nation. Activists on the Language Frontier in Imperial Austria, Cambridge MA / London 2006.

Ders., L' Autriche-Hongrie était-elle un empire?, in: Annales. Histoire, Sciences Sociales 63 (2008), S. 563-596.

Ders., Beyond Nations. Rethinking the History of Habsburg Central Europe, in: Berlin Journal (2011), S. 29-33.

Ders., Marking National Space on the Habsburg Austrian Borderlands 1880-1918, in: BARTov, Omer/Weitz, Eric (Hg.), Shatterzone of Empires. Coexistence and Violence in the East, Central, and Southeast European Borderlands, Bloomington / Indianapolis 2013, S. 122-135.

Ders., Do Multiple Languages Mean a Multicultural Society? Nationalist »Frontiers« in Rural Austria, 1880-1918, in: Feichtinger, Johannes/Cohen, Gary B., Understanding Multiculturalism. The Habsburg Central European Experience, New York/ Oxford 2014, S. 61-82.

Ders., The Habsburg Empire. A New History, Cambridge MA / London 2016.

Ders., Nationalism and Indifference, in: Feichtinger, Johannes/Uhl, Heidemarie (Hg.), Habsburg neu denken. Vielfalt und Ambivalenz in Zentraleuropa. 30 kulturwissenschaftliche Stichworte, Wien 2016, S. 148-155.

Ders., Die Habsburgermonarchie - neue Interpretationen, in: Osterkamp, Jana (Hg.), Kooperatives Imperium. Politische Zusammenarbeit in der späten Habsburgermonarchie, Göttingen 2018, S. 315-324.

Ders. / ZAhra, Tara, Introduction, in: Austrian History Yearbook 43 (2012), S. 21-27.

JuReit, Ulrike, Raum und Gewalt. Eine Einleitung, in: JuREIT, Ulrike (Hg.), Umkämpfte Räume. Raumbilder, Ordnungswille und Gewaltmobilisierung, Göttingen 2016, S. 9-25.

Kamusella, Tomasz, Silesia and Central European Nationalisms. The Emergence of National and Ethnic Groups in Prussian Silesia and Austrian Silesia, 1848-1918, West Lafayette 2007. 
KAnN, Robert A., A Study in Austrian Intellectual History. From Late Baroque to Romanticism, New York 1960.

Ders., The Dynasty and the Imperial Idea, in: Austrian History Yearbook 3 (1967), S. 11-31.

Kaplan, Benjam J., Cunegonda's Kidnapping. A Story of Religious Conflict in the Age of Einlightenment, New Haven / London 2014.

KAppus, Elke-Nicole, Regionale Identität in Istrien - oder: Auf der Suche nach der Istrianität, in: Bornewasser, Manfred/Wakenhut, Roland (Hg.), Ethnisches und nationales Bewußtsein - zwischen Globalisierung und Regionalisierung, Frankfurt a. M. 1999, S. 85-99.

Dies., Imperial Ideologies of Peoplehood in Habsburg - an Alternative Approach to Peoples and Nations in Istria, in: Annales - Anali za istrske in mediteranske studije 12 (2002), S. 321-330.

Karpowicz, Ljubinka, Riječki Corpus separatum. 1868-1924, Ljubljana 1986 [unveröff. Doktorarbeit].

Dies., Freemasonry, Politics and Rijeka (Fiume) (1785-1944), Washington 2017.

KAser, Karl, Familie und Verwandtschaft auf dem Balkan. Analyse einer untergehenden Kultur, Wien u.a. 1995.

Ders., Freier Bauer und Soldat. Die Militarisierung der agrarischen Gesellschaft an der kroatisch slawonischen Militärgrenze (1535-1881), Wien 1997.

Kavrečič, Petra, Turizem v Avstrijskem primorju. Zdravilišča, kopališca in kraške jame (1819-1914), Koper 2015.

Kelsen, Hans, Autobiographie (1947), in: Jestaedt, Matthias (Hg.), Hans Kelsen Werke, Tübingen 2007, Bd. 1, S. 29- 91.

KesSLER, Wolfgang, Vom Recht der Stände zum »kroatischen Staatsrecht «. Zum historischen Recht in der politischen Kultur des 19. Jahrhunderts in Kroatien, in: WilloweIt, Dietmar/ LEMBERG, Hans (Hg.), Reiche und Territorien in Ostmitteleuropa. Historische Beziehungen und politische Herrschaftslegitimation, München 2006, S. 379-403.

KIng, Jeremy, Budweisers into Czechs and Germans. A Local History of Bohemien Politics, 1848-1948, Princeton NJ 2002.

Kiss Gy., Csaba (Hg.), Fiume és a magyar kultúra. Művelődéstörténeti tanulmányok, Budapest 2004.

KlabJan, Borut, "Jadran je naš«. Nacionalno prisvajanje Jadranskega morja pred prvo svetovno vojno in po njej, in: Annales 21 (2011), S. 43-54.

Ders., Nicht Ost, nicht West. Triest, in: Ost-West. Europäische Perspektiven (2013), S. 114-120.

Ders. (Hg.), Borderlands of Memory. Adriatic and Central European Perspectives, Oxford 2019.

KLEINE, Christoph, »Religiöser Nonkonformismus« als religionswissenschaftliche Kategorie, in: Zeitschrift für Religionswissenschaft 23 (2015), S. 3-34.

Klemenčič, Matjaž, Croats and Croatian Americans, 1870-1940, in: BARKan, Elliott Robert (Hg.), Immigrants in American History. Arrival, Adaptation and Integration. Vol. 1, Santa Barbara u.a. 2014, S. 291-300.

Klieber, Rupert, Grandi e piccole comunità religiose nella monarchia asburgica fra lealismo e identità nazionali, in: Mazohl, Brigitte/Pombeni, Paolo (Hg.), Minoranze negli imperi. Popoli fra identità nazionale e ideologia imperiale, Bologna 2012, S. 375-396.

von KLimó, Árpád, Nation, Konfession, Geschichte. Zur nationalen Geschichtskultur Ungarn im europäischen Kontext, München 2003.

Ders., Ein »konfessionelles Zeitalter« Ungarns (1848-1948)?, in: Altermatt, Urs/Metzger, Franziska (Hg.), Religion und Nation. Katholizismen im Europa des 19. und 20. Jahrhunderts, Stuttgart 2007, S. 215-228.

Klinger, William, Negotiating the Nation. Fiume - From Autonomism to State Making (1848-1924), Florence 2007 [unveröff. Doktorarbeit].

Ders., Dall' autonomismo alla constituzione dello Stato. Fiume 1848-1918, in: BetTA, Emmanuel/ Luigia Caglioti, Daniela/Papadia, Elena (Hg.), Forme del politico. Studi di storia per Raffaele Romanelli, Roma 2012, S. 45-60.

Ders., Un capitolo della Questione d'Oriente. Il Corpus separatum di Fiume (1773-1923), in: Quaderni Vergeriani 9 (2013), S. 123-163.

Kluxen, Kurt, Religion und Nationalstaat im 19. Jahrhundert, in: Schoeps, Julius H. (Hg.), Religion und Zeitgeist im 19. Jahrhundert, Stuttgart/Bonn 1982, S. 37-57. 
Koselleck, Reinhard, Erfahrungswechsel und Methodenwechsel. Eine historisch-anthropologische Skizze, in: Ders., Zeitschichten. Studien zur Historik. Mit einem Beitrag von Hans-Georg Gadamer, Frankfurt a. M. 2003, S. 27-77.

Komlosy, Andrea, Imperial Cohesion, Nation-Building, and Regional Integration in the Habsburg Monarchy, in: Berger, Stefan/Miller, Alexei (Hg.), Nationalizing Empires, Budapest 2015, S. 369-427.

KoschORKe, Albrecht, Wie werden aus Spannungen Differenzen? Feldtheoretische Überlegungen zur Konfliktsemantik, in: Fassmann, Heinz/Müller-Funk, Wolfgang/Uhl, Heidemarie (Hg.), Kulturen der Differenz - Transformationsprozesse in Zentraleuropa nach 1989, Göttingen 2009, S. 271-285.

Kosı, Jernej, Kako je nastal slovenski narod. Začetki slovenskega nacionalnega gibanja v prvi polovici 19. stoletja, Ljubljana 2013.

Kosmač, Angel, Ricmanje - včeraj in danes, Trst [Triest] 1997.

KosnicA, Ivan, Das Problem der Staatsbürgerschaft in Kroatien und Slawonien im Ausgleichszeitraum (1868-1918), in: Máthé, Gábor/MEZEY, Barna (Hg.), Kroatisch-ungarische öffentlichrechtliche Verhältnisse zur Zeit der Doppelmonarchie, Budapest 2015, S. 187-219.

Košuta, Katarina, L' episcopato triestino di Franz Xaver Nagl (1902-1910), Trieste 2002 [unveröff. Diplomarbeit].

Kraus, Karl, Aphorismen. Sprüche und Widersprüche. Pro domo et mundo. Nachts, Frankfurt a. M. 1986.

KRIŠTO, Jure, Prešućena povijest. Katolička crkva u hrvatskoj politici 1850.-1918., Zagreb 1994.

Ders., Hrvatski katolički pokret 1903.-1945., Zagreb 2004.

Krogner-Kornalik, Kathrin, Tod in der Stadt. Religion, Alltag und Festkultur in Krakau 1869-1914, Göttingen 2015.

Kulıšić, Marija / Vuković, Ivana, Majka Božja Snježana u pučkoj pobožnosti na področju Krivoga Puta, in: Senjski Zbornik 31 (2004), S. 239-260.

Kumar, Krishan, Visions of Empire. How Five Imperial Regimes Shaped the World, Princeton / Oxford 2017.

Kuzmany, Börries, Habsburg Austria. Experiments in Non-Territorial Autonomy, in: Ethnopolitics 15 (2016), S. 43-65.

Lehmann, Hartmut, Die Säkularisierung der Religion und die Säkularisierung der Nation im 20. Jahrhundert. Varianten einer komplementären Relation, in: MANER, Hans-Christian/ Schulze Wessel, Martin, Religion im Nationalstaat zwischen den Weltkriegen 1918-1939. Polen - Tschechoslowakei - Ungarn - Rumänien, Stuttgart 2002, S. 13-27.

LeONHARD, Jörn / HirschHausen, Ulrike von, Empires und Nationalstaaten im 19. Jahrhundert, Göttingen 2009.

Lettenbauer, Wilhelm, Zur Entstehung des glagolitischen Alphabets, in: Slovo. Časopis Staroslavenskoga Instituta u Zagrebu, 1953/3, S. 35-50.

Lindenberger, Thomas / Lüdtke, Alf, Physische Gewalt - eine Kontinuität der Moderne, in: Dies. (Hg.), Physische Gewalt. Studien zur Geschichte der Neuzeit, Frankfurt a. M. 1995, S. 7-38.

Lipset, Seymour M. / Rokkan, Stein, Cleavage Structures, Party Systems, and Voter Alignments, in: Dies. (Hg.), Party Systems and Voters Alignments. Cross-National Perspectives, New York/London 1967, S. 1-64.

Ljubljanović, Srećko, Niko Gršković, in: Hrvatski Biografski Leksikon, URL: <http://hbl.lzmk. hr/clanak.aspx?id=28> (15.10.2019).

Llewelyn S. J., Dorian, Toward a Catholic Theology of Nationality, Lanham 2010.

Luckmann, Thomas, The Invisible Religion. The Problem of Religion in Modern Society, New York/London 1967.

Luhmann, Niklas, Die Religion der Gesellschaft. Hg. von André Kieserling, Frankfurt a. M. 2000.

LÜDTKe, Alf, Was ist und wer treibt Alltagsgeschichte?, in: Ders. (Hg.), Alltagsgeschichte. Zur Rekonstruktion historischer Erfahrungen und Lebensweisen, Frankfurt a. M. / New York 1989, S. 9-47.

Ders., Wo blieb die »rote Glut«? Arbeitererfahrungen und deutscher Faschismus, in: Ders. (Hg.), Alltagsgeschichte. Zur Rekonstruktion historischer Erfahrungen und Lebensweisen, Frankfurt a. M. / New York 1989, S. 224-282. 
Ders., Eigen-Sinn. Fabrikalltag, Arbeitererfahrungen und Politik vom Kaiserreich bis in den Faschismus. Neuauflage, Münster 2015.

MacClancy, Jeremy, At Play with Identity in the Basque Language Arena, in: MacDonald, Sharon (Hg.), Inside European Identities. Ethnography in Western Europe, Providence RI 1993, S. 84-97.

Magnússon, Sigurður Gylfi/SzIjáRTó, István M., What is Microhistory? Theory and Practice, Abingdon / New York 2013.

Malfèr, Stefan, Der Kampf um die slawische Liturgie in der österreichisch-ungarischen Monarchie - ein religiöses oder ein nationales Anliegen?, in: Mitteilungen des Österreichischen Staatsarchivs (44) 1996, S. 165-193.

Mallon, Florencia E., Peasant and Nation. The Making of Postcolonial Mexico and Peru, Berkeley u.a. 1995.

Manenti, Luca G. / Schuster, Martina (Hg.), Le nazioni, gli uomini e i gruppi. Trieste mosaico di genti (secoli XVIII-XX), Trieste 2018.

Maner, Hans-Christian, Zentrum und Grenzregion in der Habsburgermonarchie im 18. und 19. Jahrhundert. Eine Einleitung, in: Ders. (Hg.), Grenzregionen der Habsburgermonarchie im 18. und 19. Jahrhundert. Ihre Bedeutung und Funktion aus der Perspektive Wiens, Münster 2005, S. 9-24.

Ders., Galizien. Eine Grenzregion im Kalkül der Donaumonarchie im 18. und 19. Jahrhundert, München 2007.

Mannová, Elena/Tancer, Jozef, Mehrsprachigkeit, in: Feichtinger, Johannes/Uhl, Heidemarie (Hg.), Habsburg neu denken. Vielfalt und Ambivalenz in Zentraleuropa. 30 kulturwissenschaftliche Stichworte, Wien 2016, S. 133-139.

Marchart, Oliver, Die politische Differenz. Zum Denken des Politischen bei Nancy, Lefort, Badiou, Laclau und Agamben, Frankfurt a. M. 2010.

MARCIC, René, Verfassungsgerichtsbarkeit und Reine Rechtslehre, Wien 1966.

Marung, Steffi/Middell, Matthias/Müller, Uwe, Territorialisierung in Ostmitteleuropa bis zum Ersten Weltkrieg, in: Hadler, Frank/Middell, Matthias (Hg.), Handbuch einer transnationalen Geschichte Ostmitteleuropas, Göttingen 2017, Bd. I: Von der Mitte des 19. Jahrhunderts bis zum Ersten Weltkrieg, S. 37-130.

Matković, Stjepan, Afirmacija Khuenove autokracije. Izbori za Hrvatski sabor 1897., in: Časopis za suvremenu povijest 29 (1997), S. 469-489.

Ders., Čista stranka prava 1895.-1903., Zagreb 2001.

Maver, Aleš, Die Rolle des Klerus im nationalen Emanzipationsprozess der Slowenen, in: JAKIR, Aleksandar/Trogrlić, Marko, Klerus und Nation in Südosteuropa vom 19. bis zum 21. Jahrhundert, Frankfurt a. M. 2014, S. 49-58.

MaY, Vivian M., Pursuing Intersectionality, Unsettling Dominant Imaginaries, New York/London 2015.

Maxwell, Alexander, Everyday Nationalism in Hungary. 1789-1867, Boston / Berlin 2019.

McAdam, Doug/Tarow, Sidney/Tilly, Charles, Dynamics of Contention, Cambridge 2004.

Medved, Marko, La gerarchia cattolica italiana e la questione linguistica in diocesi plurinazionali. Il caso della Chiesa di Rijeka (Fiume) durante il fascismo, in: Revue d' histoire ecclésiastique 108 (2013), S. 931-953.

Ders., Riječka Crkva u razdoblju fašizma. Nastanak biskupije i prvi talijanski upravitelji, Zagreb 2015.

Metzger, Franziska, Religion, Geschichte, Nation. Katholische Geschichtsschreibung in der Schweiz im 19. und 20. Jahrhundert - kommunikationstheoretische Perspektiven, Stuttgart 2010 .

Milanović, Božo, Hrvatski narodni preporod u Istri. Vol. 2, Pazin 1973.

Miletić, Jasminka, Riječke Novine (1912-1914), Rijeka 1997 [unveröff. Diplomarbeit].

MilićEvić, Josip, Etnografski rad Josipa Ptašinskog, in: Istarska danica, 1992, S. 92-93.

Miller, Nicholas J., Between Nation and State. Serbian Politics in Croatia before the First World War, Pittsburgh 1997. 
Milo, Anna, Trieste, 1830-70. From Cosmopolitanism to the Nation, in: Cole, Laurence (Hg.), Different Paths to the Nation. Regional and National Identities in Central Europe and Italy, 1830-70, New York 2007, S. 60-81.

Mitterbauer, Helga/Smith-Prei, Carrie, Introduction. Crossings and Encounters, in: Dies. (Hg.), Crossing Central Europe. Continuities and Transformations. 1900 and 2000, Toronto 2017, S. VII-XVIII.

MonZali, Luciano, The Italians of Dalmatia. From Italian Unification to World War, Toronto 2016.

Morelon, Claire, Social Confict, National Strife, or Political Battle? Violence and Strikebreaking in Late Habsburg Austria, in: European History Quarterly 49 (2019), S. 650-676.

Moritsch, Andreas, Das nahe Triester Hinterland. Zur wirtschaftlichen und sozialen Entwicklung vom Beginn des 19. Jahrhunderts bis zur Gegenwart, Wien u. a. 1969.

Ders. / Baumgartner, Gerhard, The Process of National Differentiation within Rural Communities in Southern Carinthia and Southern Burgenland 1850-1940, in: WiEgandT, Ellen/ Howell, David/von Pistohlkors, Gert (Hg.), Roots of Rural Ethnic Mobilisation. Comparative Studies on Governments and Non-dominant Ethnic Groups in Europe. 1850-1940, Vol. VII, New York 1992, S. 99-143.

Motyl, Alexander J., Thinking about Empire, in: BArkey, Karen/Hagen, Mark von (Hg.), After Empire. Multiethnic Societies and Nation-Building. Soviet Union and the Russian, Ottoman, and Habsburg Empires, Colorado 1997, S. 19-29.

Mouffe, Chantal, Über das Politische. Wider die kosmopolitische Illusion. Übersetzt aus dem Englischen von Niels Neumeier, Frankfurt a. M. 2007.

Dies., Agonistik. Die Welt politisch denken. Übersetzt aus dem Englischen von Richard Barth, Frankfurt a. M. 2016.

Musil, Robert, Der Mann ohne Eigenschaften. Erstes und Zweites Buch, Hamburg 2014.

Nemes, Robert, The Uncivil Origins of Civil Marriage. Hungary, in: Clark, Christoph / KaIser, Wolfram (Hg.), Culture Wars. Secular-Catholic Conflict in Nineteenth-Century Europe, Cambridge 2003, S. 313-335.

Niedermüller, Peter, Der Mythos des Unterschieds. Vom Multikulturalismus zur Hybridität, in: Feichtinger, Johannes/Prutsch, Ursula/Csáky, Moritz (Hg.), Habsburg postcolonial. Machtstrukturen und kollektives Gedächtnis, Innsbruck u.a. 2003, S. 69-81.

NikočEvić, Lidija, State Culture and the Laboratory of Peoples. Istrian Ethnography during the Austro-Hungarian Monarchy, in: Narodna umjetnost 43 (2006), S. 41-57.

OKeY, Robin, Austrian-Hungarian Diplomacy and the Campaign for a Slavonic Liturgy in the Catholic Church. 1881-1914, in: The Slavonic and East European Review 70 (1992), S. 258-283.

OrešKović, Luc, Un diocèse des Alpes Dinariques. La rencontre des influences italienne et germanique (XVIIe-XVIIIe siècles), in: Histoire des Alpes - Storia delle Alpi - Geschichte der Alpen 12 (2007), S. 183-200.

Ders., Le diocèse de Senj-Modruš en Croatie habsbourgeoise de la Contre-Réforme aux Lumières (1650-1770), Turnhout 2008.

Osterhammel, Jürgen, Die Verwandlung der Welt. Eine Geschichte des 19. Jahrhunderts, Bonn 2010.

Osterkamp, Jana, Föderale Schwebelage - Die Habsburgermonarchie als politisches Mehrebenesystem, in: Amrosius, Gerold/Heinrich-Franke, Christian/Neutsch, Cornelius (Hg.), Föderalismus in historisch vergleichender Perspektive, Baden-Baden 2015, Bd. 2: Föderale Systeme: Kaiserreich - Donaumonarchie - Europäische Union, S. 197-219.

Dies., Zur Geschichte von »Vielfalt und Verteilung«. Einleitung, in: Vielfalt und Verteilung. Regionale, nationale und konfessionelle Verteilungsfragen in Europa. Historische Sozialkunde. Geschichte - Fachdidaktik - Politische Bildung 45 (2015), S. 2-3.

Dies., »Kooperatives Imperium«. Loyalitätsgefüge und Reich-Länder-Finanzausgleich in der späten Habsburgermonarchie, in: Geschichte und Gesellschaft 42 (2016), S. 592-620.

Dies., Cooperative Empires. Provincial Initiatives in Imperial Austria, in: Austrian History Yearbook 47 (2016), S. 128-146.

Dies., Kooperatives Imperium. Eine neue Perspektive auf Anspruch und Wirklichkeit imperialer Herrschaft, in: Dies. (Hg.), Kooperatives Imperium. Politische Zusammenarbeit in der späten Habsburgermonarchie, Göttingen 2018, S. 1-21. 
Dies. / Schulze Wessel, Martin, Texturen von Loyalität. Überlegungen zu einem analytischen Begriff, in: Geschichte und Gesellschaft 46 (2016), S. 553-573.

Öhlinger, Theo, The Genesis of the Austrian Model of Constitutional Review of Legislation, in: Ratio Juris 16 (2003), S. 206-222.

PAvličević, Dragutin, Narodni pokret 1883. u Hrvatskoj, Zagreb 1980.

Peklić, Ivan, Život i djelo križevačkoga biskupa Julija Drohobeckog, in: Podravina 3 (2004), S. 71-88.

PešUt, Damjan, Etnička i konfesionalna podjela nakon oslobođanja Like od Turaka, in: Senjski Zbornik 24 (1997), S. 85-128.

Petrovic, Ksenija, Nationale Identität und Religion in Serbien und Kroatien im Vergleich, Wiesbaden 2013.

Petrungaro, Stefano, Pietre e fucili. La protesta sociale nelle campagne croate di fine Ottocento, Roma 2009.

Ders., Fire and Honour. On the Comparability of Popular Protests in Late 19th Century CroatiaSlavonia, in: Rutar, Sabine (Hg.), Beyond the Balkans, Münster 2013, S. 247-263.

Ders., Popular Protest against Hungarian Symbols in Croatia (1883-1903). A Study in Visual History, in: Cultural and Social History 13 (2016), S. 503-520.

Pfaff-Czarnecka, Joanna, Zugehörigkeit in der mobilen Welt. Politiken der Verortung, Göttingen 2012 .

PIRIGYI, István, A magyarországi görögkatolikusok története. II. Rész, Nyíregyháza 1990.

Pirjevec, Jože, Slovene nationalism in Trieste. 1848-1982, in: Nationalities Papers 11 (1983), S. $152-161$.

Ders., Serbi, croati, sloveni. Storia di tre nazioni, Bologna 2015.

Plank, Peter, Die geschichtliche Entwicklung der orthodoxen Kirche im Südosten und Osten Europas, in: Nyssen, Wilhelm/Schulz, Hans-Joachim/Wiertz, Paul (Hg.), Handbuch der Ostkirchenkunde, Düsseldorf 1984, Bd. 1, S. 133-223.

Polıć, Maja, »Riječka krpica« 1868. godine i uvjeti za njezino naljepljivanje na hrvatsko-ugarsko nagodbu, in: Rijeka 1 (2010), S. 57-91.

Preljević, Vahidin, Nakon imperije. Književnost i politička imaginacija u (post)habsburškom kulturnom prostoru, Zagreb 2018.

Prokopovych, Markian/Bethke, Carl/Scheer, Tamara (Hg.), Language Diversity in the Late Habsburg Empire, Leiden 2019.

Pupo, Raoul, Fiume. Città di passione, Bari 2018.

Pyrah, Robert/Fellerer, Jan, Redefining "Sub-culture«. A New Lens for Understanding Hybrid Cultural Identities in East-Central Europe with a Case Study from Early 20th Century L'vivLwów-Lemberg, in: Nations and Nationalism 21 (2015), S. 700-720.

Ransmayr, Anna, Untertanen des Sultans und des Kaisers. Struktur und Organisationsformen der beiden Wiener griechischen Gemeinden von den Anfängen im 18. Jahrhundert bis 1918, Göttingen 2018.

Rebula, Alojz, Jakob Ukmar, Pordenone 1992.

Reill Kirchner, Dominique, Nationalists Who Feared the Nation. Adriatic Multi-Nationalism in Habsburg Dalmatia, Trieste, and Venice, Stanford 2012.

ŘEZník, Miloš, Die Habsburgermonarchie - ein Imperium ihrer Völker? Einführende Überlegungen zu »Österreichs Staatsidee«, in: BACHINGER, Bernhard/Dornik, Wolfram/Lehnstaedt, Stephan (Hg.), Österreich-Ungarns imperiale Herausforderungen. Nationalismen und Rivalitäten im Habsburgerreich um 1900, Göttingen 2020, S. 45-66.

Richers, Julia, Jüdisches Budapest. Kulturelle Topographien einer Stadtgemeinde im 19. Jahrhundert, Köln 2009.

Rindler Schjerve, Rosita (Hg.), Diglossia and Power. Language Policies and Practice in the 19th Century Habsburg Empire, Berlin / New York 2003.

Rотн, Joseph, Radetzkymarsch, Zürich 2010.

Rothenburg, Gunther E., The Military Border in Croatia 1740-1881. A Study of an Imperial Institution, London / Chicago 1966.

Roy, Beth, Some Troubles with Cows. Making Sense of Social Conflict, Berkeley u.a. 1994. 
RösKAU-RydeL, Isabel, Zwischen Akkulturation und Assimilation. Karrieren und Lebenswelten deutsch-österreichischer Beamtenfamilien in Galizien (1772-1918), München 2016.

Rutar, Sabine, Kultur - Nation - Milieu. Sozialdemokratie in Triest vor dem Ersten Weltkrieg, Essen 2004.

SAfran, William, Language, Ethnicity and Religion. A Complex and Persistent Linkage, in: Nations and Nationalism 14 (2008), S. 171-190.

ŠANJEK, Franjo, L'église catholique et la supranationalité en Autriche-Hongrie. Le cas croate, in: Les cahiers Irice 13 (2015), S. 27-35.

ŠEPIĆ, Dragovan, O procesu integracije hrvatske nacije u Istri, in: Gross, Mirjana (Hg.), Društveni razvoj u Hrvatskoj, Zagreb 1981, S. 251-281.

ŠETIĆ, Nevio, O procesu nastanka suvremene hrvatska nacije u Istri - skica za buduća istraživanje, in: Društvena istraživanja 2 (1993), S. 587-605.

SAnTI, Matej, Zwischen drei Kulturen. Musik und Nationalitätsbildung in Triest, Wien 2015.

SCHARR, Kurt, »Die Landschaft Bukowina«. Das Werden einer Region an der Peripherie 1774-1918, Wien 2010.

Schenk, Frithjof Benjamin, Mental Maps, in: Geschichte und Gesellschaft 28 (2002), S. 493-514.

SchöDL, Günter, Kroatische Nationalpolitik und »Jugoslavenstvo«, München 1990.

Sснмiтt, Carl, Der Begriff des Politischen, München 1932.

Ders., Römischer Katholizismus und politische Form, Stuttgart 2002.

SCHNeIder, Oliver, »Triest«. Eine Diskursanalyse, Würzburg 2003.

Schulze, Reinhard, Islamischer Puritanismus und die religiöse Gewalt, in: Аввт, Christine/ Schoeller, Donata (Hg.), Im Zeichen der Religion. Gewalt und Friedfertigkeit in Christentum und Islam, Frankfurt a. M. / New York 2008, S. 34-56.

Schulze, Thies, Nationalism and the Catholic Church. Papal Politics and "Nationalist« Clergy in Border Regions (1918-1939), in: LöHr, Isabella / Wenzlhuemer, Roland (Hg.), The Nation State and Beyond. Governing Globalization Processes in the Nineteenth and Early Twentieth Centuries, Heidelberg/ New York 2013, S. 235-256.

Schulze Wessel, Martin, Das 19. Jahrhundert als »Zweites Konfessionelles Zeitalter«? Thesen zur Religionsgeschichte der böhmischen Länder in europäischer Hinsicht, in: Zeitschrift für Ostmitteleuropaforschung 50 (2001), S. 514-530.

Ders., "Loyalität« als geschichtlicher Grundbegriff und Forschungskonzept. Zur Einleitung, in: Ders. (Hg.), Loyalitäten in der Tschechoslowakischen Republik 1918-1938. Politische, nationale und kulturelle Zugehörigkeiten, München 2004, S. 1-22.

Ders., Nationalisierung der Religion und Sakralisierung der Nation im östlichen Europa, in: Ders. (Hg.), Nationalisierung der Religion und Sakralisierung der Nation im östlichen Europa, Stuttgart 2006, S. 7-14.

Ders., Religion, Politics and the Limits of Imperial Integration. Comparing the Habsburg Monarchy and the Russian Empire, in: Leonhard, Jörn/HirschHausen, Ulrike von (Hg.), Comparing Empires. Encounters and Transfers in the Long Nineteenth Century, Göttingen 2011, S. 337-358.

Schumacher, Joseph, Die Identität des Katholischen, Heimbach / Eifel 2016.

Schumann, Dirk, Gewalt als Grenzüberschreitung. Überlegungen zur Sozialgeschichte der Gewalt im 19. und 20. Jahrhundert, in: Archiv für Sozialgeschichte 37 (1997), S. 366-386.

SenghaAs, Monika, Territorialisierung sozialer Sicherung. Raum, Identität und Sozialpolitik in der Habsburgermonarchie, Wiesbaden 2015.

ŠEPIĆ, Dragovan, O procesu integracije hrvatske nacije u Istri, in: Gross, Mirjana (Hg.), Društveni razvoj u Hrvatskoj, Zagreb 1981, S. 251-281.

ŠEŠo, Luka, Ptašinski, Josip, in: Istarska Enciklopedija, URL: <http://istra.lzmk.hr/clanak. aspx?id=2257> (15.10.2019).

ŠETIĆ, Nevio, Istra između tradicionalnog i modernog ili o procesu integracije suvremene hrvatske nacije u Istri, Pazin 1995.

Shedel, James, Emperor, Church, and People. Religion and Dynastic Loyalty during the Golden Jubilee of Franz Joseph, in: The Catholic Historical Review 76 (1990), S. 71-92. 
Ders., The Problem of Being Austrian. Religion, Law, and Nation from Empire to Anschluß, in: CsÁky, Moritz/Zeyringer, Klaus (Hg.), Pluralitäten, Religionen und kulturelle Codes. Religion-Mythos-Nation, Innsbruck u.a. 2001, S. 117-129.

Silvestri, Marina, Lassù nella Trieste asburgica. La questione dei regnicoli e l'identità rimossa, Gorizia 2017.

SimČIČ, Tomaž, Jakob Ukmar (1878-1971). Sto let slovenstva in krščanstva v Trstu, Gorica 1986.

Simon, Bernd/Mummendey, Amélie, Selbst, Identität und Gruppe. Eine sozialpsychologische Analyse des Verhältnisses von Individuum und Gruppe, in: Dies. (Hg.), Identität und Verschiedenheit. Zur Sozialpsychologie der Identität in komplexen Gesellschaften, Bern 1997, S. 11-38.

Simon, Daniela, Kulturelle Hybridität als Bedrohung? Istrien im ausgehenden 19. Jahrhundert, in: Jahrbücher für europäische Ethnologie 14 (2019), S. 53-76.

ŠKunCA, Josip, O podrijetlu glagoljice, in: Riječki teološki časopis 22 (2014), S. 135-162.

Slane, Mitja, Kirche und Nation. Die slowenische nationale Frage und der Katholizismus bis zum 1. Weltkrieg, Klagenfurt 2003.

Sloković, F., Narodne čitaonice u Istri, in: Dobrić, Bruno / HeK, Antun (Hg.), Hrvatska čitaonička društva u Istri u 19. i početkom 20. stoljeća, Pula / Pazin 1993, S. 89-101.

SLugA, Glenda, The Problem of Trieste and the Italo-Yugoslav Border. Difference, Identity, and Sovereignty in Twentieth-Century Europe, Albany NY 2001.

Dies., The Nation and the Comparative Imagination, in: Cohen, Deborah/ O' Connor, Maura (Hg.), Comparison and History. Europe in Cross-National Perspective, New York 2004, S. 103-114.

SMEžıK, Stephen, The Glagolitic or Roman-Slavonic Liturgy, Cleveland 1959.

Sokcsevits, Dénes [Šokčević, Dinko], Magyar múlt horvát szemmel, Budapest 2004.

Ders., Hrvatska od stoljeća 7. do danas, Zagreb 2016.

SoKol, Hans, Die k. k. Militärgrenze, Wien 1967.

Spannenberger, Norbert/Varga, Szabolcs (Hg.), Ein Raum im Wandel. Die osmanisch-habsburgische Grenzregion vom 16. bis zum 18. Jahrhundert, Stuttgart 2014.

Spariosu, Mihai I. (Hg.), Intercultural Conflict and Harmony in the Central European Borderlands. The Cases of Banat and Transylvania 1849-1939, Göttingen 2017.

Stachel, Peter, Ein Staat, der an einem Sprachfehler zugrunde ging. Die »Vielsprachigkeit« des Habsburgerreiches und ihre Auswirkungen, in: Feichtinger, Johannes/ders. (Hg.), Das Gewebe der Kultur. Kulturwissenschaftliche Analysen zur Geschichte und Identität Österreichs in der Moderne, Innsbruck u. a. 2001, S. 11-45.

Stauter-Halsted, Keely, Nation in the Village. The Genesis of Peasant National Identity in Austrian Poland, 1848-1914, Ithaca / London 2001.

Stelli, Giovanni, Gli autonomisti fiumani. Storia di due liquidazioni, in: NARdelli, Dino Renato / ders. (Hg.), Istria, Fiume, Dalmazia laboratorio d'Europa. La minoranza italiana in Slovenia e Croazia, Perugia 2014, S. 191-217.

Ders., Storia di Fiume - dalle origini ai giorni nostre, Pordenone 2016.

Stourzh, Gerald, Die Gleichberechtigung der Nationalitäten in der Verfassung und Verwaltung Österreichs 1848-1918, Wien 1985.

Ders., The Multinational Empire Revisited. Reflections on Late Imperial Austria, in: Austrian History Yearbook 23 (1992), S. 1-22.

Ders., The Ethnicizing of Politics and »National Indifference« in Late Imperial Austria, in: Ders., Der Umfang der österreichischen Geschichte. Ausgewählte Studien 1990-2010, Wien u.a. 2011, S. 283-323.

Stranj, Pavel, Afera cerkvene zastava Sv. Cirila in Metoda pri Sv. Jakobu, in: Jadranski koledar (1970), S. 191-195.

STrČIĆ, Petar, Prilog povijesti istarskog sabora (1861-1916), in: Arhivski vjesnik 34 / 35 (1991 / 1992), S. 53-64.

Strecha, Mario, „Sve za vjeru i domovinu«. Idejna strujanja u katolicizmu u banskoj Hrvatskoj potkraj XIX. stoljeća, in: Croatica Christiana Periodica 38 (1996), S. 73-132.

Ders., O procesu politizacije katolicizma u Banskoj Hrvatskoj potkraj 19. stoljeća, in: Bosna Franciscana (2007), S. 91-125. 
STruck, Bernhard, Grenzregionen, in: Europäische Geschichte Online (EGO), hg. v. LeibnizInstitut für Europäische Geschichte (IEG), URL: <http://ieg-ego.eu/de/threads/crossroads/ grenzregionen> (15.10.2019).

Struve, Kai, Bauern und Nation in Galizien. Über Zugehörigkeit und soziale Emanzipation im 19. Jahrhundert, Göttingen 2005.

Sujoldžıć, Anita, Transnational and Intercultural Practices in the Adriatric Littoral of the Late Habsburg Empire, in: Collegium Antropologicum 40 (2016), S. 1-12.

ŠuligoJ, Silvo, Župnija in njena vloga v življenju Slovencev pri Sv. Jakobu, in: Debelli-Turk, Lida (Hg.), Sv. Jakob. Zgodovinski razgledi po življenju Slovencev v tržaškem delavskem okraju, Trst [Triest] 1980, S. 159-179.

Surman, Jan, Postkolonialismus, in: Feichtinger, Johannes / Uhl, Heidemarie (Hg.), Habsburg neu denken. Vielfalt und Ambivalenz in Zentraleuropa. 30 kulturwissenschaftliche Stichworte, Wien 2016, S. 181-187.

Ders., Universities in Imperial Austria, 1848-1918. A Social History of a Multlingual Space, West Lafayette 2019.

TAmborra, Angelo, L'idea cirillo-metodiana in Europa nei secoli XIX-XX, in: Storia e politica 27 (1979), S. 666-702.

Taylor, Charles, The Politics of Recognition, in: Gutmann, Amy (Hg.), Multiculturalism. Examining the Politics of Recognition, Princeton 1994, S. 25-73.

Teснeт, Péter, Imperiale Loyalität unter den italienischsprachigen Katholiken in Triest der späten Habsburgermonarchie, in: Osterkamp, Jana (Hg.), Kooperatives Imperium. Politische Zusammenarbeit in der späten Habsburgermonarchie, Göttingen 2018, S. 297-314.

Ders., Die österreichisch-ungarische Küstenregion. Differenzen, Imaginationen und imperialer Kontext in einer historischen Landschaft, in: JAgodZInski, Sabine/KMAK-PAMirskA, Aleksandra / ŘEzník, Miloš (Hg.), Regionalität als historische Kategorie. Ostmitteleuropäische Perspektiven, Osnabrück 2019, S. 281-297.

Ders., Nationalismus und Katholizismus in Ungarn und Kroatien. Sakralisierung der Nation und Nationalisierung der Religion?, in: BendeL, Rainer (Hg.), Die ostmitteleuropäischen Nationalstaaten nach 1918. Transformationen nach dem Zusammenbruch der Kaiserreiche, Münster 2019, S. 157-190.

Ders., Gewaltmomente unter ländlichen Katholiken in der späten Habsburgermonarchie. Kirchenstreit in Ricmanje bei Triest, in: Bouwers, Eveline G. (Hg.), Glaubenskämpfe. Katholiken und Gewalt im langen 19. Jahrhundert, Göttingen 2019, S. 117-138.

Ders., Post-habsburgische Erinnerungspolitik als unreflektierte Nostalgie oder als antinationalistisches Gegennarrativ im heutigen Rijeka?, in: Zibaldone - Zeitschrift für italienische Kultur der Gegenwart 68 (2019), S. 119-131.

Ders., Verzahnung kirchen- und nationalpolitischer Frontlinien in Fiume/Rijeka. »Liberale» Ungarn und Italiener zur Zeit des ungarischen »Kulturkampfes« (1894/ 1895), in: BACHINGER, Bernhard/Dornik, Wolfram/Lehnstaedt, Stephan (Hg.), Österreich-Ungarns imperiale Herausforderungen. Nationalismen und Rivalitäten im Habsburgerreich um 1900, Göttingen 2020, S. 295-312.

Thaler, Peter, Fluid Identities in Central European Borderlands, in: European History Quarterly 31 (2001), S. 519-548.

Ther, Philipp, Von Ostmitteleuropa nach Zentraleuropa. Kulturgeschichte als Area Studies, in: Clio-Online. Themenportal Europäische Geschichte, URL: <http://www.europa.clio-online. de/essay/id/artikel-3307> (15.10.2019).

Tillich, Paul, Systematische Theologie III. Hg. und eingeleitet von Christian Danz, Berlin/ Boston 2017.

Tilly, Charles / Tilly, Louise / Tilly, Richard, The Rebellious Century 1830-1930, Cambridge MA 1975.

Ders., Hauptformen kollektiver Aktionen in Westeuropa 1500-1975, in: Geschichte und Gesellschaft 3 (1977) S. 153-163.

Ders., Micro, Macro, or Megim?, in: Sснцимвонм, Jürgen (Hg.), Mikrogeschichte - Makrogeschichte. Komplementär oder inkommensurabel?, Göttingen 1998, S. 33-51. 
Todorova, Maria, Is There Weak Nationalism and Is It a Useful Category?, in: Nations and Nationalism 21 (2015), S. 681-699.

Toncich, Francesco, Narrazioni e pratiche politiche antislave a Trieste tra città e campagna (1850-1871), in: Acta Histriae 25 (2017), S. 539-562.

Trauner, Karl-Reinhart, Die Los-von-Rom-Bewegung. Gesellschaftspolitische und kirchliche Strömung in der ausgehenden Habsburgermonarchie, Szentendre 1999.

Trencsényi, Balázs, Central Europe, in: Mishkova, Diana/ders. (Hg.), European Regions and Boundaries. European Regions and Boundaries. A Conceptual History, New York/Oxford 2017, S. 166-187.

TrogrLIĆ, Stipan, Katolički pokret u Istri 1895.-1914., Zagreb 2000.

Ders., Katolička crkva u Istri. Nacionalno-političke i idejne podjele 1880.-1914., Pula 2006.

Turczynski, Emanuel, Konfession und Nation. Zur Frühgeschichte der rumänischen und serbischen Nationsbildung, Düsseldorf 1976.

Ulbricht, Otto, Mikrogeschichte. Menschen und Konflikte in der Frühen Neuzeit, Frankfurt a. M. / New York 2009.

UHL, Heidemarie, Zwischen »Habsburgischem Mythos« und (Post-)Kolonialismus. Zentraleuropa als Paradigma für Identitätskonstruktionen in der (Post-)Moderne, in: Feichtinger, Johannes / Prutsch, Ursula/CsÁky, Moritz (Hg.), Habsburg postcolonial. Machtstrukturen und kollektives Gedächtnis, Innsbruck u. a. 2003, S. 45-54.

Unowsky, Daniel L., The Pomp and Politics of Patriotism, West Lafayette 2005.

Ders., Dynastic Symbolism and Popular Patriotism. Monarchy and Dynasty in the Late Imperial Austria, in: Leonhard, Jörn / HirschHausen, Ulrike von (Hg.), Comparing Empires. Encounters and Transfers in the Long Nineteenth Century, Göttingen 2011, S. 237-265.

Urbanitsch, Peter, Pluralist Myth and National Realities. The Dynastic Myth of the Habsburg Monarchy - a Futile Exercise in the Creation of Identity?, in: Austrian History Yearbook 35 (2004), S. 101-141.

Ders., Der Ausgleich zwischen den Nationen untereinander und zwischen den Nationen und dem Staat in Cisleithanien, in: BéHar, Pierre/Philippoff, Eva (Hg.), Von der Doppelmonarchie zur Europäischen Union. Österreichs Vermächtnis und Erbe, Hildesheim u. a. 2011, S. 63-92.

VAlentić, Mirko, Vojna Krajina i pitanje njezina sjedinjenja s Hrvatskom 1849-1881, Zagreb 1981.

Ders., Hrvatsko-slavonska Vojna Krajina 1790-1881, in: MoAčin, Fedor/VALENTić, Mirko, Vojna Krajina u Hrvatskoj, Zagreb 1981, S. 42-77.

VALdevit, Giampaolo, Chiesa e lotte nazionali. Il caso di Trieste (1850-1918), Udine 1979.

Ders., Trieste. Storia di una periferia insicura, Milano 2004.

Van Ginderachter, Maarten/Fox, Jon, Introduction. National Indifference and the History of Nationalism in Modern Europe, in: Dies., National Indifference and the History of Nationalism in Modern Europe, London / New York 2019, S. 1-14.

VArga, Bálint, Writing Imperial History in the Age of High Nationalism. Imperial Historians on the Fringes of the Habsburg Monarchy, in: European Review of History/ Revue européenne d'histoire 24 (2016), S. 1-16.

Ders., The Monumental Nation. Magyar Nationalism and Symbolic Politics in Fin-de-siècle Hungary, New York/ Oxford 2016.

Varshney, Ashutosh, Ethnicity and Ethnic Conflict, in: Boix, Carles / Stokes, Susan C. (Hg.), The Oxford Handbook of Comparative Politics, Oxford 2009, S. 274-294.

VeIter, Theodor, Die Italiener in der österreichisch-ungarischen Monarchie. Eine volkspolitische Studie, München 1965.

Veliz, Fernando, The Politics of Croatia-Slavonia 1903-1918. Nationalism, State Allegiance and the Changing International Order, Wiesbaden 2012.

Verginella, Marta, La comunità nazionale slovena e il mito della Trieste slovena, in: Qualestoria 35 (2007), S. 103-118.

Dies., Il paradigma città / campagna e la rappresentazione dualistica di uno spazio multietnico, in: Contemporanea 11 (2008), S. 779-792.

Dies., Radici dei conflitti nazionali nell'area alto-adriatico. Il paradigma dei "nazionalismi opposti«, in: Magherini, Alessandro (Hg.), Dall' impero austro-ungarico alle foibe. Conflitti nell' area alto-adriatico, Torino 2009, S. 11-18. 
Vervaet, Stijn, Centar i periferija u Austro-Ugarskoj. Dinamika izgradnje nacionalnih identiteta u Bosni i Hercegovini od 1878. do 1918. godine na primjeru književnih tekstova, Sarajevo 2013.

Vocelka, Karl/Vocelka, Michaela, Franz Joseph I. Kaiser von Österreich und König von Ungarn, 1830-1916, München 2015.

Voegelin, Eric, Der autoritäre Staat. Versuch über das österreichische Staatsproblem, Wien 1936.

VolpI, Gianluca, Fiumani, ungheresi, italiani. La formazione dell'identità nazionale a Fiume nell' epoca dualista (1867-1914), in: Cattaruzza, Marina (Hg.), Nazionalismi di frontiera. Identità contrapposte sull' Adriatico nord-orientale 1850-1950, Bologna 2003, S. 47-72.

VöLKL, Ekkehard, Militärgrenze und »Statuta Vlachorum«, in: ERnst, Gerhard (Hg.), Die österreichische Militärgrenze. Geschichte und Auswirkungen, Regensburg 1982, S. 9-24.

VRankić, Petar, Franz Joseph I. und Papst Leo XIII. Ihre Sorge um die katholische Kirche bei den Ost- und Südslawen, in: Archivum Historiae Pontificiae 33 (1995), S. 247-273.

VulesicA, Marija, Die Formierung des politischen Antisemitismus in den Kronländern Kroatien und Slawonien 1879-1906, Berlin 2012.

WANK, Solomon, Some Reflections on the Habsburg Empire and Its Legacy in the Nationalities Question, in: Austrian History Yearbook 28 (1997), S. 131-146.

Weber, Matthias, Ein Modell für Europa? Die Nationalitätenpolitik in der Habsburgermonarchie - Österreich und Ungarn 1867-1914 im Vergleich, in: Geschichte in Wissenschaft und Unterricht (1996/11), S. 651-672.

Weber, Max, Wirtschaft und Gesellschaft. Grundriß einer verstehenden Soziologie, Tübingen 1972.

Weismann, Stephanie, Das Potenzial der Peripherie. Leopold von Sacher-Masoch (1836-1895) und Galizien, Göttingen 2017.

Wiederin, Ewald, Denken vom Recht her. Über den modus austriacus in der Staatsrechtslehre, in: Schulze-Fielitz, Helmut (Hg.), Staatsrechtslehre als Wissenschaft, in: Die Verwaltung. Zeitschrift für Verwaltungsrecht und Verwaltungswissenschaften. Beiheft 7, Berlin 2007, S. 293-317.

Ders., Der österreichische Verfassungsgerichtshof als Schöpfung Hans Kelsens und sein Modellcharakter als eigenständiges Verfassungsgericht, in: Simon, Thomas/Kalwoda, Johannes (Hg.), Schutz der Verfassung. Normen, Institutionen, Höchst- und Verfassungsgerichte. Der Staat. Beiheft 22, Berlin 2014, S. 283-306.

Wiggermann, Frank, K. u. K. Kriegsmarine und Politik. Ein Beitrag zur Geschichte der italienischen Nationalbewegung in Istrien, Wien 2004.

Wimmer, Andreas, Ethnische Grenzziehungen. Eine prozessorientierte Mehrebenentheorie, in: Müller, Marion / Dariuš, Zifonun (Hg.), Ethnowissen. Soziologische Beiträge zu ethnischer Differenzierung und Migration, Wiesbaden 2010, S. 99-152.

Wingfield, Nancy M., Introduction, in: Dies. (Hg.), Creating the Other. Ethnic Conflicts and Nationalism in Habsburg Central Europe, New York 2003, S. 1-16.

Winkler, Eduard, Wahlrechtsreformen und Wahlen in Trieste 1905-1909. Eine Analyse der politischen Partizipation in einer multinationalen Stadtregion der Habsburgermonarchie, München 2000.

Winker, Gabriele/ Degele, Nina, Intersektionalität. Zur Analyse sozialer Ungleichheiten, Bielefeld 2009.

Wodak, Ruth/de Cillia, Rudolf/Reisigl, Martin/Liebhart, Karin/Hofstätter, Klaus / KArgL, Maria, Zur diskursiven Konstruktion nationaler Identität, Frankfurt a. M. 1998.

Wood, John Carter, "Blessed is the Nation«? Christianity and National Identity in TwentiethCentury Europe, in: Ders. (Hg.), Christianity and National Identity in Twentieth-Century Europe. Conflict, Community, and the Social Order, Göttingen 2016, S. 11-31.

WöRsDörfER, Rolf, »Slawischer« und »lateinischer« Katholizismus im Nationalitätenkonflikt. Der Streit um die Liturgie- und Unterrichtssprache in den adriatischen Diözesen ÖsterreichUngarns, Italiens und Jugoslawiens (1861-1941), in: Archiv für Sozialgeschichte 40 (2000), S. 171-201.

Ders., Krisenherd Adria 1915-1955. Konstruktion und Artikulation des Nationalen im italienischjugoslawischen Grenzraum, Paderborn 2004. 
Ders., Nationale Identitätskonzepte im Alpen-Adria-Raum. »Italiener« und »Slowenen«im 19. und 20. Jahrhundert, in: Bernik, France/Lauer, Reinhard (Hg.), Die Grundlagen der slowenischen Kultur. Bericht über die Konferenz der Kommission für interdisziplinäre SüdosteuropaForschung im September 2002 Göttingen, Berlin / New York 2010, S. 51-82.

Zahra, Tara, Kidnapped Souls. National Indifference and the Battle for Children in the Bohemian Lands. 1900-1948, Ithaca/ London 2008.

Dies., Imagined Non-Communities. National Indifference as a Category of Analysis, in: Slavic Review 69 (2010), S. 93-119.

Zayarnyuk, Andriy, Framing the Ukrainian Peasantry in Habsburg Galicia, 1846-1914, Edmonton / Toronto 2013.

Zucconi, Guido, Una città cosmopolita. Fiume e il suo fronte-mare nell' età dualistica (1870-1914), Roma 2008.

Zovatto, Pietro, Cattolicesimo a Trieste (Appunti), Trieste 1980.

Ders., Stampa cattolica slovena ed italiana, Trieste 1988.

Žıc, Igor, Kratka povijest grada Rijeke, Rijeka 2001.

Žıтко, Salvator, Avstrijsko Primorje v vrtincu nacionalnih, političnih in ideoloških nasprotij v času ustavne dobe (1861-1914), Koper 2016. 

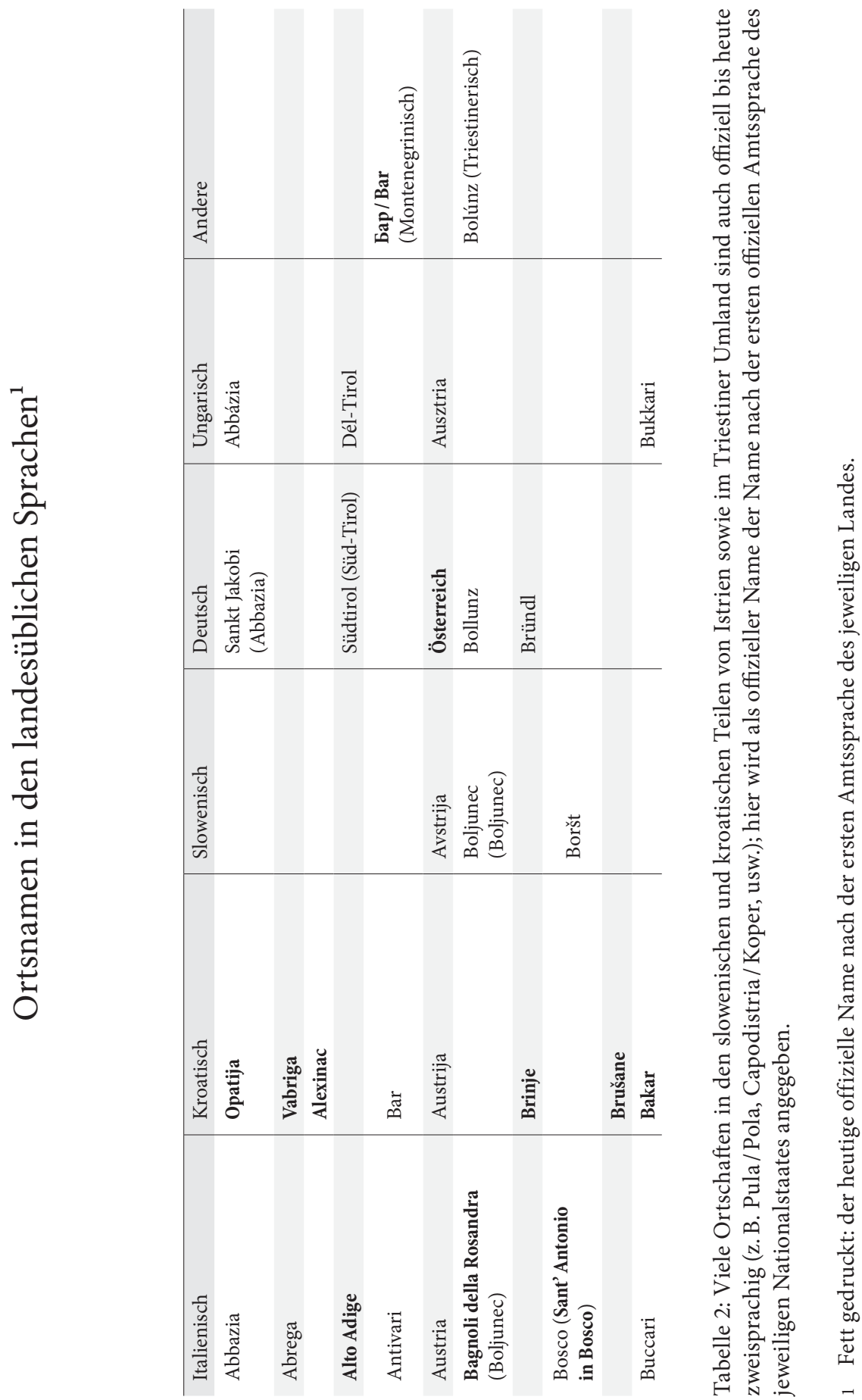


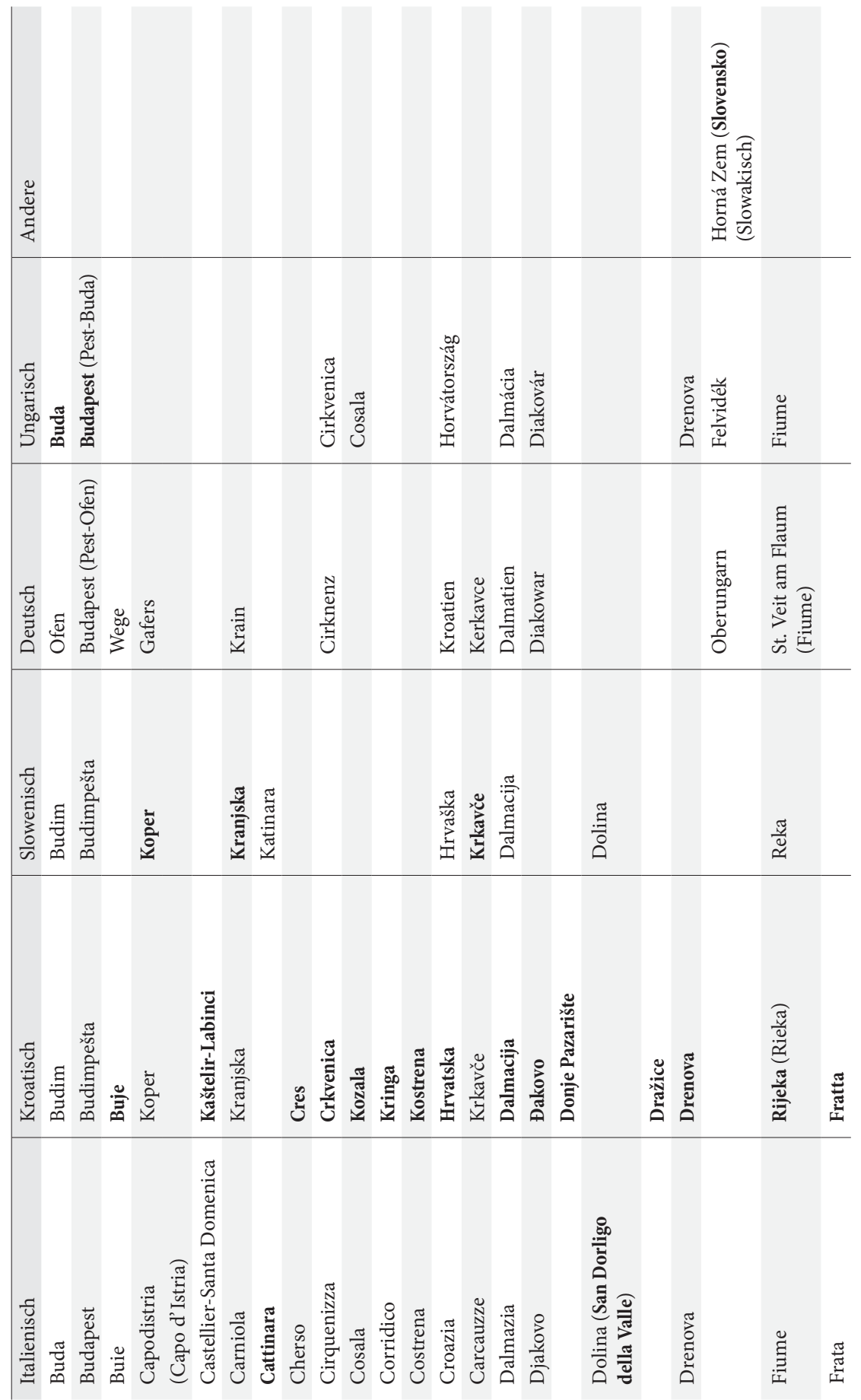




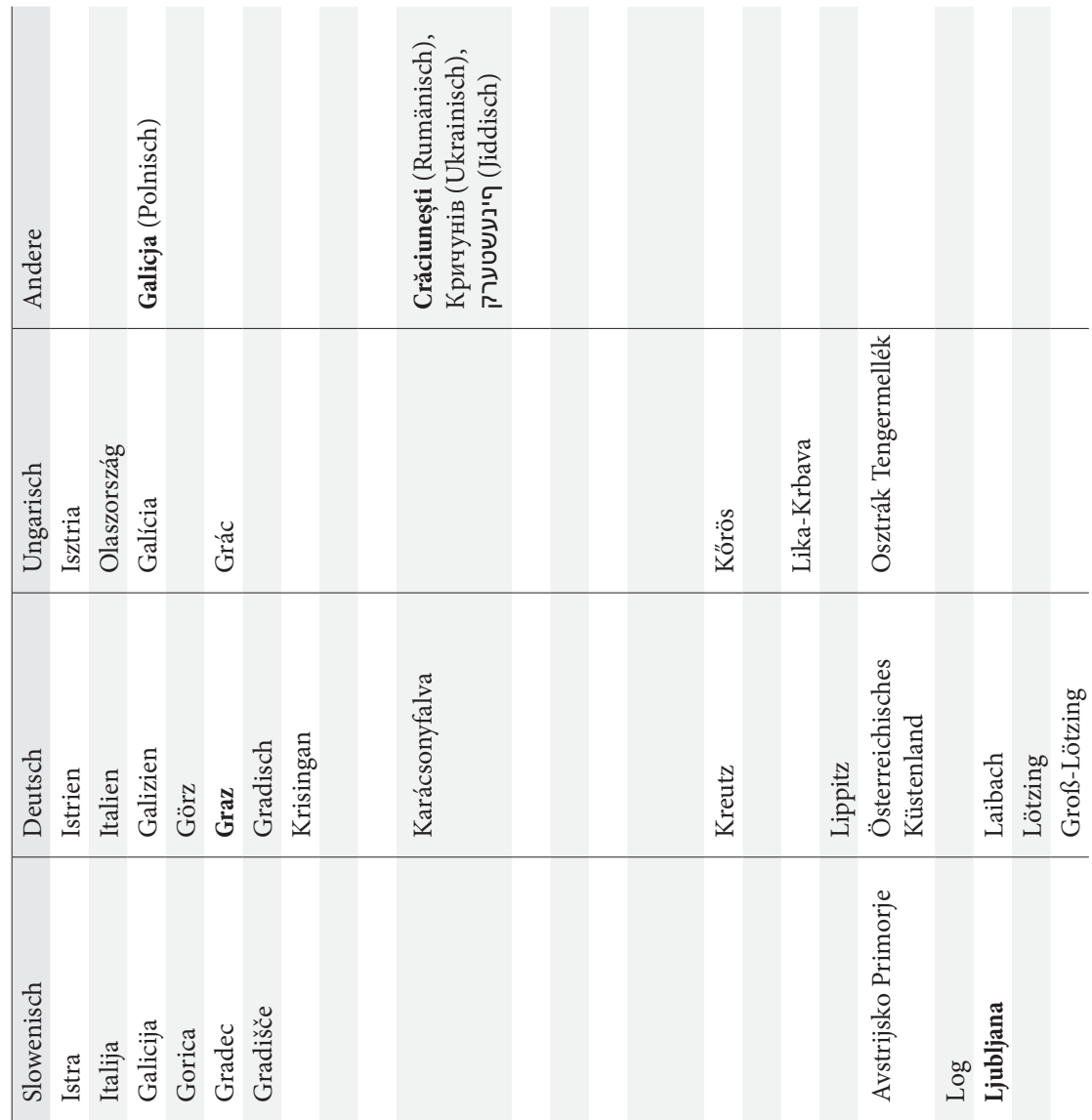

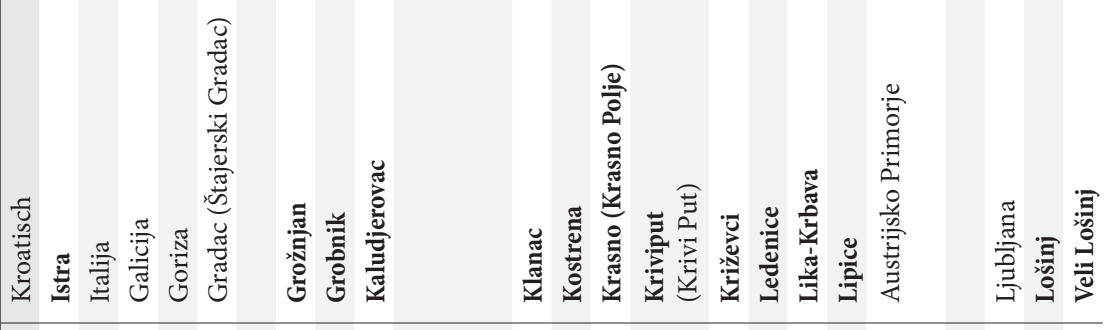

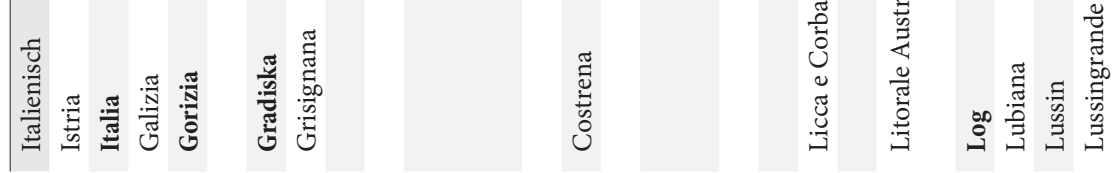




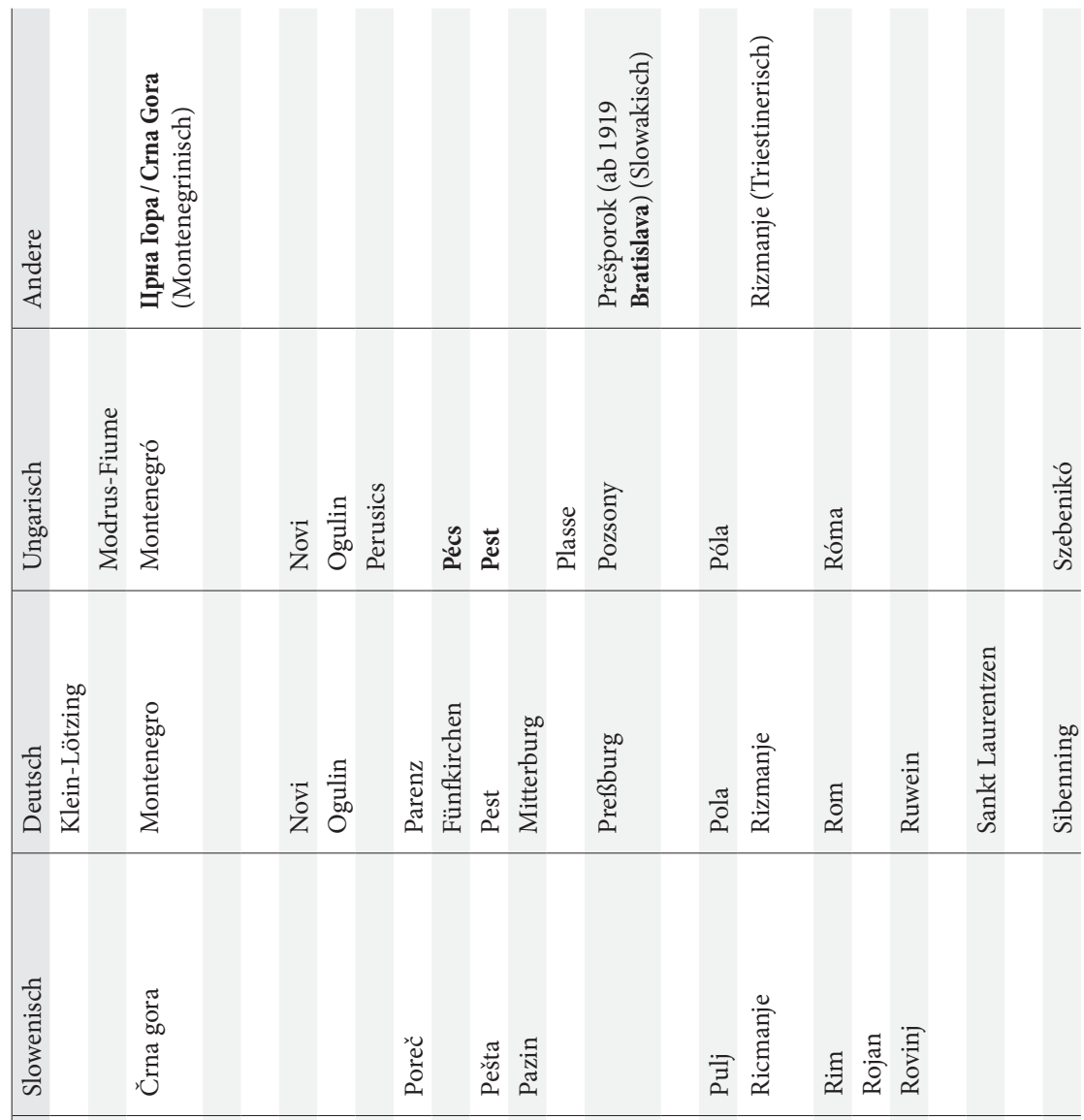
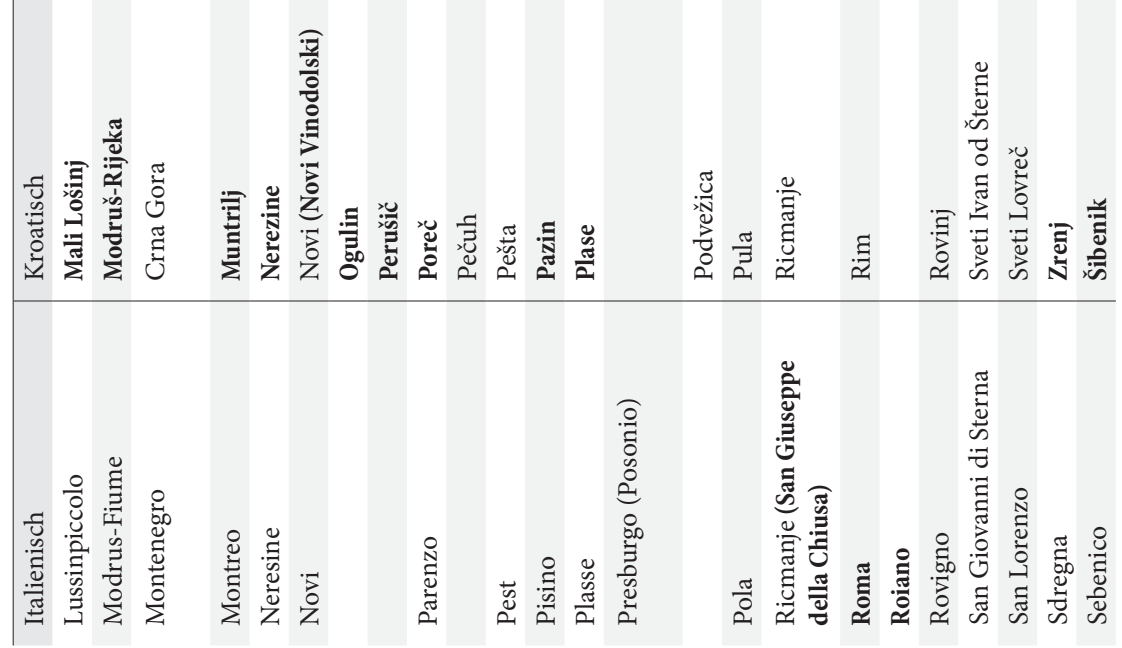


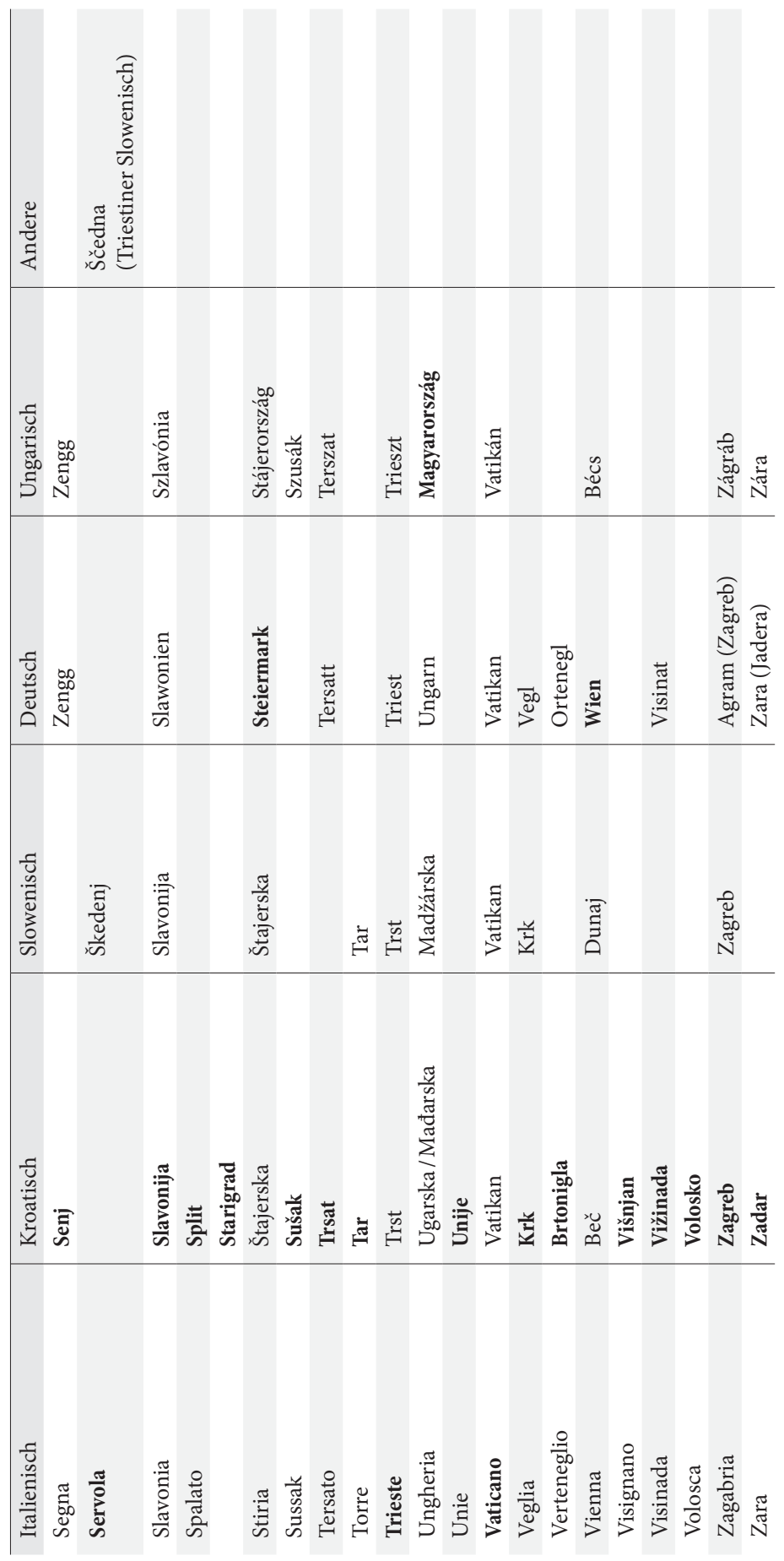




\section{Personen}

Statthalter vom Österreichischen Küstenland

1889-1897: Teodoro Freiherr von Rinaldini

1897-1904: Leopold Graf von Goëss

1904-1915: Konrad Prinz zu Hohenlohe

\section{Gouverneure von Fiume/Rijeka und}

dem Ungarisch-Kroatischen Küstenland

1892-1896: Lajos von Batthyány

1896-1897: Rezső Abele

1897: Tibor Gaál

1897-1903: László von Szapáry

1903: Tibor Gaál

1903-1905: Ervin Roszner

1905: Pál von Szapáry

1905-1906: Tibor Gaál

1906: György von Károlyi

1906-1909: Sándor Nákó von Nagyszentmiklós

1909-1917: Sándor von Wickenburg

\section{Bischöfe in Triest und Capodistria / Koper}

1882-1895: Ivan Nepomuk Glavina

1896-1901: Andrej Marija Šterk

1902-1910: Franz Xaver Nagl

1911-1919: Andrej Karlin

Bischöfe in Pola/Pula und Parenzo/Poreč

1884-1913: Giovanni Battista Flapp

1913-1941: Trifun Pederzolli

\section{Bischöfe in Veglia / Krk}

1880-1893: Franjo Anijan Feretić

1894-1896: Andrej Marija Šterk

1896-1920: Antun Mahnič

Bischöfe in Senj und Modruš

1876-1894: Jurij Posilović

1895-1908: Antun Maurović

1910-1914: Rocco Vučić 


\section{Verzeichnis von Abbildungen, Karten und Tabellen}

\section{Abbildungen und Karten}

Abb. 1: Karte der Österreichisch-Ungarischen Monarchie nach 1878 (C) Wilhelm Schier (Hg.), Atlas zur allgemeinen österreichischen Geschichte, Wien 1966, S. 50; aus: Wikipedia, URL: $<$ https://de.wikipedia.org/wiki/\%C3\%96sterreich-Ungarn\#/media/ Datei:Austria-Hungary_map_de.svg $>(15.10 .2019)$

Abb. 2: Karte vom Österreichischen Küstenland, Kärnten und Krain (1915) (c) Karl Peucker, Österreichisches Küstenland. Görz u. Gradiska Istrien u. Triest - Kärnten u. Krain, Wien 1915; aus: Digitalna Knižnica Slovenije [Digitale Bibliothek von Slowenien], URL: $<$ http://www.dlib.si/?URN=URN:NBN:SI:doc-MMEXKZBJ> (15.10.2019) ..

Abb. 3: Dr. Anton Požar (in der Mitte) mit seinen Brüdern (ohne Datum)

(C) Narodna in študijska knjižnica v Trstu [Volks- und Studienbibliothek in Triest], Odsek za zgodovino [Abteilung für Geschichte], H-HI Kultura, kraji, fasc. 4.: Ricmanje [ohne Datum]

Abb. 4: Lese- und Gesangsverein in Ricmanje zur Zeit des "Übertrittes in den griechisch-katholischen Ritus« (C) AST, C.d. Capodistria, Culto, b. 170, fol. 491

[Übersetzung aus dem Slowenischen: Péter Techet]

Abb. 5: Karikatur über Bischof Nagl als »Nagel« (1903)

(c) Škrat, 27. Juni 1903

Abb. 6: Postkarte vom Zivilbegräbnis in Ricmanje (ohne Datum)

(c) NŠKT, OZ, HA-HH Ricmanje

Abb. 7: Postkarte von einer zivilen Trauung in Ricmanje mit Ivan Berdon, dem Dorfvorsteher (ohne Datum) (c) NŠKT, OZ, HA-HH Ricmanje

Abb. 8: Postkarte aus Ricmanje (ohne Datum)

(C) AST, C.d. Capodistria, Culto, b. 170, fol. 490 
Abb. 9: Karte von Kroatien-Slawonien (1897)

(C) »Horvát-Szlavónország térképe« [»Karte von Kroatien-Slawonien«], in: A Pallas Nagy Lexikona. Összes ismeretek enciklopédiája, IX. Kötet [Das Pallas-Großlexikon. Enzyklopädie allen Wissens, Bd. IX], Budapest 1895, S. 387, URL: <http://mek.oszk.hu/00000/00060/html/kepek/ horvat-terkep_dka.jpg $>(15.10 .2019)$ [Markierung der ungarischkroatischen Hälfte des Küstenlandes: Péter Techet]

Abb. 10: Karte der ungarisch-kroatischen Gespanschaft Lika-Krbava

(C) "Lika-Krbava Vármegye Térképe« [Karte der Gespanschaft Lika-Krbava], in: A Pallas Nagylexikona, XI. Kötet [Bd. XI], S. 513, URL:

$<$ https://de.wikipedia.org/wiki/Komitat_Lika-Krbava\#/media/ File:Lika-Krbava_County_Map.jpg > (15.10.2019) [Markierung der

Städte: Péter Techet]

\section{Tabellen}

Tab. 1: Verbreitung der wichtigsten Umgangssprachen in Istrien, 1890-1910

(c) Tabelle: Péter Techet

Tab. 2: Ortsnamen in den landesüblichen Sprachen

(C) Tabelle: Péter Techet 


\section{Abkürzungen}

AAV Archivio Apostolico Vaticano (Vatikanisches Apostolisches Archiv)

ADT Archivio Diocesano di Trieste (Diözesenarchiv von Triest)

AG Atti Generali (Allgemeinakten)

AP Atti Presidiali (Präsidialakten)

AP ris. Atti presidiali riservati (Reservierte Präsidialakten)

AST Archivio di Stato di Trieste (Staatsarchiv von Triest)

AVA Allgemeines Verwaltungsarchiv des Österreichischen Staatsarchivs Wien

AŽD Arhiv Župe na Drenovi (Archiv der Pfarrei in Drenova)

b. busta (Akte)

BAS Biskupski Arhiv Senj (Bischöfliches Archiv Senj)

DAP Državni Arhiv u Pazinu (Staatsarchiv in Pisino / Pazin)

DAR Državni Arhiv u Rijeci (Staatsarchiv in Fiume/Rijeka)

GO Gestione Ordinare (Allgemeine Verwaltung)

GP Gestione Particulare (Besondere Verwaltung)

HDA Hrvatski Državni Arhiv Zagreb (Kroatisches Staatsarchiv Zagreb)

HHStA Haus-, Hof- und Staatsarchiv des Österreichischen Staatsarchivs Wien

kut. kutija (Akte)

MNL Magyar Nemzeti Levéltár (Ungarisches Nationalarchiv)

NbAZ Nadbiskupski Arhiv u Zagrebu (Erzbischöfliches Archiv in Zagreb)

NŠKT Narodna in študijska knjižnica v Trstu (Volks- und Studienbibliothek in Triest)

OL Országos Levéltár Budapest (Staatsarchiv Budapest)

Op.Sp. Opći Spisi (Allgemeine Schriften)

$\mathrm{OZ}$ Odsek za zgodovino (Abteilung für Geschichte)

Pr.Sp. Prezidijalni Spisi (Präsidialschriften)

ŽAR Župnijski arhiv v Ricmanjih (Pfarrarchiv in Ricmanje)

ŽDAD Župnijski in dekanijski arhiv Dolina (Pfarr- und Dekanatsarchiv in Dolina) 


\section{Register $^{1}$}

\section{Ortsregister}

Abrega/Vabriga 112

Aleksinac 188, 192, 193

Bar (Antivari) 177

Boljunec 138, 248

Böhmen 105, 118

Bratislava (Preßburg) 30

Brinje 185, 227

Brušane 193

Buccari/ Bakar 232

Budapest $38,41,54,56,60,78,81,173,210$, $217,220-222,224,227,232-234$

Capodistria/ Koper 38, 132, 133, 138

Carcauzze/Krkavče 123

Cattinara/Katinara 152

Cherso/Cres 91, 104

Cleveland 108

Corridico/Kringa 169

Cosala / Kozala 211

Crkvenica 226

Đakovo 80

Dalmatien 68, 77, 162, 178, 210

Dolina 54, 129, 132, 138, 139, 141

Donje Pazarište 193

Drenova 55, 208-239, 243, 245, 246, 248, $249,251,253,254$

Fiume / Rijeka 13, 15, 38, 40, 43, 54, 57, $151,171,172,177,180,202,204,207-225$, 229-234, 236, 237, 251, 259

Florenz 56

Fratta/Frata 112

Gospić 189,193

Görz 37, 38, 160

Gradiska 37
Graz 130, 143, 171

Grisignana/Grožnjan 109, 110, 120

Istrien $37,40,41,57,75,77,83,86-96,99$, $100,103,108,114,115,118,120-122,129$, $140,180,187,205,206,225,237,244-246$, 250, 251, 254

Kaludjerovac 190, 191, 194

Karácsonyfalva 135

Klanac 188, 192

Kroatien 40, 55, 56, 67-70, 77, 80, 130, 175, $178,180,181,184,189,190,194,195,196$, 201, 210, 214, 218, 232, 254

Kriviput 174, 176, 183-189, 194, 195, 237, 238

Križevci $130,135,136$

Ledenice 218,227

Lipice 227

$\log 130,132,141,146,158,248$

Ljubljana (Laibach) 153

Lussinpiccolo/Mali Lošinj 81, 103, 124

Mainz 13, 17

Montenegro 177, 178

Montreo/Muntrilj 107

Neresine/ Nerezine 101, 102, 104

Novi 225, 226

Oberungarn 75

Ogulin 213, 230

Ossero/Osor 81, 101, 102

Parenzo/Poreč 19, 38, 91, 96, 114, 124, 125

Passo/Paz 130

Pécs (Fünfkirchen) 233

Perušič 188-190, 193-195, 199, 203, 237, 238

1 Kursiv gesetzte Seitenangaben verweisen auf Anmerkungen. 
Piemont/Završje 15

Pisino/Pazin 53, 92

Plasse/Plase 211

Pola / Pula 38, 92, 96, 114, 123, 124

Prag 153

Regensburg 13

Ricmanje 54, 57, 85, 87, 126-169, 191, 243, 248-250, 254

Roiano/Rojan 138

Rom 13, 56, 78, 79, 154, 162, 224

Rovigno/ Rovinj 119, 244

San Giovanni di Sterna/ Sv. Ivan od Šterne $105-107,111,120$

Sdregna / Zrenj 108, 111, 120

Senj $38,55,78,172-174,176,178,183$, $213-215,225,226,235,236$

Servola / Ščedna 144

Slawonien 56, 67-70, 90, 175, 178, 180, 189, 190, 194, 201

Spalato/Split 77

Starigrad 227

Sušak 213
Triest $13,19,37,40,42,53,56,57,85,86$, $91,118,119,121,123,124,126-130,134$, 136, 137, 140, 143, 151, 153, 154, 157, 158, $165,166,180,259$

Torre/ Tar 112-114, 245

Unie/Unije 104

Vatikanstadt 54

Vatovlje 141

Veglia/Krk 38, 78, 80, 81, 91, 101, 102, 123,124

Venedig 204

Verteneglio/Brtonigla 119

Vigignano/Višnjan 99, 105, 112

Visinada/Vižinada 96-100, 243, 254

Vojvodina 201

Wien $38,41,78,80,91,104,118,124,136$, $150,157,159,162,224$

Zagreb (Agram) 14, 38, 54-56, 68, 70, 80, $183,191,215$

Zara/Zadar 145,162 


\section{Personenregister}

Abolić, Šandor 136

Agamben, Giorgio 249

Altermatt, Urs 166

Anderson, Benedict 49

Appiah, Kwame Anthony 65

Apponyi, Albert 82

Aust, Martin 14

Baberowski, Jörg 51

Bachinger, Bernhard 13

Baldasso, Franco 14

Banac, Ivo 69

Barčić, Erazmo 202

Batthyany, Tivadar (Teodoro) 212

Beck, Ulrich 30

Beller, Steven 63

Bendel, Rainer 14

Berdon, Ivan 147-149, 154

Beth, Roy 47

Biloslavo, Franco 15

Bobinac, Marijan 14

Bogović, Mile 205, 206

Borutta, Manuel 197

Bouwers, Eveline G. 13, 23, 24

Bukovec, Predrag 204

Brubaker, Rogers 24, 48, 49, 65, 125, 164, 168,198

Camilleri, Nicola 14

Capuzzo, Ester 13

Cavedoni, Domenico 102

Chráska, Anton 153

Clark, Christopher 165

Clewing, Konrad 13, 36

Cole, Laurence 250

Colling, Randall 51

Cooper, Frederick 48

Corazza, Giuseppe 112, 113, 245

Csáky, Moritz 29, 40, 47, 74

Csóbor, Gyula 234

Cvetko, Matej 214, 215, 217, 225

Dariž, Jože 146

D'Alessio, Vanni 13

Di Fabio, Laura 14
Dorsi, Pierpaolo 13

Drohobeczky, Julij 135, 138, 139, 149

Dudaš, Boris 14

Egry, Gábor 14, 35

Fabris, Domenico 143

Faljeivić, Toma 199

Feichtinger, Johannes 260

Fejtö, François (Ferenc) 59

Flapp, Giovanni Battista 96-99, 109, 114, 243

Fox, John 35, 246

Franz Joeph I 73

Fumo, Gianna 13

Gammerl, Benno 30

Gellner, Ernst 59

Geréby, György 27

Glavina, Ivan Nepomuk 19, 124, 166

Gottsmann, Andreas 13, 28, 29, 101, 261

Göderle, Wolfgang 14

Grailach, Christian 13

Grandits, Hannes 116

Gršković, Nikola 190, 191

Habermas, Jürgen 19

Haupt, Heinz-Gerhard 243

Haslinger, Peter 20, 198

Hein-Kircher, Heidi 14

Hobsbawm, Eric 204

Holjevac, Željko 14

Horel, Catherine 14

Höpken, Wolfgang 14

Innozenz IV 78

Iurizza, Giuseppe 132, 138

Jabec, Maria 139

Jagodzinski, Sabine 14

Jedrejčič, Frančišek 160

Jellinek, Georg 68

Jeličić, Ivan 14

Johler, Reinhard 91

Johnston, William 63

Judson, Pieter 14, 16, 20, 31, 245 
Jukopila, Ante 15

Kann, Robert A. 63

Karlin, Andrej 159, 160

Kelsen, Hans 64

Khuen-Héderváry, Károly 178, 200, 201

Kleine, Christoph 248

Kmak-Pamirska, Aleksandra 14

Koschorke, Albrecht 21

Kovačić, Franjo 188, 190, 191, 194, 200, 203

Krančič, Jožef 141, 144, 151

Kraus, Karl 241

Kukanić, Ivan 217, 218, 225, 228, 230-232

Kumbatović, Ivan 226

Kuret, Andrej 134

Kusber, Jan 13

Ladavac, Jakob 123

Laginja, Matija 157-159

Lasciac, Alois 100

Leforban, Pierre 14

Leo XIII 45, 79, 82, 136, 159, 165

Luca, Giovanni 13

Luckmann, Thomas 164

Luhmann, Niklas 48, 255, 261

Lukša, Ante 193

Lüdtke, Alf 47, 50, 237, 238, 247

Mahnič, Antun 80, 81, 102-105, 124

Malnati, Ettore 13

Malusa, Bernardo 119

Maner, Hans-Christian 13

Manin, Marco (Markus) 13

Maurović, Antun 213, 214

Medved, Marko 14

Mehlmer, Sara 13

Menasse, Robert 13

Metzger, Franziska 166

Micich, Maio 13

Miller-Idriss, Cynthia 36

Mioni, Ugo 134

Mišković, Nataša 14

Modrčin, Konrad 176, 183-186, 200

Moehrle, René 14

Morelon, Claire 21

Mouffe, Chantal 252

Musil, Robert 258
Nagl, Franz Xaver 118, 124, 127, 140-142, $144,145,152,154,155,157,165,167$

Nákó, Sándor 210, 219, 220, 226, 235

Nedved, Ante 106

Osterkamp, Jana 14, 41, 247

Ota, Ivan 139

Palacký, Franz 59

Palaoro, Angelo 99

Palent, Karl 157

Paulmann, Johannes 13

Paul, Samantha 14

Petrović, Balaž 216, 223

Petrungaro, Stefano 14, 181, 239

Pius X 141, 162, 165, 224

Pliverić, Josip 68

Polić, Mate 216, 226, 227

Posilović, Jurij 178, 182, 185, 204, 215

Požar, Anton 127, 130-134, 137, 138, 141, 143, $144,149,159,165,166$

Pregarc Uršula 85, 146

Pyrah, Robert 14

Ragusin, Antonio (Ante) 109, 110

Rampolla del Tindaro, Mariano 134

Rapljenović, Robert 14

Reill Kirchner, Dominique 259

Riedl, Matthias 14

Rigó, Máté 14

Roth, Joseph 73

Rutar, Sabine 14

Santoboni, Paolo 13

Schenk, Benjamin Fritjhof 116

Schmitt, Carl 252

Schödl, Günter 192

Schulze Wessel, Martin 75, 247

Schumacher, Joseph 261

Schüler, Sebastian 14

Scrobogna, Giuseppe (Jurij) 222

Sgambati, Alessandro 13

Slataper, Scipio 257

Sluga, Glenda 38

Sokolić, Ivan 189

Starčević, Mile 191

Stourzh, Gerald 36

Strola, Fabiano 212 
Strossmayer, Josip Jurij 79, 80, 191, 202

Stržinar, Josip 152

Szapáry, Gyula 176

Šterk, Andrej Marija 85, 101, 102, 110, 124, $129,137,140,166$

Taliani, Emidio 104, 124, 134, 150

Taylor, Charles 64

Techet, Carl 59

Tillich, Paul 261

Todorova, Maria 36

Torcoletti, Luigi 220, 221

Trefort, Ágost 176

Trogrlić, Marko 14

Ukmar, Jakob 126, 127, 154-156

Ulbricht, Otto 46

Valentič, Ivan 134

Van Ginderachter, Martin 246

Várady, Árpád Lipót 225

Vasselli, Vittorio 111
Vidaš, Lovro 188, 192

Vio, Francesco 212, 214, 217

Vivante, Angelo 121

Voegelin, Eric 63

Vrba, Rudolf 161

Vocelka, Karl 14

Vučić, Rocco 226

Weber, Max 261

Wekerle, Sándor 224

Wolff, Larry 14

Zahra, Tara 33, 34, 35, 65, 242, 245

Zakošek, Boris 13

Zanella, Riccardo 217, 219, 224

Zigar, Pavel 213-216, 218-220, 226-228, 230, 234

Zohec, Johanna 139

Zovatto, Pietro 13

Zichy, Ágost 233

Žerjar, Miha 139

Žuljan, Marijan 146 